Cochrane Database of Systematic Reviews

\title{
Interventions to improve antibiotic prescribing practices for hospital inpatients (Review)
}

Davey P, Marwick CA, Scott CL, Charani E, McNeil K, Brown E, Gould IM, Ramsay CR, Michie S

Davey P, Marwick CA, Scott CL, Charani E, McNeil K, Brown E, Gould IM, Ramsay CR, Michie S.

Interventions to improve antibiotic prescribing practices for hospital inpatients.

Cochrane Database of Systematic Reviews 2017, Issue 2. Art. No.: CD003543.

DOI: 10.1002/14651858.CD003543.pub4.

www.cochranelibrary.com 
TABLE OF CONTENTS

ABSTRACT 1

PLAIN LANGUAGE SUMMARY

SUMMARY OF FINDINGS

BACKGROUND

OBJECTIVES

METHODS

RESULTS

Figure 1.

Figure 2.

Figure 3.

Figure 4.

Figure 5.

Figure 6.

Figure 7.

Figure 8.

Figure 9.

Figure 10.

Figure 11.

Figure 12.

Figure 13.

Figure 14.

DISCUSSION

AUTHORS' CONCLUSIONS

ACKNOWLEDGEMENTS

REFERENCES

CHARACTERISTICS OF STUDIES

DATA AND ANALYSES

Analysis 1.1. Comparison 1 Effectiveness: Prescribing outcomes from RCTs of interventions to reduce unnecessary antibiotic use, Outcome 1 Dichotomous outcomes, increase in desired practice.

Analysis 1.2. Comparison 1 Effectiveness: Prescribing outcomes from RCTs of interventions to reduce unnecessary antibiotic use, Outcome 2 Dichotomous outcomes, all RCTs with results of cluster RCTs adjusted by inflation factor.

Analysis 1.3. Comparison 1 Effectiveness: Prescribing outcomes from RCTs of interventions to reduce unnecessary antibiotic use, Outcome 3 Dichotomous outcomes, low or medium 'Risk of bias' studies only.

Analysis 1.4. Comparison 1 Effectiveness: Prescribing outcomes from RCTs of interventions to reduce unnecessary antibiotic use, Outcome 4 Continuous outcomes, duration of all antibiotic treatment (days).

Analysis 1.5. Comparison 1 Effectiveness: Prescribing outcomes from RCTs of interventions to reduce unnecessary antibiotic use, Outcome 5 Continuous outcomes, duration of all antibiotic treatment with results of cluster RCTs adjusted by inflation factor.

Analysis 1.6. Comparison 1 Effectiveness: Prescribing outcomes from RCTs of interventions to reduce unnecessary antibiotic use, Outcome 6 Continuous outcomes, low or medium 'Risk of bias' studies only.

Analysis 1.7. Comparison 1 Effectiveness: Prescribing outcomes from RCTs of interventions to reduce unnecessary antibiotic use, Outcome 7 Continuous outcome, consumption of targeted antibiotic only, standardised mean reduction (original outcome cost, days or DDD).

Analysis 2.1. Comparison 2 Adverse effects: Clinical outcomes from RCTs of interventions to reduce unnecessary antibiotic use, Outcome 1 Mortality, all RCTs.

Analysis 2.2. Comparison 2 Adverse effects: Clinical outcomes from RCTs of interventions to reduce unnecessary antibiotic use, Outcome 2 Mortality, all RCTs with results of cluster RCTs adjusted by inflation factor.

Analysis 2.3. Comparison 2 Adverse effects: Clinical outcomes from RCTs of interventions to reduce unnecessary antibiotic use, Outcome 3 Mortality, low or medium 'Risk of bias' RCTs.

Analysis 2.4. Comparison 2 Adverse effects: Clinical outcomes from RCTs of interventions to reduce unnecessary antibiotic use, Outcome 4 Length of stay, all RCTs.

Analysis 2.5. Comparison 2 Adverse effects: Clinical outcomes from RCTs of interventions to reduce unnecessary antibiotic use, Outcome 5 Length of stay, all RCTs with results of cluster RCTs adjusted by inflation factor. 
Analysis 2.6. Comparison 2 Adverse effects: Clinical outcomes from RCTs of interventions to reduce unnecessary antibiotic use, Outcome 6 Length of stay, low or medium 'Risk of bias' RCTs only.

Analysis 3.1. Comparison 3 Adverse effects: Clinical outcomes of interventions targeting antibiotic choice, Outcome 1 Mortality for trial patients.

Analysis 3.2. Comparison 3 Adverse effects: Clinical outcomes of interventions targeting antibiotic choice, Outcome 2 Length of stay for trial patients.

Analysis 4.1. Comparison 4 Adverse effects: Clinical outcomes of interventions targeting antibiotic exposure, Outcome 1 Mortality for trial patients.

Analysis 4.2. Comparison 4 Adverse effects: Clinical outcomes of interventions targeting antibiotic exposure, Outcome 2 Length of stay for trial patients.

Analysis 5.1. Comparison 5 Modifiers of intended effect: Comparison of enabling interventions with and without feedback, Outcome 1 Enablement with feedback.

Analysis 5.2. Comparison 5 Modifiers of intended effect: Comparison of enabling interventions with and without feedback, Outcome 2 Enablement without feedback.

ADDITIONAL TABLES

APPENDICES

WHAT'S NEW

HISTORY 
[Intervention Review]

\section{Interventions to improve antibiotic prescribing practices for hospital inpatients}

Peter Davey ${ }^{1}$, Charis A Marwick², Claire L Scott ${ }^{3}$, Esmita Charani ${ }^{4}$, Kirsty McNeil ${ }^{5}$, Erwin Brown ${ }^{6}$, Ian M Gould7 ${ }^{7}$, Craig R Ramsay ${ }^{8}$, Susan Michie $^{9}$

1Population Health Sciences, University of Dundee, Dundee, UK. 2Population Health Sciences Division, Medical Research Institute, University of Dundee, Dundee, UK. ${ }^{3}$ Scottish Dental Clinical Effectiveness Programme, NHS Education for Scotland, Dundee, UK. ${ }^{4}$ NIHR Health Protection Research Unit in Healthcare Associated Infections and Antimicrobial Resistance, Imperial College London, London, UK. ${ }^{5}$ School of Medicine, University of Dundee, Dundee, UK. ${ }^{6}$ No affiliation, Bristol, UK. ${ }^{7}$ Department of Medical Microbiology, Aberdeen Royal Infirmary, Aberdeen, UK. ${ }^{8}$ Health Services Research Unit, Division of Applied Health Sciences, University of Aberdeen, Aberdeen, UK. ${ }^{9}$ Research Department of Primary Care and Population Health, University College London, London, UK

Contact: Peter Davey, Population Health Sciences, University of Dundee, Mackenzie Building, Kirsty Semple Way, Dundee, Scotland, DD2 4BF, UK.p.g.davey@dundee.ac.uk.

Editorial group: Cochrane Effective Practice and Organisation of Care Group.

Publication status and date: Edited (no change to conclusions), published in Issue 2, 2017.

Citation: Davey P, Marwick CA, Scott CL, Charani E, McNeil K, Brown E, Gould IM, Ramsay CR, Michie S. Interventions to improve antibiotic prescribing practices for hospital inpatients. Cochrane Database of Systematic Reviews 2017, Issue 2. Art. No.: CD003543. DOI: 10.1002/14651858.CD003543.pub4.

Copyright ( 2017 The Cochrane Collaboration. Published by John Wiley \& Sons, Ltd.

\section{A B S T R A C T}

\section{Background}

Antibiotic resistance is a major public health problem. Infections caused by multidrug-resistant bacteria are associated with prolonged hospital stay and death compared with infections caused by susceptible bacteria. Appropriate antibiotic use in hospitals should ensure effective treatment of patients with infection and reduce unnecessary prescriptions. We updated this systematic review to evaluate the impact of interventions to improve antibiotic prescribing to hospital inpatients.

\section{Objectives}

To estimate the effectiveness and safety of interventions to improve antibiotic prescribing to hospital inpatients and to investigate the effect of two intervention functions: restriction and enablement.

\section{Search methods}

We searched the Cochrane Central Register of Controlled Trials (CENTRAL) (the Cochrane Library), MEDLINE, and Embase. We searched for additional studies using the bibliographies of included articles and personal files. The last search from which records were evaluated and any studies identified incorporated into the review was January 2015.

\section{Selection criteria}

We included randomised controlled trials (RCTs) and non-randomised studies (NRS). We included three non-randomised study designs to measure behavioural and clinical outcomes and analyse variation in the effects: non- randomised trials (NRT), controlled before-after (CBA) studies and interrupted time series (ITS) studies. For this update we also included three additional NRS designs (case control, cohort, and qualitative studies) to identify unintended consequences. Interventions included any professional or structural interventions as defined by the Cochrane Effective Practice and Organisation of Care Group. We defined restriction as 'using rules to reduce the opportunity to engage in the target behaviour (or increase the target behaviour by reducing the opportunity to engage in competing behaviours)'. We defined enablement as 'increasing means/reducing barriers to increase capability or opportunity'. The main comparison was between intervention and no intervention. 


\section{Data collection and analysis}

Two review authors extracted data and assessed study risk of bias. We performed meta-analysis and meta-regression of RCTs and metaregression of ITS studies. We classified behaviour change functions for all interventions in the review, including those studies in the previously published versions. We analysed dichotomous data with a risk difference (RD). We assessed certainty of evidence with GRADE criteria.

\section{Main results}

This review includes 221 studies (58 RCTs, and 163 NRS). Most studies were from North America (96) or Europe (87). The remaining studies were from Asia (19), South America (8), Australia (8), and the East Asia (3). Although $62 \%$ of RCTs were at a high risk of bias, the results for the main review outcomes were similar when we restricted the analysis to studies at low risk of bias.

More hospital inpatients were treated according to antibiotic prescribing policy with the intervention compared with no intervention based on 29 RCTs of predominantly enablement interventions (RD 15\%, 95\% confidence interval (CI) 14\% to 16\%; 23,394 participants; highcertainty evidence). This represents an increase from $43 \%$ to $58 \%$. There were high levels of heterogeneity of effect size but the direction consistently favoured intervention.

The duration of antibiotic treatment decreased by 1.95 days ( $95 \% \mathrm{Cl} 2.22$ to $1.67 ; 14 \mathrm{RCTs} ; 3318$ participants; high-certainty evidence) from 11.0 days. Information from non-randomised studies showed interventions to be associated with improvement in prescribing according to antibiotic policy in routine clinical practice, with $70 \%$ of interventions being hospital-wide compared with $31 \%$ for RCTs. The risk of death was similar between intervention and control groups ( $11 \%$ in both arms), indicating that antibiotic use can likely be reduced without adversely affecting mortality (RD $0 \%, 95 \% \mathrm{Cl}-1 \%$ to $0 \% ; 28 \mathrm{RCTs} ; 15,827$ participants; moderate-certainty evidence). Antibiotic stewardship interventions probably reduce length of stay by 1.12 days ( $95 \% \mathrm{Cl} 0.7$ to 1.54 days; $15 \mathrm{RCTs} ; 3834$ participants; moderate-certainty evidence). One RCT and six NRS raised concerns that restrictive interventions may lead to delay in treatment and negative professional culture because of breakdown in communication and trust between infection specialists and clinical teams (low-certainty evidence).

Both enablement and restriction were independently associated with increased compliance with antibiotic policies, and enablement enhanced the effect of restrictive interventions (high-certainty evidence). Enabling interventions that included feedback were probably more effective than those that did not (moderate-certainty evidence).

There was very low-certainty evidence about the effect of the interventions on reducing Clostridium difficile infections (median -48.6\%, interquartile range $-80.7 \%$ to $-19.2 \% ; 7$ studies). This was also the case for resistant gram-negative bacteria (median $-12.9 \%$, interquartile range $-35.3 \%$ to $25.2 \%$; 11 studies) and resistant gram-positive bacteria (median $-19.3 \%$, interquartile range $-50.1 \%$ to $+23.1 \%$; 9 studies) . There was too much variance in microbial outcomes to reliably assess the effect of change in antibiotic use.

\section{Heterogeneity of intervention effect on prescribing outcomes}

We analysed effect modifiers in 29 RCTs and 91 ITS studies. Enablement and restriction were independently associated with a larger effect size (high-certainty evidence). Feedback was included in 4 (17\%) of 23 RCTs and 20 (47\%) of 43 ITS studies of enabling interventions and was associated with greater intervention effect. Enablement was included in 13 (45\%) of 29 ITS studies with restrictive interventions and enhanced intervention effect.

\section{Authors' conclusions}

We found high-certainty evidence that interventions are effective in increasing compliance with antibiotic policy and reducing duration of antibiotic treatment. Lower use of antibiotics probably does not increase mortality and likely reduces length of stay. Additional trials comparing antibiotic stewardship with no intervention are unlikely to change our conclusions. Enablement consistently increased the effect of interventions, including those with a restrictive component. Although feedback further increased intervention effect, it was used in only a minority of enabling interventions. Interventions were successful in safely reducing unnecessary antibiotic use in hospitals, despite the fact that the majority did not use the most effective behaviour change techniques. Consequently, effective dissemination of our findings could have considerable health service and policy impact. Future research should instead focus on targeting treatment and assessing other measures of patient safety, assess different stewardship interventions, and explore the barriers and facilitators to implementation. More research is required on unintended consequences of restrictive interventions.

\section{PLAIN LANGUAGE SUMMARY}

\section{Improving how physicians working in hospital settings prescribe antibiotics}

\section{Review aim}

The aim of this Cochrane review was to learn of ways to improve how physicians working in hospital settings prescribe antibiotics. We collected and analysed all relevant studies to answer this question and found 221 studies.

\section{Key messages}


The use of an antibiotic policy leads to improved prescribing practices and decreases in the duration of antibiotic treatment.

Interventions that are directed to physicians to improve their antibiotic prescribing practices reduced participant length of stay in hospitals by 1.12 days (based on findings from 15 studies) and did not increase the risk of death (based on findings from 29 studies). Interventions providing advice or feedback to physicians were more effective in improving prescribing practices than those interventions that did not provide this information to physicians. Evidence from seven studies raised concerns that with interventions applying rules to make physicians prescribe properly there were delays in treatment and a breakdown in trust between infection specialists and clinical teams.

\section{What was studied in the review?}

Antibiotics are used to treat bacterial infections such as pneumonia. Many bacteria have become resistant to antibiotics over time. Antibiotic resistance is a serious problem for patients and healthcare systems because infections caused by antibiotic-resistant bacteria can lead to higher rates of death and longer hospital stays. Bacterial resistance often occurs because antibiotics are used when they are not needed. Studies have shown that in about half of cases physicians in hospital are not prescribing antibiotics properly.

We investigated the effectiveness and safety of interventions to help physicians prescribe antibiotics properly and what techniques of behaviour change could influence the success of the interventions.

\section{Key results}

We found 221 relevant studies. Ninety-six studies were from North America. The remaining 125 studies were from Europe (87), Asia (19), South America (8), Australia (8), and East Asia (3). The studies tested interventions that fell broadly into two categories: restrictive techniques, which apply rules to make physicians prescribe properly, and enablement techniques, which provide advice or feedback to help physicians prescribe properly.

We found high-certainty evidence that interventions lead to more hospital inpatients receiving the appropriate treatment for their condition according to antibiotic prescribing policies. We found moderate-certainty evidence that interventions reduce the length of hospital stay without increasing patient deaths. Both restriction and enabling techniques were successful in achieving effectiveness of the intervention. We do not need more studies to answer the question of whether these interventions reduce unnecessary antibiotic use, but we do need more research to understand the unintended consequences of the use of restrictive interventions.

Interventions were successful in safely reducing unnecessary antibiotic use in hospitals, despite the fact that the majority did not use a widely adopted behaviour change technique, which is to audit and provide feedback on performance. Effective communication of the review results could have considerable health service and policy impact.

\section{How up-to-date is the review?}

We searched for studies published up to January 2015. 
SUMMARY OF FINDINGS

Summary of findings for the main comparison. Effects of interventions to improve use of antibiotics on prescribing, clinical outcomes, adverse events, and effect modifiers (heterogeneity)

Patient or population: adults or children undergoing inpatient antibiotic prophylaxis or treatment

Settings: mainly high-income countries (North America or Western Europe)

Intervention: any intervention targeting healthcare professionals that aimed to improve antibiotic prescribing to hospital inpatients

Comparison: usual care (varied across studies)

Effectiveness: prescribing outcomes from RCTs

Outcomes

\begin{tabular}{l} 
Absolute effect $^{\star}$ \\
\hline $\begin{array}{l}\text { Without interven- With intervention } \\
\text { tion }\end{array}$
\end{tabular}

No of participants

Certainty of the

Comments

(No of studies)

evidence (GRADE)

Proportion of par-

ticipants who were

treated according

43 per 100

58 per 100

to antibiotic pre-

scribing guidelines

Difference: 15 more participants per 100 (95\%

23,394 participants

$\oplus \oplus \oplus \oplus$

Difference: 15 more participants per $100(95 \%$
$\mathrm{Cl} 15$ to 23$)$ received appropriate treatment

(29 RCTs)

$\oplus \oplus \oplus \oplus$
High

Follow-up to end of

study

following intervention.

Duration of all an-

tibiotic treatment

11.0 days

9.1 days

Difference: 1.95 fewer days per participant ( $95 \% \mathrm{Cl} 2.22$ to 1.67 )

\begin{tabular}{|c|c|c|c|c|}
\hline Mortality & 11 per 100 & 11 per 100 & \multirow{2}{*}{$\begin{array}{l}15,827 \text { participants } \\
28 \text { (RCTs) }\end{array}$} & \multirow{2}{*}{$\begin{array}{l}\oplus \oplus \oplus \odot^{1} \\
\text { Moderate }\end{array}$} \\
\hline $\begin{array}{l}\text { Follow-up to end of } \\
\text { study }\end{array}$ & \multicolumn{2}{|c|}{$\begin{array}{l}\text { Difference: } 0 \text { more deaths per } 100 \text { partici- } \\
\text { pants ( } 95 \% \mathrm{Cl} 1 \text { to } 0 \text { fewer) }\end{array}$} & & \\
\hline \multirow{2}{*}{$\begin{array}{l}\text { Mean length of hos- } \\
\text { pital stay per par- } \\
\text { ticipant }\end{array}$} & 12.9 days & 11.8 days & \multirow{2}{*}{$\begin{array}{l}3834 \text { participants } \\
15 \text { (RCTs) }\end{array}$} & \multirow{2}{*}{$\begin{array}{l}\oplus \oplus \oplus \odot^{1} \\
\text { Moderate }\end{array}$} \\
\hline & \multicolumn{2}{|c|}{$\begin{array}{l}\text { Difference: } 1.1 \text { fewer days per participant } \\
\text { ( } 95 \% \mathrm{Cl} 1.5 \text { to } 0.7 \text { fewer) }\end{array}$} & & \\
\hline
\end{tabular}

Mortality and length of stay were measured to determine the impact of reduced antibiotic use on clinical outcomes. The results were similar for studies that targeted antibiotic choice or exposure.

Only 1 of the interventions in the RCTs with mortality or length-of-stay outcomes had a restrictive component (Singh 2000). This evidence is therefore at high risk of indirectness because 7 studies in the next section of the table (see below) raise concerns about the safety of restrictive interventions. Moreover, the ITS

Difference: 1.1 fewer days per participant ( $95 \% \mathrm{Cl} 1.5$ to 0.7 fewer)

\section{8 participants $\oplus \oplus \oplus \oplus$}

(14 RCTs) High

We have graded the certainty of evidence as high becffecterogeneity was explained by prespecified varied between the studies, but the direction of effect was consistent. Restricting the analysis to studies at $10 \%$ to $12 \%$ ). 

Monitoring Committee. delay in all 3 studies. The risk to patients re-

sulted in termination of the RCT by the Trial

Loss of trust in infection specialists because of failure to record approvals for restricted drugs or provide warning about stopping

treatment

Misleading or inaccurate information from prescribers in order to meet criteria for restricted drugs. In 1 hospital, misdiagnosis of hospital-acquired infection was large enough to trigger an outbreak investigation.
Negative professional culture
Effect modifiers (heterogeneity) for immediate effect of intervention on prescribing outcomes:

impact of behaviour change functions (enablementor restriction) and additional impact of feedback, RCTs and ITS studies. A positive value for Beta means the modifier is associated with increased effect

\begin{tabular}{|c|c|c|c|c|}
\hline Effect modifier & $\begin{array}{l}\text { Adjusted effect in meta-regression } \\
\text { Beta } \\
(95 \% \mathrm{Cl})\end{array}$ & Number of studies & $\begin{array}{l}\text { Certainty of the } \\
\text { evidence (GRADE) }\end{array}$ & Comments \\
\hline \multirow[t]{2}{*}{ Enablement } & $\begin{array}{l}15.12 \\
(8.45 \text { to } 21.8)\end{array}$ & 29 RCTs & $\begin{array}{l}\oplus \oplus \oplus \oplus \\
\text { High }\end{array}$ & \multirow{4}{*}{$\begin{array}{l}\text { The effect of enablement and restriction is similar in } \\
\text { the RCTs and ITS studies. Of the } 29 \text { RCTs, only } 8(31 \%) \\
\text { of interventions were hospital-wide, the majority be- } \\
\text { ing in single units. In contrast, } 64 \text { ( } 70 \%) \text { of the inter- } \\
\text { ventions in ITS studies were hospital-wide. }\end{array}$} \\
\hline & $\begin{array}{l}12.86 \\
\text { (4.11 to } 21.6 \text { ) }\end{array}$ & 91 ITS & & \\
\hline \multirow[t]{2}{*}{ Restriction } & $\begin{array}{l}34.91 \\
(13.52 \text { to } 56.29)\end{array}$ & 29 RCTs & $\begin{array}{l}\oplus \oplus \oplus \oplus \\
\text { High }\end{array}$ & \\
\hline & $\begin{array}{l}24.69 \\
\text { (13.74 to } 35.64)\end{array}$ & 91 ITS & & \\
\hline $\begin{array}{l}\text { Addition of feed- } \\
\text { back to enable- } \\
\text { ment }\end{array}$ & $\begin{array}{l}10.88 \\
(7.16 \text { to } 19.32)\end{array}$ & 23 RCTs & $\begin{array}{l}\oplus \oplus \oplus \odot^{2} \\
\text { Moderate }\end{array}$ & $\begin{array}{l}\text { Feedback was included in } 4(17 \%) \text { of } 23 \text { RCTs and } 20 \\
(47 \%) \text { of } 43 \text { ITS studies with interventions that includ- } \\
\text { ed enablement. There were not enough interventions }\end{array}$ \\
\hline
\end{tabular}

1 RCT, 2 cohort

$\oplus \oplus \odot \Theta^{2}$

Low

\section{1 case control, $2 \quad \oplus \oplus \ominus \ominus^{3}$} cohort, 1 qualita- Low tive

The evidence from these 7 studies of unintended consequences raises concerns about the directness of the evidence of safety from the 29 RCTs in the previous section of the table (see above).
(7.16 to 19.32$)$ 


\begin{tabular}{llll}
\hline $\begin{array}{l}\text { Addition of enable- } \\
\text { ment to restriction }\end{array}$ & 38.36 & 29 ITS & $\begin{array}{l}\oplus \oplus \ominus \ominus^{3} \\
\text { Low }\end{array}$
\end{tabular}

*The risk WITHOUT the intervention is based on the median control group risk across studies. The corresponding risk WITH the intervention (and the $95 \%$ confidence interval for the difference) is based on the overall relative effect (and its $95 \%$ confidence interval).

Cl: confidence interval; ITS: interrupted time series; RCT: randomised controlled trial; RD: risk difference

\section{GRADE Working Group grades of evidence}

High certainty: Further research is very unlikely to change our confidence in the estimate of effect.

Moderate certainty: Further research is likely to have an important impact on our confidence in the estimate of effect and may change the estimate.

Low certainty: Further research is very likely to have an important impact on our confidence in the estimate of effect and is likely to change the estimate.

Very low certainty: We are very uncertain about the estimate.

Details of five GRADE criteria for all outcomes from RCTs are in Appendix 2.

1 We downgraded the evidence to moderate because of indirectness.

2 We downgraded the evidence because most studies are non-randomised studies.

3 We graded the evidence as low because it is all from non-randomised studies.

${ }^{4}$ We graded the evidence as very low because it is all from non-randomised studies and there was too much heterogeneity for reliable evidence synthesis. 


\section{B A C K G R O U N D}

\section{Description of the condition}

Antibiotic resistance is a major public health problem. In comparison with infections caused by susceptible bacteria, those caused by multidrug-resistant bacteria are associated with higher incidences of mortality and prolonged hospital stay (de Kraker 2011). Clostridium difficile infection (CDI) is another manifestation of the collateral damage caused by antimicrobial prescribing (Davey 2010). Such infections are also associated with increased costs resulting from the need to use more expensive antibiotics, prolonged hospital stay (the principal contributor), and expenses related to screening and surveillance, eradication regimens, and consumables (the gloves, gowns, and aprons used to prevent cross-infection) (de Kraker 2011). The UK 5 Year Antimicrobial Resistance Strategy 2013 to 2018 recognises the importance of reducing inappropriate antibiotic prescribing (Department of Health 2013), the implication being that antibiotic resistance is largely a consequence of the selective pressures of antibiotic usage, and that reducing these pressures by the judicious administration of antibiotics will facilitate a return of susceptible bacteria or, at least, will prevent or slow the pace of the emergence of resistant strains.

At the same time, sepsis is a major cause of avoidable mortality in hospitals, with an estimated 100,000 cases per year in the UK alone (NCEPOD 2015).

\section{Description of the intervention}

We included any intervention to improve antibiotic prescribing to hospital inpatients. Antibiotic stewardship has two aims: first, to ensure effective treatment of patients with infection, and second, to minimise collateral damage from antimicrobial use (Davey 2010). Hence the UK Department of Health's Guidance on Antimicrobial Stewardship emphasises the need for urgent treatment of serious infections in addition to minimising unnecessary use of antibiotics (Department of Health 2013). We compared interventions to change professional behaviour with standard practice (no intervention). We classified interventions by their intervention function (Michie 2011). The previous version of this review suggested that restrictive interventions had greater immediate effect on prescribing than interventions that used education or persuasion (Davey 2013). For this update, we identified interventions that were designed to increase enablement, defined as 'increasing means/reducing barriers to increase capability or opportunity' (Michie 2011).

\section{How the intervention might work}

In this update of the review we used new data extraction sheets to classify the intervention functions and to identify the behaviour change functions that are used in antimicrobial stewardship interventions (Michie 2013). In particular, we assessed the relative effectiveness of interventions according to how they used enablement and restriction to change behaviour (Michie 2011). We divided the interventions into four groups: enablement without restriction; restriction without enablement; both enablement and restriction; and neither enablement nor restriction.

\section{Why it is important to do this review}

This review is an update of Davey 2005 and Davey 2013. It complements a review of interventions to improve prescribing of antibiotics to patients in ambulatory care (Arnold 2005).

\section{O B JECTIVES}

To estimate the effectiveness and safety of interventions to improve antibiotic prescribing to hospital inpatients and investigate the effect of two intervention functions: restriction and enablement.

\section{METHODS}

\section{Criteria for considering studies for this review}

\section{Types of studies}

We included randomised controlled trials (RCTs) and nonrandomised studies (NRS). We included three NRS study designs to measure behavioural and clinical outcomes and analyse variation in the effects: non-randomised trials (NRT), controlled before-after (CBA) studies and interrupted time series (ITS) studies. We used Cochrane Effective Practice and Organisation of Care (EPOC) Group eligibility guidance for CBAs and NRTs (EPOC 2016). In addition, for the assessment of unintended consequences, we included three additional NRS designs (case control, cohort, and qualitative studies) to identify additional evidence about long-term effects and harms of interventions in order to enhance the directness of evidence from RCTs (Schünemann 2013).

\section{Types of participants}

Healthcare professionals who prescribe antibiotics to hospital inpatients receiving acute care (including elective inpatient surgery). We excluded interventions targeted at residents in nursing homes or other long-term healthcare settings.

\section{Types of interventions}

We included interventions relevant to improving antibiotic prescribing as outlined in the EPOC taxonomy (EPOC 2015).

1. Audit and feedback defined as any summary of clinical performance of health care over a specified period of time.

2. Education through meetings or distribution of educational materials.

3. Educational outreach through academic detailing or review of individual patients with recommendation for change.

4. Reminders provided verbally, on paper, in the workplace environment (e.g. posters or messages printed on equipment) or on computer.

5. Structural: the influence on antibiotic prescribing of changing from paper to computerised records and of the introduction of new technology for rapid microbiology testing or measurement of inflammatory markers.

In addition, we included the following restrictive interventions: selective reporting of laboratory susceptibilities; formulary restriction; requiring prior authorisation (expert approval) therapeutic substitution; and automatic stop orders.

Enabling interventions were: audit and feedback; educational outreach through review of individual patients with recommendation for change; and circumstantial reminders that 
were targeted at doctors who were managing specific patients (Table 1). We classified reminders in the form of posters or pocket cards summarising antibiotic policies as environmental restructuring but not as enabling (Table 1). Terms used to describe interventions are described in more detail in the Data extraction and management section.

We did not consider studies that compared the effectiveness of antibiotic treatments (e.g. intravenous versus oral administration of antibiotics) as eligible for this review.

\section{Types of outcome measures}

\section{Primary outcomes}

The effect of interventions on antibiotic prescribing measured as either compliance with antibiotic guidelines or policies, the duration of antibiotic treatment, decision to treat, or total duration of treatment. We included studies without reliable or adequate information addressing the primary outcome measure, but we did not use these studies in data synthesis.

\section{Secondary outcomes}

Mortality, length of stay, or other clinical outcomes (e.g. surgicalsite infection or acute kidney injury), microbial outcomes (CDI, colonisation or infection with antimicrobial-resistant bacteria), unintended-consequences measures (e.g. a delay in start of antibiotic treatment, a change in threshold for diagnosis of hospital-acquired infection to justify existing prescribing practice). Note that clinical outcomes could be indicators of improved clinical outcomes associated with interventions to increase effective antibiotic treatment, or unintended consequences (e.g. to provide evidence about the safety of interventions to reduce unnecessary antibiotic treatment).

\section{Search methods for identification of studies}

\section{Electronic searches}

We searched the Cochrane Database of Systematic Reviews (CDSR) and the Database of Abstracts of Reviews of Effects (DARE) for related systematic reviews and the following databases for primary studies without language, publication year, or publication status restrictions in January 2015.

\section{Databases}

- Cochrane Central Register of Controlled Trials (CENTRAL; 2015, Issue 1) in the Cochrane Library (searched 22 January 2015)

- MEDLINE (1946 to 19 January 2015) (OvidSP)

- Embase (1947 to 22 January 2015) (OvidSP)

The MEDLINE search strategy was developed by the Cochrane EPOC Group Information Specialist in consultation with the review authors and translated for use in other databases employing appropriate syntax and vocabulary. Results were limited by two methodological filters: the Cochrane Highly Sensitive Search Strategy (sensitivity- and precision-maximising version, 2008 revision) to identify randomised trials (Higgins 2011), and a Cochrane EPOC Group study design filter to identify NRS. Full search strategies are provided in Appendix 1.

\section{Searching other resources}

We searched for additional studies using the bibliographies of included articles, personal files, and by contacting experts in the field regarding any unpublished work.

\section{Data collection and analysis}

\section{Selection of studies}

Two review authors (EB and PD) independently reviewed citations and abstracts retrieved in the search to identify all reports that included original data about interventions to change antibiotic prescribing. If either review author had doubts about eligibility, then both review authors reviewed the full papers. The review authors were not blinded to study author or location. We resolved disagreements by discussion and consensus.

We excluded studies that had no relevant and interpretable data presented or obtainable. We defined 'relevant data' as an intervention that included a change in antibiotic treatment for hospital inpatients and where at least one of the study's reported outcomes was directly attributable to change in antibiotic treatment. We defined 'interpretable data' as follows: CBA, NRT, or RCT designs had to include sufficient data to estimate effect size as change in at least one relevant outcome after the intervention. Interrupted time series studies had to include a clearly defined intervention point.

We did not exclude studies due to high risk of bias.

\section{Data extraction and management}

Working in pairs, five review authors (PD, CM, CS, EC, KM) independently performed data abstraction using data extraction sheets including information on: study design, type of intervention (intervention components and functions), presence of controls, type of targeted behaviour, participants, setting, methods (unit of allocation, unit of analysis, study power, methodological risk of bias, consumer involvement), outcomes, and results.

\section{Explanation of terms used to describe interventions}

\section{Restriction}

We defined restriction as 'using rules to reduce the opportunity to engage in the target behaviour (or increase the target behaviour by reducing the opportunity to engage in competing behaviours)'.

\section{Enablement}

We defined enablement as 'increasing means/reducing barriers to increase capability or opportunity'.

\section{Goal setting}

We documented the specific prescribing behaviour that was targeted by the intervention (e.g. switch participants from parenteral to oral antibiotics) and how this was incorporated into an aim for the intervention. Was the aim simply a directional change of the target behaviour (e.g. increase or decrease behaviour?), or did the intervention include a specific threshold to be reached (e.g. target behaviour performed more than $95 \%$ of the time) or the duration within which the target had to be achieved (e.g. more than $95 \%$ reliability within six months)? If the study reported a power calculation, we did not accept this as evidence of a specific threshold unless it was clearly communicated to 
the professionals who were the targets of the intervention. For example, a power calculation showing that the study could detect a $10 \%$ improvement in the targeted behaviour would have to be accompanied by some explicit statement about the intervention aim being at least $10 \%$ improvement.

\section{Feedback}

We classified interventions as including feedback only if they provided a "summary of clinical performance of healthcare over a specified period of time" (EPOC 2015). We found that some studies did not meet this definition, even though they described their intervention as including feedback in the title (e.g. Elligsen 2012 and Newland 2012) or in the methods (e.g. Palmay 2014). The intervention in these studies was educational outreach by review and recommended change, so the feedback was limited to the individual participants who were reviewed with no feedback about the treatment of other participants over time. In contrast, Buising 2008a is an example of an intervention in which "a formal feedback was provided to units regarding their compliance with the approval system over time" in addition to review and recommend change for individual participants. For studies that met our definition of feedback, we recorded frequency, format (verbal, written, or both) and whether it was delivered by a colleague, supervisor, or somebody external to the clinical team.

\section{Action planning}

We documented whether there was a reward for meeting a target, which could be material or social reward (either from self or others) and the use of action plans if the target was not met. Our definition of an action plan was: prompt, detailed planning of performance of the behaviour, which had to include at least one of context, frequency, duration, or intensity. If there was evidence of action planning, we recorded to whom the action plan was tailored (e.g. individual participant or group) and whether participants were involved in developing the action plan.

\section{Intervention components and functions}

In the Characteristics of included studies we have listed the intervention components (Types of interventions) and the intervention functions (Michie 2011; Michie 2013). Note that each intervention component may have more than one intervention function. We have presented definitions of intervention functions and their relationship to intervention components in Table 1.

\section{Assessment of the impact of interventions}

We have used meta-analysis to assess the impact of RCTs of interventions and meta-regression to understand variation in effect estimates for RCTs and ITS studies.

\section{Assessment of risk of bias in included studies}

We applied the 2013 EPOC 'Risk of bias' criteria to all papers in the review, including articles in the 2003 review (EPOC 2013). We scored each study for risk of bias as 'low' if all criteria were scored as 'low', 'medium' if one or two criteria were scored as 'unclear' or 'high', and 'high' if more than two criteria were scored as 'unclear' or 'high'.

We applied three additional criteria to studies with microbial outcomes, based on the ORION statement: Guidelines for transparent reporting of outbreak reports and intervention studies of nosocomial infection (Orion Statement; Stone 2007).
1. Case definition: score as 'low' if there is a clear definition either of infection or of colonisation and there were no major changes in laboratory diagnostic methods during the study period.

2. Planned intervention: score as 'low' if the intervention was planned to reduce endemic rates of colonisation or infection and was not implemented in response to an outbreak. Regression to the mean following an outbreak is an important risk of bias for estimates of the effect of interventions in ITS studies of infection (Davey-Smith 2001; Stone 2007).

3. Other infection control measures: score as 'low' if infection control practices (hand hygiene, gowning, or other personal protection) and isolation or cohorting policies are described and there were no changes coincident with the intervention to change antibiotic prescribing.

We have presented microbial 'Risk of bias' results in the Notes section of the Characteristics of included studies. We have not included them in the 'Risk of bias' tables unless there might also be a risk to prescribing outcomes (e.g. appointment of additional infection control practitioners who might have influenced prescribing).

We assessed risk of bias in case control or cohort studies of unintended consequences with ROBINS-I: a tool for assessing Risk of Bias in Non-randomised Studies of Interventions (Sterne 2016). We have reported these 'Risk of bias' assessments in the Notes section of the Characteristics of included studies.

\section{Measures of treatment effect}

We assessed the impact of interventions on clinical outcome for studies that provided reliable data about mortality, length of hospital stay, or other clinical outcomes such as acute kidney injury. We did not include clinical outcomes for studies that estimated the impact of their intervention based on modelling (Barlow 2007). We analysed dichotomous data (such as increase in desired practice and mortality) as risk differences and analysed continuous data (such as length of hospital stay) as mean differences.

We critically examined the methods of analysis of ITS data. The preferred method is a statistical comparison of time trends before and after the intervention. If the original paper did not include an analysis of this type, we extracted the data presented in tables or graphs in the original paper and used them to perform new analyses where possible. We used segmented time series regression analysis to estimate the effect of the intervention whilst taking account of time trend and autocorrelation among the observations. We obtained estimates for regression coefficients corresponding to two standardised effect sizes for each study: a change in level and a change in trend before and after the intervention. A change in level was defined as the difference between the observed level at the first intervention time point and that predicted by the pre-intervention time trend. A change in trend was defined as the difference between post- and preintervention slopes (Ramsay 2003). We evaluated the direct effect of the intervention using results reported one month after the start of the intervention. We also reported the level effects at six months, and yearly thereafter when possible. We standardised the results of some ITS studies so that they were on the same scale (per cent change in outcome), thereby facilitating comparisons of different interventions. To do this, we used the change in level and change in slope to estimate the effect size with increasing time after the intervention (one month, six months, one year, 
etc.) as the per cent change in level at each time point. We did not extrapolate beyond the end of data collection after the intervention. We anticipated that the eligible studies would exhibit significant heterogeneity, due to variations in target clinical behaviours, patient and provider populations, methodological features, characteristics of the interventions, and the contexts in which the interventions were delivered. To address the source of variation in results due to the use of enabling or restrictive interventions, we undertook a random-effects meta-regression analysis on study-level summary effect size at each time point.

We assessed the impact of interventions on microbial outcomes if the study provided reliable data about colonisation or infection with Clostridium difficile or with antibiotic-resistant bacteria. We did not include microbial outcomes for studies that estimated the future impact of their intervention based on modelling (Paul 2006), or that used clinical definitions of infection that did not distinguish between resistant and sensitive bacteria (Micek 2004; Singh 2000).

\section{Unit of analysis issues}

If an RCT did not take into account the effect of clustering in the analysis, we stated this in the 'Risk of bias' assessment. We incorporated consideration of unit of analysis issues as part of the sensitivity analyses.

We estimated intracluster correlation (ICC) for each outcome. The ICCS used reflect that process measures usually have higher ICC than outcome measures and were obtained from the database of ICCs held by the Health Services Research Unit, University of Aberdeen (Health Services Research Unit 2016).

\section{- Prescribing 0.2 \\ - Mortality 0.01 \\ - Length of stay 0.2}

Average cluster size $(\mathrm{m})=$ (total number of participants (intervention + control $)) \doteqdot$ (total number of clusters). Inflation factor $=1+(\mathrm{m}-1) \times$ ICC. For dichotomous outcomes, we divided events and participants by the inflation factor for intervention and control groups. For continuous outcomes, we multiplied intervention and control standard deviation by the inflation factor.

\section{Dealing with missing data}

We have not attempted to account for missing data in the metaanalysis of RCTs or meta-regression of ITS studies. For ITS studies, we only analysed effects at a specified time point when data were available, we have not carried forward regression lines beyond the last observation or used regression lines to estimate missing data.

\section{Assessment of heterogeneity}

We quantified heterogeneity among studies using the $1^{2}$ statistic and Cochran's Q test (Cochran 1954). The $\left.\right|^{2}$ statistic quantifies the percentage of the total variation across studies that is due to heterogeneity rather than chance (Higgins 2003); smaller percentages suggest less observed heterogeneity.

\section{Assessment of reporting biases}

We assessed publication and selective reporting bias.

\section{Data synthesis}

We have analysed the results for RCTs, CBAs, NRT, and ITS studies separately. For the RCT data, we employed a standard meta-analysis approach using Review Manager 5 for binary (e.g. compliance with guidelines) and continuous (e.g. duration of treatment) outcomes. We analysed the data with a fixed-effect model (Review Manager 5).

We used Stata 14 for all statistical re-analyses and meta-regressions (Stata 2015), and Review Manager 5 for all data synthesis (Review Manager 5).

\section{Subgroup analysis and investigation of heterogeneity}

We used meta-regression to investigate potential effect modifiers. In meta-regression, the outcome variable is the effect estimate (e.g. a mean difference or a risk difference). The explanatory variables are characteristics of studies that might influence the size of intervention effect (Higgins 2011).

We prespecified four subgroups as explanatory variables for the meta-regression (Davey 2014):

1. interventions that included enablement versus those that did not;

2. interventions that included restriction versus those that did not;

3. enabling interventions that included feedback versus those that did not;

4. feedback interventions that included goal setting or action planning versus those that did not.

Definitions of these terms can be found in Data extraction and management and Table 1 . We expected restriction, enablement, feedback goal setting and action planning to be associated with increased effectiveness of interventions (Ivers 2012).

We included the following three additional variables in the metaregression because they might influence the size of intervention effect and explain heterogeneity.

1. Target: choice of antibiotic regimen versus time to first antibiotic dose or exposure to antibiotics, effects possibly greater for interventions targeting choice.

2. Setting: single unit versus multiple wards, effects possibly greater in single unit.

3. Intent: increase effective versus decrease excessive, effects possibly greater with increase effective.

The meta-regression was performed using standard weighted (by standard error of estimate) linear regression (Higgins 2011).

\section{Sensitivity analysis}

We conducted sensitivity analyses by re-analysing data to investigate the effect of two risks of bias.

1. Lack of adjustment for the effect of clustering in cluster RCTs. We repeated all analyses that included cluster RCTs with adjusted numbers of events and total participants for dichotomous variables and adjusted standard deviation for continuous variables (Analysis 1.2; Analysis 1.5; Analysis 2.2; Analysis 2.5). 
2. Overall high risk of bias. We analysed all studies at medium and low risk of bias separately in sensitivity analyses (Analysis 1.3; Analysis 1.6; Analysis 2.3; Analysis 2.6).

\section{Summary of findings}

We summarised the findings of the main intervention comparison for the most important outcomes in Summary of findings for the main comparison. Two review authors independently assessed the certainty of the evidence for each key outcome (high, moderate, low, and very low) using the five GRADE considerations (study limitations, consistency of effect, imprecision, indirectness, and publication bias) (Guyatt 2011). We assessed the following outcomes:

1. compliance with desired practice;

2. duration of antibiotic treatment;

3. mortality;

4. length of hospital stay;

5. delay in treatment;

6. negative professional culture.

We also assessed the evidence from the meta-regression in terms of the extent to which we believed it helped explain variation of effect. We included the following effect modifiers in our analysis.

1. Enablement (Yes/No)

2. Restriction (Yes/No)
3. Addition of feedback to enablement (Yes/No)

4. Addition of enablement to restriction (Yes/No)

We used the methods and recommendations described in Section 8.5 and Chapter 12 of the Cochrane Handbook for Systematic Reviews of Interventions, Higgins 2011, and the EPOC worksheets (EPOC 2013a). Disagreements on certainty ratings were resolved by discussion, and justification for decisions to down- or upgrade the ratings are provided in footnotes in the table and comments made to aid readers' understanding of the review where necessary. We used plain language statements to report these findings in the review. Further details about each of the five GRADE criteria are in Appendix 2.

Evidence from randomised studies started at high certainty and was downgraded according to the five considerations described above. Evidence from non-randomised studies started at low certainty and was assessed against the same five criteria. We only considered upgrading for non-randomised evidence in the presence of a large treatment effect, dose response, or where plausible confounding would have reduced the observed effect.

\section{RE S U L T S}

\section{Description of studies}

\section{Results of the search}

The combined results of all literature searches are described in the study flow diagram (Figure 1). 
Figure 1. Figure 1 Study flow diagram.

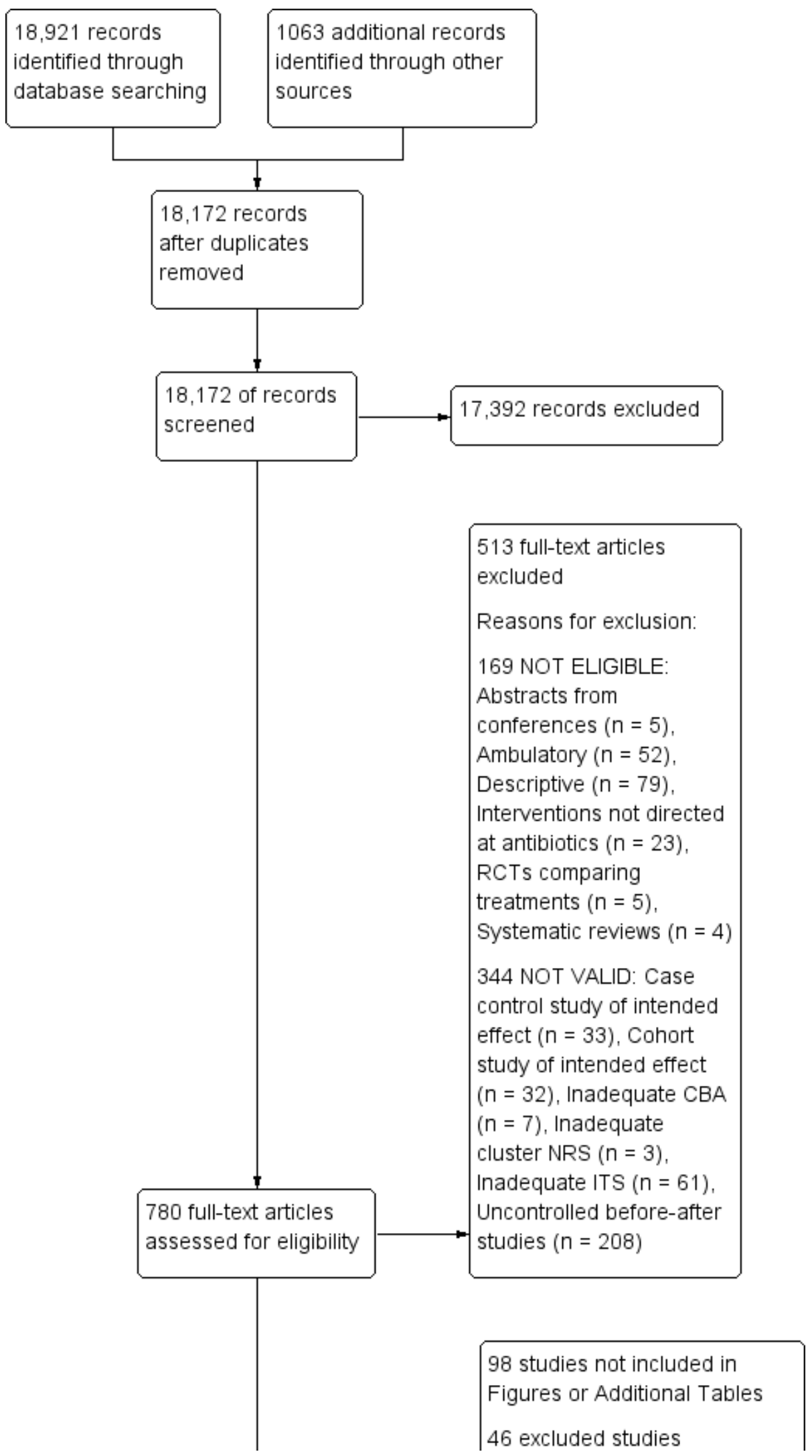


Figure 1. (Continued)

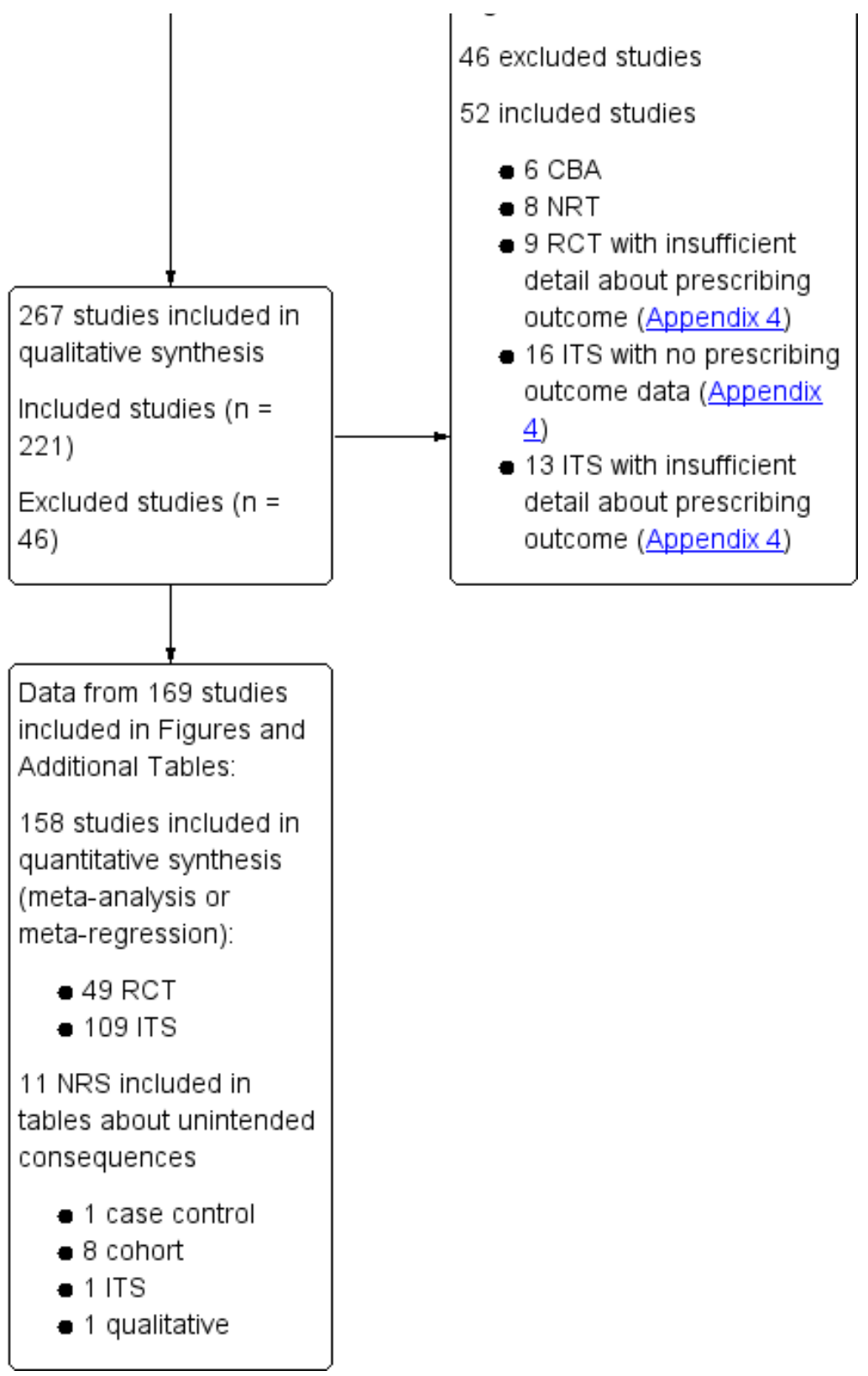

\section{Included studies}

The Characteristics of included studies table lists 221 studies, of which 211 used the following designs to evaluate the intended effect of interventions: 138 ITS studies, 58 RCTs (14 cluster RCTs), 6 CBAs, and 8 NRTs. The remaining 11 studies were designed to identify unintended consequences of interventions and used the following designs: 8 cohort (Connor 2007; Duvoisin 2014; Friedberg 2009; Kanwar 2007; LaRosa 2007; Linkin 2007; Welker 2008; Winters 2010), 1 case control (Calfee 2003), and 1 qualitative (semi-structured interviews) (Baysari 2013) and 1 ITS (Bell 2014).

\section{Geographical location of study}

Ninety-six studies were from North America. The remaining 125 were from Europe (87, includes Israel), Asia (19), South America (8), Australia (8), and East Asia (3). The number of studies by country (including the countries in four multinational studies) is: Argentina, 1; Australia, 9; Austria, 2; Belgium, 4; Brazil, 4; Canada, 8; China, 6; Colombia, 2; Croatia, 1; Denmark, 3; France, 11; Germany, 12; Greece, 1; Hong Kong, 1; Hungary, 1; India, 1; Indonesia, 1; Israel, 1; Italy, 3; Japan, 1; Korea, 3; Lebanon, 1; Mexico, 1; Netherlands, 11; Norway, 1; Serbia, 1; Singapore, 1; Spain, 5; Sweden, 2; Switzerland, 11; Taiwan, 3; Thailand, 4; Turkey, 1; UK, 22; USA, 89.

\section{Number of hospitals}

A total of $178(79 \%)$ studies were conducted in one hospital, 9 studies in 2 hospitals, 18 studies in 3 to 9 hospitals, and 16 studies in 10 or more hospitals. 


\section{Deliverer of intervention}

Of the 221 interventions, 112 (51\%) were designed and delivered by a multidisciplinary team, $54(24 \%)$ by specialist physicians (infectious diseases or microbiology), 35 (16\%) by department physicians (e.g. emergency department or critical care), and 20 (9\%) by pharmacists.

\section{Funding}

Five studies received some funding from manufacturers of drugs or laboratory tests. The remaining 216 studies were funded by government agencies or the participating hospitals. Details are provided in the Characteristics of included studies table.

\section{Power calculations}

Details of power calculations are provided in Appendix 3

\section{Excluded studies}

We excluded 32 unique studies from the review because they did not contain relevant or interpretable data (Selection of studies). For details of each study, see Characteristics of excluded studies.

\section{Risk of bias in included studies}

All 14 CBAs and NRTs were at high risk of bias (Figure 2). High risk of bias was more common in RCTs $(36 / 58,62 \%)$ than in ITS studies (20/138, 14\%) (Figure 2). All 51 studies at low risk of bias were ITS studies (Figure 2). Among RCTs, high risk of bias was much more likely in studies with two or fewer hospitals $(31 / 36$, $86 \%)$ versus three or more hospitals $(11 / 22,50 \%)$. Of the 11 RCTs with two or fewer hospitals with medium risk of bias, nine interventions were circumstantial reminders targeted at doctors who were managing specific patients (Christ-Crain 2004; ChristCrain 2006; Esposito 2011; Kerremans 2009; Lacroix 2014; Lesprit 2013; Long 2014; Senn 2004; Stocker 2010; Strom 2010), so the risks of allocation or contamination bias were relatively low compared with the other RCTs of interventions in one or two hospitals. However, the remaining two RCTs at low risk of bias show that these risks can be minimised for RCTs of review and recommend change interventions in single hospitals (Lesprit 2013; Palmay 2014). 
Figure 2. Risk of bias graph: review authors' judgements about each risk of bias item presented as percentages across all included studies. Blank sections in this graph are due to use of different ROB criteria for CBA, NRT and RCT versus ITS studies

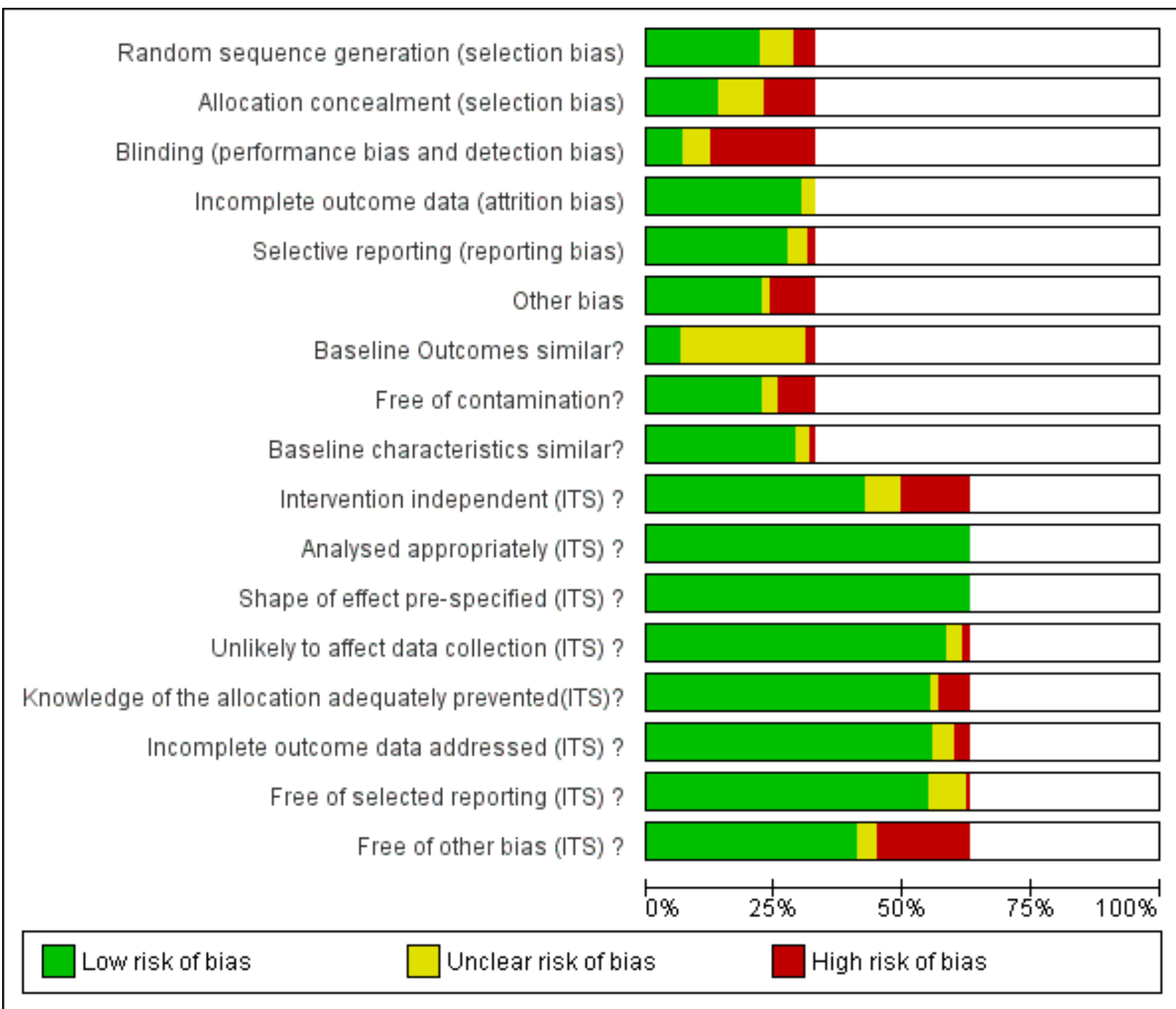

We have presented 'Risk of bias' criteria for the case control and cohort studies of unintended consequences in the Notes section in Characteristics of included studies.. For the nine studies, we assessed the risk of bias as high in two (Calfee 2003; Friedberg 2009), medium in two (Linkin 2007; Welker 2008), and low in five (Connor 2007; Duvoisin 2014; Kanwar 2007; LaRosa 2007; Winters 2010).

\section{Allocation}

Most of the RCTs had high risk of selection bias because of problems with concealment of allocation (Figure 2). The RCTs with low risk of selection bias were either cluster RCTs or interventions with circumstantial reminders, for which concealment of allocation is relatively straightforward.

\section{Blinding}

Most of the RCTs also had high risk of performance and detection bias because RCTs in single hospitals were often single-blind and it was difficult to conceal the allocation of participants in these trials (Figure 2).

\section{Incomplete outcome data}

The RCTs used data collected specifically for the trial, and all provided convincing evidence about lack of attrition bias. Most of the ITS studies used data from routine systems for prescribing (pharmacy) and microbial (microbiology) outcomes; we assessed these sources as having low risk of attrition bias (Figure 2). Examples of high risk of attrition bias in routine data are changes in the number of participants who did not have serum creatinine measure preoperatively during the study period, which may have biased ascertainment of postoperative kidney injury (Bell 2014), and use of surveillance data about surgical-site infection that did not include information about infections arising after discharge from hospital (Dua 2014). 


\section{Selective reporting}

We also assessed routine data systems as being at low risk of reporting bias (Figure 2). Most of the ITS studies used computerised pharmacy systems to measure drug consumption.

\section{Other potential sources of bias}

Less than $25 \%$ of RCTs provided clear information about baseline outcome; most of these were cluster RCTs (Figure 2). The most common single risk of bias for ITS studies was that the intervention was not independent of other changes (Figure 2). For ITS studies, the main risks of bias were that there were insufficient data to account for seasonal variation or that one or more of the microbial 'Risk of bias' criteria were present (Figure 2).

\section{Effects of interventions}

See: Summary of findings for the main comparison Effects of interventions to improve use of antibiotics on prescribing, clinical outcomes, adverse events, and effect modifiers (heterogeneity)

\section{Studies included in evidence synthesis and 'Summary of findings' tables}

Outcomes from 49 (84\%) of the 58 RCTs and 110 (80\%) of the 138 ITS studies were used in at least one meta-analysis or meta-regression or are summarised in text or Additional tables. The contribution that each RCT made can be found in Appendix 4. One ITS study contributed data about unintended consequences (Bell 2014). The contribution of 109 ITS studies to meta-regression of prescribing outcomes is summarised in Appendix 5. Reasons for exclusion of 10 RCTs and 28 ITS studies from evidence synthesis can be found in Appendix 6.

The 10 case control, cohort, or qualitative studies of unintended consequences all contributed evidence about adverse effects.

None of the 6 CBAs or 8 NRTs included evidence about adverse effects of interventions, and there were not enough studies for evidence synthesis.

\section{Intended prescribing outcomes for RCTs and ITS studies included in evidence synthesis}

Interventions were targeted at antibiotic treatment for $46(94 \%)$ of 49 RCTs and 101 (92\%) of 110 ITS studies. The remaining 11 studies targeted surgical antibiotic prophylaxis (Bell 2014; Dull 2008; Gulmezoglu 2007; Kritchevsky 2008; Meyer 2010; Perez 2003; Schwann 2011; Sun 2011; Van Kasteren 2005; Wax 2007; Weinberg 2001).

For the 148 interventions targeted at antibiotic treatment, the intended outcome of 137 (93\%) interventions was to decrease excessive use of antibiotics: 45/46 (98\%) RCTs and 93/102 (91\%) ITS studies. The only RCT that was primarily intended to increase effective treatment targeted dosing of gentamicin (Burton 1991). Two RCTs with antibiotic choice as the primary outcome did include time to first antibiotic dose for participants with communityacquired pneumonia as a secondary outcome (Schouten 2007; Yealy 2005). The only other evidence about increasing effective treatment of sepsis came from six ITS studies that aimed to reduce time to first antibiotic dose (Barlow 2007; Hitti 2012; Jobson 2015; Marwick 2013; Volpe 2012; Weiner 2009).

In contrast, reduction in excessive use of antibiotics was the intended outcome of only 3 (25\%) of the 12 interventions targeted at surgical antibiotic prophylaxis (Bell 2014; Sun 2011; Van Kasteren 2005). The remaining nine interventions were all intended to increase effective use of antibiotics by increasing the number of participants who received prophylaxis or reducing the time to first antibiotic dose.

\section{Effectiveness and adverse effects of interventions \\ Effectiveness of interventions in RCTs}

Interventions were associated with an increase in compliance with desired practice by $15 \%$ (95\% confidence interval $(\mathrm{Cl}) 14 \%$ to $16 \%$ ) in 29 RCTs (Analysis 1.1; Figure 3). We obtained similar results in sensitivity analyses for unit of analysis errors (Analysis 1.2) or risk of bias (Analysis 1.3). Interventions were associated with a reduction in duration of total antibiotic treatment by -1.95 days $(95 \% \mathrm{Cl}-2.22$ to -1.67 ) in 14 RCTs (Analysis 1.4; Figure 4). We obtained similar results in sensitivity analyses for unit of analysis errors (Analysis 1.5) or risk of bias (Analysis 1.6). 
Figure 3. Forest plot of comparison: 1 Prescribing: RCTs of all interventions to reduce unnecessary prescribing, outcome: 1.1 Dichotomous outcomes, increase in desired practice.

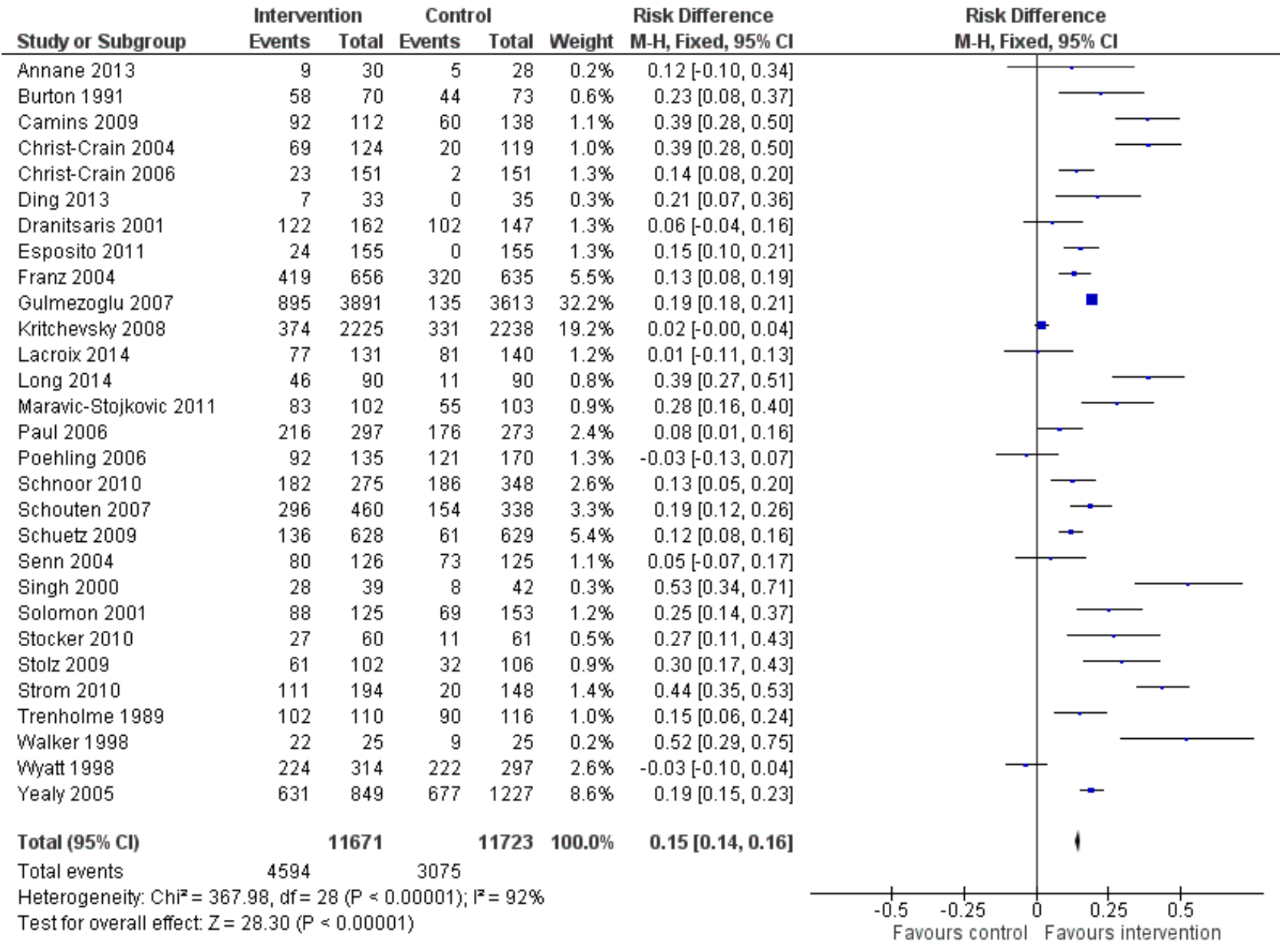

Figure 4. Forest plot of comparison: 1 Effectiveness: Prescribing outcomes from RCTs of interventions to reduce unnecessary antibiotic use, outcome: 1.4 Continuous outcomes, duration of all antibiotic treatment (days).

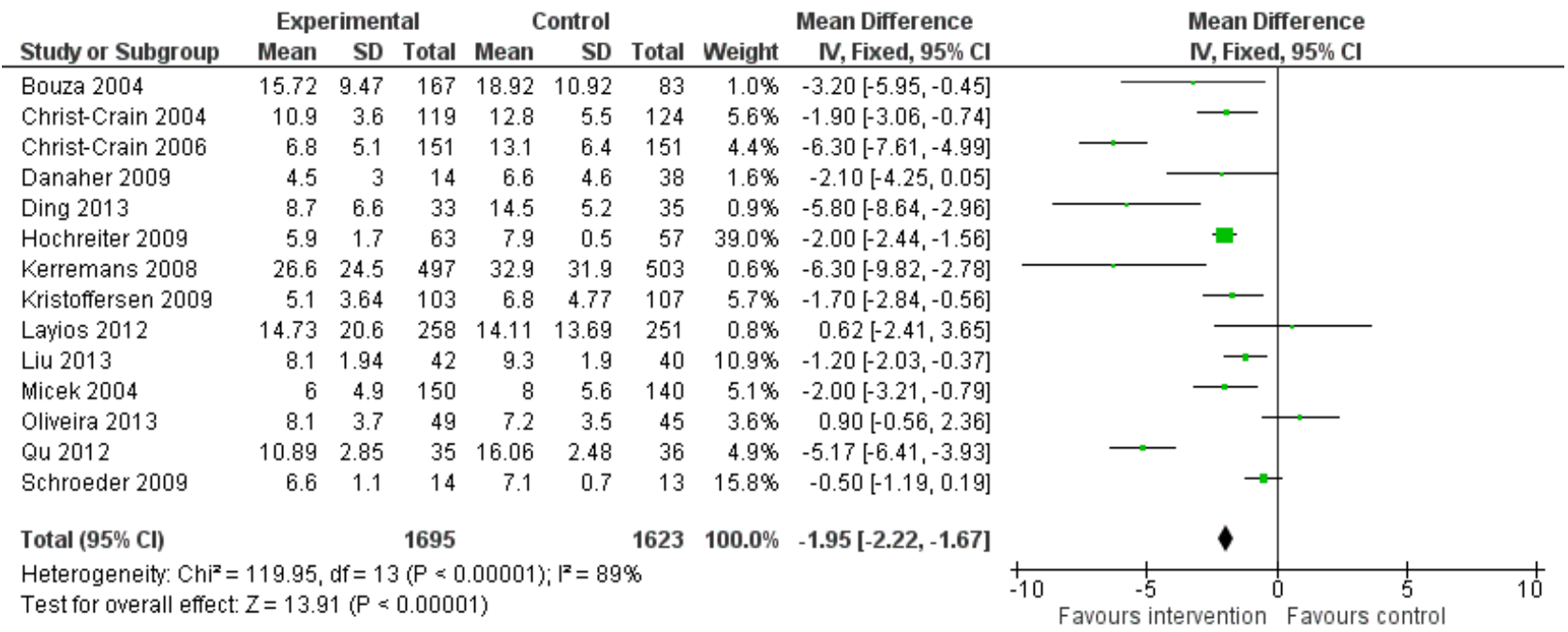


In four RCTs the prescribing outcome was the consumption of targeted antibiotics measured in different units (cost, days, or defined daily dose), so results were expressed as standardised mean reduction (Analysis 1.7.).

\section{Adverse effects of interventions}

\section{Evidence from RCTs}

Interventions were not associated with any increase in mortality ( $95 \% \mathrm{Cl} 1$ to 0 fewer deaths per 100 participants) in $28 \mathrm{RCTs}$ (Analysis
2.1; Figure 5). We obtained similar results in sensitivity analyses for unit of analysis errors (Analysis 2.2) or risk of bias (Analysis 2.3). Interventions were associated with reduction in length of stay by -1.12 days $(95 \% \mathrm{Cl}-1.54$ to -0.70$)$ in $15 \mathrm{RCTs}$ Analysis 2.4; Figure 6). We obtained similar results in sensitivity analyses for unit of analysis errors (Analysis 2.5) or risk of bias (Analysis 2.6). We found no evidence of a difference in results for interventions that targeted antibiotic exposure (decision to treat or duration of all antibiotic treatment) versus the choice of antibiotic prescribed (Analysis 3.1; Analysis 3.2; Analysis 4.1; Analysis 4.2)

\section{Figure 5. Forest plot of comparison: 2 Adverse effects: Clinical outcomes from RCTs of interventions to reduce} unnecessary antibiotic use, outcome: 2.1 Mortality, all RCTs.

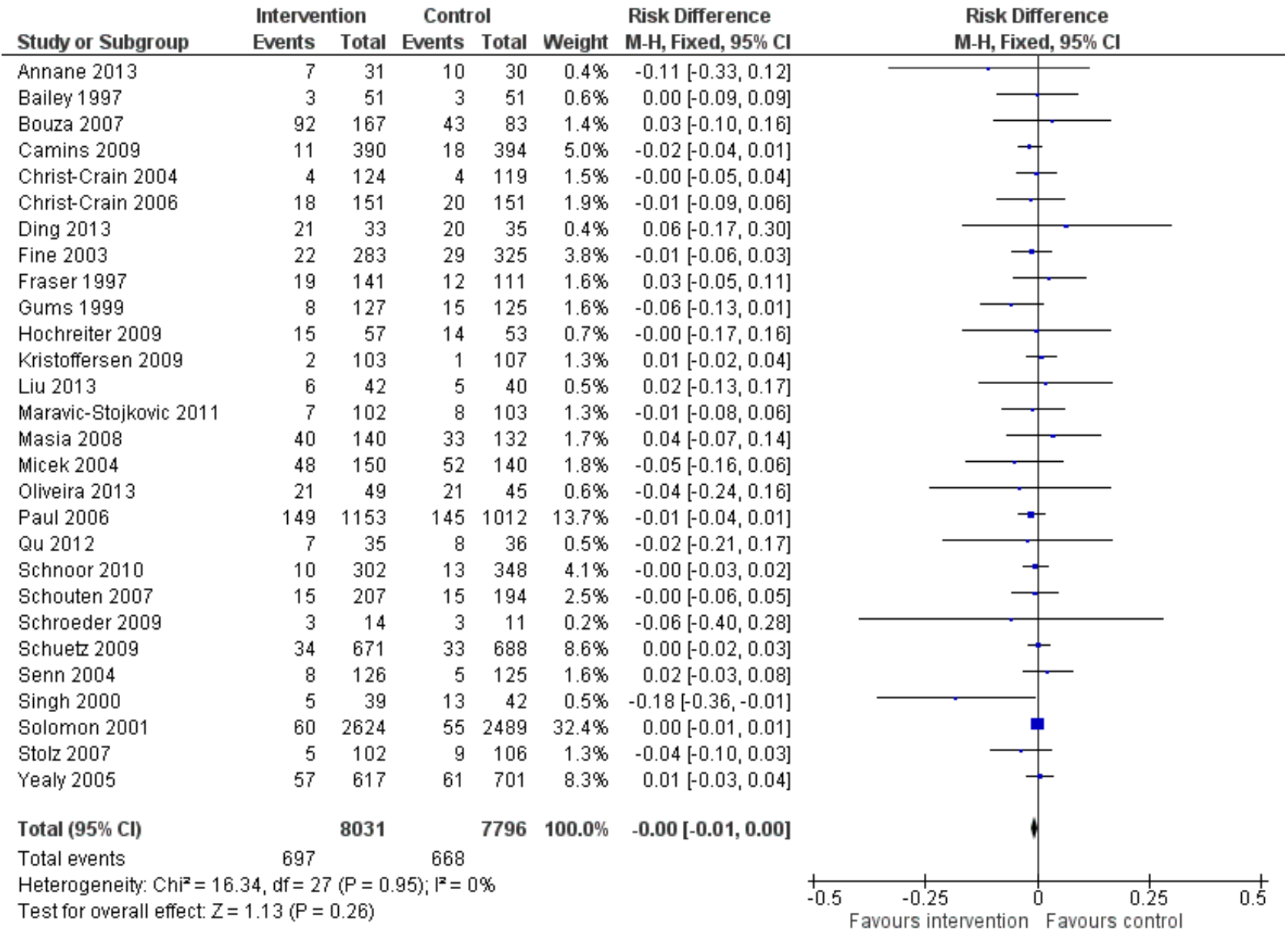


Figure 6. Forest plot of comparison: 2 Adverse effects: Clinical outcomes from RCTs of interventions to reduce unnecessary antibiotic use, outcome: 2.4 Length of stay, all RCTs.

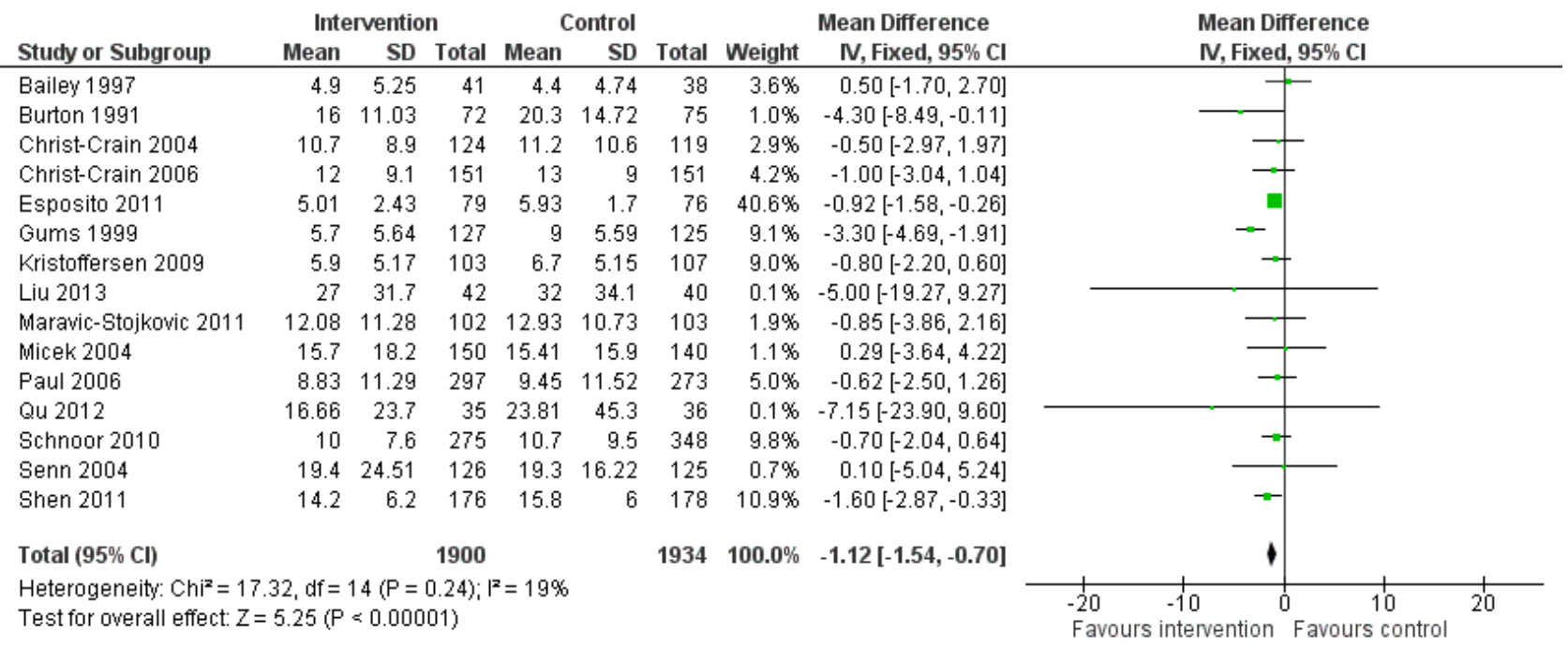

One RCT measured clinical outcome as potentially harmful delay in essential treatment (Strom 2010). The outcome was ascertained by the Trial Monitoring Committee, who stopped the trial prematurely when four participants were found to have potentially harmful delay in treatment with trimethoprim-sulphamethoxazole or warfarin. This was a restrictive intervention intended to prevent interactions between these drugs.

\section{Evidence from NRS}

\section{ITS studies}

Clinical outcome data were measured as mortality in four ITS studies (Table 2) and length of stay in one ITS study (Table 3). However, we could only calculate $95 \% \mathrm{Cl}$ for three of these studies (Lee 2014; Popovski 2015; Skaer 1993), and the outcome data came from all participants in the hospital rather than just the participants who were the targets of the interventions.

Three ITS studies reported other clinical outcomes that provided more direct evidence about unintended consequences of the interventions (Table 4). An intervention to promote gentamicin for prophylaxis was intended to reduce risk of CDI but was associated with a large increase in acute kidney injury in the participants undergoing target operations, and as a consequence the antibiotic policy change was reversed (Bell 2014). An intervention designed to shorten time to first antibiotic dose for people with sepsis was not associated with any increase in the time left without being seen for all other participants in the emergency department (Volpe 2012). An intervention to reduce the duration of surgical antibiotic prophylaxis was not associated with increased surgicalsite infection (Van Kasteren 2005).

\section{Case control, cohort and qualitative studies}

Ten studies investigated unintended consequences of interventions to change antibiotic choice with cohort ( $n=8)$, case control $(n=1)$, or qualitative case study $(n=1)$ designs (Table 5$)$.

There was a restrictive component to the intervention in seven studies. One study showed that restriction of laboratory tests of inflammation (C-reactive protein and white blood cell count) was not associated with an increase in time to first antibiotic dose (Duvoisin 2014). The remaining six studies all revealed unintended consequences of interventions that restricted antibiotic choice by requiring prior approval, as follows.

- Negative professional culture through breakdown in trust and communication (Baysari 2013; Calfee 2003; Connor 2007; Linkin 2007).

- Delay in time to first antibiotic dose (LaRosa 2007; Winters 2010). Evidence of delay in essential treatment was also seen in one RCT (Strom 2010).

In three studies (Friedberg 2009; Kanwar 2007; Welker 2008), the intervention was a national financial incentive in the USA that was intended to reduce time to first antibiotic dose for people admitted to hospital with community-acquired pneumonia (CAP). In all three studies, the unintended consequence was misdiagnosis of pneumonia, which could lead to an increase in unnecessary antibiotic treatment. In two single-centre studies, there was a decrease in the percentage of participants with correct diagnosis of CAP based on prespecified criteria (Kanwar 2007; Welker 2008). In contrast, a large, multicentre study reported no evidence of an overall increase in the diagnosis of CAP (Friedberg 2009); however, this study was at high risk of bias.

\section{Explaining heterogeneity in the intended effect of interventions}

\section{Meta-regresson of RCTs}

We performed meta-regression on 29 RCTs with dichotomous prescribing outcomes (Analysis 1.1; Figure 3). Outcomes for all of these trials could be expressed as number of participants where treatment was compliant with policy divided by total participants. We did not perform meta-regression on 15 RCTs with continuous prescribing outcomes because the outcomes were heterogeneous (Analysis 1.4; Analysis 1.7) and because none of the interventions included restriction or feedback, and only two did not include enablement (Danaher 2009; Kerremans 2008). 


\section{Meta-regression results for 29 RCTs with dichotomous outcomes}

In the meta-regression, enablement, restriction, targeting antibiotic choice versus exposure and high risk of bias were significantly associated with greater intervention effect in univariate analysis, and they all remained significant in multivariate analysis (Figure 7).

Figure 7. Meta-regression by effect modifier for 29 RCTs. A positive value for Beta indicates enhanced intervention effect. One RCT had both enabling and restrictive components in the intervention (Strom 2010).

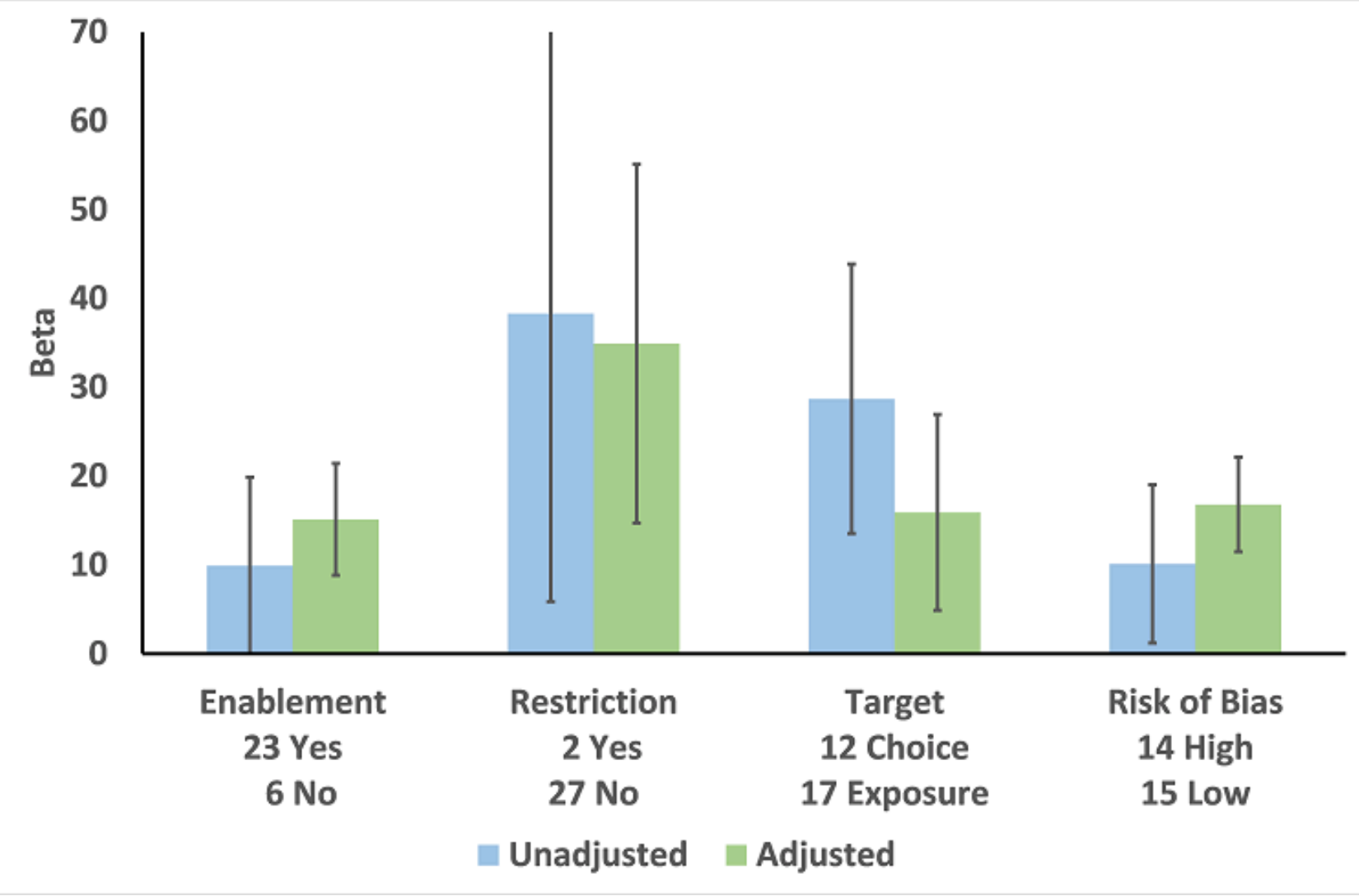

Of the 23 RCTs of enabling interventions, four also included feedback (Camins 2009; Schnoor 2010; Schouten 2007; Yealy 2005). All four of these RCTs targeted antibiotic choice, so we have compared their effects with seven RCTs of enabling interventions without feedback that also targeted antibiotic choice. The mean risk difference for interventions with feedback was $19 \%(95 \% \mathrm{Cl}$ $16 \%$ to $22 \%$ ) (Figure 8) compared with $13 \%$ (95\% Cl $9 \%$ to $17 \%)$ (Figure 9) for interventions with no feedback. Only two of the feedback RCTs also included action planning (Schouten 2007; Yealy 2005).

Figure 8. Forest plot of comparison 5: RCTs of enablement with and without feedback, outcome: 5.1 Enablement plus feedback.

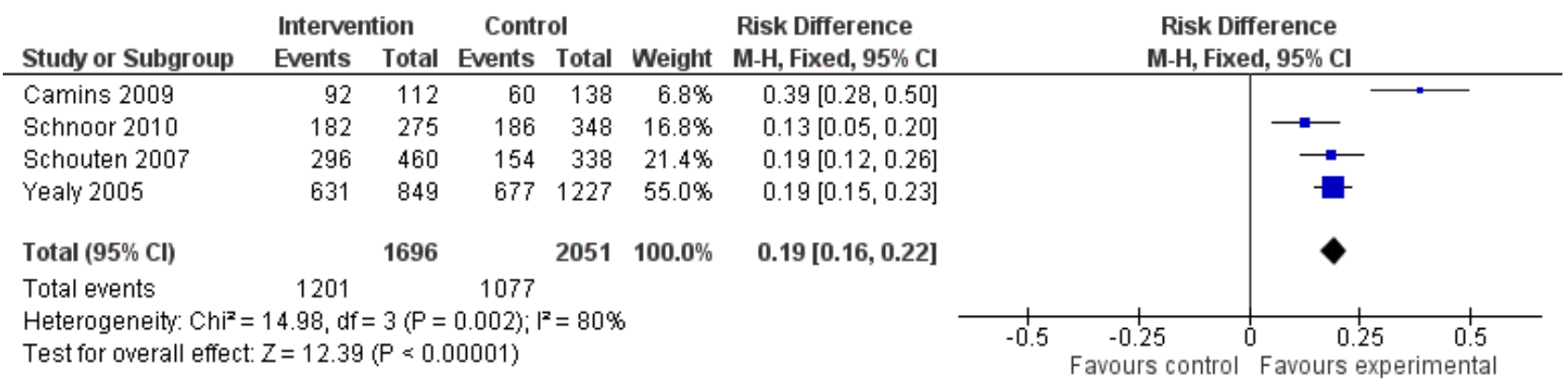


Figure 9. Forest plot of comparison 5: RCTs of enablement with and without feedback, outcome: 5.2 Enablement without feedback.

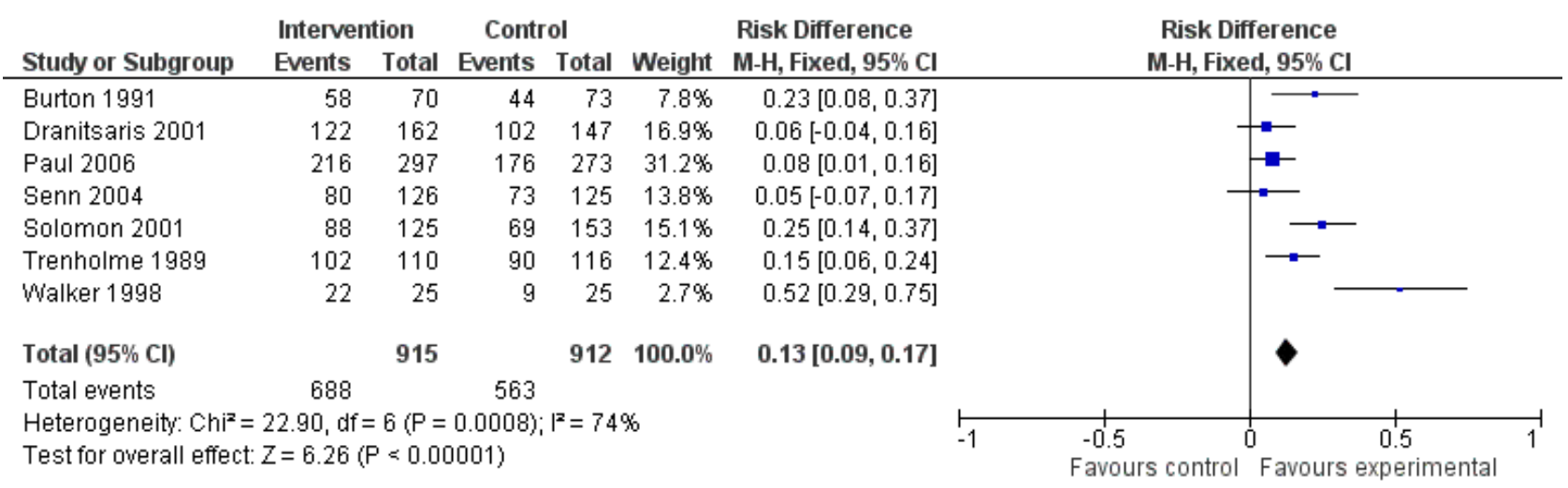

\section{Meta-regression of ITS studies}

Do interventions that involve enablement have greater initial effect?

There were 107 ITS studies with data that could be used for meta-regression of prescribing outcomes at one, six, or 12 months' postintervention. We used multivariable meta-regression to identify effect modifiers in 91 ITS studies including data about prescribing at six months' postintervention. As with the RCTs (Figure 7), both enablement and restriction were independently associated with increased effect in ITS studies (Figure 10). Of 29 ITS studies with restrictive interventions, 13 (45\%) also had enablement, and this independently enhanced intervention effect (Figure 11). In comparison with interventions targeting antibiotic exposure, those targeting choice were associated with greater effect in RCTs (Figure 7), but not in ITS studies (Figure 10). The number of studies in each category only allowed analysis of the effects of setting in ITS studies (Figure 10), and intention could only be included in meta-regression of ITS studies of enabling intervention (Figure 12). The limited evidence suggests that intention and setting were not effect modifiers (Figure 7; Figure 10). 
Figure 10. Meta-regression by effect modifiers of intervention for 91 ITS studies. Outcome is effect on prescribing six months' postintervention. There are 16 studies with both enabling and restricting intervention components (Figure 11).

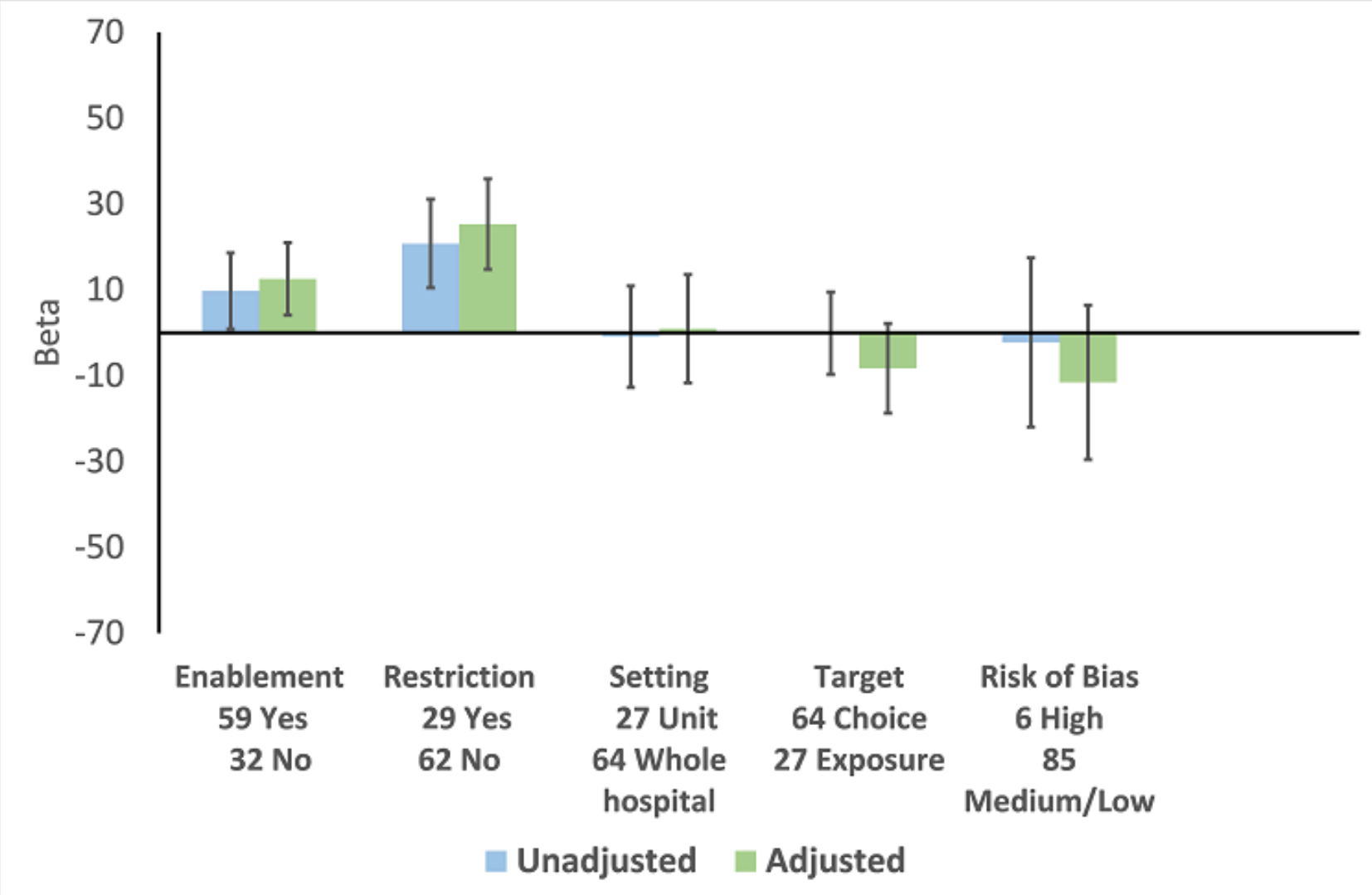


Figure 11. Meta-regression of prescribing outcome by effect modifiers for 29 ITS studies of interventions that included restriction.

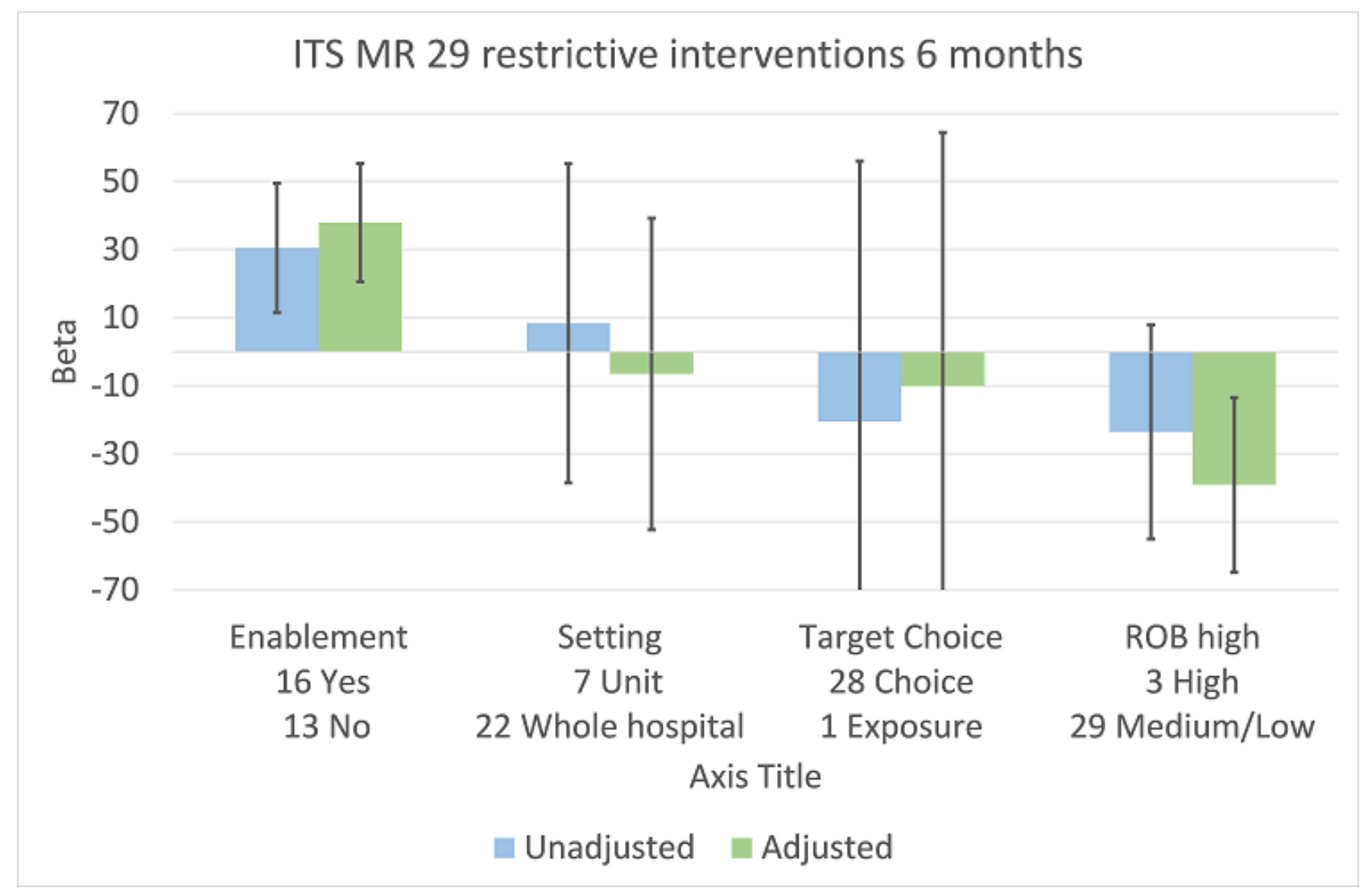


Figure 12. Meta-regression by effect modifier for 43 ITS studies of interventions that included enablement but not restriction. Outcome is effect on prescribing six months' postintervention. Note that four studies with feedback were not included in this analysis because they also included restriction.

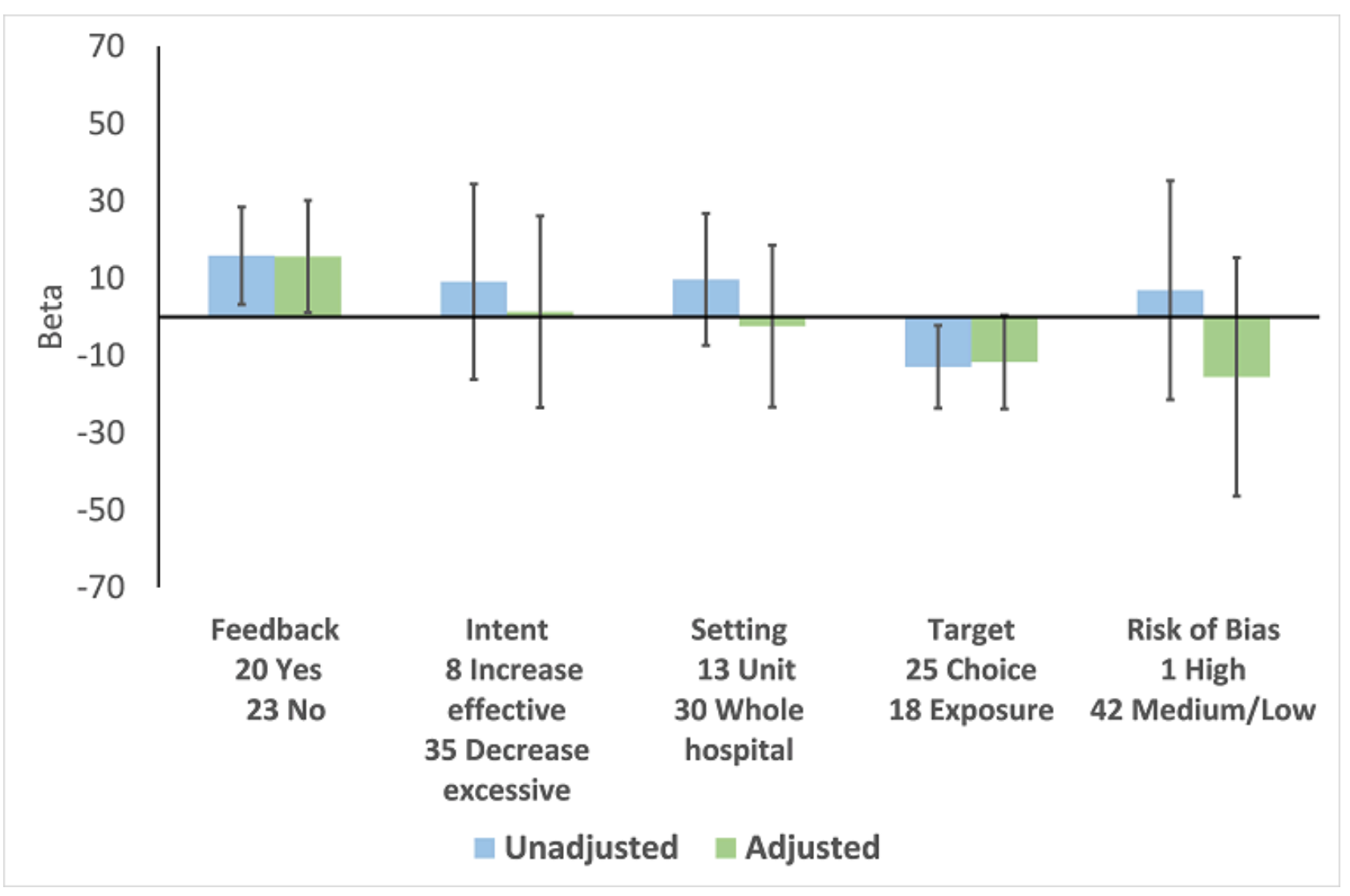

Are interventions that include feedback more effective than those that do not?

Feedback was included in 4 (17\%) of 23 RCTs (Figure 8) and 20 (47\%) of 43 ITS studies (Figure 12) of enabling interventions that did not include restriction. The intervention was audit and feedback alone in three RCTs and 10 ITS studies. In one RCT and 11 ITS studies, audit and feedback was combined with review and recommend change or circumstantial reminders. Interventions that included feedback were more effective than those that did not. However, there were too few studies with goal setting or action planning to assess their effect in addition to feedback.

There were only two ITS studies with enough data to analyse the effect of adding an additional component to an effective intervention. However, the second intervention component did not include goal setting, feedback, or action planning in either study (Mol 2005; Po 2012)

\section{Summary of interventions for the studies included in meta-regression}

In comparison with RCTs, the ITS studies were more likely to have multiple intervention components: $35(38 \%)$ of 91 ITS studies versus $5(17 \%)$ of $29 \mathrm{RCTs}$, odds ratio 3.00 ( $95 \% \mathrm{Cl} 1.05$ to 8.59$)$ (Table 6). There were also differences in the components for enabling interventions (review and recommend change was included in 53\% of ITS studies versus $25 \%$ of RCTs) and restrictive interventions (removal of target drugs from clinical areas was included in 34\% of ITS studies but in no RCTs) (Table 6). Educational meetings or distribution of educational materials was the most common intervention in studies that did include enablement or restriction ( $75 \%$ of RCTs and $89 \%$ of ITS studies) (Table 6 ).

\section{Sustainability of intervention effect}

Sustainability was assessed in 64 of 91 ITS studies, with prescribing outcome data at both 6 and 12 months' postintervention. Intervention effect was sustained at 12 months' postintervention in $55(86 \%)$ of these studies $(95 \% \mathrm{Cl} 77 \%$ to $94 \%)$. There were 13 interventions with neither enablement nor restriction; intervention effect was sustained in $11(85 \%)(95 \% \mathrm{Cl} 65 \%$ to $100 \%)$. Consequently, it was unlikely that either enablement or restriction would be associated with greater sustainability. However, the results suggest that restrictive interventions were less likely to have sustained effect if they did not include enablement: $5 / 8(62 \%)$ versus $12 / 13(92 \%)$ with enablement, risk difference $30 \%(95 \% \mathrm{Cl}$ $-7 \%$ to $66 \%)$.

Five ITS studies with data about removal of interventions provided additional information about sustainability of interventions (Table 7). Three of these studies also provided data about the effect of the intervention. The intended effect of all interventions was decrease in the use of target antibiotics. Removal of the intervention was associated with increase in the use of target antibiotics in all five studies and, with one exception (Kim 2008), the 95\% Cl for effect size did not include decrease in use of target antibiotics. Kim 2008 
was the only one of these five interventions including enablement by audit and feedback.

\section{Microbial outcomes (antibiotic resistance and CDI)}

There were 1 CBA and 5 RCTs with microbial outcome data, and these were too heterogeneous for data synthesis (Table 8).

We performed meta-regression on 26 ITS studies including reliable data about prescribing outcomes at 6 months and microbial outcomes at 12 months after the intervention (Table 9). Six unplanned interventions (in response to outbreaks) were associated with markedly greater effect on microbial outcomes (Figure 13). When studies were ranked in descending order of effect size for microbial outcome at 12 months, the top five studies were all unplanned interventions (Kim 2008; May 2000; McNulty 1997; Tangdén 2011; Valiquette 2007), with the remaining unplanned intervention ranking 9th (Lautenbach 2003).

Figure 13. Meta-regression by effect modifiers for 34 microbial outcomes 12 months' postintervention from 26 ITS studies. The bars show the results for unadjusted versus adjusted analyses, the comparison for unplanned interventions is with planned interventions in both the unadjusted and adjusted analysis. CDI: Clostridium difficile infection

GPC: infection with antibiotic-resistant gram-positive cocci

GNB: infection with antibiotic-resistant gram-negative bacteria Other infection control: 'Yes' means there were changes to infection control processes during the study period.

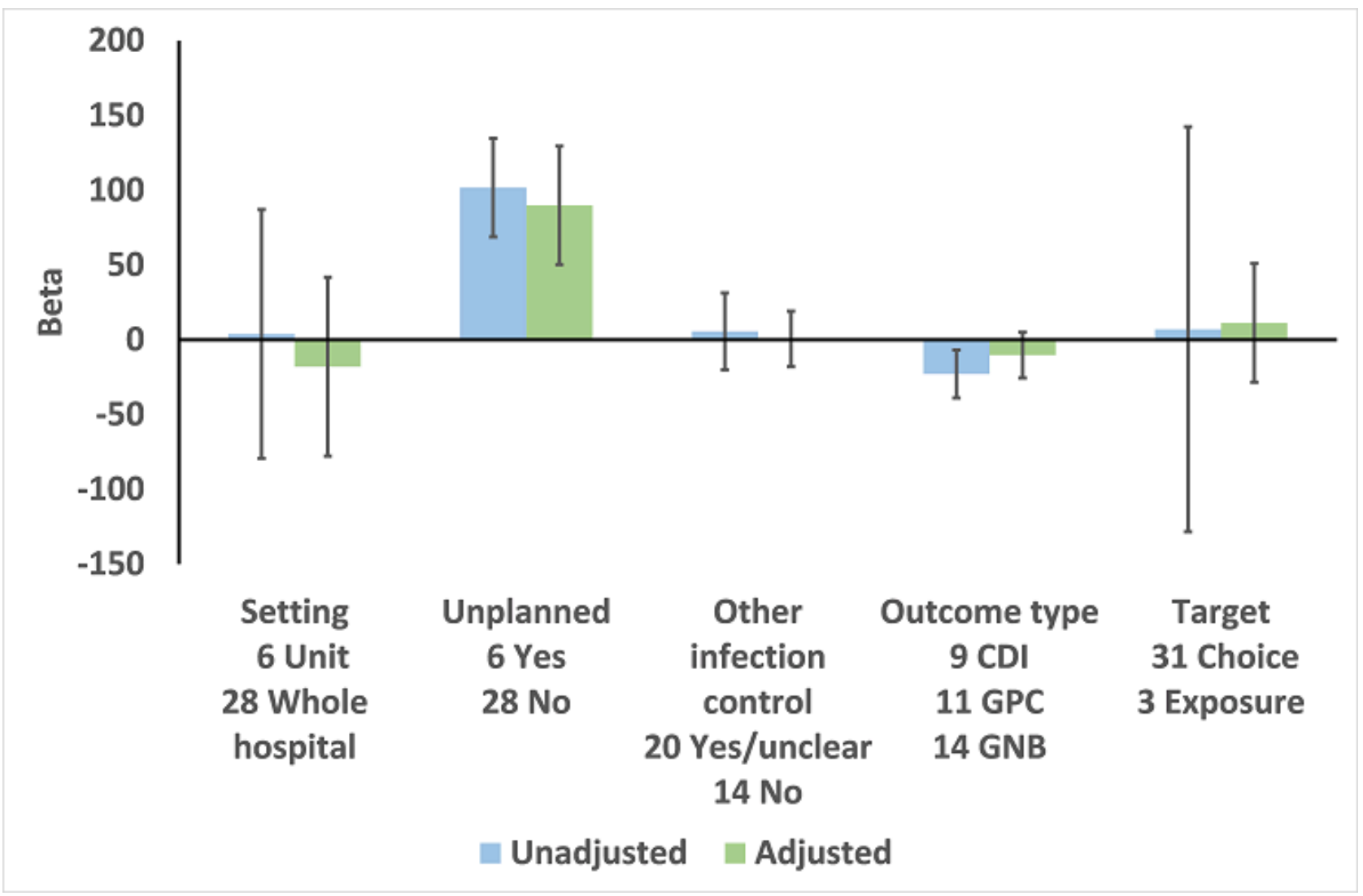

In the 20 studies of planned intervention, there were six studies with unclear information about other infection control interventions or changes during the study period (Chan 2011; Grohs 2014; Jump 2012; Liebowitz 2008; Meyer 2009; Petrikkos 2007). We performed meta-regression on the remaining 14 studies from Table 9 (Figure 14). In contrast with the meta-regression of all 27 studies (Figure 13), the effects of setting, other infection control interventions, and microbial outcome type were all reversed so that each of these variables was associated with increase in effect size in the 14 studies with planned interventions and details of other infection control interventions (Figure 14). 
Figure 14. Meta-regression by effect modifiers for 20 microbial outcomes 12 months' postintervention from 14 ITS studies of planned interventions that provided details about other infection control changes or interventions. CDI: Clostridium difficile infection

GPC: infection with antibiotic-resistant gram-positive cocci

GNB: infection with antibiotic-resistant gram-negative bacteria Other infection control: 'Yes' means there were changes to infection control processes during the study period.

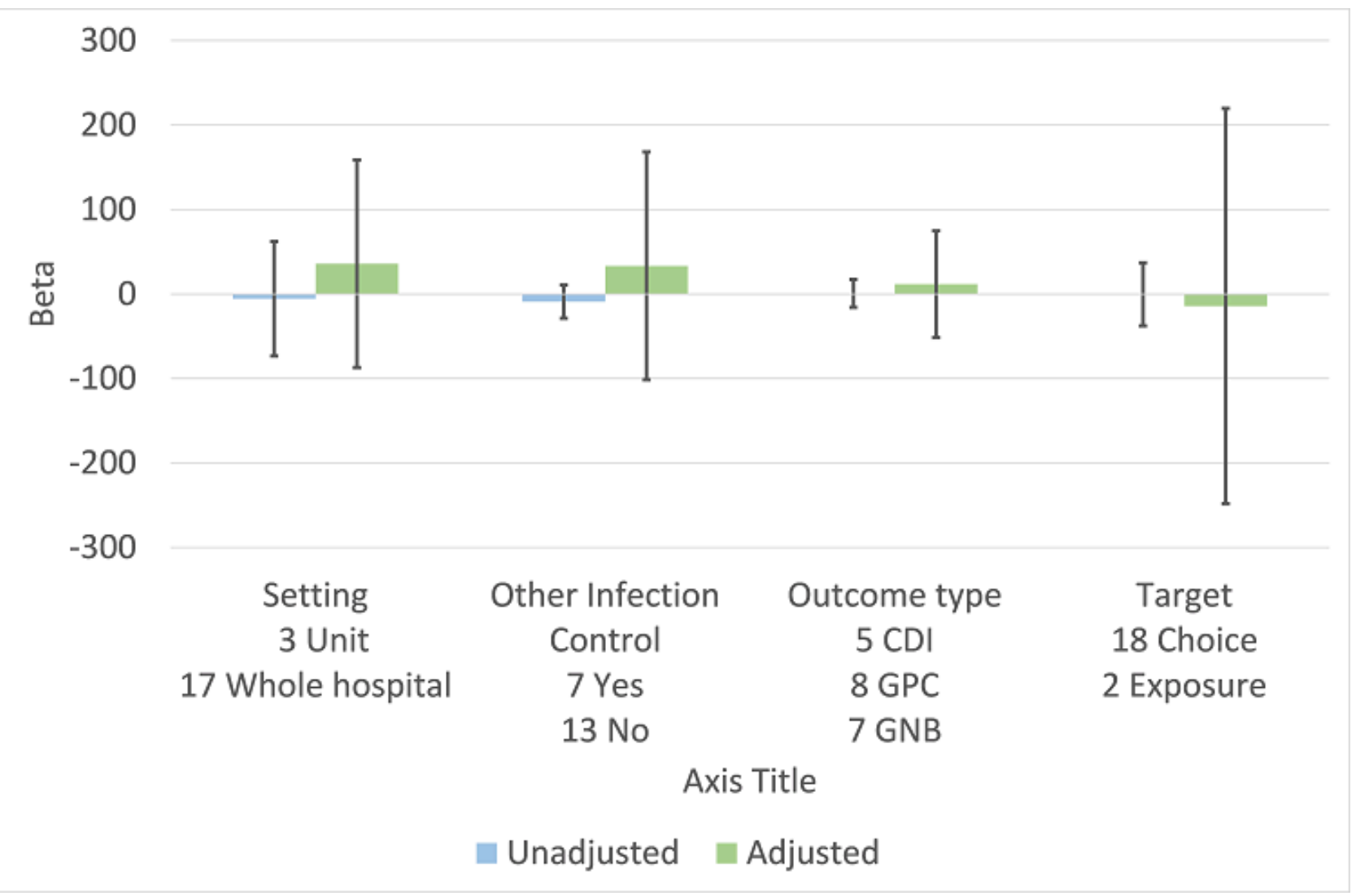

The antibiotic targets for the 20 studies of planned interventions were single antibiotic classes in nine studies (Cook 2011b; Grohs 2014; Knudsen 2014; Lafaurie 2012; Lee 2007; Meyer 2009; Petrikkos 2007; Willemsen 2010; Yoon 2014), high-risk antibiotics in nine studies (Aldeyab 2012; Aldeyab 2014; Ananda-Rajah 2010; Buising 2008a; Chan 2011; Dancer 2013; Fowler 2007; Liebowitz 2008; Talpaert 2011), and all antibiotics in the remaining two studies (Cook 2011a; Jump 2012). High-risk antibiotics were a combination of drugs from more than one class of antibiotic, which were all considered to be high risk for the microbial outcome. The prescribing outcome data reported in these nine studies varied from just one of the high-risk antibiotics, in Dancer 2013, through individual results for all of the high-risk antibiotics, in Buising 2008a, Chan 2011, Fowler 2007, and Talpaert 2011, to combined results for all of the high-risk antibiotics (Aldeyab 2012; Aldeyab 2014; Ananda-Rajah 2010; Liebowitz 2008).

One study can be used to demonstrate the technical challenges of estimation of intervention effect on microbial outcomes (Dancer 2013). The intervention was addition of complete restriction of ceftriaxone and ciprofloxacin to a pre-existing multifaceted intervention introduced seven months before restriction and remaining in place throughout the restrictive period (Dancer 2013). We could not analyse the effect of the initial multifaceted intervention because there were no pre-intervention data about prescribing or microbial outcomes. However, the available data showed CDI was lower by -0.143 cases per 1000 occupied bed days per month in the nine months prior to the addition of the restrictive intervention. At the start of the restrictive intervention, $C D I$ rates were already low (1.5 cases per 1000 occupied bed days). After the introduction of restriction, $C D I$ rates continued to decline for five months, and then stabilised at around 0.5 cases per 1000 occupied bed days. These data suggest that the restrictive intervention had no additional effect on the rate of CDI. However, the segmented regression analysis estimated that there was a relative increase of $35.8 \%$ in CDI rate 12 months after the restrictive intervention with very wide confidence intervals (from $81.0 \%$ decrease to $152.7 \%$ increase).

Our review did include one multicentre controlled ITS study comparing CDI rates in six hospitals with antimicrobial stewardship programmes versus four control hospitals (Ostrowsky 2014). We did not include this study in evidence synthesis because neither the interventions nor the prescribing outcomes were standardised across the six hospitals with stewardship programmes. Baseline rates of CDI were only 0.8 cases per 1000 occupied bed days in the intervention and control hospitals before the intervention, and the authors did not report a decrease in aggregate CDI rates either 
between intervention and non-intervention groups or within the intervention groups over time (Ostrowsky 2014).

We have not attempted to synthesise microbial outcome data because of the small number of studies, the heterogeneity of intervention targets and prescribing outcomes, and the wide confidence intervals for estimated relative effect. We have focused on the 20 ITS studies of planned interventions and separated the results by microbial outcome type. Interventions were associated with consistent reduction in CDI (median $-48.6 \%$, interquartile range $-80.7 \%$ to $-19.2 \%$ ) but inconsistent effect on resistant gramnegative bacteria (median $-12.9 \%$, interquartile range $-35.3 \%$ to $25.2 \%$ ) and resistant gram-positive bacteria (median $-19.3 \%$, interquartile range $-50.1 \%$ to $23.1 \%$ ). There were too few studies with too much variance in microbial outcomes to reliably assess the relationship between change in antibiotic use and each of the microbial outcomes.

\section{DISCUSSION}

\section{Summary of main results}

The RCTs provide high-certainty evidence that interventions are effective in increasing compliance with antibiotic policies and in reducing duration of antibiotic treatment safely, without an increase in mortality. Furthermore, interventions were associated with a reduction in length of stay. The mechanism is not clear, and further investigation is required. However, reducing length of stay is a key organisational objective for most hospitals, so this evidence should be used to prioritise antimicrobial stewardship in hospitals.

Analysis of effect modifiers in RCTs and ITS studies consistently supported the theory that involving enablement increases intervention effect, including those with restrictive components. However, feedback was only used in a minority of enablement interventions, and very few included goal setting or action planning.

\section{Overall completeness and applicability of evidence}

The RCTs show that interventions increase compliance with policies or guidelines by $15 \%$, which is a clinically important effect size. However, the result is less impressive when one considers that health professionals' adherence to prescribing recommendations increased from $43 \%$ to $58 \%$, because $58 \%$ compliance is probably still far too low. Three studies did achieve $90 \%$ compliance with guidelines by making this an explicit goal for the intervention and using action planning to revise interventions until the goal was achieved (Jobson 2015; Volpe 2012; Weinberg 2001).

The ITS studies provided important additional evidence that the results of RCTs regarding effectiveness of interventions can be reproduced in routine practice: $70 \%$ of ITS studies reported on hospital-wide interventions compared with only $31 \%$ of RCTs.

Only two ITS studies included data that enabled assessment of the effect of adding an intervention component to an existing intervention ( $M o l$ 2005; Po 2012). This is a strong study design that should be more widely used to evaluate these types of interventions.

\section{Safety and unintended consequences of interventions}

The main limitation of the RCT evidence regarding safety of reducing unnecessary use was that only two interventions included restriction, and one was stopped early because of delay in the start of treatment (Strom 2010). Two NRS also raised concerns about delay in time to first antibiotic dose associated with restrictive interventions (LaRosa 2007; Winters 2010). Furthermore, four NRS described negative effects of restrictive interventions on professional culture through breakdown in trust and communication (Baysari 2013; Calfee 2003; Connor 2007; Linkin 2007). These NRS used either case control, cohort, or qualitative designs because they required collection of data that were not available in routine clinical systems (Table 5).

The ITS studies provided very little evidence about the safety of interventions because they rely on routine clinical systems for outcome measures, which are currently largely incapable of providing information about specific patients, for example those with infection. Moreover, the range of clinical measures should be extended beyond infection outcomes to include safety indicators such as acute kidney injury (AKI). (Bell 2014). Scotland's Infection Intelligence Platform was established to improve linkage and availability of routine data (ISD 2016), but research is required to improve timeliness, quality, and relevance of clinical outcome measures and to provide a richer understanding of the unintended consequences of improvement interventions (SISCC 2016). We found only one example of a qualitative study of unintended consequences (Baysari 2013). This is an important study design for investigation of unanticipated consequences of interventions and should be more widely used (Rogers 1995).

Studying the effect of removal of an intervention can be used to provide additional evidence about the outcomes of the original intervention (Walker 2016). This study was from the same group that reported that an intervention that was intended to reduce risk of $C D I$ in people undergoing orthopaedic surgery was associated with an increased risk of postoperative AKI (Bell 2014) (Table 4). The increase in AKI was attributed to change in antibiotic surgical prophylaxis policy from cefuroxime to flucloxacillin and gentamicin. This second study showed reduction in postoperative $\mathrm{AKI}$ associated with a change away from flucloxacillin and gentamicin, which provides persuasive additional evidence that gentamicin was responsible for the original increase in postoperative AKI (Walker 2016).

Interventions were consistently associated with reduced length of stay (Analysis 2.4), and the results were similar when analysis was restricted to RCTs at low or medium risk of bias (Analysis 2.6). Measurement of length of stay was intended to provide reassurance about safety of the intervention so that reduction in length of stay is an example of an unanticipated beneficial outcome (Ash 2007; Rogers 1995). We found similar results for interventions that targeted antibiotic choice (Analysis 3.2) or antibiotic exposure (Analysis 4.2). One possible mechanism for reduction in length of stay is that interventions reduced the duration of intravenous antibiotic therapy (Carratala 2012). However, further research is required.

\section{Microbial outcomes}

Interventions were consistently associated with reduction in CDI, but less consistently associated with reduction in infection by resistant bacteria. However, intervention effects on microbial 
outcomes could only be analysed reliably in planned interventions (Figure 13), and our meta-analysis was limited by four technical challenges.

1. Each study had considerable variance because of the small number of microbial events in each time point.

2. Studies rarely had stable pre-intervention data, so that extrapolation of the pre-intervention trend throughout the postintervention phase was probably unreliable.

3. We analysed a single prescribing outcome for each study (even if more were reported). The criteria for selection of the prescribing outcome were determined by the analysis plan for the effect of interventions on prescribing behaviour. However, these criteria may not have been correct for analysis of the relationship between changes in prescribing and microbial outcomes.

4. We could only analyse the relationship between prescribing and microbial outcomes at fixed time points. We chose six and 12 months, respectively, imposing a six-month time lag for all interventions. However, the time lag will likely vary by prescribing and microbial outcomes, and by intervention context (Vernaz 2008).

\section{Quality of the evidence}

We found high-certainty evidence that interventions increase appropriate use of antibiotics, reduce duration of antibiotic treatment, and shorten hospital stay without increasing the risk of mortality. There was low-certainty evidence that these interventions can delay treatment and create a negative professional culture (Summary of findings for the main comparison). High risk of bias was associated with greater intervention effect in RCTs (Figure 7) for the outcome of compliance with desired practice. However, we have presented separate analysis of effects for RCTs at low or medium risk of bias (Analysis 1.3; Analysis 1.6; Analysis 2.3; Analysis 2.6). These analyses provide evidence supporting our decision not to downgrade for risk of bias, since excluding studies at high risk of bias did not substantively change the direction of effect. We did not downgrade for inconsistency since the direction of effect across the studies was consistent, and our meta-regression provides some explanation for the high levels of statistical heterogeneity between the results of the studies. The certainty of evidence about adverse effects was more variable, with particular concerns about the unintended consequences of restrictive interventions, namely delays in treatment and negative professional culture, for which we have low-certainty evidence.

The quality of reporting of interventions was poor, which makes it difficult for professionals and clinical teams to reliably implement interventions that have been shown to be useful and for other researchers to replicate or build on research findings (Hoffmann 2014). We found high-certainty evidence that enablement and restriction both enhanced the effectiveness of interventions. However, we found only moderate-certainty evidence for the effectiveness of feedback, and there were too few studies with action planning and goal setting to provide any reliable information about the combined effects of these behaviour change techniques.

In the analysis of risk of bias equal weight is given to all criteria (Figure 2). Our results for microbial outcomes clearly showed that the risk of bias from unplanned interventions is much greater than the risk from other infection control interventions (Figure 13; Figure 14).

We found that some NRS study designs provided important additional evidence about intervention effects and sustainability in routine clinical practice (ITS studies) and about unintended consequences (case control, cohort, and qualitative studies). However, we found no useful evidence from CBAs or NRTs and suggest that these study designs should not be included in updates to this review.

\section{Heterogeneity of intervention effect}

We found that two intervention functions, enablement and restriction, explained some of the variation in targeted prescribing behaviour. However, we found little evidence that behaviour change theory had been used to design interventions (Charani 2011). There were too few interventions with explicit goals or action planning to include these variables in meta-regression.

There was no consistent evidence that intervention setting or target explained variation in the effect of interventions (Figure 7; Figure 10)

\section{Potential biases in the review process}

Our decision not to use adjusted data for cluster RCTs for the primary analysis could be contested. The consequences of using unadjusted data would be to assign too much weight to cluster studies in the analysis, potentially biasing the effect from our analyses to their results (Higgins 2011). We believe that taking clustering into account is unlikely to impact on the strength of the results in such a way as to change the conclusions of the review. Our sensitivity analyses provide some indirect support for the approach we have undertaken. In comparison to unadjusted results, analyses based on the effective sample sizes calculated from assumed ICCS consistently gave a larger average intervention effect (Analysis 1.1 versus Analysis 1.2; Analysis 2.1 versus Analysis 2.2; Analysis 2.4 versus Analysis 2.5).The increased effect size could be explained by the lower weight assigned to the cluster studies, which tended to have smaller effects than the individually randomised studies.

The electronic literature search did not identify $42(19 \%)$ of the 221 included studies, highlighting some of the challenges in constructing sensitive search terms for reviews of behavioural interventions and the identification of non-randomised studies. It is possible that additional eligible studies have not been retrieved by the search process we undertook for this review.

We did not find evidence of publication bias in the RCTs, however publication bias is more likely in the ITS studies because the decision to publish may have been made after the analysis of intervention effect.

\section{Agreements and disagreements with other studies or reviews}

\section{Agreements}

Ivers 2012 included and analysed 140 RCTs that compared any intervention in which audit and feedback was a core, essential component to usual care and evaluated effects on professional practice. The review concluded that interventions were more effective if they also included goal setting and action planning. We were unable to reproduce their analysis because only four of 
our RCTs included feedback (Figure 8). Although 20 ITS studies included feedback (Figure 12), there were not enough studies with goal setting or action planning for reliable analysis.

Our findings are similar to a previous review that found that behavioural determinants and social norms were not given due consideration in the design and evaluation of interventions to change antibiotic prescribing (Charani 2011).

\section{Sustainability of intervention effect}

We found evidence that removal of restriction, in Himmelberg 1991, Kallen 2009, Kim 2008, and Skrlin 2011, or of review and recommend change (enablement, Standiford 2012) was associated with reversal of intervention effect (Table 7). Three previous studies have shown that removal of financial incentives is associated with reversal of intervention effects in primary care (Avery 2012; Dreischulte 2016; Lester 2010). This is an important issue because the attractiveness of interventions will be reduced if improvement resources cannot be moved on to new priorities. Restriction is a relatively low-cost intervention, but it is worrying that an enabling intervention (review and recommend change) apparently had no sustained effect on clinical teams after being in place for seven years (Standiford 2012). Review and recommend change is a timeintensive process that was included in $36(54 \%)$ of 67 of the enabling interventions in ITS studies.

\section{Disagreements}

A systematic review on current evidence about antimicrobial stewardship objectives reported that "guideline-adherent empirical therapy was associated with a reduction for mortality (odds ratio $0.65,95 \% \mathrm{Cl} 0.54-0.80) "$ (Schuts 2016). Only two of the 39 studies in this review reported an intervention: one was invalid because it was an uncontrolled before-after study (Garcia 2007), and the other was a CBA (Dean 2006). The remaining 37 studies used case control study or cohort designs to compare the outcomes of participants with and without guideline-adherent antibiotic treatment, and did not include an intervention to change professional practice. The results of this review are in marked contrast to our analysis of mortality in 11 RCTs targeting antibiotic choice (Analysis 3.1). The most likely explanation for the discrepancy between our results and Schuts 2016 is confounding by indication. It is likely that participants with less complex or severe illness were more likely to receive guideline-adherent antibiotic treatment and that there was residual confounding after adjustment for available clinical information.

A systematic review on the effect of antibiotic stewardship programmes on $\mathrm{CDI}$ reported that interventions were associated with a consistent, significant protective effect (pooled risk ratio for CDI $0.48,95 \% \mathrm{Cl} 0.38$ to 0.62 ) (Feazel 2014). Of the 16 studies included in this systematic review, four were ITS studies that were also included in our review (Elligsen 2012; Fowler 2007; Price 2010; Talpaert 2011), and the remaining 12 studies were either uncontrolled before-after or inadequate ITS studies. The statistical analysis in this review was not appropriate (Feazel 2014). Calculation of risk ratios for the post- versus pre-intervention periods is an uncontrolled before-after analysis, which does not provide a reliable estimate of intervention effect.

Additional details about the disagreements with Feazel 2014 and Schuts 2016 can be found in Appendix 7.

\section{Limitations}

There are five weaknesses in the current evidence.

1. Evidence of intended effects is unbalanced towards reducing unnecessary treatment (compliance with guidelines that are intended to reduce use of broad-spectrum antibiotics or shorten duration of treatment). More evidence is required about finessing effective treatment of sepsis without also causing excessive use of antibiotics.

2. The limited evidence regarding adverse effects of restrictive interventions suggests that they can be associated with delay in essential treatment. There is a need for better patient safety outcome measures that can be used in studies of interventions in clinical practice.

3. The majority of the interventions do not use effective behaviour change techniques such as action planning or feedback.

4. Given the critical role of junior doctors in antimicrobial stewardship in hospitals, it is surprising that there is only a single example of an intervention that involved junior doctors in self monitoring and reflection on feedback about their prescribing (Price 2010).

5. Analysis of the impact of interventions on microbial outcomes requires large, multihospital RCTs.

\section{AUTHORS' CONCLUSIONS}

\section{Implications for practice}

Reducing antimicrobial resistance and hospital-associated infection is a public health priority. Our review shows that antimicrobial stewardship interventions can safely reduce unnecessary antibiotic use in hospitals, despite the fact that the majority of interventions did not use the most effective behaviour change techniques. Consequently, effective dissemination of the review results could have considerable health service and policy impact through greater use of interventions that enhance enablement.

The randomised controlled trials provided high-certainty evidence that the interventions we have assessed are effective in increasing compliance with guidelines to reduce unnecessary treatment without increasing the risk of mortality. Furthermore, the interventions were associated with reduction in length of stay. The evidence from this review should inform implementation decisions regarding antimicrobial stewardship interventions in hospitals.

In randomised controlled trials and interrupted time series studies, enablement consistently increased the effectiveness of interventions, including restrictive interventions; however, feedback was used in only a minority of enablement interventions, and very few included goal setting or action planning. Antimicrobial management teams might consider using evidence about effective feedback from other clinical settings (Ivers 2012). Training in the design and reporting of behaviour change interventions should be a priority for antimicrobial management teams.

\section{Implications for research}

Given the high certainty of evidence for our primary outcome, we believe that additional trials comparing antibiotic stewardship with no intervention are unlikely to change our conclusions or build on our understanding of the current evidence. Future research should 
instead focus on measuring clinical outcomes and assessing other measures of patient safety and different stewardship interventions and explore the barriers and facilitators to implementation.

We included 163 NRS but only 11 of these were about unintended consequences. Moreover only one NRS used qualitative methods, which are likely to be required in addition to survey methods for the investigation of unanticipated consequences (Rogers 1995). Future research should make greater use of qualitative methods for investigation of consequences of interventions, for example in process evaluation alongside clinical trials (Grant 2013). Anticipated, undesirable consequences should be regarded as trade-offs which may need to be accepted in exchange for a greater good (Ash 2007). Future research should examine how decisions are made about the acceptability of trade-offs (SISCC 2016). The purpose, design, and use of balancing measures in quality and safety improvement has been identified as a priority for research on methods in improvement science (SISCC 2016). Antimicrobial stewardship is an important topic for further research because of the clear competing risks of excessive use of antibiotics and delayed or ineffective treatment of life threatening infection.

Antibiotic stewardship requires clinicians to change their infection control behaviours. Given that the extent to which current antibiotic stewardship programs have incorporated insights and approaches from behavioural science is limited, there is an urgent need to bring together key stakeholders in the design and delivery of stewardship programmes and research experts in improvement and social sciences to develop more impactful stewardship programmes. We propose three key questions, which a Transnational Working Group within the Joint Programming Initiative in Antimicrobial Resistance will address in 2017 (JPIAMR 2016):

1. What behaviour change approaches can be recommended now to optimise hospital stewardship programmes?

2. How can hospital stewardship programmes be designed to maximise implementation across countries?

3. What is the research agenda to optimise efficient implementation of antibiotic stewardship programmes worldwide?

We were unable to perform reliable evidence synthesis on the relationship between prescribing and microbial outcomes with segmented regression analysis of interrupted time series studies from single hospitals. There is an urgent need for co-ordinated, multicentre research studies.
We found consistent evidence of reduced length of stay as an unanticipated beneficial consequence of interventions that targeted either choice of antibiotic or duration of antibiotic treatment. Further research is required to understand the mechanism for this effect.

\section{ACKNOWLEDGEMENTS}

Lynda Fenelon, Roger Finch, Giles Hartman, Alison Holmes, Eric Taylor, Phil Wiffen, and Mark Wilcox were authors on the previous versions of this review.

We are grateful to Vittoria Lutje and Virginia Hernandez-Santiago for help with screening of titles and abstracts.

We are grateful to Weihua Meng, Celine Pulcini, and Virginia Hernandez-Santiago for help with translation of papers from Chinese, French, and Spanish.

We are grateful to Jemma Hudson (Statistician), Paul Miller (Information Specialist), Kay Wang (External Referee), Atle Fretheim (Internal Editor), Sasha Shepperd (Contact Editor), and Julia Worswick (Managing Editor) for their comments and contributions to the review.

We are grateful to the Chief Scientist Office for a major grant that funded Claire Scott full time for 18 months (CSO CZH_4_861) and to the British Society for Antimicrobial Chemotherapy for their significant financial support for the costs of meetings, literature searches, obtaining full texts of papers, and construction of a webbased system for double data entry. We are grateful to Keith Milburn for creating and managing the online database.

The authors (EC) would also like to acknowledge the National Institute of Health Research Imperial Biomedical Research Centre and the National Institute for Health Research, Health Protection Research Unit (NIHR HPRU) in Healthcare Associated Infection and Antimicrobial Resistance at Imperial College London in partnership with Public Health England (PHE) and the NIHR Imperial Patient Safety Translational Research Centre.

This project was supported by the National Institute for Health Research (NIHR), via Cochrane Infrastructure funding and a Cochrane programme grant to the EPOC Group. The views and opinions expressed therein are those of the authors and do not necessarily reflect those of the Systematic Reviews Programme, NIHR, NHS, or the Department of Health. 


\section{R E F E R E N C E S}

\section{References to studies included in this review}

Abramowitz 1982 \{published data only\}

Abramowitz PW, Nold EG, Hatfield SM. Use of clinical pharmacists to reduce cefamandole, cefoxitin and ticarcillin costs. American Journal of Hospital Pharmacy 1982;39:1176-80.

\section{Adachi 1997 \{published data only\}}

Adachi W, Bolding F, Armstrong R. Experience with vancomycin education and order sheet to limit vancomycin use. Hospital Pharmacy 1997;32:1370-3.

\section{Akenroye 2014 \{published data only\}}

Akenroye AT, Baskin MN, Samnaliev M, Stack AM. Impact of a bronchiolitis guideline on ED resource use and cost: a segmented time-series analysis. Pediatrics 2014;133:e227-34.

\section{Aldeyab 2012 \{published data only\}}

Aldeyab M, Kearney M, Scott M, Aldiab M, Alahmadi Y, Darwish Elhajji F, et al. An evaluation of the impact of antibiotic stewardship on reducing the use of high-risk antibiotics and its effect on the incidence of Clostridium difficile infection in hospital settings. Journal of Antimicrobial Chemotherapy 2012;67:2988-96.

\section{Aldeyab 2014 \{published data only\}}

Aldeyab MA, Scott MG, Kearney MP, Alahmadi YM, Magee FA, Conlon G, et al. Impact of an enhanced antibiotic stewardship on reducing methicillin-resistant Staphylococcus aureus in primary and secondary healthcare settings. Epidemiology and Infection 2014;142:494-500.

\section{Ananda-Rajah 2010 \{published data only\}}

Ananda-Rajah MR, McBryde ES, Buising KL, Redl L, Macisaac C, Cade JF, et al. The role of general quality improvement measures in decreasing the burden of endemic MRSA in a medical-surgical intensive care unit. Intensive Care Medicine 2010;36:1890-8

\section{Annane 2013 \{published data only\}}

Annane D, Maxime V, Faller JP, Mezher C, Clec'h C, Martel P, et al. Procalcitonin levels to guide antibiotic therapy in adults with non-microbiologically proven apparent severe sepsis: a randomised controlled trial. BMJ Open 2013;3:e002186.

\section{Ansari 2003 \{published data only\}}

Ansari F, Gray K, Nathwani D, Phillips G, Ogston S, Ramsay C, et al. Outcomes of an intervention to improve hospital antibiotic prescribing: interrupted time series with segmented regression analysis. Journal of Antimicrobial Chemotherapy 2003;52(5):842-8.

\section{Avorn 1988 \{published data only\}}

Avorn J, Soumerai SB, Taylor W, Wessels MR, Janousek J, Weiner M. Reduction of incorrect antibiotic dosing through a structured educational order form. Archives of Internal Medicine 1988;148:1720-4.
Bailey 1997 \{published data only\}

Bailey TC, Ritchie DJ, McMullin ST, Kahn M, Reichley RM, Casabar E, et al. A randomized, prospective evaluation of an interventional program to discontinue intravenous antibiotics at two tertiary care teaching institutions. Pharmacotherapy 1997; 17(2):277-81.

\section{Bantar 2006 \{published data only\}}

Bantar C, Franco D, Heft C, Vesco E, Arango C, Izaguirre M, et al. Does a reduction in antibiotic consumption always represent a favorable outcome from an intervention program on prescribing practice?. International Journal of Infectious Diseases 2006;10:231-5.

\section{Barlow 2007 \{published data only\}}

Barlow G, Nathwani D, Davey P. The effect of implementing the British Thoracic Society community-acquired pneumonia guidelines on antibiotic prescribing and costs in a UK teaching hospital. Clinical Microbiology and Infection 2006;12:498-500.

* Barlow G, Nathwani D, Williams F, Ogston S, Winter J, Jones $\mathrm{M}$, et al. Reducing door-to-antibiotic time in communityacquired pneumonia: Controlled before-and-after evaluation and cost-effectiveness analysis. Thorax 2007;62(1):67-74.

\section{Bassetti 2009 \{published data only\}}

Bassetti M, Righi E, Ansaldi F, Molinari MP, Rebesco B, McDermott JL, et al. Impact of limited cephalosporin use on prevalence of methicillin-resistant Staphylococcus aureus in the intensive care unit. Journal of Chemotherapy 2009;21:633-8.

Baysari 2013 \{published data only\}

Baysari MT, Oliver K, Egan B, Li L, Richardson K, Sandaradura I, et al. Audit and feedback of antibiotic use: utilising electronic prescription data. Applied Clinical Informatics 2013;4:583-95.

\section{Bell 2014 \{published data only\}}

Bell S, Davey P, Nathwani D, Marwick C, Vadiveloo T, Sneddon J, et al. Risk of Acute Kidney Injury with gentamicin as surgical prophylaxis. JASN Journal of the American Society of Nephrologists 2014;25:2625-32.

\section{Belliveau 1996 \{published data only\}}

Belliveau PP, Rothman AL, Maday CE. Limiting vancomycin use to combat vancomycin-resistant Enterococcus faecium. American Journal of Health-System Pharmacy 1996;53(13):1570-5.

\section{Benson 2014 \{published data only\}}

Benson JM. Incorporating pharmacy student activities into an antimicrobial stewardship program in a long-term acute care hospital. American Journal of Health-System Pharmacy 2014;71:227-30.

\section{Berild 2002 \{published data only\}}

Berild D, Ringertz SH, Aabyholm G, Lelek M, Fosse B. Impact of an antibiotic policy on antibiotic use in a paediatric department. Individual based follow-up shows that antibiotics 
were chosen according to diagnoses and bacterial findings. International Journal of Antimicrobial Agents 2002;20:333-8.

Borde 2014a $\{$ published and unpublished data\}

Borde JP, Kaier K, Steib-Bauert M, Vach W, Geibel-Zehender A, Busch $\mathrm{H}$, et al. Feasibility and impact of an intensified antibiotic stewardship programme targeting cephalosporin and fluoroquinolone use in a tertiary care university medical center. BMC Infectious Diseases 2014;14:201.

Borde 2014b \{published and unpublished data\}

Borde JP, Batin N, Rieg S, Feik R, Reimling C, Kern WV, et al. Adherence to an antibiotic stewardship bundle targeting Staphylococcus aureus blood stream infections at a 200-bed community hospital. Infection 2014;42(4):713-9.

Borde 2015a \{published and unpublished data\}

Borde JP, Kern WV, Hug M, Steib-Bauert M, With KD, Busch HJ, et al. Implementation of an intensified antibiotic stewardship programme targeting third-generation cephalosporin and fluoroquinolone use in an emergency medicine department. Emergency Medicine Journal (EMJ) 2015;32(7):509-15.

Borde 2015b \{published and unpublished data\}

Borde JP, Litterst S, Ruhnke M, Feik R, Hubner J, deWith K, et al. Implementing an intensified antibiotic stewardship programme targeting cephalosporin and fluoroquinolone use in a 200-bed community hospital in Germany. Infection 2015;43(1):45-50.

\section{Bouadma 2010 \{published data only\}}

Bogner J, Nitschmann S. Management of antibiotics in regard of procalcitonin levels: PRORATA trial (PROcalcitonin to Reduce Antibiotic Treatments in Acutely ill patients). Internist 2010;51:1582-4.

* Bouadma L, Luyt CE, Tubach F, Cracco C, Alvarez A, Schwebel C, et al. Use of procalcitonin to reduce patients' exposure to antibiotics in intensive care units (PRORATA trial): a multicentre randomised controlled trial. Lancet 2010;375:463-74.

\section{Bouza 2004 \{published data only\}}

Bouza E, Sousa D, Munoz P, Rodriguez-Creixems M, Fron C, Lechuz JG. Bloodstream infections: a trial of the impact of different methods of reporting positive blood culture results. Clinical Infectious Diseases 2004;39(8):1161-9.

\section{Bouza 2007 \{published data only\}}

Bouza E, Torres MV, Radice C, Cercenado E, de Diego R, SanchezCarrillo $C$, et al. Direct E-test (AB Biodisk) of respiratory samples improves antimicrobial use in ventilator-associated pneumonia. Clinical Infectious Diseases: an official publication of the Infectious Diseases Society of America 2007;44:382-7.

\section{Bradley 1999 \{published data only\}}

Bradley SJ, Wilson ALT, Allen MC, Sher HA, Goldstone AH, Scott GM. The control of hyperendemic glycopeptide-resistant Enterococcus spp. on a haematology unit by changing antibiotic usage. Journal of Antimicrobial Chemotherapy 1999;43(2):261-6.

\section{Bruins 2005 \{published data only\}}

Bruins M, Oord H, Bloembergen P, Wolfhagen M, Casparie A, Degener J, et al. Lack of effect of shorter turnaround time of microbiological procedures on clinical outcomes: a randomised controlled trial among hospitalised patients in the Netherlands. European Journal of Clinical Microbiology and Infectious Diseases 2005;24(5):305-13.

\section{Buising 2008a \{published and unpublished data\}}

Buising KL, Thursky KA, Robertson MB, Black JF, Street AC, Richards MJ, et al. Electronic antibiotic stewardship reduced consumption of broad-spectrum antibiotics using a computerized antimicrobial approval system in a hospital setting. Journal of Antimicrobial Chemotherapy 2008;62:608-16.

\section{Buising 2008b \{published and unpublished data\}}

Buising KL, Thursky KA, Black JF, MacGregor L, Street AC, Kennedy MP, et al. Improving antibiotic prescribing for adults with community acquired pneumonia: Does a computerised decision support system achieve more than academic detailing alone? A time series analysis. BMC Medical Informatics \& Decision Making 2008;8:35. [DOI: 10.1186/1472-6947-8-35]

Bunz 1990 \{published data only\} Bunz D, Gupta S, Jewesson P. Metronidazole cost containment: a two-stage intervention. Hospital Formulary 1990;25(11):1167-77.

\section{Burton 1991 \{published data only\}}

Burton ME, Ash CL, Hill DP, Handy T, Shepherd MD, Vasko MR. A controlled trial of the cost benefit of computerized bayesian aminoglycoside administration. Clinical Pharmacology Therapeutics 1991;49(6):685-94.

\section{Buyle 2010 \{published data only\}}

Buyle F, Vogelaers D, Peleman R, Van Maele G, Robays H. Implementation of guidelines for sequential therapy with fluoroquinolones in a Belgian hospital. Pharmacy World \& Science 2010;32:404-10.

\section{Calfee 2003 \{published data only\}}

Calfee DP, Brooks J, Zirk NM, Giannetta ET, Scheld WM, Farr BM A pseudo-outbreak of nosocomial infections associated with the introduction of an antibiotic management programme. Journal of Hospital Infection 2003;55(1):26-32.

\section{Calil 2001 \{published data only\}}

Calil R, Marba ST, Von Nowakonski A, Tresoldi AT. Reduction in colonization and nosocomial infection by multiresistant bacteria in a neonatal unit after institution of educational measures and restriction in the use of cephalosporins. American Journal of Infection Control 2001;29(3):133-8.

\section{Camins 2009 \{published data only\}}

Camins BC, King MD, Wells JB, Googe HL, Patel M, Kourbatova EV, et al. Impact of an antimicrobial utilization program on antimicrobial use at a large teaching hospital: a randomized controlled trial. Infection Control and Hospital Epidemiology 2009;30:931-8. 
Carling 2003 \{published data only\}

Carling P, Fung T, Killion A, Terrin N, Barza M. Favorable impact of a multidisciplinary antibiotic management program conducted during 7 years. Infection Control and Hospital Epidemiology 2003;24(9):699-706.

Chan 2011 \{published data only\}

Chan YY, Lin TY, Huang CT, Deng ST, Wu TL, Leu HS, et al. Implementation and outcomes of a hospital-wide computerised antimicrobial stewardship programme in a large medical centre in Taiwan. International Journal of Antimicrobial Agents 2011;38(6):486-92.

\section{Chan 2015 \{published data only\}}

Chan S, Hossain J, Di Pentima MC. Implications and impact of prior authorization policy on vancomycin use at a tertiary pediatric teaching hospital. Pediatric Infectious Disease Journal 2015;34(5):506-8.

\section{Chandy 2014 \{published and unpublished data\}}

Chandy SJ, Naik GS, Charles R, Jeyaseelan V, Naumova EN, Thomas K, et al. The impact of policy guidelines on hospital antibiotic use over a decade: A segmented time series analysis. PLOS ONE 2014;9(3):e92206.

\section{Charbonneau 2006 \{published data only\}}

Charbonneau P, Parienti JJ, Thibon P, Ramakers M, Daubin C, du Cheyron D, et al. Fluoroquinolone use and methicillinresistant Staphylococcus aureus isolation rates in hospitalized patients: a quasi experimental study. Clinical Infectious Diseases 2006;42(6):778-84.

\section{Cheng 2009 \{published data only\}}

Cheng VCC, To KKW, Li IWS, Tang BSF, Chan JFW, Kwan S, et al. Antimicrobial stewardship program directed at broad-spectrum intravenous antibiotics prescription in a tertiary hospital. European Journal of Clinical Microbiology \& Infectious Diseases 2009;28:1447-56.

\section{Christ-Crain 2004 \{published data only\}}

Christ-Crain M, Jaccard-Stolz D, Bingisser R, Gencay MM, Huber PR, Tamm M, et al. Effect of procalcitonin-guided treatment on antibiotic use and outcome in lower respiratory tract infections: cluster-randomised, single-blinded intervention trial. Lancet 2004;363(9409):600-7.

\section{Christ-Crain 2006 \{published data only\}}

Christ-Crain M, Stolz D, Bingisser R, Muller C, Miedinger D, Huber PR, et al. Procalcitonin guidance of antibiotic therapy in community-acquired pneumonia: a randomized trial. American Journal of Respiratory and Critical Care Medicine 2006;174(1):84-93.

\section{Chu 2003 \{published data only\}}

Chu LA, Bratzler DW, Lewis RJ, Murray C, Moore L, Shook C, et al. Improving the quality of care for patients with pneumonia in very small hospitals. Archives of Internal Medicine 2003;163(3):326-32.

\section{Clerc 2014 \{published data only\}}

Clerc O, Prod'hom G, Senn L, Jaton K, Zanetti G, Calandra T, et al. Matrix-assisted laser desorption ionization time-offlight mass spectrometry and PCR-based rapid diagnosis of Staphylococcus aureus bacteraemia. Clinical Microbiology and Infection 2014; Vol. 20, issue 4:355-60.

Climo 1998 \{published data only\}

Climo MW, Israel DS, Wong ES, Williams D, Coudron P, Markowitz SM. Hospital-wide restriction of clindamycin: effect on the incidence of Clostridium difficile-associated diarrhea and cost. Annals of Internal Medicine 1998;128(12 Pt 1):989-95.

\section{Connor 2007 \{published data only\}}

Connor DM, Binkley S, Fishman NO, Gasink LB, Linkin D, Lautenbach $\mathrm{E}$. Impact of automatic orders to discontinue vancomycin therapy on vancomycin use in an antimicrobial stewardship program. Infection Control and Hospital Epidemiology 2007;28:1408-10.

\section{Cook 2011a \{published data only\}}

Cook PP, Catrou PG, Christie JD, Young PD, Polk RE. Reduction in broad-spectrum antimicrobial use associated with no improvement in hospital antibiogram. Journal of Antimicrobial Chemotherapy 2004;53:853-9.

* Cook PP, Rizzo S, Gooch M, Jordan M, Fang X, Hudson S. Sustained reduction in antimicrobial use and decrease in methicillin-resistant Staphylococcus aureus and Clostridium difficile infections following implementation of an electronic medical record at a tertiary-care teaching hospital. Journal of Antimicrobial Chemotherapy 2011;66:205-9.

\section{Cook 2011b \{published data only\}}

Cook PP, Gooch M, Rizzo S. Reduction in fluoroquinolone use following introduction of ertapenem into a hospital formulary is associated with improvement in susceptibility of Pseudomonas aeruginosa to group 2 carbapenems: a 10-year study. Antimicrobial Agents \& Chemotherapy 2011;55:5597-601.

\section{Cortoos 2011 \{published data only\}}

Cortoos PJ, Gilissen C, Mol PG, Van den Bossche F, Simoens S, Willems $L$, et al. Empirical management of community-acquired pneumonia: impact of concurrent $\mathrm{A} / \mathrm{H} 1 \mathrm{~N} 1$ influenza pandemic on guideline implementation. Journal of Antimicrobial Chemotherapy 2011;66:2864-71.

\section{Danaher 2009 \{published data only\}}

Danaher PJ, Milazzo NA, Kerr KJ, Lagasse CA, Lane JW. The Antibiotic Support Team - a successful educational approach to antibiotic stewardship. Military Medicine 2009;174:201-5.

\section{Dancer 2013 \{published data only\}}

Dancer S, Kirkpatrick P, Corcoran D, Christison F, Farmer D, Robertson C. Approaching zero: Temporal effects of a restrictive antibiotic policy on hospital-acquired Clostridium difficile, extended-spectrum beta-lactamase-producing coliforms and meticillin-resistant Staphylococcus aureus. International Journal of Antimicrobial Agents 2013;41:137-42. 


\section{Dean 2001 \{published data only\}}

Dean NC, Silver MP, Bateman KA, James B, Hadlock CJ, Hale D. Decreased mortality after implementation of a treatment guideline for community-acquired pneumonia. American Journal of Medicine 2001;110(6):451-7.

Dean 2006 \{published data only\}

Dean NC, Bateman KA, Donnelly SM, Silver MP, Snow GL, Hale D. Improved clinical outcomes with utilization of a communityacquired pneumonia guideline. Chest 2006;130(3):794-9.

\section{de Champs 1994 \{published data only\}}

de Champs C, Franchineau P, Gourgand JM, Loriette Y, Gaulme J, Sirot J. Clinical and bacteriological survey after change in aminoglycoside treatment to control an epidemic of Enterobacter cloacae. Journal of Hospital Infection 1994;28(3):219-29.

\section{Dempsey 1995 \{published data only\}}

Dempsey CL. Nursing home-acquired pneumonia: outcomes from a clinical process improvement program. Pharmacotherapy 1995;15(1 Pt 2):33S-8S.

\section{Ding 2013 \{published data only\}}

Ding J, Chen Z, Feng K. Procalcitonin-guided antibiotic use in acute exacerbations of idiopathic pulmonary fibrosis. International Journal of Medical Sciences 2013;10:903-7.

\section{Dranitsaris 2001 \{published data only\}}

Dranitsaris G, Spizzirri D, Pitre M, McGeer A. A randomized trial to measure the optimal role of the pharmacist in promoting evidence-based antibiotic use in acute care hospitals. International Journal of Technology Assessment in Health Care 2001;17(2):171-80.

\section{Dua 2014 \{published data only\}}

Dua A, Desai SS, Seabrook GR, Brown KR, Lewis BD, Rossi PJ, et al. The effect of Surgical Care Improvement Project measures on national trends on surgical site infections in open vascular procedures. Journal of Vascular Surgery 2014;60:1635-9.

\section{Dull 2008 \{published data only\}}

Dull D, Baird SK, Dulac J, Fox L. Improving prophylactic perioperative antibiotic utilization in a hospital system. Journal for Healthcare Quality 2008;30:48-56.

\section{Duvoisin 2014 \{published data only\}}

Duvoisin G, Fischer C, Maucort-Boulch D, Giannoni E. Reduction in the use of diagnostic tests in infants with risk factors for earlyonset neonatal sepsis does not delay antibiotic treatment. Swiss Medical Weekly 2014;144:w13981.

\section{Elligsen 2012 \{published data only\}}

Elligsen M, Walker SAN, Pinto R, Simor A, Mubareka S, Rachlis A, et al. Audit and feedback to reduce broad-spectrum antibiotic use among intensive care unit patients: a controlled interrupted time series analysis. Infection Control and Hospital Epidemiology 2012;33:354-61.

\section{Esposito 2011 \{published data only\}}

Esposito S, Tagliabue C, Picciolli I, Semino M, Sabatini C, Consolo S, et al. Procalcitonin measurements for guiding antibiotic treatment in pediatric pneumonia. Respiratory Medicine 2011;105:1939-45.

Everitt 1990 \{published data only\}

Everitt DE, Soumerai SB, Avorn J, Klapholz H, Wessels M. Changing surgical antimicrobial prophylaxis practices through education targeted at senior department leaders. Infection Control and Hospital Epidemiology 1990;11(11):578-83.

Farinas 2012 \{published data only\}

Farinas M, Saravia G, Calvo-Montes J, Benito N, Martinez-Garde J, Farinas-Alvarez C, et al. Adherence to recommendations by infectious disease consultants and its influence on outcomes of intravenous antibiotic-treated hospitalized patients. BMC Infectious Diseases 2012;12:292.

Fine 2003 \{published data only\}

Fine MJ, Stone RA, Lave JR, Hough LJ, Obrosky DS, Mor MK, et al. Implementation of an evidence-based guideline to reduce duration of intravenous antibiotic therapy and length of stay for patients hospitalized with community-acquired pneumonia: a randomized controlled trial. American Journal of Medicine 2003;115(5):343-51.

\section{Fitzpatrick 2008 \{published data only\}}

Fitzpatrick RW, Edwards CMC. Evaluation of a tool to benchmark hospital antibiotic prescribing in the United Kingdom. Pharmacy World \& Science 2008;30:73-8.

\section{Fowler 2007 \{published data only\}}

Fowler S, Webber A, Cooper BS, Phimister A, Price K, Carter Y, et al. Successful use of feedback to improve antibiotic prescribing and reduce Clostridium difficile infection: a controlled interrupted time series. Journal of Antimicrobial Chemotherapy 2007;59:990-5.

\section{Franz 2004 \{published data only\}}

Franz AR, Bauer K, Schalk A, Garland SM, Bowman ED, Rex K, et al. Measurement of interleukin 8 in combination with C-reactive protein reduced unnecessary antibiotic therapy in newborn infants: a multicenter, randomized, controlled trial. Pediatrics 2004;114(1):1-8.

\section{Fraser 1997 \{published data only\}}

Fraser GL, Stogsdill P, Dickens JD, Wennberg DE, Smith RP, Prato S. Antibiotic optimization: an evaluation of patient safety and economic outcomes. Archives of Internal Medicine 1997;157:1689-94.

\section{Fridkin 2002 \{published data only\}}

Fridkin SK, Lawton R, Edwards JR, Tenover FC, McGowan JE Jr, Gaynes RP. Monitoring antimicrobial use and resistance: comparison with a national benchmark on reducing vancomycin use and vancomycin-resistant enterococci. Emerging Infectious Diseases 2002;8(7):702-7. 
Friedberg 2009 \{published data only\}

Friedberg MW, Mehrotra A, Linder JA. Reporting hospitals' antibiotic timing in pneumonia: adverse consequences for patients?. American Journal of Managed Care 2009;15:137-44.

\section{Fukuda 2014 \{published data only\}}

Fukuda T, Watanabe H, Ido S, Shiragami M. Contribution of antimicrobial stewardship programs to reduction of antimicrobial therapy costs in community hospital with 429 beds - before-after comparative two-year trial in Japan. Journal of Pharmaceutical Policy and Practice 2014;7:10.

\section{Gerding 1985 \{published data only\}}

Gerding DN, Larson TA. Aminoglycoside resistance in gramnegative bacilli during increased amikacin use. Comparison of experience in 14 United States hospitals with experience in the Minneapolis Veterans Administration Medical Center. American Journal of Medicine 1985;79(1A):1-7.

\section{Goldstein 2009 \{published data only\}}

Goldstein EJ, Citron DM, Peraino V, Elgourt T, Meibohm AR, Lu S. Introduction of ertapenem into a hospital formulary: effect on antimicrobial usage and improved in vitro susceptibility of Pseudomonas aeruginosa. Antimicrobial Agents \& Chemotherapy 2009;53:5122-6.

\section{Grohs 2014 \{published data only\}}

Grohs P, Kerneis S, Sabatier B, Lavollay M, Carbonnelle E, Rostane $\mathrm{H}$, et al. Fighting the spread of AmpC-hyperproducing Enterobacteriaceae: beneficial effect of replacing ceftriaxone with cefotaxime. Journal of Antimicrobial Chemotherapy 2014;69:786-9.

\section{Gulmezoglu 2007 \{published data only\}}

Gulmezoglu AM, Langer A, Piaggio G, Lumbiganon P, Villar J, Grimshaw J. Cluster randomised trial of an active, multifaceted educational intervention based on the WHO Reproductive Health Library to improve obstetric practices. BJOG: An International Journal of Obstetrics \& Gynaecology 2007;114:16-23.

\section{Gums 1999 \{published data only\}}

Gums JG, Yancey RW Jr, Hamilton CA, Kubilis PS. A randomized, prospective study measuring outcomes after antibiotic therapy intervention by a multidisciplinary consult team. Pharmacotherapy 1999;19(12):1369-77.

\section{Gupta 1989 \{published data only\}}

Gupta S, Bachand RL, Jewesson PJ. Impact of a two-stage intervention program on cefazolin usage at a major teaching hospital. Hospital Formulary 1989;24(1):41-4, 46.

\section{Hadi 2008 \{published data only\}}

Hadi U, Keuter M, Van Asten H, Van Den Broek P, on behalf of the study group Antimicrobial Resistance in Indonesia Prevalence, Prevention. Optimizing antibiotic usage in adults admitted with fever by a multifaceted intervention in an Indonesian governmental hospital. Tropical Medicine \& International Health 2008;13:888-99.

\section{Halm 2004 \{published data only\}}

Halm EA, Horowitz C, Silver A, Fein A, Dlugacz YD, Hirsch B, et al. Limited impact of a multicenter intervention to improve the quality and efficiency of pneumonia care. Chest 2004;126(1):100-7.

\section{Hess 1990 \{published data only\}}

Hess DA, Mahoney CD, Johnson PN, Corrao WM, Fisher A. Integration of clinical and administrative strategies to reduce expenditures for antimicrobial agents. American Journal of Hospital Pharmacy 1990;47:585-91.

Himmelberg 1991 \{published data only\}

Himmelberg CJ, Pleasants RA, Weber DJ, Kessler JM, Samsa GP, Spivey JM, et al. Use of antimicrobial drugs in adults before and after removal of a restriction policy. American Journal of Public Health 1991;48:1220-7.

Hitti 2012 \{published data only (unpublished sought but not used)\} Hitti EA, Lewin JJ III, Lopez J, Hansen J, Pipkin M, Itani T, et al. Improving door-to-antibiotic time in severely septic emergency department patients. Journal of Emergency Medicine 2012;42:462-9.

\section{Hochreiter 2009 \{published data only\}}

Hochreiter M, Kohler T, Schweiger AM, Keck FS, Bein B, von Spiegel T, et al. Procalcitonin to guide duration of antibiotic therapy in intensive care patients: a randomized prospective controlled trial. Critical Care (London, England) 2009;13:R83.

\section{Huber 1982 \{published data only\}}

Huber SL, Patry RA, Hudson HD. Influencing drug use through prescribing restrictions. American Journal of Hospital Pharmacy 1982;39:1898-901.

\section{Hulgan 2004 \{published data only\}}

Hulgan T, Rosenbloom ST, Hargrove F, Talbert DA, Arbogast PG, Bansal $P$, et al. Oral quinolones in hospitalized patients: an evaluation of a computerized decision support intervention. Journal of Internal Medicine 2004;256(4):349-57.

Inaraja 1986 \{published data only\}

Inaraja MT, Paloma JM, Giraldez J, Idoate AJ, Hualde S. Computer-assisted antimicrobial-use monitoring. American Journal of Hospital Pharmacy 1986;43:664-70.

\section{Jensen 2011 \{published data only\}}

Jensen JU, Hein L, Lundgren B, Bestle MH, Mohr TT, Andersen $\mathrm{MH}$, et al. Procalcitonin-guided interventions against infections to increase early appropriate antibiotics and improve survival in the intensive care unit: a randomized trial. Critical Care Medicine 2011;39:2048-58.

\section{Jobson 2015 \{published data only\}}

Jobson M, Sandrof M, Valeriote T, Liberty AL, Walsh-Kelly C, Jackson C. Decreasing time to antibiotics in febrile patients with central lines in the emergency department. Pediatrics 2015;135:e187-95. 
Jump 2012 \{published data only\}

Jump R, Olds D, Seifi N, Kypriotakis G, Jury L, Peron E, et al. Effective antimicrobial stewardship in a long-term care facility through an infectious disease consultation service: Keeping a LID on antibiotic use. Infection Control and Hospital Epidemiology 2012;33:1185-92.

\section{Kallen 2009 \{published and unpublished data\}}

Kallen AJ, Thompson A, Ristaino P, Chapman L, Nicholson A, $\mathrm{Sim} B T$, et al. Complete restriction of fluoroquinolone use to control an outbreak of Clostridium difficile infection at a community hospital. Infection Control \& Hospital Epidemiology 2009;30:264-72.

\section{Kanwar 2007 \{published data only\}}

Kanwar M, Brar N, Khatib R, Fakih MG. Misdiagnosis of community-acquired pneumonia and inappropriate utilization of antibiotics: side effects of the 4-h antibiotic administration rule. Chest 2007;131:1865-9.

\section{Kerremans 2008 \{published data only\}}

Kerremans JJ, Verboom P, Stijnen T, Hakkaart-van Roijen L, Goessens W, Verbrugh HA, et al. Rapid identification and antimicrobial susceptibility testing reduce antibiotic use and accelerate pathogen-directed antibiotic use. Journal of Antimicrobial Chemotherapy 2008;61:428-35.

\section{Kerremans 2009 \{published data only\}}

Kerremans JJ, van der Bij AK, Goessens W, Verbrugh HA, Vos MC. Immediate incubation of blood cultures outside routine laboratory hours of operation accelerates antibiotic switching. Journal of Clinical Microbiology 2009;47:3520-3.

\section{Khan 2003 \{published data only\}}

Khan R, Cheesbrough J. Impact of changes in antibiotic policy on Clostridium difficile-associated diarrhoea (CDAD) over a fiveyear period in a district general hospital. Journal of Hospital Infection 2003;54(2):104-8.

\section{Kim 2008 \{published data only\}}

Kim JY, Sohn JW, Park DW, Yoon YK, Kim YM, Kim MJ. Control of extended-spectrum \{beta\}-lactamase-producing Klebsiella pneumoniae using a computer-assisted management program to restrict third-generation cephalosporin use. Journal of Antimicrobial Chemotherapy 2008;62:416-21.

\section{Knudsen 2014 \{published data only\}}

Knudsen JD, Andersen SE, Bispebjerg Intervention Group. A multidisciplinary intervention to reduce infections of ESBLand AmpC-producing, gram-negative bacteria at a University Hospital. PLOS ONE 2014;9:e86457.

\section{Kristoffersen 2009 \{published data only\}}

Kristoffersen KB, Sogaard OS, Wejse C, Black FT, Greve T, Tarp B, et al. Antibiotic treatment interruption of suspected lower respiratory tract infections based on a single procalcitonin measurement at hospital admission - a randomized trial. Clinical Microbiology \& Infection 2009;15:481-7.

\section{Kritchevsky 2008 \{published data only\}}

Kritchevsky SB, Braun BI, Bush AJ, Bozikis MR, Kusek L, Burke JP, et al. The effect of a quality improvement collaborative to improve antimicrobial prophylaxis in surgical patients: a randomized trial. Annals of Internal Medicine 2008;149:472-80.

Kumana 2001 \{published data only\}

Kumana CR, Ching TY, Kong Y, Ma EC, Kou M, Lee RA, et al. Curtailing unnecessary vancomycin usage in a hospital with high rates of methicillin resistant Staphylococcus aureus infections. British Journal of Clinical Pharmacology 2001;52(4):427-32.

\section{Lacroix 2014 \{published data only\}}

Lacroix L, Manzano S, Vandertuin L, Hugon F, Galetto-Lacour A, Gervaix A. Impact of the lab-score on antibiotic prescription rate in children with fever without source: a randomized controlled trial. PLoS One 2014;9:e115061.

\section{Lafaurie 2012 \{published data only\}}

Lafaurie M, Porcher R, Donay JL, Touratier S, Molina JM. Reduction of fluoroquinolone use is associated with a decrease in methicillin-resistant Staphylococcus aureus and fluoroquinolone-resistant Pseudomonas aeruginosa isolation rates: a 10 year study. Journal of Antimicrobial Chemotherapy 2012;67:1010-5.

\section{Landgren 1988 \{published data only\}}

Landgren FT, Harvey KJ, Mashford ML, Moulds RFW, Guthrie B, Hemming M. Changing antibiotic prescribing by educational marketing. Medical Journal of Australia 1988;149:595-9.

\section{Landman 1999 \{published data only\}}

Landman D, Chockalingam M, Quale JM. Reduction in the incidence of methicillin-resistant Staphylococcus aureus and ceftazidime-resistant Klebsiella pneumoniae following changes in a hospital antibiotic formulary. Clinical Infectious Diseases 1999;28(5):1062-6.

\section{LaRosa 2007 \{published data only\}}

LaRosa LA, Fishman NO, Lautenbach E, Koppel RJ, Morales KH, Linkin DR. Evaluation of antimicrobial therapy orders circumventing an antimicrobial stewardship program: investigating the strategy of "stealth dosing". Infection Control and Hospital Epidemiology 2007;28:551-6.

\section{Lautenbach 2003 \{published data only\}}

Lautenbach E, LaRosa LA, Marr AM, Nachamkin I, Bilker WB, Fishman NO. Changes in the prevalence of vancomycinresistant enterococci in response to antimicrobial formulary interventions: impact of progressive restrictions on use of vancomycin and third-generation cephalosporins. Clinical Infectious Diseases 2003;36(4):440-6.

\section{Lawes 2012 \{published data only\}}

Lawes T, Edwards B, Lopez-Lozano J, Gould I. Trends in Staphylococcus aureus bacteraemia and impacts of infection control practices including universal MRSA admission screening in a hospital in Scotland, 2006-2010: Retrospective cohort 
study and time-series intervention analysis. BMJ Open 2012;2:e000797.

\section{Layios 2012 \{published data only\}}

Layios N, Lambermont B, Canivet JL, Morimont P, Preiser JC, Garweg $C$, et al. Procalcitonin usefulness for the initiation of antibiotic treatment in intensive care unit patients. Critical Care Medicine 2012;40:2304-9.

\section{Lee 1995 \{published data only\}}

Lee J, Carlson JA, Chamberlain MA. A team approach to hospital formulary replacement. Diagnostic Microbiology and Infectious Diseases 1995;22:239-42.

\section{Lee 2007 \{published data only\}}

Lee J, Pai H, Kim YK, Kim NH, Eun BW, Kang HJ, et al. Control of extended-spectrum beta-lactamase-producing Escherichia coli and Klebsiella pneumoniae in a children's hospital by changing antimicrobial agent usage policy. Journal of Antimicrobial Chemotherapy 2007;60:629-37.

\section{Lee 2014 \{published data only\}}

Lee TC, Frenette C, Jayaraman D, Green L, Pilote L. Antibiotic self-stewardship: trainee-led structured antibiotic time-outs to improve antimicrobial use. Annals of Internal Medicine 2014;161:S53-8.

\section{Lesprit 2013 \{published data only\}}

Lesprit P, Landelle C, Brun-Buisson C. Clinical impact of unsolicited post-prescription antibiotic review in surgical and medical wards: a randomized controlled trial. Clinical Microbiology and Infection: the official publication of the European Society of Clinical Microbiology and Infectious Diseases 2013;19:E91-7.

\section{Leverstein-van Hall 2001 \{published data only\}}

Leverstein-van Hall MA, Fluit AC, Blok HE, Box AT, Peters ED, Weersink AJ, et al. Control of nosocomial multiresistant Enterobacteriaceae using a temporary restrictive antibiotic agent policy. European Journal of Clinical Microbiology and Infectious Diseases 2001;20:785-91.

\section{Liebowitz 2008 \{published data only\}}

Liebowitz LD, Blunt MC. Modification in prescribing practices for third-generation cephalosporins and ciprofloxacin is associated with a reduction in meticillin-resistant Staphylococcus aureus bacteraemia rate. Journal of Hospital Infection 2008;69:328-36.

\section{Linkin 2007 \{published data only\}}

Linkin DR, Fishman NO, Landis JR, Barton TD, Gluckman S, Kostman J, et al. Effect of communication errors during calls to an antimicrobial stewardship program. Infection Control and Hospital Epidemiology 2007;28:1374-81.

\section{Liu 2013 \{published data only\}}

Liu BH, Li HF, Lei Y, Zhao SX, Sun ML. Clinical significance of dynamic monitoring of procalcitonin in guiding the use of antibiotics in patients with sepsis in ICU. Chinese Critical Care Medicine 2013;25(11):690-3.

\section{Long 2014 \{published data only\}}

Long W, Li LJ, Huang GZ, Zhang XM, Zhang YC, Tang JG, et al. Procalcitonin guidance for reduction of antibiotic use in patients hospitalized with severe acute exacerbations of asthma: A randomized controlled study with 12-month followup. Critical Care 2014;18(5):471.

\section{Madaras-Kelly 2006 \{published data only\}}

Madaras-Kelly KJ, Remington RE, Lewis PG, Stevens DL. Evaluation of an intervention designed to decrease the rate of nosocomial methicillin-resistant Staphylococcus aureus infection by encouraging decreased fluoroquinolone use. Infection Control and Hospital Epidemiology 2006;27(2):155-69.

\section{Magedanz 2012 \{published data only\}}

Magedanz L, Silliprandi EM, Santos RP. Impact of the pharmacist on a multidisciplinary team in an antimicrobial stewardship program: a quasi-experimental study. International Journal of Clinical Pharmacy 2012;34:290-4.

\section{Maravic-Stojkovic 2011 \{published data only\}}

Maravic-Stojkovic V, Lausevic-Vuk L, Jovic M, Rankovic A, Borzanovic M, Marinkovic J. Procalcitonin-based therapeutic strategy to reduce antibiotic use in patients after cardiac surgery: a randomized controlled trial. Srpski Arhiv Za Celokupno Lekarstvo 2011;139:736-42.

\section{Marwick 2013 \{published data only\}}

Marwick C, Guthrie B, Pringle J, Evans J, Nathwani D, Donnan $P$, et al. A multifaceted intervention to improve sepsis management in general hospital wards with evaluation using segmented regression of interrupted time series. BMJ Quality \& Safety 2014;23:e2. [DOI: 10.1136/bmjqs-2013-002176]

\section{Masia 2008 \{published data only\}}

Masia M, Matoses C, Padilla S, Murcia A, Sanchez V, Romero I, et al. Limited efficacy of a nonrestricted intervention on antimicrobial prescription of commonly used antibiotics in the hospital setting: results of a randomized controlled trial. European Journal of Clinical Microbiology \& Infectious Diseases 2008;27:597-605.

\section{May 2000 \{published data only\}}

May AK, Melton SM, McGwin G, Cross JM, Moser SA, Rue LW. Reduction of vancomycin-resistant enterococcal infections by limitation of broad-spectrum cephalosporin use in a trauma and burn intensive care unit. Shock 2000;14(3):259-64.

\section{McElnay 1995 \{published data only\}}

McElnay JC, Scott MG, Sidara JY, Kearney P. Audit of antibiotic usage in medium-sized general hospital over an 11-year period. The impact of antibiotic policies. Pharmacy World and Science 1995;17(6):207-13.

\section{McGowan 1976 \{published data only\}}

McGowan JE, Findland M. Usage of antibiotics in a general hospital: Effect of requiring justification. Journal of Infectious Diseases 1974;130(2):165-8. 
* McGowan JE, Finland M. Effects of monitoring the usage of antibiotics: An interhospital comparison. Southern Medical Journal 1976;69(2):193-5.

\section{McLaughlin 2005 \{published data only\}}

McLaughlin CM, Bodasing N, Boyter AC, Fenelon C, Fox JG, Seaton RA. Pharmacy-implemented guidelines on switching from intravenous to oral antibiotics: an intervention study. Quarterly Journal of Medicine 2005;98(10):745-52.

\section{McNulty 1997 \{published data only\}}

McNulty C, Logan M, Donald IP, Ennis D, Taylor D, Baldwin RN, et al. Successful control of Clostridium difficile infection in an elderly care unit through use of a restrictive antibiotic policy. Journal of Antimicrobial Chemotherapy 1997;40:707-11.

\section{Mercer 1999 \{published data only\}}

Mercer KA, Chintalapudi SR, Visconti EB. Impact of targeted antibiotic restriction on usage and cost in a community hospital. Journal of Pharmacy Technology 1999;15:79-84.

\section{Meyer 1993 \{published data only\}}

Meyer KS, Urban C, Eagan JA, Berger BJ, Rahal JJ. Nosocomial outbreak of Klebsiella infection resistant to late-generation cephalosporins. Annals of Internal Medicine 1993;119(5):353-8.

\section{Meyer 2007 \{published data only\}}

Meyer E, Buttler J, Schneider C, Strehl E, Schroeren-Boersch B, Gastmeier $P$, et al. Modified guidelines impact on antibiotic use and costs: duration of treatment for pneumonia in a neurosurgical ICU is reduced. Journal of Antimicrobial Chemotherapy 2007;59:1148-54.

\section{Meyer 2009 \{published data only\}}

Meyer E, Lapatschek M, Bechtold A, Schwarzkopf G, Gastmeier P, Schwab F. Impact of restriction of third generation cephalosporins on the burden of third generation cephalosporin resistant $\mathrm{K}$. pneumoniae and $\mathrm{E}$. coli in an ICU. Intensive Care Medicine 2009;35:862-70.

\section{Meyer 2010 \{published data only\}}

Meyer E, Schwab F, Pollitt A, Bettolo W, Schroeren-Boersch B, Trautmann M. Impact of a change in antibiotic prophylaxis on total antibiotic use in a surgical intensive care unit. Infection 2010;38:19-24.

\section{Micek 2004 \{published data only\}}

Micek ST, Ward S, Fraser VJ, Kollef MH. A randomized controlled trial of an antibiotic discontinuation policy for clinically suspected ventilator-associated pneumonia. Chest 2004;125(5):1791-9.

\section{Mittal 2014 \{published data only\}}

Mittal V, Darnell C, Walsh B, Mehta A, Badawy M, Morse R, et al. Inpatient bronchiolitis guideline implementation and resource utilization. Pediatrics 2014;133:e730-7.

\section{Mol 2005 \{published data only\}}

Mol PGM, Wieringa JE, Nannan Panday PV, Gans ROB, Degener JE, Laseur M, et al. Improving compliance with hospital antibiotic guidelines: a time-series intervention analysis. Journal of Antimicrobial Chemotherapy 2005;55(4):550-7.

Newland 2012 \{published data only\}

* Newland JG, Stach LM, De Lurgio SA, Hedican E, Yu D, Herigon JC, et al. Impact of a prospective-audit-withfeedback antimicrobial stewardship program at a children's hospital. Journal of the Pediatric Infectious Diseases Society 2012;1:179-86.

Newman RE, Hedican EB, Herigon JC, Williams DD, Williams AR, Newland JG. Impact of a guideline on management of children hospitalized with community-acquired pneumonia. Pediatrics 2012;129:e597-604.

\section{Nobre 2008 \{published data only\}}

Nobre V, Harbarth S, Graf JD, Rohner P, Pugin J. Use of procalcitonin to shorten antibiotic treatment duration in septic patients: a randomized trial. American Journal of Respiratory \& Critical Care Medicine 2008;177:498-505.

Nuila 2008 \{published data only\} Nuila F, Cadle RM, Logan N, Musher DM. Antibiotic stewardship and Clostridium difficile-associated disease. Infection Control and Hospital Epidemiology 2008;29:1096-7.

\section{Oliveira 2013 \{published data only\}}

Oliveira CF, Botoni FA, Oliveira CRA, Silva CB, Pereira HA, Serufo JC, et al. Procalcitonin versus $\mathrm{C}$-reactive protein for guiding antibiotic therapy in sepsis: a randomized trial. Critical Care Medicine 2013;41:2336-43.

\section{Oosterheert 2005 \{published data only\}}

Oosterheert JJ, Van Loon AM, Schuurman R, Hoepelman AI, Hak E, Thijsen S, et al. Impact of rapid detection of viral and atypical bacterial pathogens by real-time polymerase chain reaction for patients with lower respiratory tract infection. Clinical Infectious Diseases 2005;41(10):1438-44.

\section{Ostrowsky 2014 \{published data only\}}

Ostrowsky B, Ruiz R, Brown S, Chung P, Koppelman E, van Deusen $\mathrm{LC}$, et al. Lessons learned from implementing Clostridium difficile-focused antibiotic stewardship interventions. Infection Control and Hospital Epidemiology 2014;35:S86-95.

\section{Ozkaya 2009 \{published data only\}}

Ozkaya E, Cambaz N, Coskun Y, Mete F, Geyik M, Samanci N. The effect of rapid diagnostic testing for influenza on the reduction of antibiotic use in paediatric emergency department. Acta Paediatrica 2009;98:1589-92.

Palmay 2014 \{published data only\} Palmay L, Elligsen M, Walker SAN, Pinto R, Walker S, Einarson T, et al. Hospital-wide rollout of antimicrobial stewardship: A stepped-wedge randomized trial. Clinical Infectious Diseases 2014;59(6):867-74.

\section{Parienti 2011 \{published data only\}}

Parienti JJ, Cattoir V, Thibon P, Lebouvier G, Verdon R, Daubin C, et al. Hospital-wide modification of fluoroquinolone policy 
and meticillin-resistant Staphylococcus aureus rates: a 10-year interrupted time-series analysis. Journal of Hospital Infection 2011;78:118-22.

\section{Parikh 2014 \{published data only\}}

Parikh K, Hall M, Teach SJ. Bronchiolitis management before and after the AAP guidelines. Pediatrics 2014;133:e1-7.

\section{Patel 1989 \{published data only\}}

Patel M, Jackson C. Targeted interventions on oral antibiotic expenditure. British Journal of Pharmaceutical Practice 1989;11:306-8.

\section{Paul 2006 \{published data only\}}

Kofoed K, Zalounina A, Andersen O, Lisby G, Paul M, Leibovici L, et al. Performance of the TREAT decision support system in an environment with a low prevalence of resistant pathogens. Journal of Antimicrobial Chemotherapy 2009;63:400-4.

Leibovici I, Kariv G, Paul M. Long-term survival in patients included in a randomized controlled trial of TREAT, a decision support system for antibiotic treatment. Journal of Antimicrobial Chemotherapy 2013;68:2664-6.

* Paul M, Andreassen S, Tacconelli E, Nielsen AD, Almanasreh N, Frank $U$, et al. Improving empirical antibiotic treatment using TREAT, a computerized decision support system: cluster randomized trial. Journal of Antimicrobial Chemotherapy 2006;58(6):1238-45.

\section{Pear 1994 \{published data only\}}

Pear SM, Williamson TH, Bettin KM, Gerding DN, Galgiani JN. Decrease in nosocomial Clostridium difficile-associated diarrhea by restricting clindamycin use. Annals of Internal Medicine 1994;120(4):272-7.

\section{Perez 2003 \{published data only\}}

Perez A, Dennis RJ, Rodriguez B, Castro AY, Delgado V, Lozano JM, et al. An interrupted time series analysis of parenteral antibiotic use in Colombia. Journal of Clinical Epidemiology 2003;56(10):1013-20.

\section{Peto 2008 \{published data only\}}

Peto Z, Benko R, Matuz M, Csullog E, Molnar A, Hajdu E. Results of a local antibiotic management program on antibiotic use in a tertiary intensive care unit in Hungary. Infection 2008;36:560-4.

\section{Petrikkos 2007 \{published data only\}}

Petrikkos G, Markogiannakis A, Papaparaskevas J, Daikos GL, Stefanakos G, Zissis NP, et al. Differences in the changes in resistance patterns to third- and fourth-generation cephalosporins and piperacillin/tazobactam among Klebsiella pneumoniae and Escherichia coli clinical isolates following a restriction policy in a Greek tertiary care hospital. International Journal of Antimicrobial Agents 2007;29:34-8.

\section{Pires 2011 \{published data only\}}

Pires dos Santos R, Jacoby T, Pires Machado D, Lisboa T, Gastal SL, Nagel FM, et al. Hand hygiene, and not ertapenem use, contributed to reduction of carbapenem-resistant Pseudomonas aeruginosa rates. Infection Control \& Hospital Epidemiology 2011;32:584-90.
Po 2012 \{published data only\}

Po JL, Nguyen BQ, Carling PC. The impact of an infectious diseases specialist-directed computerized physician order entry antimicrobial stewardship program targeting linezolid use. Infection Control \& Hospital Epidemiology 2012;33:434-5.

Poehling 2006 \{published data only\}

Poehling KA, Zhu Y, Tang YW, Edwards K. Accuracy and impact of a point-of-care rapid influenza test in young children with respiratory illnesses. Archives of Pediatrics \& Adolescent Medicine 2006;160:713-8.

\section{Popovski 2015 \{published data only\}}

Popovski Z, Mercuri M, Main C, Sne N, Walsh K, Sung M, et al. Multifaceted intervention to optimize antibiotic use for intraabdominal infections. Journal of Antimicrobial Chemotherapy 2015;70:1226-9.

\section{Price 2010 \{published and unpublished data\}}

Price J, Cheek E, Lippett S, Cubbon M, Gerding DN, Sambol SP, et al. Impact of an intervention to control Clostridium difficile infection on hospital- and community-onset disease; an interrupted time series analysis. Clinical Microbiology \& Infection 2010;16:1297-302.

\section{Pulcini 2011 \{published and unpublished data\}}

Pulcini C, Defres S, Aggarwal I, Nathwani D, Davey P. Design of a 'day 3 bundle' to improve the reassessment of inpatient empirical antibiotic prescriptions. Journal of Antimicrobial Chemotherapy 2008;61(6):1384-8. doi: 10.1093/jac/dkn113.

* Pulcini C, Dellamonica J, Bernardin G, Molinari N, Sotto A. Impact of an intervention designed to improve the documentation of the reassessment of antibiotic therapies in an intensive care unit. Medecine et Maladies Infectieuses 2011;41:546-52.

\section{Qu 2012 \{published data only\}}

Qu R, Ji Y, Ling Y, Ye CY, Yang SM, Liu YY, et al. Procalcitonin is a good tool to guide duration of antibiotic therapy in patients with severe acute pancreatitis. A randomized prospective single-center controlled trial. Saudi Medical Journal 2012;33:382-7.

Rattanaumpawan 2010 \{published data only\}

Rattanaumpawan P, Sutha P, Thamlikitkul V. Effectiveness of drug use evaluation and antibiotic authorization on patients' clinical outcomes, antibiotic consumption, and antibiotic expenditures. American Journal of Infection Control 2010;38:38-43.

Rattanaumpawan 2011 \{published data only\}

Rattanaumpawan P, Morales KH, Binkley S, Synnestvedt M, Weiner MG, Gasink LB, et al. Impact of antimicrobial stewardship programme changes on unnecessary double anaerobic coverage therapy. Journal of Antimicrobial Chemotherapy 2011;66:2655-8.

\section{Richards 2003 \{published data only\}}

Richards MJ, Robertson MB, Dartnell JG, Duarte MM, Jones NR, Kerr DA, et al. Impact of a web-based antimicrobial approval 
system on broad-spectrum cephalosporin use at a teaching hospital. Medical Journal of Australia 2003;178:386-90.

\section{Richardson 2000 \{published data only\}}

Richardson LP, Wiseman SW, Melani PN, Lyons MJ, Kauffman CA. Effectiveness of a vancomycin restriction policy in changing the prescribing patterns of house staff. Microbial Drug Resistance 2000;6(4):327-30.

\section{Ross 2014 \{published data only\}}

Ross RK, Hersh AL, Kronman MP, Newland JG, Metjian TA, Localio AR, et al. Impact of Infectious Diseases Society of America/Pediatric Infectious Diseases Society guidelines on treatment of community-acquired pneumonia in hospitalized children. Clinical Infectious Diseases: an official publication of the Infectious Diseases Society of America 2014;58:834-8.

\section{Saizy-Callaert 2003 \{published data only\}}

Saizy-Callaert S, Causse R, Furhman C, Le Paih MF, Thebault A, Chouaid C. Impact of a multidisciplinary approach to the control of antibiotic prescription in a general hospital. Journal of Hospital Infection 2003;53(3):177-82.

\section{Salama 1996 \{published data only\}}

Salama S, Rotstein C, Mandell L. A multidisciplinary hospitalbased antimicrobial use program: impact on hospital pharmacy expenditures and drug use. Canadian Journal of Infectious Diseases 1996;7:104-9.

Schnoor 2010 \{published data only (unpublished sought but not used)\}

Schnoor M, Meyer T, Suttorp N, Raspe H, Welte T, Schafer T, et al. Development and evaluation of an implementation strategy for the German guideline on community-acquired pneumonia. Quality \& Safety in Health Care 2010;19:498-502.

\section{Schouten 2007 \{published data only\}}

Schouten JA, Hulscher MEJL, Trap-Liefers J, Akkermans RP, Kullberg BJ, Grol RPTM, et al. Tailored interventions to improve antibiotic use for lower respiratory tract infections in hospitals: a cluster-randomized, controlled trial. Clinical Infectious Diseases 2007;44:931-41.

\section{Schroeder 2009 \{published data only\}}

Schroeder S, Hochreiter M, Koehler T, Schweiger AM, Bein B, Keck FS, et al. Procalcitonin (PCT)-guided algorithm reduces length of antibiotic treatment in surgical intensive care patients with severe sepsis: results of a prospective randomized study. Langenbeck's Archives of Surgery/Deutsche Gesellschaft fur Chirurgie 2009;394:221-6.

\section{Schuetz 2009 \{published data only\}}

Schuetz P, Batschwaroff M, Dusemund F, Albrich W, Burgi U, Maurer M, et al. Effectiveness of a procalcitonin algorithm to guide antibiotic therapy in respiratory tract infections outside of study conditions: a post-study survey. European Journal of Clinical Microbiology \& Infectious Diseases 2010;29:269-77.

Schuetz P, Christ-Crain M, Albrich W, Zimmerli W, Mueller B, Pro Hosp Study Group. Guidance of antibiotic therapy with procalcitonin in lower respiratory tract infections: insights into the ProHOSP study. Virulence 2010;1:88-92.

* Schuetz P, Christ-Crain M, Thomann R, Falconnier C, Wolbers M, Widmer I, et al. Effect of procalcitonin-based guidelines vs standard guidelines on antibiotic use in lower respiratory tract infections: the ProHOSP randomized controlled trial. JAMA 2009;302:1059-66.

\section{Schwann 2011 \{published data only\}}

Schwann NM, Bretz KA, Eid S, Burger T, Fry D, Ackler F, et al. Point-of-care electronic prompts: an effective means of increasing compliance, demonstrating quality, and improving outcome. Anesthesia \& Analgesia 2011;113:869-76.

\section{Schwartz 2007 \{published data only\}}

Schwartz DN, Abiad H, DeMarais PL, Armeanu E, Trick WE, Wang Y, et al. An educational intervention to improve antimicrobial use in a hospital-based long-term care facility. Journal of the American Geriatrics Society 2007;55:1236-42.

\section{Senn 2004 \{published data only\}}

Senn L, Burnand B, Francioli P, Zanetti G. Improving appropriateness of antibiotic therapy: randomized trial of an intervention to foster reassessment of prescription after 3 days. Journal of Antimicrobial Chemotherapy 2004;53(6):1062-7.

\section{Shehabi 2014 \{published data only\}}

Shehabi Y, Sterba M, Garrett PM, Rachakonda KS, Stephens D, Harrigan P, et al. Procalcitonin algorithm in critically ill adults with undifferentiated infection or suspected sepsis. A randomized controlled trial. American Journal of Respiratory and Critical Care Medicine 2014;190:1102-10.

\section{Shen 2011 \{published data only\}}

Shen J, Sun Q, Zhou X, Wei Y, Qi Y, Zhu J, et al. Pharmacist interventions on antibiotic use in inpatients with respiratory tract infections in a Chinese hospital. International Journal of Clinical Pharmacy 2011;33:929-33.

\section{Shojania 1998 \{published data only\}}

Shojania KG, Yokoe D, Platt R, Fiskio J, Ma'luf N, Bates DW. Reducing vancomycin use utilizing a computer guideline: results of a randomized controlled trial. Journal of the American Medical Informatics Association 1998;5(6):554-62.

\section{Singh 2000 \{published data only\}}

Singh N, Rogers P, Atwood CW, Wagener MM, Yu VL. Shortcourse empiric antibiotic therapy for patients with pulmonary infiltrates in the intensive care unit. A proposed solution for indiscriminate antibiotic prescription. American Journal of Respiratory and Critical Care Medicine 2000;162(2 Pt 1):505-11.

\section{Sirinavin 1998 \{published data only\}}

Sirinavin S, Suvanakoot P, Sathapatayavongs B, Malatham K. Effect of antibiotic order form guiding rational use of expensive drugs on cost containment. Southeast Asian Journal of Tropical Medicine and Public Health 1998;29(3):636-42. 
Skaer 1993 \{published data only\}

Skaer TL, Sclar DA, Won JKH, Markowski DJ. Effect of academic detailing on the utilization of intravenous antimicrobial therapy. Current Therapeutic Research 1993;53(4):349-55.

\section{Skrlin 2011 \{published data only\}}

Skrlin J, Bacic Vrca V, Marusic S, Ciric-Crncec M, Mayer L. Impact of ceftriaxone de-restriction on the occurrence of ESBLpositive bacterial strains and antibiotic consumption. Journal of Chemotherapy 2011;23:341-4.

\section{Solomon 2001 \{published data only\}}

Solomon DH, Van Houten L, Glynn RJ, Baden L, Curtis K, Schrager $\mathrm{H}$, et al. Academic detailing to improve use of broadspectrum antibiotics at an academic medical center. Archives of Internal Medicine 2001;161(15):1897-902.

\section{Standiford 2012 \{published data only\}}

Standiford HC, Chan S, Tripoli M, Weekes E, Forrest GN. Antimicrobial stewardship at a large tertiary care academic medical center: cost analysis before, during, and after a 7year program. Infection Control and Hospital Epidemiology 2012;33:338-45.

\section{Stevenson 1988 \{published data only\}}

Hampson JP, Corkhill JE, Murray A, Griffiths LR, Smith JC, Bartzokas CA. Potential financial benefits of a local antibiotic policy. Pharmaceutical Journal 1988;241:660-2.

* Stevenson RC, Blackman SC, Williams CL, Bartzokas CA. Measuring the saving attributable to an antibiotic prescribing policy. Journal of Hospital Infection 1988;11:16-25.

\section{Stocker 2010 \{published data only\}}

Stocker M, Fontana M, el Helou S, Wegscheider K, Berger TM. Use of procalcitonin-guided decision-making to shorten antibiotic therapy in suspected neonatal early-onset sepsis: prospective randomized intervention trial. Neonatology 2010;97:165-74.

\section{Stolz 2007 \{published data only\}}

Stolz D, Christ-Crain M, Bingisser R, Leuppi J, Miedinger D, Muller C, et al. Antibiotic treatment of exacerbations of COPD: a randomized, controlled trial comparing procalcitonin-guidance with standard therapy. Chest 2007;131:9-19.

\section{Stolz 2009 \{published data only\}}

Stolz D, Smyrnios N, Eggimann P, Pargger H, Thakkar N, Siegemund $\mathrm{M}$, et al. Procalcitonin for reduced antibiotic exposure in ventilator-associated pneumonia: a randomised study. European Respiratory Journal 2009;34:1364-75.

\section{Strom 2010 \{published data only\}}

Strom BL, Schinnar R, Aberra F, Bilker W, Hennessy S, Leonard CE, et al. Unintended effects of a computerized physician order entry nearly hard-stop alert to prevent a drug interaction: a randomized controlled trial. Archives of Internal Medicine 2010;170:1578.

\section{Sun 2011 \{published data only\}}

Sun TB, Chao SF, Chang BS, Chen TY, Gao PY, Shyr MH. Quality Improvements of antimicrobial prophylaxis in coronary artery bypass grafting. Journal of Surgical Research 2011;167:329-35.

\section{Suwangool 1991 \{published data only\}}

Suwangool P, Moola-Or P, Waiwatana A, Sitthi-amorn C, Israsena S, Hanvanich M. Effect of a selective restriction policy on antibiotic expenditure and use: an institutional model. Journal of the Medical Association of Thailand 1991;74:272-5.

\section{Talpaert 2011 \{published data only\}}

Talpaert MJ, Rao GG, Cooper BS, Wade P. Impact of guidelines and enhanced antibiotic stewardship on reducing broadspectrum antibiotic usage and its effect on incidence of Clostridium difficile infection. Journal of Antimicrobial Chemotherapy 2011;66:2168-74.

\section{Tangdén 2011 \{published data only\}}

Tängdén T, Eriksson BM, Melhus A, Svennblad B, Cars O. Radical reduction of cephalosporin use at a tertiary hospital after educational antibiotic intervention during an outbreak of extended-spectrum beta-lactamase-producing Klebsiella pneumoniae. Journal of Antimicrobial Chemotherapy 2011;66:1161-7.

\section{Toltzis 1998 \{published data only\}}

Toltzis P, Yamashita T, Vilt L, Green M, Morrissey A, SpinnerBlock $\mathrm{S}$, et al. Antibiotic restriction does not alter endemic colonization with resistant gram-negative rods in a pediatric intensive care unit. Critical Care Medicine 1998;26(11):1893-9.

\section{Toltzis 2002 \{published data only\}}

Toltzis P, Dul MJ, Hoyen C, Salvator A, Walsh M, Zetts L, et al. The effect of antibiotic rotation on colonization with antibioticresistant bacilli in a neonatal intensive care unit. Pediatrics 2002;110:707-11.

\section{Toltzis 2014 \{published data only\}}

Toltzis P, O'Riordan M, Cunningham DJ, Ryckman FC, Bracke TM, Olivea J, et al. A statewide collaborative to reduce pediatric surgical site infections. Pediatrics 2014;134:e1174-80.

\section{Trenholme 1989 \{published data only\}}

Trenholme GM, Kaplan RL, Karakusis PH, Stine T, Fuhrer J, Landau W, et al. Clinical impact of rapid identification and susceptibility testing of bacterial blood culture isolates. Journal of Clinical Microbiology 1989;27(6):1342-5.

\section{Uçkay 2009 \{published data only\}}

Uçkay I, Vernaz-Hegi N, Harbarth S, Stern R, Legout L, Vauthey L, et al. Activity and impact on antibiotic use and costs of a dedicated infectious diseases consultant on a septic orthopaedic unit. Journal of Infection 2009;58:205-12.

\section{Valiquette 2007 \{published data only\}}

Valiquette L, Cossette B, Garant M-P, Diab H, Pépin J. Impact of a reduction in the use of high-risk antibiotics on the course of an epidemic of Clostridium difficile-associated disease caused by the hypervirulent NAP1/027 strain. Clinical Infectious Diseases 2007:45:S112-21. 
van Hees 2008 \{published data only\}

van Hees BC, de Ruiter E, Wiltink EH, de Jongh BM, Tersmette M. Optimizing use of ciprofloxacin: a prospective intervention study. Journal of Antimicrobial Chemotherapy 2008;61:210-3.

\section{Van Kasteren 2005 \{published data only\}}

Mannien J, van Kasteren ME, Nagelkerke NJ, Gyssens IC, Kullberg BJ, Wille JC, et al. Effect of optimized antibiotic prophylaxis on the incidence of surgical site infection. Infection Control \& Hospital Epidemiology 2006;27:1340-6.

* Van Kasteren ME, Mannien J, Kullberg BJ, de Boer AS, Nagelkerke NJ, Ridderhof M, et al. Quality improvement of surgical prophylaxis in Dutch hospitals: evaluation of a multisite intervention by time series analysis. Journal of Antimicrobial Chemotherapy 2005;56(6):1094-102.

\section{Volpe 2012 \{published data only\}}

Volpe D, Harrison S, Damian F, Rachh P, Kahlon PS, Morrissey L, et al. Improving timeliness of antibiotic delivery for patients with fever and suspected neutropenia in a pediatric emergency department. Pediatrics 2012;130:e201-10.

\section{Walker 1998 \{published data only\}}

Walker SE. Physicians' acceptance of a preformatted pharmacy intervention chart note in a community hospital antibiotic step down program. Journal of Pharmacy Technology 1998;14:141-5.

\section{Wang 2014 \{published data only\}}

Wang HY, Chiu CH, Huang CT, Cheng CW, Lin YJ, Hsu YJ, et al. Blood culture-guided de-escalation of empirical antimicrobial regimen for critical patients in an online antimicrobial stewardship programme. International Journal of Antimicrobial Agents 2014;44(6):520-7.

\section{Wax 2007 \{published data only\}}

Wax DB, Beilin Y, Levin M, Chadha N, Krol M, Reich DL. The effect of an interactive visual reminder in an anesthesia information management system on timeliness of prophylactic antibiotic administration. Anesthesia \& Analgesia 2007;104:1462-6.

\section{Weinberg 2001 \{published data only\}}

Weinberg M, Fuentes JM, Ruiz A I, Lozano FW, Angel E, Gaitan H, et al. Reducing infections among women undergoing cesarean section in Colombia by means of continuous quality improvement methods. Archives of Internal Medicine 2001;161(19):2357-65.

\section{Weiner 2009 \{published data only\}}

Weiner SG, Brown SF, Goetz JD, Webber CA. Weekly E-mail reminders influence emergency physician behavior: a case study using the Joint Commission and Centers for Medicare and Medicaid Services Pneumonia Guidelines. Academic Emergency Medicine 2009;16:626-31.

\section{Weiss 2013 \{published data only\}}

* Weiss CH, Dibardino D, Rho J, Sung N, Collander B, Wunderink RG. A clinical trial comparing physician prompting with an unprompted automated electronic checklist to reduce empirical antibiotic utilization. Critical Care Medicine 2013;41:2563-9.
Weiss CH, Persell SD, Wunderink RG, Baker DW. Empiric antibiotic, mechanical ventilation, and central venous catheter duration as potential factors mediating the effect of a checklist prompting intervention on mortality: an exploratory analysis. BMC Health Services Research 2012;12:198. [DOI: 10.1186/1472-6963-12-198]

\section{Welker 2008 \{published data only\}}

Welker JA, Huston M, McCue JD. Antibiotic timing and errors in diagnosing pneumonia. Archives of Internal Medicine 2008;168:351-6.

\section{Wenisch 2014 \{published data only\}}

Wenisch JM, Equiluz-Bruck S, Fudel M, Reiter I, Schmid A, Singer $E$, et al. Decreasing Clostridium difficile infections by an antimicrobial stewardship program that reduces moxifloxacin use. Antimicrobial Agents and Chemotherapy 2014;58 (9):5079-83.

\section{Willemsen 2010 \{published data only\}}

Willemsen I, Cooper B, van Buitenen C, Winters M, Andriesse G, Kluytmans J. Improving quinolone use in hospitals by using a bundle of interventions in an interrupted time series analysis. Antimicrobial Agents and Chemotherapy 2010;54:3763-9.

\section{Wilson 1991 \{published data only\}} Wilson J, Gordon A, French S, Aslam M. The effectiveness of prescribers newsletters in influencing hospital drug expenditure. Hospital Pharmacy Practice 1991;1:33-8.

\section{Winters 2010 \{published data only\}}

Winters BD, Thiemann DR, Brotman DJ. Impact of a restrictive antimicrobial policy on the process and timing of antimicrobial administration. Journal of Hospital Medicine 2010;5:E41-5.

\section{Wishaupt 2011 \{published data only\}}

Wishaupt JO, Russcher A, Smeets LC, Versteegh FG, Hartwig NG. Clinical impact of RT-PCR for pediatric acute respiratory infections: a controlled clinical trial. Pediatrics 2011;128:e1113-20.

\section{Woodward 1987 \{published data only\}}

Woodward RS, Medoff G, Smith MD, Gray JLI. Antibiotic cost savings from formulary restrictions and physician monitoring in a medical-school-affiliated hospital. American Journal of Medicine 1987;83(5):817-23.

\section{Wyatt 1998 \{published data only\}}

Wyatt JC, Paterson-Brown S, Johanson R, Altman DG, Bradburn MJ, Fisk NM. Randomised trial of educational visits to enhance use of systematic reviews in 25 obstetric units. BMJ 1998;317(7165):1041-6.

\section{Yealy 2005 \{published data only\}}

Hsu DJ, Stone RA, Obrosky DS, Yealy DM, Meehan TP, Fine JM, et al. Predictors of timely antibiotic administration for patients hospitalized with community-acquired pneumonia from the cluster-randomized EDCAP trial. American Journal of the Medical Sciences 2010;339:307-13. 
* Yealy DM, Auble TE, Stone RA, Lave JR, Meehan TP, Graff LG, et al. Effect of increasing the intensity of implementing pneumonia guidelines: A randomized, controlled trial. Annals of Internal Medicine 2005;143:881-94.

Yeo 2012 \{published data only\}

Yeo CL, Chan DSG, Earnest A, Wu TS, Yeoh SF, Lim R, et al. Prospective audit and feedback on antibiotic prescription in an adult hematology-oncology unit in Singapore. European Journal of Clinical Microbiology \& Infectious Diseases 2012;31:583-90.

\section{Yong 2010 \{published data only\}}

Yong MK, Buising KL, Cheng AC, Thursky KA. Improved susceptibility of Gram-negative bacteria in an intensive care unit following implementation of a computerized antibiotic decision support system. Journal of Antimicrobial Chemotherapy 2010;65:1062-9.

\section{Yoon 2014 \{published data only\}}

Yoon YK, Yang KS, Lee SE, Kim HJ, Sohn JW, Kim MJ. Effects of Group 1 versus Group 2 carbapenems on the susceptibility of Acinetobacter baumannii to carbapenems: A before and after intervention study of carbapenem-use stewardship. PLOS ONE 2014;9(6):e99101.

\section{Young 1985 \{published data only\}}

Young EJ, Sewell CM, Koza MA, Clarridge JE. Antibiotic resistance patterns during aminoglycoside restriction. American Journal of Medical Science 1985;290(6):223-7.

\section{Yu 2014 \{published data only\}}

Yu K, Rho J, Morcos M, Nomura J, Kaplan D, Sakamoto K, et al. Evaluation of dedicated infectious diseases pharmacists on antimicrobial stewardship teams. American Journal of HealthSystem Pharmacy 2014;71:1019-28.

\section{Zanetti 2003 \{published data only\}}

Zanetti G, Flanagan HL Jr, Cohn LH, Giardina R, Platt R. Improvement of intraoperative antibiotic prophylaxis in prolonged cardiac surgery by automated alerts in the operating room. Infection Control and Hospital Epidemiology 2003;24:13-6.

\section{References to studies excluded from this review}

\section{Ahronheim 2000 \{published data only\}}

Ahronheim JC, Morrison RS, Morris J, Baskin S, Meier DE. Palliative care in advanced dementia: a randomized controlled trial and descriptive analysis. Journal of Palliative Medicine 2000; Vol. 3, issue 3:265-73.

\section{Bruno-Murtha 2005 \{published data only\}}

Bruno-Murtha LA, Brusch J, Bor D, Li W, Zucker D. A pilot study of antibiotic cycling in the community hospital setting. Infection Control and Hospital Epidemiology 2005;26:81-7.

\section{Burke 1997 \{published data only\}}

Burke CE, Piper J, Holloway W. Order form for restricting vancomycin prescribing. American Journal of Health-System Pharmacy 1997;54(16):1893, 1897.

\section{Cook 2006 \{published data only\}}

Cook PP, Catrou P, Gooch M, Holbert D. Effect of reduction in ciprofloxacin use on prevalence of meticillin-resistant Staphylococcus aureus rates within individual units of a tertiary care hospital. Journal of Hospital Infection 2006;64:348-51.

\section{Crist 1987 \{published data only\}}

Crist KD, Nahata MC, Ety J. Positive impact of a therapeutic drug-monitoring program on total aminoglycoside dose and cost of hospitalization. Therapeutic Drug Monitoring 1987;9(3):306-10.

\section{Cunningham 2008 \{published data only\}}

Cunningham TR, Geller ES, Clarke SW. Impact of electronic prescribing in a hospital setting: a process-focused evaluation. International Journal of Medical Informatics 2008;77:546-54.

Dellinger 2005 \{published data only\}

Dellinger EP, Hausmann SM, Bratzler DW, Johnson RM, Daniel DM, Bunt KM, et al. Hospitals collaborate to decrease surgical site infections. American Journal of Surgery 2005;190(1):9-15.

\section{Destache 1990 \{published data only\}}

Destache CJ, Meyer SK, Bittner MJ, Hermann KG. Impact of a clinical pharmacokinetic service on patients treated with aminoglycosides: a cost-benefit analysis. Therapeutic Drug Monitoring 1990;12(5):419-26.

\section{Ehrenkranz 1992 \{published data only\}}

Ehrenkranz NJ, Nerenberg DE, Shultz JM, Slater KC. Intervention to discontinue parenteral antimicrobial therapy in patients hospitalized with pulmonary infections: effect on shortening patient stay. Infection Control and Hospital Epidemiology 1992;13(1):21-32.

\section{Ehrenkranz 1993 \{published data only\}}

Ehrenkranz NJ, Nerenberg DE, Slater KC, Shultz JM. Intervention to discontinue parenteral antimicrobial therapy in hospitalized patients with urinary tract infection, skin and soft tissue infection, or no evident infection. Infection Control and Hospital Epidemiology 1993;14(9):517-22.

\section{Evans 1994 \{published data only\}}

Evans RS, Classen DC, Pestotnik SL, Lundsgaarde HP, Burke JP. Improving empiric antibiotic selection using computer decision support. Archives of Internal Medicine. 1994;154(8):878-84.

\section{Foy 2004 \{published data only\}}

Foy R, Penney GC, Grimshaw JM, Ramsay CR, Walker AE, Maclennan G, et al. A randomised controlled trial of a tailored multifaceted strategy to promote implementation of a clinical guideline on induced abortion care. BJOG: An International Journal of Obstetrics \& Gynaecology 2004;111:726-33.

\section{Garcia-San Miguel 2014 \{published data only\}}

Garcia-San Miguel L, Cobo J, Martinez JA, Arnau JM, Murillas J, Pena C, et al. 'Third day intervention': an analysis of the factors associated with following the recommendations on the prescribing of antibiotics. Enfermedades Infecciosas y Microbiología Clínica 2014;32:654-61. 


\section{Gerding 1991 \{published data only\}}

Gerding DN, Larson TA, Hughes RA, Weiler M, Shanholtzer C, Peterson LR. Aminoglycoside resistance and aminoglycoside usage: ten years of experience in one hospital. Antimicrobial Agents and Chemotherapy 1991;35(7):1284-90.

Kolar 1999 \{published data only\}

* Kolar M, Latal T. Implementation of a practical antibiotic policy in the Czech Republic. Infection Control and Hospital Epidemiology 1999;20(6):440-3.

Monnet DL, Sørensen TL, Jepsen OB. Implementation of a practical antibiotic policy in the Czech Republic. Infect Control Hosp Epidemiol. 2000;21(1):7-8.

\section{Lan 2003 \{published data only\}}

Lan CK, Hsueh PR, Wong WW, Fung CP, Lau YT, Yeung JY, et al. Association of antibiotic utilization measures and reduced incidence of infections with extended-spectrum betalactamase-producing organisms. Journal of Microbiology, Immunology, and Infection 2003;36(3):182-6.

\section{Lee 2004 \{published data only\}}

Lee SO, Lee ES, Park SY, Kim SY, Seo YH, Cho YK. Reduced use of third-generation cephalosporins decreases the acquisition of extended-spectrum beta-lactamase-producing Klebsiella pneumoniae. Infection Control and Hospital Epidemiology 2004;25(10):832-7.

\section{MacCosbe 1985 \{published data only\}}

MacCosbe PE, Gartenberg G. Modifying empiric antibiotic prescribing: experience with one strategy in a medical residency program. Hospital Formulary 1985;20(9):986-8, 993-5, 999.

\section{Marrie 2000 \{published data only\}}

* Marrie TJ, Lau CY, Wheeler SL, Wong CJ, Vandervoort MK, Feagan BG. A controlled trial of a critical pathway for treatment of community-acquired pneumonia. CAPITAL Study Investigators. Community-Acquired Pneumonia Intervention Trial Assessing Levofloxacin. JAMA 2000;283(6):749-55.

Palmer CS, Zhan C, Elixhauser A, Halpern MT, Rance L, Feagan BG, et al. Economic assessment of the communityacquired pneumonia intervention trial employing levofloxacin Clinical Therapeutics 2000; Vol. 22, issue 2:250-64.

\section{Martin 2005 \{published data only\}}

Martin C, Ofotokun I, Rapp R, Empey K, Armitstead J, Pomeroy $\mathrm{C}$, et al. Results of an antimicrobial control program at a university hospital. American Journal of Health-System Pharmacy 2005;62(7):732-8.

\section{McGregor 2006 \{published data only\}}

McGregor JC, Weekes E, Forrest GN, Standiford HC, Perencevich EN, Furuno JP, et al. Impact of a computerized clinical decision support system on reducing inappropriate antimicrobial use: a randomized controlled trial. Journal of the American Medical Informatics Association 2006;13(4):378-84.

\section{Nagao 2010 \{published data only\}}

Nagao M, linuma Y, Saito T, Matsumura Y, Shirano M, Matsushima A, et al. Close cooperation between infectious disease physicians and attending physicians can result in better management and outcome for patients with Staphylococcus aureus bacteraemia. Clinical Microbiology \& Infection 2010;16:1783-8.

\section{Naughton 2001 \{published data only\}}

Naughton BJ, Mylotte JM, Ramadan F, Karuza J, Priore RL. Antibiotic use, hospital admissions, and mortality before and after implementing guidelines for nursing home-acquired pneumonia. Journal of the American Geriatrics Society 2001:49:1020-4.

\section{Pastel 1992 \{published data only\}}

Pastel DA, Chang S, Nessim S, Shane R, Morgan MA. Department of pharmacy-initiated program for streamlining empirical antibiotic therapy. Hospital Pharmacy 1992;27(7):596-603, 614.

Ronning 1998 \{published data only\}

Ronning OM, Guldvog B. Stroke unit versus general medical wards, II: neurological deficits and activities of daily living: a quasi-randomized controlled trial. Stroke 1998;29(3):586-90.

Sanazaro 1978 \{published data only\}

Sanazaro PJ, Worth RM. Concurrent quality assurance in hospital care. Report of a study by private initiative in PSRO. New England Journal of Medicine 1978; Vol. 298, issue 21:1171-7.

\section{Takahashi 2010 \{published data only\}}

Takahashi Y, Takesue Y, Nakajima K, Ichiki K, Wada Y, Tsuchida T, et al. Implementation of a hospital-wide project for appropriate antimicrobial prophylaxis. Journal of Infection and Chemotherapy 2010;16:418-23.

\section{Thomas 2002 \{published data only\}}

Thomas AR, Cieslak PR, Strausbaugh LJ, Fleming DW. Effectiveness of pharmacy policies designed to limit inappropriate vancomycin use: a population-based assessment. Infection Control and Hospital Epidemiology 2002;23(11):683-8.

\section{Tiley 2003 \{published data only\}}

Tiley SM, MacDonald JJ, Doherty PL, Ferguson JK, Fergusson JE. Active promotion of antibiotic guidelines: an intensive program. Communicable Disease Intelligence 2003; Vol. 27 Suppl:13-8.

Tsiata 2001 \{published data only\}

Tsiata C, Tsekouras V, Karokis A, Starakis J, Bassaris HP, Maragoudakis $\mathrm{M}$, et al. Cost effectiveness of antibacterial restriction strategies in a tertiary care university teaching hospital. Disease Management and Health Outcomes 2001;9:23-32

\section{Van Loon 2005 \{published data only\}}

Van Loon HJ, Vriens MR, Fluit AC, Troelstra A, Van der Werken C, Verhoef $\mathrm{J}$, et al. Antibiotic rotation and development of gramnegative antibiotic resistance. American Journal of Respiratory and Critical Care Medicine 2005;171(5):480-7. 
Wahlstrom 2003 \{published data only\}

Wahlstrom R, Kounnavong S, Sisounthone B, Phanyanouvong A, Southammavong T, Eriksson B, et al. Effectiveness of feedback for improving case management of malaria, diarrhoea and pneumonia - a randomized controlled trial at provincial hospitals in Lao PDR. Tropical Medicine and International Health 2003;8(10):901-9.

\section{Additional references}

\section{Arnold 2005}

Arnold SR, Straus SE. Interventions to improve antibiotic prescribing practices in ambulatory care. Cochrane Database of Systematic Reviews 2005, Issue 4. [DOI: 10.1002/14651858.CD003539.pub2]

\section{Ash 2007}

Ash JS, Sittig DF, Dykstra RH, Guappone K, Carpenter JD, Seshadri V. Categorizing the unintended sociotechnical consequences of computerized provider order entry. International Journal of Medical Informatics 2007;76 Suppl 1:S21-7.

\section{Avery 2012}

Avery AJ, Rodgers S, Cantrill JA, Armstrong S, Cresswell K, Eden $\mathrm{M}$, et al. A pharmacist-led information technology intervention for medication errors (PINCER): a multicentre, cluster randomised, controlled trial and cost-effectiveness analysis. Lancet 2012;379:1310-9.

\section{Carratala 2012}

Carratala J, Garcia-Vidal C, Ortega L, Fernandez-Sabe N, Clemente M, Albero G, et al. Effect of a 3-step critical pathway to reduce duration of intravenous antibiotic therapy and length of stay in community-acquired pneumonia: a randomized controlled trial. Archives of Internal Medicine 2012;172:922-8.

\section{Charani 2011}

Charani E, Edwards R, Sevdalis N, Alexandrou B, Sibley E, Mullett $D$, et al. Behavior change strategies to influence antimicrobial prescribing in acute care: a systematic review. Clinical Infectious Diseases 2011;53(7):651-62.

\section{Cochran 1954}

Cochran WG. The combination of estimates from different experiments. Biometrics 1954;10:101-29.

\section{Conlon 2011}

Conlon G, Aldeyab MA, McElnay JC, Scott MG, Magee FA, Davies $\mathrm{E}$, et al. Improving and maintaining adherence with hospital antibiotic policies: a strategy for success. Journal of Hospital Infection 2011;77:88-9.

\section{Davey 2010}

Davey P, Sneddon J, Nathwani D. Overview of strategies for overcoming the challenge of antimicrobial resistance. Expert Reviews in Clinical Pharmacology 2010;3(5):667-86.

\section{Davey-Smith 2001}

Davey Smith G, Ebrahim S. Epidemiology - is it time to call it a day?. International Journal of Epidemiology 2001;30:1-11.

\section{de Kraker 2011}

de Kraker ME, Davey PG, Grundmann H. Mortality and hospital stay associated with resistant Staphylococcus aureus and Escherichia coli bacteremia: estimating the burden of antibiotic resistance in Europe. PLoS Medicine 2011;8(10):e1001104.

\section{Department of Health 2013}

Department of Health. UK 5 Year Antimicrobial Resistance Strategy 2013 to 2018. www.gov.uk/government/publications/ uk-5-year-antimicrobial-resistance-strategy-2013-to-2018 2013 (accessed prior to 6 January 2017).

\section{Doern 1994}

Doern G V, Vautour R, Gaudet M, Levy B. Clinical impact of rapid in vitro susceptibility testing and bacterial identification. Journal of Clinical Microbiology 1994;32:1757-62.

\section{Dreischulte 2016}

Dreischulte T, Donnan P, Grant A, Hapca A, McCowan C, Guthrie B. Safer prescribing - a trial of education, informatics, and financial incentives. New England Journal of Medicine 2016;374:1053-64.

\section{Elligson 2012a}

Elligsen M, Walker SA, Simor A, Daneman N. Prospective audit and feedback of antimicrobial stewardship in critical care: program implementation, experience, and challenges. Canadian Journal of Hospital Pharmacy 2012;65:31-6.

\section{EPOC 2013}

Effective Practice, Organisation of Care (EPOC). Suggested risk of bias criteria for EPOC reviews. EPOC Resources for review authors. Oslo: Norwegian Knowledge Centre for the Health Services; 2013. epoc.cochrane.org/epoc-specific-resourcesreview-authors (accessed prior to 6 January 2017).

\section{EPOC 2013a}

Effective Practice, Organisation of Care (EPOC). EPOC worksheets for preparing a 'Summary of findings' (SoF) table using GRADE. EPOC Resources for review authors. Oslo: Norwegian Knowledge Centre for the Health Services; 2013. epoc.cochrane.org/epoc-specific-resources-review-authors (accessed prior to 6 January 2017).

\section{EPOC 2015}

Effective Practice, Organisation of Care (EPOC). EPOC Taxonomy; 2015. epoc.cochrane.org/epoc-taxonomy (accessed prior to 6 January 2017).

\section{EPOC 2016}

Effective Practice, Organisation of Care (EPOC). What study designs should be included in an EPOC review? EPOC Resources for review authors. Oslo: Norwegian Knowledge Centre for the Health Services; 2016. epoc.cochrane.org/epoc-specificresources-review-authors (accessed prior to 6 January 2017). 


\section{Feazel 2014}

Feazel LM, Malhotra A, Perencevich EN, Kaboli P, Diekema DJ, Schweizer ML. Effect of antibiotic stewardship programmes on Clostridium difficile incidence: a systematic review and meta-analysis. Journal of Antimicrobial Chemotherapy 2014;69(7):1748-54.

\section{Garcia 2007}

Garcia JC, Ferreira FOF, Grion CM, Carrilho CM. Impact of the implementation of a therapeutic guideline on the treatment of nosocomial pneumonia acquired in the intensive care unit of a university hospital. Jornal Brasileiro de Pneumologia $i$ 2007;33:175-84.

\section{Grant 2013}

Grant A, Treweek S, Dreischulte T, Foy R, Guthrie B. Process evaluations for cluster-randomised trials of complex interventions: a proposed framework for design and reporting. Trials 2013;14:15.

\section{Guyatt 2011}

Guyatt GH, Oxman AD, Montori V, Vist G, Kunz R, Brozek J, et al. GRADE guidelines: 5 . Rating the quality of evidence - publication bias. Journal of Clinical Epidemiology 2011;64:1277-82.

\section{Health Services Research Unit 2016}

Health Services Research Unit. Empirical estimates of ICCs from changing professional practice studies. www.abdn.ac.uk/hsru/ documents/iccs-web.xls Vol. 2016 (accessed prior to 6 January 2017).

\section{Higgins 2003}

Higgins J P, Thompson S G, Deeks J J, Altman D G. Measuring inconsistency in meta-analyses. BMJ 2003;327:557-60.

\section{Higgins 2011}

Higgins JP, Green S (editors). Cochrane Handbook for Systematic Reviews of Interventions. Version 5.1.0 [updated March 2011]. The Cochrane Collaboration, 2011. Available from handbook.cochrane.org.

\section{Hoffmann 2014}

Hoffmann TC, Glasziou PP, Boutron I, Milne R, Perera R, Moher $\mathrm{D}$, et al. Better reporting of interventions: template for intervention description and replication (TIDieR) checklist and guide. BMJ 2014;348:g1687. [DOI: 10.1136/bmj.g1687]

\section{ISD 2016}

ISD Scotland. NHS Scotland's Infection Intelligence Platform (IIP) - a shared resource for Healthcare Associated Infection surveillance and research. www.isdscotland.org/Health-Topics/ Health-and-Social-Community-Care/Infection-IntelligencePlatform/ 2016 (accessed prior to 6 January 2017).

\section{Ivers 2012}

Ivers N, Jamtvedt G, Flottorp S, Young JM, OdgaardJensen J, French SD, et al. Audit and feedback: effects on professional practice and healthcare outcomes. Cochrane Database of Systematic Reviews 2012, Issue 6. [DOI: 10.1002/14651858.CD000259.pub3]

\section{JPIAMR 2016}

JPIAMR Joint Programming Initiative on Antimicrobial Resistance. 4th Joint Call: Networks Working Groups. www.jpiamr.eu/activities/4th-joint-call-research-networkinggroups/ 2016 (accessed prior to 6 January 2017).

\section{Jump 2013}

Jump RL, Olds DM, Jury LA, Sitzlar B, Saade E, Watts B, et al. Specialty care delivery: bringing infectious disease expertise to the residents of a Veterans Affairs long-term care facility. Journal of the American Geriatrics Society 2013;61:782-7.

\section{Lester 2010}

Lester H, Schmittdiel J, Selby J, Fireman B, Campbell S, Lee J, et al. The impact of removing financial incentives from clinical quality indicators: longitudinal analysis of four Kaiser Permanente indicators. BMJ 2010;340:c1898.

\section{Michie 2011}

Michie S, van Stralen MM, West R. The behaviour change wheel: a new method for characterising and designing behaviour change interventions. Implementation Science 2011;6:42.

\section{Michie 2013}

Michie S, Richardson M, Johnston M, Abraham C, Francis J, Hardeman W, et al. The Behavior Change Technique Taxonomy (v1) of 93 Hierarchically Clustered Techniques: Building an International Consensus for the Reporting of Behavior Change Interventions. Annals of Behavioral Medicine 2013;46:81-95.

\section{Monnet 2000}

Monnet DL, Sørensen TL, Jepsen OB. Implementation of a practical antibiotic policy in the Czech Republic. Infection Control and Hospital Epidemiology 2000;21(1):7-8.

\section{NCEPOD 2015}

NCEPOD National Confidential Enquiry Into Patient Outcome and Death. Just Say Sepsis! A review of the process of care received by patients with sepsis. www.ncepod.org.uk/2015report2/downloads/JustSaySepsis_ SummarySheet.pdf 2015 (accessed prior to 6 January 2017).

\section{Pulcini 2008}

Pulcini C, Defres S, Aggarwal I, Nathwani D, Davey P. Design of a 'day 3 bundle' to improve the reassessment of inpatient empirical antibiotic prescriptions. Journal of Antimicrobial Chemotherapy 2008;61(6):1384-8. doi: 10.1093/jac/dkn113.

\section{Ramsay 2003}

Ramsay C, Brown E, Hartman G, Davey P. Room for improvement: a systematic review of the quality of evaluations of interventions to improve hospital antibiotic prescribing. Journal of Antimicrobial Chemotherapy 2003;52:764-71.

\section{Review Manager 5 [Computer program]}

Nordic Cochrane Centre, The Cochrane Collaboration. Review Manager 5 (RevMan 5). Version 5.3. Copenhagen: Nordic Cochrane Centre, The Cochrane Collaboration, 2014. 


\section{Rogers 1995}

Rogers ER. Consequences of innovations. Diffusion of Innovations. New York: Free Press, 1995:405-39.

\section{Schuts 2016}

Schuts EC, Hulscher ME, Mouton JW, Verduin CM, Stuart JW, Overdiek HW, et al. Current evidence on hospital antimicrobial stewardship objectives: a systematic review and meta-analysis. Lancet Infectious Diseases 2016;16:847-56.

\section{Schünemann 2013}

Schünemann HJ, Tugwell P, Reeves BC, Akl EA, Santesso N, Spencer FA, et al. Non-randomized studies as a source of complementary, sequential or replacement evidence for randomized controlled trials in systematic reviews on the effects of interventions. Research Synthesis Methods 2013;4:49-62.

\section{SISCC 2016}

SISCC Improvement Science Methods Research Theme. SISCC Snapshot - April 2016. www.siscc.dundee.ac.uk/Media/Default/ Documents/2016-05-11\%20SISCC\%20ISM\%20Snapshot \%20v0.4.pdf 2016 (accessed prior to 6 January 2017).

\section{Stata 2015}

StataCorp. Stata Data Analysis and Statistical Software: Stata 14. www.stata.com/new-in-stata/ 2015.

\section{Sterne 2016}

Sterne JA, Hernán MA, Reeves BC, Savović J, Berkman ND, Viswanathan N, et al. ROBINS-I: a tool for assessing risk of bias in non-randomised studies of interventions. BMJ 2016; Vol. 355::i4919.

\section{Stone 2007}

Stone SP, Cooper BS, Kibbler CC, Cookson BD, Roberts JA, Medley GF, et al. The ORION statement: guidelines for transparent reporting of outbreak reports and intervention studies of nosocomial infection. Lancet Infectious Diseases 2007;7(4):282-8.

\section{Thursky 2006}

Thursky KA, Buising KL, Bak N, Macgregor L, Street AC, Macintyre $C R$, et al. Reduction of broad-spectrum antibiotic use with computerized decision support in an intensive care unit. International Journal for Quality in Health Care 2006;18:224-31.

\section{Vernaz 2008}

Vernaz N, Sax H, Pittet D, Bonnabry P, Schrenzel J, Harbarth S. Temporal effects of antibiotic use and hand rub consumption on the incidence of MRSA and Clostridium difficile. Journal of Antimicrobial Chemotherapy 2008;62:601-7.

\section{Walker 2016}

Walker H, Patton A, Bayne G, Marwick C, Sneddon J, Davey P, et al. Reduction in post-operative acute kidney injury following a change in antibiotic prophylaxis policy for orthopaedic surgery: an observational study. Journal of Antimicrobial Chemotherapy 2016 May 26.[Epub ahead of print]. [DOI: 10.1093/jac/dkw166]

\section{Weiss 2011}

Weiss CH, Moazed F, McEvoy CA, Singer BD, Szleifer I, Amaral LA, et al. Prompting physicians to address a daily checklist and process of care and clinical outcomes: a single-site study. American Journal of Respiratory and Critical Care Medicine 2011;184:680-6.

\section{Yealy 2004}

Yealy DM, Auble TE, Stone RA, Lave JR, Meehan TP, Graff LG, et al. The emergency department community-acquired pneumonia trial: Methodology of a quality improvement intervention. Annals of Emergency Medicine 2004;43:770-82.

\section{References to other published versions of this review Davey 2005}

Davey P, Brown E, Fenelon L, Finch R, Gould I, Hartman G, et al. Interventions to improve antibiotic prescribing practices for hospital inpatients. Cochrane Database of Systematic Reviews 2005, Issue 4. [DOI: 10.1002/14651858.CD003543.pub2]

\section{Davey 2013}

Davey P, Brown E, Charani E, Fenelon L, Gould IM, Holmes A, et al. Interventions to improve antibiotic prescribing practices for hospital inpatients. Cochrane Database of Systematic Reviews 2013, Issue 4. [DOI: 10.1002/14651858.CD003543.pub3]

\section{Davey 2014}

Davey P, Peden C, Brown E, Charani E, Michie S, Ramsay CR, et al. Interventions to improve antibiotic prescribing practices for hospital inpatients (updated protocol). Cochrane Database of Systematic Reviews 2014, Issue 8. [DOI: 10.1002/14651858.CD011236]

* Indicates the major publication for the study

\section{CHARACTERISTICS OF STUDIES}

Characteristics of included studies [ordered by study ID]

Abramowitz 1982

Methods STUDY DESIGN: ITS

Risk of Bias: MEDIUM

Participants PROVIDERS: all physicians in hospital


Abramowitz 1982 (Continued)

PARTICIPANTS: all adult patients in the hospital

CLINICAL PROBLEM: receiving treatment with target antibiotics

SETTING: single university hospital in the USA

Interventions $\quad$ FORMAT, Interventions: educational meetings with dissemination of materials; audit and feedback;
educational outreach by review and recommend change

Intervention Functions: education; enablement; persuasion

DELIVERER: pharmacist

COMPARISON: 9 months' pre-intervention. Usual care

DESIRED CHANGE: reduce inappropriate

Outcomes PRESCRIBING: Choice: decrease in use of cefoxitin and cefamandole

COST: total cost of 6 target antibiotics (calculated from data in Tables 1 and 2)

\begin{tabular}{ll}
\hline Notes & FINANCIAL SUPPORT: no information provided \\
& ADDITIONAL DATA: no response from authors to request for additional data
\end{tabular}

\section{Risk of bias}

\begin{tabular}{|c|c|c|}
\hline Bias & Authors' judgement & Support for judgement \\
\hline $\begin{array}{l}\text { Intervention independent } \\
\text { (ITS)? }\end{array}$ & Unclear risk & Not stated. \\
\hline $\begin{array}{l}\text { Analysed appropriately } \\
\text { (ITS)? }\end{array}$ & Low risk & $\begin{array}{l}\text { Re-analysed. Not done in original paper (comparison of means, uncontrolled } \\
\text { before-after). }\end{array}$ \\
\hline $\begin{array}{l}\text { Shape of effect pre-speci- } \\
\text { fied (ITS)? }\end{array}$ & Low risk & $\begin{array}{l}\text { Done, intended effect was decrease in primary outcome and point of analysis } \\
\text { was point of intervention. }\end{array}$ \\
\hline $\begin{array}{l}\text { Unlikely to affect data col- } \\
\text { lection (ITS)? }\end{array}$ & Low risk & $\begin{array}{l}\text { Done, data were from routine systems and unlikely to change over study peri- } \\
\text { od. }\end{array}$ \\
\hline $\begin{array}{l}\text { Knowledge of the alloca- } \\
\text { tion adequately prevent- } \\
\text { ed(ITS)? }\end{array}$ & Low risk & $\begin{array}{l}\text { Done, data were from routine systems and unlikely to change over study peri- } \\
\text { od. }\end{array}$ \\
\hline $\begin{array}{l}\text { Incomplete outcome data } \\
\text { addressed (ITS)? }\end{array}$ & Low risk & $\begin{array}{l}\text { Done, data were from routine systems and unlikely to change over study peri- } \\
\text { od. }\end{array}$ \\
\hline $\begin{array}{l}\text { Free of selected reporting } \\
\text { (ITS) ? }\end{array}$ & Low risk & Done, data were from routine pharmacy systems database. \\
\hline Free of other bias (ITS) ? & Low risk & Price of target antibiotics constant over the study period. \\
\hline
\end{tabular}

$\begin{array}{ll}\text { Methods } & \text { STUDY DESIGN: ITS } \\ & \text { Risk of Bias: MEDIUM }\end{array}$


Adachi 1997 (Continued)

Participants

PROVIDERS: all physicians in the hospital

PARTICIPANTS: all patients in the hospital

CLINICAL PROBLEM: patients requiring antibiotic treatment

SETTING: single hospital in the USA

Interventions

FORMAT, Interventions: dissemination of educational materials; educational outreach by review and recommend change; reminders (physical - newsletter)

Intervention Functions: education, enablement, environmental restructuring, persuasion

DELIVERER: pharmacist

COMPARISON: usual care

DESIRED CHANGE: decrease excessive

\begin{tabular}{ll} 
Outcomes & PRESCRIBING: Choice: reduce vancomycin prescribing and increase appropr \\
& COST: valid financial savings \\
\hline Notes & FINANCIAL SUPPORT: no information provided \\
& ADDITIONAL DATA: no response from authors to request for additional data
\end{tabular}

\section{Risk of bias}

\begin{tabular}{|c|c|c|}
\hline Bias & Authors' judgement & Support for judgement \\
\hline $\begin{array}{l}\text { Intervention independent } \\
\text { (ITS)? }\end{array}$ & Low risk & $>1$ year data pre- and postintervention \\
\hline $\begin{array}{l}\text { Analysed appropriately } \\
\text { (ITS)? }\end{array}$ & Low risk & $\begin{array}{l}\text { Re-analysed. Not done in original paper (comparison of means, uncontrolled } \\
\text { before and after). }\end{array}$ \\
\hline $\begin{array}{l}\text { Shape of effect pre-speci- } \\
\text { fied (ITS)? }\end{array}$ & Low risk & $\begin{array}{l}\text { Done, intended effect was decrease in primary outcome, and point of analysis } \\
\text { was point of intervention. }\end{array}$ \\
\hline $\begin{array}{l}\text { Unlikely to affect data col- } \\
\text { lection (ITS)? }\end{array}$ & Low risk & $\begin{array}{l}\text { Done, data were from routine systems and unlikely to change over study peri- } \\
\text { od. }\end{array}$ \\
\hline $\begin{array}{l}\text { Knowledge of the alloca- } \\
\text { tion adequately prevent- } \\
\text { ed(ITS)? }\end{array}$ & Low risk & $\begin{array}{l}\text { Done, data were from routine systems and unlikely to change over study peri- } \\
\text { od. }\end{array}$ \\
\hline $\begin{array}{l}\text { Incomplete outcome data } \\
\text { addressed (ITS)? }\end{array}$ & Low risk & $\begin{array}{l}\text { Done, data were from routine systems and unlikely to change over study peri- } \\
\text { od. }\end{array}$ \\
\hline $\begin{array}{l}\text { Free of selected reporting } \\
\text { (ITS)? }\end{array}$ & Low risk & $\begin{array}{l}\text { Done, data were from routine systems and unlikely to change over study peri- } \\
\text { od. }\end{array}$ \\
\hline Free of other bias (ITS)? & Unclear risk & $\begin{array}{l}\text { Not clear, no information about changes in price of vancomycin over the study } \\
\text { period. }\end{array}$ \\
\hline
\end{tabular}

Akenroye 2014

$\begin{array}{ll}\text { Methods } & \text { STUDY DESIGN: ITS } \\ & \text { Risk of Bias: LOW }\end{array}$


Akenroye 2014 (Continued)

Participants
PROVIDERS: all paediatricians and nurses in the ED

PARTICIPANTS: all children with bronchiolitis

CLINICAL PROBLEM: acute bronchiolitis presenting to a paediatric ED

SETTING: 1 university hospital in the USA

Interventions

FORMAT, Interventions: audit and feedback; dissemination of educational materials; educational outreach by review and recommend change; reminders (physical - posters and email)

Intervention Functions: education, enablement, environmental restructuring, persuasion

DELIVERER: departmental physicians, nurses, and managers

COMPARISON: usual care

DESIRED CHANGE: decrease excessive

Outcomes PRESCRIBING: exposure, \% children treated with antibiotics

CLINICAL: balancing, \% admission rate, \% return ED visit rate, ED length of stay (minutes)

FINANCIAL: total cost per patient. No data about the intervention cost.

Notes

FINANCIAL SUPPORT: Funding: Boston Children's Hospital Department of Medicine Quality Improvement Publication (QIPub) grant. Competing Interest: none declared

ADDITIONAL INFORMATION: care pathway is in a supplementary online file

\section{Risk of bias}

Bias Authors' judgement Support for judgement

Intervention independent Low risk

(ITS) ?

Analysed appropriately Low risk $\quad$ Segmented regression analysis
(ITS)?

(ITS) ?

Shape of effect pre-speci- Low risk Point of intervention was point of analysis.

fied (ITS) ?

Unlikely to affect data col- Low risk Electronic outcome data

lection (ITS) ?

Knowledge of the alloca- Low risk Electronic outcome data

tion adequately prevent-

ed(ITS)?

Incomplete outcome data Low risk $\quad$ Electronic outcome data
addressed (ITS) ?

\begin{tabular}{lll}
\hline $\begin{array}{l}\text { Free of selected reporting } \\
\text { (ITS) } ?\end{array}$ & Low risk & Electronic outcome data \\
\hline Free of other bias (ITS) ? & Low risk & $>1$ year of data pre- and postintervention \\
\hline
\end{tabular}

Aldeyab 2012

Methods STUDY DESIGN: ITS


Aldeyab 2012 (Continued)

\section{Risk of Bias: MEDIUM}

PROVIDERS: all physicians in the hospital
PARTICIPANTS: all adult patients in the hospital
CLINICAL PROBLEM: patients requiring therapeutic or prophylactic antibiotics
SETTING: 1 university hospital in the UK

Interventions

FORMAT, Interventions: audit and feedback; restrictive - expert approval

Intervention Functions: enablement, restriction

DELIVERER: AMT

COMPARISON: usual care

DESIRED CHANGE: decrease excessive

\begin{tabular}{ll} 
Outcomes & PRESCRIBING: Choice: use of target antibiotics in DDD/100 OBD \\
& MICROBIAL: Clostridium difficile infections/100 OBD \\
\hline Notes & FINANCIAL SUPPORT: Funding: Deanship of Scientific Research (DSR), King Abdulaziz University, Jed- \\
& dah grant no. 7-968-D1432. Competing interest: none declared \\
& ADDITIONAL DATA: restriction policy is described in detail in an additional online file for this paper and \\
in Conlon 2011.
\end{tabular}

Microbial Risk of Bias: LOW, case definition Low, planned intervention Low, other infection control Low

\section{Risk of bias}

\begin{tabular}{lll}
\hline Bias & Authors' judgement & Support for judgement \\
\hline $\begin{array}{l}\text { Intervention independent } \\
(\text { ITS) } ?\end{array}$ & High risk & $\begin{array}{l}\text { Changes in CDI screening policy and cleaning policy occurred between Phases } \\
1 \text { and 2 (Figure 1). }\end{array}$ \\
\hline $\begin{array}{l}\text { Analysed appropriately } \\
\text { (ITS) ? }\end{array}$ & Low risk & Segmented regression analysis \\
\hline
\end{tabular}

Shape of effect pre-speci- Low risk Point of intervention was point of analysis.

fied (ITS) ?

Unlikely to affect data col- Low risk $\quad$ Electronic data from pharmacy and microbiology
lection (ITS) ?

Knowledge of the alloca- Low risk $\quad$ Electronic data from pharmacy and microbiology
tion adequately prevent-
tion adequately prevented(ITS)?

Incomplete outcome data Low risk $\quad$ Electronic data from pharmacy and microbiology
addressed (ITS)?

Free of selected reporting Low risk Electronic data from pharmacy and microbiology
(ITS) ?

Free of other bias (ITS) ? Low risk >1 year data pre- and postintervention


Aldeyab 2014

\begin{tabular}{ll}
\hline Methods & STUDY DESIGN: ITS \\
& Risk of Bias: LOW \\
\hline Participants & PROVIDERS: all physicians in the hospital \\
& PARTICIPANTS: all adult patients in the hospital \\
CLINICAL PROBLEM: patients requiring therapeutic or prophylactic antibiotics \\
SETTING: 1 university hospital in the UK
\end{tabular}

FORMAT: same as in Aldeyab 2012; this article provides additional microbial outcome data for impact
on MRSA infections
DELIVERER: AMT
COMPARISON: usual care
DESIRED CHANGE: decrease excessive

\begin{tabular}{ll}
\hline Outcomes & PRESCRIBING: same as in Aldeyab 2012 \\
& MICROBIAL: MRSA infections/100 OBD \\
\hline Notes & FINANCIAL SUPPORT: same as in Aldeyab 2012 \\
& ADDITIONAL DATA: restriction policy is described in detail in an additional online file for Aldeyab 2012 \\
& and in Conlon 2011 (additional studies) \\
& Microbial Risk of Bias: LOW, case definition Low, planned intervention Low, other infection control \\
& Low
\end{tabular}

\section{Risk of bias}

\begin{tabular}{lll}
\hline Bias & Authors' judgement & Support for judgement \\
\hline $\begin{array}{l}\text { Intervention independent } \\
\text { (ITS) ? }\end{array}$ & Low risk & $\begin{array}{l}\text { Data and segmented regression model of alcohol-based hand rub included as } \\
\text { a proxy measure for infection control practices. }\end{array}$ \\
\hline $\begin{array}{l}\text { Analysed appropriately } \\
\text { (ITS)? }\end{array}$ & Low risk & Segmented regression analysis \\
\hline $\begin{array}{l}\text { Shape of effect pre-speci- } \\
\text { fied (ITS) ? }\end{array}$ & Low risk & Point of intervention was point of analysis. \\
\hline $\begin{array}{l}\text { Unlikely to affect data col- } \\
\text { lection (ITS) ? }\end{array}$ & Low risk & Electronic data from microbiology \\
\hline $\begin{array}{l}\text { Knowledge of the alloca- } \\
\text { tion adequately prevent- } \\
\text { ed(ITS)? }\end{array}$ & Low risk & Electronic data from microbiology \\
\hline $\begin{array}{l}\text { Incomplete outcome data } \\
\text { addressed (ITS) ? }\end{array}$ & Low risk & \\
\hline $\begin{array}{l}\text { Free of selected reporting } \\
\text { (ITS) ? }\end{array}$ & Low risk & Electronic data from microbiology \\
\hline \begin{tabular}{l} 
Free of other bias (ITS) ? \\
\hline
\end{tabular} & Low risk & Electronic data from microbiology \\
\hline
\end{tabular}


Ananda-Rajah 2010

\begin{tabular}{ll}
\hline Methods & STUDY DESIGN: ITS \\
& Risk of Bias: MEDIUM \\
\hline Participants & PROVIDERS: all physicians in the medical-surgical ICU \\
& PARTICIPANTS: all patients in the ICU \\
& CLINICAL PROBLEM: reduction in use of broad-spectrum antibiotics considered high risk for selection \\
of MRSA & SETTING: 1 university hospital in Australia \\
\hline
\end{tabular}

Interventions
Intervention Functions: education, enablement, persuasion
DELIVERER: AMT
COMPARISON: usual care
DESIRED CHANGE: decrease excessive

Outcomes $\quad$ PRESCRIBING: Choice: use of broad-spectrum antibiotics in DDD/1000 OBD

MICROBIAL: MRSA bacteraemia rate

Notes
FINANCIAL SUPPORT: none declared. Competing Interest: none declared
ADDITIONAL DATA: no response from authors to request for additional data

Microbial Risk of Bias: HIGH, case definition Low, planned intervention Low, other infection control High. Infection control interventions close to antibiotic stewardship interventions clearly documented in Figure 1.

\begin{tabular}{|c|c|c|}
\hline \multicolumn{3}{|l|}{ Risk of bias } \\
\hline Bias & Authors' judgement & Support for judgement \\
\hline $\begin{array}{l}\text { Intervention independent } \\
\text { (ITS) ? }\end{array}$ & High risk & $\begin{array}{l}\text { Other changes are clearly documented in Figure } 1 \text {. This includes an outbreak } \\
\text { of Acinetobacter infection co-incident with the stewardship intervention, } \\
\text { which resulted in appointment of } 2 \text { infection control practitioners and associ- } \\
\text { ated interventions. The additional staff could have influenced prescribing out- } \\
\text { come. }\end{array}$ \\
\hline $\begin{array}{l}\text { Analysed appropriately } \\
\text { (ITS)? }\end{array}$ & Low risk & Segmented regression analysis \\
\hline $\begin{array}{l}\text { Shape of effect pre-speci- } \\
\text { fied (ITS)? }\end{array}$ & Low risk & Point of intervention is point of analysis. \\
\hline $\begin{array}{l}\text { Unlikely to affect data col- } \\
\text { lection (ITS)? }\end{array}$ & Low risk & Pharmacy and microbiology routine data \\
\hline $\begin{array}{l}\text { Knowledge of the alloca- } \\
\text { tion adequately prevent- } \\
\text { ed(ITS)? }\end{array}$ & Low risk & Pharmacy and microbiology routine data \\
\hline $\begin{array}{l}\text { Incomplete outcome data } \\
\text { addressed (ITS)? }\end{array}$ & Low risk & Pharmacy and microbiology routine data \\
\hline $\begin{array}{l}\text { Free of selected reporting } \\
\text { (ITS)? }\end{array}$ & Low risk & Pharmacy and microbiology routine data \\
\hline
\end{tabular}


Ananda-Rajah 2010 (Continued)

Free of other bias (ITS) ? Low risk $\quad>1$ year data pre- and postintervention

Annane 2013

\begin{tabular}{ll} 
Methods & STUDY DESIGN: RCT \\
& Risk of Bias: HIGH \\
\hline Participants & PROVIDERS: all physicians in participating ICUs \\
& PARTICIPANTS: all patients in the ICUs with sepsis. Over a 3-year period, $62 / 1250$ screened patients \\
& Were eligible for the study, of whom 31 were randomised to each arm \\
& CLINICAL PROBLEM: sepsis \\
& SETTING: 8 hospitals in France
\end{tabular}

FORMAT, Interventions: structural - rapid testing of PCT with decision support algorithm

Intervention Functions: enablement, environmental restructuring

DELIVERER: departmental physician

COMPARISON: usual care

DESIRED CHANGE: decrease excessive

POWER CALCULATION: yes, 140 participants in total (70 in each arm) would be needed (details in Appendix 3)

\begin{tabular}{|c|c|}
\hline \multirow[t]{3}{*}{ Outcomes } & PRESCRIBING: exposure, \% receiving antibiotics at day 5 \\
\hline & CLINICAL: mortality, length of ICU stay, length of hospital stay \\
\hline & MICROBIAL: colonisation with MRSA (nasal swab) and GNRB (rectal swabs) \\
\hline \multirow[t]{2}{*}{ Notes } & $\begin{array}{l}\text { FINANCIAL SUPPORT: Funding: commercial, Thermo Fisher B.R.A.H.M.S. France, a subsidiary of the } \\
\text { maker of the PCT assay used in this study. Competing interests: none declared }\end{array}$ \\
\hline & $\begin{array}{l}\text { ADDITIONAL INFORMATION: supplementary online file has PCT algorithm, authors provided full study } \\
\text { protocol (in French) }\end{array}$ \\
\hline
\end{tabular}

Microbial Risk of Bias: MEDIUM (no data about infection control)

\begin{tabular}{lll}
\hline Risk of bias & & \\
\hline Bias & Authors' judgement & Support for judgement \\
\hline $\begin{array}{l}\text { Random sequence genera- } \\
\text { tion (selection bias) }\end{array}$ & Low risk & Computer generated \\
\hline $\begin{array}{l}\text { Allocation concealment } \\
\text { (selection bias) }\end{array}$ & Low risk & Central allocation \\
\hline $\begin{array}{l}\text { Blinding (performance } \\
\text { bias and detection bias) } \\
\text { All outcomes }\end{array}$ & High risk & PCT levels not reported on control participants. \\
\hline $\begin{array}{l}\text { Incomplete outcome data } \\
\text { (attrition bias) } \\
\begin{array}{l}\text { All outcomes } \\
\end{array}\end{array}$ & Low risk & No participants lost to follow-up. \\
\hline
\end{tabular}


Annane 2013 (Continued)

\begin{tabular}{|c|c|c|}
\hline $\begin{array}{l}\text { Selective reporting (re- } \\
\text { porting bias) }\end{array}$ & Low risk & No participants lost to follow-up. \\
\hline Other bias & High risk & Study stopped prematurely because of low recruitment. \\
\hline $\begin{array}{l}\text { Baseline Outcomes simi- } \\
\text { lar? }\end{array}$ & Unclear risk & No data \\
\hline Free of contamination? & Low risk & РCT levels not reported on control participants. \\
\hline $\begin{array}{l}\text { Baseline characteristics } \\
\text { similar? }\end{array}$ & Low risk & Table 1 \\
\hline
\end{tabular}

Ansari 2003

Methods STUDY DESIGN: ITS

\section{Risk of Bias: LOW}

Participants PROVIDERS: all physicians in the hospital

PARTICIPANTS: all patients in the hospital

CLINICAL PROBLEM: antibiotics dispensed to hospital wards for administration for therapy or prophylaxis

SETTING: 1 university hospital in the UK

\begin{tabular}{ll}
\hline Interventions & FORMAT, Interventions: educational meetings; dissemination of educational materials; educational \\
outreach by review and recommend change
\end{tabular}

Intervention Functions: education, enablement, persuasion

DELIVERER: AMT

COMPARISON: usual care

DESIRED CHANGE: decrease excessive

PRESCRIBING: Choice: total use of Alert Antibiotics in DDD/1000 OBD
FINANCIAL: cost of antibiotics adjusted for changes in price over the 4-year study period. Cost of the
Alert Antibiotic Monitoring intervention and of the setup and analysis of the ward antimicrobial supply
database (Table 3)

Notes

FINANCIAL SUPPORT: no financial support. Competing Interests: none declared

ADDITIONAL DATA: email response from authors to request for additional data

\section{Risk of bias}

\begin{tabular}{|c|c|c|}
\hline Bias & Authors' judgement & Support for judgement \\
\hline $\begin{array}{l}\text { Intervention independent } \\
\text { (ITS)? }\end{array}$ & Low risk & $\begin{array}{l}\text { "In 2000, the Antibiotic Subcommittee of Tayside University Hospitals Trust } \\
\text { devised an Alert Antibiotic Policy to reduce inappropriate use of key antibi- } \\
\text { otics, targeted because they should be reserved for infections caused by or- } \\
\text { ganisms that are resistant to first line antimicrobials." There were no other } \\
\text { changes in local or national policy likely to influence use of Alert Antibiotics. }\end{array}$ \\
\hline
\end{tabular}


Ansari 2003 (Continued)
Analysed appropriately
Low risk
Done in original paper: segmented regression analysis with adjustment for au- (ITS) ? tocorrelation and seasonality.

Shape of effect pre-speci- Low risk fied (ITS) ?
Unlikely to affect data col- Low risk lection (ITS) ?
Done, intended effect was decrease in primary outcome, and point of analysis was point of intervention.

Knowledge of the alloca- Low risk tion adequately prevented(ITS)?

"The aim of this study was to use routine data from the pharmacy stock control computer to evaluate this intervention". Sources and methods of data collection were the same before and after the intervention.

"After evaluation of the intervention according to patient records and its shortcomings, we decided to use the pharmacy stock data. During the 4 year period of analysis no restriction policy for dispensing the Alert Antibiotics was implemented by the hospital pharmacy, therefore the pharmacy data about dispensed Alert Antibiotics would provide us with the best available independent indicator for evaluation of the intervention."

$\begin{array}{ll}\begin{array}{l}\text { Incomplete outcome data } \\ \text { addressed (ITS) ? }\end{array} & \begin{array}{l}\text { Dow risk, data were from routine systems and unlikely to change over study peri- } \\ \text { od. }\end{array}\end{array}$

addressed (ITS) ?

Done, data were from routine systems and unlikely to change over study peri-

Free of selected reporting Low risk (ITS) ? od.

Free of other bias (ITS)? Low risk

\begin{abstract}
"Correcting for autocorrelation avoids underestimating standard errors and overestimated significance of the effects of an intervention. For estimating seasonal autocorrelation, the autoregression model needs to evaluate correlations between error terms separated by multiples of 12 months. Accounting for seasonally correlated errors usually requires at least 24 monthly data points."

Data about cost of antibiotics adjusted for price changes during study period.
\end{abstract}

Avorn 1988

\begin{tabular}{ll}
\hline Methods & STUDY DESIGN: ITS \\
& Risk of Bias: LOW \\
\hline Participants & PROVIDERS: all physicians at 1 teaching hospital \\
& PARTICIPANTS: all patients with clinical problem \\
CLINICAL PROBLEM: patients receiving therapy with cefazolin, clindamycin, or metronidazole \\
SETTING: a 460-bed teaching hospital in the USA
\end{tabular}

Interventions $\quad$ FORMAT, Interventions: educational meetings; dissemination of educational materials; reminders circumstantial (order form triggered by receiving target antibiotic) and physical (posters)

Intervention Functions: education, enablement, environmental restructuring, persuasion

DELIVERER: AMT

COMPARISON: usual care

DESIRED CHANGE: decrease excessive

\section{Outcomes}

PRESCRIBING: Choice: inappropriate dosing intervals of cefazolin, clindamycin, and metronidazole FINANCIAL: estimated annual expenditure on the 3 drugs

\section{Notes}


Avorn 1988 (Continued)

ADDITIONAL DATA: no response from authors to request for additional data

\section{Risk of bias}

\begin{tabular}{lll}
\hline Bias & Authors' judgement & Support for judgement \\
\hline $\begin{array}{l}\text { Intervention independent } \\
\text { (ITS) ? }\end{array}$ & Low risk & No price changes in the target antibiotics during the study period. \\
\hline $\begin{array}{l}\text { Analysed appropriately } \\
\text { (ITS)? }\end{array}$ & Low risk & Done in original paper: segmented regression analysis. \\
\hline $\begin{array}{l}\text { Shape of effect pre-speci- } \\
\text { fied (ITS)? }\end{array}$ & Low risk & $\begin{array}{l}\text { Done, intended effect was decrease in primary outcome, and point of analysis } \\
\text { was point of intervention. }\end{array}$ \\
\hline $\begin{array}{l}\text { Unlikely to affect data col- } \\
\text { lection (ITS) ? }\end{array}$ & Low risk & $\begin{array}{l}\text { Done, data were from routine systems and unlikely to change over study peri- } \\
\text { od. }\end{array}$ \\
\hline $\begin{array}{l}\text { Knowledge of the alloca- } \\
\text { tion adequately prevent- } \\
\text { ed(ITS)? }\end{array}$ & Low risk & $\begin{array}{l}\text { Done, data were from routine systems and unlikely to change over study peri- } \\
\text { od. }\end{array}$ \\
\hline $\begin{array}{l}\text { Incomplete outcome data } \\
\text { addressed (ITS) ? }\end{array}$ & Low risk & $\begin{array}{l}\text { Done, data were from routine systems and unlikely to change over study peri- } \\
\text { od. }\end{array}$ \\
\hline $\begin{array}{l}\text { Free of selected reporting } \\
\text { ITS) ? }\end{array}$ & Low risk & $\begin{array}{l}\text { Done, data were from routine systems and unlikely to change over study peri- } \\
\text { od. }\end{array}$ \\
\hline \begin{tabular}{l} 
Free of other bias (ITS) ? \\
\hline
\end{tabular} & Low risk & \begin{tabular}{l} 
No other apparent biases found. \\
\hline
\end{tabular}
\end{tabular}

\section{Bailey 1997}

Methods STUDY DESIGN: RCT stratified by type of infection

\section{Risk of Bias: HIGH}

\section{Participants}

PROVIDERS: all physicians at 2 teaching hospitals, excluding ICUs

PARTICIPANTS: a total of 102 inpatients, 51 intervention and 51 control

CLINICAL PROBLEM: patients receiving IV ABs for at least 3 days, but excluded if in ICU or with uncontrolled infection or close to discharge

SETTING: 2 tertiary-care teaching hospitals in USA

Intervention Functions: education, enablement, persuasion

DELIVERER: pharmacist

COMPARISON: usual care

DESIRED CHANGE: decrease excessive

POWER CALCULATION: none reported 
Bailey 1997 (Continued)

Outcomes
PRESCRIBING: patients switched from parenteral to oral antibiotics or discontinuation of 1 or more antibiotics and mean IV antibiotic days

COST: mean antibiotic costs

CLINICAL: 30-day re-admission (total and infection-related) and in-hospital mortality

FINANCIAL SUPPORT: Funding: Department of Pharmacy. Competing Interests: none declared

ADDITIONAL DATA: no response from authors to request for additional data

\section{Risk of bias}

\begin{tabular}{|c|c|c|}
\hline Bias & Authors' judgement & Support for judgement \\
\hline $\begin{array}{l}\text { Random sequence genera- } \\
\text { tion (selection bias) }\end{array}$ & Unclear risk & $\begin{array}{l}\text { "Physicians of patients considered candidates for intervention were ran- } \\
\text { domised to be either contacted by the clinical pharmacist ... or to be ob- } \\
\text { served" }\end{array}$ \\
\hline $\begin{array}{l}\text { Allocation concealment } \\
\text { (selection bias) }\end{array}$ & Unclear risk & Not stated \\
\hline $\begin{array}{l}\text { Blinding (performance } \\
\text { bias and detection bias) } \\
\text { All outcomes }\end{array}$ & Unclear risk & Not stated \\
\hline $\begin{array}{l}\text { Incomplete outcome data } \\
\text { (attrition bias) } \\
\text { All outcomes }\end{array}$ & Low risk & No problems found. \\
\hline $\begin{array}{l}\text { Selective reporting (re- } \\
\text { porting bias) }\end{array}$ & Low risk & No problems found. \\
\hline Other bias & High risk & $\begin{array}{l}\text { No power calculation. Prices of antibiotics unlikely to change over the } 6 \text { - } \\
\text { month study period. }\end{array}$ \\
\hline $\begin{array}{l}\text { Baseline Outcomes simi- } \\
\text { lar? }\end{array}$ & Unclear risk & Not stated \\
\hline Free of contamination? & Unclear risk & Not stated \\
\hline $\begin{array}{l}\text { Baseline characteristics } \\
\text { similar? }\end{array}$ & Low risk & See Table 1 in study. \\
\hline
\end{tabular}

Bantar 2006

\begin{tabular}{ll}
\hline Methods & STUDY DESIGN: ITS \\
& Risk of Bias: MEDIUM \\
\hline Participants & PROVIDERS: all physicians in the hospital \\
& PARTICIPANTS: all patients in the hospital \\
& CLINICAL PROBLEM: IV antibiotics, restriction applied to carbapenems \\
& SETTING: a single university hospital in Argentina. Total use was compared for $>2$ years before and af- \\
ter the intervention
\end{tabular}


Bantar 2006 (Continued) Interventions

FORMAT, Intervention 1: educational outreach by review and recommend change; restrictive - compulsory order form

Intervention Functions: education, enablement, persuasion, restriction

Intervention 2: unavailability of antibiotics during a national financial crisis

DELIVERER: AMT

COMPARISON: usual care

DESIRED CHANGE: decrease excessive (choice)

Outcomes $\quad$ PRESCRIBING: use of all IV antibiotics and carbapenems in DDD/1000 OBD

CLINICAL: all-cause inpatient mortality

Notes

FUNDING: none. Competing Interests: 2 authors declared conflicts of interest for speaker and advisory board fees

ADDITIONAL INFORMATION: no response from authors

\section{Risk of bias}

\begin{tabular}{lll}
\hline Bias & Authors' judgement & Support for judgement \\
\hline $\begin{array}{ll}\text { Intervention independent } \\
\text { (ITS) ? }\end{array}$ & Low risk & $\begin{array}{l}\text { Intervention } 1 \text { was independent of other changes. The "crisis" (following the } \\
\text { intervention) was a national economic crisis and will be reported separately in } \\
\text { the review. }\end{array}$
\end{tabular}

Analysed appropriately Low risk Segmented regression analysis

(ITS) ?

Shape of effect pre-speci- Low risk fied (ITS) ?

Point of intervention was point of analysis.

Unlikely to affect data col- Low risk Data were obtained from pharmacy systems.
lection (ITS)?
lection (ITS)?

\begin{tabular}{|c|c|c|}
\hline $\begin{array}{l}\text { Knowledge of the alloca- } \\
\text { tion adequately prevent- }\end{array}$ & High risk & $\begin{array}{l}\text { Prescribing data were processed by the investigators to convert grams to DDD } \\
\text { and identify only IV antibiotics. }\end{array}$ \\
\hline
\end{tabular}
ed(ITS)?

\begin{tabular}{lll}
\hline $\begin{array}{l}\text { Incomplete outcome data } \\
\text { addressed (ITS) ? }\end{array}$ & Low risk & Routine pharmacy data \\
\hline $\begin{array}{l}\text { Free of selected reporting } \\
\text { (ITS) } ?\end{array}$ & Unclear risk & Processing of data has potential for selective outcome reporting. \\
\hline Free of other bias (ITS) ? & Low risk & 3 years' data pre- and 2 years' data postintervention \\
\hline
\end{tabular}

Barlow 2007

\begin{tabular}{ll}
\hline Methods & STUDY DESIGN: Controlled ITS \\
& Risk of Bias: MEDIUM \\
\hline Participants & PROVIDERS: all physicians in hospital \\
\hline
\end{tabular}


Barlow 2007 (Continued)

PARTICIPANTS: all patients presenting with pneumonia were recruited prospectively

CLINICAL PROBLEM: adults with community-acquired pneumonia

SETTING: 2 acute university hospitals in Scotland

Interventions

FORMAT, Interventions: audit and feedback; educational meetings; dissemination of educational materials; reminders - physical by posters and email

Intervention Functions: education, enablement, environmental restructuring, persuasion

DELIVERER: AMT

COMPARISON: control hospital with no intervention

DESIRED CHANGE: increase effective

Outcomes $\quad$ PRESCRIBING: Choice: $\%$ appropriate antibiotics within $4 \mathrm{~h}$ of admission

COST: cost-effectiveness, intervention cost, and estimated impact on mortality

Notes FINANCIAL SUPPORT: Funding: NHS Education Scotland and Chief Scientist Office, Scotland. Competing Interests: none declared

ADDITIONAL DATA: email response from authors with additional information about intervention

\section{Risk of bias}

\begin{tabular}{|c|c|c|}
\hline Bias & Authors' judgement & Support for judgement \\
\hline $\begin{array}{l}\text { Intervention independent } \\
\text { (ITS) ? }\end{array}$ & Low risk & \\
\hline $\begin{array}{l}\text { Analysed appropriately } \\
\text { (ITS)? }\end{array}$ & Low risk & \\
\hline
\end{tabular}

\section{Shape of effect pre-speci- Low risk} fied (ITS) ?

\section{Unlikely to affect data col- Low risk} lection (ITS) ?

\section{Knowledge of the alloca- High risk} tion adequately prevented(ITS)?

\section{Incomplete outcome data Low risk addressed (ITS) ?}

\section{Free of selected reporting Low risk (ITS) ?}

Free of other bias (ITS) ? High risk

\section{Bassetti 2009}

Methods STUDY DESIGN: ITS


Bassetti 2009 (Continued)

\section{Risk of Bias: LOW}

Participants

PROVIDERS: all physicians in the ICU (mixed medical/surgical)

PARTICIPANTS: all patients in the ICU

CLINICAL PROBLEM: requiring empirical antibiotic therapy

SETTING: 1 university hospital in Italy

Interventions

FORMAT, Interventions: educational outreach by review and recommend change; restrictive - compulsory order form

Intervention Functions: education, enablement, persuasion, restriction

DELIVERER: specialist physicians (ID)

COMPARISON: usual care

DESIRED CHANGE: decrease excessive

Outcomes $\quad$ PRESCRIBING: Choice: use of cephalosporins in DDD/1000 OBD

MICROBIAL: MRSA

Notes FINANCIAL SUPPORT: none. Competing Interests: none declared

ADDITIONAL DATA: no response from authors to request for additional data

Microbial Risk of Bias: LOW

\section{Risk of bias}

Bias Authors' judgement Support for judgement

Intervention independent Low risk

(ITS) ?

Analysed appropriately Low risk $\quad$ Segmented regression analysis
(ITS)?

(ITS) ?

Shape of effect pre-speci- Low risk

fied (ITS) ?

\begin{tabular}{lll}
\hline $\begin{array}{l}\text { Unlikely to affect data col- } \\
\text { lection (ITS) }\end{array}$ & Low risk & Routine pharmacy data \\
\hline $\begin{array}{l}\text { Knowledge of the alloca- } \\
\text { tion adequately prevent- } \\
\text { ed(ITS)? }\end{array}$ & Low risk & Routine pharmacy data \\
\hline $\begin{array}{l}\text { Incomplete outcome data } \\
\text { addressed (ITS) ? }\end{array}$ & Low risk & Routine pharmacy data \\
\hline $\begin{array}{l}\text { Free of selected reporting } \\
\text { (ITS) ? }\end{array}$ & Low risk & Routine pharmacy data \\
\hline $\begin{array}{l}\text { Free of other bias (ITS) ? } \\
\text { Low risk }\end{array}$ & > 1 year data pre- and postintervention. Microbial Risk of Bias: case defintion \\
\end{tabular}


Baysari 2013

\begin{tabular}{ll}
\hline Methods & STUDY DESIGN: unintended consequences, qualitative \\
& Risk of Bias: not assessed (qualitative study) \\
\hline Participants & PROVIDERS: 36 physicians \\
& PARTICIPANTS: patients receiving antibiotic treatment \\
& CLINICAL PROBLEM: patients receiving antibiotics that the hospital policy designated as requiring ap- \\
proval & SETTING: 1 hospital in Australia \\
\hline
\end{tabular}

Interventions FORMAT, Intervention: audit and feedback; restriction by prior approval

Intervention Functions: enablement, persuasion, restriction

DELIVERER: AMT

DESIRED CHANGE: decrease excessive

$\begin{array}{ll}\text { Outcomes } & \text { UNINTENDED CONSEQUENCES: problems with antibiotic policy and approval process identified } \\ \text { through semi-structured interviews with prescribers who had received feedback letters }\end{array}$

Notes $\quad$ FINANCIAL SUPPORT: Funding: St Vincent's Clinic Foundation Research Grant, annual Grant \#3 and National Health and Medical Research Council program grant \#568612. Competing Interests: none declared

ADDITIONAL DATA: email from authors with additional data about the antibiotic policy and feedback

Bell 2014

Methods STUDY DESIGN: unintended consequences, ITS

\section{Risk of Bias: MEDIUM}

Participants

PROVIDERS: all physicians in general, gynaecological, orthopaedic, urological, and vascular surgery wards

PARTICIPANTS: 12,883 patients undergoing elective surgery

CLINICAL PROBLEM: risk of postoperative AKI following policy change to gentamicin for prophylaxis SETTING: 1 hospital in the UK

Interventions

FORMAT: Interventions: audit and feedback; educational meetings; dissemination of antibiotic policy; reminders (physical - posters in operating theatres)

Intervention Functions: education, enablement, environmental restructuring, persuasion

DELIVERER: AMT

COMPARISON: usual care

DESIRED CHANGE: decrease excessive, the policy was intended to reduce Clostridium difficile infection

\begin{tabular}{ll}
\hline Outcomes & UNINTENDED CONSEQUENCES: \% postoperative AKI before and after antibiotic policy change \\
\hline Notes & $\begin{array}{l}\text { FINANCIAL SUPPORT: Funding: Scottish Government Healthcare Associated Infection Task Force. Com- } \\
\text { peting Interests: none declared }\end{array}$
\end{tabular}

ADDITIONAL DATA: email response from authors but no additional data

\section{Risk of bias}

Bias Authors' judgement Support for judgement


Bell 2014 (Continued)

Intervention independent Low risk
(ITS)?

(ITS) ?

Analysed appropriately $\quad$ Low risk $\quad$ Segmented regression analysis
(ITS)?

Shape of effect pre-speci- Low risk $\quad$ Point of analysis was point of intervention.
fied (ITS)?

fied (ITS) ?

Unlikely to affect data col- $\quad$ Low risk $\quad$ Data from laboratory computer system (serum creatinine)
lection (ITS)?

lection (ITS)?

Knowledge of the alloca- Low risk $\quad$ Data from laboratory computer system
tion adequately prevent-
ed(ITS)?

\begin{tabular}{lll}
\hline $\begin{array}{l}\text { Incomplete outcome data } \\
\text { addressed (ITS) ? }\end{array}$ & High risk & $\begin{array}{l}\text { Completeness of pre- and postoperative creatinine data presented in full for } \\
\text { all services (Table 2). There was a significant increase in testing after policy } \\
\text { change in gynaecology. }\end{array}$ \\
\hline $\begin{array}{l}\text { Free of selected reporting } \\
\text { (ITS) } ?\end{array}$ & Low risk & Data from laboratory computer system \\
\hline Free of other bias (ITS) ? & Low risk & $>1$ year data pre- and postintervention \\
\hline
\end{tabular}

\section{Belliveau 1996}

\begin{tabular}{ll}
\hline Methods & STUDY DESIGN: ITS \\
& Risk of Bias: LOW \\
\hline
\end{tabular}

Participants
PARTICIPANTS: all patients in hospital
CLINICAL PROBLEM: patients receiving vancomycin therapy
SETTING: 1 university hospital in the USA

Interventions
FORMAT, Interventions: educational meetings; dissemination of educational materials; educational
outreach by academic detailing; reminders (physical - posters and newsletter); restrictive - expert ap-

Intervention Functions: education, environmental restructuring, persuasion, restriction

DELIVERER: AMT

COMPARISON: usual care

DESIRED CHANGE: decrease excessive

\begin{tabular}{ll}
\hline Outcomes & PRESCRIBING: Choice: vancomycin doses/1000 OBD \\
\hline Notes & FINANCIAL SUPPORT: no information provided \\
& ADDITIONAL DATA: no response from authors to request for additional data
\end{tabular}


Belliveau 1996 (Continued)

\section{Risk of bias}

\begin{tabular}{lll}
\hline Bias & Authors' judgement & Support for judgement \\
\hline $\begin{array}{l}\text { Intervention independent } \\
\text { (ITS) ? }\end{array}$ & Low risk & $>12$ months' pre- and postrestriction data \\
\hline $\begin{array}{l}\text { Analysed appropriately } \\
\text { (ITS)? }\end{array}$ & Low risk & $\begin{array}{l}\text { Re-analysed. Not done in original paper (comparison of means with t-test, un- } \\
\text { controlled before-after). }\end{array}$ \\
\hline $\begin{array}{l}\text { Shape of effect pre-speci- } \\
\text { fied (ITS) ? }\end{array}$ & Low risk & $\begin{array}{l}\text { Done, intended effect was decrease in primary outcome, and point of analysis } \\
\text { was point of intervention. Outcome data were collected from all participants. }\end{array}$ \\
\hline $\begin{array}{l}\text { Unlikely to affect data col- } \\
\text { lection (ITS) ? }\end{array}$ & Low risk & $\begin{array}{l}\text { Done, data were from routine systems and unlikely to change over study peri- } \\
\text { od. }\end{array}$ \\
\hline $\begin{array}{l}\text { Knowledge of the alloca- } \\
\text { tion adequately prevent- } \\
\text { ed(ITS)? }\end{array}$ & Low risk & $\begin{array}{l}\text { Done, data were from routine systems and unlikely to change over study peri- } \\
\text { od. }\end{array}$ \\
\hline $\begin{array}{l}\text { Incomplete outcome data } \\
\text { addressed (ITS) ? }\end{array}$ & Low risk & $\begin{array}{l}\text { Done, data were from routine systems and unlikely to change over study peri- } \\
\text { od. }\end{array}$ \\
\hline $\begin{array}{l}\text { Free of selected reporting } \\
\text { (ITS) ? }\end{array}$ & Low risk & $\begin{array}{l}\text { Done, data were from routine systems and unlikely to change over study peri- } \\
\text { od. }\end{array}$ \\
\hline \begin{tabular}{l} 
Free of other bias (ITS) ? \\
\hline
\end{tabular} & Low risk & \begin{tabular}{l} 
No other apparent biases found. \\
\hline
\end{tabular}
\end{tabular}

Benson 2014

\begin{tabular}{ll}
\hline Methods & STUDY DESIGN: ITS \\
& Risk of Bias: LOW \\
\hline Participants & PROVIDERS: all physicians in the hospital \\
& PARTICIPANTS: all patients in the hospital \\
CLINICAL PROBLEM: patients receiving therapeutic antibiotics & SETTING: 1 university hospital in the USA \\
\hline
\end{tabular}

Interventions

FORMAT, Interventions: audit and feedback; educational outreach by academic detailing

Intervention Functions: education, enablement, persuasion

DELIVERER: AMT

COMPARISON: usual care

DESIRED CHANGE: decrease excessive

\begin{tabular}{ll}
\hline Outcomes & PRESCRIBING: Choice: antibiotic cost per patient day \\
\hline Notes & FINANCIAL SUPPORT: none. Competing Interests; none declared \\
& ADDITIONAL INFORMATION: no response from author
\end{tabular}

ADDITIONAL INFORMATION: no response from author

\section{Risk of bias}


Benson 2014 (Continued)

Intervention independent Low risk

(ITS) ?

Analysed appropriately $\quad$ Low risk $\quad$ Re-analysed
(ITS)?

Shape of effect pre-speci- Low risk Point of intervention was point of analysis.
fied (ITS)?
fied (ITS) ?

Unlikely to affect data col- Low risk Electronic data from pharmacy computer
lection (ITS)?
lection (ITS) ?

Knowledge of the alloca- Low risk Electronic data from pharmacy computer
tion adequately prevent-
ed(ITS)?

\begin{tabular}{lll}
\hline $\begin{array}{l}\text { Incomplete outcome data } \\
\text { addressed (ITS) ? }\end{array}$ & Low risk & Electronic data from pharmacy computer \\
\hline $\begin{array}{l}\text { Free of selected reporting } \\
\text { (ITS) ? }\end{array}$ & Low risk & Electronic data from pharmacy computer \\
\hline Free of other bias (ITS) ? & Low risk & $>1$ year data pre- and postintervention \\
\hline
\end{tabular}

Berild 2002

\begin{tabular}{|c|c|}
\hline Methods & $\begin{array}{l}\text { STUDY DESIGN: ITS } \\
\text { Risk of Bias: LOW }\end{array}$ \\
\hline Participants & $\begin{array}{l}\text { PROVIDERS: physicians (paediatricians) in the hospital } \\
\text { PARTICIPANTS: all paediatric patients in the hospital } \\
\text { CLINICAL PROBLEM: children with infections requiring antibiotic therapy } \\
\text { SETTING: } 1 \text { paediatric university hospital in Norway }\end{array}$ \\
\hline Interventions & $\begin{array}{l}\text { FORMAT, Interventions: audit and feedback; educational meetings; dissemination of educational ma- } \\
\text { terials } \\
\text { Intervention Functions: education, enablement } \\
\text { DELIVERER: AMT } \\
\text { COMPARISON: usual care } \\
\text { DESIRED CHANGE: decrease excessive }\end{array}$ \\
\hline Outcomes & $\begin{array}{l}\text { PRESCRIBING: Choice: total antibiotic usage and usage of } 5 \text { specific groups of antibiotics in DDD/100 } \\
\text { OBD }\end{array}$ \\
\hline Notes & $\begin{array}{l}\text { FINANCIAL SUPPORT: no information provided } \\
\text { ADDITIONAL DATA: no response from authors to request for additional data }\end{array}$ \\
\hline
\end{tabular}

\section{Risk of bias}


Berild 2002 (Continued)

\begin{tabular}{|c|c|c|}
\hline Bias & Authors' judgement & Support for judgement \\
\hline $\begin{array}{l}\text { Intervention independent } \\
\text { (ITS) ? }\end{array}$ & Low risk & Done, 3 years' pre-intervention and 2 years' postintervention data \\
\hline $\begin{array}{l}\text { Analysed appropriately } \\
\text { (ITS)? }\end{array}$ & Low risk & $\begin{array}{l}\text { Re-analysed. Not done in original paper (run charts, Figure 1, with no statisti- } \\
\text { cal analysis). }\end{array}$ \\
\hline $\begin{array}{l}\text { Shape of effect pre-speci- } \\
\text { fied (ITS)? }\end{array}$ & Low risk & $\begin{array}{l}\text { Done, intended effect was decrease in primary outcome, and point of analysis } \\
\text { was point of intervention. }\end{array}$ \\
\hline $\begin{array}{l}\text { Unlikely to affect data col- } \\
\text { lection (ITS)? }\end{array}$ & Low risk & $\begin{array}{l}\text { Done, data were from routine systems and unlikely to change over study peri- } \\
\text { od. }\end{array}$ \\
\hline $\begin{array}{l}\text { Knowledge of the alloca- } \\
\text { tion adequately prevent- } \\
\text { ed(ITS)? }\end{array}$ & Low risk & $\begin{array}{l}\text { Done, data were from routine systems and unlikely to change over study peri- } \\
\text { od. }\end{array}$ \\
\hline $\begin{array}{l}\text { Incomplete outcome data } \\
\text { addressed (ITS)? }\end{array}$ & Low risk & $\begin{array}{l}\text { Done, data were from routine systems and unlikely to change over study peri- } \\
\text { od. }\end{array}$ \\
\hline $\begin{array}{l}\text { Free of selected reporting } \\
\text { (ITS)? }\end{array}$ & Low risk & $\begin{array}{l}\text { Done, data were from routine systems and unlikely to change over study peri- } \\
\text { od. }\end{array}$ \\
\hline Free of other bias (ITS) ? & Low risk & $\begin{array}{l}\text { Changes in antibiotic price were documented with their contribution to reduc- } \\
\text { tion in cost over the study period (Table } 1 \text { in study). }\end{array}$ \\
\hline
\end{tabular}

Borde 2014a

Methods STUDY DESIGN: ITS

\section{Risk of Bias: LOW}

Participants PROVIDERS: all physicians and pharmacists in the Medical Service

PARTICIPANTS: all adult patients in the Medical Service

CLINICAL PROBLEM: patients receiving antibiotics

SETTING: 1 university hospital in Germany

Interventions $\quad$ FORMAT, Interventions: audit and feedback; educational meetings; dissemination of educational materials; educational outreach by review and recommend change; reminders - circumstantial, on rounds

Intervention Functions: education, enablement, persuasion

DELIVERER: AMT

COMPARISON: usual care

DESIRED CHANGE: decrease excessive, aim was to reduce use of 3rd-generation cephalosporins and fluoroquinolones by $30 \%$ in 12 months

\begin{tabular}{ll}
\hline Outcomes & PRESCRIBING: Choice: drug use measured in RDD/100 OBD \\
& FINANCIAL: cost of intervention and impact on prescribing cost \\
\hline Notes & FINANCIAL SUPPORT: Funding: internal funds from the Department of Medicine and Federal Ministry of \\
& Health (BMG grant IIA5-2011-2511FSB340). Competing Interests: none declared
\end{tabular}


Borde 2014a (Continued)

Risk of bias

\begin{tabular}{|c|c|c|}
\hline Bias & Authors' judgement & Support for judgement \\
\hline $\begin{array}{l}\text { Intervention independent } \\
\text { (ITS) ? }\end{array}$ & Low risk & \\
\hline $\begin{array}{l}\text { Analysed appropriately } \\
\text { (ITS)? }\end{array}$ & Low risk & Segmented regression analysis \\
\hline $\begin{array}{l}\text { Shape of effect pre-speci- } \\
\text { fied (ITS)? }\end{array}$ & Low risk & Point of intervention was point of analysis. \\
\hline $\begin{array}{l}\text { Unlikely to affect data col- } \\
\text { lection (ITS)? }\end{array}$ & Low risk & Prescribing data from pharmacy computer \\
\hline $\begin{array}{l}\text { Knowledge of the alloca- } \\
\text { tion adequately prevent- } \\
\text { ed(ITS)? }\end{array}$ & Low risk & Prescribing data from pharmacy computer \\
\hline $\begin{array}{l}\text { Incomplete outcome data } \\
\text { addressed (ITS)? }\end{array}$ & Low risk & Prescribing data from pharmacy computer \\
\hline $\begin{array}{l}\text { Free of selected reporting } \\
\text { (ITS) ? }\end{array}$ & Low risk & Prescribing data from pharmacy computer \\
\hline Free of other bias (ITS) ? & Low risk & $>24$ months' data pre- and postintervention \\
\hline
\end{tabular}

Borde 2014b

\begin{tabular}{ll}
\hline Methods & STUDY DESIGN: ITS \\
& Risk of Bias: HIGH \\
\hline Participants & PROVIDERS: all physicians in the hospital \\
& PARTICIPANTS: all patients with Staphylococcus aureus bacteraemia \\
CLINICAL PROBLEM: compliance with a bundle of indicators of effective treatment and investigation \\
SETTING: 1 community hospital in Southern Germany
\end{tabular}

Interventions

FORMAT, Interventions: dissemination of educational materials; reminders - circumstantial, on microbiology reports for positive blood cultures

Intervention Functions: education, enablement, environmental restructuring

DELIVERER: ID physician

COMPARISON: usual care

DESIRED CHANGE: increase effective

\begin{tabular}{ll}
\hline Outcomes & PRESCRIBING: Choice: average score per participant, with 0.5 points for each of 4 prescribing indica- \\
tors, maximum score 2.0 per participant \\
CLINICAL: not valid (mean mortality in pre- and postintervention phases) \\
\hline Fotes & FINANCIAL SUPPORT: Funding: internal funds from the Department of Medicine and Federal Ministry of \\
& Health (BMG grant IIA5-2011-2511FSB340). Competing Interests: none declared
\end{tabular}


Borde 2014b (Continued)

ADDITIONAL DATA: the original paper reports average scores per participant for compliance, with 5 bundle elements of which only 2 were about antibiotic prescribing (Figure 2). The authors provided us with additional data about scores for the 2 prescribing elements in the bundle.

\section{Risk of bias}

\begin{tabular}{lll}
\hline Bias & Authors' judgement & Support for judgement \\
\hline $\begin{array}{l}\text { Intervention independent } \\
\text { (ITS) ? }\end{array}$ & Low risk & \\
\hline $\begin{array}{l}\text { Analysed appropriately } \\
\text { (ITS) ? }\end{array}$ & Low risk & Re-analysed \\
\hline $\begin{array}{l}\text { Shape of effect pre-speci- } \\
\text { fied (ITS) ? }\end{array}$ & Low risk & Point of intervention was point of analysis. \\
\hline $\begin{array}{l}\text { Unlikely to affect data col- } \\
\text { lection (ITS) ? }\end{array}$ & High risk & Prescribing outcomes were collected by the investigators. \\
\hline $\begin{array}{l}\text { Knowledge of the alloca- } \\
\text { tion adequately prevent- } \\
\text { ed(ITS)? }\end{array}$ & High risk & Prescribing outcomes were collected by the investigators. \\
\hline $\begin{array}{l}\text { Incomplete outcome data } \\
\text { addressed (ITS) ? }\end{array}$ & Unclear risk & $\begin{array}{l}\text { Data are presented as \% compliance per quarter, but it is not clear whether } \\
\text { complete data were collected from all participants. }\end{array}$ \\
\hline $\begin{array}{l}\text { Free of selected reporting } \\
\text { (ITS) ? }\end{array}$ & Unclear risk & $\begin{array}{l}\text { Data are presented as \% compliance per quarter, but it is not clear whether } \\
\text { complete data were collected from all participants. }\end{array}$ \\
\hline \begin{tabular}{l} 
Free of other bias (ITS) ? \\
\hline
\end{tabular} & High risk & \begin{tabular}{l} 
Only 9 months' data postintervention \\
\hline
\end{tabular}
\end{tabular}

\section{Borde 2015a}

\begin{tabular}{ll}
\hline Methods & STUDY DESIGN: ITS \\
& Risk of Bias: LOW \\
\hline Participants & PROVIDERS: all physicians caring for medical emergency patients \\
& PARTICIPANTS: all medical patients in the ED \\
CLINICAL PROBLEM: patients requiring antibiotic treatment & SETTING: 1 university hospital in Germany
\end{tabular}

Interventions

FORMAT, Interventions: audit and feedback; educational meetings; dissemination of educational materials; educational outreach by review and recommend change; reminders - circumstantial, on rounds

Intervention Functions: education, enablement, persuasion

DELIVERER: AMT

COMPARISON: usual care

DESIRED CHANGE: decrease excessive, aim was to reduce use of 3rd-generation cephalosporins by $20 \%$ in 12 to 24 months 
Borde 2015a (Continued)

Notes
FINANCIAL SUPPORT: Funding: internal funds from the Department of Medicine and Federal Ministry of Health (BMG grant IIA5-2011-2511FSB340). Competing Interests: none declared

\section{Risk of bias}

\begin{tabular}{lll}
\hline Bias & Authors' judgement & Support for judgement \\
\hline $\begin{array}{l}\text { Intervention independent } \\
\text { (ITS) }\end{array}$ & Low risk & \\
\hline $\begin{array}{l}\text { Analysed appropriately } \\
\text { (ITS) }\end{array}$ & Low risk & Segmented regression analysis \\
\hline $\begin{array}{l}\text { Shape of effect pre-speci- } \\
\text { fied (ITS) ? }\end{array}$ & Low risk & Point of intervention was point of analysis. \\
\hline $\begin{array}{l}\text { Unlikely to affect data col- } \\
\text { lection (ITS) ? }\end{array}$ & Low risk & Data from pharmacy computer \\
\hline $\begin{array}{l}\text { Knowledge of the alloca- } \\
\text { tion adequately prevent- } \\
\text { ed(ITS)? }\end{array}$ & Low risk & Data from pharmacy computer \\
\hline $\begin{array}{l}\text { Incomplete outcome data } \\
\text { addressed (ITS) ? }\end{array}$ & Low risk & \\
\hline $\begin{array}{l}\text { Free of selected reporting } \\
\text { (ITS) ? }\end{array}$ & Low risk & Data from pharmacy computer \\
\hline \begin{tabular}{l} 
Free of other bias (ITS) ? \\
\hline
\end{tabular} & Low risk & Data from pharmacy computer \\
\hline
\end{tabular}

Borde 2015b

Methods STUDY DESIGN: ITS

\section{Risk of Bias: LOW}

PROVIDERS: all physicians and pharmacists in the Medical Service
PARTICIPANTS: all adult patients in the Medical Service
CLINICAL PROBLEM: patients receiving antibiotics
SETTING: 1 200-bed community hospital

Interventions $\quad$ FORMAT, Interventions: educational meetings; dissemination of educational materials; educational outreach by review and recommend change in ICU and for bacteraemic patients in other wards; reminders - circumstantial, on rounds

Intervention Functions: education, enablement, persuasion

DELIVERER: AMT

COMPARISON: usual care

DESIRED CHANGE: decrease excessive, aim was to reduce use of 3rd-generation cephalosporins and fluoroquinolones by $30 \%$ in 12 months

Outcomes

PRESCRIBING: Choice: target drug use measured in RDD/100 OBD. Exposure: impact on total anti-infective use was measured 
Borde 2015b (Continued)

Notes

FINANCIAL SUPPORT: Funding: none. Competing Interests: none declared

\section{Risk of bias}

\begin{tabular}{lll}
\hline Bias & Authors' judgement & Support for judgement \\
\hline $\begin{array}{l}\text { Intervention independent } \\
\text { (ITS) }\end{array}$ & Low risk & \\
\hline $\begin{array}{l}\text { Analysed appropriately } \\
\text { (ITS) ? }\end{array}$ & Low risk & Segmented regression analysis \\
\hline $\begin{array}{l}\text { Shape of effect pre-speci- } \\
\text { fied (ITS) ? }\end{array}$ & Low risk & Point of intervention was point of analysis. \\
\hline $\begin{array}{l}\text { Unlikely to affect data col- } \\
\text { lection (ITS) ? }\end{array}$ & Low risk & Data from pharmacy computer \\
\hline $\begin{array}{l}\text { Knowledge of the alloca- } \\
\text { tion adequately prevent- } \\
\text { ed(ITS)? }\end{array}$ & Low risk & Data from pharmacy computer \\
\hline $\begin{array}{l}\text { Incomplete outcome data } \\
\text { addressed (ITS) ? }\end{array}$ & Low risk & \\
\hline $\begin{array}{l}\text { Free of selected reporting } \\
\text { (ITS) ? }\end{array}$ & Low risk & Data from pharmacy computer \\
\hline \begin{tabular}{l} 
Free of other bias (ITS)? \\
\hline
\end{tabular} & Low risk & Data from pharmacy computer \\
\hline
\end{tabular}

Bouadma 2010

\begin{tabular}{ll}
\hline Methods & STUDY DESIGN: RCT \\
& Risk of Bias: HIGH \\
\hline Participants & PROVIDERS: all physicians in the ICU \\
& PARTICIPANTS: all patients in the ICU, 311 randomised to intervention and 319 to control \\
CLINICAL PROBLEM: patients requiring antibiotic treatment \\
SETTING: 5 hospitals in France, 4 university and 1 general
\end{tabular}

Interventions $\quad$ FORMAT, Interventions: reminders - circumstantial; structural - procalcitonin testing with decision support by treatment algorithm

Intervention Functions: enablement, environmental restructuring

DELIVERER: departmental physicians (Anaesthesiology and Intensive Care)

COMPARISON: usual care

DESIRED CHANGE: decrease excessive

POWER CALCULATION: yes, 133 participants per study group (details in Appendix 3)
Outcomes
PRESCRIBING: Exposure: days of antibiotic exposure per 1000 patient days
CLINICAL: primary outcome measure 28-day mortality, also 60-day mortality, length of ICU stay, and length of hospital stay


Bouadma 2010 (Continued)

Notes
FINANCIAL SUPPORT: Funding: Assistance Publique-Hopitaux de Paris, France and B.R.A.H.M.S, Germany. Competing Interests: 4 authors declared conflicts of interest from several pharmaceutical companies

ADDITIONAL DATA: no response from authors to request for additional data

\section{Risk of bias}

\begin{tabular}{|c|c|c|}
\hline Bias & Authors' judgement & Support for judgement \\
\hline $\begin{array}{l}\text { Random sequence genera- } \\
\text { tion (selection bias) }\end{array}$ & Low risk & Computer-generated randomisation sequence \\
\hline $\begin{array}{l}\text { Allocation concealment } \\
\text { (selection bias) }\end{array}$ & Low risk & Assignment concealed before allocation. \\
\hline $\begin{array}{l}\text { Blinding (performance } \\
\text { bias and detection bias) } \\
\text { All outcomes }\end{array}$ & High risk & Assignment not concealed postallocation. \\
\hline $\begin{array}{l}\text { Incomplete outcome data } \\
\text { (attrition bias) } \\
\text { All outcomes }\end{array}$ & Low risk & $\begin{array}{l}\text { Outcome data reported on } 98 \% \text { of participants in control and intervention } \\
\text { groups. }\end{array}$ \\
\hline $\begin{array}{l}\text { Selective reporting (re- } \\
\text { porting bias) }\end{array}$ & Low risk & Outcome data reported fully on all included participants. \\
\hline Other bias & High risk & $\begin{array}{l}\text { Patients assigned to the trial were }<50 \% \text { of all patients receiving antibiotics } \\
(630 / 1315) \text {. }\end{array}$ \\
\hline $\begin{array}{l}\text { Baseline Outcomes simi- } \\
\text { lar? }\end{array}$ & High risk & No data \\
\hline Free of contamination? & Low risk & Procalcitonin only reported on intervention participants. \\
\hline $\begin{array}{l}\text { Baseline characteristics } \\
\text { similar? }\end{array}$ & Low risk & ITS \\
\hline
\end{tabular}

Bouza 2004

\begin{tabular}{ll}
\hline Methods & $\begin{array}{l}\text { STUDY DESIGN: RCT } \\
\text { Risk of bias: } \text { HIGH }\end{array}$ \\
\hline Participants & PROVIDERS: ICU staff \\
& PARTICIPANTS: 297 patients with bloodstream infection in hospital, 109 control and 188 intervention \\
& CLINICAL PROBLEM: bacteraemia/fungaemia (bloodstream infection) \\
& SETTING: 1 university hospital in Spain
\end{tabular}

Interventions

FORMAT, Interventions: educational outreach by review and recommend change

Intervention Functions: education, enablement, persuasion

DELIVERER: microbiologists (specialist physicians) 
COMPARISON: usual care

DESIRED CHANGE: reduce inappropriate

POWER CALCULATION: no information about sample size

Outcomes PRESCRIBING: Choice: proportion of days on which adequate treatment received

CLINICAL: Intended: length of stay, mortality

Notes

FINANCIAL SUPPORT: Funding: Red Española de Investigación de Patología Infecciosa (REIPI C03-14) and Fondo de Investigaciones Sanitarias of Spain (FIS 02-1049). Competing Interest: none declared

ADDITIONAL DATA: no response from authors to request for additional data

\section{Risk of bias}

\begin{tabular}{|c|c|c|}
\hline Bias & Authors' judgement & Support for judgement \\
\hline $\begin{array}{l}\text { Random sequence genera- } \\
\text { tion (selection bias) }\end{array}$ & Low risk & $\begin{array}{l}\text { "We randomly classified the patients ... into } 3 \text { different group by means of a } \\
\text { computer assisted random list" }\end{array}$ \\
\hline $\begin{array}{l}\text { Allocation concealment } \\
\text { (selection bias) }\end{array}$ & Unclear risk & No information \\
\hline $\begin{array}{l}\text { Blinding (performance } \\
\text { bias and detection bias) } \\
\text { All outcomes }\end{array}$ & High risk & Not possible with this study design \\
\hline $\begin{array}{l}\text { Incomplete outcome data } \\
\text { (attrition bias) } \\
\text { All outcomes }\end{array}$ & Unclear risk & Not stated \\
\hline $\begin{array}{l}\text { Selective reporting (re- } \\
\text { porting bias) }\end{array}$ & Unclear risk & Not stated \\
\hline Other bias & High risk & $\begin{array}{l}\text { Not done, adequate prescription was defined by } 7 \text { criteria, some of which re- } \\
\text { quired clinical judgement. The reliability of the primary outcome measure was } \\
\text { not assessed. }\end{array}$ \\
\hline $\begin{array}{l}\text { Baseline Outcomes simi- } \\
\text { lar? }\end{array}$ & Unclear risk & Not stated \\
\hline Free of contamination? & High risk & All doctors in the hospital were distributed across all 3 study groups. \\
\hline $\begin{array}{l}\text { Baseline characteristics } \\
\text { similar? }\end{array}$ & Unclear risk & Not stated \\
\hline
\end{tabular}

Bouza 2007

Methods STUDY DESIGN: RCT

\section{Risk of bias: HIGH}

Participants

PROVIDERS: ICU staff

PARTICIPANTS: 250 patients in the adult ICU, 167 intervention and 83 control 
Bouza 2007 (Continued)

CLINICAL PROBLEM: ventilator-associated pneumonia with bacteria identified on gram stain of first tracheal aspirate

SETTING: single general, teaching, and referral hospital in Spain

Interventions

FORMAT, Interventions: educational outreach by review and recommend change

Intervention Functions: education, enablement, persuasion

DELIVERER: microbiologists (specialist physicians)

COMPARISON: usual care

DESIRED CHANGE: reduce inappropriate

POWER CALCULATION: no information about sample size

PRESCRIBING: Exposure: mean days of therapy
MICROBIAL: Clostridium difficile infection
CLINICAL:Balancing: median days of fever and mechanical ventilation

FINANCIAL: cost of antibiotics

Notes

Microbial Risk of Bias HIGH: no case definition, no details of other infection control measures

ADDITIONAL DATA: no response from authors to request for additional data

FINANCIAL SUPPORT: Red Española de Investigación de Patología Infecciosas (REIPI) and Fondo de Investigación Sanitaria (FIS). The Spanish Ministry of Health (BEFI BF03/00237, to M.V.T.). Competing Interest: none declared

\section{Risk of bias}

\begin{tabular}{|c|c|c|}
\hline Bias & Authors' judgement & Support for judgement \\
\hline $\begin{array}{l}\text { Random sequence genera- } \\
\text { tion (selection bias) }\end{array}$ & Low risk & Computer generated \\
\hline $\begin{array}{l}\text { Allocation concealment } \\
\text { (selection bias) }\end{array}$ & Low risk & Computer generated \\
\hline $\begin{array}{l}\text { Blinding (performance } \\
\text { bias and detection bias) } \\
\text { All outcomes }\end{array}$ & High risk & No blinding \\
\hline $\begin{array}{l}\text { Incomplete outcome data } \\
\text { (attrition bias) } \\
\text { All outcomes }\end{array}$ & Low risk & Outcomes reported on all participants. \\
\hline $\begin{array}{l}\text { Selective reporting (re- } \\
\text { porting bias) }\end{array}$ & Unclear risk & $\begin{array}{l}\text { No primary outcome measure identified. Defined daily dose of antibiotic ther- } \\
\text { apy free from selective reporting, but other outcomes (e.g. \% adequate days of } \\
\text { antibiotic therapy) were not. }\end{array}$ \\
\hline Other bias & High risk & High microbial risk of bias \\
\hline $\begin{array}{l}\text { Baseline Outcomes simi- } \\
\text { lar? }\end{array}$ & Unclear risk & No data \\
\hline Free of contamination? & Low risk & ETEST results only available for intervention group. \\
\hline
\end{tabular}

Interventions to improve antibiotic prescribing practices for hospital inpatients (Review) 
Bouza 2007 (Continued)

Baseline characteristics Low risk
similar?

Bradley 1999

Methods STUDY DESIGN: ITS

\section{Risk of Bias: MEDIUM}

PROVIDERS: physicians in an adult haematology unit
PARTICIPANTS: all patients with clinical problem
CLINICAL PROBLEM: adult patients receiving treatment for haematological malignancy
SETTING: adult haematology unit in a university hospital in the UK

\begin{tabular}{ll}
\hline Interventions & FORMAT, Interventions: restrictive \\
Intervention Functions: restriction by removal \\
DELIVERER: specialist physician (microbiologist) \\
COMPARISON: usual care \\
DESIRED CHANGE: decrease excessive
\end{tabular}

\begin{tabular}{ll}
\hline Outcomes & PRESCRIBING: Choice: use of 4 principal IV antibiotics in patient days per month \\
& MICROBIAL: probability of remaining free of colonisation by GRE by weeks of exposure on the ward \\
from date of first admission
\end{tabular}

\section{Risk of bias}

\begin{tabular}{lll}
\hline Bias & Authors' judgement & Support for judgement \\
\hline $\begin{array}{l}\text { Intervention independent } \\
\text { (ITS) }\end{array}$ & High risk & Only 4 months' pre-intervention data, so secular changes possible. \\
\hline $\begin{array}{l}\text { Analysed appropriately } \\
\text { (ITS) }\end{array}$ & Low risk & Done in original paper: Kaplan-Meier plot and log rank test. \\
\hline $\begin{array}{l}\text { Shape of effect pre-speci- } \\
\text { fied (ITS) ? }\end{array}$ & Low risk & $\begin{array}{l}\text { Done, intended effect was decrease in primary outcome, and point of analysis } \\
\text { was point of intervention. }\end{array}$ \\
\hline $\begin{array}{l}\text { Unlikely to affect data col- } \\
\text { lection (ITS) ? }\end{array}$ & Low risk & Done, screening protocol was the same throughout the study period. \\
\hline $\begin{array}{l}\text { Knowledge of the alloca- } \\
\text { tion adequately prevent- } \\
\text { ed(ITS)? }\end{array}$ & Low risk & Done, screening protocol was the same throughout the study period. \\
\hline
\end{tabular}


Bradley 1999 (Continued)

Incomplete outcome data Low risk Done, screening protocol was the same throughout the study period. addressed (ITS) ?

Free of selected reporting Low risk Done, screening protocol was the same throughout the study period. (ITS) ?

Free of other bias (ITS)? Low risk

Microbiology Risk of Bias Criteria: Case definition: DONE, colonisation by screening; Planned intervention: DONE; Other infection control, isolation, and IC practices: DONE, same throughout study.

Bruins 2005

\begin{tabular}{ll}
\hline Methods & STUDY DESIGN: NRT \\
& Risk of Bias: HIGH \\
\hline Participants & PROVIDERS: all physicians in hospital \\
& PARTICIPANTS: 1833 patients with bacterial infection in hospital in 3 study periods. Period 1: 294 inter- \\
& vention, 320 control; Period 2: 303 intervention, 317 control; Period 3: 308 intervention, 328 control \\
& CLINICAL PROBLEM: inappropriate antibiotic therapy \\
& SETTING: 1 university hospital in the Netherlands
\end{tabular}

Interventions

FORMAT, Interventions: structural - rapid microbiology laboratory testing

Intervention Functions: environmental restructuring

DELIVERER: specialist physician (microbiologist)

COMPARISON: usual care

DESIRED CHANGE: reduce inappropriate

POWER CALCULATION: yes, 296 participants in each study arm (details in Appendix 3)

Outcomes PRESCRIBING: \% of participants who receive appropriate treatment in first $48 \mathrm{~h}$. Turnaround times for
microbiology tests and results

CLINICAL: intended clinical outcomes, total hospital mortality rate and length of hospital stay

COST: valid financial savings

Notes $\quad$ FINANCIAL SUPPORT: Funding: commercial, bioMerieux and Stichting Zorg op Regionale ' Grondslag
(ZORG). Competing Interest: no information

ADDITIONAL DATA: no response from authors to request for additional data

\section{Risk of bias}

\begin{tabular}{lll}
\hline Bias & Authors' judgement & Support for judgement \\
\hline $\begin{array}{l}\text { Random sequence genera- } \\
\text { tion (selection bias) }\end{array}$ & High risk & $\begin{array}{l}\text { Quasi-randomised. "Patients were randomised on the basis of the sum of the } \\
\text { day and month of their date of birth ... even numbers assigned to the control } \\
\text { group ... odd number to the intervention group" }\end{array}$ \\
\hline
\end{tabular}

\begin{tabular}{lll}
\hline $\begin{array}{l}\text { Allocation concealment } \\
\text { (selection bias) }\end{array}$ & High risk
\end{tabular}


Bruins 2005 (Continued)

Blinding (performance $\quad$ High risk No blinding
bias and detection bias)
All outcomes

All outcomes

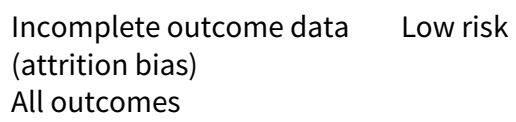

Baseline Outcomes simi- Unclear risk No data
lar?

\begin{tabular}{lll}
\hline Free of contamination? & Low risk & Rapid reports only received by intervention group. \\
\hline $\begin{array}{l}\text { Baseline characteristics } \\
\text { similar? }\end{array}$ & Low risk & Table 1 \\
\hline
\end{tabular}

Buising 2008a

\begin{tabular}{ll}
\hline Methods & STUDY DESIGN: ITS \\
& Risk of Bias: LOW \\
\hline Participants & PROVIDERS: all physicians in the hospital \\
& PARTICIPANTS: all patients in the hospital \\
CLINICAL PROBLEM: use of restricted antibiotics: cephalosporins, carbapenems, quinolones, glycopep- \\
tides, and aminoglycosides \\
SETTING: 1 university hospital in Australia
\end{tabular}

Interventions $\quad$ FORMAT, Interventions: audit and feedback; educational outreach by review and recommend change; restrictive - expert approval and removal

Intervention Functions: education, enablement, environmental, persuasion, restriction

DELIVERER: AMT

COMPARISON: usual care

DESIRED CHANGE: decrease excessive

PRESCRIBING: Choice: use of restricted antibiotics in DDD/1000 OBD
MICROBIAL: ARGNB (Escherichia coli,Pseudomonas aeruginosa); ARGPB (MRSA)

Notes

FINANCIAL SUPPORT: Funding: National Health and Medical Research Council of Australia; Biotechnology Innovation Fund from the Commonwealth Government of Australia; Melbourne Health. Competing Interest: none declared

Microbial Risk of Bias: LOW (case definition, planned intervention, and other infection control measures all low risk)

\section{Risk of bias}

\section{Bias}

Authors' judgement Support for judgement 
Buising 2008a (Continued)

Intervention independent Low risk

(ITS) ?

Analysed appropriately $\quad$ Low risk $\quad$ Segmented regression analysis
(ITS)?

(ITS) ?

Shape of effect pre-speci- Low risk $\quad$ Point of analysis is point of intervention.
fied (ITS)?

fied (ITS) ?

$\begin{array}{lll}\text { Unlikely to affect data col- Low risk Data from pharmacy and microbiology systems } & \text { D }\end{array}$
lection (ITS)?

Knowledge of the alloca- Low risk $\quad$ Data from pharmacy and microbiology systems
tion adequately prevent-
ed(ITS)?

\begin{tabular}{lll}
\hline $\begin{array}{l}\text { Incomplete outcome data } \\
\text { addressed (ITS) ? }\end{array}$ & Low risk & Data from pharmacy and microbiology systems \\
\hline $\begin{array}{l}\text { Free of selected reporting } \\
\text { (ITS) ? }\end{array}$ & Low risk & Data from pharmacy and microbiology systems \\
\hline Free of other bias (ITS) ? & Low risk & 5 years' pre- and 2 years' postintervention data \\
\hline
\end{tabular}

Buising 2008b

\begin{tabular}{ll}
\hline Methods & STUDY DESIGN: ITS \\
& Risk of Bias: HIGH \\
\hline Participants & PROVIDERS: all physicians in the ED \\
& PARTICIPANTS: all patients with community-acquired pneumonia in the ED \\
& CLINICAL PROBLEM: rate of empiric antibiotic prescribing that was concordant with recommendations \\
& SETTING: 1 university hospital in Australia
\end{tabular}

Interventions

FORMAT, Interventions 1: educational outreach by academic detailing; reminders - physical, posters

Intervention Functions: education, environmental restructuring, persuasion

Intervention 2: structural - computerised decision support

Intervention Functions: enablement, environmental restructuring

DELIVERER: AMT

COMPARISON: usual care

DESIRED CHANGE: decrease excessive

\begin{tabular}{ll}
\hline Outcomes & PRESCRIBING: Choice: $\%$ prescribing concordant with recommendation \\
\hline Notes & FINANCIAL SUPPORT: Funding: National Health and Medical Research Council of Australia. Competing \\
Interest: none declared
\end{tabular}

ADDITIONAL DATA: email response from authors with further details about intervention

\section{Risk of bias}

Bias Authors' judgement Support for judgement


Buising 2008b (Continued)

Intervention independent High risk Junior staff who were targets of the intervention rotated every 3 months. (ITS) ?

Analysed appropriately $\quad$ Low risk $\quad$ Segmented regression analysis
(ITS)?

Shape of effect pre-speci- Low risk Point of intervention was point of analysis.
fied (ITS) ?

\begin{tabular}{lll}
\hline $\begin{array}{l}\text { Unlikely to affect data col- } \\
\text { lection (ITS) }\end{array}$ & Low risk & Data collection was identical in all 3 phases. \\
\hline $\begin{array}{l}\text { Knowledge of the alloca- } \\
\text { tion adequately prevent- } \\
\text { ed(ITS)? }\end{array}$ & High risk & The nurse and physicians who collected data were not blinded to allocation. \\
\hline $\begin{array}{l}\text { Incomplete outcome data } \\
\text { addressed (ITS) ? }\end{array}$ & Low risk & Data were collected from all eligible participants. \\
\hline $\begin{array}{l}\text { Free of selected reporting } \\
\text { (ITS) ? }\end{array}$ & Low risk & $\begin{array}{l}\text { Data were collected from all eligible participants. The accuracy of data collec- } \\
\text { tion was checked in a 5\% sample of participants. }\end{array}$ \\
\hline $\begin{array}{l}\text { Free of other bias (ITS) ? } \\
\text { High risk }\end{array}$ & $\begin{array}{l}\text { 1 year of data in pre- and Intervention 1 time series, but only } 6 \text { months' data } \\
\text { for Intervention } 2\end{array}$ \\
\hline
\end{tabular}

\section{Bunz 1990}

\begin{tabular}{|c|c|}
\hline Methods & $\begin{array}{l}\text { STUDY DESIGN: ITS } \\
\text { Risk of Bias: LOW }\end{array}$ \\
\hline Participants & $\begin{array}{l}\text { PROVIDERS: all physicians in hospital } \\
\text { PARTICIPANTS: all patients in hospital } \\
\text { CLINICAL PROBLEM: receiving metronidazole } \\
\text { SETTING: single university hospital in Canada }\end{array}$ \\
\hline Interventions & $\begin{array}{l}\text { FORMAT, Interventions: educational meetings; dissemination of educational materials; reminders - } \\
\text { circumstantial, on rounds; restrictive - review and make change } \\
\text { Intervention Functions: education, enablement, restriction } \\
\text { DELIVERER: pharmacist } \\
\text { COMPARISON: usual care } \\
\text { DESIRED CHANGE: decrease excessive }\end{array}$ \\
\hline Outcomes & PRESCRIBING: Choice: $\%$ doses of metronidazole prescribed 12 -hourly \\
\hline Notes & $\begin{array}{l}\text { FINANCIAL SUPPORT: no information } \\
\text { ADDITIONAL DATA: no response from authors to request for additional data }\end{array}$ \\
\hline
\end{tabular}

\section{Risk of bias}


Bunz 1990 (Continued)

\begin{tabular}{lll} 
Bias & Authors' judgement & Support for judgement \\
\hline $\begin{array}{ll}\text { Intervention independent } \\
\text { (ITS)? }\end{array}$ & Low risk & $\begin{array}{l}\text { Although the pre- and postintervention phases were only a 6-month period, } \\
\text { data from 1 year prior to the intervention were used to control for any season- } \\
\text { al variation in prescribing patterns. }\end{array}$ \\
\hline
\end{tabular}

\begin{tabular}{|c|c|c|}
\hline $\begin{array}{l}\text { Analysed appropriately } \\
\text { (ITS)? }\end{array}$ & Low risk & Re-analysed. Not done in original paper: run charts with no statistical analysis. \\
\hline $\begin{array}{l}\text { Shape of effect pre-speci- } \\
\text { fied (ITS)? }\end{array}$ & Low risk & $\begin{array}{l}\text { Done, intended effect was decrease in primary outcome, and point of analysis } \\
\text { was point of intervention. }\end{array}$ \\
\hline $\begin{array}{l}\text { Unlikely to affect data col- } \\
\text { lection (ITS)? }\end{array}$ & Low risk & $\begin{array}{l}\text { Done, data were from routine systems and unlikely to change over study peri- } \\
\text { od. }\end{array}$ \\
\hline $\begin{array}{l}\text { Knowledge of the alloca- } \\
\text { tion adequately prevent- } \\
\text { ed(ITS)? }\end{array}$ & Low risk & $\begin{array}{l}\text { Done, data were from routine systems and unlikely to change over study peri- } \\
\text { od. }\end{array}$ \\
\hline $\begin{array}{l}\text { Incomplete outcome data } \\
\text { addressed (ITS)? }\end{array}$ & Low risk & $\begin{array}{l}\text { Done, data were from routine systems and unlikely to change over study peri- } \\
\text { od. }\end{array}$ \\
\hline $\begin{array}{l}\text { Free of selected reporting } \\
\text { (ITS) ? }\end{array}$ & Low risk & Done, the analysis included all prescriptions for metronidazole. \\
\hline Free of other bias (ITS) ? & Low risk & No other apparent biases found. \\
\hline
\end{tabular}

Burton 1991

\begin{tabular}{ll}
\hline Methods & STUDY DESIGN: RCT \\
& Risk of Bias: HIGH \\
\hline Participants & PROVIDERS: all physicians in hospital \\
PARTICIPANTS: 147 receiving aminoglycosides \\
CLINICAL PROBLEM: patients receiving IV aminoglycosides \\
SETTING: 1 hospital in the USA
\end{tabular}

Interventions

FORMAT, Interventions: educational outreach by review and recommend change

Intervention Functions: education, enablement, persuasion

DELIVERER: pharmacist

COMPARISON: usual care

DESIRED CHANGE: reduce inappropriate

POWER CALCULATION: no information about sample size

\begin{tabular}{ll}
\hline Outcomes & PRESCRIBING: Choice: aminoglycoside dosing and serum concentration \\
& CLINICAL: Intended: length of stay \\
\hline Notes & FINANCIAL SUPPORT: no information
\end{tabular}




\section{Risk of bias}

\begin{tabular}{|c|c|c|}
\hline Bias & Authors' judgement & Support for judgement \\
\hline $\begin{array}{l}\text { Random sequence genera- } \\
\text { tion (selection bias) }\end{array}$ & Low risk & $\begin{array}{l}\text { "Random numbers table used to assign } 9 \text { of } 17 \text { house staff teams to the in- } \\
\text { tervention group. Patients allocated to intervention or control groups based } \\
\text { on house staff team to which they were admitted. The other } 8 \text { teams were as- } \\
\text { signed as control groups" }\end{array}$ \\
\hline $\begin{array}{l}\text { Allocation concealment } \\
\text { (selection bias) }\end{array}$ & Unclear risk & $\begin{array}{l}\text { Not stated but unlikely: } 9 \text { house staff teams were in the intervention group, } 8 \\
\text { control, groups swapped over after } 4 \text { months. }\end{array}$ \\
\hline $\begin{array}{l}\text { Blinding (performance } \\
\text { bias and detection bias) } \\
\text { All outcomes }\end{array}$ & High risk & "Blinding as to patient status was not performed" \\
\hline $\begin{array}{l}\text { Incomplete outcome data } \\
\text { (attrition bias) } \\
\text { All outcomes }\end{array}$ & Low risk & No problems found. \\
\hline $\begin{array}{l}\text { Selective reporting (re- } \\
\text { porting bias) }\end{array}$ & Low risk & No problems found. \\
\hline Other bias & High risk & $\begin{array}{l}\text { Unit of analysis error for length of stay. This was a cluster RCT, but length of } \\
\text { stay was analysed at participant level. }\end{array}$ \\
\hline $\begin{array}{l}\text { Baseline Outcomes simi- } \\
\text { lar? }\end{array}$ & Unclear risk & Not measured before interventions. \\
\hline Free of contamination? & High risk & $\begin{array}{l}\text { Not done, } 9 \text { house staff teams were in the intervention group, } 8 \text { control, groups } \\
\text { swapped over after } 4 \text { months. }\end{array}$ \\
\hline $\begin{array}{l}\text { Baseline characteristics } \\
\text { similar? }\end{array}$ & Low risk & See Table 2 in paper. \\
\hline
\end{tabular}

\section{Buyle 2010}

$\begin{array}{ll}\text { Methods } & \text { STUDY DESIGN: ITS } \\ & \text { Risk of Bias: LOW }\end{array}$

PROVIICipants
PARTICIPANTS: all patients receiving IV fluoroquinolones
CLINICAL PROBLEM: switch from IV fluoroquinolones to oral
SETTING: 1 hospital in Belgium

Interventions

FORMAT, Interventions: educational meetings; dissemination of guideline; reminders - circumstantial and physical (pre-printed note placed in patient notes when the patient fulfilled criteria for IV to oral switch). NB: the circumstantial reminder was only implemented on some wards (abdominal surgery, gastro-enterology, and plastic surgery) over 2 months, and there are no reliable data to estimate the effect of this component. 
Buyle 2010 (Continued)

Intervention Functions: education, enablement (only for the circumstantial reminder), environmental restructuring (only for the circumstantial reminder)

DELIVERER: AMT

COMPARISON: usual care

DESIRED CHANGE: reduce inappropriate

\begin{tabular}{ll}
\hline Outcomes & PRESCRIBING: Choice: \% IV/(IV + oral) fluoroquinolone usage \\
\hline Notes & FINANCIAL SUPPORT: Funding: none. Competing Interest: none declared \\
& ADDITIONAL DATA: email from authors with further information about the intervention \\
\hline
\end{tabular}

\section{Risk of bias}

\begin{tabular}{lll}
\hline Bias & Authors' judgement & Support for judgement \\
\hline $\begin{array}{l}\text { Intervention independent } \\
\text { (ITS) ? }\end{array}$ & Low risk & \\
\hline $\begin{array}{l}\text { Analysed appropriately } \\
\text { (ITS) ? }\end{array}$ & Low risk & Re-analysed \\
\hline $\begin{array}{l}\text { Shape of effect pre-speci- } \\
\text { fied (ITS) ? }\end{array}$ & Low risk & Point of intervention was point of analysis. \\
\hline $\begin{array}{l}\text { Unlikely to affect data col- } \\
\text { lection (ITS)? }\end{array}$ & Low risk & $\begin{array}{l}\text { Data for ITS from pharmacy computer (Figure 1). Other data in Tables 2 and 3 } \\
\text { not valid, UBA. }\end{array}$ \\
\hline $\begin{array}{l}\text { Knowledge of the alloca- } \\
\text { tion adequately prevent- } \\
\text { ed(ITS)? }\end{array}$ & Low risk & $\begin{array}{l}\text { Data for ITS from pharmacy computer (Figure 1). Other data in Tables 2 and 3 } \\
\text { not valid, UBA. }\end{array}$ \\
\hline $\begin{array}{l}\text { Incomplete outcome data } \\
\text { addressed (ITS) ? }\end{array}$ & Low risk & $\begin{array}{l}\text { Data for ITS from pharmacy computer (Figure 1). Other data in Tables 2 and 3 } \\
\text { not valid, UBA. }\end{array}$ \\
\hline $\begin{array}{l}\text { Free of selected reporting } \\
\text { (ITS) ? }\end{array}$ & Low risk & $\begin{array}{l}\text { Data for ITS from pharmacy computer (Figure 1). Other data in Tables 2 and 3 } \\
\text { not valid, UBA. }\end{array}$ \\
\hline $\begin{array}{l}\text { Free of other bias (ITS)? } \\
\text { 21 months' pre- and 24 months' postintervention }\end{array}$ \\
\hline
\end{tabular}

\section{Calfee 2003}

Methods STUDY DESIGN: unintended consequences, case control

\section{Risk of Bias: HIGH}

Participants

PROVIDERS: all physicians in adult medical and surgical units

PARTICIPANTS: all patients in the units

CLINICAL PROBLEM: use of targeted antibiotics (3rd-generation cephalosporins, piperacillin/tazobactam, aztreonam, carbapenems, parenteral clindamycin, oral and parenteral vancomycin, parenteral fluoroquinolones and macrolides, and fluconazole) SETTING: 1 hospital in the USA 
Calfee 2003 (Continued) Interventions
FORMAT, Interventions: restrictive by review and make change, automatic stop order for prescriptions not meeting policy indications

Intervention Functions: restriction

DELIVERER: AMT

COMPARISON: case control study

DESIRED CHANGE: decrease excessive use of targeted drugs
UNINTENDED CONSEQUENCES: proportion of nosocomial infections reported solely on the basis of a treating physician's diagnosis during the endemic and epidemic periods (Table 1)

Notes

\section{ROBINS-I RISK OF BIAS CRITERIA:}

1. Confounding: Low, confounding unlikely

2. Selection of participants into the study: Unclear, insufficient detail about selection of cases for the endemic and epidemic period

3. Measurement classification of interventions: Low, intervention status well defined, recorded at the time of intervention, and unaffected by knowledge of the outcome or risk of the outcome

4. Deviation from intended interventions: Low, no switches to other interventions or evidence of intervention failure

5. Missing data: Unclear, outcomes are reported as \% with no numerator or denominator data

6. Measurement of outcome: High, outcome measure objective, but outcome assessors were aware of the intervention status, and the study does not report the actual number of cases

7. Selection of the reported result: High, reported effect selected from multiple measurements within the outcome domain

FINANCIAL SUPPORT:Funding: no information. Competing Interests: no information

ADDITIONAL DATA: no response from authors to request for additional data

\section{Calil 2001}

Methods STUDY DESIGN: ITS

Risk of Bias: MEDIUM

PROrticipants
PARTICIPANTS: all patients in the neonatal care unit

CLINICAL PROBLEM: requiring neonatal care

SETTING: 1 neonatal care unit in a university hospital in Brazil

FORMAT: no valid prescribing data. Restrictive
DELIVERER: specialist physician
COMPARISON: usual carer
DESIRED CHANGE: decrease exessive

Outcomes MICROBIAL: monthly incidence of Enterobacter cloacae infections

Notes FINANCIAL SUPPORT: no information provided


Calil 2001 (Continued)

ADDITIONAL DATA: no response from authors to request for additional data

\section{Risk of bias}

\begin{tabular}{|c|c|c|}
\hline Bias & Authors' judgement & Support for judgement \\
\hline $\begin{array}{l}\text { Intervention independent } \\
\text { (ITS)? }\end{array}$ & Low risk & More than 1 year of data before and after intervention \\
\hline $\begin{array}{l}\text { Analysed appropriately } \\
\text { (ITS)? }\end{array}$ & Low risk & $\begin{array}{l}\text { Re-analysed. Not done in original paper: comparison of means (uncontrolled } \\
\text { before-after) with logistic regression analysis of relationship between antibiot- } \\
\text { ic prescribing and resistance. }\end{array}$ \\
\hline $\begin{array}{l}\text { Shape of effect pre-speci- } \\
\text { fied (ITS)? }\end{array}$ & Low risk & $\begin{array}{l}\text { Done, intended effect was decrease in primary outcome, and point of analysis } \\
\text { was point of intervention. }\end{array}$ \\
\hline $\begin{array}{l}\text { Unlikely to affect data col- } \\
\text { lection (ITS)? }\end{array}$ & Low risk & $\begin{array}{l}\text { Done, data were from routine systems and unlikely to change over study peri- } \\
\text { od. }\end{array}$ \\
\hline $\begin{array}{l}\text { Knowledge of the alloca- } \\
\text { tion adequately prevent- } \\
\text { ed(ITS)? }\end{array}$ & Low risk & $\begin{array}{l}\text { Done, data were from routine systems and unlikely to change over study peri- } \\
\text { od. }\end{array}$ \\
\hline $\begin{array}{l}\text { Incomplete outcome data } \\
\text { addressed (ITS)? }\end{array}$ & Low risk & $\begin{array}{l}\text { Done, data were from routine systems and unlikely to change over study peri- } \\
\text { od. }\end{array}$ \\
\hline $\begin{array}{l}\text { Free of selected reporting } \\
\text { (ITS)? }\end{array}$ & Unclear risk & $\begin{array}{l}\text { Not clear, no information about changes in sampling or testing protocol over } \\
\text { study period. }\end{array}$ \\
\hline \multirow[t]{2}{*}{ Free of other bias (ITS)? } & High risk & Not done. \\
\hline & & $\begin{array}{l}\text { Microbial Risk of Bias Criteria: Case definition: infection, monthly infections } \\
\text { with E cloacae; Unplanned intervention: other infection control measures: bar- } \\
\text { rier precautions, isolation of participants, and personal IC procedures fully de- } \\
\text { scribed and same in both phases. }\end{array}$ \\
\hline
\end{tabular}

Camins 2009

Methods STUDY DESIGN: cluster RCT, service level

\section{Risk of Bias: HIGH}

Participants $\quad$ PROVIDERS: all internal medicine teams in the hospital

PARTICIPANTS: 784 patients prescribed antibiotics in the hospital (390 intervention, 394 control), 12 clusters (internal medicine teams)

CLINICAL PROBLEM: patients receiving therapeutic piperacillin-tazobactam, levofloxacin, or vancomycin

SETTING: 1 hospital in the USA

Interventions

Interventions: audit and feedback; dissemination of guidelines; educational outreach by review and recommend change

Intervention Functions: education, enablement, persuasion

DELIVERER: AMT 


\section{COMPARISON: usual care}

DESIRED CHANGE: decrease in excessive treatment

POWER CALCULATION: assuming a baseline proportion of inappropriate use for target antimicrobials of 35\% (with inappropriate-use data based on preliminary-usage data from Grady Memorial Hospital), review of at least 330 antimicrobial prescriptions in each arm would allow for detection of a $10 \%$ reduction in inappropriate antimicrobial use.

\begin{tabular}{ll}
\hline Outcomes & PRESCRIBING: Choice: \% appropriate \\
\hline Notes & FINANCIAL SUPPORT: Emory Medical Care Foundation; National Institutes of Health (UL1RR024992 to \\
BCC, K12 RR017643 to MDK and HMB, K23 AI054371 to MDK, and UL1 RR025008 to HMB). Competing In- \\
terests: BCC reports was on the speakers' bureau for Wyeth Pharmaceuticals. All other authors report \\
no conflicts of interest. \\
ADDITIONAL DATA: no additional data requested
\end{tabular}

\section{Risk of bias}

\begin{tabular}{lll}
\hline Bias & Authors' judgement & Support for judgement \\
\hline $\begin{array}{l}\text { Random sequence genera- } \\
\text { tion (selection bias) }\end{array}$ & Low risk & $\begin{array}{l}\text { Each month, } 6 \text { internal medicine teams were randomly assigned to the inter- } \\
\text { vention arm, and } 6 \text { teams were randomly assigned to the control group by } \\
\text { means of a random number list. }\end{array}$ \\
\hline $\begin{array}{l}\text { Allocation concealment } \\
\text { (selection bias) }\end{array}$ & High risk & Not concealed \\
\hline $\begin{array}{l}\text { Blinding (performance } \\
\text { bias and detection bias) } \\
\text { All outcomes }\end{array}$ & High risk & Not blinded \\
\hline
\end{tabular}

\begin{tabular}{l}
\hline Incomplete outcome data Low risk Outcomes reported on all participants. \\
(attrition bias) \\
All outcomes
\end{tabular}

\begin{tabular}{lll}
\hline $\begin{array}{l}\text { Selective reporting (re- } \\
\text { porting bias) }\end{array}$ & Low risk & Outcomes reported on all participants. \\
\hline Other bias & Low risk & No data \\
\hline $\begin{array}{l}\text { Baseline Outcomes simi- } \\
\text { lar? }\end{array}$ & Unclear risk & $\begin{array}{l}\text { Doctors randomised to intervention were in the same hospital as control doc- } \\
\text { tors. }\end{array}$ \\
\hline \begin{tabular}{l} 
Free of contamination? \\
\hline
\end{tabular}
\end{tabular}

Baseline characteristics Low risk

similar?

\begin{tabular}{ll}
\hline Methods & STUDY DESIGN: ITS \\
& Risk of Bias: MEDIUM
\end{tabular}


Carling 2003 (Continued)

Participants

PROVIDERS: all physicians in the hospital

PARTICIPANTS: all patients in the hospital

CLINICAL PROBLEM: NOT CLEAR

SETTING: 1 community teaching hospital in the USA

FORMAT: no valid prescribing data. Educational outreach - review and recommend change; education-
al meetings with dissemination of educational materials
DELIVERER: AMT
COMPARISON: usual care
DESIRED CHANGE: decrease excessive

MICROBIAL: prevalence of Clostridium difficile, ceftazidime-resistant Enterobacteriaceae, and MRSA
FINANCIAL: cost of intervention

Notes

FINANCIAL SUPPORT: Funding: institutional support. Competing Interests: none declared

ADDITIONAL DATA: no additional data requested

\begin{tabular}{|c|c|c|}
\hline \multicolumn{3}{|l|}{ Risk of bias } \\
\hline Bias & Authors' judgement & Support for judgement \\
\hline $\begin{array}{l}\text { Intervention independent } \\
\text { (ITS)? }\end{array}$ & Low risk & 3 years' pre-intervention data \\
\hline $\begin{array}{l}\text { Analysed appropriately } \\
\text { (ITS)? }\end{array}$ & Low risk & $\begin{array}{l}\text { Done in original paper: regression analysis with adjustment for autocorrela- } \\
\text { tion. Analysis repeated by review team because of incomplete reporting of re- } \\
\text { sults. }\end{array}$ \\
\hline $\begin{array}{l}\text { Shape of effect pre-speci- } \\
\text { fied (ITS)? }\end{array}$ & Low risk & $\begin{array}{l}\text { Done, intended effect was decrease in primary outcome, and point of analysis } \\
\text { was point of intervention. }\end{array}$ \\
\hline $\begin{array}{l}\text { Unlikely to affect data col- } \\
\text { lection (ITS) ? }\end{array}$ & Low risk & $\begin{array}{l}\text { Done, data were from routine systems and unlikely to change over study peri- } \\
\text { od. }\end{array}$ \\
\hline $\begin{array}{l}\text { Knowledge of the alloca- } \\
\text { tion adequately prevent- } \\
\text { ed(ITS)? }\end{array}$ & Low risk & $\begin{array}{l}\text { Done, data were from routine systems and unlikely to change over study peri- } \\
\text { od. }\end{array}$ \\
\hline $\begin{array}{l}\text { Incomplete outcome data } \\
\text { addressed (ITS)? }\end{array}$ & Low risk & $\begin{array}{l}\text { Done, data were from routine systems and unlikely to change over study peri- } \\
\text { od. }\end{array}$ \\
\hline $\begin{array}{l}\text { Free of selected reporting } \\
\text { (ITS)? }\end{array}$ & Unclear risk & $\begin{array}{l}\text { Not clear, no information about changes in sampling or testing protocol over } \\
\text { study period. }\end{array}$ \\
\hline Free of other bias (ITS)? & Low risk & $\begin{array}{l}\text { VRE isolation unlikely to have influenced C difficile or resistant gram-negative } \\
\text { bacteria. Microbial Risk of Bias Criteria: Planned intervention: DONE Imple- } \\
\text { mentation of antimicrobial management team in response to increase in use } \\
\text { of target drugs. Case definition: DONE for C difficile infection (diarrhoea and } \\
\text { toxin positive) or infection with clinical isolates of gram-negative bacteria re- } \\
\text { sistant to ceftazidime, or MRSA (CDC definition of nosocomial infection). Other } \\
\text { infection control measures: DONE For C difficile contact precautions and pro- } \\
\text { cedures for cleansing equipment and patient care areas remained unchanged. } \\
\text { Other infection control processes are not described in detail but may have } \\
\text { changed during the study period (e.g. VRE isolation introduced after interven- } \\
\text { tion). Data about VRE infections NOT RELIABLE: There were no cases in the } \\
\text { pre-intervention phase and none in the first } 3 \text { years postintervention, but there }\end{array}$ \\
\hline
\end{tabular}


Chan 2011

\begin{tabular}{ll} 
Methods & STUDY DESIGN: ITS \\
& Risk of Bias: MEDIUM \\
\hline Participants & PROVIDERS: all physicians in the hospital \\
& CLINICAL PROBLEM: use of restricted antibiotics (amikacin, 3rd- and 4th-generation cephalosporins, \\
& carbapenems, fluoroquinolones, glycopeptides, and piperacillin/tazobactam) \\
& SETTING: 1 university hospital in Taiwan
\end{tabular}

Interventions $\quad$ FORMAT, Interventions: educational outreach by review and recommend change; restrictive - expert approval required plus review and make change

Intervention Functions: education, enablement, persuasion, restriction

DELIVERER: AMT

COMPARISON: usual care

DESIRED CHANGE: decrease excessive

\begin{tabular}{ll}
\hline Outcomes & PRESCRIBING: Choice: DDD/1000 OBD of restricted antibiotics \\
& MICROBIAL: isolation rates Clostridium difficile, MRSA, and multidrug-resistant gram-negative bacteria \\
\hline Notes & ADDITIONAL DATA: no response from authors to request for additional data \\
& FINANCIAL SUPPORT: Funding: Chang Gung Memorial Hospital (Taoyuan, Taiwan) (grant CM- \\
& RPG340236). Competing Interests: none declared \\
& Microbial Risk of Bias: HIGH (case definition clear, planned intervention but no data about infection \\
& control)
\end{tabular}

\section{Risk of bias}

\begin{tabular}{lll}
\hline Bias & Authors' judgement & Support for judgement \\
\hline $\begin{array}{l}\text { Intervention independent } \\
\text { (ITS) } ?\end{array}$ & Low risk & $\begin{array}{l}\text { States in discussion that biggest limitation was lack of external controls, but } \\
\text { that is common to all ITS studies. }\end{array}$ \\
\hline $\begin{array}{l}\text { Analysed appropriately } \\
\text { (ITS) ? }\end{array}$ & Low risk & Re-analysed \\
\hline $\begin{array}{l}\text { Shape of effect pre-speci- } \\
\text { fied (ITS) ? }\end{array}$ & Low risk & Point of analysis was point of intervention. \\
\hline $\begin{array}{l}\text { Unlikely to affect data col- } \\
\text { lection (ITS) ? }\end{array}$ & Unclear risk & DDD data from pharmacy computer, the same pre- and postintervention \\
\hline $\begin{array}{l}\text { Knowledge of the alloca- } \\
\text { tion adequately prevent- } \\
\text { ed(ITS)? }\end{array}$ & Low risk & DDD data from pharmacy computer, the same pre- and postintervention \\
\hline $\begin{array}{l}\text { Incomplete outcome data } \\
\text { addressed (ITS) ? }\end{array}$ & Low risk & \\
\hline
\end{tabular}


Chan 2011 (Continued)

Free of selected reporting Low risk DDD data from pharmacy computer, the same pre- and postintervention (ITS) ?

Free of other bias (ITS) ? Low risk > 1 year data pre- and postintervention

Chan 2015

\begin{tabular}{ll}
\hline Methods & STUDY DESIGN: ITS \\
& Risk of Bias: LOW \\
\hline Participants & PROVIDERS: all physicians in the hospital \\
& PARTICIPANTS: all patients requring vancomycin \\
& CLINICAL PROBLEM: patients requiring more than 2 doses of vancomycin treatment \\
& SETTING: 1 university hospital in the USA
\end{tabular}

Interventions $\quad$ FORMAT Interventions: restrictive - expert approval

Intervention Functions: restriction

DELIVERER: AMT

COMPARISON: pre-existing antimicrobial stewardship programme with audit and feedback. No valid data about impact of this programme (UBA).

DESIRED CHANGE: decrease excessive

\begin{tabular}{ll}
\hline Outcomes & PRESCRIBING: Choice: use of vancomycin in DDD/1000 OBD \\
\hline Notes & FINANCIAL SUPPORT: none. Competing Interests: none declared \\
& ADDITIONAL DATA: no response from authors to request for additional data
\end{tabular}

\section{Risk of bias}

\begin{tabular}{lll}
\hline Bias & Authors' judgement & Support for judgement \\
\hline $\begin{array}{l}\text { Intervention independent } \\
\text { (ITS) }\end{array}$ & Low risk & \\
\hline $\begin{array}{l}\text { Analysed appropriately } \\
\text { (ITS) }\end{array}$ & Low risk & Segmented regression analysis \\
\hline $\begin{array}{l}\text { Shape of effect pre-speci- } \\
\text { fied (ITS) ? }\end{array}$ & Low risk & \\
\hline $\begin{array}{l}\text { Unlikely to affect data col- } \\
\text { lection (ITS) ? }\end{array}$ & Low risk & Routine data from pharmacy computer \\
\hline $\begin{array}{l}\text { Knowledge of the alloca- } \\
\text { tion adequately prevent- } \\
\text { ed(ITS)? }\end{array}$ & Low risk & Routine data from pharmacy computer \\
\hline $\begin{array}{l}\text { Incomplete outcome data } \\
\text { addressed (ITS) ? }\end{array}$ & Low risk & Routine data from pharmacy computer \\
\hline $\begin{array}{l}\text { Free of selected reporting } \\
\text { (ITS) ? }\end{array}$ & Low risk & Routine data from pharmacy computer \\
\hline
\end{tabular}


Chan 2015 (Continued)

Free of other bias (ITS) ? Low risk 21 months' pre- and 51 months' postintervention data

Chandy 2014

$\begin{array}{ll}\text { Methods } & \text { STUDY DESIGN: ITS } \\ \text { Risk of Bias: LOW }\end{array}$

\section{Risk of Bias: LOW}

PROVIIicipants
PARTICIPANTS: all patients receiving antibiotics
CLINICAL PROBLEM: total antibiotic use in the hospital
SETTING: 1 university hospital in India

Interventions
FORMAT Interventions: dissemination of educational materials (guidelines)
Intervention Functions: education
DELIVERER: AMT
COMPARISON: pre-dissemination
DESIRED CHANGE: decrease excessive

\begin{tabular}{ll}
\hline Outcomes & PRESCRIBING: Exposure: total antibiotic use in DDD/100 OBD \\
\hline Notes & FINANCIAL SUPPORT: none. Competing Interests: none declared \\
& $\begin{array}{l}\text { ADDITIONAL INFORMATION: authors provided additional detail about the antibiotic policy and con- } \\
\text { firmed that feedback was not used in this intervention }\end{array}$
\end{tabular}

\section{Risk of bias}

\begin{tabular}{|c|c|c|}
\hline Bias & Authors' judgement & Support for judgement \\
\hline $\begin{array}{l}\text { Intervention independent } \\
\text { (ITS)? }\end{array}$ & Low risk & \\
\hline $\begin{array}{l}\text { Analysed appropriately } \\
\text { (ITS)? }\end{array}$ & Low risk & Segmented regression analysis \\
\hline $\begin{array}{l}\text { Shape of effect pre-speci- } \\
\text { fied (ITS)? }\end{array}$ & Low risk & \\
\hline $\begin{array}{l}\text { Unlikely to affect data col- } \\
\text { lection (ITS)? }\end{array}$ & Low risk & Routine data from pharmacy computer \\
\hline $\begin{array}{l}\text { Knowledge of the alloca- } \\
\text { tion adequately prevent- } \\
\text { ed(ITS)? }\end{array}$ & Low risk & Routine data from pharmacy computer \\
\hline $\begin{array}{l}\text { Incomplete outcome data } \\
\text { addressed (ITS)? }\end{array}$ & Low risk & Routine data from pharmacy computer \\
\hline $\begin{array}{l}\text { Free of selected reporting } \\
\text { (ITS)? }\end{array}$ & Low risk & Routine data from pharmacy computer \\
\hline Free of other bias (ITS)? & Low risk & $>18$ months' data pre- and postintervention \\
\hline
\end{tabular}


Charbonneau 2006

\begin{tabular}{ll}
\hline Methods & STUDY DESIGN: Controlled ITS \\
& Risk of Bias: MEDIUM \\
\hline Participants & PROVIDERS: all physicians in hospital \\
& PARTICIPANTS: all patients who qualified for fluoroquinolone therapy \\
& CLINICAL PROBLEM: infection with MRSA \\
& SETTING: 1 university hospital in France \\
\hline Interventions & FORMAT: no valid prescribing data. Restriction, educational meetings, and dissemination of education- \\
& DELIVERER: AMT \\
COMPARISON: usual care & DESIRED CHANGE: decrease excessive \\
\hline MICROBIAL: reduction of MRSA infections \\
\hline FINANCIAL SUPPORT: Funding: Programme Hospitalier de Recherche Clinique. Competing Interests: \\
nOne declared \\
ADDITIONAL DATA: no request for additional data
\end{tabular}

\section{Risk of bias}

\begin{tabular}{lll}
\hline Bias & Authors' judgement & Support for judgement \\
\hline $\begin{array}{l}\text { Intervention independent } \\
\text { (ITS) ? }\end{array}$ & Low risk & $\begin{array}{l}1 \text { year post- and 2 years' pre-intervention data, so secular changes unlikely. In- } \\
\text { fection control protocols were unchanged pre- and postintervention. }\end{array}$ \\
\hline $\begin{array}{l}\text { Analysed appropriately } \\
\text { (ITS) ? }\end{array}$ & Low risk & $\begin{array}{l}\text { Done in original paper: the study is analysed as a CBA adjusting for con- } \\
\text { founders and slope and level. The ITS analyses are correct, but the results are } \\
\text { not well reported. }\end{array}$ \\
\hline $\begin{array}{l}\text { Shape of effect pre-speci- } \\
\text { fied (ITS)? }\end{array}$ & Low risk & $\begin{array}{l}\text { Done, intended effect was decrease in primary outcome, and point of analysis } \\
\text { was point of intervention. }\end{array}$ \\
\hline $\begin{array}{l}\text { Unlikely to affect data col- } \\
\text { lection (ITS) ? }\end{array}$ & Low risk & $\begin{array}{l}\text { Done, data were from routine systems and unlikely to change over study peri- } \\
\text { od. }\end{array}$ \\
\hline $\begin{array}{l}\text { Knowledge of the alloca- } \\
\text { tion adequately prevent- } \\
\text { ed(ITS)? }\end{array}$ & Low risk & $\begin{array}{l}\text { Done, data were from routine systems and unlikely to change over study peri- } \\
\text { od. }\end{array}$ \\
\hline $\begin{array}{l}\text { Incomplete outcome data } \\
\text { addressed (ITS) ? }\end{array}$ & Low risk & $\begin{array}{l}\text { Done, data were from routine systems and unlikely to change over study peri- } \\
\text { od. }\end{array}$ \\
\hline $\begin{array}{l}\text { Free of selected reporting } \\
\text { (ITS) ? }\end{array}$ & $\begin{array}{l}\text { Unclear risk } \\
\text { Not clear, no information about changes in sampling or testing protocol over } \\
\text { study period. }\end{array}$ \\
\hline
\end{tabular}

\footnotetext{
Free of other bias (ITS) ? Low risk
}

Microbial Risk of Bias Criteria: Planned intervention: DONE Case definition: DONE clear case definition of clinical infection: "A new case was defined as a case in a patient with no previous history of MRSA or ESBL-EB colonization or infection who was infected with MRSA or ESBL-EB no less than $48 \mathrm{~h}$ after hos- 
pital admission." Other infection control measures: DONE "The measures recommended by French national guidelines for the prevention of nosocomial infections were implemented in the 4 study hospitals several years before the study began"

Cheng 2009

\begin{tabular}{ll}
\hline Methods & STUDY DESIGN: ITS \\
& Risk of Bias: MEDIUM \\
\hline Participants & PROVIDERS: all physicians in the hospital \\
& PARTICIPANTS: all patients receiving IV antibiotics \\
CLINICAL PROBLEM: reduce inappropriate prescribing of broad-spectrum IV antibiotics in hospital in- \\
patients \\
SETTING: 1 university hospital in China
\end{tabular}

FORMAT, Interventions: educational meetings with dissemination of guidelines; educational outreach
by review and recommend change
Intervention Functions: education, enablement, persuasion
DELIVERER: AMT
COMPARISON: usual care
DESIRED CHANGE: decrease excessive

\begin{tabular}{ll}
\hline Outcomes & PRESCRIBING: Choice: use of targeted antibiotics in DDD/1000 OBD \\
\hline Notes & FINANCIAL SUPPORT: no information \\
& ADDITIONAL DATA: no response from authors to request for additional data \\
\hline
\end{tabular}

\section{Risk of bias}

\begin{tabular}{lll}
\hline Bias & Authors' judgement & Support for judgement \\
\hline $\begin{array}{l}\text { Intervention independent } \\
\text { (ITS) }\end{array}$ & Unclear risk & $\begin{array}{l}\text { Does not mention other changes apart from preceding Antimicrobial Steward- } \\
\text { ship Programme. }\end{array}$ \\
\hline $\begin{array}{l}\text { Analysed appropriately } \\
\text { (ITS) ? }\end{array}$ & Low risk & Re-analysed \\
\hline $\begin{array}{l}\text { Shape of effect pre-speci- } \\
\text { fied (ITS) ? }\end{array}$ & Low risk & Point of intervention was point of analysis. \\
\hline $\begin{array}{l}\text { Unlikely to affect data col- } \\
\text { lection (ITS) ? }\end{array}$ & Low risk & Routine pharmacy data used for outcome, so assume complete. \\
\hline $\begin{array}{l}\text { Knowledge of the alloca- } \\
\text { tion adequately prevent- } \\
\text { ed(ITS)? }\end{array}$ & Low risk & Routine pharmacy data used for outcome, so assume complete. \\
\hline $\begin{array}{l}\text { Incomplete outcome data } \\
\text { addressed (ITS) ? }\end{array}$ & Low risk & \\
\hline $\begin{array}{l}\text { Free of selected reporting } \\
\text { (ITS) ? }\end{array}$ & Low risk & Routine pharmacy data used for outcome, so assume complete. \\
\hline
\end{tabular}


Cheng 2009 (Continued)

Free of other bias (ITS) ? Low risk > $\quad$ year data pre- and postintervention

Christ-Crain 2004

\begin{tabular}{ll} 
Methods & STUDY DESIGN: cluster RCT \\
& Risk of bias: MEDIUM \\
\hline Participants & PROVIDERS: physicians in hospital \\
& PARTICIPANTS: 234 patients (124 intervention, 119 control), 16 clusters (weeks randomly assigned to \\
either standard or procalcitonin)
\end{tabular}

CLINICAL PROBLEM: suspected lower respiratory tract infection

SETTING: 1 university hospital in Switzerland

Interventions $\quad$ FORMAT, Interventions: dissemination of educational materials; reminders - circumstantial and physical (procalcitonin algorithm) triggered by prescribing antibiotics; structural

Intervention Functions: education, enablement, environmental restructuring, persuasion

DELIVERER: department physician

COMPARISON: usual care

DESIRED CHANGE: decrease excessive

POWER CALCULATION: yes, 105 participants in each group

Outcomes PRESCRIBING: Choice: relative risk of antibiotic exposure measured in percentage and patient-days

CLINICAL: Balancing: length of stay; mortality

Notes

FINANCIAL SUPPORT: Funding: B.R.A.H.M.S (Hennigsdorf, Germany) and Orgenium Laboratories (Turku, Finland) provided assay material and partial support of this investigator-initiated project. Freiwillige Akademische Gesellschaft Basel, Switzerland; internal from the Department of Internal Medicine and the Divisions of Endocrinology and Pneumology. Competing Interests: BM served as consultant and received payments from B.R.A.H.M.S (the manufacturer of procalcitonin assays) to attend meetings related to the trial and for travel expenses, speaking engagements, or research

ADDITIONAL DATA: email response from authors to request for additional data

\section{Risk of bias}

\begin{tabular}{|c|c|c|}
\hline Bias & Authors' judgement & Support for judgement \\
\hline $\begin{array}{l}\text { Random sequence genera- } \\
\text { tion (selection bias) }\end{array}$ & Low risk & $\begin{array}{l}\text { "We randomly assigned eligible patients ... according to a computer generated } \\
\text { week wise randomisation scheme" }\end{array}$ \\
\hline $\begin{array}{l}\text { Allocation concealment } \\
\text { (selection bias) }\end{array}$ & Unclear risk & $\begin{array}{l}\text { "We randomly assigned eligible patients either standard antimicrobial thera- } \\
\text { py (standard group) or procalcitonin-guided antimicrobial treatment (procal- } \\
\text { citonin group) according to a computer-generated week wise randomisation } \\
\text { scheme". No information about concealment of allocation }\end{array}$ \\
\hline $\begin{array}{l}\text { Blinding (performance } \\
\text { bias and detection bias) } \\
\text { All outcomes }\end{array}$ & Low risk & "Single blinded intervention trial" \\
\hline
\end{tabular}


Christ-Crain 2004 (Continued)

Incomplete outcome data Low risk Antibiotic data from all treated participants

(attrition bias)

All outcomes

Selective reporting (re- Low risk $\quad$ Objective outcome measure in all participants
porting bias)

\begin{tabular}{lll}
\hline Other bias & Low risk & No other apparent biases found. \\
\hline $\begin{array}{l}\text { Baseline Outcomes simi- } \\
\text { lar? }\end{array}$ & Unclear risk & Not stated \\
\hline Free of contamination? & Low risk & $\begin{array}{l}\text { Although same doctors treated participants in non-intervention weeks, they } \\
\text { did not have data about procalcitonin results. }\end{array}$ \\
\hline $\begin{array}{l}\text { Baseline characteristics } \\
\text { similar? }\end{array}$ & Low risk & Done, Tables 1 and 2 in the original paper \\
\hline
\end{tabular}

\section{Christ-Crain 2006}

\begin{tabular}{ll}
\hline Methods & STUDY DESIGN: RCT \\
& Risk of bias: MEDIUM \\
\hline
\end{tabular}

\section{Participants}

PROVIDERS: physicians in hospital

PARTICIPANTS: 302 patients (151 intervention, 151 control)

CLINICAL PROBLEM: suspected community-acquired pneumonia

SETTING: 1 university hospital in Switzerland

Interventions $\quad$ FORMAT, Interventions: dissemination of educational materials; reminders - circumstantial and physi-

cal (procalcitonin algorithm) triggered by prescribing antibiotics; structural

Intervention Functions: education, enablement, environmental restructuring, persuasion

DELIVERER: department physician

COMPARISON: usual care

DESIRED CHANGE: decrease excessive

POWER CALCULATION: yes, 150 participants in each group

\section{Outcomes}

PRESCRIBING: Choice: relative risk of antibiotic exposure, total antibiotic use. Duration of antibiotic course

CLINICAL: Balancing: mortality and length of hospital stay

FINANCIAL: total antibiotic cost and cost per patient

\section{Notes}

FINANCIAL SUPPORT: Funding: B.R.A.H.M.S (Hennigsdorf, Germany), Pfizer (Schweiz AG), and Mepha (Schweiz AG) was used for assay material and salaries of technical personnel; internal from Departments of Internal Medicine and Emergency Medicine, the Stiftung Forschung Infektionskrankheiten (SFI), and Departments of Endocrinology and Pulmonary Medicine, University Hospital Basel, Switzerland. Competing Interests: 2 authors received payments from B.R.A.H.M.S AG, the manufacturer of the procalcitonin assay. 
Christ-Crain 2006 (Continued)

ADDITIONAL DATA: no response from authors to request for additional data

\section{Risk of bias}

\begin{tabular}{|c|c|c|}
\hline Bias & Authors' judgement & Support for judgement \\
\hline $\begin{array}{l}\text { Random sequence genera- } \\
\text { tion (selection bias) }\end{array}$ & Unclear risk & $\begin{array}{l}\text { "Patients were randomly assigned to one of the two groups by sealed opaque } \\
\text { envelopes", no information about generation of randomisation sequence }\end{array}$ \\
\hline $\begin{array}{l}\text { Allocation concealment } \\
\text { (selection bias) }\end{array}$ & Low risk & "Sealed opaque envelopes" \\
\hline $\begin{array}{l}\text { Blinding (performance } \\
\text { bias and detection bias) } \\
\text { All outcomes }\end{array}$ & Low risk & \\
\hline $\begin{array}{l}\text { Incomplete outcome data } \\
\text { (attrition bias) } \\
\text { All outcomes }\end{array}$ & Low risk & \\
\hline $\begin{array}{l}\text { Selective reporting (re- } \\
\text { porting bias) }\end{array}$ & Low risk & \\
\hline Other bias & Low risk & \\
\hline $\begin{array}{l}\text { Baseline Outcomes simi- } \\
\text { lar? }\end{array}$ & Unclear risk & No data \\
\hline Free of contamination? & Low risk & $\begin{array}{l}\text { Same doctors in the intervention and control weeks, but they did not have ac- } \\
\text { cess to procalcitonin results in the control weeks. }\end{array}$ \\
\hline $\begin{array}{l}\text { Baseline characteristics } \\
\text { similar? }\end{array}$ & Low risk & Done, Table 1 in the original paper \\
\hline
\end{tabular}

Chu 2003

\begin{tabular}{ll} 
Methods & STUDY DESIGN: CBA \\
& Risk of Bias: HIGH \\
\hline Participants & PROVIDERS: all physicians in hospital \\
& PARTICIPANTS: patients with clinical problem \\
& CLINICAL PROBLEM: community-acquired pneumonia \\
& SETTING: a total of 36 (20 intervention, 16 control), non-university community hospitals in USA
\end{tabular}

Interventions

FORMAT, Interventions: audit and feedback; educational meetings; dissemination of educational materials - pack including guideline and literature review

Intervention Functions: education, enablement

DELIVERER: AMT

COMPARISON: usual care

DESIRED CHANGE: increase effective

Outcomes

PRESCRIBING: Choice: process measures sputum and blood cultures within 4 hours, antibiotics within 4 hours, first antibiotic in emergency room

CLINICAL: Intended: mortality and LOS 
Chu 2003 (Continued)

Notes
FINANCIAL SUPPORT: Funding: contract 500-99-P619 "Utilization and Quality Control Peer Review Organization for the State of Oklahoma" from the Centers for Medicare and Medicaid Services. Competing Interests: none declared

ADDITIONAL DATA: no response from authors to request for additional data

\section{Risk of bias}

\begin{tabular}{|c|c|c|}
\hline Bias & Authors' judgement & Support for judgement \\
\hline $\begin{array}{l}\text { Random sequence genera- } \\
\text { tion (selection bias) }\end{array}$ & High risk & Control cohort study (CBA) \\
\hline $\begin{array}{l}\text { Allocation concealment } \\
\text { (selection bias) }\end{array}$ & High risk & Control cohort study (CBA) \\
\hline $\begin{array}{l}\text { Blinding (performance } \\
\text { bias and detection bias) } \\
\text { All outcomes }\end{array}$ & High risk & Control cohort study (CBA) \\
\hline $\begin{array}{l}\text { Incomplete outcome data } \\
\text { (attrition bias) } \\
\text { All outcomes }\end{array}$ & Low risk & Objective primary outcome collected on all participants. \\
\hline $\begin{array}{l}\text { Selective reporting (re- } \\
\text { porting bias) }\end{array}$ & Low risk & Objective primary outcome collected on all participants. \\
\hline Other bias & Low risk & No other apparent biases found. \\
\hline $\begin{array}{l}\text { Baseline Outcomes simi- } \\
\text { lar? }\end{array}$ & Low risk & Tables 1 and 2 \\
\hline Free of contamination? & Low risk & Intervention and control were at different sites. \\
\hline $\begin{array}{l}\text { Baseline characteristics } \\
\text { similar? }\end{array}$ & Low risk & Tables 3 and 4 \\
\hline
\end{tabular}

\section{Clerc 2014}

Methods STUDY DESIGN: NRT

\section{Risk of Bias: HIGH}

Participants PROVIDERS: all physicians in the hospital

PARTICIPANTS: "We planned to include around 100 patients in the intervention group". No power calculation provided. Recruited 106 intervention and 91 control participants.

CLINICAL PROBLEM: first episode of Staphylococcus aureus bacteraemia

SETTING: 1 university hospital in Switzerland

Interventions

FORMAT, Interventions: structural - rapid laboratory testing for meticillin resistance Intervention Functions: environmental restructuring DELIVERER: specialist physician (ID and Microbiology) COMPARISON: usual care DESIRED CHANGE: decrease excessive 
Clerc 2014 (Continued)

Notes

FINANCIAL SUPPORT: Funding: none. Competing Interests: none declared

ADDITIONAL INFORMATION: the authors confirmed that this intervention did not include feedback to participants

\section{Risk of bias}

\begin{tabular}{|c|c|c|}
\hline Bias & Authors' judgement & Support for judgement \\
\hline $\begin{array}{l}\text { Random sequence genera- } \\
\text { tion (selection bias) }\end{array}$ & Low risk & Odd versus even hospital number \\
\hline $\begin{array}{l}\text { Allocation concealment } \\
\text { (selection bias) }\end{array}$ & Unclear risk & $\begin{array}{l}\text { "Mode of allocation was concealed from the clinicians", but unclear how this } \\
\text { was achieved. }\end{array}$ \\
\hline $\begin{array}{l}\text { Blinding (performance } \\
\text { bias and detection bias) } \\
\text { All outcomes }\end{array}$ & High risk & Open study \\
\hline $\begin{array}{l}\text { Incomplete outcome data } \\
\text { (attrition bias) } \\
\text { All outcomes }\end{array}$ & Low risk & Primary outcome reported on all participants. \\
\hline $\begin{array}{l}\text { Selective reporting (re- } \\
\text { porting bias) }\end{array}$ & Unclear risk & $\begin{array}{l}\text { Primary outcome reported on all participants. Authors did a secondary analy- } \\
\text { sis excluding participants with penicillin allergy, but this was not prespecified. }\end{array}$ \\
\hline Other bias & Low risk & \\
\hline $\begin{array}{l}\text { Baseline Outcomes simi- } \\
\text { lar? }\end{array}$ & Unclear risk & No data \\
\hline Free of contamination? & Unclear risk & $\begin{array}{l}\text { Clinicians received results verbally and electronically, so it is likely that they } \\
\text { were aware of the intervention, which may have influenced their management } \\
\text { of other participants. }\end{array}$ \\
\hline $\begin{array}{l}\text { Baseline characteristics } \\
\text { similar? }\end{array}$ & Low risk & Table 1 \\
\hline
\end{tabular}

Climo 1998

\begin{tabular}{ll}
\hline Methods & STUDY DESIGN: ITS \\
& Risk of Bias: MEDIUM \\
\hline Participants & PROVIDERS: all physicians in the hospital \\
& PARTICIPANTS: all patients in the hospital \\
CLINICAL PROBLEM: all patients in the hospital \\
SETTING: a 703-bed tertiary-care university hospital in the USA
\end{tabular}

Interventions FORMAT: no reliable prescribing data. Restriction by expert approval

DELIVERER: specialist physician

COMPARISON: usual care

DESIRED CHANGE: decrease excessive 
Climo 1998 (Continued)

Outcomes

MICROBIAL: cases of Clostridium difficile-associated diarrhoea per quarter (ITS data). Prevalence of clindamycin-resistant $C$ difficile

Notes

FINANCIAL SUPPORT: no information provided

ADDITIONAL DATA: no response from authors to request for additional data

\section{Risk of bias}

\begin{tabular}{|c|c|c|}
\hline Bias & Authors' judgement & Support for judgement \\
\hline $\begin{array}{l}\text { Intervention independent } \\
\text { (ITS)? }\end{array}$ & Low risk & Done, infection control measures fully described and same in both phases. \\
\hline $\begin{array}{l}\text { Analysed appropriately } \\
\text { (ITS)? }\end{array}$ & Low risk & $\begin{array}{l}\text { Re-analysed. Not done in original paper: comparison of means (uncontrolled } \\
\text { before-after) with t-test. }\end{array}$ \\
\hline $\begin{array}{l}\text { Shape of effect pre-speci- } \\
\text { fied (ITS)? }\end{array}$ & Low risk & $\begin{array}{l}\text { Done, intended effect was decrease in primary outcome, and point of analysis } \\
\text { was point of intervention. }\end{array}$ \\
\hline $\begin{array}{l}\text { Unlikely to affect data col- } \\
\text { lection (ITS)? }\end{array}$ & Low risk & $\begin{array}{l}\text { Done, data were from routine systems and unlikely to change over study peri- } \\
\text { od. }\end{array}$ \\
\hline $\begin{array}{l}\text { Knowledge of the alloca- } \\
\text { tion adequately prevent- } \\
\text { ed(ITS)? }\end{array}$ & Low risk & $\begin{array}{l}\text { Done, data were from routine systems and unlikely to change over study peri- } \\
\text { od. }\end{array}$ \\
\hline $\begin{array}{l}\text { Incomplete outcome data } \\
\text { addressed (ITS)? }\end{array}$ & Low risk & $\begin{array}{l}\text { Done, data were from routine systems and unlikely to change over study peri- } \\
\text { od. }\end{array}$ \\
\hline $\begin{array}{l}\text { Free of selected reporting } \\
\text { (ITS)? }\end{array}$ & Unclear risk & $\begin{array}{l}\text { Not clear, no information about changes in sampling or testing protocol over } \\
\text { study period }\end{array}$ \\
\hline Free of other bias (ITS)? & High risk & $\begin{array}{l}\text { NOT DONE Microbial Risk of Bias Criteria: Planned intervention: NOT DONE; } \\
\text { Case definition: DONE infection, diarrhoea, and toxin positive Other infection } \\
\text { control measures: DONE barrier precautions, isolation of participants with C } \\
\text { difficile-associated diarrhoea, and personal IC procedures fully described and } \\
\text { same in both phases. }\end{array}$ \\
\hline
\end{tabular}

Connor 2007

\begin{tabular}{ll} 
Methods & STUDY DESIGN: unintended consequences, cohort study \\
& Risk of Bias: LOW \\
\hline Participants & PROVIDERS: all physicians prescribing vancomycin \\
& PARTICIPANTS: 120 patients with vancomycin prescription approved for only 72 hours \\
& CLINICAL PROBLEM: interruption of vancomycin treatment \\
& SETTING: 1 hospital in the USA \\
\hline Interventions & FORMAT, Interventions: reminders (circumstantial and physical) stickers in medical records on day 3 \\
& warning of impending stop order; restrictive: stop order if approval not obtained \\
& Intervention Functions: enablement, environmental restructuring, restriction \\
& DELIVERER: AMT \\
COMPARISON: participants with and without sticker & DESIRED CHANGE: decrease excessive
\end{tabular}


Connor 2007 (Continued)

Outcomes UNINTENDED CONSEQUENCES: interruption of vancomycin treatment

\section{Notes}

ROBINS-I RISK OF BIAS CRITERIA:

1. Confounding: Low, confounding unlikely

2. Selection of participants into the study: Low, selection into the study unrelated to intervention (sticker in notes) or outcome

3. Measurement classification of interventions: Low, intervention status well defined, recorded at the time of intervention and unaffected by knowledge of the outcome

4. Deviations from intended interventions: Low, the study was designed to detect intervention failure (no warning sticker)

5. Missing data: Low, outcome data and intervention status complete on all 120 participants

6. Measurement of outcome: Low, outcome measure objective and unaffected by intervention status

7. Selection of the reported result: Low, reported effect predefined

FINANCIAL SUPPORT: Funding: none. Competing Interests: EL received research support from Merck Pharmaceuticals and Ortho-McNeil Pharmaceuticals. All other authors reported no conflicts of interest.

\section{Cook 2011a}

Methods STUDY DESIGN: ITS

Risk of Bias: LOW

PROVIDERS: all physicians in the hospital
PARTICIPANTS: all patients receiving antibiotics
CLINICAL PROBLEM: use of all prophylactic and therapeutic antibiotics
SETTING: 1 university hospital in the USA

Interventions

FORMAT, Interventions: educational outreach by review and recommend change

Intervention Functions: education, enablement, persuasion

DELIVERER: AMT

COMPARISON: usual care

DESIRED CHANGE: decrease excessive

Outcomes

PRESCRIBING: Exposure: total use of all antibiotics in DDD/1000 OBD

MICROBIAL: Clostridium difficile and MRSA infections/1000 OBD

Notes

FINANCIAL SUPPORT: Funding: none. Competing Interests: PPC is a member of the speakers' bureau of Pfizer, Astellas, and Merck. PPC has received research funding from GlaxoSmithKline, Merck, Gilead, Pfizer, and Bristol-Myers Squibb. All other authors have none to declare.

ADDITIONAL DATA: email response from authors with additional data about intervention

Microbial Risk of Bias HIGH: case definition low; planned intervention, other infection control high new policy for screening and isolation of MRSA introduced just before prescribing intervention

\section{Risk of bias}

Bias Authors' judgement Support for judgement


Cook 2011a (Continued)
Intervention independent
Low risk
(ITS) ?

Analysed appropriately $\quad$ Low risk $\quad$ Segmented regression analysis
(ITS)?

(ITS) ?

Shape of effect pre-speci- Low risk Point of intervention was point of analysis.
fied (ITS) ?

fied (ITS) ?

Unlikely to affect data col- Low risk $\quad$ Routine data from pharmacy computer
lection (ITS)?

lection (ITS)?

Knowledge of the alloca- Low risk Routine data from pharmacy computer
tion adequately prevent-
ed(ITS)?

\begin{tabular}{lll}
\hline $\begin{array}{l}\text { Incomplete outcome data } \\
\text { addressed (ITS) } ?\end{array}$ & Low risk & Routine data from pharmacy computer \\
\hline $\begin{array}{l}\text { Free of selected reporting } \\
\text { (ITS) }\end{array}$ & Low risk & Routine data from pharmacy computer \\
\hline Free of other bias (ITS) ? & Low risk & 2 years' pre- and postintervention data \\
\hline
\end{tabular}

\section{Cook 2011b}

\begin{tabular}{ll}
\hline Methods & STUDY DESIGN: ITS \\
& Risk of Bias: LOW \\
\hline Participants & PROVIDERS: all physicians in the hospital \\
& PARTICIPANTS: all patients receiving antibiotics \\
& CLINICAL PROBLEM: patients receiving ciprofloxacin for treatment of any infection \\
& SETTING: 1 university hospital in the USA \\
\hline Interventions & FORMAT, Intervention 1 component: educational outreach by review and recommend change \\
& Intervention 1 functions: education, enablement, persuasion \\
& Intervention 2 component: restrictive by expert approval \\
& Intervention $\mathbf{2}$ function: restriction \\
& DELIVERER: AMT \\
COMPARISON: usual care & DESIRED CHANGE: decrease excessive \\
\hline
\end{tabular}

Outcomes

PRESCRIBING: Choice: use of ciprofloxacin in DDD/1000 OBD

MICROBIAL: infections with ARGNB - \% carbapenem resistant Pseudomonas aeruginosa

FINANCIAL SUPPORT: Funding: commercial, grant from Merck \& Co., Inc. Competing Interests: PC is a
member of the speakers' bureau of Merck and Astellas. He has received research support from Merck,
Gilead, and Pfizer.

ADDITIONAL DATA: email response from authors with additional data about intervention 
Cook 2011b (Continued)

Microbial Risk of Bias HIGH case definition low; planned intervention, other infection control high change in screening and isolation for MRSA just before prescribing intervention may have impacted on transmission of $P$ aeruginosa

\section{Risk of bias}

\begin{tabular}{lll}
\hline Bias & Authors' judgement & Support for judgement \\
\hline $\begin{array}{l}\text { Intervention independent } \\
\text { (ITS) }\end{array}$ & Low risk & \\
\hline $\begin{array}{l}\text { Analysed appropriately } \\
\text { (ITS) }\end{array}$ & Low risk & Segmented regression analysis \\
\hline $\begin{array}{l}\text { Shape of effect pre-speci- } \\
\text { fied (ITS) ? }\end{array}$ & Low risk & Point of intervention was point of analysis. \\
\hline $\begin{array}{l}\text { Unlikely to affect data col- } \\
\text { lection (ITS) ? }\end{array}$ & Low risk & Routine data from pharmacy computer \\
\hline $\begin{array}{l}\text { Knowledge of the alloca- } \\
\text { tion adequately prevent- } \\
\text { ed(ITS)? }\end{array}$ & Low risk & Routine data from pharmacy computer \\
\hline $\begin{array}{l}\text { Incomplete outcome data } \\
\text { addressed (ITS) ? }\end{array}$ & Low risk & \\
\hline $\begin{array}{l}\text { Free of selected reporting } \\
\text { (ITS) ? }\end{array}$ & Low risk & Routine data from pharmacy computer \\
\hline \begin{tabular}{l} 
Free of other bias (ITS) ? \\
\hline
\end{tabular} & Low risk & Routine data from pharmacy computer \\
\hline
\end{tabular}

\section{Cortoos 2011}

\begin{tabular}{ll}
\hline Methods & STUDY DESIGN: ITS \\
& Risk of Bias: HIGH
\end{tabular}

PROVIDERS: all physicians in the hospital
PARTICIPANTS: all adult patients with community-acquired pneumonia
CLINICAL PROBLEM: compliance with guideline for community-acquired pneumonia
SETTING: 1 university hospital in the Netherlands

Interventions

FORMAT: Intervention 1: dissemination of educational materials

Intervention 1 function: education

Intervention 2: reminders - physical, questionnaire about guideline compliance, distributed once Intervention 2 functions: environmental restructuring, persuasion

DELIVERER: AMT

COMPARISON: usual care

DESIRED CHANGE: decrease excessive

\begin{tabular}{ll}
\hline Outcomes & PRESCRIBING: Choice: \% guideline compliance \\
\hline Notes & FINANCIAL SUPPORT: Funding: none. Competing Interests: none declared
\end{tabular}




\section{Risk of bias}

\begin{tabular}{lll}
\hline Bias & Authors' judgement & Support for judgement \\
\hline $\begin{array}{ll}\text { Intervention independent } \\
\text { (ITS) ? }\end{array}$ & High risk & $\begin{array}{l}\text { This and all other ROB criteria are for interventions } 1 \text { and } 2 \text { only. Intervention } 3 \\
\text { and } 4 \text { could not be evaluated because they are too close together and also co- } \\
\text { incided with an influenza epidemic. Neither intervention } 3 \text { nor intervention } 4 \\
\text { meets the EPOC minimum criteria for ITS. There are insufficient data to adjust } \\
\text { for seasonal effects, and the target condition (pneumonia) has large seasonal } \\
\text { variation. }\end{array}$
\end{tabular}

\begin{tabular}{lll}
\hline $\begin{array}{l}\text { Analysed appropriately } \\
\text { (ITS) }\end{array}$ & Low risk & Re-analysed \\
\hline $\begin{array}{l}\text { Shape of effect pre-speci- } \\
\text { fied (ITS) ? }\end{array}$ & Low risk & Point of intervention was point of analysis. \\
\hline $\begin{array}{l}\text { Unlikely to affect data col- } \\
\text { lection (ITS) ? }\end{array}$ & High risk & Data collection was different in the postintervention phase (see below). \\
\hline $\begin{array}{l}\text { Knowledge of the alloca- } \\
\text { tion adequately prevent- } \\
\text { ed(ITS)? }\end{array}$ & Unclear risk & $\begin{array}{l}\text { Compliance to therapy was assessed with a "computerised algorithm". How- } \\
\text { ever, the criteria for guideline adherence presented in the supplementary ma- } \\
\text { terials (Table S2) would require chart review, unless the hospitals had very so- } \\
\text { phisticated electronic patient records, which is not stated. The fact that pa- } \\
\text { tients were excluded because of "incomplete files" suggests that chart review } \\
\text { was required, so knowledge of the allocated interventions could not be ade- } \\
\text { quately prevented. }\end{array}$
\end{tabular}

Incomplete outcome data Unclear risk

The 477 included participants had complete data for assessment of outcomes. addressed (ITS) ? 5 patients were excluded because of incomplete patient records.

\section{Free of selected reporting Low risk} (ITS) ?

Free of other bias (ITS) ? Unclear risk

Insufficient data to account for seasonal effects. Although information about guideline compliance is reported for 2 hospitals, the ITS in Figure 1 only has data from 1 hospital (UZL). The data for the second hospital (ZOL) are actually a UBA and have been excluded.

Methods STUDY DESIGN: RCT

\section{Risk of Bias: HIGH}

PROVIDERS: all physicians in the hospital
PARTICIPANTS: 52 patients (14 intervention, 38 control)
CLINICAL PROBLEM: excessive prescribing of antibiotics
SETTING: 1 military teaching hospital in USA


FORMAT: Persuasive: educational outreach - review and recommend change

DELIVERER: AMT

COMPARISON: usual care

DESIRED CHANGE: decrease excessive

POWER CALCULATION: "Since this was an explanatory study, no a priori estimates of effect size were available to perform power and sample size calculations." The goal was to have 180 participants in the trial.

Outcomes PRESCRIBING: Choice: antibiotic use (DDDs and days of treatment)

CLINICAL: Balancing: clinical outcomes, mortality, and re-admission

Notes

FINANCIAL SUPPORT: Funding: none. Competing Interests: none declared

ADDITIONAL DATA: no response from authors to request for additional data

\section{Risk of bias}

\begin{tabular}{lll}
\hline Bias & Authors' judgement & Support for judgement \\
\hline $\begin{array}{l}\text { Random sequence genera- } \\
\text { tion (selection bias) }\end{array}$ & Low risk & Computer generated \\
\hline $\begin{array}{l}\text { Allocation concealment } \\
\text { (selection bias) }\end{array}$ & Unclear risk & $\begin{array}{l}21 \text { of } 73 \text { patients considered for enrolment were excluded, but it is not clear if } \\
\text { this was pre- or postrandomisation. The number of participants in the study } \\
\text { group was 14, versus 38 in the control group, with no justification for the un- } \\
\text { equal numbers. }\end{array}$
\end{tabular}

\begin{tabular}{|c|c|c|}
\hline $\begin{array}{l}\text { Blinding (performance } \\
\text { bias and detection bias) } \\
\text { All outcomes }\end{array}$ & Low risk & Primary outcome data from pharmacy computer \\
\hline $\begin{array}{l}\text { Incomplete outcome data } \\
\text { (attrition bias) } \\
\text { All outcomes }\end{array}$ & Low risk & Outcomes reported on all participants. \\
\hline $\begin{array}{l}\text { Selective reporting (re- } \\
\text { porting bias) }\end{array}$ & Low risk & Outcomes reported on all participants. \\
\hline Other bias & High risk & $\begin{array}{l}\text { Aim was to enrol } 180 \text { patients, but only } 72 \text { patients were identified, and } 21 \text { of } \\
\text { them were excluded. }\end{array}$ \\
\hline $\begin{array}{l}\text { Baseline Outcomes simi- } \\
\text { lar? }\end{array}$ & Unclear risk & No data \\
\hline Free of contamination? & High risk & Education intervention with study and control in same hospital \\
\hline $\begin{array}{l}\text { Baseline characteristics } \\
\text { similar? }\end{array}$ & Low risk & \\
\hline
\end{tabular}

Dancer 2013

Methods STUDY DESIGN: ITS


Dancer 2013 (Continued)

\section{Risk of Bias: MEDIUM}

Participants

PROVIDERS: all physicians in the hospital

PARTICIPANTS: all patients in the hospital

CLINICAL PROBLEM: requiring antibiotic prophylaxis or treatment

SETTING: 1 district general hospital in the UK
FORMAT: Interventions: restrictive

Intervention Functions: restriction by removal from all wards except for ED and ICU and by therapeutic substitution ("empirical prescription of ceftriaxone and ciprofloxacin for systemic sepsis and surgical prophylaxis was changed to amoxicillin, gentamicin and metronidazole")

DELIVERER: AMT

COMPARISON: multifaceted intervention introduced 7 months before restriction and remaining in place throughout restrictive period. Components: audit and feedback; educational outreach by review and recommend change; educational meetings and reminders on microbiology reports. There is only 2 months' data before the multifaceted intervention, so it is not possible to estimate its effect. DESIRED CHANGE: decrease excessive

Outcomes $\quad$ PRESCRIBING: Choice: use of cephalosporins and ciprofloxacin in DDD/1000 OBD

MICROBIAL: CDI, MRSA, and resistant gram-negative bacteria

Notes $\quad$ FINANCIAL SUPPORT: Funding: none. Competing Interests: SD received financial support for attending conferences by Janssen-Cilag, Pfizer, and Novartis

ADDITIONAL DATA: authors provided additional details about the intervention, including information about regular feedback to participants that was not in the original paper

Microbial Risk of Bias LOW case definition Low, planned intervention Low, other infection control practices Low

\begin{tabular}{lll}
\hline Risk of bias & \\
\hline Bias & Authors' judgement & Support for judgement \\
\hline $\begin{array}{ll}\text { Intervention independent } \\
\text { (ITS) ? }\end{array}$ & Unclear risk & $\begin{array}{l}9 \text { months' data pre-restriction includes an additional persuasive intervention } 7 \\
\text { months' pre-restriction; effect cannot be assessed because of insufficient pre- } \\
\text { intervention data. }\end{array}$ \\
\hline $\begin{array}{l}\text { Analysed appropriately } \\
\text { (ITS) ? }\end{array}$ & Low risk & $\begin{array}{l}\text { Analysed by correlation and time-lag modelling, but re-analysed as segmented } \\
\text { regression analysis. }\end{array}$ \\
\hline
\end{tabular}

Shape of effect pre-speci- Low risk fied (ITS) ?

\begin{tabular}{lll}
\hline $\begin{array}{l}\text { Unlikely to affect data col- } \\
\text { lection (ITS) } ?\end{array}$ & Low risk & Routine data from microbiology and pharmacy computers \\
\hline $\begin{array}{l}\text { Knowledge of the alloca- } \\
\text { tion adequately prevent- } \\
\text { ed(ITS)? }\end{array}$ & Low risk & Routine data from microbiology and pharmacy computers \\
\hline $\begin{array}{l}\text { Incomplete outcome data } \\
\text { addressed (ITS) ? }\end{array}$ & Low risk & Routine data from microbiology and pharmacy computers \\
\hline $\begin{array}{l}\text { Free of selected reporting } \\
\text { (ITS) ? }\end{array}$ & Low risk & Routine data from microbiology and pharmacy computers \\
\hline \begin{tabular}{l} 
Free of other bias (ITS) ? \\
\hline
\end{tabular} & High risk & Only 9 months' pre-intervention data \\
\hline
\end{tabular}


de Champs 1994

Methods STUDY DESIGN: ITS

\section{Risk of Bias: HIGH}

Participants PROVIDERS: physicians on a paediatric ICU

PARTICIPANTS: all patients on paediatric ICU

CLINICAL PROBLEM: neonates requiring intensive care including empirical antibiotic treatment

SETTING: paediatric ICU in a university hospital in France

Interventions
DERMAT: No valid prescribing data. Restrictive: change in antibiotic policy from gentamicin to amikacin
COMPARISON: usual care
DESIRED CHANGE: decrease excessive

\begin{tabular}{ll}
\hline Outcomes & MICROBIAL: monthly incidence of infection with multiresistant Enterobacter cloacae \\
\hline Notes & FINANCIAL SUPPORT: Funding: grant from D.R.E.D. (Direction de la Recherche et des Etudes Doctor- \\
ales). Competing Interests: none declared \\
ADDITIONAL DATA: no response from authors to request for additional data
\end{tabular}

\section{Risk of bias}

\begin{tabular}{lll}
\hline Bias & Authors' judgement & Support for judgement \\
\hline $\begin{array}{ll}\text { Intervention independent } \\
\text { (ITS) ? }\end{array}$ & High risk & $\begin{array}{l}\text { Only } 7 \text { months' pre-intervention data, so secular/seasonal changes possible. } \\
\text { Very complex case definition with no information about how this was applied } \\
\text { reliably across the pre- and postintervention periods. }\end{array}$ \\
\hline
\end{tabular}

\begin{tabular}{lll}
\hline $\begin{array}{l}\text { Analysed appropriately } \\
\text { (ITS) ? }\end{array}$ & Low risk & $\begin{array}{l}\text { Re-analysed. Not done in original paper: comparison of means (uncontrolled } \\
\text { before-after) with t-test. }\end{array}$ \\
\hline $\begin{array}{l}\text { Shape of effect pre-speci- } \\
\text { fied (ITS) ? }\end{array}$ & Low risk & $\begin{array}{l}\text { Done, intended effect was decrease in primary outcome, and point of analysis } \\
\text { was point of intervention. }\end{array}$ \\
\hline $\begin{array}{l}\text { Unlikely to affect data col- } \\
\text { lection (ITS) ? }\end{array}$ & Unclear risk & Case definition included clinical interpretation. \\
\hline
\end{tabular}

\begin{tabular}{lll}
\hline $\begin{array}{l}\text { Knowledge of the alloca- } \\
\text { tion adequately prevent- } \\
\text { ed(ITS)? }\end{array}$ & Unclear risk & NOT CLEAR because of case definition \\
\hline $\begin{array}{l}\text { Incomplete outcome data } \\
\text { addressed (ITS) ? }\end{array}$ & Unclear risk & Availability of all data required for the case definition not documented. \\
\hline $\begin{array}{l}\text { Free of selected reporting } \\
\text { (ITS) ? }\end{array}$ & Unclear risk & $\begin{array}{l}\text { Not clear, no information about changes in sampling or testing protocol over } \\
\text { study period. }\end{array}$ \\
\hline Free of other bias (ITS) ? & High risk & $\begin{array}{l}\text { Microbial outcome risk of bias: Unplanned intervention: implementation of } \\
\text { change in response to emergence of gentamicin-resistant } E \text { cloacae; Case defi- } \\
\text { nition:infection from clinical or screening isolates combined with } 7 \text { clinical cri- } \\
\text { teria and } 5 \text { additional laboratory criteria assessed by a resident paediatrician } \\
\text { and a consultant microbiologist and verified by a consultant paediatrician. Re- } \\
\text { liability of this outcome measure not clear. Other infection control measures: } \\
\text { well documented, no changes during the study period }\end{array}$
\end{tabular}


Dean 2001

Methods

STUDY DESIGN: CBA

\section{Risk of Bias: HIGH}

Participants PROVIDERS: all inpatient and outpatient services in the state of Utah

PARTICIPANTS: 22,985 Medicare beneficiaries aged 65 or older with 28,661 episodes of community-ac-

quired pneumonia, of which 7719 were hospitalised

CLINICAL PROBLEM: community-acquired pneumonia

SETTING: 23 hospitals (and 60 outpatient clinics), all in Utah, USA

Interventions $\quad$ FORMAT: no valid prescribing data. Reminder; educational outreach - academic detailing; and educational meetings or dissemination of educational material

DELIVERER: AMT

COMPARISON: usual care

DESIRED CHANGE: increase effective

\begin{tabular}{ll}
\hline Outcomes & CLINICAL: Intended: 30 -day mortality and length of stay \\
\hline Notes & FINANCIAL SUPPORT: supported by HealthInsight and Intermountain Healthcare. The analyses upon \\
& which this publication is based were performed under contract number 500-96-P604, entitled "Utiliza- \\
tion and Quality Control Peer Review Organization for the State of Utah", sponsored by the Health Care & Financing Administration (HCFA), Department of Health and Human Services. This article is a direct re- \\
& sult of the Health Care Quality Improvement Program initiated by HCFA, which has encouraged iden- \\
tification of quality improvement projects derived from analysis of patterns of care, and therefore re- \\
quired no special funding on the part of the contractor. Conflict of interest: no information
\end{tabular}

ADDITIONAL DATA: authors provided additional data

\section{Risk of bias}

\begin{tabular}{|c|c|c|}
\hline Bias & Authors' judgement & Support for judgement \\
\hline $\begin{array}{l}\text { Random sequence genera- } \\
\text { tion (selection bias) }\end{array}$ & High risk & CBA \\
\hline $\begin{array}{l}\text { Allocation concealment } \\
\text { (selection bias) }\end{array}$ & High risk & CBA \\
\hline $\begin{array}{l}\text { Blinding (performance } \\
\text { bias and detection bias) } \\
\text { All outcomes }\end{array}$ & High risk & CBA \\
\hline $\begin{array}{l}\text { Incomplete outcome data } \\
\text { (attrition bias) } \\
\text { All outcomes }\end{array}$ & Low risk & Objective outcome measure collected on all participants. \\
\hline $\begin{array}{l}\text { Selective reporting (re- } \\
\text { porting bias) }\end{array}$ & Low risk & Objective outcome measure collected on all participants. \\
\hline Other bias & Low risk & No other apparent biases found. \\
\hline $\begin{array}{l}\text { Baseline Outcomes simi- } \\
\text { lar? }\end{array}$ & Low risk & Table 1 \\
\hline Free of contamination? & Unclear risk & $\begin{array}{l}\text { NOT CLEAR, some hospitals had both intervention and control physicians. In- } \\
\text { termountain Healthcare provides } 50 \% \text { of regional health care delivery in Utah. }\end{array}$ \\
\hline
\end{tabular}


Dean 2001 (Continued)

In rural IHC hospitals, $90 \%$ of pneumonia admissions were cared for by IHC-affiliated physicians, whereas in urban IHC hospitals only $44 \%$ of pneumonia admissions were cared for by IHC-affiliated physicians. Non-affiliated physicians caring for patients at IHC hospitals may have been influenced by guideline implementation at these hospitals.

$\begin{array}{lll}\begin{array}{l}\text { Baseline characteristics } \\ \text { similar? }\end{array} & \text { Low risk } & \text { Table } 1 \\ \end{array}$

Dean 2006

$\begin{array}{ll}\text { Methods } & \text { STUDY DESIGN: CBA } \\ \text { Risk of bias: HIGH }\end{array}$

Participants

PROVIDERS: all physicians in hospital

PARTICIPANTS: a total of 17,728 patients aged 66 years or older

CLINICAL PROBLEM: admitted with community-acquired pneumonia

SETTING: 35 hospitals in Utah, USA (16 from Intermountain Healthcare and 19 from other systems)

FORMAT: no valid prescribing data. Reminder; educational outreach by academic detailing; and educa-
tional meetings with dissemination of educational materials
DELIVERER: specialist physician
COMPARISON: usual care
DESIRED CHANGE: increase effective

\begin{tabular}{ll}
\hline Outcomes & CLINICAL: Intended: 30 -day mortality, LOS, and 30-day re-admission \\
\hline Notes & $\begin{array}{l}\text { FINANCIAL SUPPORT: this study was funded by the Deseret Foundation and HealthInsight, Salt Lake } \\
\text { City. The authors have no relevant conflicts of interest to report. }\end{array}$ \\
ADDITIONAL DATA: authors provided additional data
\end{tabular}

\section{Risk of bias}

\begin{tabular}{|c|c|c|}
\hline Bias & Authors' judgement & Support for judgement \\
\hline $\begin{array}{l}\text { Random sequence genera- } \\
\text { tion (selection bias) }\end{array}$ & High risk & CBA \\
\hline $\begin{array}{l}\text { Allocation concealment } \\
\text { (selection bias) }\end{array}$ & High risk & CBA \\
\hline $\begin{array}{l}\text { Blinding (performance } \\
\text { bias and detection bias) } \\
\text { All outcomes }\end{array}$ & High risk & CBA \\
\hline $\begin{array}{l}\text { Incomplete outcome data } \\
\text { (attrition bias) } \\
\text { All outcomes }\end{array}$ & Low risk & Electronic record linkage used. \\
\hline $\begin{array}{l}\text { Selective reporting (re- } \\
\text { porting bias) }\end{array}$ & Low risk & 30-day mortality was primary outcome. \\
\hline
\end{tabular}


Dean 2006 (Continued)

\begin{tabular}{lll} 
Other bias & Low risk & Objective primary outcome measure \\
\hline $\begin{array}{l}\text { Baseline Outcomes simi- } \\
\text { lar? }\end{array}$ & Low risk & Table 3 \\
\hline
\end{tabular}

Free of contamination? Low risk

NOT CLEAR, some hospitals had both intervention and control physicians. The 100,000 annual inpatient admissions of Intermountain Healthcare represent almost one-half of Utah hospital admissions. Intermountain Healthcare has an employed physician group and several non-Medicare health maintenance organisation insurance plans, but many non-employed physicians and nonhealth maintenance organisation patients also utilise its facilities. Non-affiliated physicians caring for patients at Intermountain Healthcare hospitals may have been influenced by guideline implementation at these hospitals.

Baseline characteristics $\quad$ Unclear risk $\quad$ Not stated
similar?

\section{Dempsey 1995}

\begin{tabular}{ll}
\hline Methods & STUDY DESIGN: ITS \\
& Risk of Bias: MEDIUM \\
\hline Participants & PROVIDERS: all physicians in the hospital \\
& PARTICIPANTS: all patients with clinical problem \\
CLINICAL PROBLEM: patients with nursing home-acquired pneumonia \\
SETTING: 1 hospital in the USA
\end{tabular}

FORMAT: no valid prescribing data. Audit and feedback; reminders; and educational meetings with dis-
semination of educational materials
DELIVERER: AMT
COMPARISON: usual care
DESIRED CHANGE: increase effective

\section{Outcomes}

CLINICAL: Intended: length of stay

FINANCIAL: charge per case of nursing home-acquired pneumonia

\begin{tabular}{ll}
\hline Notes & FINANCIAL SUPPORT: no information provided \\
& ADDITIONAL DATA: no response from authors to request for additional data
\end{tabular}

\section{Risk of bias}

\begin{tabular}{lll}
\hline Bias & Authors' judgement & Support for judgement \\
\hline $\begin{array}{l}\text { Intervention independent } \\
(\text { ITS })\end{array}$ & High risk & $\begin{array}{l}<1 \text { year data pre- and postintervention, so seasonal trends cannot be exclud- } \\
\text { ed. }\end{array}$ \\
\hline $\begin{array}{l}\text { Analysed appropriately } \\
\text { (ITS)? }\end{array}$ & Low risk & Re-analysed \\
\hline $\begin{array}{l}\text { Shape of effect pre-speci- } \\
\text { fied (ITS) ? }\end{array}$ & Low risk & Point of intervention was point of analysis. \\
\hline
\end{tabular}


Dempsey 1995 (Continued)

Unlikely to affect data col- Low risk Patient administration system lection (ITS) ?

Knowledge of the alloca- Low risk Patient administration system
tion adequately prevented(ITS)?

Incomplete outcome data $\quad$ Unclear risk $\quad$ No explicit statement about complete follow-up
addressed (ITS)?

Free of selected reporting Low risk

(ITS) ?

Free of other bias (ITS)? Low risk

Ding 2013

\begin{tabular}{ll} 
Methods & STUDY DESIGN: RCT \\
& Risk of Bias: HIGH \\
\hline Participants & PROVIDERS: all physicians \\
& PARTICIPANTS: 78 patients with acute exacerbations of idiopathic pulmonary fibrosis (39 intervention, \\
& 39 control) \\
CLINICAL PROBLEM: management of acute exacerbations \\
SETTING: 1 hospital in China
\end{tabular}

Interventions $\quad$ FORMAT, Interventions: structural - introduction of procalcitonin testing with decision support algorithm

Intervention Functions: enablement, environmental restructuring

DELIVERER: respiratory physicians

COMPARISON: usual care

DESIRED CHANGE: decrease excessive

POWER CALCULATION: no information

PRESCRIBING: Exposure: \% participants treated and duration of antibiotic treatment
CLINICAL: Balancing: mortality, length of stay, duration of mechanical ventilation

CLINICAL: Balancing: mortality, length of stay, duration of mechanical ventilation

Notes $\quad$ FINANCIAL SUPPORT: Funding: none. Competing Interests: none declared

ADDITIONAL DATA: no response to request from authors

\begin{tabular}{lll}
\hline \multicolumn{1}{l}{ Risk of bias } & \\
\hline Bias & Authors' judgement & Support for judgement \\
\hline $\begin{array}{l}\text { Random sequence genera- } \\
\text { tion (selection bias) }\end{array}$ & Low risk & Computer-generated numbers \\
\hline $\begin{array}{l}\text { Allocation concealment } \\
\text { (selection bias) }\end{array}$ & Low risk & Computer-generated numbers \\
\hline $\begin{array}{l}\text { Blinding (performance } \\
\text { bias and detection bias) }\end{array}$ & High risk & No blinding \\
\hline
\end{tabular}


Ding 2013 (Continued)

All outcomes

\begin{tabular}{lll}
\hline $\begin{array}{l}\text { Incomplete outcome data } \\
\text { (attrition bias) } \\
\text { All outcomes }\end{array}$ & Low risk & Outcomes reported on all participants. \\
\hline $\begin{array}{l}\text { Selective reporting (re- } \\
\text { porting bias) }\end{array}$ & Low risk & Outcomes reported on all participants. \\
\hline Other bias & High risk & No power calculation \\
\hline $\begin{array}{l}\text { Baseline Outcomes simi- } \\
\text { lar? }\end{array}$ & Unclear risk & No data \\
\hline $\begin{array}{l}\text { Free of contamination? } \\
\text { Baseline characteristics }\end{array}$ & Low risk risk & Procalcitonin results only available for intervention participants. \\
\hline similar? & & Table 1 \\
\hline
\end{tabular}

\section{Dranitsaris 2001}

\begin{tabular}{ll}
\hline Methods & STUDY DESIGN: RCT \\
& Risk of Bias: HIGH \\
\hline Participants & PROVIDERS: physicians assigned to the 7 services \\
& PARTICIPANTS: 309 patients with clinical problem (162 intervention, 147 control) \\
CLINICAL PROBLEM: adult patients with infections requiring IV cefotaxime \\
SETTING: 2 hospitals in Canada
\end{tabular}

Interventions $\quad$ FORMAT: Interventions: educational outreach - review and recommend change

Intervention Functions: enablement, persuasion

DELIVERER: pharmacist

COMPARISON: usual care

DESIRED CHANGE: decrease excessive

POWER CALCULATION: yes, 330 participants, 165 in each group. Details in Appendix 3

\begin{tabular}{ll}
\hline Outcomes & PRESCRIBING: Choice: percentage of cefotaxime prescriptions that were consistent with guideline for \\
both indication and dosage \\
SECONDARY: mean duration of therapy and cost per treatment course
\end{tabular}

Notes FINANCIAL SUPPORT: no information provided

ADDITIONAL DATA: no response from authors to request for additional data

\section{Risk of bias}

\begin{tabular}{lll}
\hline Bias & Authors' judgement & Support for judgement \\
\hline $\begin{array}{l}\text { Random sequence genera- } \\
\text { tion (selection bias) }\end{array}$ & Low risk & "Randomised on a one to one basis via a computer generated list" \\
\hline $\begin{array}{l}\text { Allocation concealment } \\
\text { (selection bias) }\end{array}$ & Low risk & $\begin{array}{l}\text { Randomisations carried out in central pharmacy and "telephone on a consec- } \\
\text { utive basis". }\end{array}$ \\
\hline
\end{tabular}


Dranitsaris 2001 (Continued)

Blinding (performance High risk Not done, acknowledged as a limitation by authors on page 179. bias and detection bias)

All outcomes

\begin{tabular}{|c|c|c|}
\hline $\begin{array}{l}\text { Incomplete outcome data } \\
\text { (attrition bias) } \\
\text { All outcomes }\end{array}$ & Low risk & See Table 3; all participants included \\
\hline $\begin{array}{l}\text { Selective reporting (re- } \\
\text { porting bias) }\end{array}$ & Low risk & See Table 3; all participants included \\
\hline Other bias & Low risk & \\
\hline $\begin{array}{l}\text { Baseline Outcomes simi- } \\
\text { lar? }\end{array}$ & Unclear risk & No data \\
\hline Free of contamination? & High risk & $\begin{array}{l}\text { Control participants were managed by the same physicians as intervention } \\
\text { participants. }\end{array}$ \\
\hline $\begin{array}{l}\text { Baseline characteristics } \\
\text { similar? }\end{array}$ & Low risk & Table 1 \\
\hline
\end{tabular}

Dua 2014

\begin{tabular}{ll}
\hline Methods & STUDY DESIGN: ITS \\
& Risk of Bias: HIGH \\
\hline Participants & PROVIDERS: all physicians involved in vascular surgery \\
& PARTICIPANTS: all patients undergoing vascular surgery \\
& CLINICAL PROBLEM: surgical-site infection following vascular surgery \\
& SETTING: USA, multiple hospitals (stratified, random sample of $20 \%$ of all non-federal inpatient hospi- \\
tal admissions throughout the USA)
\end{tabular}

Outcomes PRESCRIBING: no data

CLINICAL: inpatient surgical-site infection

Notes FINANCIAL SUPPORT: no funding. Competing Interests: none declared

ADDIDIONAL DATA: authors responded to request but had no additional relevant data

\section{Risk of bias}

\begin{tabular}{lll}
\hline Bias & Authors' judgement & Support for judgement \\
\hline $\begin{array}{l}\text { Intervention independent } \\
\text { (ITS)? }\end{array}$ & Unclear risk & No data about antibiotic prescribing \\
\hline
\end{tabular}


Dua 2014 (Continued)

\begin{tabular}{lll}
$\begin{array}{l}\text { Analysed appropriately } \\
\text { (ITS) ? }\end{array}$ & Low risk & Re-analysed \\
\hline $\begin{array}{l}\text { Shape of effect pre-speci- } \\
\text { fied (ITS) ? }\end{array}$ & Low risk & Point of intervention was point of analysis.
\end{tabular}

fied (ITS) ?

\begin{tabular}{|c|c|c|}
\hline $\begin{array}{l}\text { Unlikely to affect data col- } \\
\text { lection (ITS)? }\end{array}$ & Unclear risk & $\begin{array}{l}\text { Outcome relied on ICD discharge coding to identify surgical-site infection, may } \\
\text { have been influenced by financial incentives to meet SCIP targets. }\end{array}$ \\
\hline
\end{tabular}

lection (ITS) ?

Electronic outcome data

Knowledge of the alloca- Low risk $\quad$ Electronic outcome data
tion adequately prevent-

ed(ITS)?

\begin{tabular}{ll}
\hline $\begin{array}{l}\text { Incomplete outcome data } \\
\text { addressed (ITS) ? }\end{array}$ & $\begin{array}{l}\text { Outcome data were restricted to inpatient coding, but most surgical-site infec- } \\
\text { tions likely to present postdischarge. }\end{array}$ \\
\hline
\end{tabular}

\begin{tabular}{lll}
\hline $\begin{array}{l}\text { Free of selected reporting } \\
\text { (ITS) ? }\end{array}$ & Low risk & Electronic outcome data \\
\hline Free of other bias (ITS) ? & Low risk & $>1$ year of pre- and postintervention data \\
\hline
\end{tabular}

\section{Dull 2008}

\begin{tabular}{|c|c|}
\hline Methods & $\begin{array}{l}\text { STUDY DESIGN: ITS } \\
\text { Risk of Bias: MEDIUM }\end{array}$ \\
\hline Participants & $\begin{array}{l}\text { PROVIDERS: all physicians, pharmacists, and nurses in surgical department } \\
\text { PARTICIPANTS: all patients undergoing elective surgery } \\
\text { CLINICAL PROBLEM: choice, timing, and duration of antibiotic prophylaxis } \\
\text { SETTING: } 7 \text { hospitals in the USA }\end{array}$ \\
\hline Interventions & $\begin{array}{l}\text { FORMAT: Interventions: audit and feedback; educational meetings with dissemination of educational } \\
\text { materials; educational outreach by academic detailing; reminders (physical, posters, intranet, and fax- } \\
\text { es to physicians) } \\
\text { Intervention Functions: education, enablement, environmental restructuring, persuasion } \\
\text { DELIVERER: AMT } \\
\text { COMPARISON: usual care } \\
\text { DESIRED CHANGE: decrease excessive }\end{array}$ \\
\hline
\end{tabular}

\begin{tabular}{ll}
\hline Outcomes & PRESCRIBING: Exposure: \% participants with prophylaxis discontinued within 24 h of surgery \\
\hline Notes & FINANCIAL SUPPORT: no information provided \\
& ADDITIONAL DATA: no response from authors to request for additional data \\
\hline
\end{tabular}

\section{Risk of bias}

\begin{tabular}{lll}
\hline Bias & Authors' judgement & Support for judgement \\
\hline $\begin{array}{l}\text { Intervention independent } \\
\text { (ITS) ? }\end{array}$ & Low risk & \\
\hline $\begin{array}{l}\text { Analysed appropriately } \\
\text { (ITS)? }\end{array}$ & Low risk & Re-analysed \\
\hline
\end{tabular}


Dull 2008 (Continued)

Shape of effect pre-speci- Low risk Point of intervention was point of analysis. fied (ITS) ?

Unlikely to affect data col- Low risk Electronic outcome data lection (ITS) ?

Knowledge of the alloca- Low risk Electronic outcome data
tion adequately prevent-
ed(ITS)?

Incomplete outcome data Low risk $\quad$ Electronic outcome data
addressed (ITS) ?

\begin{tabular}{lll}
\hline $\begin{array}{l}\text { Free of selected reporting } \\
\text { (ITS) ? }\end{array}$ & Low risk & Electronic outcome data \\
\hline Free of other bias (ITS) ? & High risk & 10 months' pre- and 12 months' postintervention data \\
\hline
\end{tabular}

\section{Duvoisin 2014}

\begin{tabular}{ll}
\hline Methods & STUDY DESIGN: unintended consequences, cohort study \\
& Risk of Bias: LOW \\
\hline Participants & PROVIDERS: all physicians \\
& PARTICIPANTS: 222 infants with early-onset neonatal sepsis \\
& CLINICAL PROBLEM: early onset sepsis \\
& SETTING: 1 hospital in Switzerland \\
\hline Interventions & FORMAT, Interventions: restrictive by review and make change targeted at ordering of CBC and CRP \\
& tests \\
& Intervention Functions: restriction \\
& DELIVERER: specialist physician (ID) \\
COMPARISON: usual care & DESIRED CHANGE: decrease excessive use of diagnostic tests
\end{tabular}

Outcomes UNINTENDED CONSEQUENCES: time to first antibiotic dose and complications (requirement for catecholamine treatment and/or mechanical ventilation, meningitis, or death)

Notes

ROBINS-I RISK OF BIAS CRITERIA:

1. Confounding: Low, confounding unlikely

2. Selection of participants into the study: Low, selection into the study unrelated to intervention or outcome

3. Measurement classification of interventions: Low, intervention status well defined, recorded at the time of intervention and unaffected by knowledge of the outcome

4. Deviations from intended interventions: Low, the study demonstrated large reduction in CBC (30\%) and CRP (91\%)

5. Missing data: Low, outcome data and intervention status complete on all 222 participants

6. Measurement of outcome: Low, outcome measure objective and unaffected by intervention status

7. Selection of the reported result: Low, reported outcomes predefined and measured from routine data 
Duvoisin 2014 (Continued)

FINANCIAL SUPPORT: Funding: SICPA Foundation and the Société Académique Vaudoise. Competing Interests: none declared

ADDITIONAL DATA: email from authors with additional data about intervention

Elligsen 2012

Methods STUDY DESIGN: CITS

\section{Risk of Bias: MEDIUM}

PROVIDERS: all physicians in the critical care team
PARTICIPANTS: all critical care patients in the hospits

CLINICAL PROBLEM: decrease use of broad-spectrum antibiotics in critical care patients

SETTING: 1 tertiary-care centre in Ontario, Canada

Interventions $\quad$ FORMAT: Interventions: educational outreach by review and recommend change

Intervention Functions: education, enablement, persuasion

DELIVERER: AMT

COMPARISON: usual care

DESIRED CHANGE: decrease excessive

\begin{tabular}{ll}
\hline Outcomes & PRESCRIBING: Choice: use of targeted broad-spectrum antibiotics (days of therapy/1000 OBD) \\
\hline Notes & FINANCIAL SUPPORT: Funding: Canadian Institutes of Health Research, Ontario Ministry of Health, and \\
& Long Term Care Academic Health Services Centre Innovation Award. Competing Interests: none de- \\
& clared \\
& ADDITIONAL DATA: no response from authors to request for additional data
\end{tabular}

\section{Risk of bias}

\begin{tabular}{lll}
\hline Bias & Authors' judgement & Support for judgement \\
\hline $\begin{array}{l}\text { Intervention independent } \\
\text { (ITS) }\end{array}$ & Low risk & Done. October to August both pre- and postintervention \\
\hline $\begin{array}{l}\text { Analysed appropriately } \\
\text { (ITS) ? }\end{array}$ & Low risk & Re-analysed \\
\hline
\end{tabular}

Shape of effect pre-speci- Low risk Done, point of analysis was point of intervention.
fied (ITS)?
fied (ITS) ?

\begin{tabular}{lll}
$\begin{array}{l}\text { Unlikely to affect data col- } \\
\text { lection (ITS) ? }\end{array}$ & Low risk & $\begin{array}{l}\text { Done, data were from routine systems and unlikely to change over study peri- } \\
\text { od. }\end{array}$ \\
\hline $\begin{array}{l}\text { Knowledge of the alloca- } \\
\text { tion adequately prevent- } \\
\text { ed(ITS)? }\end{array}$ & High risk & $\begin{array}{l}\text { No, the intervention was open to all participants and prescribers, difficult to } \\
\text { conceal. }\end{array}$
\end{tabular}
ed(ITS)?

Incomplete outcome data Low risk
addressed (ITS)?
addressed (ITS) ?
Done, data were from routine systems and unlikely to change over study period. 
Elligsen 2012 (Continued)

Free of selected reporting Low risk Done, Figures 1 and 2

(ITS) ?

Free of other bias (ITS) ? Low risk Done, no other apparent biases

Esposito 2011

\begin{tabular}{ll}
\hline Methods & STUDY DESIGN: RCT \\
& Risk of Bias: MEDIUM \\
\hline Participants & PROVIDERS: all paediatric physicians \\
& PARTICIPANTS: 319 children with pneumonia were enrolled and randomly assigned $1: 1$ to the treat- \\
& ment groups, but, as consent was withdrawn during the study in 9 cases (5 intervention and 4 control), \\
the final analysis was based on 310 children (155 intervention and control) \\
CLINICAL PROBLEM: children hospitalised with community-acquired pneumonia \\
SETTING: 1 university hospital in Italy
\end{tabular}

Interventions $\quad$ FORMAT: Interventions: structural - rapid testing for procalcitonin and decision support algorithm Intervention Functions: enablement, environmental restructuring

DELIVERER: AMT

COMPARISON: usual care

DESIRED CHANGE: decrease excessive

POWER CALCULATION: yes, 76 participants in each group. Details in Appendix 3

Outcomes $\quad$ PRESCRIBING: Exposure: $\%$ started on antibiotics and $\%$ children treated for $>10$ days

CLINICAL: length of stay, duration of fever, antibiotic adverse effects

Notes $\quad$ FINANCIAL SUPPORT: Funding: Italian Ministry of Health (Bando Giovani Ricercatori 2007). Competing

Interests: none declared

ADDITIONAL DATA: no response from authors to request for additional data

\section{Risk of bias}

\begin{tabular}{lll}
\hline Bias & Authors' judgement & Support for judgement \\
\hline $\begin{array}{l}\text { Random sequence genera- } \\
\text { tion (selection bias) }\end{array}$ & Low risk & Computer generated \\
\hline $\begin{array}{l}\text { Allocation concealment } \\
\text { (selection bias) }\end{array}$ & Low risk & Sealed envelopes \\
\hline $\begin{array}{l}\text { Blinding (performance } \\
\text { bias and detection bias) }\end{array}$ & Low risk & PCT levels only reported on intervention participants. \\
\hline $\begin{array}{l}\text { All outcomes } \\
\begin{array}{l}\text { Incomplete outcome data } \\
\text { (attrition bias) }\end{array}\end{array}$ & Low risk & $\begin{array}{l}\text { 319 randomised, consent was withdrawn during the study in 9 cases (3\% par- } \\
\text { ticipants, } 5 \text { in the PCT group and 4 in the control group). Outcomes reported } \\
\text { on all participants (Tables 2-3). All 310 children came to the planned follow-up } \\
\text { visits. }\end{array}$ \\
\hline $\begin{array}{l}\text { Selective reporting (re- } \\
\text { porting bias) }\end{array}$ & Low risk & $\begin{array}{l}\text { Outcomes reported on all 310 participants (Tables 2-3). All 310 children came } \\
\text { to the planned follow-up visits. }\end{array}$ \\
\hline
\end{tabular}


Esposito 2011 (Continued)

\begin{tabular}{lll} 
Other bias & Low risk & \\
\hline $\begin{array}{l}\text { Baseline Outcomes simi- } \\
\text { lar? }\end{array}$ & Unclear risk & No data \\
\hline Free of contamination? & Low risk & PCT levels only reported on intervention participants. \\
\hline $\begin{array}{l}\text { Baseline characteristics } \\
\text { similar? }\end{array}$ & Low risk & Table 1 \\
\hline
\end{tabular}

\section{Everitt 1990}

\begin{tabular}{ll}
\hline Methods & STUDY DESIGN: ITS \\
& Risk of Bias: MEDIUM \\
\hline Participants & PROVIDERS: physicians in Obstetrics \& Gynaecology \\
& PARTICIPANTS: patients (women) with clinical problem \\
& CLINICAL PROBLEM: Caesarean section \\
& SETTING: 1 university hospital in the USA
\end{tabular}

Interventions

FORMAT: Interventions: educational meetings with dissemination of guidelines; reminders (circumstantial, on the structured order form for intravenous antibiotics, which was triggered for every order for IV antibiotics); restriction by expert approval and by removal

Intervention Functions: education, enablement, environmental restructuring, restriction

DELIVERER: department physician

COMPARISON: usual care

DESIRED CHANGE: decrease excessive

\begin{tabular}{|c|c|}
\hline Outcomes & $\begin{array}{l}\text { PRESCRIBING: relative use of cefazolin or cefoxitin in Caesarean sections that received }<5 \mathrm{~g} \text { of either } \\
\text { drug perioperatively } \\
\text { FINANCIAL: estimated financial savings }\end{array}$ \\
\hline Notes & $\begin{array}{l}\text { FINANCIAL SUPPORT: Funding: Beth Israel Hospital, Boston, Massachusetts and Fund for Cooperative } \\
\text { Innovation of Blue Cross of Massachusetts and the Massachusetts Hospital Association. Competing In- } \\
\text { terests: no information provided }\end{array}$ \\
\hline & ADDITIONAL DATA: no response from authors to request for additional data \\
\hline
\end{tabular}

\section{Risk of bias}

\begin{tabular}{lll}
\hline Bias & Authors' judgement & Support for judgement \\
\hline $\begin{array}{l}\text { Intervention independent } \\
\text { (ITS) }\end{array}$ & High risk & Only 9 months pre-intervention data, so secular/seasonal changes possible. \\
\hline $\begin{array}{l}\text { Analysed appropriately } \\
\text { (ITS)? }\end{array}$ & Low risk & Done in original paper, segmented regression analysis \\
\hline $\begin{array}{l}\text { Shape of effect pre-speci- } \\
\text { fied (ITS) ? }\end{array}$ & Low risk & $\begin{array}{l}\text { Done, intended effect was decrease in primary outcome, and point of analysis } \\
\text { was point of intervention. }\end{array}$ \\
\hline $\begin{array}{l}\text { Unlikely to affect data col- } \\
\text { lection (ITS) ? }\end{array}$ & Low risk & $\begin{array}{l}\text { Done, data were from routine systems and unlikely to change over study peri- } \\
\text { od. }\end{array}$ \\
\hline
\end{tabular}


Everitt 1990 (Continued)

Knowledge of the alloca- Low risk Done, data were from routine systems and unlikely to change over study perition adequately preventod. ed(ITS)?

\begin{tabular}{lll}
$\begin{array}{l}\text { Incomplete outcome data } \\
\text { addressed (ITS) ? }\end{array}$ & Low risk & $\begin{array}{l}\text { Done, data were from routine systems and unlikely to change over study peri- } \\
\text { od. }\end{array}$ \\
\hline $\begin{array}{l}\text { Free of selected reporting } \\
\text { (ITS) ? }\end{array}$ & Low risk & $\begin{array}{l}\text { Done, data were from routine systems and unlikely to change over study peri- } \\
\text { od. }\end{array}$
\end{tabular}

Free of other bias (ITS)? Low risk Antibiotic costs adjusted to 1986 prices over the whole study period.

Farinas 2012

\begin{tabular}{ll}
\hline Methods & STUDY DESIGN: RCT \\
& Risk of Bias: HIGH \\
\hline Participants & PROVIDERS: all physicians in the hospital \\
& PARTICIPANTS: 1185 patients receiving at least 3 days of IV antibiotics (571 intervention, 614 control) \\
& CLINICAL PROBLEM: adherence to recommendations for change of therapy \\
& SETTING: 1 university hospital in Spain
\end{tabular}

Interventions FORMAT: no valid prescribing outcome data. Educational outreach (review and recommend change) DELIVERER: specialist (ID) physicians

COMPARISON: usual care

DESIRED CHANGE: increase appropriate antibiotic treatment

SAMPLE SIZE: 571 intervention, 614 control

POWER CALCULATION: no power calculation. No adjustment for intracluster correlation

Outcomes PRESCRIBING: Choice but no valid outcome data (\% adherence with recommendations, but no data about antibiotic use in terms of choice, route, or duration of treatment)

CLINICAL: Balancing: length of stay and \% treatment failure

Notes

FINANCIAL SUPPORT: Funding: Fondo de Investigaciones Sanitarias (FIS PI06/90094), and Instituto de Formación e Investigación Marqués de Valdecilla (IFIMAV) (API 06/03). Competing Interests: none declared

ADDITIONAL DATA: no response from authors to request for additional data

\section{Risk of bias}

\begin{tabular}{lll}
\hline Bias & Authors' judgement & Support for judgement \\
\hline $\begin{array}{l}\text { Random sequence genera- } \\
\text { tion (selection bias) }\end{array}$ & Low risk & Computer \\
\hline $\begin{array}{l}\text { Allocation concealment } \\
\text { (selection bias) }\end{array}$ & High risk & $\begin{array}{l}\text { Randomisation stratified by clinical units, not blinded. Participants were ran- } \\
\text { domised by groups (stratified randomisation by clinical units) to interven- } \\
\text { tion or non-intervention using the EPIDAT 3.1 programme (Dirección Xeral de } \\
\text { Saúde Pública, Xunta de Galicia \& Organización Panamericana de la Salud. } \\
\text { Santiago de Compostela, Coruña, Spain, 2003). }\end{array}$ \\
\hline
\end{tabular}


Farinas 2012 (Continued)

Blinding (performance $\quad$ High risk Randomisation not blinded
bias and detection bias)

\begin{tabular}{|c|c|c|}
\hline $\begin{array}{l}\text { Incomplete outcome data } \\
\text { (attrition bias) } \\
\text { All outcomes }\end{array}$ & Low risk & Outcomes reported on all participants. \\
\hline $\begin{array}{l}\text { Selective reporting (re- } \\
\text { porting bias) }\end{array}$ & Unclear risk & The primary outcome (clinical failure) was complex and not entirely objective. \\
\hline Other bias & High risk & Unit of analysis error, no adjustment for intracluster correlation \\
\hline $\begin{array}{l}\text { Baseline Outcomes simi- } \\
\text { lar? }\end{array}$ & Unclear risk & No data \\
\hline Free of contamination? & Low risk & $\begin{array}{l}19 \text { participants in the control group were excluded because they had ID con- } \\
\text { sultation. }\end{array}$ \\
\hline $\begin{array}{l}\text { Baseline characteristics } \\
\text { similar? }\end{array}$ & Low risk & Table 1 \\
\hline
\end{tabular}

Fine 2003

\begin{tabular}{ll}
\hline Methods & STUDY DESIGN: cluster RCT, service level \\
& Risk of bias: HIGH \\
\hline Participants & PROVIDERS: all physicians in hospitals \\
& PARTICIPANTS: 608 patients with community-acquired pneumonia (263 intervention, 325 control), 7 \\
& clusters (sites) \\
& CLINICAL PROBLEM: duration of IV antibiotic therapy and LOS \\
& SETTING: 7 nonprofit hospitals in Pittsburgh, Pennsylvania, USA
\end{tabular}

Interventions

FORMAT: Interventions: dissemination of educational materials, educational outreach by review and recommend change; reminders (circumstantial, physical, detail sheets in physician notes for patients with community-acquired pneumonia and verbal, telephone calls); restrictive; structural

Intervention Functions: education, enablement, environmental restructuring, persuasion, restriction

DELIVERER: AMT

COMPARISON: usual care

DESIRED CHANGE: decrease excessive

POWER CALCULATION: yes, 600 participants in total. Details in Appendix 3

\begin{tabular}{ll}
\hline Outcomes & PRESCRIBING: Choice: duration of IV antibiotic therapy \\
& CLINICAL: intended clinical outcomes, mortality, re-admission \\
\hline Notes & $\begin{array}{l}\text { FINANCIAL SUPPORT: Funding: Agency for Healthcare Research and Quality and the National Institute } \\
\text { of Allergy and Infectious Diseases (HS08282), Robert Wood Johnson Foundation. Competing Interests: } \\
\text { no statement }\end{array}$
\end{tabular}


Fine 2003 (Continued)

ADDITIONAL DATA: authors provided additional data

\section{Risk of bias}

\begin{tabular}{lll}
\hline Bias & Authors' judgement & Support for judgement \\
\hline $\begin{array}{l}\text { Random sequence genera- } \\
\text { tion (selection bias) }\end{array}$ & Unclear risk & $\begin{array}{l}\text { Physician groups were randomly assigned after stratification for practice type, } \\
\text { group size, and patient volume, but details not clear. }\end{array}$ \\
\hline
\end{tabular}

\section{Allocation concealment High risk}

(selection bias)

Blinding (performance Low risk
bias and detection bias)
All outcomes

\begin{tabular}{|c|c|c|}
\hline $\begin{array}{l}\text { Incomplete outcome data } \\
\text { (attrition bias) } \\
\text { All outcomes }\end{array}$ & Low risk & \\
\hline $\begin{array}{l}\text { Selective reporting (re- } \\
\text { porting bias) }\end{array}$ & Low risk & \\
\hline Other bias & Low risk & \\
\hline $\begin{array}{l}\text { Baseline Outcomes simi- } \\
\text { lar? }\end{array}$ & Unclear risk & No data about LOS prior to intervention \\
\hline Free of contamination? & Low risk & \\
\hline $\begin{array}{l}\text { Baseline characteristics } \\
\text { similar? }\end{array}$ & Low risk & \\
\hline
\end{tabular}

\section{Fitzpatrick 2008}

\begin{tabular}{ll}
\hline Methods & STUDY DESIGN: ITS \\
& Risk of Bias: MEDIUM \\
\hline Participants & PROVIDERS: all physicians in the hospital \\
PARTICIPANTS: all patients in the hospital \\
CLINICAL PROBLEM: prescribing of cefuroxime and quinolones \\
SETTING: 1 hospital in the UK
\end{tabular}

Interventions $\quad$ FORMAT: Interventions: dissemination of guideline

Intervention Functions: education

DELIVERER: pharmacist

COMPARISON: usual care

DESIRED CHANGE: decrease excessive

\begin{tabular}{ll}
\hline Outcomes & PRESCRIBING: Choice: use of cefuroxime and ciprofloxacin (DDD/Finished Consultant Episode ratio) \\
\hline Notes & FINANCIAL SUPPORT: no information provided \\
\hline
\end{tabular}


Fitzpatrick 2008 (Continued)

ADDITIONAL DATA: no response from authors to request for additional data

\section{Risk of bias}

\begin{tabular}{|c|c|c|}
\hline Bias & Authors' judgement & Support for judgement \\
\hline $\begin{array}{l}\text { Intervention independent } \\
\text { (ITS)? }\end{array}$ & Unclear risk & No mention of any other changes, although little information given. \\
\hline $\begin{array}{l}\text { Analysed appropriately } \\
\text { (ITS)? }\end{array}$ & Low risk & Re-analysed \\
\hline $\begin{array}{l}\text { Shape of effect pre-speci- } \\
\text { fied (ITS)? }\end{array}$ & Low risk & Done. Intervention point was clear. \\
\hline $\begin{array}{l}\text { Unlikely to affect data col- } \\
\text { lection (ITS)? }\end{array}$ & Low risk & $\begin{array}{l}\text { Done, data were from routine systems and unlikely to change over study peri- } \\
\text { od. }\end{array}$ \\
\hline $\begin{array}{l}\text { Knowledge of the alloca- } \\
\text { tion adequately prevent- } \\
\text { ed(ITS)? }\end{array}$ & Low risk & Done. Outcomes are objective. \\
\hline $\begin{array}{l}\text { Incomplete outcome data } \\
\text { addressed (ITS)? }\end{array}$ & Low risk & $\begin{array}{l}\text { Done, data were from routine systems and unlikely to change over study peri- } \\
\text { od. }\end{array}$ \\
\hline $\begin{array}{l}\text { Free of selected reporting } \\
\text { (ITS)? }\end{array}$ & Low risk & Done. Figures 1 and 2 \\
\hline Free of other bias (ITS) ? & Low risk & Done. No other bias apparent. \\
\hline
\end{tabular}

Fowler 2007

\begin{tabular}{ll}
\hline Methods & STUDY DESIGN: ITS \\
& Risk of Bias: MEDIUM \\
\hline Participants & PROVIDERS: physicians in the hospital \\
& CLINICAL PROBLEM: Clostridium difficile infection in the elderly \\
& SETTING: 3 acute medical wards for the elderly in 1 university hospital in the UK \\
\hline Interventions & FORMAT: Interventions: audit and feedback, dissemination of guideline; reminders (physical, laminat- \\
& ed pocket version of guideline) \\
Intervention Functions: education, enablement, environmental restructuring & DELIVERER: AMT \\
& COMPARISON: usual care \\
& DESIRED CHANGE: reduce inappropriate
\end{tabular}

Outcomes

PRESCRIBING: Choice: monthly use of target antibiotics

MICROBIAL: monthly count of cases of CDI 
Fowler 2007 (Continued) Notes
FINANCIAL SUPPORT: no funding. Competing Interests: none declared

ADDITIONAL DATA: email response from authors but no additional data

Microbial Risk of Bias LOW: Planned intervention: Low Case definition: Low, National definition. Other infection control measures: Low

\section{Risk of bias}

\begin{tabular}{lll}
\hline Bias & Authors' judgement & Support for judgement \\
\hline $\begin{array}{l}\text { Intervention independent } \\
\text { (ITS) ? }\end{array}$ & High risk & Ongoing audit and feedback \\
\hline $\begin{array}{l}\text { Analysed appropriately } \\
\text { (ITS) ? }\end{array}$ & Low risk & Re-analysed \\
\hline $\begin{array}{l}\text { Shape of effect pre-speci- } \\
\text { fied (ITS) ? }\end{array}$ & Low risk & Done. Point of analysis is point of the intervention. \\
\hline $\begin{array}{l}\text { Unlikely to affect data col- } \\
\text { lection (ITS) ? }\end{array}$ & Low risk & Done, data were from routine systems and unlikely to change over study peri- \\
\hline $\begin{array}{l}\text { Knowledge of the alloca- } \\
\text { tion adequately prevent- } \\
\text { ed(ITS)? }\end{array}$ & High risk & No, not possible \\
\hline $\begin{array}{l}\text { Incomplete outcome data } \\
\text { addressed (ITS) ? }\end{array}$ & Low risk & \\
\hline $\begin{array}{l}\text { Free of selected reporting } \\
\text { (ITS) ? }\end{array}$ & Low risk & Done, data were from routine systems so unlikely to be incomplete. \\
\hline \begin{tabular}{l} 
Free of other bias (ITS) ? \\
\hline
\end{tabular} & Low risk & Done, Figures 3 and 4 \\
\hline
\end{tabular}

\section{Franz 2004}

\begin{tabular}{ll}
\hline Methods & STUDY DESIGN: RCT \\
& Risk of Bias: MEDIUM \\
\hline
\end{tabular}

Participants PROVIDERS: physicians in neonatal units

PARTICIPANTS: 1291 neonates < 72 hours of age were randomised (656 intervention, 635 control)

CLINICAL PROBLEM: suspected bacterial infection

SETTING: 8 centres in 5 countries (Australia, Austria, Belgium, Germany, Sweden)

Interventions

FORMAT, Interventions: dissemination of guideline; structural, introduction of testing for C-reactive protein and interleukin-8 with decision support algorithm Intervention Functions: education, enablement, environmental restructuring

DELIVERER: department physician

COMPARISON: usual care

DESIRED CHANGE: decrease excessive 
Franz 2004 (Continued)

POWER CALCULATION: yes, total of 1150 participants. Details in Appendix 3

Outcomes PRESCRIBING: Exposure: number of newborn infants who received antibiotic therapy

Notes

FINANCIAL SUPPORT: Funding: grant P.575 from the Center for Applied Clinical Studies of the University of Ulm and Swedish Research Council. DPC (Los Angeles, CA) provided the Immulite automated analysers and the kits for determination of IL-8 and sponsored the initial meeting of the investigators.

Competing Interests: no information

ADDITIONAL DATA: no response from authors to request for additional data

\section{Risk of bias}

\begin{tabular}{|c|c|c|}
\hline Bias & Authors' judgement & Support for judgement \\
\hline $\begin{array}{l}\text { Random sequence genera- } \\
\text { tion (selection bias) }\end{array}$ & Low risk & $\begin{array}{l}\text { "Randomly assigned to } 1 \text { or } 2 \text { diagnostic algorithms using sealed opaque en- } \\
\text { velopes" }\end{array}$ \\
\hline $\begin{array}{l}\text { Allocation concealment } \\
\text { (selection bias) }\end{array}$ & Low risk & \\
\hline $\begin{array}{l}\text { Blinding (performance } \\
\text { bias and detection bias) } \\
\text { All outcomes }\end{array}$ & Low risk & Done, IL- 8 results were only provided to physicians in the intervention group. \\
\hline $\begin{array}{l}\text { Incomplete outcome data } \\
\text { (attrition bias) } \\
\text { All outcomes }\end{array}$ & Low risk & \\
\hline $\begin{array}{l}\text { Selective reporting (re- } \\
\text { porting bias) }\end{array}$ & Low risk & \\
\hline Other bias & Low risk & \\
\hline $\begin{array}{l}\text { Baseline Outcomes simi- } \\
\text { lar? }\end{array}$ & High risk & No data \\
\hline Free of contamination? & Low risk & \\
\hline $\begin{array}{l}\text { Baseline characteristics } \\
\text { similar? }\end{array}$ & Low risk & \\
\hline
\end{tabular}

\section{Fraser 1997}

\begin{tabular}{ll}
\hline Methods & STUDY DESIGN: RCT \\
& Risk of Bias: HIGH \\
\hline Participants & PROVIDERS: medical, surgery, intensive care, haematology, and oncology \\
& PARTICIPANTS: patients with the clinical problem \\
& CLINICAL PROBLEM: adult inpatients receiving 1 or more of 10 designated parenteral antibiotics for 3 \\
or more consecutive days \\
SETTING: single teaching hospital in the USA
\end{tabular}


Fraser 1997 (Continued)

DELIVERER: AMT

COMPARISON: usual care

DESIRED CHANGE: decrease excessive

SAMPLE SIZE CALCULATION: no information

Outcomes $\quad$ PRESCRIBING: Choice: days receiving IV antibiotic therapy per participant, DDDs of IV antibiotics per
participant. Antibiotic charges (USD) per participant

CLINICAL: Balancing: clinical response at 3 days after completion of antibiotics; retreatment with antibiotics within 7 days; inpatient mortality; re-admission within 30 days of discharge

FINANCIAL: savings on drug costs in USD

Notes

FINANCIAL SUPPORT: Funding: commercial (Bayer Pharmaceuticals) and the Maine Medical Center Research Committee. Competing Interests: no information

ADDITIONAL DATA: no response from authors to request for additional data

\begin{tabular}{|c|c|c|}
\hline \multicolumn{3}{|l|}{ Risk of bias } \\
\hline Bias & Authors' judgement & Support for judgement \\
\hline $\begin{array}{l}\text { Random sequence genera- } \\
\text { tion (selection bias) }\end{array}$ & Low risk & $\begin{array}{l}\text { "Patients randomised ... using an unblocked computer generated random } \\
\text { number table" }\end{array}$ \\
\hline $\begin{array}{l}\text { Allocation concealment } \\
\text { (selection bias) }\end{array}$ & High risk & $\begin{array}{l}\text { Not possible; "The patient population was assigned to } 1 \text { of } 4 \text { medical service } \\
\text { groups based on where they were treated at randomizations" }\end{array}$ \\
\hline $\begin{array}{l}\text { Blinding (performance } \\
\text { bias and detection bias) } \\
\text { All outcomes }\end{array}$ & High risk & Not possible \\
\hline $\begin{array}{l}\text { Incomplete outcome data } \\
\text { (attrition bias) } \\
\text { All outcomes }\end{array}$ & Low risk & For primary outcomes, not secondary \\
\hline $\begin{array}{l}\text { Selective reporting (re- } \\
\text { porting bias) }\end{array}$ & Low risk & Based on microbial response and other clinical parameters \\
\hline Other bias & Low risk & No problems noted. \\
\hline $\begin{array}{l}\text { Baseline Outcomes simi- } \\
\text { lar? }\end{array}$ & Unclear risk & No information about baseline outcomes pretrial in the allocated groups. \\
\hline Free of contamination? & High risk & Doctors likely to have cared for participants in all groups. \\
\hline $\begin{array}{l}\text { Baseline characteristics } \\
\text { similar? }\end{array}$ & Low risk & Table 1 \\
\hline
\end{tabular}

Fridkin 2002

$\begin{array}{ll}\text { Methods } & \text { STUDY DESIGN: CBA } \\ & \text { Risk of Bias: HIGH }\end{array}$


Fridkin 2002 (Continued)
Participants

PROVIDERS: a total of 50 ICUs located in 20 hospitals

PARTICIPANTS: patients in the ICU

CLINICAL PROBLEM: vancomycin use, prevalence of VRE

SETTING: hospitals in the USA participating in the ICU surveillance component of National Nosocomial Infection Surveillance

Interventions

FORMAT: 5 interventions were used by 3 to 19 hospitals (some hospitals used more than 1 ). 3 interventions were hospital-wide and 2 were unit-specific.

\section{Hospital-wide interventions (22 ICUs)}

Intervention 1: educational meetings with dissemination of educational materials, 9 ICUs. Intervention function: education.

Intervention 2: audit and feedback, 19 ICUs. Intervention function: enablement.

Intervention 3: restriction, 3 ICUs. Intervention function: restriction.

\section{Unit-specific interventions (11 ICUs)}

Intervention 4: educational meetings with dissemination of educational materials. Intervention function: education.

Intervention 5: restriction, 3 ICUs. Intervention function: restriction.

DELIVERER: AMT

COMPARISON: national benchmark data

DESIRED CHANGE: decrease excessive

\begin{tabular}{ll} 
Outcomes & PRESCRIBING: Choice: DDDs of vancomycin \\
& MICROBIAL: percentages of VRE and MRSA \\
\hline Notes & FINANCIAL SUPPORT: Funding: CDC Emerging Infections Program. Competing Interests: no informa- \\
& tion \\
& ADDITIONAL DATA: email response from authors but no additional data
\end{tabular}

\section{Risk of bias}

\begin{tabular}{lll}
\hline Bias & Authors' judgement & Support for judgement \\
\hline $\begin{array}{l}\text { Random sequence genera- } \\
\text { tion (selection bias) }\end{array}$ & High risk & CBA - not randomised \\
\hline $\begin{array}{l}\text { Allocation concealment } \\
\text { (selection bias) }\end{array}$ & High risk & CBA - not randomised \\
\hline $\begin{array}{l}\text { Blinding (performance } \\
\text { bias and detection bias) }\end{array}$ & High risk & CBA, allocation not blinded \\
\hline $\begin{array}{l}\text { All outcomes } \\
\begin{array}{l}\text { Incomplete outcome data } \\
\text { (attrition bias) } \\
\text { All outcomes }\end{array}\end{array}$ & Low risk & $\begin{array}{l}\text { Not clear: "Susceptibility reports from isolates obtained as part of infec- } \\
\text { tion-control surveillance were excluded." Criteria for exclusion of isolates are } \\
\text { not described and may not have been consistent across all hospitals. }\end{array}$ \\
\hline
\end{tabular}


Fridkin 2002 (Continued)

Selective reporting (re- Low risk Not clear: "Susceptibility reports from isolates obtained as part of infecporting bias) tion-control surveillance were excluded." Criteria for exclusion of isolates are not described and could have led to reporting bias.

Other bias Unclear risk

NOT CLEAR Microbial Risk of Bias Criteria: Case definition: percentage VRE or percentage MRSA in clinical isolates; Planned intervention: DONE; Other infection control isolation: NOT CLEAR; IC practices: NOT CLEAR Data were collected about infection control changes in response to feedback of data, but the paper does not report any results.

\begin{tabular}{lll}
\hline $\begin{array}{l}\text { Baseline Outcomes simi- } \\
\text { lar? }\end{array}$ & Unclear risk & Not stated \\
\hline Free of contamination? & Low risk & Interventions were at different hospitals from control sites. \\
\hline $\begin{array}{l}\text { Baseline characteristics } \\
\text { similar? }\end{array}$ & Unclear risk & Not stated \\
\hline
\end{tabular}

Friedberg 2009

Methods STUDY DESIGN: unintended consequences, cohort study

\section{Risk of Bias: HIGH}

\begin{tabular}{ll}
\hline Participants & PROVIDERS: all physicians in EDs \\
& PARTICIPANTS: 13,042 adult patients \\
CLINICAL PROBLEM: presenting with respiratory symptoms \\
SETTING: 385 hospitals in the USA
\end{tabular}

FORMAT, Interventions: audit and feedback, public reporting of antibiotic timing measure as 1 of 10
national quality indicators; financial, institution incentive
Intervention Functions: enablement, incentive
DELIVERER: Hospital Quality Alliance
COMPARISON: usual care
DESIRED CHANGE: increase effective

Outcomes UNINTENDED CONSEQUENCES: rates of pneumonia diagnosis, antibiotic use, and waiting times to see
a physician

Notes $\quad$ ROBINS-I RISK OF BIAS CRITERIA:

1. Confounding: Unclear, analysis says it was adjusted for confounding of the effect of intervention but insufficient detail

2. Selection of participants into the study: Low, selection into the study unrelated to intervention or outcome

3. Measurement classification of interventions: Low, intervention status well defined, recorded at the time of intervention and unaffected by knowledge of the outcome or risk of the outcome

4. Deviations from intended interventions: Low, no switches to other interventions or evidence of intervention failure

5. Missing data: Unclear, outcome data reported as \% with no numerator/denominator (Table 2)

6. Measurement of outcome: High, the effect estimate is based on regression analysis of annual data for 3 years pre- and 2 years postintervention (i.e. only 2 postintervention time points). The authors say that "based on the NHAMCS sample, there were an estimated 40 million (95\% confidence interval, 39 to 42 
million) ED visits to hospitals by adults with respiratory symptoms between 2001 and 2005." In Table 1, around $10 \%$ of these patients had a diagnosis of CAP, so they were not short of data! They should surely have split their data into more time points.

7. Selection of the reported result: Low, single analysis of the intervention-outcome relationship

FINANCIAL SUPPORT:Funding: Primary Care Teaching and Education Fund (internal), Health Resources and Services Administration, and Agency for Healthcare Research and Quality. Competing Interests: none declared

ADDITIONAL DATA: no response from authors to request for additional data

\section{Fukuda 2014}

Methods STUDY DESIGN: ITS

Risk of Bias: MEDIUM

PROVIDERS: all physicians in the hospital
PARTICIPANTS: all adult inpatients receiving target antibiotics for 14 days or more
CLINICAL PROBLEM: de-escalation of treatment in patients who received carbapenems,
cephalosporins, or quinolones for at least 14 days
SETTING: 1 community hospital in Japan

Interventions $\quad$ FORMAT: Interventions: educational outreach by review and recommend change Intervention Functions: enablement, persuasion

DELIVERER: AMT

COMPARISON: usual care

DESIRED CHANGE: decrease excessive and decrease cost

\begin{tabular}{ll}
\hline Outcomes & PRESCRIBING: Choice: cost of target antibiotics (USD/1000 OBD) \\
\hline Notes & FINANCIAL SUPPORT: Funding: none. Competing Interests: none declared \\
& ADDITIONAL DATA: no response from authors to request for additional data \\
\hline
\end{tabular}

\section{Risk of bias}

\begin{tabular}{lll}
\hline Bias & Authors' judgement & Support for judgement \\
\hline $\begin{array}{l}\text { Intervention independent } \\
\text { (ITS) }\end{array}$ & Low risk & \\
\hline $\begin{array}{l}\text { Analysed appropriately } \\
\text { (ITS) }\end{array}$ & Low risk & Re-analysed \\
\hline $\begin{array}{l}\text { Shape of effect pre-speci- } \\
\text { fied (ITS) ? }\end{array}$ & Low risk & Point of intervention was point of analysis. \\
\hline $\begin{array}{l}\text { Unlikely to affect data col- } \\
\text { lection (ITS) ? }\end{array}$ & Low risk & Outcome data from pharmacy computer \\
\hline $\begin{array}{l}\text { Knowledge of the alloca- } \\
\text { tion adequately prevent- } \\
\text { ed(ITS)? }\end{array}$ & Low risk & Outcome data from pharmacy computer \\
\hline
\end{tabular}


Fukuda 2014 (Continued)

Incomplete outcome data Low risk $\quad$ Outcome data from pharmacy computer
addressed (ITS)?

Free of selected reporting Low risk Outcome data from pharmacy computer
(ITS)?
(ITS)

Free of other bias (ITS) ? High risk

Only 6 month pre-intervention data, so cannot adjust for seasonal effects.

\section{Gerding 1985}

\begin{tabular}{ll}
\hline Methods & STUDY DESIGN: ITS \\
& Risk of Bias: HIGH \\
\hline Participants & PROVIDERS: all prescribers in the hospital \\
& PARTICIPANTS: all patients in the hospital \\
& CLINICAL PROBLEM: requiring aminoglycoside treatment \\
& SETTING: 1 Veterans Administration hospital in the USA. UBA data about resistance from 14 other simi- \\
& lar hospitals
\end{tabular}

\begin{tabular}{ll}
\hline Interventions & FORMAT: no valid prescribing data. Restrictive. \\
& DELIVERER: specialist physician \\
COMPARISON: usual care & \\
& DESIRED CHANGE: decrease excessive \\
\hline Outcomes & MICROBIAL: resistance to gentamicin and aminoglycoside use \\
\hline Notes & FINANCIAL SUPPORT: Funding: commercial, Bristol Laboratories and the Veterans Administration. \\
Competing Interests: no information & ADDITIONAL DATA: no response from authors to request for additional data \\
& $\begin{array}{l}\text { Microbial Risk of Bias: } \text { MEDIUM, case definition Low, planned intervention Low, other infection con- } \\
\text { trol Unclear, no information }\end{array}$
\end{tabular}

\section{Risk of bias}

\begin{tabular}{lll}
\hline Bias & Authors' judgement & Support for judgement \\
\hline $\begin{array}{l}\text { Intervention independent } \\
\text { (ITS) }\end{array}$ & Unclear risk & $\begin{array}{l}\text { Only 4 months' pre-intervention data, so secular/seasonal changes possible. } \\
\text { No information about infection control measures. }\end{array}$ \\
\hline $\begin{array}{l}\text { Analysed appropriately } \\
\text { (ITS)? }\end{array}$ & Low risk & Re-analysed \\
\hline $\begin{array}{l}\text { Shape of effect pre-speci- } \\
\text { fied (ITS) ? }\end{array}$ & Low risk & Point of analyses was point of intervention. \\
\hline $\begin{array}{l}\text { Unlikely to affect data col- } \\
\text { lection (ITS) ? }\end{array}$ & Low risk & Routine data \\
\hline $\begin{array}{l}\text { Knowledge of the alloca- } \\
\text { tion adequately prevent- } \\
\text { ed(ITS)? }\end{array}$ & Low risk & Routine data \\
\hline \hline
\end{tabular}


Gerding 1985 (Continued)

Incomplete outcome data Low risk Routine data
addressed (ITS) ?

Free of selected reporting Low risk Routine data
(ITS) ?

\begin{tabular}{ll}
\hline Free of other bias (ITS) ? $\quad$ Unclear risk & NOT CLEARMicrobial Outcome Risk of Bias: Planned intervention: DONE Im- \\
& plementation in response to emergence of gentamicin resistance over the pre- \\
& vious 5 years; Case definition: DONE Infection from clinical isolates; Other in- \\
fection control measures: NOT CLEAR, no information provided.
\end{tabular}

Goldstein 2009

\begin{tabular}{ll}
\hline Methods & STUDY DESIGN: ITS \\
& Risk of Bias: MEDIUM \\
\hline Participants & PROVIDERS: all physicians \\
& CLINICALANTS: all adult patients in the hospital \\
& SETTING: 1 university hospital in the USA \\
\hline Interventions & FORMAT: Interventions: dissemination of formulary \\
& Intervention Function: education \\
& After 9 months there was an additional restrictive intervention (autosubstitution of ampicillin sulbac- \\
tam by ertapenem), but this was not targeted at imipenem use, and no data are provided about pre- \\
Scribing or microbial outcomes for ampicillin sulbactam. \\
DELIVERER: AMT \\
COMPARISON: usual care \\
DESIRED CHANGE: decrease excessive
\end{tabular}

Outcomes PRESCRIBING: Choice: imipenem use in DDD

MICROBIAL: \% susceptibility to imipenem in clinical isolates of Pseudomonas aeruginosa
Notes FINANCIAL SUPPORT: Funding: commercial Merck (manufacturers of ertapenem). Competing Inter- ests: Ellie JC Goldstein is on the advisory boards of Merck, is in the speakers' bureau of Merck, and re- ceived research support from Merck; Shuang Lu is employed by Merck Research Laboratories and may own stock or stock options. Anne R Meibohm was formerly employed by Merck Research Laboratories and may own stock or stock options.

ADDITIONAL DATA: email response from authors to request for additional data

Microbial Risk of Bias LOW: case definition low risk, planned intervention low risk, other infection control measures low risk, no change

\begin{tabular}{lll}
\hline Risk of bias & \\
\hline Bias & Authors' judgement & Support for judgement \\
\hline $\begin{array}{l}\text { Intervention independent } \\
\text { (ITS) ? }\end{array}$ & Low risk & \\
\hline $\begin{array}{l}\text { Analysed appropriately } \\
\text { (ITS)? }\end{array}$ & Low risk & Segmented regression analysis \\
\hline
\end{tabular}


Goldstein 2009 (Continued)

Shape of effect pre-speci- Low risk Point of intervention was point of analysis. fied (ITS) ?

Unlikely to affect data col- Low risk lection (ITS) ?

Data from pharmacy and microbiology computers

\begin{tabular}{lll}
\hline $\begin{array}{l}\text { Knowledge of the alloca- } \\
\text { tion adequately prevent- } \\
\text { ed(ITS)? }\end{array}$ & Low risk & Data from pharmacy and microbiology computers \\
\hline $\begin{array}{l}\text { Incomplete outcome data } \\
\text { addressed (ITS) } ?\end{array}$ & Low risk & Data from pharmacy and microbiology computers \\
\hline $\begin{array}{l}\text { Free of selected reporting } \\
\text { (ITS) ? }\end{array}$ & Low risk & Data from pharmacy and microbiology computers \\
\hline $\begin{array}{l}\text { Free of other bias (ITS) ? } \\
\text { High risk }\end{array}$ & $\begin{array}{l}\text { Only } 6 \text { months' pre-intervention data for intervention } 1 \text { and } 9 \text { months' for in- } \\
\text { tervention } 2\end{array}$ \\
\hline
\end{tabular}

Grohs 2014

\begin{tabular}{ll}
\hline Methods & STUDY DESIGN: ITS \\
& Risk of Bias: MEDIUM \\
\hline Participants & PROVIDERS: all physicians \\
& PARTICIPANTS: all adult patients \\
CLINICAL PROBLEM: requiring treatment with IV 3rd-generation cephalosporin \\
SETTING: 1 university hospital in France
\end{tabular}

\begin{tabular}{ll}
\hline Interventions & FORMAT: Intervention: distribution of antibiotic policy \\
& Intervention Function: education \\
DELIVERER: AMT \\
COMPARISON: usual care \\
DESIRED CHANGE: decrease excessive \\
\hline PRESCRIBING: Choice: ceftriaxone use in DDD/1000 OBD \\
MICROBIAL: number of participants carrying high level AmpC beta-lactamase \\
\hline Fotes & FINANCIAL SUPPORT: Funding: none. Competing Interests: none declared \\
& MDDITIONAL DATA: no response from authors to request for additional data \\
Microbial Risk of Bias: HIGH case definition low, planned intervention low, other infection control \\
measures unclear (no data)
\end{tabular}

\section{Risk of bias}

\begin{tabular}{|c|c|c|}
\hline Bias & Authors' judgement & Support for judgement \\
\hline $\begin{array}{l}\text { Intervention independent } \\
\text { (ITS)? }\end{array}$ & Low risk & \\
\hline
\end{tabular}


Grohs 2014 (Continued)

Analysed appropriately Low risk $\quad$ Segmented regression analysis
(ITS) ?

Shape of effect pre-speci- Low risk Point of intervention was point of analysis.

fied (ITS) ?

Unlikely to affect data col- Low risk $\quad$ Outcome data from microbiology and pharmacy computers
lection (ITS)?

\begin{tabular}{lll}
\hline $\begin{array}{l}\text { Knowledge of the alloca- } \\
\text { tion adequately prevent- } \\
\text { ed(ITS)? }\end{array}$ & Low risk & Outcome data from microbiology and pharmacy computers \\
\hline $\begin{array}{l}\text { Incomplete outcome data } \\
\text { addressed (ITS) ? }\end{array}$ & Low risk & Outcome data from microbiology and pharmacy computers \\
\hline $\begin{array}{l}\text { Free of selected reporting } \\
\text { (ITS) ? }\end{array}$ & Low risk & Outcome data from microbiology and pharmacy computers \\
\hline Free of other bias (ITS) ? & High risk & $\begin{array}{l}\text { Short time series, annual data with only } 5 \text { pre- and 7 postintervention data } \\
\text { points }\end{array}$ \\
\hline
\end{tabular}

Gulmezoglu 2007

\begin{tabular}{ll}
\hline Methods & STUDY DESIGN: cluster RCT, hospital level \\
& Risk of Bias: HIGH \\
\hline Participants & PROVIDERS: obstetric teams \\
& PARTICIPANTS: 1000 consecutively delivered women in obstetric units, 40 clusters (hospitals) \\
& CLINICAL PROBLEM: women undergoing Caesarean section \\
& SETTING: 22 hospitals in Mexico City and 18 in Thailand
\end{tabular}

FORMAT: Interventions: educational meetings and dissemination of brochures; reminders (physical,
posters and brochures)
Intervention Functions: education, environmental restructuring, persuasion
DELIVERER: AMT
COMPARISON: usual care
DESIRED CHANGE: increase effective
POWER CALCULATION: yes, 40 hospitals. Details in Appendix 3

\begin{tabular}{ll}
\hline Outcomes & PRESCRIBING: Exposure: \% women receiving antibiotic prophylaxis for Caesarean section \\
\hline Notes & FINANCIAL SUPPORT: Funding: UNDP/UNFPA/WHO/World Bank Special Programme of Research, De- \\
velopment and Research Training in Human Reproduction (HRP). Competing Interests: 4 authors \\
were editors of The WHO Reproductive Health Library since its inception in 1997 to date of publication. \\
ADDITIONAL DATA: no response from authors to request for additional data
\end{tabular}

\section{Risk of bias}

\begin{tabular}{lll}
\hline Bias & Authors' judgement & Support for judgement \\
\hline $\begin{array}{l}\text { Random sequence genera- } \\
\text { tion (selection bias) }\end{array}$ & Low risk & Random number generator used (detailed in other article). \\
\hline
\end{tabular}


Gulmezoglu 2007 (Continued)

\begin{tabular}{lll}
$\begin{array}{l}\text { Allocation concealment } \\
\text { (selection bias) }\end{array}$ & Low risk & Allocation by hospital \\
\hline $\begin{array}{l}\text { Blinding (performance } \\
\text { bias and detection bias) } \\
\text { All outcomes }\end{array}$ & Unclear risk & No mention of this \\
\hline
\end{tabular}

\begin{tabular}{|c|c|c|}
\hline $\begin{array}{l}\text { Incomplete outcome data } \\
\text { (attrition bias) } \\
\text { All outcomes }\end{array}$ & Low risk & $\begin{array}{l}\text { Field workers collected from hospital data and were able to consult mothers } \\
\text { for any missing data. }\end{array}$ \\
\hline $\begin{array}{l}\text { Selective reporting (re- } \\
\text { porting bias) }\end{array}$ & Low risk & $\begin{array}{l}\text { Field workers collected from hospital data and were able to consult mothers } \\
\text { for any missing data. }\end{array}$ \\
\hline Other bias & High risk & $\begin{array}{l}\text { End of study in Thai control hospital was conducted at a later stage due to oth- } \\
\text { er healthcare-related activities going on. }\end{array}$ \\
\hline $\begin{array}{l}\text { Baseline Outcomes simi- } \\
\text { lar? }\end{array}$ & Unclear risk & Appear to be different but unclear \\
\hline Free of contamination? & Low risk & Allocation by hospital \\
\hline $\begin{array}{l}\text { Baseline characteristics } \\
\text { similar? }\end{array}$ & Unclear risk & No data \\
\hline
\end{tabular}

Gums 1999

\begin{tabular}{ll}
\hline Methods & STUDY DESIGN: RCT \\
& Risk of Bias: HIGH \\
\hline Participants & PROVIDERS: all physicians in the hospital \\
& PARTICIPANTS: a total of 272 patients \\
CLINICAL PROBLEM: patients receiving inappropriate antibiotic therapy judged on culture results, risk \\
of toxicity or drug interaction, drug cost, and duration of treatment \\
SETTING: single 275 -bed community hospital in the USA
\end{tabular}

Interventions FORMAT: Interventions: educational outreach by review and recommend change; reminders (circum-
stantial and physical, placed in notes of patients who were receiving antibiotics)

Intervention Functions: enablement, environmental restructuring, persuasion

DELIVERER: AMT

COMPARISON: usual care

DESIRED CHANGE: decrease excessive

POWER CALCULATION: no justification provided for the sample size

\begin{tabular}{ll}
\hline Outcomes & PRESCRIBING: Choice: cost of antibiotic therapy \\
CLINICAL: Balancing: length of stay \\
FINANCIAL: charges for antibiotics, laboratory and radiology services, total patient charges. Implemen- \\
tation cost based on days per week required for Pharmacy and Infectious Diseases staff. \\
\hline Fotes & FINANCIAL SUPPORT: no information \\
& ADDITIONAL INFORMATION: no response from authors
\end{tabular}


Gums 1999 (Continued)

Risk of bias

\begin{tabular}{|c|c|c|}
\hline Bias & Authors' judgement & Support for judgement \\
\hline $\begin{array}{l}\text { Random sequence genera- } \\
\text { tion (selection bias) }\end{array}$ & Unclear risk & $\begin{array}{l}\text { Method of sequence generation not clear; "eligible patients were blindly ran- } \\
\text { domised to the intervention or control group" }\end{array}$ \\
\hline $\begin{array}{l}\text { Allocation concealment } \\
\text { (selection bias) }\end{array}$ & High risk & $\begin{array}{l}\text { Not possible to conceal allocation because all intervention participants had a } \\
\text { consultation, whereas no control participants did. }\end{array}$ \\
\hline $\begin{array}{l}\text { Blinding (performance } \\
\text { bias and detection bias) } \\
\text { All outcomes }\end{array}$ & Unclear risk & $\begin{array}{l}\text { Unclear, despite objective primary outcome measure (LOS), it is not clearly } \\
\text { stated that record linkage was without knowledge of allocation. }\end{array}$ \\
\hline $\begin{array}{l}\text { Incomplete outcome data } \\
\text { (attrition bias) } \\
\text { All outcomes }\end{array}$ & Low risk & No problems found, data were analysed from $93 \%$ of randomised participants. \\
\hline $\begin{array}{l}\text { Selective reporting (re- } \\
\text { porting bias) }\end{array}$ & Low risk & No problems found. \\
\hline Other bias & Low risk & No other apparent biases found. \\
\hline $\begin{array}{l}\text { Baseline Outcomes simi- } \\
\text { lar? }\end{array}$ & Low risk & Done for primary outcome \\
\hline Free of contamination? & Low risk & $\begin{array}{l}\text { Participants were randomised to receive a consultation from an ID specialist } \\
\text { (intervention) or no consultation (control), so no contamination likely. }\end{array}$ \\
\hline $\begin{array}{l}\text { Baseline characteristics } \\
\text { similar? }\end{array}$ & Low risk & Done, Table 1 of the original paper \\
\hline
\end{tabular}

Gupta 1989

\begin{tabular}{ll}
\hline Methods & STUDY DESIGN: ITS \\
& Risk of Bias: MEDIUM \\
\hline Participants & PROVIDERS: all physicians in the hospital \\
& PARTICIPANTS: patients with clinical problem \\
& SETTING: 1 university hospital in Canada \\
\hline Interventions & FORMAT: Interventions: dissemination of memo; reminders (physical, newsletter); restrictive by re- \\
& view and make change \\
Intervention Functions: education, environmental restructuring, persuasion, restriction \\
DELIVERER: pharmacist \\
COMPARISON: usual care \\
DESIRED CHANGE: decrease excessive
\end{tabular}

Outcomes

PRESCRIBING: Choice: $\%$ of cefazolin doses prescribed at $<8$-hour intervals

Notes FINANCIAL SUPPORT: no information provided


Gupta 1989 (Continued)

ADDITIONAL DATA: no response from authors to request for additional data

\section{Risk of bias}

\begin{tabular}{lll}
\hline Bias & Authors' judgement & Support for judgement \\
\hline $\begin{array}{l}\text { Intervention independent } \\
\text { (ITS) ? }\end{array}$ & High risk & Only 3 months' pre-intervention data, so secular/seasonal changes possible. \\
\hline $\begin{array}{l}\text { Analysed appropriately } \\
\text { (ITS)? }\end{array}$ & Low risk & Re-analysed. Not done in original paper, X2 test on mean before-after. \\
\hline $\begin{array}{l}\text { Shape of effect pre-speci- } \\
\text { fied (ITS) ? }\end{array}$ & Low risk & $\begin{array}{l}\text { Done, intended effect was decrease in primary outcome, and point of analysis } \\
\text { was point of intervention. }\end{array}$ \\
\hline $\begin{array}{l}\text { Unlikely to affect data col- } \\
\text { lection (ITS) ? }\end{array}$ & Low risk & $\begin{array}{l}\text { Done, data were from routine systems and unlikely to change over study peri- } \\
\text { od. }\end{array}$ \\
\hline $\begin{array}{l}\text { Knowledge of the alloca- } \\
\text { tion adequately prevent- } \\
\text { ed(ITS)? }\end{array}$ & Low risk & $\begin{array}{l}\text { Done, data were from routine systems and unlikely to change over study peri- } \\
\text { od. }\end{array}$ \\
\hline $\begin{array}{l}\text { Incomplete outcome data } \\
\text { addressed (ITS) ? }\end{array}$ & Low risk & $\begin{array}{l}\text { Done, data were from routine systems and unlikely to change over study peri- } \\
\text { od. }\end{array}$ \\
\hline $\begin{array}{l}\text { Free of selected reporting } \\
\text { ITS) ? }\end{array}$ & Low risk & $\begin{array}{l}\text { Done, data were from routine systems and unlikely to change over study peri- } \\
\text { od. }\end{array}$ \\
\hline \begin{tabular}{l} 
Free of other bias (ITS) ? \\
\hline
\end{tabular} & Low risk & \begin{tabular}{l} 
No other apparent biases found. \\
\hline
\end{tabular}
\end{tabular}

Hadi 2008

\begin{tabular}{ll}
\hline Methods & STUDY DESIGN: ITS \\
& Risk of Bias: MEDIUM \\
\hline Participants & PROVIDERS: residents in internal medicine department \\
& CLINICALIPANTS: patients with clinical problem \\
& SETTING: 5 wards in internal medicine department of teaching hospital in Indonesia
\end{tabular}

Interventions

FORMAT: Interventions: educational meetings with dissemination of guidelines; educational outreach by academic detailing; reminders (physical, pocket book version of guideline) Intervention Functions: education, environmental restructuring, persuasion DELIVERER: AMT

COMPARISON: usual care

DESIRED CHANGE: reduce inappropriate

\begin{tabular}{ll}
\hline Outcomes & PRESCRIBING: Exposure: \% patients treated and total antibiotic consumption (DDD/100 patient days) \\
\hline Notes & FINANCIAL SUPPORT: Funding: Royal Netherlands Academy of Arts and Sciences, Scientific Pro- \\
& gramme Indonesia-Netherlands (SPIN). Competing Interests: no information
\end{tabular}


Hadi 2008 (Continued)

ADDITIONAL DATA: no response from authors to request for additional data

\section{Risk of bias}

\begin{tabular}{lll}
\hline Bias & Authors' judgement & Support for judgement \\
\hline $\begin{array}{l}\text { Intervention independent } \\
\text { (ITS) }\end{array}$ & High risk & No, seasonal variation \\
\hline $\begin{array}{l}\text { Analysed appropriately } \\
\text { (ITS) ? }\end{array}$ & Low risk & Re-analysed \\
\hline $\begin{array}{l}\text { Shape of effect pre-speci- } \\
\text { fied (ITS) ? }\end{array}$ & Low risk & Done, point of analysis is point of intervention. \\
\hline $\begin{array}{l}\text { Unlikely to affect data col- } \\
\text { lection (ITS) ? }\end{array}$ & Low risk & Done, data was collected by trained data collectors. \\
\hline $\begin{array}{l}\text { Knowledge of the alloca- } \\
\text { tion adequately prevent- } \\
\text { ed(ITS)? }\end{array}$ & High risk & No, blinding was not possible. \\
\hline $\begin{array}{l}\text { Incomplete outcome data } \\
\text { addressed (ITS) ? }\end{array}$ & Low risk & \\
\hline $\begin{array}{l}\text { Free of selected reporting } \\
\text { (ITS) ? }\end{array}$ & Low risk & $\begin{array}{l}\text { Done, states they assured completeness of data by collecting while patients } \\
\text { were still in the department. }\end{array}$ \\
\hline \begin{tabular}{l} 
Free of other bias (ITS) ? \\
\hline
\end{tabular} & Low risk & Done, Figure 2 \\
\hline
\end{tabular}

Halm 2004

\begin{tabular}{ll}
\hline Methods & STUDY DESIGN: ITS \\
& Risk of Bias: HIGH \\
\hline Participants & PROVIDERS: all physicians in the hospitals \\
& CLINICAL PROBLEM: adults with community-acquired pneumonia \\
& SETTING: 4 university hospitals, New York, USA \\
\hline Interventions & FORMAT: Interventions: educational meetings with dissemination of guidelines; reminders (circum- \\
& Stantial and physical, on computer order system for antibiotics and pocket version of guideline) \\
& DELIVERER: AMT \\
& COMPARISON: usual care \\
& DESIRED CHANGE: decrease excessive \\
\hline PRESCRIBING: Choice: percentage of patients treated with guideline-recommended antibiotics
\end{tabular}


Halm 2004 (Continued)

ADDITIONAL DATA: no response from authors to request for additional data

\section{Risk of bias}

\begin{tabular}{|c|c|c|}
\hline Bias & Authors' judgement & Support for judgement \\
\hline $\begin{array}{l}\text { Intervention independent } \\
\text { (ITS)? }\end{array}$ & High risk & NOT DONE, subjective outcome measure, not blinded \\
\hline $\begin{array}{l}\text { Analysed appropriately } \\
\text { (ITS)? }\end{array}$ & Low risk & $\begin{array}{l}\text { Re-analysed. Not done in original paper: comparison of means (uncontrolled } \\
\text { before-after) with } x^{2} \text { test. }\end{array}$ \\
\hline $\begin{array}{l}\text { Shape of effect pre-speci- } \\
\text { fied (ITS)? }\end{array}$ & Low risk & $\begin{array}{l}\text { Done, intended effect was decrease in primary outcome, and point of analysis } \\
\text { was point of intervention. }\end{array}$ \\
\hline $\begin{array}{l}\text { Unlikely to affect data col- } \\
\text { lection (ITS)? }\end{array}$ & Low risk & Done, data collection same pre- and postintervention. \\
\hline $\begin{array}{l}\text { Knowledge of the alloca- } \\
\text { tion adequately prevent- } \\
\text { ed(ITS)? }\end{array}$ & High risk & NOT DONE, subjective outcome measure, not blinded \\
\hline $\begin{array}{l}\text { Incomplete outcome data } \\
\text { addressed (ITS)? }\end{array}$ & Unclear risk & Not stated whether outcome data collected on all participants. \\
\hline $\begin{array}{l}\text { Free of selected reporting } \\
\text { (ITS)? }\end{array}$ & Unclear risk & Not stated whether outcome data collected on all participants. \\
\hline Free of other bias (ITS)? & High risk & $\begin{array}{l}\text { NOT DONE, the only reliable data for analysis are about compliance with the } \\
\text { antibiotic policy, which was } 80 \% \text { at baseline. Serious risk of ceiling effect. }\end{array}$ \\
\hline
\end{tabular}

Hess 1990

\begin{tabular}{ll} 
Methods & STUDY DESIGN: ITS \\
& Risk of Bias: MEDIUM \\
\hline Participants & PROVIDERS: all physicians in the hospital \\
& CLINICIPANTS: all patients in the hospital \\
SETTING: a 719 -bed tertiary-care medical centre in the USA
\end{tabular}

Interventions $\quad$ FORMAT: Interventions: dissemination of guideline; educational outreach by review and recommend change

Intervention Functions: education, enablement, persuasion

DELIVERER: pharmacist

COMPARISON: usual care

DESIRED CHANGE: decrease excessive

Outcomes PRESCRIBING: Choice: cefazolin expenditure per patient day

FINANCIAL: savings in drug costs

\section{Notes}

FINANCIAL SUPPORT: no information 
Hess 1990 (Continued)

ADDITIONAL DATA: no response from authors to request for additional data

\section{Risk of bias}

\begin{tabular}{|c|c|c|}
\hline Bias & Authors' judgement & Support for judgement \\
\hline $\begin{array}{l}\text { Intervention independent } \\
\text { (ITS)? }\end{array}$ & Low risk & 12 months' data pre- and postintervention \\
\hline $\begin{array}{l}\text { Analysed appropriately } \\
\text { (ITS)? }\end{array}$ & Low risk & $\begin{array}{l}\text { Re-analysed. Not done in original paper, no statistical analysis, and only com- } \\
\text { parison was between mean (uncontrolled) before and after. }\end{array}$ \\
\hline $\begin{array}{l}\text { Shape of effect pre-speci- } \\
\text { fied (ITS)? }\end{array}$ & Low risk & $\begin{array}{l}\text { Done, intended effect was decrease in primary outcome, and point of analysis } \\
\text { was point of intervention. }\end{array}$ \\
\hline $\begin{array}{l}\text { Unlikely to affect data col- } \\
\text { lection (ITS)? }\end{array}$ & Low risk & $\begin{array}{l}\text { Done, data were from routine systems and unlikely to change over study peri- } \\
\text { od. }\end{array}$ \\
\hline $\begin{array}{l}\text { Knowledge of the alloca- } \\
\text { tion adequately prevent- } \\
\text { ed(ITS)? }\end{array}$ & Low risk & $\begin{array}{l}\text { Done, data were from routine systems and unlikely to change over study peri- } \\
\text { od. }\end{array}$ \\
\hline $\begin{array}{l}\text { Incomplete outcome data } \\
\text { addressed (ITS)? }\end{array}$ & Low risk & $\begin{array}{l}\text { Done, data were from routine systems and unlikely to change over study peri- } \\
\text { od. }\end{array}$ \\
\hline $\begin{array}{l}\text { Free of selected reporting } \\
\text { (ITS)? }\end{array}$ & Low risk & $\begin{array}{l}\text { Done, data were from routine systems and unlikely to change over study peri- } \\
\text { od. }\end{array}$ \\
\hline Free of other bias (ITS) ? & Unclear risk & $\begin{array}{l}\text { On page } 588 \text { the authors state that "a proportion of these savings can be at- } \\
\text { tributed to a decrease in acquisition cost", but they do not say how much. }\end{array}$ \\
\hline
\end{tabular}

Himmelberg 1991

\begin{tabular}{ll} 
Methods & STUDY DESIGN: ITS \\
& Risk of Bias: LOW \\
\hline Participants & PROVIDERS: physicians in the hospital \\
& CLINICAL PROBLEM: patients receiving restricted antibiotics \\
& SETTING: a tertiary-care teaching hospital in the USA \\
\hline Interventions & FORMAT: Interventions: restrictive, removal of restriction \\
& Intervention Functions: restriction \\
& DELIVERER: specialist physician \\
COMPARISON: 6 months in the restriction period were compared with 6 months after restriction was \\
lifted. \\
DESIRED CHANGE: decrease excessive
\end{tabular}

\begin{tabular}{ll}
\hline Outcomes & PRESCRIBING: Choice: number of courses and cost of restricted drugs \\
& FINANCIAL: cost of drugs \\
\hline Notes & $\begin{array}{l}\text { FINANCIAL SUPPORT:Funding: commercial, Pfizer Roerig and the Upjohn companies. Competing In- } \\
\text { terests: no information }\end{array}$
\end{tabular}


Himmelberg 1991 (Continued)

ADDITIONAL DATA: no response from authors to request for additional data

\section{Risk of bias}

\begin{tabular}{lll}
\hline Bias & Authors' judgement & Support for judgement \\
\hline $\begin{array}{l}\text { Intervention independent } \\
\text { (ITS) }\end{array}$ & Low risk & Data collected in same months in 2 consecutive years. \\
\hline $\begin{array}{l}\text { Analysed appropriately } \\
\text { (ITS)? }\end{array}$ & Low risk & $\begin{array}{l}\text { Re-analysed. Not done in original paper: comparison of means (uncontrolled } \\
\text { before-after) with t-test. }\end{array}$ \\
\hline $\begin{array}{l}\text { Shape of effect pre-speci- } \\
\text { fied (ITS) ? }\end{array}$ & Low risk & $\begin{array}{l}\text { Done, intended effect was decrease in primary outcome, and point of analysis } \\
\text { was point of intervention. }\end{array}$ \\
\hline $\begin{array}{l}\text { Unlikely to affect data col- } \\
\text { lection (ITS) ? }\end{array}$ & Low risk & $\begin{array}{l}\text { Done, data were from routine systems and unlikely to change over study peri- } \\
\text { od. }\end{array}$ \\
\hline $\begin{array}{l}\text { Knowledge of the alloca- } \\
\text { tion adequately prevent- } \\
\text { ed(ITS)? }\end{array}$ & Low risk & $\begin{array}{l}\text { Done, data were from routine systems and unlikely to change over study peri- } \\
\text { od. }\end{array}$ \\
\hline $\begin{array}{l}\text { Incomplete outcome data } \\
\text { addressed (ITS) ? }\end{array}$ & Low risk & $\begin{array}{l}\text { Done, data were from routine systems and unlikely to change over study peri- } \\
\text { od. }\end{array}$ \\
\hline $\begin{array}{l}\text { Free of selected reporting } \\
\text { (ITS) ? }\end{array}$ & Low risk & $\begin{array}{l}\text { Done, data were from routine systems and unlikely to change over study peri- } \\
\text { od. }\end{array}$ \\
\hline \begin{tabular}{l} 
Free of other bias (ITS) ? \\
\hline
\end{tabular} & Low risk & \begin{tabular}{l} 
No other apparent biases found. \\
\hline
\end{tabular}
\end{tabular}

Hitti 2012

\begin{tabular}{ll}
\hline Methods & STUDY DESIGN: ITS \\
& Risk of Bias: MEDIUM \\
\hline Participants & PROVIDERS: all physicians in the ED \\
& PARTICIPANTS: all patients with sepsis in the ED \\
& SETTING: 1 hospital in Beirut, Lebanon \\
\hline Interventions & FORMAT, Interventions: structural \\
Intervention Functions: environmental restructuring, antibiotics required for sepsis treatment were \\
Stored in an Automated Dispensing Cabinet in the ED instead of having to be ordered from pharmacy \\
DELIVERER: AMT \\
COMPARISON: usual care \\
DESIRED CHANGE: decrease excessive \\
PRESCRIBING: Choice: time to first antibiotic dose in minutes measured both from arrival in the ED and \\
from ordering the antibiotic \\
\hline Outcomes & FINANCIAL SUPPORT: no information \\
& ADDITIONAL DATA: no response from authors to request for additional data
\end{tabular}

\section{Risk of bias}


Hitti 2012 (Continued)

\begin{tabular}{lll} 
Bias & Authors' judgement & Support for judgement \\
\hline $\begin{array}{l}\text { Intervention independent } \\
\text { (ITS) }\end{array}$ & Low risk & \\
\hline $\begin{array}{l}\text { Analysed appropriately } \\
\text { (ITS) }\end{array}$ & Low risk & Re-analysed \\
\hline $\begin{array}{l}\text { Shape of effect pre-speci- } \\
\text { fied (ITS) ? }\end{array}$ & Low risk & Point of intervention is point of analysis. \\
\hline $\begin{array}{l}\text { Unlikely to affect data col- } \\
\text { lection (ITS) ? }\end{array}$ & Low risk & Retrospective data collection using the same methods throughout \\
\hline $\begin{array}{l}\text { Knowledge of the alloca- } \\
\text { tion adequately prevent- } \\
\text { ed(ITS)? }\end{array}$ & High risk & Data were collected from case records, and allocation was not concealed. \\
\hline $\begin{array}{l}\text { Incomplete outcome data } \\
\text { addressed (ITS) ? }\end{array}$ & Low risk & \\
\hline $\begin{array}{l}\text { Free of selected reporting } \\
\text { (ITS) ? }\end{array}$ & Low risk & Outcome data reported on all 110 included participants. \\
\hline $\begin{array}{l}\text { Free of other bias (ITS) ? } \\
\text { High risk }\end{array}$ & \begin{tabular}{l} 
Exclusion rates similar pre- (13/69) and post- (11/65) intervention. \\
\hline
\end{tabular} & $\begin{array}{l}\text { Data only collected for } 7 \text { months pre- and 8 months postintervention, so secu- } \\
\text { lar trends possible. }\end{array}$ \\
\hline
\end{tabular}

Hochreiter 2009

\begin{tabular}{ll}
\hline Methods & STUDY DESIGN: RCT \\
& Risk of Bias: HIGH \\
\hline Participants & PROVIDERS: all physicians in ICU \\
& PARTICIPANTS: all patients with the clinical problem \\
& CLINICAL PROBLEM: duration of antibiotic therapy in 110 patients with suspected bacterial infections \\
& (57 intervention, 53 control) \\
& SETTING: surgical intensive care ward in 1 hospital in Germany
\end{tabular}

Interventions $\quad$ FORMAT, Interventions: reminders (circumstantial and physical, procalcitonin-based decision support algorithm); structural (introduction of procalcitonin testing)

Intervention Functions: enablement, environmental restructuring, persuasion

DELIVERER: department (ICU) physician

COMPARISON: usual care

DESIRED CHANGE: decrease excessive

POWER CALCULATION: no information provided

\begin{tabular}{ll}
\hline Outcomes & PRESCRIBING: Exposure: duration of all antibiotic therapy in days \\
\hline Notes & FINANCIAL SUPPORT: Funding: none. Competing Interests: SS has served as consultant and received \\
payments from B.R.A.H.M.S AG for speaking engagements. All other authors declare no conflicts of in- \\
terest. \\
ADDITIONAL DATA: no response from authors to request for additional data
\end{tabular}


Hochreiter 2009 (Continued)

\section{Risk of bias}

\begin{tabular}{|c|c|c|}
\hline Bias & Authors' judgement & Support for judgement \\
\hline $\begin{array}{l}\text { Random sequence genera- } \\
\text { tion (selection bias) }\end{array}$ & Unclear risk & No explanation of randomisation process \\
\hline $\begin{array}{l}\text { Allocation concealment } \\
\text { (selection bias) }\end{array}$ & Unclear risk & Details of allocation process not provided. \\
\hline $\begin{array}{l}\text { Blinding (performance } \\
\text { bias and detection bias) } \\
\text { All outcomes }\end{array}$ & High risk & Open trial \\
\hline $\begin{array}{l}\text { Incomplete outcome data } \\
\text { (attrition bias) } \\
\text { All outcomes }\end{array}$ & Low risk & Done, Table 1 and text regarding excluded patients \\
\hline $\begin{array}{l}\text { Selective reporting (re- } \\
\text { porting bias) }\end{array}$ & Unclear risk & No explicit statement, so selective outcome reporting is possible. \\
\hline Other bias & Low risk & Done, all biases addressed. \\
\hline $\begin{array}{l}\text { Baseline Outcomes simi- } \\
\text { lar? }\end{array}$ & Unclear risk & No baseline outcome measurement \\
\hline Free of contamination? & Low risk & Done, procalcitonin results not available for controls. \\
\hline $\begin{array}{l}\text { Baseline characteristics } \\
\text { similar? }\end{array}$ & Low risk & Done, mainly similar (IC days slightly different) \\
\hline
\end{tabular}

Huber 1982

\begin{tabular}{ll}
\hline Methods & STUDY DESIGN: ITS \\
& Risk of Bias: LOW \\
\hline Participants & PROVIDERS: all physicians in the hospital \\
& PARTICIPANTS: all patients in hospital \\
CLINICAL PROBLEM: appropriateness of inpatient prescribing of cephalexin \\
SETTING: 1 university hospital in the USA
\end{tabular}

Interventions

FORMAT, Interventions: restrictive by expert approval and removal Intervention Functions: restriction

DELIVERER: pharmacists

COMPARISON: usual care

DESIRED CHANGE: decrease excessive

\begin{tabular}{ll}
\hline Outcomes & PRESCRIBING: Choice: cephalexin dosing units \\
\hline Notes & FINANCIAL SUPPORT: Funding: none. Competing Interests: none declared \\
& ADDITIONAL DATA: no response from authors to request for additional data
\end{tabular}

\section{Risk of bias}


Huber 1982 (Continued)

\begin{tabular}{|c|c|c|}
\hline Bias & Authors' judgement & Support for judgement \\
\hline $\begin{array}{l}\text { Intervention independent } \\
\text { (ITS)? }\end{array}$ & Low risk & $>2$ years' data pre- and postintervention \\
\hline $\begin{array}{l}\text { Analysed appropriately } \\
\text { (ITS) ? }\end{array}$ & Low risk & $\begin{array}{l}\text { Re-analysed. Not done in original paper: no statistical analysis of time series, } \\
\text { presented as chart. }\end{array}$ \\
\hline $\begin{array}{l}\text { Shape of effect pre-speci- } \\
\text { fied (ITS) ? }\end{array}$ & Low risk & $\begin{array}{l}\text { Done, intended effect was decrease in primary outcome, and point of analysis } \\
\text { was point of intervention. }\end{array}$ \\
\hline $\begin{array}{l}\text { Unlikely to affect data col- } \\
\text { lection (ITS)? }\end{array}$ & Low risk & $\begin{array}{l}\text { Done, data were from routine systems and unlikely to change over study peri- } \\
\text { od. }\end{array}$ \\
\hline $\begin{array}{l}\text { Knowledge of the alloca- } \\
\text { tion adequately prevent- } \\
\text { ed(ITS)? }\end{array}$ & Low risk & $\begin{array}{l}\text { Done, data were from routine systems and unlikely to change over study peri- } \\
\text { od. }\end{array}$ \\
\hline $\begin{array}{l}\text { Incomplete outcome data } \\
\text { addressed (ITS)? }\end{array}$ & Low risk & $\begin{array}{l}\text { Done, data were from routine systems and unlikely to change over study peri- } \\
\text { od. }\end{array}$ \\
\hline $\begin{array}{l}\text { Free of selected reporting } \\
\text { (ITS)? }\end{array}$ & Low risk & $\begin{array}{l}\text { Done, data were from routine systems and unlikely to change over study peri- } \\
\text { od. }\end{array}$ \\
\hline Free of other bias (ITS) ? & Low risk & No other apparent biases found. \\
\hline
\end{tabular}

Hulgan 2004

\begin{tabular}{|c|c|}
\hline Methods & $\begin{array}{l}\text { STUDY DESIGN: ITS } \\
\text { Risk of Bias: LOW }\end{array}$ \\
\hline Participants & $\begin{array}{l}\text { PROVIDERS: physicians in the hospital } \\
\text { PATIENTS: all patients with clinical problem } \\
\text { CLINICAL PROBLEM: use of IV and oral quinolones } \\
\text { SETTING: university hospital in the USA }\end{array}$ \\
\hline Interventions & $\begin{array}{l}\text { FORMAT, Interventions: reminders (circumstantial and physical, computerised decision support sys- } \\
\text { tem integrated into an existing provider order entry system) } \\
\text { Intervention Functions: enablement, environmental restructuring, persuasion } \\
\text { DELIVERER: AMT } \\
\text { COMPARISON: usual care } \\
\text { DESIRED CHANGE: decrease excessive use of IV quinolones }\end{array}$ \\
\hline Outcomes & $\begin{array}{l}\text { PRESCRIBING: Choice: number of orders for oral quinolone } \\
\text { FINANCIAL: savings on drug costs in USD }\end{array}$ \\
\hline Notes & $\begin{array}{l}\text { FINANCIAL SUPPORT: Funding: NIH Training Grant T32 AI 07474-08 and Vanderbilt Clinical Research } \\
\text { Scholar Award K12 RR17697 (TH). Competing Interests: DAT and RAM receive authorship royalties } \\
\text { through Vanderbilt University from the commercial distribution of WizOrder. STR has received consult- } \\
\text { ing fees from McKesson Information Solutions, which has licensed WizOrder for commercial distribu- } \\
\text { tion. None of the other authors has related disclosures or potential conflicts of interest. }\end{array}$ \\
\hline
\end{tabular}


Hulgan 2004 (Continued)

ADDITIONAL DATA: email response from authors with additional data

\section{Risk of bias}

\begin{tabular}{|c|c|c|}
\hline Bias & Authors' judgement & Support for judgement \\
\hline $\begin{array}{l}\text { Intervention independent } \\
\text { (ITS)? }\end{array}$ & Low risk & Objective outcome measure \\
\hline $\begin{array}{l}\text { Analysed appropriately } \\
\text { (ITS)? }\end{array}$ & Low risk & Done in original paper: segmented regression analysis \\
\hline $\begin{array}{l}\text { Shape of effect pre-speci- } \\
\text { fied (ITS)? }\end{array}$ & Low risk & $\begin{array}{l}\text { Done, intended effect was increase in primary outcome, and point of analysis } \\
\text { was point of intervention. }\end{array}$ \\
\hline $\begin{array}{l}\text { Unlikely to affect data col- } \\
\text { lection (ITS)? }\end{array}$ & Low risk & $\begin{array}{l}\text { Done, data were from routine systems and unlikely to change over study peri- } \\
\text { od. }\end{array}$ \\
\hline $\begin{array}{l}\text { Knowledge of the alloca- } \\
\text { tion adequately prevent- } \\
\text { ed(ITS)? }\end{array}$ & Low risk & $\begin{array}{l}\text { Done, data were from routine systems and unlikely to change over study peri- } \\
\text { od. }\end{array}$ \\
\hline $\begin{array}{l}\text { Incomplete outcome data } \\
\text { addressed (ITS)? }\end{array}$ & Low risk & $\begin{array}{l}\text { Done, data were from routine systems and unlikely to change over study peri- } \\
\text { od. }\end{array}$ \\
\hline $\begin{array}{l}\text { Free of selected reporting } \\
\text { (ITS)? }\end{array}$ & Low risk & 1 year of data pre- and postintervention \\
\hline Free of other bias (ITS) ? & Low risk & Objective primary outcome, cost analysis adjusted to 2003 prices. \\
\hline
\end{tabular}

Inaraja 1986

\begin{tabular}{ll}
\hline Methods & STUDY DESIGN: ITS \\
& Risk of Bias: MEDIUM \\
\hline Participants & PROVIDERS: all physicians in the hospital \\
& PARTICIPANTS: all patients receiving antibiotics \\
& SETTING: 1 447-bed university hospital in Spain \\
\hline Interventions & Interventions: educational outreach by review and recommend change; restrictive antibiotic policy \\
but mode of restriction not clear & Intervention Functions: enablement, persuasion, restriction \\
& DELIVERER: pharmacist \\
& COMPARISON: usual care \\
& DESIRED CHANGE: decrease excessive \\
\hline PRESCRIBING: Choice: cephalosporin use measured with costs as a percentage of cephalosporins plus \\
Penicillins plus aminoglycosides \\
\hline FINANCIAL SUPPORT: Funding: none. Competing Interests: none declared \\
ADDITIONAL DATA: no response from authors to request for additional data
\end{tabular}


Inaraja 1986 (Continued)

Risk of bias

\begin{tabular}{|c|c|c|}
\hline Bias & Authors' judgement & Support for judgement \\
\hline $\begin{array}{l}\text { Intervention independent } \\
\text { (ITS)? }\end{array}$ & Unclear risk & $\begin{array}{l}\text { Only } 12 \text { months' data ( } 9 \text { months' pre- and } 3 \text { months' postintervention), so can- } \\
\text { not control for seasonal effects. }\end{array}$ \\
\hline $\begin{array}{l}\text { Analysed appropriately } \\
\text { (ITS) ? }\end{array}$ & Low risk & $\begin{array}{l}\text { Re-analysed. Not done in original paper: comparison of means (uncontrolled } \\
\text { before-after). }\end{array}$ \\
\hline $\begin{array}{l}\text { Shape of effect pre-speci- } \\
\text { fied (ITS)? }\end{array}$ & Low risk & $\begin{array}{l}\text { Done, intended effect was decrease in primary outcome, and point of analysis } \\
\text { was point of intervention. }\end{array}$ \\
\hline $\begin{array}{l}\text { Unlikely to affect data col- } \\
\text { lection (ITS)? }\end{array}$ & Low risk & $\begin{array}{l}\text { Done, data were from routine systems and unlikely to change over study peri- } \\
\text { od. }\end{array}$ \\
\hline $\begin{array}{l}\text { Knowledge of the alloca- } \\
\text { tion adequately prevent- } \\
\text { ed(ITS)? }\end{array}$ & Low risk & $\begin{array}{l}\text { Done, data were from routine systems and unlikely to change over study peri- } \\
\text { od. }\end{array}$ \\
\hline $\begin{array}{l}\text { Incomplete outcome data } \\
\text { addressed (ITS)? }\end{array}$ & Low risk & $\begin{array}{l}\text { Done, data were from routine systems and unlikely to change over study peri- } \\
\text { od. }\end{array}$ \\
\hline $\begin{array}{l}\text { Free of selected reporting } \\
\text { (ITS) ? }\end{array}$ & Low risk & $\begin{array}{l}\text { Done, data were from routine systems and unlikely to change over study peri- } \\
\text { od. }\end{array}$ \\
\hline Free of other bias (ITS) ? & Low risk & No other apparent biases found. \\
\hline
\end{tabular}

Jensen 2011

\begin{tabular}{ll}
\hline Methods & STUDY DESIGN: RCT \\
Risk of Bias: MEDIUM \\
\hline
\end{tabular}

Participants

PROVIDERS: all physicians in ICUs

PARTICIPANTS: All adult patients in ICUs for $>24 \mathrm{hrs}$

CLINICAL PROBLEM: suspected sepsis

SETTING: 9 multidisciplinary ICUs across Denmark

Interventions

FORMAT:Interventions: reminders (circumstantial and physical, drug-escalation algorithm and intensified diagnostics based on daily procalcitonin measurements); structural (rapid procalcitonin testing) Intervention Functions: enablement, environmental restructuring, persuasion

DELIVERER: deparmental physicians (ICU)

COMPARISON: usual care

DESIRED CHANGE: increase effective

SAMPLE SIZE: yes, total 1200 participants. Details in Appendix 3

1200 participants were randomised and included in the analysis.

Outcomes $\quad$ PRESCRIBING: Choice: time to first antibiotic dose; number (\%) ICU days spent with at least 3 antibiotics

CLINICAL: intended 28-day mortality; unintended (balancing) days in ICU; relative risk of renal impairment 
Jensen 2011 (Continued)

Notes
FINANCIAL SUPPORT: Funding: Danish State, the Lundbeck Foundation, the Toyota Foundation, the A.P. Møller Foundation, the Horboe Foundation, and the Capitol Region of Denmark. Competing Interests: Dr. Jensen received speaker fee and travel reimbursement from B.R.A.H.M.S Diagnostica and an unrestricted grant from the organisation for sample transport and analysis. The remaining authors have not disclosed any potential conflicts of interest.

ADDITIONAL DATA: no response from authors to request for additional data

\section{Risk of bias}

\begin{tabular}{|c|c|c|}
\hline Bias & Authors' judgement & Support for judgement \\
\hline $\begin{array}{l}\text { Random sequence genera- } \\
\text { tion (selection bias) }\end{array}$ & Low risk & $\begin{array}{l}\text { Randomisation was performed 1:1 using a computerised algorithm created by } \\
\text { the database manager. }\end{array}$ \\
\hline $\begin{array}{l}\text { Allocation concealment } \\
\text { (selection bias) }\end{array}$ & Low risk & $\begin{array}{l}\text { Investigators were masked to assignment before randomisation. Concealed } \\
\text { block size, pre-stratified for site of recruitment, initial Acute Physiology and } \\
\text { Chronic Health Evaluation, and age (entered in an encrypted screening form in } \\
\text { a password-protected website) }\end{array}$ \\
\hline $\begin{array}{l}\text { Blinding (performance } \\
\text { bias and detection bias) } \\
\text { All outcomes }\end{array}$ & Low risk & $\begin{array}{l}\text { Investigators, treating physicians, and the co-ordinator were unaware of out- } \\
\text { comes during the study. }\end{array}$ \\
\hline $\begin{array}{l}\text { Incomplete outcome data } \\
\text { (attrition bias) } \\
\text { All outcomes }\end{array}$ & Low risk & Outcomes reported on all randomised participants. \\
\hline $\begin{array}{l}\text { Selective reporting (re- } \\
\text { porting bias) }\end{array}$ & Low risk & Outcomes reported on all randomised participants. \\
\hline Other bias & Low risk & \\
\hline $\begin{array}{l}\text { Baseline Outcomes simi- } \\
\text { lar? }\end{array}$ & Unclear risk & No data \\
\hline Free of contamination? & Low risk & PCT measures only reported for intervention participants. \\
\hline $\begin{array}{l}\text { Baseline characteristics } \\
\text { similar? }\end{array}$ & Low risk & Table 1 \\
\hline
\end{tabular}

Jobson 2015

\begin{tabular}{ll} 
Methods & STUDY DESIGN: ITS \\
& Risk of Bias: MEDIUM \\
\hline Participants & PROVIDERS: all physicians and nurses in the paediatric ED \\
PARTICIPANTS: all children with central lines \\
CLINICAL PROBLEM: time to first antibiotic dose in children with fever \\
SETTING: 1 university hospital in the USA
\end{tabular}

Interventions

FORMAT: Interventions: audit and feedback at individual and group level; educational meetings, dissemination of educational materials; educational outreach by academic detailing at individual and group level; reminders (circumstantial (on electronic health record), physical (cards attached to computers, weekly email newsletter), and verbal); structural (placing antibiotics in front-line Pyxis stock) 
Intervention Functions: education, enablement, environmental restructuring, persuasion DELIVERER: departmental physicians

COMPARISON: usual care

DESIRED CHANGE: increase effective

\begin{tabular}{ll}
\hline Outcomes & PRESCRIBING: Choice: $\%$ of participants receiving first antibiotic dose within 60 minutes \\
\hline Notes & FINANCIAL SUPPORT: Funding: no external. Competing Interests: none declared \\
& ADDITIONAL DATA: authors provided additional data about intervention
\end{tabular}

\section{Risk of bias}

\begin{tabular}{lll}
\hline Bias & Authors' judgement & Support for judgement \\
\hline $\begin{array}{l}\text { Intervention independent } \\
\text { (ITS) }\end{array}$ & Low risk & \\
\hline $\begin{array}{l}\text { Analysed appropriately } \\
\text { (ITS) } ?\end{array}$ & Low risk & Statistical process control chart \\
\hline $\begin{array}{l}\text { Shape of effect pre-speci- } \\
\text { fied (ITS) ? }\end{array}$ & Low risk & Point of analysis was point of intervention. \\
\hline $\begin{array}{l}\text { Unlikely to affect data col- } \\
\text { lection (ITS) ? }\end{array}$ & Low risk & $\begin{array}{l}\text { Primary outcome was time to first antibiotic dose from patient administration } \\
\text { system. }\end{array}$ \\
\hline $\begin{array}{l}\text { Knowledge of the alloca- } \\
\text { tion adequately prevent- } \\
\text { ed(ITS)? }\end{array}$ & Low risk & $\begin{array}{l}\text { Primary outcome was time to first antibiotic dose from patient administration } \\
\text { system. }\end{array}$ \\
\hline $\begin{array}{l}\text { Incomplete outcome data } \\
\text { addressed (ITS) ? }\end{array}$ & Low risk & $\begin{array}{l}\text { Primary outcome was time to first antibiotic dose from patient administration } \\
\text { system. }\end{array}$ \\
\hline $\begin{array}{l}\text { Free of selected reporting } \\
\text { (ITS) ? }\end{array}$ & Low risk & $\begin{array}{l}\text { Primary outcome was time to first antibiotic dose from patient administration } \\
\text { system. }\end{array}$ \\
\hline \begin{tabular}{l} 
Free of other bias (ITS) ? \\
\hline
\end{tabular} & High risk & \begin{tabular}{l} 
Only 8 months' pre-intervention data, so seasonal effects cannot be excluded. \\
\hline
\end{tabular}
\end{tabular}

Jump 2012

\begin{tabular}{ll}
\hline Methods & STUDY DESIGN: CITS \\
& Risk of Bias: LOW \\
\hline Participants & PROVIDERS: all physicians and nurses in the hospitals \\
& PARTICIPANTS: all patients in the hospitals \\
& CLINICAL PROBLEM: patients requiring antibiotics or with suspected Clostridium difficile infection \\
& SETTING: 1 long-term care facility (intervention) and 1 hospital (control) in the USA \\
\hline Interventions & FORMAT: Interventions: audit and feedback; educational outreach by review and recommend change \\
& Intervention Functions: education, enablement, persuasion \\
& DELIVERER: AMT \\
& COMPARISON: usual care \\
& DESIRED CHANGE: decrease excessive
\end{tabular}

Outcomes PRESCRIBING: Exposure: days of therapy with all antibiotics/1000 OBD



DK087919 to PED, and R01-AI063517 to RAB), Veterans Affairs Merit Review Program, Veterans Integrated Service Network 10 Geriatric Research Education and Clinical Center (VISN 10 GRECC). Competing Interests: RLPJ reports that she has consulted for GOJO and Pfizer and has received grant support ViroPharma. RAB reports that he has consulted for AstraZeneca and has received grant support from AstraZeneca, Ribx, Pfizer, and Steris. CJD reports that he has consulted for BioK, Optimer, and GOJO and has received grant support from ViroPharma, Merck, and Pfizer. All other authors report no conflicts of interest.

ADDITIONAL DATA: email with additional data; further information about the intervention is given in Jump 2013.

Microbial Risk of Bias: HIGH. Case definition low; Planned intervention low; Other infection control high, no data about infection control other than that the intervention also increased isolation of participants with $C$ difficile infection. Moreover, the intervention discouraged repeat testing of participants with known $C$ difficile infection, which may have biased the microbial outcome.

\section{Risk of bias}

\begin{tabular}{lll}
\hline Bias & Authors' judgement & Support for judgement \\
\hline $\begin{array}{l}\text { Intervention independent } \\
\text { (ITS) }\end{array}$ & Low risk & \\
\hline $\begin{array}{l}\text { Analysed appropriately } \\
\text { (ITS) ? }\end{array}$ & Low risk & Segmented regression analysis \\
\hline $\begin{array}{l}\text { Shape of effect pre-speci- } \\
\text { fied (ITS) ? }\end{array}$ & Low risk & Point of intervention was point of analysis. \\
\hline $\begin{array}{l}\text { Unlikely to affect data col- } \\
\text { lection (ITS) ? }\end{array}$ & Low risk & Outcome data from pharmacy and microbiology computers \\
\hline $\begin{array}{l}\text { Knowledge of the alloca- } \\
\text { tion adequately prevent- } \\
\text { ed(ITS)? }\end{array}$ & Low risk & Outcome data from pharmacy and microbiology computers \\
\hline $\begin{array}{l}\text { Incomplete outcome data } \\
\text { addressed (ITS) ? }\end{array}$ & Low risk & \\
\hline $\begin{array}{l}\text { Free of selected reporting } \\
\text { (ITS) ? }\end{array}$ & Low risk & Outcome data from pharmacy and microbiology computers \\
\hline \begin{tabular}{l} 
Free of other bias (ITS) ? \\
\hline
\end{tabular} & Low risk & Outcome data from pharmacy and microbiology computers \\
\hline
\end{tabular}

Kallen 2009

\begin{tabular}{ll}
\hline Methods & STUDY DESIGN: ITS \\
& Risk of Bias: MEDIUM \\
\hline Participants & PROVIDERS: all physicians in the hospital \\
& PARTICIPANTS: all patients in the hospital \\
& CLINICAL PROBLEM: patients requiring therapeutic antibiotics \\
SETTING: 1 community hospital in the USA
\end{tabular}


Kallen 2009 (Continued) Interventions
FORMAT: Intervention: restrictive by removal from all wards

Intervention Function: restriction

DELIVERER: AMT

COMPARISON: usual care

DESIRED CHANGE: decrease use of fluoroquinolones in order to contain an outbreak of Clostridium dif-

ficile infection

PRESCRIBING: Choice: use of fluoroquinolones, DDD/100 OBD

MICROBIAL: C difficile infections

Notes FINANCIAL SUPPORT: Funding: none. Competing Interests: none declared

Microbial Risk of Bias: HIGH, case definition yes, planned intervention no (part of response to outbreak), other infection control measures no (several important changes made at the same time as prescribing intervention)

\section{Risk of bias}

\begin{tabular}{lll}
\hline Bias & Authors' judgement & Support for judgement \\
\hline $\begin{array}{l}\text { Intervention independent } \\
\text { (ITS) ? }\end{array}$ & High risk & No, as this was during an outbreak \\
\hline $\begin{array}{l}\text { Analysed appropriately } \\
\text { (ITS) ? }\end{array}$ & Low risk & Segmented regression analysis \\
\hline $\begin{array}{l}\text { Shape of effect pre-speci- } \\
\text { fied (ITS) ? }\end{array}$ & Low risk & Point of analysis was point of intervention. \\
\hline $\begin{array}{l}\text { Unlikely to affect data col- } \\
\text { lection (ITS) ? }\end{array}$ & Low risk & Data from pharmacy computer \\
\hline $\begin{array}{l}\text { Knowledge of the alloca- } \\
\text { tion adequately prevent- } \\
\text { ed(ITS)? }\end{array}$ & Low risk & Data from pharmacy computer \\
\hline $\begin{array}{l}\text { Incomplete outcome data } \\
\text { addressed (ITS) ? }\end{array}$ & Low risk & \\
\hline $\begin{array}{l}\text { Free of selected reporting } \\
\text { (ITS) ? }\end{array}$ & Low risk & Data from pharmacy computer \\
\hline \begin{tabular}{l} 
Free of other bias (ITS) ? \\
\hline
\end{tabular} & High risk & Data from pharmacy computer \\
\hline
\end{tabular}

\section{Kanwar 2007}

Methods STUDY DESIGN: unintended consequences, cohort study

\section{Risk of Bias: LOW}

PROVIDERS: all physicians in the ED
PARTICIPANTS: 518 adult patients
CLINICAL PROBLEM: hospital admission diagnosis of CAP
SETTING: 1 hospital in the USA


Kanwar 2007 (Continued)

Interventions

FORMAT, Interventions: audit and feedback; financial, institution incentive

Intervention Functions: enablement, incentive

DELIVERER: Blue Cross-Blue Shield of Michigan incentive program

COMPARISON: usual care

DESIRED CHANGE: increase effective

Outcomes

UNINTENDED CONSEQUENCES: confirmation of admission diagnosis by chest X-ray, mean antibiotic administration per patient admitted with CAP

Notes

NRSI RISK OF BIAS CRITERIA:

1. Confounding: Low, confounding of the effect of intervention unlikely in this study

2. Selection of participants into the study: Low, selection into the study unrelated to intervention or outcome

3. Measurement class of interventions: Low, intervention status well defined, recorded at the time of intervention and unaffected by knowledge of the outcome or risk of the outcome

4. Departures from intended interventions: Low, no switches to other interventions or evidence of intervention failure

5. Missing data: Low, outcome data and intervention status reported on all 518 patients

6. Measurement of outcome: Low, outcome measure objective and measured from patient administration system

7. Selection of the reported result: Low, single, prespecified analysis of the intervention-outcome relationship

FINANCIAL SUPPORT: Funding, none. Competing Interests: none declared

ADDITIONAL DATA: no response from authors to request for additional data

Methods STUDY DESIGN: RCT

\section{Risk of Bias: HIGH}

Participants PROVIDERS: all physicians in hospital

PARTICIPANTS: 1498 patients with bacterial infections (746 intervention, 752 control)

CLINICAL PROBLEM: antibiotic use in adult patients with bacterial infections

SETTING: 1 university hospital in the Netherlands

Interventions

FORMAT: Intervention: structural (rapid microbiology laboratory testing)

Intervention Functions: environmental restructuring

DELIVERER: specialist physician

COMPARISON: usual care

DESIRED CHANGE: decrease excessive

POWER CALCULATION: yes, 1500 participants in total. Details in Appendix 3

Outcomes

PRESCRIBING: Exposure: total antibiotic use (average DDDs per patient) 
Kerremans 2008 (Continued)

CLINICAL: Intended: mortality

Notes FINANCIAL SUPPORT: Funding: Dutch Association of University Hospitals ('VAZ-Doelmatigheidproject' no. 99207). bioMerieux provided additional funding through an unrestricted grant. Competing Interests: none declared

ADDITIONAL DATA: no response from authors to request for additional data

\section{Risk of bias}

\begin{tabular}{|c|c|c|}
\hline Bias & Authors' judgement & Support for judgement \\
\hline $\begin{array}{l}\text { Random sequence genera- } \\
\text { tion (selection bias) }\end{array}$ & Low risk & Done, computer-generated randomisation \\
\hline $\begin{array}{l}\text { Allocation concealment } \\
\text { (selection bias) }\end{array}$ & High risk & No, states concealment was impossible. \\
\hline $\begin{array}{l}\text { Blinding (performance } \\
\text { bias and detection bias) } \\
\text { All outcomes }\end{array}$ & High risk & No formal blinding attempted. \\
\hline $\begin{array}{l}\text { Incomplete outcome data } \\
\text { (attrition bias) } \\
\text { All outcomes }\end{array}$ & Low risk & Done, Figure 1 \\
\hline $\begin{array}{l}\text { Selective reporting (re- } \\
\text { porting bias) }\end{array}$ & Low risk & Done, all outcomes reported. \\
\hline Other bias & Low risk & No other apparent issues \\
\hline $\begin{array}{l}\text { Baseline Outcomes simi- } \\
\text { lar? }\end{array}$ & Unclear risk & No baseline measurement of outcome \\
\hline Free of contamination? & Low risk & Done \\
\hline $\begin{array}{l}\text { Baseline characteristics } \\
\text { similar? }\end{array}$ & Low risk & Done, Table 1 \\
\hline
\end{tabular}

Kerremans 2009

\begin{tabular}{ll}
\hline Methods & STUDY DESIGN: RCT \\
& Risk of Bias: MEDIUM \\
\hline Participants & PROVIDERS: all physicians in hospital \\
& PARTICIPANTS: 211 patients with positive blood cultures ( 93 intervention, 108 control) \\
& CLINICAL PROBLEM: antibiotic use in adult patients with bacterial infections \\
& SETTING: 1 tertiary-care university medical centre in the Netherlands
\end{tabular}

Interventions FORMAT: Intervention: structural - other (out-of-hours blood culture incubator intended to reduce laboratory turnaround time)

Intervention Function: environmental restructuring

DELIVERER: specialist physician 
Kerremans 2009 (Continued)

COMPARISON: usual care

DESIRED CHANGE: increase effective

POWER CALCULATION: no information. In the Discussion, the authors say "our sample size was too small to study the impacts of time to positivity (Gram stain), identification, and susceptibility testing separately on outcome".

Outcomes $\quad$ PRESCRIBING: Choice: time to first antibiotic regimen change

CLINICAL: Intended: mortality and length of stay

Notes

FINANCIAL SUPPORT: Funding: Becton Dickinson provided the outside BACTEC incubator used in this study. Competing Interests: none declared

ADDITIONAL DATA: no response from authors to request for additional data

\begin{tabular}{|c|c|c|}
\hline \multicolumn{3}{|l|}{ Risk of bias } \\
\hline Bias & Authors' judgement & Support for judgement \\
\hline $\begin{array}{l}\text { Random sequence genera- } \\
\text { tion (selection bias) }\end{array}$ & Low risk & Computer-generated list by independent epidemiologist \\
\hline $\begin{array}{l}\text { Allocation concealment } \\
\text { (selection bias) }\end{array}$ & High risk & Allocation not concealed \\
\hline $\begin{array}{l}\text { Blinding (performance } \\
\text { bias and detection bias) } \\
\text { All outcomes }\end{array}$ & Unclear risk & No blinding \\
\hline $\begin{array}{l}\text { Incomplete outcome data } \\
\text { (attrition bias) } \\
\text { All outcomes }\end{array}$ & Low risk & 1 episode of missing data in each arm of study \\
\hline $\begin{array}{l}\text { Selective reporting (re- } \\
\text { porting bias) }\end{array}$ & Low risk & Complete outcomes reported. \\
\hline Other bias & Low risk & \\
\hline $\begin{array}{l}\text { Baseline Outcomes simi- } \\
\text { lar? }\end{array}$ & Low risk & States no significant differences at baseline. \\
\hline Free of contamination? & Low risk & Rapid reporting only occurred for intervention participants. \\
\hline $\begin{array}{l}\text { Baseline characteristics } \\
\text { similar? }\end{array}$ & Low risk & States no significant differences at baseline. \\
\hline
\end{tabular}

Khan 2003

\begin{tabular}{ll}
\hline Methods & STUDY DESIGN: ITS \\
& Risk of Bias: MEDIUM \\
\hline Participants & PROVIDERS: all physicians in hospital \\
& PARTICIPANTS: all patients in hospital \\
& CLINICAL PROBLEM: Clostridium difficile-associated diarrhoea
\end{tabular}


Khan 2003 (Continued)

SETTING: an 800-bed non-teaching hospital in the UK

FORMAT: no valid prescribing data. Restriction with educational meetings and dissemination of guide-
line.
DELIVERER: specialist physician
COMPARISON: usual care
DESIRED CHANGE: decrease excessive

\begin{tabular}{ll}
\hline Outcomes & MICROBIAL: incidence of $C$ difficile-associated diarrhoea \\
\hline Notes & FINANCIAL SUPPORT: no information \\
& ADDITIONAL DATA: no response from authors to request for additional data \\
\hline
\end{tabular}

\section{Risk of bias}

\begin{tabular}{|c|c|c|}
\hline Bias & Authors' judgement & Support for judgement \\
\hline $\begin{array}{l}\text { Intervention independent } \\
\text { (ITS)? }\end{array}$ & Low risk & $>1$ year data in each of the 3 phases \\
\hline $\begin{array}{l}\text { Analysed appropriately } \\
\text { (ITS)? }\end{array}$ & Low risk & $\begin{array}{l}\text { Re-analysed. Not done in original paper: no statistical analysis, mean cases per } \\
\text { quarter compared between periods. }\end{array}$ \\
\hline $\begin{array}{l}\text { Shape of effect pre-speci- } \\
\text { fied (ITS) ? }\end{array}$ & Low risk & $\begin{array}{l}\text { Done, intended effect was decrease in primary outcome, and point of analysis } \\
\text { was point of intervention. }\end{array}$ \\
\hline $\begin{array}{l}\text { Unlikely to affect data col- } \\
\text { lection (ITS)? }\end{array}$ & Low risk & $\begin{array}{l}\text { Done, data were from routine systems and unlikely to change over study peri- } \\
\text { od. }\end{array}$ \\
\hline $\begin{array}{l}\text { Knowledge of the alloca- } \\
\text { tion adequately prevent- } \\
\text { ed(ITS)? }\end{array}$ & Low risk & $\begin{array}{l}\text { Done, data were from routine systems and unlikely to change over study peri- } \\
\text { od. }\end{array}$ \\
\hline $\begin{array}{l}\text { Incomplete outcome data } \\
\text { addressed (ITS)? }\end{array}$ & Low risk & $\begin{array}{l}\text { Done, data were from routine systems and unlikely to change over study peri- } \\
\text { od. }\end{array}$ \\
\hline $\begin{array}{l}\text { Free of selected reporting } \\
\text { (ITS)? }\end{array}$ & Low risk & $\begin{array}{l}\text { Done: "The standard operating procedure for selection and processing stool } \\
\text { specimens did not change over the study period. All stool specimens from in- } \\
\text { patients with liquid or bloody diarrhoea and those receiving antibiotic thera- } \\
\text { py were tested for C. difficile toxin. C. difficile toxin was detected by cytotoxic } \\
\text { activity on a fibroblast cell line, with specific neutralization by Clostridium sor- } \\
\text { delli antiserum" }\end{array}$ \\
\hline Free of other bias (ITS)? & High risk & $\begin{array}{l}\text { NOT DONE for the intervention that was intended to reduce } C \text { difficile infection } \\
\text { in Phase } 3 \text { Microbial Outcome Risk of Bias: Planned intervention: NOT DONE } \\
\text { for unplanned intervention Phase } 3 \text { Case definition: DONE } C \text { difficile infection; } \\
\text { all stool specimens from inpatients with liquid or bloody diarrhoea and those } \\
\text { receiving antibiotic therapy were tested for } C \text { difficile toxin. Other infection } \\
\text { control measures: DONE, well described and same in all } 3 \text { phases }\end{array}$ \\
\hline
\end{tabular}


Kim 2008 (Continued)

PROVIDERS: all physicians in the hospital
PARTICIPANTS: all patients receiving therapeutic antibiotics
CLINICAL PROBLEM: outbreak of ESBL infections
SETTING: 1 hospital in Korea

FORMAT: Interventions: audit and feedback; restrictive by expert approval
Intervention Functions: enablement, restriction
DELIVERER: AMT
COMPARISON: usual care
DESIRED CHANGE: decrease excessive, use of cephalosporins to contain outbreak of ESBL

\begin{tabular}{ll}
\hline Outcomes & PRESCRIBING: use of cephalosporins (DDD/1000 OBD) \\
& MICROBIAL: isolates of ESBL and new patients with ESBL infection \\
\hline Notes & FINANCIAL SUPPORT: Funding: City of Seoul grant \#10920 and KICOS project grant (Battelle Institute, \\
& Korea University). Competing Interests: none declared \\
& ADDITIONAL DATA: no response from authors to request for additional data \\
& Microbial Risk of Bias HIGH. Case definition Low, planned intervention High (response to outbreak of \\
& ESBL), other infection control Unclear (no detail, and authors state that they did not take this into ac- \\
Count in their analysis)
\end{tabular}

\section{Risk of bias}

Bias Authors' judgement Support for judgement

Intervention independent Low risk
(ITS)?

(ITS) ?

\begin{tabular}{lll}
\hline $\begin{array}{l}\text { Analysed appropriately } \\
\text { (ITS) ? }\end{array}$ & Low risk & Not in original paper but re-analysed \\
\hline $\begin{array}{l}\text { Shape of effect pre-speci- } \\
\text { fied (ITS) ? }\end{array}$ & Low risk & Point of analysis was point of intervention.
\end{tabular}

fied (ITS) ?

Unlikely to affect data col- Low risk Data from pharmacy and microbiology computers
lection (ITS) ?

\begin{tabular}{lll}
\hline $\begin{array}{l}\text { Knowledge of the alloca- } \\
\text { tion adequately prevent- } \\
\text { ed(ITS)? }\end{array}$ & Low risk & Data from pharmacy and microbiology computers \\
\hline $\begin{array}{l}\text { Incomplete outcome data } \\
\text { addressed (ITS) ? }\end{array}$ & Low risk & Data from pharmacy and microbiology computers \\
\hline $\begin{array}{l}\text { Free of selected reporting } \\
\text { (ITS) }\end{array}$ & Low risk & Data from pharmacy and microbiology computers \\
\hline Free of other bias (ITS)? & Low risk & \\
\hline
\end{tabular}

Methods STUDY DESIGN: CITS


Knudsen 2014 (Continued)

\section{Risk of Bias: MEDIUM}

Participants

PROVIDERS: all physicians, nurses, and pharmacists in the hospital

PARTICIPANTS: all patients in the hospital

CLINICAL PROBLEM: the intervention was intended to reduce infections caused by ESBL- and Am-

pC-producing gram-negative bacteria

SETTING: 1 university hospital (intervention) and 4 additional hospitals (control) in Denmark

FORMAT: Interventions: audit and feedback; educational meetings; dissemination of guidelines; educational outreach by review and recommend change; reminders (physical, intranet and pocket guidelines; circumstantial, verbal by pharmacy technicians and infection control nurses) Intervention Functions: education, enablement, environmental restructuring, persuasion.

The intervention also included the same components targeted at infection control measures (hand hygiene and isolation).

DELIVERER: AMT

COMPARISON: usual care

DESIRED CHANGE: decrease excessive

Outcomes $\quad$ PRESCRIBING: Choice: cefuroxime use in DDD/1000 OBD

MICROBIAL: cases per 1000 OBD per month

Notes

FINANCIAL SUPPORT: Funding: none. Competing Interests: none declared

ADDITIONAL DATA: the authors provided multiple additional files of information about the intervention, including examples of the feedback newsletters (in Danish).

Microbial Risk of Bias: LOW, case definition low, planned intervention low, other infection control measures low

\section{Risk of bias}

\begin{tabular}{lll}
\hline Bias & Authors' judgement & Support for judgement \\
\hline $\begin{array}{l}\text { Intervention independent } \\
\text { (ITS) ? }\end{array}$ & High risk & $\begin{array}{l}\text { The antimicrobial stewardship intervention was simultaneous with an inter- } \\
\text { vention to improve infection control practice (personal protection and isola- } \\
\text { tion). }\end{array}$ \\
\hline $\begin{array}{l}\text { Analysed appropriately } \\
\text { (ITS) }\end{array}$ & Low risk & Segmented regression analysis \\
\hline
\end{tabular}

Shape of effect pre-speci- Low risk Point of intervention was point of analysis.

fied (ITS) ?

Unlikely to affect data col- Low risk Outcome data from pharmacy and microbiology computuers lection (ITS) ?

Knowledge of the alloca- Low risk Outcome data from pharmacy and microbiology computuers
tion adequately prevented(ITS)?

Incomplete outcome data Low risk $\quad$ Outcome data from pharmacy and microbiology computuers
addressed (ITS)?
addressed (ITS) ?

Free of selected reporting Low risk Outcome data from pharmacy and microbiology computuers
(ITS)?

Free of other bias (ITS) ? Low risk > $\quad$ 1 year of data pre- and postintervention. Microbial risk of bias low


Kristoffersen 2009

\begin{tabular}{ll}
\hline Methods & STUDY DESIGN: RCT \\
& Risk of Bias: MEDIUM \\
\hline Participants & PROVIDERS: all physicians in the hospital \\
& PARTICIPANTS: 210 patients with suspected lower respiratory tract infection (103 intervention, 107 \\
& Control) \\
CLINICAL PROBLEM: antibiotic consumption and length of stay in patients with suspected lower respi- \\
ratory tract infections \\
SETTING: 3 hospitals in Denmark
\end{tabular}

Interventions $\quad$ FORMAT: Interventions: dissemination of guideline; reminders (circumstantial and physical, decision
support algorithm triggered by PCT test result); structural, introduction of PCT testing Intervention Functions: education, enablement, environmental restructuring

DELIVERER: specialist physician

COMPARISON: usual care

DESIRED CHANGE: decrease excessive

POWER CALCULATION: yes, 107 participants in each group. Details in Appendix 3

PRESCRIBING: Choice and exposure: antibiotics prescribed and duration of antibiotic treatment
CLINICAL: Balancing: length of stay and mortality

CLINICAL: Balancing: length of stay and mortality

Notes $\quad$ FINANCIAL SUPPORT: Funding: Danish Medical Research Council and the Danish Lung Association
Study ID: NCT00415753, 271-05-0765. Competing Interests: none declared

ADDITIONAL DATA: no response from authors to request for additional data

\section{Risk of bias}

\begin{tabular}{lll}
\hline Bias & Authors' judgement & Support for judgement \\
\hline $\begin{array}{l}\text { Random sequence genera- } \\
\text { tion (selection bias) }\end{array}$ & Low risk & Computer generated \\
\hline $\begin{array}{l}\text { Allocation concealment } \\
\text { (selection bias) }\end{array}$ & Low risk & Concealed until PCT test results available \\
\hline $\begin{array}{l}\text { Blinding (performance } \\
\text { bias and detection bias) } \\
\text { All outcomes }\end{array}$ & Low risk & Objective outcome measure: length of stay from routine data system \\
\hline $\begin{array}{l}\text { Incomplete outcome data } \\
\text { (attrition bias) }\end{array}$ & Low risk & States that 3 patients died, 2 in PCT and 1 in control \\
\hline $\begin{array}{l}\text { All outcomes } \\
\text { pelective reporting (re- }\end{array}$ & Low risk & Objective outcome measure: length of stay from routine data system \\
\hline $\begin{array}{l}\text { Other bias } \\
\text { Baseline Outcomes simi- } \\
\text { lar? }\end{array}$ & Unclear risk & Adequately powered \\
\hline
\end{tabular}


Kristoffersen 2009 (Continued)

\begin{tabular}{lll} 
Free of contamination? & Low risk & PCT results only available for intervention participants. \\
\hline $\begin{array}{l}\text { Baseline characteristics } \\
\text { similar? }\end{array}$ & Low risk & $\begin{array}{l}\text { Mostly similar apart from those with cancer (7 in PCT and } 0 \text { in control), al- } \\
\text { though this was adjusted for using sensitivity analysis. }\end{array}$ \\
\hline
\end{tabular}

Kritchevsky 2008

\begin{tabular}{ll}
\hline Methods & STUDY DESIGN: cluster RCT, hospital level \\
& Risk of Bias: MEDIUM
\end{tabular}

PROVIDERS: physicians responsible for antimicrobial prophylaxis
PARTICIPANTS: patients undergoing cardiac surgery, hip and knee replacements, and hysterectomy,
44 clusters (hospitals)
CLINICAL PROBLEM: Preoperative antimicrobial prophylaxis
SETTING: 44 acute care hospitals in the USA

Interventions $\quad$ FORMAT: Interventions: educational meetings with dissemination of guideline; educational outreach

Intervention Functions: education, persuasion

DELIVERER: AMT

COMPARISON: usual care

DESIRED CHANGE: increase effective

POWER CALCULATION: yes, 40 hospitals sampling 100 cases per measurement period. Details in Appen$\operatorname{dix} 3$

\begin{tabular}{ll}
\hline Outcomes & PRESCRIBING: Choice and exposure: 5 performance measures of antimicrobial prophylaxis (timing, re- \\
ceipt, duration, selection, and single preoperative dose)
\end{tabular}
ceipt, duration, selection, and single preoperative dose)

Notes FINANCIAL SUPPORT: Funding: grant R01 HS11331-01A1 from the Agency for Healthcare Research and Quality and Centers for Disease Control and Prevention. Competing Interests: none declared

ADDITIONAL DATA: authors provided additional data

\begin{tabular}{lll}
\hline Risk of bias & & \\
\hline Bias & Authors' judgement & Support for judgement \\
\hline $\begin{array}{l}\text { Random sequence genera- } \\
\text { tion (selection bias) }\end{array}$ & Low risk & Computerised random number generator \\
\hline $\begin{array}{l}\text { Allocation concealment } \\
\text { (selection bias) }\end{array}$ & Low risk & By institution \\
\hline $\begin{array}{l}\text { Blinding (performance } \\
\text { bias and detection bias) }\end{array}$ & Unclear risk & Does not say if it was blinded or not \\
$\begin{array}{l}\text { All outcomes } \\
\begin{array}{l}\text { Incomplete outcome data } \\
\text { (attrition bias) } \\
\text { All outcomes }\end{array}\end{array}$ & Low risk & Trained data collectors, completeness assured by project staff. \\
\hline
\end{tabular}


Kritchevsky 2008 (Continued)

Selective reporting (re- Low risk $\quad$ All outcomes reported.
porting bias)

\begin{tabular}{|c|c|c|}
\hline Other bias & High risk & $\begin{array}{l}\text { High risk of selection bias, as hospitals nominated themselves to be included } \\
\text { into the study. }\end{array}$ \\
\hline $\begin{array}{l}\text { Baseline Outcomes simi- } \\
\text { lar? }\end{array}$ & Low risk & See Table 3 \\
\hline Free of contamination? & Low risk & By institution \\
\hline $\begin{array}{l}\text { Baseline characteristics } \\
\text { similar? }\end{array}$ & Low risk & See Table 2 \\
\hline
\end{tabular}

Kumana 2001

\begin{tabular}{ll}
\hline Methods & STUDY DESIGN: ITS \\
& Risk of Bias: LOW
\end{tabular}

Participants PROVIDERS: all physicians in the hospital

PATIENTS: all patients in the hospital

CLINICAL PROBLEM: patients receiving glycopeptides (teicoplanin or vancomycin)

SETTING: 1 hospital in Hong Kong

Interventions $\quad$ FORMAT: Interventions: audit and feedback; educational meetings with dissemination of guidelines Intervention Functions: education, enablement

DELIVERER: AMT

COMPARISON: usual care

DESIRED CHANGE: decrease excessive

Outcomes PRESCRIBING: Choice: DDD per month of glycopeptides

CLINICAL: Balancing: cohort study of patients who died following Staphylococcus aureus bacteraemia

Notes FINANCIAL SUPPORT: Funding: none. Competing Interests: no information

ADDITIONAL DATA: no response from authors to request for additional data

\section{Risk of bias}

\begin{tabular}{lll}
\hline Bias & Authors' judgement & Support for judgement \\
\hline $\begin{array}{l}\text { Intervention independent } \\
\text { (ITS) ? }\end{array}$ & Low risk & $\begin{array}{l}\text { Done, 32 months' pre- and 11 months' postintervention, so secular or seasonal } \\
\text { effects unlikely. }\end{array}$ \\
\hline $\begin{array}{l}\text { Analysed appropriately } \\
\text { (ITS) }\end{array}$ & Low risk & $\begin{array}{l}\text { Re-analysed. Not done in original paper: comparison of means (uncontrolled } \\
\text { before and after) with } x^{2} \text { test. }\end{array}$ \\
\hline $\begin{array}{l}\text { Shape of effect pre-speci- } \\
\text { fied (ITS) ? }\end{array}$ & Low risk & $\begin{array}{l}\text { Done, intended effect was decrease in primary outcome, and point of analysis } \\
\text { was point of intervention. }\end{array}$ \\
\hline
\end{tabular}


Kumana 2001 (Continued)

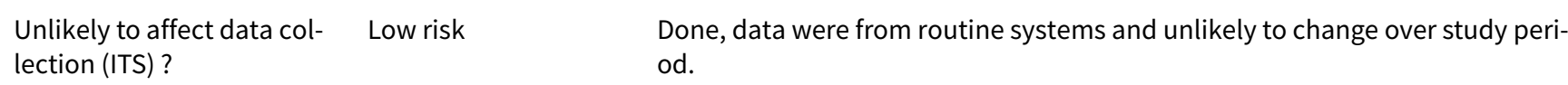

Knowledge of the alloca- Low risk tion adequately preventDone, data were from routine systems and unlikely to change over study peried(ITS)? od.

\begin{tabular}{ll}
\hline $\begin{array}{l}\text { Incomplete outcome data } \\
\text { addressed (ITS) ? }\end{array}$ & $\begin{array}{l}\text { Done, data were from routine systems and unlikely to change over study peri- } \\
\text { od. }\end{array}$
\end{tabular}

Free of selected reporting Low risk 11 months' postintervention data, 32 months' pre-intervention data
(ITS)?
(ITS) ?

Free of other bias (ITS) ? Low risk Reliable primary outcome

\section{Lacroix 2014}

\begin{tabular}{ll}
\hline Methods & STUDY DESIGN: RCT \\
& Risk of Bias: MEDIUM \\
\hline Participants & PROVIDERS: 30 physicians \\
& PARTICIPANTS: 271 children with fever (131 intervention, 140 control) \\
& CLINICAL PROBLEM: fever without source \\
& SETTING: 1 university hospital in Switzerland
\end{tabular}
Interventions $\quad$ FORMAT: Interventions: reminders (circumstantial and physical, decision support lab score derived from PCT, C-reactive protein, and urine dipstick); structural, introduction of PCT testing Intervention Functions: enablement, environmental lab score derived from PCT, C-reactive protein, and urine dipstick DELIVERER: departmental physicians COMPARISON: usual care DESIRED CHANGE: decrease excessive POWER CALCULATION: yes, 140 participants taking into account dropouts. Details in Appendix 3

Outcomes PRESCRIBING: Exposure: \% patients receiving antibiotics

CLINICAL: re-admission and time to clinical resolution

Notes $\quad$ FINANCIAL SUPPORT: Funding: commercial, bioMérieux for data management, statistical analysis, and loan of the procalcitonin assay. Competing Interests: none declared

ADDITIONAL DATA: no response from authors to request for additional data

\section{Risk of bias}

\begin{tabular}{lll}
\hline Bias & Authors' judgement & Support for judgement \\
\hline $\begin{array}{l}\text { Random sequence genera- } \\
\text { tion (selection bias) }\end{array}$ & Low risk & Excel-generated random numbers table \\
\hline $\begin{array}{l}\text { Allocation concealment } \\
\text { (selection bias) }\end{array}$ & Low risk & Sealed envelopes \\
\hline $\begin{array}{l}\text { Blinding (performance } \\
\text { bias and detection bias) }\end{array}$ & Low risk & Outcome measured from routine data. \\
\hline
\end{tabular}


Lacroix 2014 (Continued)

All outcomes

\begin{tabular}{lll}
\hline $\begin{array}{l}\text { Incomplete outcome data } \\
\text { (attrition bias) } \\
\text { All outcomes }\end{array}$ & Low risk & $\begin{array}{l}\text { Incomplete outcome data on } 3 \text { of } 134 \text { control and } 4 \text { of } 140 \text { intervention chil- } \\
\text { dren. }\end{array}$ \\
\hline $\begin{array}{l}\text { Selective reporting (re- } \\
\text { porting bias) }\end{array}$ & Low risk & Outcomes reported on all remaining children. \\
\hline $\begin{array}{l}\text { Other bias } \\
\text { Laseline Outcomes simi- }\end{array}$ & Unclear risk & No data \\
\hline $\begin{array}{l}\text { lar? } \\
\text { Free of contamination? }\end{array}$ & Low risk & $\begin{array}{l}\text { The trial ended after completion of a sufficient number of children at the ex- } \\
\text { pected timing. }\end{array}$ \\
\hline $\begin{array}{l}\text { Baseline characteristics } \\
\text { similar? }\end{array}$ & Low risk & No lab score released for control children. \\
\hline
\end{tabular}

Lafaurie 2012

\begin{tabular}{ll}
\hline Methods & STUDY DESIGN: CITS \\
& Risk of Bias: LOW \\
\hline Participants & PROVIDERS: all physicians in the hospital \\
& PARTICIPANTS: all patients receiving antibiotics \\
& CLINICAL PROBLEM: use of fluoroquinolones \\
& SETTING: 1 university hospital in France (intervention) with control data from 700 hospitals in the Co- \\
& ordinating Centres for Nosocomial Infection Control
\end{tabular}

FORMAT: Interventions: audit and feedback; educational meeting with dissemination of guideline; ed-
ucational outreach by review and recommend change
Intervention Functions: education, enablement, persuasion
DELIVERER: AMT
COMPARISON: usual care
DESIRED CHANGE: decrease excessive

\begin{tabular}{ll}
\hline Outcomes & PRESCRIBING: Choice: fluoroquinolone use in DDD/1000 OBD \\
\hline Notes & FINANCIAL SUPPORT: Funding: none
\end{tabular}

Notes $\quad$ FINANCIAL SUPPORT: Funding: none. Competing Interests: none declared

ADDITIONAL DATA: no response from authors to request for additional data

Microbial Risk of Bias: HIGH, case definition Low, planned intervention Low, other infection control

High, increase in use of alcohol-based handrub throughout study period

\section{Risk of bias}

\begin{tabular}{lll}
\hline Bias & Authors' judgement & Support for judgement \\
\hline $\begin{array}{l}\text { Intervention independent } \\
\text { (ITS)? }\end{array}$ & Low risk & Low risk for prescribing outcome \\
\hline
\end{tabular}


Lafaurie 2012 (Continued)

Analysed appropriately Low risk $\quad$ Segmented regression analysis
(ITS) ?

Low risk

Point of intervention was point of anaysis.

Shape of effect pre-speci- Low risk $\quad$ Point of intervention was point of anaysis.
fied (ITS)?

Unlikely to affect data col- Low risk lection (ITS)?

Data from pharmacy and microbiology computers

\begin{tabular}{lll}
\hline $\begin{array}{l}\text { Knowledge of the alloca- } \\
\text { tion adequately prevent- } \\
\text { ed(ITS)? }\end{array}$ & Low risk & Data from pharmacy and microbiology computers \\
\hline $\begin{array}{l}\text { Incomplete outcome data } \\
\text { addressed (ITS) ? }\end{array}$ & Low risk & Data from pharmacy and microbiology computers \\
\hline $\begin{array}{l}\text { Free of selected reporting } \\
\text { (ITS) }\end{array}$ & Low risk & Data from pharmacy and microbiology computers \\
\hline Free of other bias (ITS) ? & Low risk & $>1$ year of data pre- and postintervention \\
\hline
\end{tabular}

Landgren 1988

\begin{tabular}{ll}
\hline Methods & STUDY DESIGN: CBA \\
& Risk of Bias: HIGH \\
\hline Participants & PROVIDERS: all surgeons at the hospitals \\
& PARTICIPANTS: all patients with clinical problem \\
& CLINICAL PROBLEM: patients receiving surgical antibiotic prophylaxis \\
& SETTING: 12 hospitals in Australia
\end{tabular}

Interventions

FORMAT: Interventions: audit and feedback; educational meetings with dissemination of guidelines; educational outreach by academic detailing; reminders (physical, posters)

Intervention Functions: education, enablement, environmental restructuring, persuasion

DELIVERER: pharmacist

COMPARISON: 6 hospitals were used as control in year 1 , then intervention and control hospitals were crossed over in year 2

DESIRED CHANGE: decrease excessive

\begin{tabular}{ll}
\hline Outcomes & PRESCRIBING: Choice and exposure: appropriate duration and timing of prophylaxis \\
& FINANCIAL: drug cost savings in AUD
\end{tabular}

Notes

FINANCIAL SUPPORT: Funding: Commonwealth Department of Health. Competing Interests: no information

ADDITIONAL DATA: no response from authors to request for additional data

\section{Risk of bias}

\begin{tabular}{lll}
\hline Bias & Authors' judgement & Support for judgement \\
\hline $\begin{array}{l}\text { Random sequence genera- } \\
\text { tion (selection bias) }\end{array}$ & High risk & $\begin{array}{l}\text { CBA; "hospitals were paired being matched as far as possible for type size and } \\
\text { surgical load" }\end{array}$ \\
\hline
\end{tabular}


Landgren 1988 (Continued)

\begin{tabular}{|c|c|c|}
\hline $\begin{array}{l}\text { Allocation concealment } \\
\text { (selection bias) }\end{array}$ & High risk & Not done, CBA \\
\hline $\begin{array}{l}\text { Blinding (performance } \\
\text { bias and detection bias) } \\
\text { All outcomes }\end{array}$ & High risk & Not stated; all hospitals in same Australian state, CBA so not possible \\
\hline $\begin{array}{l}\text { Incomplete outcome data } \\
\text { (attrition bias) } \\
\text { All outcomes }\end{array}$ & Unclear risk & No statement \\
\hline $\begin{array}{l}\text { Selective reporting (re- } \\
\text { porting bias) }\end{array}$ & Low risk & Objective primary outcome measure on all patients \\
\hline Other bias & Low risk & No other apparent biases found. \\
\hline $\begin{array}{l}\text { Baseline Outcomes simi- } \\
\text { lar? }\end{array}$ & Low risk & $\begin{array}{l}\text { Done, pre-intervention data for primary outcome similar in intervention and } \\
\text { control hospitals. }\end{array}$ \\
\hline Free of contamination? & Low risk & Intervention and control sites were different hospitals. \\
\hline $\begin{array}{l}\text { Baseline characteristics } \\
\text { similar? }\end{array}$ & Unclear risk & $\begin{array}{l}\text { Only information is about characteristics of hospital (teaching, rural, etc.), no } \\
\text { data about case mix and unlikely to change over study period. }\end{array}$ \\
\hline
\end{tabular}

Landman 1999

\begin{tabular}{ll}
\hline Methods & STUDY DESIGN: ITS \\
& Risk of Bias: HIGH \\
\hline
\end{tabular}

PROVIDERS: all physicians in the hospital
PARTICIPANTS: all patients in the hospital
CLINICAL PROBLEM: patients requiring antibiotic treatment
SETTING: university hospital in the USA

Interventions

FORMAT: no valid prescribing outcome data. Restriction.

DELIVERER: specialist physician

COMPARISON: usual care

DESIRED CHANGE: decrease excessive
Outcomes MICROBIAL: Incidence (new cases per 1000 discharges per month) of ceftazidime-resistant Klebsiella pneumoniae, MRSA, and cefotaxime-resistant Acinetobacter species (ITS data)

Notes

FINANCIAL SUPPORT: no information

ADDITIONAL DATA: no response from authors to request for additional data

Microbial Risk of Bias MEDIUM: case definition: Low; planned intervention: Low; infection control practices: High. At the start of the intervention, contact precautions were changed to include patients with Clostridium difficile infection.

\section{Risk of bias}


Landman 1999 (Continued)

Intervention independent Low risk Reliable primary outcome

(ITS) ?

$\begin{array}{ll}\begin{array}{l}\text { Analysed appropriately } \\ \text { (ITS) ? }\end{array} & \text { Low risk } \\ \end{array}$

$\begin{array}{ll}\begin{array}{l}\text { Shape of effect pre-speci- } \\ \text { fied (ITS) ? }\end{array} & \text { Low risk } \\ & \text { was point of intervention. }\end{array}$

\begin{tabular}{lll}
\hline $\begin{array}{l}\text { Unlikely to affect data col- } \\
\text { lection (ITS) ? }\end{array}$ & Low risk & $\begin{array}{l}\text { Done, data were from routine systems and unlikely to change over study peri- } \\
\text { od. }\end{array}$ \\
\hline $\begin{array}{l}\text { Knowledge of the alloca- } \\
\text { tion adequately prevent- } \\
\text { ed(ITS)? }\end{array}$ & Low risk & $\begin{array}{l}\text { Done, data were from routine systems and unlikely to change over study peri- } \\
\text { od. }\end{array}$
\end{tabular}
ed(ITS)?

\begin{tabular}{lll}
\hline $\begin{array}{l}\text { Incomplete outcome data } \\
\text { addressed (ITS) } ?\end{array}$ & Unclear risk & $\begin{array}{l}\text { Done, data were from routine systems and unlikely to change over study peri- } \\
\text { od. }\end{array}$ \\
\hline $\begin{array}{l}\text { Free of selected reporting } \\
\text { (ITS) } ?\end{array}$ & Unclear risk & Not clear, no information about protocols for clinical sampling or testing \\
\hline Free of other bias (ITS) ? & High risk & Change in infection control practices at start of intervention \\
\hline
\end{tabular}

\section{LaRosa 2007}

Methods STUDY DESIGN: unintended consequences, cross-sectional and cohort study

\section{Risk of Bias: LOW}

PROVIDERS: all physicians in the hospital
PARTICIPANTS: 15,440 patients (cross-sectional) and 360 patients (cohort)
CLINICAL PROBLEM: receiving restricted antibiotics
SETTING: 1 hospital in the USA

\begin{tabular}{ll}
\hline Interventions & FORMAT, Interventions: restrictive by prior approval \\
Intervention Functions: restriction \\
DELIVERER: AMT \\
COMPARISON: usual care \\
DESIRED CHANGE: decrease excessive
\end{tabular}

\begin{tabular}{ll}
\hline Outcomes & UNINTENDED CONSEQUENCES: delay in ordering of restricted antibiotics \\
\hline Notes & ROBINS-I RISK OF BIAS CRITERIA: \\
1. Confounding: Low, confounding of the effect of intervention unlikely in this study \\
2. Selection of participants into the study: Low, selection into the study unrelated to intervention or \\
outcome \\
3. Measurement of interventions: Low, intervention status well defined, recorded at the time of inter- \\
vention and unaffected by knowledge of the outcome or risk of the outcome \\
$\begin{array}{l}\text { 4. Departures from intended interventions: Low, no switches to other interventions or evidence of inter- } \\
\text { vention failure } \\
\text { 5. Missing data: Low, outcome data and intervention status complete for both cross-sectional and co- } \\
\text { hort study }\end{array}$
\end{tabular}


6. Measurement of outcome: Low, outcome measures objective and ascertained from patient administration system

7. Selection of the reported result: Low, single analysis of prespecified outcomes

FINANCIAL SUPPORT: Funding: Centers for Education and Research on Therapeutics grant (U18HS10399) from the Agency for Healthcare Research and Quality (AHRQ), the Mentored Patient-Oriented Research Career Development Award (K23-AI-060887-01) of the NIH from the National Institute of Allergy and Infectious Diseases, Public Health Service grant (DK-02987-01) of the NIH, and an Improving Patient Safety Through Reduction in Medication Errors grant (P01-HS11530-01) from the AHRQ.

Competing Interests: none declared

ADDITIONAL DATA: no response from authors to request for additional data

Lautenbach 2003

\begin{tabular}{ll}
\hline Methods & STUDY DESIGN: ITS \\
& Risk of Bias: LOW
\end{tabular}

PROrticipants
PARTICIPANTS: all patients in the hospital
CLINICAL PROBLEM: requiring antibiotic treatment
SETTING: 1 university hospital in the USA

Interventions $\quad$ FORMAT: Intervention: restrictive by expert approval, not clear if there was also removal Intervention Functions: restriction

DELIVERER: AMT

COMPARISON: usual care

DESIRED CHANGE: decrease excessive

\begin{tabular}{ll}
\hline Outcomes & PRESCRIBING: Choice: vancomycin use in DDD per 1000 patient days \\
& MICROBIAL: proportion of enterococci resistant to vancomycin \\
\hline Notes & FINANCIAL SUPPORT: Funding: Public Health Service (grant DK-02987-01) of the National Institutes of \\
& Health (to EL). This study was also supported in part by an Agency for Healthcare Research and Quality \\
& Centers for Education and Research on Therapeutics co-operative agreement (U18-HS10399). Compet- \\
ing Interests: no information
\end{tabular}

ADDITIONAL DATA: authors provided additional prescribing data to enable segmented regression analysis

Microbial Risk of Bias HIGH: Case definition: Low. Planned intervention: High: unplanned intervention in response to emergence of VRE over the previous 3 years. Other infection control measures: Low

\section{Risk of bias}

\begin{tabular}{|c|c|}
\hline Bias & Authors' judgement Support for judgement \\
\hline $\begin{array}{l}\text { Intervention independent } \\
\text { (ITS)? }\end{array}$ & Low risk \\
\hline $\begin{array}{l}\text { Analysed appropriately } \\
\text { (ITS)? }\end{array}$ & Low risk \\
\hline
\end{tabular}


Lautenbach 2003 (Continued)

Shape of effect pre-speci- Low risk fied (ITS) ?

Unlikely to affect data col- Low risk lection (ITS) ?

\section{Knowledge of the alloca- Low risk tion adequately prevent- ed(ITS)?}

Incomplete outcome data Low risk
addressed (ITS) ?

Free of selected reporting Low risk (ITS) ?

Free of other bias (ITS) ? High risk Microbial outcome risk of bias: HIGH .

Lawes 2012

\begin{tabular}{ll}
\hline Methods & STUDY DESIGN: ITS \\
& Risk of Bias: MEDIUM \\
\hline Participants & PROVIDERS: all physicians in the hospital \\
& PARTICIPANTS: all patients in the hospital \\
& CLINICAL PROBLEM: Staphylococcus aureus bacteraemia and use of antibiotics considered to be high \\
risk for Clostridium difficile infection \\
SETTING: 1 university hospital in the UK
\end{tabular}

Interventions $\quad$ FORMAT: Interventions: dissemination of new antibiotic policy 3 months before the structural intervention; restrictive: the new antibiotic policy included requirement for expert approval; structural: introduction of universal screening for MRSA

Intervention Functions: education, environmental restructuring, restriction

DELIVERER: AMT

COMPARISON: usual care

DESIRED CHANGE: decrease excessive

Outcomes $\quad$ PRESCRIBING: Choice: no valid data for re-analysis in the paper, but the authors' ARIMA time series analysis includes the effect of the change in antibiotic policy on the microbial outcomes

MICROBIAL: S aureus bacteraemias, MRSA, and MSSA

Notes

FINANCIAL SUPPORT: Funding: Scottish government Health Directorate. Competing Interests: IG has received personal and grant financial support from companies manufacturing diagnostics and therapeutics for MRSA. BE has received grant financial support from Novartis. Other authors: none

ADDITIONAL DATA: authors provided additional data

Microbial Risk of Bias MEDIUM: case definition High, MRSA screening introduced the same time as change in antibiotic policy, planned intervention Low, other infection control Low for isolation and personal infection control

\section{Risk of bias}

Bias Authors' judgement Support for judgement


Lawes 2012 (Continued)

Intervention independent High risk The change in antibiotic policy was 9 months after the introduction of MRSA (ITS) ? screening. The authors' analysis suggests an independent effect from the policy change.

Analysed appropriately $\quad$ Low risk $\quad$ ARIMA time series analysis
(ITS)?

Shape of effect pre-speci- Low risk Point of analysis was point of intervention.

fied (ITS) ?

Unlikely to affect data col- Low risk $\quad$ Routine patient administration systems
lection (ITS) ?

Knowledge of the alloca- Low risk Routine patient administration systems
tion adequately prevent-

\begin{tabular}{lll}
\hline $\begin{array}{l}\text { Incomplete outcome data } \\
\text { addressed (ITS) } ?\end{array}$ & Low risk & Routine patient administration systems \\
\hline $\begin{array}{l}\text { Free of selected reporting } \\
\text { (ITS) } ?\end{array}$ & Low risk & Routine patient administration systems \\
\hline Free of other bias (ITS) ? & Low risk & Other microbial ROB criteria low \\
\hline
\end{tabular}

\section{Layios 2012}

\begin{tabular}{ll}
\hline Methods & STUDY DESIGN: RCT \\
& Risk of Bias: HIGH \\
\hline Participants & PROVIDERS: all physicians in the ICUs \\
& PARTICIPANTS: 389 patients in the ICUs for $>48$ h and with PCT measured (211 intervention, 178 con- \\
trol) & CLINICAL PROBLEM: duration of antibiotic treatment \\
& SETTING: 5 ICUs in 1 university hospital in Belgium \\
\hline Interventions & FORMAT: Interventions: reminders (circumstantial and physical, decision support algorithm triggered \\
& by PCT test result); structural, introduction of PCT testing \\
& Intervention Functions: enablement, environmental restructuring \\
& DELIVERER: specialist physician (ICU and respiratory) \\
COMPARISON: usual care & DESIRED CHANGE: decrease excessive \\
& POWER CALCULATION: yes, 250 participants in each group. Details in Appendix 3
\end{tabular}

Outcomes PRESCRIBING: Exposure: antibiotic consumption as \% ICU days and DDD/100 OBD

CLINICAL: mortality, length of ICU stay, days on ventilator

Notes $\quad$ FINANCIAL SUPPORT: Funding: none. Competing Interests: none declared

ADDITIONAL DATA: no response from authors to request for additional data

\section{Risk of bias}


Layios 2012 (Continued)

\begin{tabular}{|c|c|c|}
\hline Bias & Authors' judgement & Support for judgement \\
\hline $\begin{array}{l}\text { Random sequence genera- } \\
\text { tion (selection bias) }\end{array}$ & Unclear risk & "patients were prospectively randomized", but no information about how \\
\hline $\begin{array}{l}\text { Allocation concealment } \\
\text { (selection bias) }\end{array}$ & Unclear risk & "patients were prospectively randomized", but no information about how \\
\hline $\begin{array}{l}\text { Blinding (performance } \\
\text { bias and detection bias) } \\
\text { All outcomes }\end{array}$ & Low risk & Procalcitonin only reported for intervention participants. \\
\hline $\begin{array}{l}\text { Incomplete outcome data } \\
\text { (attrition bias) } \\
\text { All outcomes }\end{array}$ & Low risk & Outcomes reported on all participants. \\
\hline $\begin{array}{l}\text { Selective reporting (re- } \\
\text { porting bias) }\end{array}$ & Low risk & Outcomes reported on all participants. \\
\hline Other bias & High risk & Study did not achieve recruitment required by power calculation. \\
\hline $\begin{array}{l}\text { Baseline Outcomes simi- } \\
\text { lar? }\end{array}$ & Unclear risk & No data \\
\hline Free of contamination? & Low risk & Procalcitonin only reported for intervention participants. \\
\hline $\begin{array}{l}\text { Baseline characteristics } \\
\text { similar? }\end{array}$ & Low risk & Table 1 \\
\hline
\end{tabular}

Lee 1995

\begin{tabular}{ll}
\hline Methods & STUDY DESIGN: ITS \\
& Risk of Bias: MEDIUM \\
\hline
\end{tabular}

PROVIDERS: physicians
PATIENTS: a total of 480 patients reviewed during study period
CLINICAL PROBLEM: patients receiving ceftriaxone
SETTING: a hospital in the USA

Interventions

FORMAT: Interventions: educational meetings with dissemination of guidelines; reminders (circumstantial and physical, letters sent to physicians when intervention needed plus posters)

Intervention Functions: education, enablement, environmental restructuring, persuasion

DELIVERER: AMT

COMPARISON: usual care

DESIRED CHANGE: decrease excessive

Outcomes

PRESCRIBING: Choice: grams of ceftriaxone and cefotaxime

FINANCIAL: cost of intervention (0.5 FTE ID physician and savings on drug costs)

Notes $\quad$ FINANCIAL SUPPORT: no information


Lee 1995 (Continued)

ADDITIONAL DATA: no response from authors to request for additional data

\section{Risk of bias}

\begin{tabular}{|c|c|c|}
\hline Bias & Authors' judgement & Support for judgement \\
\hline $\begin{array}{l}\text { Intervention independent } \\
\text { (ITS)? }\end{array}$ & Low risk & \\
\hline $\begin{array}{l}\text { Analysed appropriately } \\
\text { (ITS)? }\end{array}$ & Low risk & Re-analysed \\
\hline $\begin{array}{l}\text { Shape of effect pre-speci- } \\
\text { fied (ITS)? }\end{array}$ & Low risk & Point of intervention was point of analysis. \\
\hline $\begin{array}{l}\text { Unlikely to affect data col- } \\
\text { lection (ITS)? }\end{array}$ & Low risk & Data from pharmacy computer \\
\hline $\begin{array}{l}\text { Knowledge of the alloca- } \\
\text { tion adequately prevent- } \\
\text { ed(ITS)? }\end{array}$ & Low risk & Data from pharmacy computer \\
\hline $\begin{array}{l}\text { Incomplete outcome data } \\
\text { addressed (ITS)? }\end{array}$ & Low risk & Data from pharmacy computer \\
\hline $\begin{array}{l}\text { Free of selected reporting } \\
\text { (ITS)? }\end{array}$ & Low risk & Data from pharmacy computer \\
\hline Free of other bias (ITS) ? & High risk & $\begin{array}{l}>1 \text { year data pre- and postintervention, but only } 4 \text { postintervention time } \\
\text { points (quarterly data) }\end{array}$ \\
\hline
\end{tabular}

Lee 2007

\begin{tabular}{ll} 
Methods & STUDY DESIGN: ITS \\
& Risk of Bias: LOW \\
\hline Participants & PROVIDERS: all staff in the hospital \\
& PARTICIPANTS: all patients receiving cephalosporins \\
CLINICAL PROBLEM: high endemic rate of ESBL infections \\
SETTING: 1 university children's hospital in Korea
\end{tabular}

Interventions $\quad$ FORMAT: Intervention: educational outreach by review and recommend change Intervention Functions: enablement, persuasion

DELIVERER: specialist physicians (paediatric ID)

COMPARISON: pre-intervention

DESIRED CHANGE: decrease in use of extended-spectrum cephalosporins to reduce ESBL infections

Outcomes $\quad$ PRESCRIBING: Choice: days on target antibiotics/1000 OBD

MICROBIAL: ESBL strains as \% total isolates

Notes FINANCIAL SUPPORT: Funding: Wyeth Research. Competing Interests: none declared.

ADDITIONAL DATA: no response from authors to request for additional data 
Microbial Risk of Bias LOW: case definition yes, planned intervention yes, stable ESBL for 3 years preintervention, other infection control yes

\begin{tabular}{|c|c|c|}
\hline \multicolumn{3}{|l|}{ Risk of bias } \\
\hline Bias & Authors' judgement & Support for judgement \\
\hline $\begin{array}{l}\text { Intervention independent } \\
\text { (ITS)? }\end{array}$ & Low risk & Infection control policies unchanged throughout (page 631). \\
\hline $\begin{array}{l}\text { Analysed appropriately } \\
\text { (ITS)? }\end{array}$ & Low risk & Re-analysed \\
\hline $\begin{array}{l}\text { Shape of effect pre-speci- } \\
\text { fied (ITS)? }\end{array}$ & Low risk & Decrease \\
\hline $\begin{array}{l}\text { Unlikely to affect data col- } \\
\text { lection (ITS)? }\end{array}$ & Low risk & $\begin{array}{l}\text { Data about prescribing and microbial outcomes were from routine, electronic } \\
\text { data systems. }\end{array}$ \\
\hline $\begin{array}{l}\text { Knowledge of the alloca- } \\
\text { tion adequately prevent- } \\
\text { ed(ITS)? }\end{array}$ & Low risk & $\begin{array}{l}\text { Data about prescribing and microbial outcomes were from routine, electronic } \\
\text { data systems. }\end{array}$ \\
\hline $\begin{array}{l}\text { Incomplete outcome data } \\
\text { addressed (ITS)? }\end{array}$ & Low risk & $\begin{array}{l}\text { Data about prescribing and microbial outcomes were from routine, electronic } \\
\text { data systems. }\end{array}$ \\
\hline $\begin{array}{l}\text { Free of selected reporting } \\
\text { (ITS)? }\end{array}$ & Low risk & $\begin{array}{l}\text { Data about prescribing and microbial outcomes were from routine, electronic } \\
\text { data systems. }\end{array}$ \\
\hline Free of other bias (ITS)? & Low risk & $\begin{array}{l}4 \text { years' data pre- and } 3 \text { years' data postintervention, so can account for tem- } \\
\text { poral trends. }\end{array}$ \\
\hline
\end{tabular}

\section{Lee 2014}

Methods STUDY DESIGN: ITS

\section{Risk of Bias: LOW}

PROVIDERS: all physicians in the units
PARTICIPANTS: all patients in the units
CLINICAL PROBLEM: requiring therapeutic antibiotics
SETTING: internal medicine ( 2 units) at 1 university hospital in Canada

Interventions

FORMAT: Interventions: audit and feedback; educational meetings (monthly with residents) with dissemination of educational materials

Intervention Functions: education, enablement, persuasion

DELIVERER: AMT

COMPARISON: usual care

DESIRED CHANGE: decrease excessive

PRESCRIBING: Choice: DDD/1000 OBD of target antibiotics
FINANCIAL: intervention cost and savings (cost of all antibiotics)

Notes

FINANCIAL SUPPORT: Funding: none. Competing Interests: none declared 
Lee 2014 (Continued)

ADDITIONAL DATA: authors provided additional data about the intervention and for the meta-regression

\begin{tabular}{|c|c|c|}
\hline \multicolumn{3}{|l|}{ Risk of bias } \\
\hline Bias & Authors' judgement & Support for judgement \\
\hline $\begin{array}{l}\text { Intervention independent } \\
\text { (ITS)? }\end{array}$ & Low risk & \\
\hline $\begin{array}{l}\text { Analysed appropriately } \\
\text { (ITS)? }\end{array}$ & Low risk & Segmented regression analysis \\
\hline $\begin{array}{l}\text { Shape of effect pre-speci- } \\
\text { fied (ITS)? }\end{array}$ & Low risk & Point of intervention was point of analysis. \\
\hline $\begin{array}{l}\text { Unlikely to affect data col- } \\
\text { lection (ITS)? }\end{array}$ & Low risk & Outcomes were measured from electronic pharmacy data. \\
\hline $\begin{array}{l}\text { Knowledge of the alloca- } \\
\text { tion adequately prevent- } \\
\text { ed(ITS)? }\end{array}$ & Low risk & Outcomes were measured from electronic pharmacy data. \\
\hline $\begin{array}{l}\text { Incomplete outcome data } \\
\text { addressed (ITS)? }\end{array}$ & Low risk & Outcomes were measured from electronic pharmacy data. \\
\hline $\begin{array}{l}\text { Free of selected reporting } \\
\text { (ITS)? }\end{array}$ & Low risk & Outcomes were measured from electronic pharmacy data. \\
\hline Free of other bias (ITS)? & Low risk & $>12$ months' data pre- and postintervention \\
\hline
\end{tabular}

Lesprit 2013

\begin{tabular}{ll} 
Methods & STUDY DESIGN: RCT \\
& Risk of Bias: MEDIUM \\
\hline Participants & PROVIDERS: all physicians in medical and surgical wards \\
& PARTICIPANTS: 753 patients receiving antibiotics ( 376 intervention, 377 control) \\
& CLINICAL PROBLEM: duration of treatment in patients receiving 1 of the targeted antibiotics for at least \\
& 3 days \\
& SETTING: 1 university hospital in France
\end{tabular}

Interventions

FORMAT: Intervention: educational outreach by review and recommend change

Intervention Functions: enablement, persuasion

DELIVERER: AMT

COMPARISON: usual care

DESIRED CHANGE: decrease excessive

POWER CALCULATION: yes, 253 participants in each group. Details in Appendix 3
Outcomes
PRESCRIBING: Exposure: duration of all antibiotic treatment
CLINICAL: Balancing: mortality, ICU admission, new course of antibiotic treatment, length of stay
FINANCIAL: intervention cost and savings (supplementary file) 
MICROBIAL: secondary infection and/or colonisation with multidrug-resistant bacteria in the 6 months following randomisation

Notes

FINANCIAL SUPPORT:Funding: none. Competing Interests: none declared

ADDITIONAL DATA: supplementary file online with data about financial and microbial outcomes, no response from authors to request for additional data

Microbial Risk of Bias: case defintion low, planned intervention low, other infection control unclear, no information

\section{Risk of bias}

\begin{tabular}{|c|c|c|}
\hline Bias & Authors' judgement & Support for judgement \\
\hline $\begin{array}{l}\text { Random sequence genera- } \\
\text { tion (selection bias) }\end{array}$ & Low risk & $\begin{array}{l}\text { Eligible patients were allocated to either the intervention or the control group } \\
\text { using a computer-generated randomisation list, which was maintained inde- } \\
\text { pendently of the IDP. }\end{array}$ \\
\hline $\begin{array}{l}\text { Allocation concealment } \\
\text { (selection bias) }\end{array}$ & Low risk & $\begin{array}{l}\text { Concealment of the allocation was maintained, as the physician in charge of } \\
\text { the patient and the IDP were involved only after randomisation. }\end{array}$ \\
\hline $\begin{array}{l}\text { Blinding (performance } \\
\text { bias and detection bias) } \\
\text { All outcomes }\end{array}$ & High risk & Blinding was not possible. \\
\hline $\begin{array}{l}\text { Incomplete outcome data } \\
\text { (attrition bias) } \\
\text { All outcomes }\end{array}$ & Low risk & No participants were lost to follow-up. \\
\hline $\begin{array}{l}\text { Selective reporting (re- } \\
\text { porting bias) }\end{array}$ & Low risk & Outcomes reported on all participants. \\
\hline Other bias & Low risk & \\
\hline $\begin{array}{l}\text { Baseline Outcomes simi- } \\
\text { lar? }\end{array}$ & Unclear risk & No data \\
\hline Free of contamination? & Low risk & IDP only visited intervention participants. \\
\hline $\begin{array}{l}\text { Baseline characteristics } \\
\text { similar? }\end{array}$ & Low risk & Table 1 \\
\hline
\end{tabular}

Leverstein-van Hall 2001

Methods STUDY DESIGN: ITS

\section{Risk of Bias: HIGH}

Participants

PROVIDERS: Departments of Neurology and Neurosurgery

PARTICIPANTS: all patients in the departments

CLINICAL PROBLEM: colonisation with gentamicin-resistant Enterobacteriaceae

SETTING: 1 858-bed university hospital in the Netherlands

Interventions

FORMAT: no valid prescribing data, restriction by expert approval and removal 
Leverstein-van Hall 2001 (Continued)

DELIVERER: specialist physician

COMPARISON: usual care

DESIRED CHANGE: decrease excessive

\begin{tabular}{ll}
\hline Outcomes & MICROBIAL: prevalence of gentamicin-resistant Enterobacteriaceae in weekly screening stool swabs \\
\hline Notes & FINANCIAL SUPPORT: no information \\
& ADDITIONAL DATA: no response from authors to request for additional data
\end{tabular}

\section{Risk of bias}

\begin{tabular}{lll}
\hline Bias & Authors' judgement & Support for judgement \\
\hline $\begin{array}{ll}\text { Intervention independent } \\
\text { (ITS) ? }\end{array}$ & High risk & $\begin{array}{l}\text { NOT DONE, major changes in infection control } 4 \text { weeks before the antibiotic } \\
\text { restriction. Separate effect cannot be estimated because no screening before } \\
\text { change in infection control. }\end{array}$
\end{tabular}

\begin{tabular}{|c|c|c|}
\hline $\begin{array}{l}\text { Analysed appropriately } \\
\text { (ITS)? }\end{array}$ & Low risk & $\begin{array}{l}\text { Re-analysed. Not done in original paper: no statistical analysis, time series da- } \\
\text { ta presented as run chart. }\end{array}$ \\
\hline $\begin{array}{l}\text { Shape of effect pre-speci- } \\
\text { fied (ITS) ? }\end{array}$ & Low risk & $\begin{array}{l}\text { Done, intended effect was decrease in primary outcome, and point of analysis } \\
\text { was point of intervention. }\end{array}$ \\
\hline $\begin{array}{l}\text { Unlikely to affect data col- } \\
\text { lection (ITS)? }\end{array}$ & Low risk & Screening protocol was the same pre- and postintervention. \\
\hline $\begin{array}{l}\text { Knowledge of the alloca- } \\
\text { tion adequately prevent- } \\
\text { ed(ITS)? }\end{array}$ & Low risk & Screening protocol was the same pre- and postintervention. \\
\hline $\begin{array}{l}\text { Incomplete outcome data } \\
\text { addressed (ITS)? }\end{array}$ & Unclear risk & $\begin{array}{l}\text { NOT CLEAR, no explicit statement about complete screening samples for all } \\
\text { participants }\end{array}$ \\
\hline $\begin{array}{l}\text { Free of selected reporting } \\
\text { (ITS)? }\end{array}$ & Unclear risk & $\begin{array}{l}\text { NOT CLEAR, no explicit statement about complete screening samples for all } \\
\text { participants }\end{array}$ \\
\hline Free of other bias (ITS)? & High risk & $\begin{array}{l}\text { Microbial Outcome Risk of Bias Criteria: Case definition: DONE colonisation } \\
\text { by screening; Planned intervention: NOT DONE, in response to increase in GRE; } \\
\text { Other infection control practices: NOT DONE changes } 4 \text { weeks before antibiot- } \\
\text { ic restriction; Isolation: isolation of gentamicin-resistantEnterobacteriaceae- } \\
\text { positive patients in either side-rooms or cohorted with other positive patients; } \\
\text { IC practices: increase in education plus several new hygiene practices: dispos- } \\
\text { able washing gloves, elbow-directed soap dispensers; new room-cleaning pro- } \\
\text { tocol. Hygiene was emphasised and more stringent barrier precautions. }\end{array}$ \\
\hline
\end{tabular}

Liebowitz 2008

\begin{tabular}{ll}
\hline Methods & STUDY DESIGN: ITS \\
& Risk of Bias: LOW \\
\hline Participants & PROVIDERS: all physicians in the hospital \\
& PARTICIPANTS: all patients in the hospital \\
& CLINICAL PROBLEM: incidences of MRSA \\
\hline
\end{tabular}


Liebowitz 2008 (Continued)

SETTING: 1 general hospital in the UK

FORMAT: Intervention: educational meetings with dissemination of guideline; reminders, verbal on rounds

Intervention Function: education, persuasion

DELIVERER: AMT

COMPARISON: usual care

DESIRED CHANGE: reduce inappropriate

\begin{tabular}{ll}
\hline Outcomes & PRESCRIBING: Choice: DDDs per 1000 OBD each month \\
& MICROBIAL: Episodes of MRSA blood isolates per 1000 OBD each month \\
\hline Notes & FINANCIAL SUPPORT: Funding: unrestricted educational grant from Wyeth. Competing Interests: LDL \\
& received honoraria for lectures from Bayer and Bard. \\
& ADDITIONAL DATA: no response from authors to request for additional data \\
& $\begin{array}{l}\text { Microbial ROB HIGH; case definition Low, planned intervention Low, other infection control High, no } \\
\text { information about infection control other than screening for MRSA }\end{array}$
\end{tabular}

\section{Risk of bias}

\begin{tabular}{lll}
\hline Bias & Authors' judgement & Support for judgement \\
\hline $\begin{array}{l}\text { Intervention independent } \\
\text { (ITS) }\end{array}$ & Low risk & 18 months' pre- and 15 months' postintervention data \\
\hline $\begin{array}{l}\text { Analysed appropriately } \\
\text { (ITS) ? }\end{array}$ & Low risk & Segmented regresssion analysis \\
\hline $\begin{array}{l}\text { Shape of effect pre-speci- } \\
\text { fied (ITS) ? }\end{array}$ & Low risk & Point of analysis is point of intervention. \\
\hline $\begin{array}{l}\text { Unlikely to affect data col- } \\
\text { lection (ITS) ? }\end{array}$ & Low risk & Pharmacy data used pre- and postintervention. \\
\hline $\begin{array}{l}\text { Knowledge of the alloca- } \\
\text { tion adequately prevent- } \\
\text { ed(ITS)? }\end{array}$ & Low risk & Pharmacy data used pre- and postintervention. \\
\hline
\end{tabular}

Incomplete outcome data Low risk Pharmacy data used pre- and postintervention.
addressed (ITS) ?

Free of selected reporting Low risk Pharmacy data used pre- and postintervention.
(ITS)?

Free of other bias (ITS) ? Low risk >1 year data pre- and postintervention

Linkin 2007

Methods STUDY DESIGN: unintended consequences, cohort study

\section{Risk of Bias: MEDIUM}

Interventions to improve antibiotic prescribing practices for hospital inpatients (Review) 
Linkin 2007 (Continued)

Participants
PROVIDERS: all physicians in the hospital

PARTICIPANTS: 200 patients

CLINICAL PROBLEM: requests for restricted antibiotic to the Antimicrobial Stewardship Program SETTING: 1 hospital in the USA

Interventions

FORMAT: Interventions: restrictive

Intervention Functions: restriction

DELIVERER: AMT

COMPARISON: patients with appropriate vs inappropriate requests

DESIRED CHANGE: decrease excessive

\section{Outcomes}

UNINTENDED CONSEQUENCES: accuracy of laboratory and clinical information provided in calls to the Antimicrobial Stewardship Program

Notes

ROBINS-I RISK OF BIAS CRITERIA:

1. Confounding: Low, the effects of inaccurate communication and each of the potential confounders on the risk of inappropriate antimicrobial recommendations were evaluated in bivariable analyses

2. Selection of participants into the study: Low, selection into the study unrelated to intervention or outcome

3. Measurement of interventions: Low, antimicrobial recommendations were evaluated for appropriateness by a 3-person panel of infectious diseases experts blinded to the accuracy of information communicated during the Antimicrobial Stewardship Program call

4. Departures from intended interventions: Low, no switches to other interventions or evidence of intervention failure

5. Missing data: High, panelists could not agree on appropriateness of treatment for 37 patients. Outcome data complete for the 163 included patients

6. Measurement of outcome: Low, outcome measures objective and ascertained from patient administration system

7. Selection of the reported result: High, multiple secondary analyses were performed using the main study outcome

FINANCIAL SUPPORT: Funding: National Institutes of Health, Agency for Healthcare Research and Quality, and University of Pennsylvania. Competing Interests: none declared.

ADDITIONAL DATA: no response from authors to request for additional data

Methods STUDY DESIGN: RCT

\section{Risk of Bias: HIGH}

Participants

PROVIDERS: Department of Emergency Medicine, ICU staff

PARTICIPANTS: adults (age $>18$ ) with sepsis

CLINICAL PROBLEM: sepsis without 7 exclusion criteria (cultures positive with Pseudomonas aeruginosa,Acinetobacter baumannii,Mycobacterium tuberculosis or any fungi, viral or parasitic infection, chronic localised inflammation, antibacterial therapy for $>48 \mathrm{~h}$, immunosuppression, cancer, or refusal to consent) SETTING: ICU in 1 university hospital in China 
Liu 2013 (Continued)

Interventions
FORMAT: Interventions: reminders (circumstantial, decision support algorithm triggered by measurement of PCT); structural, introduction of PCT testing

Intervention Functions: enablement, environmental restructuring

DELIVERER: specialist physician

COMPARISON: usual care

DESIRED CHANGE: decrease excessive

POWER CALCULATION: no information
PRESCRIBING: Exposure: duration of all antibiotic treatment

CLINICAL: Balancing: 28-day mortality, length of hospital stay, length of ICU stay, recurrence within 28 days

FUNDING: no information

ADDITIONAL DATA: no response from authors to request for additional data

\section{Risk of bias}

\begin{tabular}{|c|c|c|}
\hline Bias & Authors' judgement & Support for judgement \\
\hline $\begin{array}{l}\text { Random sequence genera- } \\
\text { tion (selection bias) }\end{array}$ & Low risk & Random number table method \\
\hline $\begin{array}{l}\text { Allocation concealment } \\
\text { (selection bias) }\end{array}$ & Unclear risk & No information about concealment \\
\hline $\begin{array}{l}\text { Blinding (performance } \\
\text { bias and detection bias) } \\
\text { All outcomes }\end{array}$ & Unclear risk & No information about blinding \\
\hline $\begin{array}{l}\text { Incomplete outcome data } \\
\text { (attrition bias) } \\
\text { All outcomes }\end{array}$ & Low risk & Outcome reported on all participants. \\
\hline $\begin{array}{l}\text { Selective reporting (re- } \\
\text { porting bias) }\end{array}$ & Low risk & Outcome reported on all participants. \\
\hline Other bias & High risk & $\begin{array}{l}\text { The study had } 7 \text { exclusion criteria that are not all clearly defined, so there is } \\
\text { a high risk of selection bias, especially as allocation was probably not con- } \\
\text { cealed. }\end{array}$ \\
\hline $\begin{array}{l}\text { Baseline Outcomes simi- } \\
\text { lar? }\end{array}$ & Unclear risk & No data about baseline outcomes \\
\hline Free of contamination? & Low risk & PCT results only for intervention participants. \\
\hline $\begin{array}{l}\text { Baseline characteristics } \\
\text { similar? }\end{array}$ & Low risk & Table 1, age, gender, APACHE score, comorbidities \\
\hline
\end{tabular}


Long 2014

\begin{tabular}{ll}
\hline Methods & STUDY DESIGN: RCT \\
& Risk of Bias: MEDIUM \\
\hline Participants & PROVIDERS: all physicians \\
& PARTICIPANTS: 216 consecutive patients hospitalised with exacerbations of acute asthma \\
CLINICAL PROBLEM: antibiotic treatment of acute asthma \\
SETTING: 1 university hospital in China
\end{tabular}

Interventions

FORMAT: Interventions: reminders (circumstantial, decision support algorithm triggered by measurement of PCT); structural, introduction of PCT testing

Intervention Functions: enablement, environmental restructuring

DELIVERER: departmental physicians (Internal and Geriatric Medicine)

COMPARISON: usual care

DESIRED CHANGE: decrease excessive

POWER CALCULATION: yes, 90 participants per group. Details in Appendix 3

\begin{tabular}{ll}
\hline Outcomes & PRESCRIBING: Exposure: \% treated with antibiotics \\
& CLINICAL: Balancing: length of hospital stay; clinical, laboratory, and spirometry outcomes at dis- \\
charge; and results of spirometry at the 12-month follow-up examination, as well as the results of the \\
Asthma Control Test
\end{tabular}

\section{Risk of bias}

\begin{tabular}{lll}
\hline Bias & Authors' judgement & Support for judgement \\
\hline $\begin{array}{l}\text { Random sequence genera- } \\
\text { tion (selection bias) }\end{array}$ & Low risk & $\begin{array}{l}\text { "Allocation to either intervention was conducted according to computer-gen- } \\
\text { erated random numbers produced by an independent statistician." }\end{array}$ \\
\hline $\begin{array}{l}\text { Allocation concealment } \\
\text { (selection bias) }\end{array}$ & Low risk & $\begin{array}{l}\text { "After randomization, an opaque, sealed, sequentially numbered envelope } \\
\text { containing the PCT or control protocol was prepared for each subject accord- } \\
\text { ing to group assignment" }\end{array}$ \\
\hline $\begin{array}{l}\text { Blinding (performance } \\
\text { bias and detection bias) }\end{array}$ & High risk & Blinding was not possible. \\
\hline $\begin{array}{l}\text { All outcomes } \\
\text { (attrition bias) }\end{array}$ & Oll outcomes & Outcomes reported on all 180 randomised participants. \\
\hline $\begin{array}{l}\text { Selective reporting (re- } \\
\text { porting bias) }\end{array}$ & Low risk & Antibiotic use reported for all 180 participants. \\
\hline $\begin{array}{l}\text { Other bias } \\
\text { Baseline Outcomes simi- }\end{array}$ & Unclear risk & No data \\
\hline $\begin{array}{l}\text { lar? } \\
\text { Free of contamination? }\end{array}$ & Low risk & Procalcitonin only reported on intervention participants. \\
\hline
\end{tabular}


Long 2014 (Continued)

\begin{tabular}{|c|c|}
\hline Baseline characteristics & Low risk \\
\hline
\end{tabular}

Madaras-Kelly 2006

Methods STUDY DESIGN: ITS

Risk of Bias: HIGH

PROVIDERS: all prescribers and staff
PATIENTS: all inpatients
CLINICAL PROBLEM: patients receiving antibiotic treatment and patients with MRSA infections
SETTING: university-affiliated veterans hospital in the USA

\begin{tabular}{ll}
\hline Interventions & FORMAT: Interventions: educational meetings, in-service training sessions with dissemination of \\
& guideline; reminders (circumstantial, electronic, triggered by prescribing target drugs) \\
Intervention Functions: education, enablement, environmental restructuring
\end{tabular}

\author{
DELIVERER: AMT
}

COMPARISON: usual care

DESIRED CHANGE: decrease excessive

\begin{tabular}{ll}
\hline Outcomes & PRESCRIBING: Choice: change in use of levofloxacin, ciprofloxacin, and other antibiotics \\
& MICROBIAL: MRSA infection rate (number/1000 OBD) \\
\hline Notes & $\begin{array}{l}\text { FINANCIAL SUPPORT: This article is the result of work supported with resources and the use of facili- } \\
\text { ties at the Boise Veterans Affairs Medical Center, and is partially funded by an unrestricted educational } \\
\text { grant from Wyeth Pharmaceuticals. Conflict of interest: no information }\end{array}$
\end{tabular}

ADDITIONAL DATA: email response from authors but no additional data

Microbial ROB: MEDIUM. Case definition Low, Planned intervention Low, Other infection control High, prescribing intervention coincident with infection control interventions

\title{
Risk of bias
}

\begin{tabular}{|c|c|c|}
\hline Bias & Authors' judgement & Support for judgement \\
\hline $\begin{array}{l}\text { Intervention independent } \\
\text { (ITS) ? }\end{array}$ & Unclear risk & $\begin{array}{l}\text { Data collected for } 11 \text { months postintervention. Season included as a variable } \\
\text { in the model, and summer found to be associated with lower MRSA infection } \\
\text { rate. Coincident with infection control intervention for norovirus outbreak, in- } \\
\text { fection control variables included in the model and significantly associated } \\
\text { with lower MRSA rate. }\end{array}$ \\
\hline
\end{tabular}

\begin{tabular}{lll}
\hline $\begin{array}{l}\text { Analysed appropriately } \\
\text { (ITS) } ?\end{array}$ & Low risk & Done in original paper: segmented regression analysis \\
\hline $\begin{array}{l}\text { Shape of effect pre-speci- } \\
\text { fied (ITS) ? }\end{array}$ & Low risk & $\begin{array}{l}\text { Done, intended effect was decrease in primary outcome, and point of analysis } \\
\text { was point of intervention. }\end{array}$ \\
\hline
\end{tabular}

\begin{tabular}{|c|c|c|}
\hline $\begin{array}{l}\text { Unlikely to affect data col- } \\
\text { lection (ITS)? }\end{array}$ & Unclear risk & $\begin{array}{l}\text { Not clear, no information about protocols for sampling or testing for MRSA } \\
\text { over the study period }\end{array}$ \\
\hline
\end{tabular}


Madaras-Kelly 2006 (Continued)
Knowledge of the alloca-
Low risk
Objective data about MRSA tion adequately prevented(ITS)?

\begin{tabular}{|c|c|c|}
\hline $\begin{array}{l}\text { Incomplete outcome data } \\
\text { addressed (ITS)? }\end{array}$ & Low risk & Identification of cases was the same in the pre- and postintervention phases. \\
\hline $\begin{array}{l}\text { Free of selected reporting } \\
\text { (ITS)? }\end{array}$ & Low risk & $\begin{array}{l}\text { In addition to the primary outcome of MRSA infections, the figure shows per- } \\
\text { centage of MRSA for all Staphylococcus aureus isolates with a reduction coinci- } \\
\text { dent with the intervention. }\end{array}$ \\
\hline
\end{tabular}

Free of other bias (ITS) ? High risk

NOT DONE data are MRSA infection rates in 6-month time periods based on very small numbers of cases ( 80 cases in $3 \frac{1}{2}$ years).

Microbial Outcome Risk of Bias: Case definition: MRSA infection. Screening for nosocomial infections was performed through daily review of hospital admissions and discharges, intravenous antibiotic use by patients admitted to the emergency department, and laboratory reports with case confirmation by review of medical records. "An infection was assumed to be caused by MRSA if cultures of blood, intravenous line, sputum, urine, tissue, or stool obtained at the time of symptom development yielded MRSA." Planned intervention: YES. Intervention introduced in July 2003 in response to May 2003 SHEA recommendations that institutions where MRSA is endemic should consider limiting the use of broad-spectrum antibiotics, especially fluoroquinolones. Other infection control: NOT DONE. Antibiotic intervention coincident with environmental decontamination and hand hygiene campaign because of norovirus outbreak. Data about some infection control variables showed no change after start of intervention.

Methods STUDY DESIGN: ITS

Risk of Bias: LOW

Participants PROVIDERS: physicians in the hospital

PARTICIPANTS: all patients in hospital

CLINICAL PROBLEM: antibiotic use in cardiology hospital, primary target fluorquinolone use

SETTING: 1 cardiology hospital in Brazil

$\begin{array}{ll}\text { Interventions } & \text { FORMAT: Interventions: educational outreach by review and recommend change } \\ \text { Intervention Functions: enablement, persuasion }\end{array}$

DELIVERER: Intervention 1 ID physician (2 h per day), Intervention 2 AMT (physician plus pharmacist, 4 h per day)

COMPARISON: usual care

DESIRED CHANGE: reduce inappropriate

\begin{tabular}{ll}
\hline Outcomes & $\begin{array}{l}\text { PRESCRIBING: Choice: monthly consumption (DDDs/100 OBD) of antibiotics, primary target fluoro- } \\
\text { quinolones }\end{array}$
\end{tabular}

FINANCIAL: hours of time to implement the intervention 
Magedanz 2012 (Continued)

ADDITIONAL DATA: no response from authors to request for additional data

\section{Risk of bias}

\begin{tabular}{lll}
\hline Bias & Authors' judgement & Support for judgement \\
\hline $\begin{array}{l}\text { Intervention independent } \\
\text { (ITS) }\end{array}$ & Low risk & States in discussion that most changes not related to any other external factor. \\
\hline $\begin{array}{l}\text { Analysed appropriately } \\
\text { (ITS)? }\end{array}$ & Low risk & Segmented regression analysis \\
\hline $\begin{array}{l}\text { Shape of effect pre-speci- } \\
\text { fied (ITS) ? }\end{array}$ & Low risk & Point of intervention is point of analysis. \\
\hline $\begin{array}{l}\text { Unlikely to affect data col- } \\
\text { lection (ITS) ? }\end{array}$ & Low risk & Data from electronic pharmacy records \\
\hline $\begin{array}{l}\text { Knowledge of the alloca- } \\
\text { tion adequately prevent- } \\
\text { ed(ITS)? }\end{array}$ & Low risk & Data from electronic pharmacy records \\
\hline $\begin{array}{l}\text { Incomplete outcome data } \\
\text { addressed (ITS) ? }\end{array}$ & Low risk & \\
\hline $\begin{array}{l}\text { Free of selected reporting } \\
\text { (ITS) ? }\end{array}$ & Low risk & Data from electronic pharmacy records \\
\hline \begin{tabular}{l} 
Free of other bias (ITS) ? \\
\hline
\end{tabular} & Low risk & Data from electronic pharmacy records \\
\hline
\end{tabular}

Maravic-Stojkovic 2011

\begin{tabular}{ll}
\hline Methods & STUDY DESIGN: RCT \\
& Risk of Bias: HIGH \\
\hline Participants & PROVIDERS: all physicians in cardiac surgery \\
& PARTICIPANTS: 205 patients undergoing cardiac surgery \\
& CLINICAL PROBLEM: antibiotic treatment after surgery \\
& SETTING: 1 university hospital in Serbia \\
\hline Interventions & FORMAT: Interventions: reminders (circumstantial, decision support algorithm triggered by measure- \\
& ment of PCT); structural, introduction of PCT testing \\
Intervention Functions: enablement, environmental restructuring & DELIVERER: departmental physicians (ICU and cardiology) \\
& COMPARISON: usual care \\
& DESIRED CHANGE: decrease excessive \\
& POWER CALCULATION: unclear, target effect size decrease from 45\% of antibiotic use in the standard \\
& group to $22 \%$ in the procalcitonin group, but no data about sample size \\
\hline PRESCRIBING: Exposure: $\%$ treated with antibiotics \\
CLINICAL: ICU stays, hospital stay, rehospitalisation, incidence of infections, severe non-infection com- \\
plications, and mortality rate with 1-year follow-up \\
FINANCIAL: cost of antibiotics and PCT tests
\end{tabular}


Maravic-Stojkovic 2011 (Continued)
Notes
FINANCIAL SUPPORT: no information provided
ADDITIONAL DATA: no response from authors to request for additional data

\section{Risk of bias}

\begin{tabular}{|c|c|c|}
\hline Bias & Authors' judgement & Support for judgement \\
\hline $\begin{array}{l}\text { Random sequence genera- } \\
\text { tion (selection bias) }\end{array}$ & Low risk & Computer-generated randomisation scheme \\
\hline $\begin{array}{l}\text { Allocation concealment } \\
\text { (selection bias) }\end{array}$ & Unclear risk & No information about concealment \\
\hline $\begin{array}{l}\text { Blinding (performance } \\
\text { bias and detection bias) } \\
\text { All outcomes }\end{array}$ & High risk & Blinding not possible \\
\hline $\begin{array}{l}\text { Incomplete outcome data } \\
\text { (attrition bias) } \\
\text { All outcomes }\end{array}$ & Low risk & Outcomes reported on all 205 participants. \\
\hline $\begin{array}{l}\text { Selective reporting (re- } \\
\text { porting bias) }\end{array}$ & Low risk & Antibiotic treatment reported on all participants. \\
\hline Other bias & Low risk & \\
\hline $\begin{array}{l}\text { Baseline Outcomes simi- } \\
\text { lar? }\end{array}$ & Unclear risk & No data \\
\hline Free of contamination? & Low risk & PCT only measured on intervention participants. \\
\hline $\begin{array}{l}\text { Baseline characteristics } \\
\text { similar? }\end{array}$ & Low risk & Tables 1 and 2 \\
\hline
\end{tabular}

Marwick 2013

\begin{tabular}{ll}
\hline Methods & STUDY DESIGN: ITS \\
& Risk of Bias: MEDIUM \\
\hline Participants & PROVIDERS: all physicians in medical and surgical wards \\
& PARTICIPANTS: all patients in medical and surgical wards \\
& CLINICAL PROBLEM: suspected sepsis (systemic inflammatory response and clinical suspicion of infec- \\
tion) & SETTING: 1 university hospital in Scotland \\
\hline Interventions & FORMAT: Interventions: audit and feedback; educational meetings with dissemination of guidelines; \\
& reminders (physical, posters in the wards and monthly email to doctors) \\
Intervention Functions: education, enablement, environmental restructuring, persuasion & DELIVERER: AMT \\
COMPARISON: usual care & DESIRED CHANGE: increase effective \\
\hline Outcomes & PRESCRIBING: Choice: time to first antibiotic dose \\
\hline
\end{tabular}


Marwick 2013 (Continued)

Notes
FINANCIAL SUPPORT: Funding: Scottish Government Chief Scientist Office (CSO) Clinical Academic Training Fellowship (CAF/07/06). Competing Interests: salary costs for 2 investigators from CSO, no others declared

ADDITIONAL DATA: email response from authors to request for additional data with additional detail from a PhD thesis

\section{Risk of bias}

\begin{tabular}{lll}
\hline Bias & Authors' judgement & Support for judgement \\
\hline $\begin{array}{ll}\text { Intervention independent } \\
\text { (ITS)? }\end{array}$ & High risk & $\begin{array}{l}\text { There was a national intervention (Scottish Patient Safety Program) that in- } \\
\text { cluded reducing time to rescue of deteriorating patients throughout the pre- } \\
\text { and postintervention phases. }\end{array}$ \\
\hline
\end{tabular}

Analysed appropriately Low risk Segmented regression analysis

(ITS) ?

Shape of effect pre-speci- Low risk $\quad$ Point of intervention was point of analysis.
fied (ITS)?
fied (ITS) ?

$\begin{array}{lll}\begin{array}{l}\text { Unlikely to affect data col- } \\ \text { lection (ITS) ? }\end{array} & \text { Low risk } & \begin{array}{l}\text { Objective primary outcome measure (time to first antibiotic dose) collected by } \\ \text { single person (CM). }\end{array} \\ \begin{array}{l}\text { Knowledge of the alloca- } \\ \text { tion adequately prevent- } \\ \text { ed(ITS)? }\end{array} & \text { Low risk } & \begin{array}{l}\text { Objective primary outcome measure (time to first antibiotic dose) collected by } \\ \text { single person (CM). }\end{array}\end{array}$
ed(ITS)?

\begin{tabular}{lll}
\hline $\begin{array}{l}\text { Incomplete outcome data } \\
\text { addressed (ITS) ? }\end{array}$ & Low risk & Outcome data collected on all participants. \\
\hline $\begin{array}{l}\text { Free of selected reporting } \\
\text { (ITS) }\end{array}$ & Low risk & Outcome data collected on all participants. \\
\hline Free of other bias (ITS) ? & Low risk & Data collected over winter months in pre- and postintervention period. \\
\hline
\end{tabular}

\section{Masia 2008}

\begin{tabular}{ll}
\hline Methods & STUDY DESIGN: RCT \\
& Risk of Bias: HIGH \\
\hline Participants & PROVIDERS: all physicians in the hospital \\
& PARTICIPANTS: 278 patients receiving antibiotics, 146 intervention, 132 control \\
& CLINICAL PROBLEM: prescription of target antibiotics \\
& SETTING: 1 university hospital in Spain \\
\hline Interventions & FORMAT: Interventions: educational outreach by review and recommend change \\
& Intervention Functions: education, enablement \\
& DELIVERER: AMT \\
& COMPARISON: usual care \\
& DESIRED CHANGE: decrease excessive \\
& POWER CALCULATION: yes, 140 participants in each group \\
\hline
\end{tabular}

Outcomes

PRESCRIBING: Choice: use of target drugs in DDD 
Masia 2008 (Continued)

CLINICAL: length of stay, mortality, re-admissions

Notes FINANCIAL SUPPORT: no information

ADDITIONAL DATA: no response from authors to request for additional data

\section{Risk of bias}

\begin{tabular}{|c|c|c|}
\hline Bias & Authors' judgement & Support for judgement \\
\hline $\begin{array}{l}\text { Random sequence genera- } \\
\text { tion (selection bias) }\end{array}$ & Low risk & $\begin{array}{l}\text { Eligible prescriptions were allocated daily to either the intervention or the } \\
\text { control group using a computer-generated randomisation list. }\end{array}$ \\
\hline $\begin{array}{l}\text { Allocation concealment } \\
\text { (selection bias) }\end{array}$ & Low risk & $\begin{array}{l}\text { Concealment of allocation was pharmacy controlled. Instruction in allocation } \\
\text { concealment was provided. }\end{array}$ \\
\hline $\begin{array}{l}\text { Blinding (performance } \\
\text { bias and detection bias) } \\
\text { All outcomes }\end{array}$ & High risk & Blinding was not possible. \\
\hline $\begin{array}{l}\text { Incomplete outcome data } \\
\text { (attrition bias) } \\
\text { All outcomes }\end{array}$ & Low risk & Outcome data reported on all randomised participants. \\
\hline $\begin{array}{l}\text { Selective reporting (re- } \\
\text { porting bias) }\end{array}$ & Low risk & Outcome data reported on all randomised participants. \\
\hline Other bias & Low risk & \\
\hline $\begin{array}{l}\text { Baseline Outcomes simi- } \\
\text { lar? }\end{array}$ & Unclear risk & No data \\
\hline Free of contamination? & High risk & $\begin{array}{l}\text { The authors say: "To minimize contamination bias, that is, any change in an- } \\
\text { tibiotic prescription practice in the control group, only the infectious diseases } \\
\text { physicians and hospital pharmacists were informed about the implementa- } \\
\text { tion of the program." However, they were placing written recommendations in } \\
\text { case notes for intervention patients, and physicians caring for those patients } \\
\text { would also be caring for control patients. }\end{array}$ \\
\hline $\begin{array}{l}\text { Baseline characteristics } \\
\text { similar? }\end{array}$ & Low risk & Table 1 \\
\hline
\end{tabular}

May 2000

Methods STUDY DESIGN: Controlled ITS

Risk of bias: MEDIUM

Participants

PROVIDERS: staff of Trauma \& Burns ICU (TBICU), Medical ICU (MICU), and Surgical ICU (SICU)

PATIENTS: all patients in these ICUs

CLINICAL PROBLEM: adults needing intensive care

SETTING: single > 500-bed university hospital in the USA

Interventions

FORMAT: Intervention: dissemination of guideline 
May 2000 (Continued)

Intervention Function: education

DELIVERER: department physician

COMPARISON: usual care

DESIRED CHANGE: decrease excessive

$\begin{array}{ll}\text { Outcomes } & \text { PRESCRIBING: Choice: use of vancomycin, 3rd-generation cephalosporins, and piperacillin tazobactam } \\ \text { per } 1000 \text { patient days } \\ \text { MICROBIAL: MRSA infections and VRE infections per } 1000 \text { patient days } \\ \text { FINANCIAL SUPPORT: no information } \\ \text { ADDITIONAL DATA: no response from authors to request for additional data } \\ \text { Microbial ROB HIGH: Case definition: Low. Planned intervention: High for intervention ward (response } \\ \text { to increasing VRE in previous } 2 \text { years). However, steady increase not an outbreak and VRE data present- } \\ \text { ed for other wards with no intervention. Other infection control: High, no information about isolation } \\ \text { or infection control practices before or after the intervention }\end{array}$

\section{Risk of bias}

\begin{tabular}{|c|c|c|}
\hline Bias & Authors' judgement & Support for judgement \\
\hline $\begin{array}{l}\text { Intervention independent } \\
\text { (ITS)? }\end{array}$ & High risk & $\begin{array}{l}\text { Only } 9 \text { months' data pre-intervention, so secular/seasonal effects possible. No } \\
\text { information about infection control practices before or after the intervention }\end{array}$ \\
\hline $\begin{array}{l}\text { Analysed appropriately } \\
\text { (ITS)? }\end{array}$ & Low risk & $\begin{array}{l}\text { Re-analysed. Not done in original paper: } x^{2} \text { test, uncontrolled before-after with } \\
\text { Poisson regression analysis of VRE rates. }\end{array}$ \\
\hline $\begin{array}{l}\text { Shape of effect pre-speci- } \\
\text { fied (ITS)? }\end{array}$ & Low risk & $\begin{array}{l}\text { Done, intended effect was decrease in primary outcome, and point of analysis } \\
\text { was point of intervention. }\end{array}$ \\
\hline $\begin{array}{l}\text { Unlikely to affect data col- } \\
\text { lection (ITS)? }\end{array}$ & Low risk & Done, objective outcome measure \\
\hline $\begin{array}{l}\text { Knowledge of the alloca- } \\
\text { tion adequately prevent- } \\
\text { ed(ITS)? }\end{array}$ & Low risk & Objective outcome measure, VRE infections \\
\hline $\begin{array}{l}\text { Incomplete outcome data } \\
\text { addressed (ITS)? }\end{array}$ & Low risk & Done, objective outcome measure \\
\hline $\begin{array}{l}\text { Free of selected reporting } \\
\text { (ITS)? }\end{array}$ & Unclear risk & $\begin{array}{l}\text { Not clear, no information about protocol for sampling or testing over study pe- } \\
\text { riod }\end{array}$ \\
\hline Free of other bias (ITS) ? & Low risk & $>1$ year of data pre- and post-intervention \\
\hline
\end{tabular}

\section{McElnay 1995}

\begin{tabular}{ll} 
Methods & STUDY DESIGN: ITS \\
& Risk of Bias: LOW \\
\hline Participants & PROVIDERS: all physicians in hospital \\
& PARTICIPANTS: all patients in hospital
\end{tabular}


McElnay 1995 (Continued)

CLINICAL PROBLEM: all patients receiving antibiotics

SETTING: 370-bed District General Hospital in the UK

Interventions

FORMAT: Interventions: educational meetings and dissemination of new antibiotic policy; educational outreach by academic detailing, "education of junior medical staff on the rationale behind the antibiotic selection was also carried out by clinical pharmacists" (p208); restrictive by compulsory order form and removal

Intervention Functions: education, persuasion, restriction

DELIVERER: department physician

COMPARISON: usual care

DESIRED CHANGE: decrease excessive

Outcomes PRESCRIBING: Choice: dosage units of target antibiotic

FINANCIAL: expenditure on antibiotics

Notes

FINANCIAL SUPPORT: no information

ADDITIONAL DATA: no response from authors to request for additional data

\section{Risk of bias}

\begin{tabular}{lll}
\hline Bias & Authors' judgement & Support for judgement \\
\hline $\begin{array}{l}\text { Intervention independent } \\
\text { (ITS) }\end{array}$ & Low risk & 12 months' data pre- and postintervention \\
\hline $\begin{array}{l}\text { Analysed appropriately } \\
\text { (ITS) }\end{array}$ & Low risk & $\begin{array}{l}\text { Re-analysed. Not done in original paper: comparison of means (uncontrolled } \\
\text { before-after). }\end{array}$ \\
\hline $\begin{array}{l}\text { Shape of effect pre-speci- } \\
\text { fied (ITS) ? }\end{array}$ & Low risk & $\begin{array}{l}\text { Done, intended effect was decrease in primary outcome, and point of analysis } \\
\text { was point of intervention. }\end{array}$ \\
\hline $\begin{array}{l}\text { Unlikely to affect data col- } \\
\text { lection (ITS)? }\end{array}$ & Low risk & $\begin{array}{l}\text { Done, data were from routine systems and unlikely to change over study peri- } \\
\text { od. }\end{array}$ \\
\hline $\begin{array}{l}\text { Knowledge of the alloca- } \\
\text { tion adequately prevent- } \\
\text { ed(ITS)? }\end{array}$ & Low risk & $\begin{array}{l}\text { Done, data were from routine systems and unlikely to change over study peri- } \\
\text { od. }\end{array}$ \\
\hline $\begin{array}{l}\text { Incomplete outcome data } \\
\text { addressed (ITS) ? }\end{array}$ & Low risk & $\begin{array}{l}\text { Done, data were from routine systems and unlikely to change over study peri- } \\
\text { od. }\end{array}$ \\
\hline $\begin{array}{l}\text { Free of selected reporting } \\
\text { (ITS) ? }\end{array}$ & Low risk & $\begin{array}{l}\text { Done, data were from routine systems and unlikely to change over study peri- } \\
\text { od. }\end{array}$ \\
\hline \begin{tabular}{l} 
Free of other bias (ITS) ? \\
\hline
\end{tabular} & Low risk & \begin{tabular}{l} 
Antibiotic costs were adjusted to 1989 prices. \\
\hline
\end{tabular}
\end{tabular}

McGowan 1976

\begin{tabular}{ll}
\hline Methods & STUDY DESIGN: ITS \\
& Risk of Bias: LOW \\
\hline Participants & PROVIDERS: all physicians in the hospital \\
& PARTICIPANTS: all patients in the hospital
\end{tabular}


McGowan 1976 (Continued)

CLINICAL PROBLEM: patients requiring antibiotic treatment

SETTING: single university hospital in USA

\begin{tabular}{ll}
\hline Interventions & FORMAT: Intervention: restrictive by exp \\
Intervention Function: restriction \\
DELIVERER: specialist physician \\
COMPARISON: usual care \\
DESIRED CHANGE: decrease excessive
\end{tabular}

Outcomes

PRESCRIBING: Choice: grams of chloramphenicol (thousands), data are also presented for other drugs (ampicillin, nafcillin, and cloxacillin)

\section{Notes}

FINANCIAL SUPPORT: Funding: grants 5R01-A1-23, 2T01-AJ-08, and IT01-Ai-447 from the National Institute of Allergy and Infectious Diseases. Competing Interests: no information

ADDITIONAL DATA: no response from authors to request for additional data

\begin{tabular}{|c|c|c|}
\hline \multicolumn{3}{|l|}{ Risk of bias } \\
\hline Bias & Authors' judgement & Support for judgement \\
\hline $\begin{array}{l}\text { Intervention independent } \\
\text { (ITS)? }\end{array}$ & Low risk & Data over 8 years, 4 years pre- and 4 years postintervention \\
\hline $\begin{array}{l}\text { Analysed appropriately } \\
\text { (ITS)? }\end{array}$ & Low risk & $\begin{array}{l}\text { Re-analysed. Not done in original paper: comparison of means (uncontrolled } \\
\text { before-after). }\end{array}$ \\
\hline $\begin{array}{l}\text { Shape of effect pre-speci- } \\
\text { fied (ITS)? }\end{array}$ & Low risk & $\begin{array}{l}\text { Done, intended effect was decrease in primary outcome, and point of analysis } \\
\text { was point of intervention. }\end{array}$ \\
\hline $\begin{array}{l}\text { Unlikely to affect data col- } \\
\text { lection (ITS)? }\end{array}$ & Low risk & $\begin{array}{l}\text { Done, data were from routine systems and unlikely to change over study peri- } \\
\text { od. }\end{array}$ \\
\hline $\begin{array}{l}\text { Knowledge of the alloca- } \\
\text { tion adequately prevent- } \\
\text { ed(ITS)? }\end{array}$ & Low risk & $\begin{array}{l}\text { Done, data were from routine systems and unlikely to change over study peri- } \\
\text { od. }\end{array}$ \\
\hline $\begin{array}{l}\text { Incomplete outcome data } \\
\text { addressed (ITS)? }\end{array}$ & Low risk & $\begin{array}{l}\text { Done, data were from routine systems and unlikely to change over study peri- } \\
\text { od. }\end{array}$ \\
\hline $\begin{array}{l}\text { Free of selected reporting } \\
\text { (ITS)? }\end{array}$ & Low risk & $\begin{array}{l}\text { Done, data were from routine systems and unlikely to change over study peri- } \\
\text { od. }\end{array}$ \\
\hline Free of other bias (ITS)? & Low risk & No other apparent biases found. \\
\hline
\end{tabular}

McLaughlin 2005

\begin{tabular}{ll}
\hline Methods & STUDY DESIGN: ITS \\
& Risk of Bias: HIGH \\
\hline Participants & PROVIDERS: staff from 12 medical wards \\
& PATIENTS: all patients in the wards \\
& CLINICAL PROBLEM: adults requiring IV antibiotic therapy
\end{tabular}


McLaughlin 2005 (Continued)

SETTING: single university hospital in the UK

Interventions $\quad$ FORMAT: Interventions: educational meetings with dissemination of protocol for IV to oral switch; educational outreach by academic detailing; reminders (circumstantial, sticker in charts of patients receiving IV antibiotics and physical, posters in wards and at nursing stations)

Intervention Functions: education, enablement, environmental restructuring, persuasion

\section{DELIVERER: AMT}

COMPARISON: usual care

DESIRED CHANGE: modification of existing management (faster switch from IV to oral administration of antibiotics)

\begin{tabular}{ll}
\hline Outcomes & PRESCRIBING: Choice: appropriateness of timing of IV to oral switch \\
\hline Notes & FINANCIAL SUPPORT: Funding: Greater Glasgow Health Board. Competing Interests: no information \\
& ADDITIONAL DATA: authors provided additional data
\end{tabular}

\section{Risk of bias}

\begin{tabular}{lll}
\hline Bias & Authors' judgement & Support for judgement \\
\hline $\begin{array}{l}\text { Intervention independent } \\
\text { (ITS)? }\end{array}$ & Low risk & $\begin{array}{l}\text { Not done, data were only collected for 4 weeks before and after the interven- } \\
\text { tion, so secular changes could have accounted for any differences. }\end{array}$ \\
\hline $\begin{array}{l}\text { Analysed appropriately } \\
\text { (ITS)? }\end{array}$ & Low risk & $\begin{array}{l}\text { Re-analysed. Not done in original paper: comparison of means (uncontrolled } \\
\text { before-after) with } x^{2} \text { test. }\end{array}$ \\
\hline $\begin{array}{l}\text { Shape of effect pre-speci- } \\
\text { fied (ITS) ? }\end{array}$ & Low risk & $\begin{array}{l}\text { Done, intended effect was decrease in primary outcome, and point of analysis } \\
\text { was point of intervention. }\end{array}$ \\
\hline $\begin{array}{l}\text { Unlikely to affect data col- } \\
\text { lection (ITS) ? }\end{array}$ & Unclear risk & Not stated \\
\hline
\end{tabular}

Knowledge of the alloca- High risk tion adequately prevented(ITS)?

Incomplete outcome data $\quad$ Unclear risk No information about reliability or completeness of primary outcome
addressed (ITS)?

Free of selected reporting Unclear risk No information about reliability or completeness of primary outcome
(ITS)?

Free of other bias (ITS)? High risk Only 4 weekly time points pre- and postintervention

\section{McNulty 1997}

\begin{tabular}{ll}
\hline Methods & STUDY DESIGN: ITS \\
& Risk of Bias: MEDIUM \\
\hline Participants & PROVIDERS: all physicians in the elderly care unit \\
& PARTICIPANTS: all patients in the elderly care unit \\
CLINICAL PROBLEM: Clostridium difficile in the elderly care unit
\end{tabular}


McNulty 1997 (Continued)

SETTING: elderly care unit in 1 District General Hospital (non-teaching) in the UK

Interventions FORMAT: Interventions: dissemination of new antibiotic policy; restrictive by removal and by review and make change

Intervention Functions: education, enablement, environmental restructuring, persuasion, restriction

DELIVERER: pharmacist

COMPARISON: usual care

DESIRED CHANGE: decrease excessive

\begin{tabular}{ll} 
Outcomes & PRESCRIBING: Choice: monthly cost of cefuroxime (ITS data) \\
& MICROBIAL: cases of CDI per month (ITS data) \\
\hline Notes & FINANCIAL SUPPORT: no information \\
& ADDITIONAL DATA: no response from authors to request for additional data \\
& Microbial ROB HIGH: Case definition: Low, CDI, definition unchanged during the study periods. Un- \\
planned intervention: High, antibiotic restriction was implemented in response to increasing cases of \\
CDI in the preceding 7 months despite increased infection control. Other infection control measures: \\
High, changes to environmental cleaning and reminders about hand hygiene implemented 3 months \\
before the start of intervention
\end{tabular}

Risk of bias

\begin{tabular}{|c|c|}
\hline Bias & Authors' judgement Support for judgement \\
\hline $\begin{array}{l}\text { Intervention independent } \\
\text { (ITS)? }\end{array}$ & High risk \\
\hline $\begin{array}{l}\text { Analysed appropriately } \\
\text { (ITS)? }\end{array}$ & Low risk \\
\hline
\end{tabular}

\section{Shape of effect pre-speci- Low risk fied (ITS) ?}
Unlikely to affect data col- Low risk lection (ITS)?

Knowledge of the alloca- Low risk
tion adequately prevent-
ed(ITS)?

\begin{tabular}{ll}
\hline $\begin{array}{l}\text { Incomplete outcome data } \\
\text { addressed (ITS) ? }\end{array}$ & Low risk \\
\hline $\begin{array}{l}\text { Free of selected reporting } \\
\text { (ITS) ? }\end{array}$ & Low risk \\
\hline Free of other bias (ITS) ? & Low risk \\
\hline
\end{tabular}

\section{Mercer 1999}

\begin{tabular}{ll}
\hline Methods & STUDY DESIGN: ITS \\
& Risk of Bias: LOW
\end{tabular}


Mercer 1999 (Continued)

Participants
PROVIDERS: physicians

PARTICIPANTS: all patients with clinical problem

CLINICAL PROBLEM: patients receiving ceftriaxone

SETTING: a 360-bed community hospital in the USA

Interventions

FORMAT: Interventions: dissemination of guidelines; educational outreach by academic detailing; educational outreach by review and recommend change; reminders (physical, posters in clinical areas); restrictive by compulsory order form, expert approval required, removal and review and make change Intervention Functions: education, environmental restructuring, restriction

DELIVERER: specialist physician (ID)

COMPARISON: usual care

DESIRED CHANGE: reduction in established management (reduction in antibiotic costs)

Outcomes PRESCRIBING: Choice: cost of antibiotics (USD) as an indicator of use

COSTS: cost of antibiotics

Notes $\quad$ FINANCIAL SUPPORT: no information

ADDITIONAL DATA: no response from authors to request for additional data

\section{Risk of bias}

\begin{tabular}{|c|c|c|}
\hline Bias & Authors' judgement & Support for judgement \\
\hline $\begin{array}{l}\text { Intervention independent } \\
\text { (ITS)? }\end{array}$ & Low risk & Full year before and after \\
\hline $\begin{array}{l}\text { Analysed appropriately } \\
\text { (ITS)? }\end{array}$ & Low risk & $\begin{array}{l}\text { Re-analysed. Not done in original paper: comparison of means (uncontrolled } \\
\text { before-after). }\end{array}$ \\
\hline $\begin{array}{l}\text { Shape of effect pre-speci- } \\
\text { fied (ITS)? }\end{array}$ & Low risk & $\begin{array}{l}\text { Done, intended effect was decrease in primary outcome, and point of analysis } \\
\text { was point of intervention. }\end{array}$ \\
\hline $\begin{array}{l}\text { Unlikely to affect data col- } \\
\text { lection (ITS)? }\end{array}$ & Low risk & $\begin{array}{l}\text { Done, data were from routine systems and unlikely to change over study peri- } \\
\text { od. }\end{array}$ \\
\hline $\begin{array}{l}\text { Knowledge of the alloca- } \\
\text { tion adequately prevent- } \\
\text { ed(ITS)? }\end{array}$ & Low risk & $\begin{array}{l}\text { Done, data were from routine systems and unlikely to change over study peri- } \\
\text { od. }\end{array}$ \\
\hline $\begin{array}{l}\text { Incomplete outcome data } \\
\text { addressed (ITS)? }\end{array}$ & Low risk & $\begin{array}{l}\text { Done, data were from routine systems and unlikely to change over study peri- } \\
\text { od. }\end{array}$ \\
\hline $\begin{array}{l}\text { Free of selected reporting } \\
\text { (ITS)? }\end{array}$ & Low risk & $\begin{array}{l}\text { Done, data were from routine systems and unlikely to change over study peri- } \\
\text { od. }\end{array}$ \\
\hline Free of other bias (ITS)? & Low risk & $\begin{array}{l}\text { Antibiotic costs were adjusted to } 1995 \text { prices and excluded ancillary or admin- } \\
\text { istrative charges. }\end{array}$ \\
\hline
\end{tabular}

Meyer 1993

Methods STUDY DESIGN: ITS


Meyer 1993 (Continued)

\section{Risk of Bias: HIGH}

Participants

PROVIDERS: all physicians in the hospital

PARTICIPANTS: all patients in the hospital

CLINICAL PROBLEM: patients receiving antibiotics

SETTING: 1 university hospital in the USA

FORMAT: Interventions: restrictive by expert approval required

Intervention Functions: restriction

COMPARISON: usual care

DESIRED CHANGE: decrease excessive

PRESCRIBING: Choice: use of ceftazidime, imipenem, and ceftriaxone reported as number of approvals
for these drugs
MICROBIAL: incidence of ceftazidime-resistant Klebsiella pneumoniae as the rate per 1000 average daily
census

Notes

FINANCIAL SUPPORT: Funding: BMA Medical Foundation. Competing Interests: no information

ADDITIONAL DATA: no response from authors to request for additional data

Microbial ROB: HIGH Case definition Low, Unplanned intervention High, Other infection control High

\section{Risk of bias}

\begin{tabular}{|c|c|c|}
\hline Bias & Authors' judgement & Support for judgement \\
\hline $\begin{array}{l}\text { Intervention independent } \\
\text { (ITS)? }\end{array}$ & High risk & $\begin{array}{l}\text { Infection control intervention simultaneous with antibiotic intervention. } 14 \\
\text { months' pre- and } 11 \text { months' postintervention, so secular change unlikely. }\end{array}$ \\
\hline $\begin{array}{l}\text { Analysed appropriately } \\
\text { (ITS)? }\end{array}$ & Low risk & Re-analysed. Not done in original paper: run chart with no statistical analysis. \\
\hline $\begin{array}{l}\text { Shape of effect pre-speci- } \\
\text { fied (ITS)? }\end{array}$ & Low risk & $\begin{array}{l}\text { Done, intended effect was decrease in primary outcome, and point of analysis } \\
\text { was point of intervention. }\end{array}$ \\
\hline $\begin{array}{l}\text { Unlikely to affect data col- } \\
\text { lection (ITS)? }\end{array}$ & Low risk & $\begin{array}{l}\text { Done, data were from routine systems and unlikely to change over study peri- } \\
\text { od. }\end{array}$ \\
\hline $\begin{array}{l}\text { Knowledge of the alloca- } \\
\text { tion adequately prevent- } \\
\text { ed(ITS)? }\end{array}$ & Low risk & $\begin{array}{l}\text { Done, data were from routine systems and unlikely to change over study peri- } \\
\text { od. }\end{array}$ \\
\hline $\begin{array}{l}\text { Incomplete outcome data } \\
\text { addressed (ITS)? }\end{array}$ & High risk & Pre-intervention data were incomplete. \\
\hline $\begin{array}{l}\text { Free of selected reporting } \\
\text { (ITS)? }\end{array}$ & Low risk & $\begin{array}{l}\text { Done, data were from routine systems and unlikely to change over study peri- } \\
\text { od. Criteria for sampling and testing were unchanged over the study period. }\end{array}$ \\
\hline Free of other bias (ITS) ? & High risk & $\begin{array}{l}\text { NOT DONE. Microbial Outcome Risk of Bias Criteria: Planned intervention: } \\
\text { NOT DONE, unplanned intervention. Case definition: DONE, microbial out- } \\
\text { come was colonisation by surveillance screening. Clinical infection was diag- } \\
\text { nosed by CDC definition but not used as an outcome. Infection or colonisation } \\
\text { by case note review. Other infection control measures: NOT DONE, barrier pre- } \\
\text { cautions were instituted on colonised and infected patients at the same time } \\
\text { that ceftazidime restriction was implemented. }\end{array}$ \\
\hline
\end{tabular}


Meyer 2007

\begin{tabular}{ll}
\hline Methods & STUDY DESIGN: ITS \\
& Risk of Bias: MEDIUM \\
\hline Participants & PROVIDERS: physicians in the neurosurgical ICU \\
& CLINICAL PROBLEM: antibiotic treatment for pneumonia in neurosurgical ICU \\
& SETTING: neurosurgical ICU in 1 hospital in Germany \\
\hline Interventions & FORMAT: Interventions: educational meeting with neurosurgeons and dissemination of guideline \\
Intervention Functions: education & DELIVERER: AMT \\
& COMPARISON: usual care \\
& DESIRED CHANGE: decrease excessive, in the new guideline the duration of antibiotic therapy for noso- \\
COmial pneumonia was reduced from 14 to 7 days, while for community-acquired pneumonia the peri- \\
Od fell from 10 to 5 days
\end{tabular}

Outcomes

PRESCRIBING: Exposure: total antibiotic use and cost/1000 OBD

FINANCIAL: changes in total antibiotic cost

Notes $\quad$ FINANCIAL SUPPORT: Funding: none. Competing Interests: none declared

ADDITIONAL DATA: no response from authors to request for additional data

\begin{tabular}{|c|c|c|}
\hline \multicolumn{3}{|l|}{ Risk of bias } \\
\hline Bias & Authors' judgement & Support for judgement \\
\hline $\begin{array}{l}\text { Intervention independent } \\
\text { (ITS)? }\end{array}$ & Low risk & \\
\hline $\begin{array}{l}\text { Analysed appropriately } \\
\text { (ITS) ? }\end{array}$ & Low risk & Segmented regression analysis \\
\hline $\begin{array}{l}\text { Shape of effect pre-speci- } \\
\text { fied (ITS)? }\end{array}$ & Low risk & Point of intervention was point of analysis. \\
\hline $\begin{array}{l}\text { Unlikely to affect data col- } \\
\text { lection (ITS)? }\end{array}$ & Low risk & Outcome from pharmacy database pre- and postintervention. \\
\hline $\begin{array}{l}\text { Knowledge of the alloca- } \\
\text { tion adequately prevent- } \\
\text { ed(ITS)? }\end{array}$ & Unclear risk & No mention of blinding \\
\hline $\begin{array}{l}\text { Incomplete outcome data } \\
\text { addressed (ITS)? }\end{array}$ & Low risk & Outcome from pharmacy database pre- and postintervention. \\
\hline $\begin{array}{l}\text { Free of selected reporting } \\
\text { (ITS)? }\end{array}$ & Low risk & Outcome from pharmacy database pre- and postintervention. \\
\hline Free of other bias (ITS) ? & Low risk & $>1$ year of data pre- and postintervention \\
\hline
\end{tabular}


Meyer 2009

Methods STUDY DESIGN: ITS

\section{Risk of Bias: LOW}

PROVIDERS: all patients in an adult surgical ICU
PARTICIPANTS: all staff in the ICU
CLINICAL PROBLEM: use of 3rd-generation cephalosporins for treatment and prophylaxis of specific in-
fections plus duration of prophylaxis for fractures
SETTING: 1 surgical ICU in a teaching hospital in Germany

FORMAT: Interventions: dissemination of guidelines and educational meetings in departments of
surgery and anaesthesiology
Intervention Functions: education
DELIVERER: multidisciplinary AMT
COMPARISON: pre-intervention outcomes
DESIRED CHANGE: reduction in use of cephalosporins and resistance in gram-negative bacteria

\begin{tabular}{ll}
\hline Outcomes & PRESCRIBING: Choice: use of cephalosporins in DDD/1000 OBD \\
& MICROBIAL: resistance to cephalosporins and piperacillin in gram-negative bacteria isolated from clini- \\
cal and surveillance cultures
\end{tabular}

Notes FINANCIAL SUPPORT: Funding: Federal Ministry of Education and Research (01KI 9907). Competing In-
terests: none declared

ADDITIONAL DATA: no response from authors to request for additional data

Microbial ROB: HIGH Case definition Low; Planned intervention Low; Other infection control Unclear, no clear information about isolation or personal-protection policies

\section{Risk of bias}

Bias Authors' judgement Support for judgement

Intervention independent Low risk (ITS) ?

\begin{tabular}{lll}
\hline $\begin{array}{l}\text { Analysed appropriately } \\
\text { (ITS) }\end{array}$ & Low risk & Segmented regression analysis \\
\hline $\begin{array}{l}\text { Shape of effect pre-speci- } \\
\text { fied (ITS) ? }\end{array}$ & Low risk & Point of intervention was point of analysis. \\
\hline $\begin{array}{l}\text { Unlikely to affect data col- } \\
\text { lection (ITS) ? }\end{array}$ & Low risk & Outcome data from pharmacy and microbiology computers \\
\hline $\begin{array}{l}\text { Knowledge of the alloca- } \\
\text { tion adequately prevent- } \\
\text { ed(ITS)? }\end{array}$ & Low risk & Outcome data from pharmacy and microbiology computers \\
\hline $\begin{array}{l}\text { Incomplete outcome data } \\
\text { addressed (ITS) ? }\end{array}$ & Low risk & Outcome data from pharmacy and microbiology computers \\
\hline
\end{tabular}


Meyer 2009 (Continued)

Free of selected reporting Low risk Outcome data from pharmacy and microbiology computers (ITS) ?

Free of other bias (ITS)? Low risk

Data for $>2$ years' pre- and postintervention, so secular trends accounted for.

Meyer 2010

\begin{tabular}{ll}
\hline Methods & STUDY DESIGN: ITS \\
& Risk of Bias: MEDIUM \\
\hline Participants & PROVIDERS: all physicians in the ICU \\
& PARTICIPANTS: all patients with clinical problem \\
& CLINICAL PROBLEM: reducing length of antibiotic prophylaxis for cerebrospinal shunts \\
& SETTING: ICU department in 1 teaching hospital in Germany
\end{tabular}

Interventions

FORMAT: Intervention: educational meeting and dissemination of new policy. In autumn 2003, a comprehensive teaching session on antibiotic prophylaxis in cerebrospinal shunts was organised by the infection control and neurosurgery teams. This resulted in a revised recommendation of single-shot prophylaxis with cefuroxime for shunt catheters, beginning in January 2004. Prior to implementation of this recommendation, cefuroxime was administered for the whole duration of external cerebrospinal fluid drainage, which could be up to 2 to 3 weeks.

Intervention Functions: education, persuasion

DELIVERER: AMT

COMPARISON: usual care

DESIRED CHANGE: decrease excessive, shorten duration of prophylaxis

Outcomes PRESCRIBING: Exposure: total antibiotic use in DDD/1000 OBD

Notes

FINANCIAL SUPPORT: Funding: Federal Ministry of Education and Research (01KI 9907). Competing Interests: none declared

ADDITIONAL DATA: no response from authors to request for additional data

\section{Risk of bias}

\begin{tabular}{lll}
\hline Bias & Authors' judgement & Support for judgement \\
\hline $\begin{array}{l}\text { Intervention independent } \\
\text { (ITS) }\end{array}$ & Unclear risk & $\begin{array}{l}\text { Says they could not control for changes over time and that an antimicrobial } \\
\text { stewardship programme was implemented }\end{array}$ \\
\hline $\begin{array}{l}\text { Analysed appropriately } \\
\text { (ITS) }\end{array}$ & Low risk & Segmented regression analysis \\
\hline $\begin{array}{l}\text { Shape of effect pre-speci- } \\
\text { fied (ITS) ? }\end{array}$ & Low risk & Point of intervention was point of analysis. \\
\hline $\begin{array}{l}\text { Unlikely to affect data col- } \\
\text { lection (ITS) ? }\end{array}$ & Low risk & Data from pharamacy computers \\
\hline
\end{tabular}


Meyer 2010 (Continued)

Knowledge of the alloca- Low risk Data from pharamacy computers tion adequately prevented(ITS)?

\begin{tabular}{lll}
\hline $\begin{array}{l}\text { Incomplete outcome data } \\
\text { addressed (ITS) }\end{array}$ & Low risk & Data from pharamacy computers \\
\hline $\begin{array}{l}\text { Free of selected reporting } \\
\text { (ITS) } ?\end{array}$ & Low risk & Data from pharamacy computers \\
\hline Free of other bias (ITS) ? & Low risk & $>1$ year data pre- and postintervention \\
\hline
\end{tabular}

Micek 2004

\begin{tabular}{ll}
\hline Methods & $\begin{array}{l}\text { STUDY DESIGN: RCT } \\
\text { Risk of Bias: HIGH }\end{array}$ \\
\hline Participants & PROVIDERS: ICU physicians \\
& PATIENTS: 302 adults in the ICU (154 intervention, 148 control) \\
& CLINICAL PROBLEM: VAP requiring antibiotics \\
& SETTING: single ICU in a teaching hospital in the USA
\end{tabular}

Interventions $\quad$ FORMAT: Interventions: educational outreach by review and recommend change
Intervention Functions: enablement, persuasion

DELIVERER: AMT

COMPARISON: usual care

DESIRED CHANGE: decrease excessive

POWER CALCULATION: no information

\begin{tabular}{|c|c|c|}
\hline Outcomes & \multicolumn{2}{|c|}{ PRESCRIBING: Exposure: duration of all antibiotic therapy } \\
\hline Notes & \multicolumn{2}{|c|}{$\begin{array}{l}\text { FINANCIAL SUPPORT: Funding: part commercial, Barnes-Jewish Hospital Foundation and an unre- } \\
\text { stricted grant from Elan Pharmaceuticals. Competing Interests: no information }\end{array}$} \\
\hline & \multicolumn{2}{|c|}{ ADDITIONAL DATA: no response from authors to request for additional data } \\
\hline \multicolumn{3}{|l|}{ Risk of bias } \\
\hline Bias & Authors' judgement & Support for judgement \\
\hline $\begin{array}{l}\text { Random sequence genera- } \\
\text { tion (selection bias) }\end{array}$ & Unclear risk & $\begin{array}{l}\text { "Patients were randomly assigned", but no details of how the sequence was } \\
\text { generated }\end{array}$ \\
\hline $\begin{array}{l}\text { Allocation concealment } \\
\text { (selection bias) }\end{array}$ & Unclear risk & Not stated \\
\hline $\begin{array}{l}\text { Blinding (performance } \\
\text { bias and detection bias) } \\
\text { All outcomes }\end{array}$ & High risk & Not possible \\
\hline
\end{tabular}


Micek 2004 (Continued)

$\begin{array}{ll}\text { Incomplete outcome data Low risk } & \text { Outcome data were missing from } 4(2.6 \%) \text { patients in the intervention group } \\ \text { (attrition bias) } & \text { and } 8(5.4 \%) \text { patients in the control group. }\end{array}$

All outcomes

and $8(5.4 \%)$ patients in the control group.

\begin{tabular}{lll}
\hline $\begin{array}{l}\text { Selective reporting (re- } \\
\text { porting bias) }\end{array}$ & Low risk & Done, outcomes were obtained from routine data systems. \\
\hline Other bias & High risk & $\begin{array}{l}\text { The policy was only implemented at weekends or on holidays when } 1 \text { of the } 2 \\
\text { investigators was available in the hospital. }\end{array}$ \\
\hline $\begin{array}{l}\text { Baseline Outcomes simi- } \\
\text { lar? }\end{array}$ & Unclear risk & No data about duration of therapy before the intervention \\
\hline $\begin{array}{l}\text { Free of contamination? } \\
\text { Baseline characteristics }\end{array}$ & High risk & $\begin{array}{l}\text { Physicians managing patients in the control group would have seen reminders } \\
\text { for the intervention group. }\end{array}$ \\
\hline
\end{tabular}

Mittal 2014

\begin{tabular}{ll}
\hline Methods & STUDY DESIGN: ITS \\
& Risk of Bias: MEDIUM \\
\hline Participants & PROVIDERS: all physicians in the Department of Paediatrics \\
& PARTICIPANTS: all children < 2 years old with bronchiolitis \\
& CLINICAL PROBLEM: antibiotic use as part of a new Clinical Practice Guideline to improve management \\
of bronchiolitis & SETTING: 1 university hospital in the USA
\end{tabular}

Interventions

FORMAT: Interventions: audit and feedback, educational meeting with dissemination of guideline; reminders (verbal (on rounds, so may have been circumstantial) and physical (pocket-size guideline, screensavers))

Intervention Functions: education, enablement, persuasion

DELIVERER: departmental physicians (paediatrics and respiratory)

COMPARISON: usual care

DESIRED CHANGE: decrease excessive

Outcomes PRESCRIBING: Exposure: \% treated with antibiotics

CLINICAL: length of stay, re-admission

Notes

FINANCIAL SUPPORT: Funding: no external. Competing Interests: none declared

ADDITIONAL DATA: no response from authors to request for additional data

\section{Risk of bias}

\begin{tabular}{lll}
\hline Bias & Authors' judgement & Support for judgement \\
\hline $\begin{array}{l}\text { Intervention independent } \\
\text { (ITS) ? }\end{array}$ & High risk & $\begin{array}{l}\text { Antibiotic use was } 1 \text { of } 10 \text { recommendations in the guideline; the other } 9 \\
\text { would have impacted on clinical outcomes. }\end{array}$ \\
\hline $\begin{array}{l}\text { Analysed appropriately } \\
\text { (ITS)? }\end{array}$ & Low risk & Statistical process control charts \\
\hline
\end{tabular}


Mittal 2014 (Continued)

Shape of effect pre-speci- Low risk Point of intervention was point of analysis. fied (ITS) ?

Unlikely to affect data col- Low risk lection (ITS) ?
All outcome data from hospital patient administration system

\begin{tabular}{lll}
\hline $\begin{array}{l}\text { Knowledge of the alloca- } \\
\text { tion adequately prevent- } \\
\text { ed(ITS)? }\end{array}$ & Low risk & All outcome data from hospital patient administration system \\
\hline $\begin{array}{l}\text { Incomplete outcome data } \\
\text { addressed (ITS) ? }\end{array}$ & Low risk & All outcome data from hospital patient administration system \\
\hline $\begin{array}{l}\text { Free of selected reporting } \\
\text { (ITS) ? }\end{array}$ & Low risk & All outcome data from hospital patient administration system \\
\hline \begin{tabular}{l} 
Free of other bias (ITS) ? \\
\hline
\end{tabular} & Low risk & Data collected over 3 winters, 1 pre- and 2 postintervention. \\
\hline
\end{tabular}

\section{Mol 2005}

\begin{tabular}{ll}
\hline Methods & STUDY DESIGN: ITS \\
& Risk of Bias: HIGH
\end{tabular}

\begin{tabular}{l} 
PROVIIicipants \\
PATIENTS: all patients in the wards \\
CLINICAL PROBLEM: receiving antibiotic therapy \\
SETTING: 1 university hospital in the Netherlands \\
\hline FORMAT: 1st Intervention: audit and feedback; educational meetings with dissemination of guideline \\
$\begin{array}{l}\text { 1st Intervention Functions: education, enablement } \\
\text { 2nd Intervention: audit and feedback; educational meetings with dissemination of guideline; educa- } \\
\text { tional outreach by academic detailing }\end{array}$
\end{tabular}

2nd Intervention Functions: education, enablement, persuasion

DELIVERER: AMT

COMPARISON: usual care

DESIRED CHANGE: decrease excessive

\begin{tabular}{ll}
\hline Outcomes & PRESCRIBING: Choice: $\%$ compliance with guideline; antibiotic cost \\
& FINANCIAL: antibiotic cost
\end{tabular}

Notes $\quad$ FINANCIAL SUPPORT: Funding: none. Competing Interests: none declared

ADDITIONAL DATA: no response from authors to request for additional data

\section{Risk of bias}


Mol 2005 (Continued)

Intervention independent Low risk
(ITS)?

(ITS) ?

Analysed appropriately Low risk Done in original paper: segmented regression analysis
(ITS)?

\begin{tabular}{|c|c|c|}
\hline $\begin{array}{l}\text { Shape of effect pre-speci- } \\
\text { fied (ITS)? }\end{array}$ & Low risk & $\begin{array}{l}\text { Done, intended effect was increase in primary outcome, and point of analysis } \\
\text { was point of intervention. }\end{array}$ \\
\hline $\begin{array}{l}\text { Unlikely to affect data col- } \\
\text { lection (ITS)? }\end{array}$ & Low risk & Data collection method was same throughout study. \\
\hline $\begin{array}{l}\text { Knowledge of the alloca- } \\
\text { tion adequately prevent- } \\
\text { ed(ITS)? }\end{array}$ & High risk & Subjective outcome without blinded assessment \\
\hline $\begin{array}{l}\text { Incomplete outcome data } \\
\text { addressed (ITS)? }\end{array}$ & Unclear risk & Not stated whether compliance was assessed in all patients. \\
\hline $\begin{array}{l}\text { Free of selected reporting } \\
\text { (ITS)? }\end{array}$ & Unclear risk & Not stated whether compliance was assessed in all patients. \\
\hline Free of other bias (ITS)? & Low risk & $\begin{array}{l}\text { The kappa value for the primary outcome measure was } 0.71 \text {, which is below } \\
\text { the level set by EPOC, but for the reasons given in the text we feel is adequate } \\
\text { for assessment of compliance with an antibiotic guideline. Drug costs were ad- } \\
\text { justed to April } 2001 \text { prices. }\end{array}$ \\
\hline
\end{tabular}

Newland 2012

\begin{tabular}{ll}
\hline Methods & STUDY DESIGN: CITS \\
& Risk of Bias: MEDIUM \\
\hline Participants & PROVIDERS: all physicians in hospital \\
& PARTICIPANTS: all patients in children's hospital \\
CLINICAL PROBLEM: inappropriate use of antimicrobials; a group of broad-spectrum, or "select", an- \\
tibiotics 2 calendar days after they were initiated by the clinician \\
SETTING: 1 children's hospital in the USA (intervention) with data from 25 similar hospitals of the Child \\
Health Corporation of America as control
\end{tabular}

Interventions $\quad$ FORMAT: Interventions: educational outreach by review and recommend change.

NB the authors describe their intervention as "audit and feedback", but there was no feedback of data over time about progress to goal, just review with feedback about individual patients

Intervention Functions: enablement, persuasion

DELIVERER: AMT

COMPARISON: usual care

DESIRED CHANGE: decrease excessive

\begin{tabular}{ll}
\hline Outcomes & PRESCRIBING: Exposure: total antibiotic use (days of therapy/1000 patient days) \\
\hline Notes & $\begin{array}{l}\text { FINANCIAL SUPPORT: Funding: Agency for Healtcare Quality and Reseach (grant U18-HS10399). Com- } \\
\text { peting Interests: none declared }\end{array}$
\end{tabular}


Newland 2012 (Continued)

ADDITIONAL DATA: authors provided additional data

\section{Risk of bias}

\begin{tabular}{lll}
\hline Bias & Authors' judgement & Support for judgement \\
\hline $\begin{array}{l}\text { Intervention independent } \\
\text { (ITS) ? }\end{array}$ & Unclear risk & Unclear, there were some infection control initiatives running. \\
\hline $\begin{array}{l}\text { Analysed appropriately } \\
\text { (ITS) ? }\end{array}$ & Low risk & Re-analysed \\
\hline $\begin{array}{l}\text { Shape of effect pre-speci- } \\
\text { fied (ITS) ? }\end{array}$ & Low risk & Yes, point of analysis is point of intervention. \\
\hline $\begin{array}{l}\text { Unlikely to affect data col- } \\
\text { lection (ITS) ? }\end{array}$ & Low risk & Yes, data collection was the same pre- and postintervention. \\
\hline $\begin{array}{l}\text { Knowledge of the alloca- } \\
\text { tion adequately prevent- } \\
\text { ed(ITS)? }\end{array}$ & Low risk & Yes, objective outcomes \\
\hline $\begin{array}{l}\text { Incomplete outcome data } \\
\text { addressed (ITS) ? }\end{array}$ & Low risk & \\
\hline $\begin{array}{l}\text { Free of selected reporting } \\
\text { (ITS) ? }\end{array}$ & Low risk & Routine data, so could assume complete. \\
\hline \begin{tabular}{l} 
Free of other bias (ITS) ? \\
\hline
\end{tabular} & Low risk & Yes, all relevant outcomes reported. \\
\hline
\end{tabular}

Nobre 2008

\begin{tabular}{ll}
\hline Methods & STUDY DESIGN: RCT \\
& Risk of Bias: HIGH \\
\hline Participants & PROVIDERS: all physicians in the ICU \\
& PARTICIPANTS: 282 patients with suspected sepsis, 79 randomised (39 intervention, 40 control) \\
CLINICAL PROBLEM: duration of antibiotic treatment in patients with sepsis \\
SETTING: 1 ICU in 1 university hospital in Switzerland
\end{tabular}

Interventions $\quad$ FORMAT: Interventions: reminders (circumstantial, decision support algorithm with each PCT test); structural, introduction of PCT testing

Intervention Functions: enablement, environmental restructuring

DELIVERER: departmental physician (ICU)

COMPARISON: usual care

DESIRED CHANGE: decrease excessive

POWER CALCULATION: yes, a total of at least 66 participants. Details in Appendix 3

Outcomes PRESCRIBING: Exposure: duration of treatment in days

CLINICAL: Balancing: mortality, relapse of infection, length of ICU stay, length of hospital stay

FINANCIAL SUPPORT: Funding: commercial B.R.A.H.M.S AG (USD 50,000). Competing Interests: 2 au-
thors received speaker honoraria from B.R.A.H.M.S AG.


Nobre 2008 (Continued)

ADDITIONAL DATA: online supplementary file with addtional infromation about stopping rules in PCT group. No response from authors to request for additional data

\begin{tabular}{|c|c|c|}
\hline \multicolumn{3}{|l|}{ Risk of bias } \\
\hline Bias & Authors' judgement & Support for judgement \\
\hline $\begin{array}{l}\text { Random sequence genera- } \\
\text { tion (selection bias) }\end{array}$ & Low risk & $\begin{array}{l}\text { The randomisation was performed using a computer-based random number } \\
\text { generation. }\end{array}$ \\
\hline $\begin{array}{l}\text { Allocation concealment } \\
\text { (selection bias) }\end{array}$ & Low risk & Allocation was issued using opaque, sealed, numbered envelopes. \\
\hline $\begin{array}{l}\text { Blinding (performance } \\
\text { bias and detection bias) } \\
\text { All outcomes }\end{array}$ & High risk & No blinding \\
\hline $\begin{array}{l}\text { Incomplete outcome data } \\
\text { (attrition bias) } \\
\text { All outcomes }\end{array}$ & Low risk & \\
\hline $\begin{array}{l}\text { Selective reporting (re- } \\
\text { porting bias) }\end{array}$ & High risk & $\begin{array}{l}8 / 39(20 \%) \text { patients excluded from intervention versus } 3 / 40(7 \%) \text { from control; } \\
4 \text { patients excluded from intervention for "complicated infections", which is } \\
\text { likely to have biased the results on duration of antibiotic treatment. }\end{array}$ \\
\hline Other bias & Low risk & \\
\hline $\begin{array}{l}\text { Baseline Outcomes simi- } \\
\text { lar? }\end{array}$ & Unclear risk & No data \\
\hline Free of contamination? & Low risk & PCT only measured for intervention group. \\
\hline $\begin{array}{l}\text { Baseline characteristics } \\
\text { similar? }\end{array}$ & Low risk & Table 1 \\
\hline
\end{tabular}

Nuila 2008

\begin{tabular}{ll}
\hline Methods & STUDY DESIGN: ITS \\
& Risk of Bias: MEDIUM \\
\hline Participants & PROVIDERS: all physicians in hospital \\
& PARTICIPANTS: all patients receiving antibiotics \\
& CLINICAL PROBLEM: reduce cases of Clostridium difficile-associated disease in hospital by restricting \\
& use of parenteral antibiotics \\
& SETTING: 1 teaching hospital in the USA \\
& FORMAT: no valid prescribing data. Restriction and educational outreach - review and recommend \\
change & DELIVERER: AMT \\
Interventions & COMPARISON: usual care \\
& DESIRED CHANGE: reduce inappropriate
\end{tabular}


Nuila 2008 (Continued)

Outcomes MICROBIAL: incidence of Clostridium difficile-associated disease

Notes $\quad$ FINANCIAL SUPPORT: Funding: Merit Review Funding and Department of Veterans Affairs. Competing Interests: none declared

ADDITIONAL DATA: email from authors but no additional data

Microbial ROB: MEDIUM: Case definition Low, Planned intervention Low, Other infection control High

\section{Risk of bias}

\begin{tabular}{lll}
\hline Bias & Authors' judgement & Support for judgement \\
\hline $\begin{array}{l}\text { Intervention independent } \\
\text { (ITS) } ?\end{array}$ & High risk & MRSA control programme introduced simultaneously. \\
\hline $\begin{array}{l}\text { Analysed appropriately } \\
\text { (ITS) } ?\end{array}$ & Low risk & Re-analysed \\
\hline
\end{tabular}

Shape of effect pre-speci- Low risk Point of intervention was point of analysis.

fied (ITS) ?

Unlikely to affect data col- Low risk $\quad$ Routine data from microbiology computer
lection (ITS)?

Knowledge of the alloca- Low risk Routine data from microbiology computer
tion adequately prevented(ITS)?

\begin{tabular}{lll}
\hline $\begin{array}{l}\text { Incomplete outcome data } \\
\text { addressed (ITS) ? }\end{array}$ & Low risk & Routine data from microbiology computer \\
\hline $\begin{array}{l}\text { Free of selected reporting } \\
\text { (ITS) } ?\end{array}$ & Low risk & Routine data from microbiology computer \\
\hline
\end{tabular}

Free of other bias (ITS) ? High risk Only 6 months' data postintervention

Microbial Outcome Risk of Bias Criteria: Case definition: DONE, CDC definition of $C$ difficile. Planned intervention: DONE. Other infection control measures: NOT DONE, MRSA control programme introduced simultaneously.

\section{Oliveira 2013}

\begin{tabular}{ll}
\hline Methods & STUDY DESIGN: RCT \\
& Risk of Bias: HIGH \\
\hline Participants & PROVIDERS: all physicians \\
& PARTICIPANTS: 355 ICU patients assessed for inclusion, 94 patients randomised \\
& CLINICAL PROBLEM: 94 patients with suspected sepsis randomised (49 intervention, 45 control) \\
& SETTING: 1 university hospital ICU in Brazil \\
\hline Interventions & FORMAT: Interventions: reminders (circumstantial, decision support algorithm with each PCT test); \\
& Structural, introduction of PCT testing \\
& Intervention Functions: enablement, environmental restructuring \\
& DELIVERER: specialist physician (Infectious Diseases) \\
& COMPARISON: usual care, patients monitored with C-reactive protein \\
\hline
\end{tabular}


POWER CALCULATION: yes, 58 participants per group. Details in Appendix 3

\begin{tabular}{ll}
\hline Outcomes & PRESCRIBING: Exposure: duration of treatment in days \\
& CLINICAL: mortality, recurrence of infection, ICU length of stay, hospital length of stay, nosocomial in- \\
fection & \\
\hline FINANCIAL SUPPORT: Funding: Minas Gerais Research Foundation (Fundação de Amparo à Pesquisa \\
do Estado de Minas Gerais). Competing Interests: 1 author received payment for lectures from bio- \\
Mérieux. No others declared. \\
ADDITIONAL DATA: online Microsoft Word document with additional information about the criteria for \\
stopping antibiotics, no response from authors to request for additional data
\end{tabular}

\section{Risk of bias}

\begin{tabular}{|c|c|c|}
\hline Bias & Authors' judgement & Support for judgement \\
\hline $\begin{array}{l}\text { Random sequence genera- } \\
\text { tion (selection bias) }\end{array}$ & Low risk & $\begin{array}{l}\text { Randomisation was performed using a table of computer-generated random } \\
\text { numbers. }\end{array}$ \\
\hline $\begin{array}{l}\text { Allocation concealment } \\
\text { (selection bias) }\end{array}$ & Low risk & Sealed, opaque envelopes were used for the randomisation. \\
\hline $\begin{array}{l}\text { Blinding (performance } \\
\text { bias and detection bias) } \\
\text { All outcomes }\end{array}$ & High risk & Not blinded \\
\hline $\begin{array}{l}\text { Incomplete outcome data } \\
\text { (attrition bias) } \\
\text { All outcomes }\end{array}$ & Low risk & $\begin{array}{l}1 \text { patient excluded from intervention and } 2 \text { from control. Outcomes measured } \\
\text { on all other randomised participants. }\end{array}$ \\
\hline $\begin{array}{l}\text { Selective reporting (re- } \\
\text { porting bias) }\end{array}$ & Low risk & Duration of antibiotics measured from patient administration system. \\
\hline \multirow[t]{3}{*}{ Other bias } & Unclear risk & $\begin{array}{l}\text { "Patients showing reduction in SOFA and no sign of active infection were to re- } \\
\text { ceive no more than } 7 \text { days of antibiotic therapy. We used the }\end{array}$ \\
\hline & & $\begin{array}{l}\text { biomarker-guided protocols to further reduce this duration (i.e., to less than } \\
\text { seven days)". This suggests that the ID physicians imposed a ceiling of } 7 \text { days' } \\
\text { treatment for these patients for both intervention and control groups. }\end{array}$ \\
\hline & & Study did not achieve required recruitment. \\
\hline $\begin{array}{l}\text { Baseline Outcomes simi- } \\
\text { lar? }\end{array}$ & Unclear risk & No data \\
\hline Free of contamination? & Low risk & PCT only measured for intervention group. \\
\hline $\begin{array}{l}\text { Baseline characteristics } \\
\text { similar? }\end{array}$ & Low risk & Table 1 \\
\hline
\end{tabular}

Methods STUDY DESIGN: RCT


Oosterheert 2005 (Continued)

\section{Risk of Bias: HIGH}

PROVIDERS: hospital physicians
PATIENTS: inpatients with LRTI, 107 randomised (55 intervention, 52 control)
CLINICAL PROBLEM: admitted to hospital for treatment of LRTI
SETTING: 2 Dutch hospitals

Interventions

FORMAT: Interventions: educational meetings; dissemination of written information about study procedures, test characteristics discussed and results from previous studies; structural, rapid laboratory testing (PCR) for viral and atypical bacterial pathogens

Intervention Functions: education, environmental restructuring

DELIVERER: specialist physician (Medical Microbiology)

COMPARISON: usual care

DESIRED CHANGE: decrease excessive

POWER CALCULATION: yes, a total of 100 patients. Details in Appendix 3

PRESCRIBING: Exposure: \% patients treated
CLINICAL: mortality, median duration of antibiotic treatment
FINANCIAL: cost of hospitalisation, all diagnostic and treatment costs

Notes $\quad$ FINANCIAL SUPPORT: Funding: Association of Academic Hospitals and the Dutch Health Insurance Council (grant 01233). Competing Interests: none declared

ADDITIONAL DATA: no response from authors to request for additional data

\section{Risk of bias}

\begin{tabular}{|c|c|c|}
\hline Bias & Authors' judgement & Support for judgement \\
\hline $\begin{array}{l}\text { Random sequence genera- } \\
\text { tion (selection bias) }\end{array}$ & Low risk & $\begin{array}{l}\text { "Patients were randomly allocated ... by means of a computer generated ta- } \\
\text { ble" }\end{array}$ \\
\hline $\begin{array}{l}\text { Allocation concealment } \\
\text { (selection bias) }\end{array}$ & High risk & Allocation by investigators \\
\hline $\begin{array}{l}\text { Blinding (performance } \\
\text { bias and detection bias) } \\
\text { All outcomes }\end{array}$ & High risk & Investigators were not blinded to patient randomisation. \\
\hline $\begin{array}{l}\text { Incomplete outcome data } \\
\text { (attrition bias) } \\
\text { All outcomes }\end{array}$ & Low risk & Reported on all 107 patients \\
\hline $\begin{array}{l}\text { Selective reporting (re- } \\
\text { porting bias) }\end{array}$ & Low risk & \\
\hline Other bias & Low risk & \\
\hline $\begin{array}{l}\text { Baseline Outcomes simi- } \\
\text { lar? }\end{array}$ & Unclear risk & No data \\
\hline
\end{tabular}


Oosterheert 2005 (Continued)

\begin{tabular}{lll} 
Free of contamination? & Low risk & Test data only reported for intervention patients. \\
\hline $\begin{array}{l}\text { Baseline characteristics } \\
\text { similar? }\end{array}$ & High risk & $\begin{array}{l}\text { "slightly more patients in the intervention group had received previous antibi- } \\
\text { otic treatment ": } 42 \% \text { vs } 23 \%, \text { which is not "slighly more" }\end{array}$ \\
\hline
\end{tabular}

\section{Ostrowsky 2014}

\begin{tabular}{ll}
\hline Methods & STUDY DESIGN: CITS \\
& Risk of Bias: MEDIUM \\
\hline Participants & PROVIDERS: all physicians in the hospitals \\
& PARTICIPANTS: all patients in the hospitals \\
& CLINICAL PROBLEM: reduce use of antibiotics considered high risk for Clostridium difficile infection \\
& SETTING: 10 hospitals in the USA, 6 intervention and 4 control
\end{tabular}

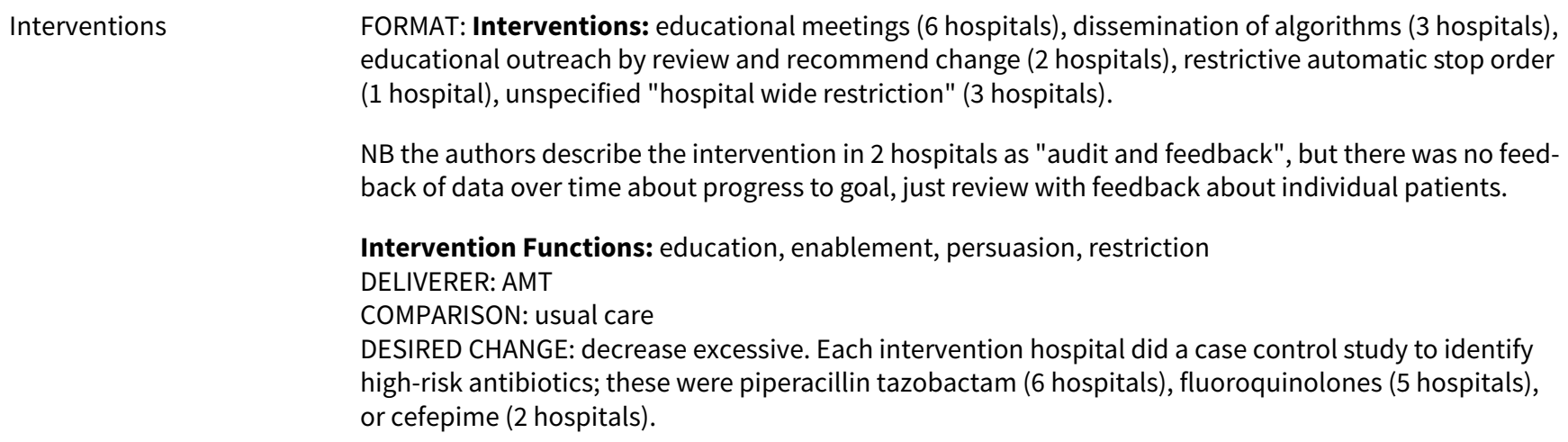

Outcomes

PRESCRIBING: Choice: use of target antibiotics in DDD/1000 OBD and in days of therapy

MICROBIAL: C difficile infection (cases per 10,000 OBD)

Notes $\quad$ FINANCIAL SUPPORT: Funding: Agency for Healthcare Research and Quality; US Department of Health and Human Services. Competing Interests: none declared

ADDITIONAL DATA: email response from authors with additional data about the intervention used by each of the 6 intervention hospitals

\section{Risk of bias}

\begin{tabular}{ll}
\hline Bias & Authors' judgement $\quad$ Support for judgement \\
\hline $\begin{array}{l}\text { Intervention independent } \\
\text { (ITS)? }\end{array}$ & Low risk
\end{tabular}

\begin{tabular}{ll}
\hline $\begin{array}{l}\text { Analysed appropriately } \\
\text { (ITS) ? }\end{array}$ & Low risk \\
\hline
\end{tabular}

Shape of effect pre-speci- Low risk Point of intervention was point of analysis.


Ostrowsky 2014 (Continued)

Knowledge of the alloca- Low risk Outcome data from pharmacy and microbiology computers tion adequately prevented(ITS)?

\begin{tabular}{lll}
\hline $\begin{array}{l}\text { Incomplete outcome data } \\
\text { addressed (ITS) ? }\end{array}$ & Low risk & Outcome data from pharmacy and microbiology computers \\
\hline $\begin{array}{l}\text { Free of selected reporting } \\
\text { (ITS) } ?\end{array}$ & Low risk & Outcome data from pharmacy and microbiology computers \\
\hline Free of other bias (ITS) ? & High risk & $\begin{array}{l}\text { Intervention targets and intervention design were different in each of the } 6 \\
\text { hospitals. Microbial ROB MEDIUM: case definition low, planned intervention } \\
\text { low, other infection control UNCLEAR }\end{array}$ \\
\hline
\end{tabular}

Ozkaya 2009

\begin{tabular}{|c|c|c|}
\hline Methods & \multicolumn{2}{|l|}{$\begin{array}{l}\text { STUDY DESIGN: NRT } \\
\text { Risk of Bias: HIGH }\end{array}$} \\
\hline Participants & \multicolumn{2}{|c|}{$\begin{array}{l}\text { PROVIDERS: all staff in the ED } \\
\text { PARTICIPANTS: all children with influenza-like illness } \\
\text { CLINICAL PROBLEM: reduction in antibiotic prescribing for influenza } \\
\text { SETTING: } 1 \text { university hospital in Turkey }\end{array}$} \\
\hline Interventions & \multicolumn{2}{|c|}{$\begin{array}{l}\text { Intervention Function: environmental restructuring } \\
\text { DELIVERER: specialist physicians, Department of Paediatrics } \\
\text { COMPARISON: usual care } \\
\text { DESIRED CHANGE: decrease excessive }\end{array}$} \\
\hline Outcomes & \multicolumn{2}{|c|}{ PRESCRIBING: Exposure: $\%$ children prescribed antibiotics } \\
\hline Notes & \multicolumn{2}{|c|}{$\begin{array}{l}\text { FINANCIAL SUPPORT: no information } \\
\text { ADDITIONAL DATA: email response from authors but no additional data }\end{array}$} \\
\hline \multicolumn{3}{|l|}{ Risk of bias } \\
\hline Bias & Authors' judgement & Support for judgement \\
\hline $\begin{array}{l}\text { Random sequence genera- } \\
\text { tion (selection bias) }\end{array}$ & Unclear risk & Does not say how groups were allocated \\
\hline $\begin{array}{l}\text { Allocation concealment } \\
\text { (selection bias) }\end{array}$ & Unclear risk & Says there was blinding but unclear who was blinded. \\
\hline $\begin{array}{l}\text { Blinding (performance } \\
\text { bias and detection bias) } \\
\text { All outcomes }\end{array}$ & Unclear risk & Says there was blinding but unclear who was blinded. \\
\hline $\begin{array}{l}\text { Incomplete outcome data } \\
\text { (attrition bias) } \\
\text { All outcomes }\end{array}$ & Low risk & All included \\
\hline
\end{tabular}


Ozkaya 2009 (Continued)

Selective reporting (re- Low risk $\quad$ Yes, all outcomes reported.
porting bias)

\begin{tabular}{|c|c|}
\hline Other bias & Low risk \\
\hline $\begin{array}{l}\text { Baseline Outcomes simi- } \\
\text { lar? }\end{array}$ & Unclear risk \\
\hline
\end{tabular}

\begin{tabular}{lll}
\hline Free of contamination? & High risk & Within same ward \\
\hline $\begin{array}{l}\text { Baseline characteristics } \\
\text { similar? }\end{array}$ & Low risk & Yes, Table 1 \\
\hline
\end{tabular}

Palmay 2014

Methods STUDY DESIGN: cluster RCT, stepped wedge, service level

\section{Risk of Bias: MEDIUM}

Participants PROVIDERS: all physicians in 6 hospital services

PARTICIPANTS: all patients in 6 hospital services, 6 clusters (services)

CLINICAL PROBLEM: use of targeted antibiotics (carbapenems (ertapenem, meropenem), piperacillin-tazobactam, 3rd-generation cephalosporins (ceftazidime, ceftriaxone), fluoroquinolones (ciprofloxacin, levofloxacin, moxifloxacin), and intravenous vancomycin)

SETTING: 1 university hospital in Canada, 6 services: Neurosurgery, Orthopaedics, Nephrology, General Internal Medicine, Cardiology, General Surgery/Trauma

Interventions

FORMAT: Interventions: educational outreach by review and recommend change; reminders (circumstantial, physical, written recommendation on each patient reviewed)

NB the authors describe their intervention as "audit and feedback", but there was no feedback of data over time about progress to goal, just review with feedback about individual patients.

Intervention Functions: enablement, environmental restructuring, persuasion

DELIVERER: AMT

COMPARISON: usual care

DESIRED CHANGE: decrease excessive

POWER CALCULATION: no information

Outcomes PRESCRIBING: Choice: use of target antibiotics in days of therapy/1000 OBD

MICROBIAL: Clostridium difficile infection and infection with antibiotic-resistant organisms

FINANCIAL: time required to implement the intervention in critical-care wards is described in Elligson 2012a.

Notes FINANCIAL SUPPORT: Funding: Ontario Ministry of Health and Canadian Institutes of Health Research. Competing Interests: none declared

ADDITIONAL DATA: email response with additional details about the intervention from authors including Elligson 2012a describing the design and cost of implementing the intervention in critical-care wards

Microbial Risk of Bias: MEDIUM: case definition low, unplanned intervention low, other infection control UNCLEAR

\section{Risk of bias}


Palmay 2014 (Continued)

\begin{tabular}{lll} 
Bias & Authors' judgement & Support for judgement \\
\hline $\begin{array}{l}\text { Random sequence genera- } \\
\text { tion (selection bias) }\end{array}$ & Low risk & $\begin{array}{l}\text { The order of implementation of the intervention on the } 6 \text { clinical services was } \\
\text { determined by random number generation performed by a statistician unin- } \\
\text { volved in daily stewardship activities. }\end{array}$ \\
\hline $\begin{array}{l}\text { Allocation concealment } \\
\text { (selection bias) }\end{array}$ & Low risk & $\begin{array}{l}\text { Following a 6-month control period during which none of the services received } \\
\text { antimicrobial stewardship (1 May 2010 to 31 October 2011), the intervention } \\
\text { was introduced to each additional service at 1-month intervals, beginning on } 1 \\
\text { November 2010. By } 1 \text { April 2011, clinical rollout was complete. }\end{array}$
\end{tabular}

Blinding (performance $\quad$ High risk Blinding was not possible.
bias and detection bias)

bias and detection bias)

All outcomes

Incomplete outcome data Low risk Prescribing outcome data were from pharmacy computer.

(attrition bias)

All outcomes

Selective reporting (re- Low risk $\quad$ Prescribing outcome data were from pharmacy computer.
porting bias)

\begin{tabular}{|c|c|c|}
\hline Other bias & Low risk & $\begin{array}{l}\text { Unit of analysis was service, and clustering was included in the model. "Nega- } \\
\text { tive binomial regression, accounting for clustering at the level of service using } \\
\text { random effects as well as for secular and seasonal trends, was used to com- } \\
\text { pare overall targeted antimicrobial utilization in the control and intervention } \\
\text { periods for the analysis involving patients qualifying for the stewardship in- } \\
\text { tervention as well as the analysis of all admitted patients. The unit of analysis } \\
\text { was each service's mean monthly targeted days of therapy count. The covari- } \\
\text { ates included in these multivariable models were study period, study month } \\
\text { (as a continuous variable), and season" }\end{array}$ \\
\hline $\begin{array}{l}\text { Baseline Outcomes simi- } \\
\text { lar? }\end{array}$ & Low risk & Table 4 \\
\hline Free of contamination? & High risk & $\begin{array}{l}\text { Contamination could have occurred during the rollout of intervention over } 6 \\
\text { months. }\end{array}$ \\
\hline $\begin{array}{l}\text { Baseline characteristics } \\
\text { similar? }\end{array}$ & Low risk & \\
\hline
\end{tabular}

Parienti 2011

\begin{tabular}{ll} 
Methods & STUDY DESIGN: ITS \\
& Risk of Bias: LOW \\
\hline Participants & PROVIDERS: all physicians in the hospital \\
& CLINICALANTS: all patients receiving antibiotics in the hospital \\
& restriction \\
& SETTING: 1 university hospital in France
\end{tabular}

Interventions

FORMAT: no reliable prescribing data. The intervention was removal of restriction, but only 1 prescribing outcome data point during restriction and 3 after restriction lifted.

DELIVERER: AMT 
Parienti 2011 (Continued)

COMPARISON: usual care

DESIRED CHANGE: decrease excessive

\begin{tabular}{ll}
\hline Outcomes & MICROBIAL: monthly MRSA rate (\%) \\
\hline Notes & FINANCIAL SUPPORT:Funding: Centre Hospitalier Universitaire de Caen and the French Health Ministry \\
& (Programme Hospitalier de Recherche Clinique National). Competing Interests: none declared \\
& ADDITIONAL DATA: no response from authors to request for additional data \\
\hline
\end{tabular}

\section{Risk of bias}

\begin{tabular}{|c|c|c|}
\hline Bias & Authors' judgement & Support for judgement \\
\hline $\begin{array}{l}\text { Intervention independent } \\
\text { (ITS) ? }\end{array}$ & Low risk & \\
\hline $\begin{array}{l}\text { Analysed appropriately } \\
\text { (ITS)? }\end{array}$ & Low risk & Segmented regression analysis \\
\hline $\begin{array}{l}\text { Shape of effect pre-speci- } \\
\text { fied (ITS)? }\end{array}$ & Low risk & Point of intervention was point of analysis. \\
\hline $\begin{array}{l}\text { Unlikely to affect data col- } \\
\text { lection (ITS)? }\end{array}$ & Low risk & MRSA data from microbiology computer \\
\hline $\begin{array}{l}\text { Knowledge of the alloca- } \\
\text { tion adequately prevent- } \\
\text { ed(ITS)? }\end{array}$ & Low risk & MRSA data from microbiology computer \\
\hline $\begin{array}{l}\text { Incomplete outcome data } \\
\text { addressed (ITS)? }\end{array}$ & Low risk & MRSA data from microbiology computer \\
\hline $\begin{array}{l}\text { Free of selected reporting } \\
\text { (ITS)? }\end{array}$ & Low risk & MRSA data from microbiology computer \\
\hline Free of other bias (ITS) ? & Low risk & $\begin{array}{l}\text { MICROBIAL RISK OF BIAS: case defiinition Low, planned intervention Low, } \\
\text { other infection control Low, use of alchohol-based hand rub (ABHR) un- } \\
\text { changed during period of fluoroquinolone restriction (2001-2) and for } 3 \text { years } \\
\text { after restriction lifted (2003-5). Data are also presented for a further } 6 \text { years of } \\
\text { increased use of ABHR (2006-11). }\end{array}$ \\
\hline
\end{tabular}

Parikh 2014

\begin{tabular}{ll} 
Methods & STUDY DESIGN: ITS \\
& Risk of Bias: LOW \\
\hline Participants & PROVIDERS: all paediatric physicians in the hospitals \\
& PARTICIPANTS: children aged 28 days to 2 years \\
CLINICAL PROBLEM: antibiotic use in children with a primary diagnosis of acute bronchiolitis \\
SETTING: 41 hospitals in the USA
\end{tabular}

Interventions

FORMAT: Intervention: publication of American Academy of Pediatricians (AAP) bronchiolitis guidelines

Intervention Functions: education but no information about how the guidelines were disseminated 
Parikh 2014 (Continued)

DELIVERER: departmental physicians (Pediatrics)

COMPARISON: usual care

DESIRED CHANGE: decrease excessive

\begin{tabular}{ll}
\hline Outcomes & PRESCRIBING: Exposure: $\%$ children treated with antibiotics \\
\hline Notes & FINANCIAL SUPPORT: Funding: Academic Pediatric Association. Competing Interests: none declared \\
& $\begin{array}{l}\text { ADDITIONAL DATA: no response from authors to request for additional data. AAP 2006 Bronchiolitis } \\
\text { Guidelines downloaded. }\end{array}$
\end{tabular}

\section{Risk of bias}

\begin{tabular}{|c|c|c|}
\hline Bias & Authors' judgement & Support for judgement \\
\hline $\begin{array}{l}\text { Intervention independent } \\
\text { (ITS)? }\end{array}$ & Low risk & \\
\hline $\begin{array}{l}\text { Analysed appropriately } \\
\text { (ITS)? }\end{array}$ & Low risk & Segmented regression analysis \\
\hline $\begin{array}{l}\text { Shape of effect pre-speci- } \\
\text { fied (ITS)? }\end{array}$ & Low risk & Point of intervention was point of analysis. \\
\hline $\begin{array}{l}\text { Unlikely to affect data col- } \\
\text { lection (ITS)? }\end{array}$ & Low risk & Data from patient administration systems \\
\hline $\begin{array}{l}\text { Knowledge of the alloca- } \\
\text { tion adequately prevent- } \\
\text { ed(ITS)? }\end{array}$ & Low risk & Data from patient administration systems \\
\hline $\begin{array}{l}\text { Incomplete outcome data } \\
\text { addressed (ITS)? }\end{array}$ & Low risk & Data from patient administration systems \\
\hline $\begin{array}{l}\text { Free of selected reporting } \\
\text { (ITS)? }\end{array}$ & Low risk & Data from patient administration systems \\
\hline Free of other bias (ITS)? & Low risk & $\begin{array}{l}\text { Monthly data points for } 20 \text { months' pre- and } 60 \text { months' postintervention. } \\
\text { "Guideline published in October } 2006 \text {. Study phases: preguideline (November } \\
2004 \text { to March 2005), postguideline early (November } 2007 \text { to March 2008), and } \\
\text { postguideline late (November } 2011 \text { to March 2012). These time periods were } \\
\text { selected for the unadjusted analysis because they represent } 3 \text { bronchiolitis } \\
\text { seasons, before and after guideline publication; the } 2006 \text { to } 2007 \text { season was } \\
\text { not included because this is the year the guideline was published and was a } \\
\text { period of distribution and assimilation. For the adjusted segmented regres- } \\
\text { sion analysis, publication of the guidelines, October 2006, was considered the } \\
\text { event point." }\end{array}$ \\
\hline
\end{tabular}

Patel 1989

\begin{tabular}{ll} 
Methods & STUDY DESIGN: ITS \\
& Risk of Bias: MEDIUM \\
\hline Participants & PROVIDERS: all physicians in the hospital \\
& PARTICIPANTS: all patients in the hospital \\
& CLINICAL PROBLEM: patients requiring antibiotic treatment
\end{tabular}


Patel 1989 (Continued)

SETTING: single hospital in the UK

Interventions $\quad$ FORMAT: Interventions: educational meetings with dissemination of guidelines; educational outreach by review and recommend change; reminders (physical and verbal, posters and intervention promoted at weekly ward meetings)

Intervention Functions: education, enablement, environmental restructuring, persuasion

DELIVERER: pharmacist

COMPARISON: usual care

DESIRED CHANGE: decrease excessive

\begin{tabular}{ll}
\hline Outcomes & PRESCRIBING: Choice: expenditure on oral co-amoxiclav \\
\hline Notes & FINANCIAL SUPPORT: no information \\
& ADDITIONAL DATA: no response from authors to request for additional data \\
\hline
\end{tabular}

\section{Risk of bias}

\begin{tabular}{lll}
\hline Bias & Authors' judgement & Support for judgement \\
\hline $\begin{array}{l}\text { Intervention independent } \\
\text { (ITS) ? }\end{array}$ & High risk & Only 5 months' pre-intervention data, so secular changes possible. \\
\hline $\begin{array}{l}\text { Analysed appropriately } \\
\text { (ITS) ? }\end{array}$ & Low risk & $\begin{array}{l}\text { Re-analysed. Not done in original paper: comparison of means (uncontrolled } \\
\text { before-after). }\end{array}$ \\
\hline $\begin{array}{l}\text { Shape of effect pre-speci- } \\
\text { fied (ITS) ? }\end{array}$ & Low risk & $\begin{array}{l}\text { Done, intended effect was decrease in primary outcome, and point of analysis } \\
\text { was point of intervention. }\end{array}$ \\
\hline $\begin{array}{l}\text { Unlikely to affect data col- } \\
\text { lection (ITS) ? }\end{array}$ & Low risk & $\begin{array}{l}\text { Done, data were from routine systems and unlikely to change over study peri- } \\
\text { od. }\end{array}$ \\
\hline $\begin{array}{l}\text { Knowledge of the alloca- } \\
\text { tion adequately prevent- } \\
\text { ed(ITS)? }\end{array}$ & Low risk & $\begin{array}{l}\text { Done, data were from routine systems and unlikely to change over study peri- } \\
\text { od. }\end{array}$ \\
\hline $\begin{array}{l}\text { Incomplete outcome data } \\
\text { addressed (ITS) ? }\end{array}$ & Low risk & $\begin{array}{l}\text { Done, data were from routine systems and unlikely to change over study peri- } \\
\text { od. }\end{array}$ \\
\hline $\begin{array}{l}\text { Free of selected reporting } \\
\text { (ITS) ? }\end{array}$ & Low risk & $\begin{array}{l}\text { Done, data were from routine systems and unlikely to change over study peri- } \\
\text { od. }\end{array}$ \\
\hline \begin{tabular}{l} 
Free of other bias (ITS)? \\
\hline
\end{tabular} & Low risk & \begin{tabular}{l} 
No other apparent biases found. \\
\hline
\end{tabular}
\end{tabular}

Paul 2006

\begin{tabular}{ll}
\hline Methods & STUDY DESIGN: cluster RCT, service level \\
& Risk of Bias: MEDIUM \\
\hline Participants & PROVIDERS: all physicians in the hospital \\
& PATIENTS: all patients in the 3 hospitals (intervention 8 wards with 1245 patients, 297 with microbio- \\
& logically documented infections; control 7 wards with 1081 patients, 273 with microbiologically docu- \\
mented infections), 15 clusters (wards) & CLINICAL PROBLEM: antibiotic prescribing
\end{tabular}


Paul 2006 (Continued)

SETTING: 3 hospitals in 3 countries: Israel, Germany, and Italy

Interventions $\quad$ FORMAT: Intervention: reminders (circumstantial, triggered by prescription of antibiotics); structural, computer decision support system

Intervention Functions: education, enablement, environmental restructuring, persuasion

DELIVERER: AMT

COMPARISON: usual care

DESIRED CHANGE: decrease excessive

POWER CALCULATION: yes, 1500 patients with microbiologically documented infections. Details in Appendix 3

PRESCRIBING: Choice: appropriate antibiotic treatments
COST: Costs, which included the estimated ecological cost of inappropriate antibiotic treatment
CLINICAL: Balancing: length of stay, 30-day mortality

Notes $\quad$ FINANCIAL SUPPORT: Funding: EU Fifth Framework, Information Society Technologies,
IST-9999-11459. Competing Interests: none declared

ADDITIONAL DATA: no response from authors to request for additional data

\section{Risk of bias}

\begin{tabular}{|c|c|c|}
\hline Bias & Authors' judgement & Support for judgement \\
\hline $\begin{array}{l}\text { Random sequence genera- } \\
\text { tion (selection bias) }\end{array}$ & Low risk & $\begin{array}{l}\text { "Wards were randomly allocated ... by drawing a random code from a closed } \\
\text { opaque box" }\end{array}$ \\
\hline $\begin{array}{l}\text { Allocation concealment } \\
\text { (selection bias) }\end{array}$ & High risk & Allocation could not be concealed. \\
\hline $\begin{array}{l}\text { Blinding (performance } \\
\text { bias and detection bias) } \\
\text { All outcomes }\end{array}$ & Low risk & Primary outcome was measured by the CDSS. \\
\hline $\begin{array}{l}\text { Incomplete outcome data } \\
\text { (attrition bias) } \\
\text { All outcomes }\end{array}$ & Low risk & Outcomes reported on all patients. \\
\hline $\begin{array}{l}\text { Selective reporting (re- } \\
\text { porting bias) }\end{array}$ & Low risk & $\begin{array}{l}\text { The primary outcome was objective, based on whether or not the prescriber } \\
\text { selected one of the CDSS top } 3 \text { recommendations. }\end{array}$ \\
\hline Other bias & High risk & $\begin{array}{l}\text { Trial was underpowered for the primary outcome measure. } \\
\text { Adjustment of drug costs for changes in prices not necessary because the in- } \\
\text { tervention lasted only } 6 \text { months. }\end{array}$ \\
\hline $\begin{array}{l}\text { Baseline Outcomes simi- } \\
\text { lar? }\end{array}$ & Low risk & Table 1 , cohort study before trial \\
\hline Free of contamination? & Low risk & Only intervention wards had CDSS. \\
\hline $\begin{array}{l}\text { Baseline characteristics } \\
\text { similar? }\end{array}$ & Low risk & \\
\hline
\end{tabular}


Pear 1994

Methods STUDY DESIGN: ITS

\section{Risk of Bias: HIGH}

PROVIDERS: all physicians in the hospital
PARTICIPANTS: all patients in the hospital
CLINICAL PROBLEM: patients requiring antibiotic treatment
SETTING: single university hospital in the USA

\begin{tabular}{ll}
\hline Interventions & FORMAT: restrictive, no valid prescribing data \\
& $\begin{array}{l}\text { DELIVERER: specialist physician } \\
\text { COMPARISON: usual care } \\
\text { DESIRED CHANGE: decrease excessive }\end{array}$ \\
\hline Outcomes & $\begin{array}{l}\text { MICROBIAL: cases of CDAD per month (ITS data). Prevalence of clindamycin-resistant Clostridium diffi- } \\
\text { cile }\end{array}$ \\
\hline Notes & FINANCIAL SUPPORT: none \\
\hline
\end{tabular}

\section{Risk of bias}

\begin{tabular}{lll}
\hline Bias & Authors' judgement & Support for judgement \\
\hline $\begin{array}{l}\text { Intervention independent } \\
\text { (ITS) ? }\end{array}$ & Low risk & $\begin{array}{l}\text { Enough data to account for seasonal variation, and infection control measures } \\
\text { did not change over study period. }\end{array}$ \\
\hline $\begin{array}{l}\text { Analysed appropriately } \\
\text { (ITS)? }\end{array}$ & Low risk & Re-analysed. Not done in original paper: run chart with no statistical analysis. \\
\hline
\end{tabular}

\begin{tabular}{|c|c|c|}
\hline $\begin{array}{l}\text { Shape of effect pre-speci- } \\
\text { fied (ITS)? }\end{array}$ & Low risk & $\begin{array}{l}\text { Done, intended effect was decrease in primary outcome, and point of analysis } \\
\text { was point of intervention. }\end{array}$ \\
\hline
\end{tabular}

Unlikely to affect data col- High risk lection (ITS)?
Not done, the method of detection of $C$ difficile toxin changed from cell culture assay in the first 4 years of the study to a latex test in the final year ( 5 months after the start of clindamycin restriction).

\begin{tabular}{lll}
\hline $\begin{array}{l}\text { Knowledge of the alloca- } \\
\text { tion adequately prevent- } \\
\text { ed(ITS)? }\end{array}$ & Low risk & $\begin{array}{l}\text { Done, data were from routine systems and unlikely to change over study peri- } \\
\text { od. }\end{array}$ \\
\hline $\begin{array}{l}\text { Incomplete outcome data } \\
\text { addressed (ITS) ? }\end{array}$ & Low risk & $\begin{array}{l}\text { Done, data were from routine systems and unlikely to change over study peri- } \\
\text { od. }\end{array}$ \\
\hline $\begin{array}{l}\text { Free of selected reporting } \\
\text { (ITS) ? }\end{array}$ & High risk & $\begin{array}{l}\text { Not done, change in method of testing for C difficile during the study period } \\
\text { (see case definition). }\end{array}$ \\
\hline Free of other bias (ITS)? & High risk & $\begin{array}{l}\text { Microbial Outcome Risk of Bias Criteria: Case definition: NOT DONE Infec- } \\
\text { tion: diarrhoea with positive assay for C difficile cytotoxin and antibiotic ther- } \\
\text { apy within the previous } 60 \text { days. However, the method of detection of toxin } \\
\text { changed from cell culture assay in the first } 4 \text { years of the study to a latex test } \\
\text { in the final year (5 months after the start of clindamycin restriction). Planned } \\
\text { intervention: NOT DONE Response to an outbreak of CDAD starting } 12 \text { months } \\
\text { before restriction. Other infection control, isolation, and IC practices: DONE In- } \\
\text { fection control measures were identical in the year before and after the start of } \\
\text { clindamycin restriction. Hospital staff education and increased availability of } \\
\text { gloves and improvement of environmental hygiene were implemented a year }\end{array}$ \\
\hline
\end{tabular}




\begin{tabular}{ll}
\hline Methods & STUDY DESIGN: ITS \\
& Risk of Bias: LOW \\
\hline Participants & PROVIDERS: physicians, surgeons, paediatricians, obstetricians-gynaecologists, and intensivists \\
& PARTICIPANTS: adults and children with normal renal function \\
CLINICAL PROBLEM: inappropriate prescribing of antibiotics (specifically in relation to intervals be- & tween doses of aminoglycosides and 1st- and 3rd-generation cephalosporins for Intervention 1 and \\
timing of surgical prophylaxis for Intervention 2) & SETTING: university hospital in Colombia
\end{tabular}

Interventions

FORMAT: Interventions: Intervention 1: reminders (posters, not circumstantial); educational meetings and dissemination of guidelines; restrictive by expert approval. Intervention 2: reminder (circumstantial, on blood pressure cuffs in operating theatre); educational meetings and dissemination of guidelines

Intervention Functions: Intervention 1: education, environmental restructuring, persuasion. Intervention 2: education, enablement, environmental restructuring, persuasion

DELIVERER: pharmacists

COMPARISON: usual care

DESIRED CHANGE: Intervention 1: increase effective; Intervention 2: decrease excessive

\begin{tabular}{ll}
\hline Outcomes & $\begin{array}{l}\text { PRESCRIBING: Choice: reduction in incidence of incorrect antibiotic prescriptions (dosing intervals and } \\
\text { timing of surgical prophylaxis). }\end{array}$ \\
\hline Notes & $\begin{array}{l}\text { FINANCIAL SUPPORT: Funding: International Clinical Epidemiology Network (INCLEN, grant } \\
\text { \#1004-97-6501) and by Pontificia Universidad Javeriana (grant \#12-24-01- 31). Competing Interests: } \\
\text { no information }\end{array}$
\end{tabular}

\section{Risk of bias}

\begin{tabular}{lll}
\hline Bias & Authors' judgement & Support for judgement \\
\hline $\begin{array}{l}\text { Intervention independent } \\
\text { (ITS) ? }\end{array}$ & Low risk & $>1$ year data pre- and postintervention \\
\hline $\begin{array}{l}\text { Analysed appropriately } \\
\text { (ITS) }\end{array}$ & Low risk & $\begin{array}{l}\text { Done in original paper: ARIMA analysis, selected in preference to segmented } \\
\text { regression analysis because of nonlinear outcome data. }\end{array}$ \\
\hline $\begin{array}{l}\text { Shape of effect pre-speci- } \\
\text { fied (ITS) ? }\end{array}$ & Low risk & $\begin{array}{l}\text { Done, intended effect was decrease in primary outcome, and point of analysis } \\
\text { was point of intervention. }\end{array}$ \\
\hline $\begin{array}{l}\text { Unlikely to affect data col- } \\
\text { lection (ITS) ? }\end{array}$ & Low risk & $\begin{array}{l}\text { Done, data were from routine systems and unlikely to change over study peri- } \\
\text { od. }\end{array}$ \\
\hline $\begin{array}{l}\text { Knowledge of the alloca- } \\
\text { tion adequately prevent- } \\
\text { ed(ITS)? }\end{array}$ & Low risk & $\begin{array}{l}\text { Done, data were from routine systems and unlikely to change over study peri- } \\
\text { od. }\end{array}$ \\
\hline $\begin{array}{l}\text { Incomplete outcome data } \\
\text { addressed (ITS) ? }\end{array}$ & Low risk & $\begin{array}{l}\text { Done, data were from routine systems and unlikely to change over study peri- } \\
\text { od. }\end{array}$ \\
\hline \hline
\end{tabular}


Perez 2003 (Continued)

\begin{tabular}{|c|c|c|}
\hline $\begin{array}{l}\text { ree of selected reporting } \\
\text { ITS)? }\end{array}$ & Low risk & $\begin{array}{l}\text { one, data were from routine systems and unlikely to change over study peri- } \\
\text { d. }\end{array}$ \\
\hline
\end{tabular}

(ITS) ? od.

Free of other bias (ITS) ? Low risk No other apparent biases found.

Peto 2008

\begin{tabular}{ll}
\hline Methods & STUDY DESIGN: ITS \\
& Risk of Bias: LOW \\
\hline Participants & PROVIDERS: all physicians in the surgical ICU \\
& PARTICIPANTS: adult patients in surgical ICU (excluding general surgical and medical) \\
& CLINICAL PROBLEM: excessive antibiotic use \\
& SETTING: surgical ICU in a university hospital in Hungary \\
\hline Interventions & FORMAT: Interventions: educational outreach by review and recommend change; restrictive by expert \\
approval & Intervention Functions: enablement, persuasion, restriction \\
& DELIVERER: specialist physician \\
& COMPARISON: usual care \\
& DESIRED CHANGE: decrease excessive \\
\hline Outcomes & PRESCRIBING: Exposure: total antibiotic consumption (DDD per 100 patient days) \\
\hline Notes & FINANCIAL SUPPORT: no information
\end{tabular}

\section{Risk of bias}

\begin{tabular}{lll}
\hline Bias & Authors' judgement & Support for judgement \\
\hline $\begin{array}{l}\text { Intervention independent } \\
\text { (ITS) }\end{array}$ & Low risk & \\
\hline $\begin{array}{l}\text { Analysed appropriately } \\
\text { (ITS) ? }\end{array}$ & Low risk & Segmented regression analysis \\
\hline $\begin{array}{l}\text { Shape of effect pre-speci- } \\
\text { fied (ITS) ? }\end{array}$ & Low risk & Point of intervention was point of analysis. \\
\hline $\begin{array}{l}\text { Unlikely to affect data col- } \\
\text { lection (ITS) ? }\end{array}$ & Low risk & Routine data from pharmacy \\
\hline $\begin{array}{l}\text { Knowledge of the alloca- } \\
\text { tion adequately prevent- } \\
\text { ed(ITS)? }\end{array}$ & Low risk & Routine data from pharmacy \\
\hline $\begin{array}{l}\text { Incomplete outcome data } \\
\text { addressed (ITS) ? }\end{array}$ & Low risk & \\
\hline $\begin{array}{l}\text { Free of selected reporting } \\
\text { (ITS) ? }\end{array}$ & Low risk & Routine data from pharmacy \\
\hline \hline
\end{tabular}


Peto 2008 (Continued)

Free of other bias (ITS) ? Low risk > $\quad$ 1 year data pre- and postintervention

Petrikkos 2007

\begin{tabular}{ll}
\hline Methods & STUDY DESIGN: ITS \\
& Risk of Bias: MEDIUM \\
\hline Participants & PROVIDERS: all physicians in the hospital \\
& PARTICIPANTS: all patients requiring antibiotics \\
CLINICAL PROBLEM: decrease use of cephalosporins & SETTING: 1 university hospital in Greece
\end{tabular}

Interventions
FORMAT: Intervention: restrictive by expert approval
Intervention Function: restriction
DELIVERER: AMT
COMPARISON: usual care
DESIRED CHANGE: decrease excessive

Outcomes PRESCRIBING: Choice: use of cephalosporins in DDD/100 OBD

MICROBIAL: \% ESBL-producing Klebsiella pneumoniae and Escherichia coli

\begin{tabular}{ll}
\hline Notes & FINANCIAL SUPPORT: no information \\
& ADDITIONAL DATA: no response from authors to request for additional data
\end{tabular}

Microbial Risk of Bias: HIGH case definition Low, planned intervention Low, other infection control Unclear, no data about other infection control measures

\begin{tabular}{lll}
\hline Risk of bias & Authors' judgement & Support for judgement \\
\hline Bias & Low risk & \\
\hline $\begin{array}{l}\text { Intervention independent } \\
\text { (ITS) ? }\end{array}$ & Re-analysed \\
\hline $\begin{array}{l}\text { Analysed appropriately } \\
\text { (ITS) ? }\end{array}$ & Low risk & Point of intervention was point of analysis. \\
\hline $\begin{array}{l}\text { Shape of effect pre-speci- } \\
\text { fied (ITS) ? }\end{array}$ & Low risk & Data from pharmacy and microbiology computers \\
\hline $\begin{array}{l}\text { Unlikely to affect data col- } \\
\text { lection (ITS) ? }\end{array}$ & Low risk & Data from pharmacy and microbiology computers \\
\hline $\begin{array}{l}\text { Knowledge of the alloca- } \\
\text { tion adequately prevent- } \\
\text { ed(ITS)? }\end{array}$ & Low risk & \\
\hline $\begin{array}{l}\text { Incomplete outcome data } \\
\text { addressed (ITS) ? }\end{array}$ & Low risk & Data from pharmacy and microbiology computers \\
\hline $\begin{array}{l}\text { Free of selected reporting } \\
\text { (ITS) ? }\end{array}$ & Low risk & Data from pharmacy and microbiology computers \\
\hline
\end{tabular}


Petrikkos 2007 (Continued)

Free of other bias (ITS) ? Unclear risk $\quad 1$ year $(6 \times 2$-monthly time points) pre- and postintervention

Pires 2011

\begin{tabular}{ll} 
Methods & STUDY DESIGN: ITS \\
& Risk of Bias: LOW \\
\hline Participants & PROVIDERS: all prescribers in the hospital \\
& PARTICIPANTS: all patients in the hospital \\
CLINICAL PROBLEM: patients receiving carbapenems & SETTING: 1 teaching hospital in Brazil
\end{tabular}

Interventions

FORMAT: Intervention: restriction by removal from availability in the hospital

Intervention Function: restriction

DELIVERER: Infection Control Committee

COMPARISON: pre-intervention

DESIRED CHANGE: reduction in use of targeted carbapenems and in resistance

\begin{tabular}{ll} 
Outcomes & PRESCRIBING: Choice: use of target antibiotics \\
& MICROBIAL: carbapenem resistance in Pseudomonas aeruginosa \\
\hline Notes & $\begin{array}{l}\text { FINANCIAL SUPPORT: Funding: Fundo de Incentivo a Pesquisa e Eventos, Hospital de Clinicas de Port } \\
\text { Alegre. Competing Interests: none declared }\end{array}$
\end{tabular}

\section{Risk of bias}

\begin{tabular}{lll}
\hline Bias & Authors' judgement & Support for judgement \\
\hline $\begin{array}{l}\text { Intervention independent } \\
(\text { ITS) } ?\end{array}$ & Low risk & No outbreak or other changes coincident with intervention \\
\hline $\begin{array}{l}\text { Analysed appropriately } \\
\text { (ITS) } ?\end{array}$ & Low risk & Segmented regression analysis \\
\hline
\end{tabular}

Shape of effect pre-speci- Low risk fied (ITS) ?

Unlikely to affect data col- Low risk $\quad$ Data from pharmacy and microbiology computers
lection (ITS)?

\begin{tabular}{lll}
\hline $\begin{array}{l}\text { Knowledge of the alloca- } \\
\text { tion adequately prevent- } \\
\text { ed(ITS)? }\end{array}$ & Low risk & Data from pharmacy and microbiology computers \\
\hline $\begin{array}{l}\text { Incomplete outcome data } \\
\text { addressed (ITS) }\end{array}$ & Low risk & Data from pharmacy and microbiology computers \\
\hline $\begin{array}{l}\text { Free of selected reporting } \\
\text { (ITS) ? }\end{array}$ & Low risk & Data from pharmacy and microbiology computers \\
\hline Free of other bias (ITS) ? & Low risk & Data for 18 months' pre- and 3 years' postintervention \\
\hline \hline
\end{tabular}




\section{Risk of Bias: MEDIUM}

Participants

PROVIDERS: all physicians in the hospital

PARTICIPANTS: all patients in the hospital

CLINICAL PROBLEM: reduce linezolid use

SETTING: 1 hospital in the USA

FORMAT: Interventions: Intervention 1: educational mettings or dissemination of educational materi-
als. Intervention 2: reminders, structural, circumstantial - computerised physician order entry system
(CPOE) and educational meetings or dissemination of educational materials

Intervention Functions: Intervention 1: education. Intervention 2: education, enablement, environmental restructuring

DELIVERER: specialist physician

COMPARISON: usual care

DESIRED CHANGE: reduce inappropriate

\begin{tabular}{ll}
\hline Outcomes & PRESCRIBING: Choice: linezolid use (DDD per 1000 patient days) \\
\hline Notes & FINANCIAL SUPPORT: Funding: none. Competing Interests: none declared \\
& ADDITIONAL DATA: no response from authors to request for additional data
\end{tabular}

\section{Risk of bias}

\begin{tabular}{lll}
\hline Bias & Authors' judgement & Support for judgement \\
\hline $\begin{array}{l}\text { Intervention independent } \\
\text { (ITS)? }\end{array}$ & Low risk & Yes, reports on all likely influencing interventions. \\
\hline $\begin{array}{l}\text { Analysed appropriately } \\
\text { (ITS)? }\end{array}$ & Low risk & Re-analysed \\
\hline
\end{tabular}

Shape of effect pre-speci- Low risk Yes, the point of analysis is the point of the intervention.
fied (ITS)?
fied (ITS) ?

Unlikely to affect data col- Low risk $\quad$ Yes, pharmacy data used both pre- and postintervention.
lection (ITS) ?
lection (ITS) ?

Knowledge of the alloca- Low risk $\quad$ Outcome is objective.
tion adequately prevent-
ed(ITS)?

\begin{tabular}{lll}
\hline $\begin{array}{l}\text { Incomplete outcome data } \\
\text { addressed (ITS) ? }\end{array}$ & Low risk & Yes, pharmacy data, so should be complete. \\
\hline $\begin{array}{l}\text { Free of selected reporting } \\
\text { (ITS) }\end{array}$ & Low risk & Yes, all outcomes reported. \\
\hline Free of other bias (ITS) ? & High risk & $<1$ year data for phases 1 and 2 \\
\hline
\end{tabular}


Poehling 2006

Methods

STUDY DESIGN: RCT

\section{Risk of Bias: HIGH}

PROVIDERS: doctors in the ED
PARTICIPANTS: children with influenza-like illness
CLINICAL PROBLEM: decrease antibiotic prescribing for influenza
SETTING: 1 university hospital in the USA

Interventions

FORMAT: Interventions: structural, rapid influenza testing

Intervention Functions: environmental restructuring

DELIVERER: specialist physicians, Department of Pediatrics

COMPARISON: usual care

DESIRED CHANGE: decrease excessive

\begin{tabular}{ll}
\hline Outcomes & PRESCRIBING: Exposure: \% children treated \\
\hline Notes & $\begin{array}{l}\text { FINANCIAL SUPPORT: Funding: New Vaccine Surveillance Network and Robert Wood Johnson General- } \\
\text { ist Physicians Faculty Scholars Program. Competing Interests: none declared }\end{array}$ \\
\hline
\end{tabular}

\section{Risk of bias}

\begin{tabular}{|c|c|c|}
\hline Bias & Authors' judgement & Support for judgement \\
\hline $\begin{array}{l}\text { Random sequence genera- } \\
\text { tion (selection bias) }\end{array}$ & Low risk & Random number generator \\
\hline $\begin{array}{l}\text { Allocation concealment } \\
\text { (selection bias) }\end{array}$ & Unclear risk & Does not say, but possibly not due to nature of study \\
\hline $\begin{array}{l}\text { Blinding (performance } \\
\text { bias and detection bias) } \\
\text { All outcomes }\end{array}$ & Unclear risk & No information \\
\hline $\begin{array}{l}\text { Incomplete outcome data } \\
\text { (attrition bias) } \\
\text { All outcomes }\end{array}$ & Low risk & From records, outcomes on all included children \\
\hline $\begin{array}{l}\text { Selective reporting (re- } \\
\text { porting bias) }\end{array}$ & Low risk & From records, outcomes on all included children \\
\hline Other bias & Low risk & \\
\hline $\begin{array}{l}\text { Baseline Outcomes simi- } \\
\text { lar? }\end{array}$ & Unclear risk & No baseline outcomes taken. \\
\hline Free of contamination? & Low risk & Influenza testing only on children in intervention group \\
\hline $\begin{array}{l}\text { Baseline characteristics } \\
\text { similar? }\end{array}$ & Low risk & Table 1 \\
\hline
\end{tabular}


Popovski 2015

\begin{tabular}{ll}
\hline Methods & STUDY DESIGN: ITS \\
& Risk of Bias: LOW \\
\hline Participants & PROVIDERS: all physicians in the hospital \\
& PARTICIPANTS: all patients with intra-abdominal infections \\
& CLINICAL PROBLEM: decrease use of ciprofloxacin for empirical treatment \\
& SETTING: 1 university hospital in Canada \\
\hline Interventions & FORMAT: Interventions: educational meetings with dissemination of guidelines; reminders (physical, \\
& POSters, and on intranet) \\
& Intervention Functions: education, environmental restructuring \\
& DELIVERER: AMT \\
& COMPARISON: usual care \\
& DESIRED CHANGE: decrease excessive
\end{tabular}

\begin{tabular}{ll} 
Outcomes & PRESCRIBING: Choice: use of ciprofloxacin in DDD/1000 OBD \\
& CLINICAL: mortality, re-admission (cohort data) \\
\hline Notes & FINANCIAL SUPPORT: Funding: commercial Merck, Pfizer, Astellas, and the Medbuy Corporation. \\
& Hamilton Health Sciences Foundation (Jack Hirsh Fellowship). Competing Interests: 1 author received \\
& honoraria from Merck and Astellas for lectures. All other authors: none to declare \\
& ADDITIONAL DATA: email response from authors with guideline and additional data about the interven- \\
& tion
\end{tabular}

\section{Risk of bias}

\begin{tabular}{lll}
\hline Bias & Authors' judgement & Support for judgement \\
\hline $\begin{array}{l}\text { Intervention independent } \\
\text { (ITS) }\end{array}$ & Low risk & \\
\hline $\begin{array}{l}\text { Analysed appropriately } \\
\text { (ITS) }\end{array}$ & Low risk & Re-analysed \\
\hline $\begin{array}{l}\text { Shape of effect pre-speci- } \\
\text { fied (ITS) ? }\end{array}$ & Low risk & Point of intervention was point of analysis. \\
\hline $\begin{array}{l}\text { Unlikely to affect data col- } \\
\text { lection (ITS) ? }\end{array}$ & Low risk & Outcome data from pharmacy computer \\
\hline $\begin{array}{l}\text { Knowledge of the alloca- } \\
\text { tion adequately prevent- } \\
\text { ed(ITS)? }\end{array}$ & Low risk & Outcome data from pharmacy computer \\
\hline $\begin{array}{l}\text { Incomplete outcome data } \\
\text { addressed (ITS) ? }\end{array}$ & Low risk & \\
\hline $\begin{array}{l}\text { Free of selected reporting } \\
\text { (ITS) ? }\end{array}$ & Low risk & Outcome data from pharmacy computer \\
\hline \begin{tabular}{l} 
Free of other bias (ITS) ? \\
\hline
\end{tabular} & Low risk & Outcome data from pharmacy computer \\
\hline
\end{tabular}


Price 2010

\begin{tabular}{ll}
\hline Methods & STUDY DESIGN: ITS \\
& Risk of Bias: MEDIUM \\
\hline Participants & PROVIDERS: all physicians in the hospital \\
& PARTICIPANTS: all patients in the hospital \\
CLINICAL PROBLEM: requiring antibiotic treatment or prophylaxis \\
SETTING: 1 university hospital in the UK
\end{tabular}
$\begin{array}{ll}\text { Interventions } & \text { FORMAT: Interventions: dissemination of guidelines; restrictive by removal and expert approval } \\ \text { Intervention Functions: education, restriction }\end{array}$

Note that the published paper says: "The policy was widely disseminated in the hospital but no specific measures were put in place to enforce compliance". However, the antibiotic policy provided by the authors says: "Cephalosporins and fluoroquinolones. These agents will NOT be ward stock on any general medical or surgical wards - continuation of therapy beyond 24 hours (in Medicine) and single dose prophylaxis (in Surgery) requires consultant review, prescription by consultant and discussion with Micro ID".

DELIVERER: AMT

COMPARISON: usual care

DESIRED CHANGE: decrease excessive

Outcomes

PRESCRIBING: Choice: use of cephalosporins and quinolones (combined) in DDD/1000 OBD

MICROBIAL: Clostridium difficile infection

Notes

FINANCIAL SUPPORT: Funding: part commercial, Optimer Pharmaceuticals and US Department of Veterans Affairs. Competing Interests: 1 author declared multiple commercial sources of research funding and held patents relevant to $C$ difficile infection licensed to ViroPharma

ADDITIONAL INFORMATION: authors provided the 2008 version of the hospital antibiotic policy, which included details about the restrictions on use of target drugs

Microbial Risk of Bias MEDIUM: case definition yes, planned intervention yes, infection control no (a cohorting ward was introduced at the same time as the antibiotic policy)

\section{Risk of bias}

\begin{tabular}{lll}
\hline Bias & Authors' judgement & Support for judgement \\
\hline $\begin{array}{l}\text { Intervention independent } \\
\text { (ITS) ? }\end{array}$ & Low risk & For prescrbiing outcome \\
\hline $\begin{array}{l}\text { Analysed appropriately } \\
\text { (ITS) ? }\end{array}$ & Low risk & Segmented regression analysis \\
\hline
\end{tabular}

Shape of effect pre-speci- Low risk Point of intervention was point of analysis.

fied (ITS) ?

Unlikely to affect data col- Low risk Pharmacy computer

lection (ITS) ?

Knowledge of the alloca-

Low risk

Pharmacy computer

tion adequately prevent-

ed(ITS)? 
Price 2010 (Continued)

Incomplete outcome data Low risk $\quad$ Pharmacy computer
addressed (ITS)?

Free of selected reporting Low risk Pharmacy computer
(ITS)?

(ITS) ?

Free of other bias (ITS) ? High risk

1 year data pre- and postintervention

Microbial Risk of Bias: cohorting introduced at the same time as prescribing intervention.

\section{Pulcini 2011}

\begin{tabular}{ll}
\hline Methods & STUDY DESIGN: ITS \\
& Risk of Bias: MEDIUM \\
\hline Participants & PROVIDERS: all physicians in the Medical ICU \\
& PARTICIPANTS: all patients in the ICU \\
CLINICAL PROBLEM: receiving antibiotics for $24 \mathrm{~h}$ to $96 \mathrm{~h}$ \\
SETTING: 1 university hospital in France
\end{tabular}

Interventions

FORMAT: Interventions: audit and feedback; educational outreach by academic detailing; reminders (physical, circumstantial, stickers placed in notes of patients receiving target antibiotics)

Intervention Functions: enablement, environmental restructuring, persuasion

DELIVERER: departmental physician (ICU consultant)

COMPARISON: usual care

DESIRED CHANGE: increase appropriate

\begin{tabular}{ll}
\hline Outcomes & PRESCRIBING: Choice: $\%$ appropriate treatment \\
\hline Notes & FINANCIAL SUPPORT: Funding: none. Competing Interests: none declared \\
& $\begin{array}{l}\text { ADDITIONAL INFORMATION: email from authors with additional information about intervention. The in- } \\
\text { tervention design is described in more detail in Pulcini } 2008 .\end{array}$
\end{tabular}

\section{Risk of bias}

\begin{tabular}{lll}
\hline Bias & Authors' judgement & Support for judgement \\
\hline $\begin{array}{l}\text { Intervention independent } \\
\text { (ITS) }\end{array}$ & Low risk & \\
\hline $\begin{array}{l}\text { Analysed appropriately } \\
\text { (ITS) }\end{array}$ & Low risk & Segmented regression analysis \\
\hline $\begin{array}{l}\text { Shape of effect pre-speci- } \\
\text { fied (ITS) ? }\end{array}$ & Low risk & \\
\hline $\begin{array}{l}\text { Unlikely to affect data col- } \\
\text { lection (ITS) ? }\end{array}$ & Low risk & $\begin{array}{l}\text { Primary outcome was appropriateness of treatment at 24 to } 96 \text { hours, which } \\
\text { was the same in pre- and postintervention period. }\end{array}$ \\
\hline
\end{tabular}


Pulcini 2011 (Continued)

Knowledge of the alloca- Low risk Dual data entry, the ICU consultant was blinded to study period, although the tion adequately preventID physician was not. ed(ITS)?

Incomplete outcome data Low risk $\quad$ Outcome data on all participants
addressed (ITS)?

Free of selected reporting Low risk No evidence of selective reporting

(ITS)?

Free of other bias (ITS) ? High risk < 1 year of data (25 weeks) in the pre- and postintervention phases

Qu 2012

\begin{tabular}{ll} 
Methods & STUDY DESIGN: RCT \\
& Risk of Bias: HIGH \\
\hline Participants & PROVIDERS: all physicians in the ICU \\
& PARTICIPANTS: 71 patients with with confirmed severe acute pancreatitis \\
& CLINICAL PROBLEM: PCT for guiding duration of antibiotic therapy \\
& SETTING: 1 hospital in China
\end{tabular}

FORMAT: Interventions: reminders (circumstantial, decision support algorithm with each PCT test);
structural, introduction of PCT testing
Intervention Functions: enablement, environmental restructuring
DELIVERER: department physician (ICU)
COMPARISON: usual care
DESIRED CHANGE: decrease excessive

PRESCRIBING: Exposure: duration of all antibiotic treatment
CLINICAL: Balancing: mortality and length of stay
FINANCIAL: cost of hospitalisation, but no information about cost of intervention

Notes

FINANCIAL SUPPORT: Funding: none. Competing Interests: none declared

ADDITIONAL DATA: no response from authors to request for additional data

\section{Risk of bias}

\begin{tabular}{lll}
\hline Bias & Authors' judgement & Support for judgement \\
\hline $\begin{array}{l}\text { Random sequence genera- } \\
\text { tion (selection bias) }\end{array}$ & Unclear risk & Says it was randomised, but no further information \\
\hline $\begin{array}{l}\text { Allocation concealment } \\
\text { (selection bias) }\end{array}$ & Unclear risk & No information \\
\hline $\begin{array}{l}\text { Blinding (performance } \\
\text { bias and detection bias) }\end{array}$ & Unclear risk & No mention of blinding \\
\hline
\end{tabular}


Qu 2012 (Continued)

All outcomes

\begin{tabular}{lll}
\hline $\begin{array}{l}\text { Incomplete outcome data } \\
\text { (attrition bias) } \\
\text { All outcomes }\end{array}$ & Low risk & Outcomes on all 71 participants \\
\hline $\begin{array}{l}\text { Selective reporting (re- } \\
\text { porting bias) }\end{array}$ & Low risk & \\
\hline Other bias & Low risk & No information \\
\hline $\begin{array}{l}\text { Baseline Outcomes simi- } \\
\text { lar? }\end{array}$ & Unclear risk & PCT results only reported for intervention participants. \\
\hline $\begin{array}{l}\text { Free of contamination? } \\
\text { Baseline characteristics }\end{array}$ & Low risk risk & Yes, Table 1 \\
similar? & & \\
\hline
\end{tabular}

Rattanaumpawan 2010

\begin{tabular}{ll}
\hline Methods & STUDY DESIGN: NRT \\
& Risk of Bias: HIGH \\
\hline Participants & PROVIDERS: all physicians in the hospital \\
& PARTICIPANTS: 953 hospitalised adults (1028 prescriptions) \\
CLINICAL PROBLEM: receiving treatment with piperacillin/tazobactam, imipenem, and meropenem \\
SETTING: 1 hospital in Thailand
\end{tabular}

\begin{tabular}{ll}
\hline Interventions & FORMAT: Interventions: educational outreach by review and recommend change \\
Intervention Functions: education, enablement, persuasion, restriction
\end{tabular}

DELIVERER: AMT

COMPARISON: usual care

DESIRED CHANGE: reduce excessive

PRESCRIBING: Choice: use of target antibiotics
CLINICAL: Balancing: mortality, length of stay

FINANCIAL: cost of target antibiotics and all antibiotics. No information about cost of intervention

Notes FINANCIAL SUPPORT: Funding: none. Competing Interests: none declared

ADDITIONAL DATA: email from authors but no additional data

\begin{tabular}{lll}
\hline Risk of bias & \\
\hline Bias & Authors' judgement & Support for judgement \\
\hline $\begin{array}{l}\text { Random sequence genera- } \\
\text { tion (selection bias) }\end{array}$ & High risk & By hospital number, even number in last digit received intervention \\
\hline
\end{tabular}


Rattanaumpawan 2010 (Continued)

\begin{tabular}{lll}
$\begin{array}{l}\text { Allocation concealment } \\
\text { (selection bias) }\end{array}$ & High risk & Not concealed \\
\hline $\begin{array}{l}\text { Blinding (performance } \\
\text { bias and detection bias) }\end{array}$ & High risk & No blinding \\
All outcomes & &
\end{tabular}

Incomplete outcome data Low risk Complete data reported.
(attrition bias)
All outcomes

\begin{tabular}{|c|c|c|}
\hline $\begin{array}{l}\text { Selective reporting (re- } \\
\text { porting bias) }\end{array}$ & High risk & $\begin{array}{l}\text { Some outcomes (favourable clinical outcome, death from infection) subject to } \\
\text { selective outcome reporting. No discussion of why there was a significant dif- } \\
\text { ference for death because of infection but no difference in the \% of patients } \\
\text { alive on discharge from hospital. }\end{array}$ \\
\hline
\end{tabular}

\begin{tabular}{lll}
\hline Other bias & Low risk & \\
\hline $\begin{array}{l}\text { Baseline Outcomes simi- } \\
\text { lar? }\end{array}$ & Unclear risk & $\begin{array}{l}\text { Baseline frequency of inappropriate treatment was 50\% in January 2007, but } \\
\text { no information about risk of inappropriate treatment in the control group in } \\
\text { August 2007. }\end{array}$ \\
\hline Free of contamination? & High risk & $\begin{array}{l}\text { Invervention and control participants were in the same hospital, and physi- } \\
\text { cians were likely to have patients in both groups. }\end{array}$ \\
\hline $\begin{array}{l}\text { Baseline characteristics } \\
\text { similar? }\end{array}$ & Low risk & Table 1 \\
\hline
\end{tabular}

Rattanaumpawan 2011

\begin{tabular}{ll}
\hline Methods & STUDY DESIGN: ITS \\
& Risk of Bias: HIGH \\
\hline Participants & PROVIDERS: all physicians in the hospital \\
& PARTICIPANTS: adult patients receiving antibiotics \\
& CLINICAL PROBLEM: unnecessary double coverage for infection with anaerobic bacteria \\
& SETTING: 1 hospital in Thailand \\
\hline Interventions & FORMAT: Interventions: restrictive by prior approval, the intervention was removal of this restriction \\
& Intervention Functions: restriction \\
DELIVERER: AMT & COMPARISON: unnecessary treatment before and after removal of the restriction \\
& DESIRED CHANGE: decrease excessive
\end{tabular}

\begin{tabular}{ll}
\hline Outcomes & PRESCRIBING: Choice: cumulative incidence of unnecessary treatment in DDD/admission \\
\hline Notes & FINANCIAL SUPPORT: Funding: National Institutes of Health grant K24-AI080942. Competing Inter- \\
& ests: 1 author received research support from Merck, Ortho-McNeil, Cubist, and AstraZeneca. \\
& ADDITIONAL DATA: email response from authors but no additional data \\
\hline
\end{tabular}

\section{Risk of bias}


Rattanaumpawan 2011 (Continued)

\begin{tabular}{|c|c|c|}
\hline Bias & Authors' judgement & Support for judgement \\
\hline $\begin{array}{l}\text { Intervention independent } \\
\text { (ITS) ? }\end{array}$ & Low risk & 1 year of data pre- and postintervention \\
\hline $\begin{array}{l}\text { Analysed appropriately } \\
\text { (ITS)? }\end{array}$ & Low risk & Segmented regression analysis \\
\hline $\begin{array}{l}\text { Shape of effect pre-speci- } \\
\text { fied (ITS) ? }\end{array}$ & Low risk & Point of intervention was point of analysis. \\
\hline $\begin{array}{l}\text { Unlikely to affect data col- } \\
\text { lection (ITS)? }\end{array}$ & High risk & Primary outcome (unnecessary DACT) not objective. \\
\hline $\begin{array}{l}\text { Knowledge of the alloca- } \\
\text { tion adequately prevent- } \\
\text { ed(ITS)? }\end{array}$ & High risk & Primary outcome (unnecessary DACT) not objective. \\
\hline $\begin{array}{l}\text { Incomplete outcome data } \\
\text { addressed (ITS)? }\end{array}$ & High risk & $\begin{array}{l}\text { Figure } 1 \text { includes } 4 \text { months with no unnecessary DACT, but it is not clear } \\
\text { whether this was because there was no DACT or because all DACT was neces- } \\
\text { sary. With the exception of July } 2008 \text {, these months had relatively high use of } \\
\text { ampicillin/sulbactam and metronidazole, so suggests they missed some DACT } \\
\text { patients. }\end{array}$ \\
\hline
\end{tabular}

Free of selected reporting Unclear risk Not clear if outcome was reported on all patients.

(ITS) ?

Free of other bias (ITS) ? Low risk

Richards 2003

\begin{tabular}{ll} 
Methods & STUDY DESIGN: ITS \\
& Risk of Bias: MEDIUM \\
\hline Participants & PROVIDERS: all physicians in the hospital \\
& PARTICIPANTS: all patients except ICU, ER, ID \\
& CLINICAL PROBLEM: receiving treatment with target antibiotics \\
& SETTING: 1 university hospital in Australia
\end{tabular}

Interventions $\quad$ FORMAT: Interventions: audit and feedback; educational meetings with dissemination of guidelines; reminders (circumstantial and physical, on computer order form when prescribing antibiotics); restrictive by compulsory order form, expert approval, and removal

Intervention Functions: education, enablement, environmental restructuring, persuasion, restriction DELIVERER: AMT

COMPARISON: usual care

DESIRED CHANGE: reduction in established management (reduction in use of target drugs)

\begin{tabular}{ll}
\hline Outcomes & PRESCRIBING: Choice: Primary: use of cefotaxime or ceftriaxone \\
& Secondary: use of other antibiotics: gentamicin, benzyl penicillin, carbapenems, piperacillin, ticarcillin, \\
and ciprofloxacin & \\
FINANCIAL: cost of intervention
\end{tabular}


Richards 2003 (Continued)

ADDITIONAL DATA: no response from authors to request for additional data

\section{Risk of bias}

\begin{tabular}{lll}
\hline Bias & Authors' judgement & Support for judgement \\
\hline $\begin{array}{l}\text { Intervention independent } \\
\text { (ITS) }\end{array}$ & Unclear risk & $\begin{array}{l}\text { 8 months data pre-intervention, 15 months postintervention, not enough to } \\
\text { adjust for seasonal variation }\end{array}$ \\
\hline $\begin{array}{l}\text { Analysed appropriately } \\
\text { (ITS)? }\end{array}$ & Low risk & $\begin{array}{l}\text { Re-analysed. Not done in original paper: comparison of means (uncontrolled } \\
\text { before-after) with Kruskal-Wallis test. }\end{array}$ \\
\hline $\begin{array}{l}\text { Shape of effect pre-speci- } \\
\text { fied (ITS) ? }\end{array}$ & Low risk & $\begin{array}{l}\text { Done, intended effect was decrease in primary outcome, and point of analysis } \\
\text { was point of intervention. }\end{array}$ \\
\hline $\begin{array}{l}\text { Unlikely to affect data col- } \\
\text { lection (ITS) ? }\end{array}$ & Low risk & $\begin{array}{l}\text { Done, data were from routine systems and unlikely to change over study peri- } \\
\text { od. }\end{array}$ \\
\hline $\begin{array}{l}\text { Knowledge of the alloca- } \\
\text { tion adequately prevent- } \\
\text { ed(ITS)? }\end{array}$ & Low risk & $\begin{array}{l}\text { Done, data were from routine systems and unlikely to change over study peri- } \\
\text { od. }\end{array}$ \\
\hline $\begin{array}{l}\text { Incomplete outcome data } \\
\text { addressed (ITS) ? }\end{array}$ & Low risk & $\begin{array}{l}\text { Done, data were from routine systems and unlikely to change over study peri- } \\
\text { od. }\end{array}$ \\
\hline $\begin{array}{l}\text { Free of selected reporting } \\
\text { (ITS) ? }\end{array}$ & Low risk & $\begin{array}{l}\text { Done, data were from routine systems and unlikely to change over study peri- } \\
\text { od. }\end{array}$ \\
\hline \begin{tabular}{l} 
Free of other bias (ITS) ? \\
\hline
\end{tabular} & Low risk & \begin{tabular}{l} 
No other apparent biases found. \\
\hline
\end{tabular}
\end{tabular}

\section{Richardson 2000}

\begin{tabular}{ll}
\hline Methods & STUDY DESIGN: ITS \\
& Risk of Bias: HIGH \\
\hline Participants & PROVIDERS: all physicians in the hospital. Number, age, and time since qualification NOT CLEAR. 3 in- \\
& tensive care units, 3 general medical, and 1 general surgical \\
& PARTICIPANTS: a total of 618 episodes of vancomycin use (220 pre- and 398 postintervention). Number \\
& of patients, age, gender, and ethnicity NOT CLEAR. \\
& CLINICAL PROBLEM: patients requiring antibiotic treatment \\
& SETTING: single tertiary-care teaching hospital in the USA with 150 acute care and 90 long-term care \\
beds
\end{tabular}

Interventions

FORMAT: Interventions: educational outreach by review and recommend change Intervention Functions: enablement, persuasion COMPARISON: data for 3 months in the previous year (April, August, and January) DESIRED CHANGE: decrease excessive (reduction in inappropriate use of vancomycin with the aim of reducing prevalence of VRE infections)

Outcomes PRESCRIBING: Choice: \% episodes of vancomycin use deemed inappropriate

Notes FINANCIAL SUPPORT: no information

ADDITIONAL DATA: no response from authors to request for additional data 
Richardson 2000 (Continued)

\section{Risk of bias}

\begin{tabular}{|c|c|c|}
\hline Bias & Authors' judgement & Support for judgement \\
\hline $\begin{array}{l}\text { Intervention independent } \\
\text { (ITS)? }\end{array}$ & High risk & $\begin{array}{l}\text { Data only collected for } 3 \text { months pre- and } 6 \text { months postintervention, so secu- } \\
\text { lar/seasonal changes possible. }\end{array}$ \\
\hline $\begin{array}{l}\text { Analysed appropriately } \\
\text { (ITS)? }\end{array}$ & Low risk & Re-analysed \\
\hline $\begin{array}{l}\text { Shape of effect pre-speci- } \\
\text { fied (ITS)? }\end{array}$ & Low risk & $\begin{array}{l}\text { Done, intended effect was decrease in primary outcome, and point of analysis } \\
\text { was point of intervention. }\end{array}$ \\
\hline $\begin{array}{l}\text { Unlikely to affect data col- } \\
\text { lection (ITS)? }\end{array}$ & Unclear risk & $\begin{array}{l}\text { The reliability of the assessment of appropriate vancomycin use was not re- } \\
\text { ported. }\end{array}$ \\
\hline $\begin{array}{l}\text { Knowledge of the alloca- } \\
\text { tion adequately prevent- } \\
\text { ed(ITS)? }\end{array}$ & High risk & $\begin{array}{l}\text { Retrospective assessment of appropriateness without concealment of study } \\
\text { phase. }\end{array}$ \\
\hline $\begin{array}{l}\text { Incomplete outcome data } \\
\text { addressed (ITS)? }\end{array}$ & High risk & $\begin{array}{l}\text { Assessment of appropriateness from retrospective assessment of all patients } \\
\text { treated in } 1 \text { month but only done every } 4 \text { to } 6 \text { months. }\end{array}$ \\
\hline $\begin{array}{l}\text { Free of selected reporting } \\
\text { (ITS)? }\end{array}$ & Unclear risk & Not clear, data were only collected intermittently. \\
\hline Free of other bias (ITS) ? & Low risk & No other apparent biases found. \\
\hline
\end{tabular}

\section{Ross 2014}

\begin{tabular}{ll} 
Methods & STUDY DESIGN: ITS \\
& Risk of Bias: LOW \\
\hline Participants & PROVIDERS: all paediatricians in the hospitals \\
& PARTICIPANTS: children with community-acquired pneumonia \\
SETTING: 38 hospitals in the USA
\end{tabular}

Interventions

FORMAT: Intervention: dissemination of national guidelines

Intervention Function: education

DELIVERER: specialist physicians

COMPARISON: usual care

DESIRED CHANGE: decrease excessive

\begin{tabular}{ll}
\hline Outcomes & PRESCRIBING: Choice: \% patients treated with guideline-recommended antibiotics \\
\hline Notes & FINANCIAL SUPPORT: Funding: none. Competing Interests: 1 author has received research funding \\
from Merck and Cubist and has served as a consultant for Merck, Pfizer, Astellas Pharma, and Cubist, \\
and 3 authors have received research funding from Pfizer. \\
ADDITIONAL DATA: email from authors with no additional data. Paediatric infectious diseases guide- \\
lines available online (cid.oxfordjournals.org/content/early/2011/08/30/cid.cir531.full)
\end{tabular}

\section{Risk of bias}


Ross 2014 (Continued)

\begin{tabular}{|c|c|c|}
\hline Bias & Authors' judgement & Support for judgement \\
\hline $\begin{array}{l}\text { Intervention independent } \\
\text { (ITS) ? }\end{array}$ & Low risk & \\
\hline $\begin{array}{l}\text { Analysed appropriately } \\
\text { (ITS) ? }\end{array}$ & Low risk & Segmented regression analysis \\
\hline $\begin{array}{l}\text { Shape of effect pre-speci- } \\
\text { fied (ITS)? }\end{array}$ & Low risk & Point of intervention was point of analysis. \\
\hline $\begin{array}{l}\text { Unlikely to affect data col- } \\
\text { lection (ITS) ? }\end{array}$ & Low risk & Outcome data from Pediatric Health Information System \\
\hline $\begin{array}{l}\text { Knowledge of the alloca- } \\
\text { tion adequately prevent- } \\
\text { ed(ITS)? }\end{array}$ & Low risk & Outcome data from Pediatric Health Information System \\
\hline $\begin{array}{l}\text { Incomplete outcome data } \\
\text { addressed (ITS)? }\end{array}$ & Low risk & Outcome data from Pediatric Health Information System \\
\hline $\begin{array}{l}\text { Free of selected reporting } \\
\text { (ITS)? }\end{array}$ & Low risk & Outcome data from Pediatric Health Information System \\
\hline Free of other bias (ITS)? & Low risk & $>1$ year data pre- and postintervention \\
\hline
\end{tabular}

Saizy-Callaert 2003

\begin{tabular}{ll}
\hline Methods & STUDY DESIGN: ITS \\
& Risk of Bias: HIGH \\
\hline Participants & PROVIDERS: all physicians in the hospital \\
& PARTICIPANTS: all patients in the hospital \\
& CLINICAL PROBLEM: patients requiring antibiotic treatment \\
SETTING: single 600-bed university hospital in France
\end{tabular}

Interventions $\quad$ FORMAT: Interventions: educational meetings and dissemination of protocol; reminders (physical, pocket-size guideline); restrictive by compulsory order form and expert approval

Intervention Functions: education, environmental restructuring, restriction

COMPARISON: data for 3 years after implementation of the programme

DESIRED CHANGE: reduce excessive

\begin{tabular}{ll}
\hline Outcomes & PRESCRIBING: Choice: anti-infective expenditure per hospital patient \\
\hline Notes & FINANCIAL SUPPORT: no information \\
& ADDITIONAL DATA: no response from authors to request for additional data
\end{tabular}

\section{Risk of bias}

\begin{tabular}{lll}
\hline Bias & Authors' judgement & Support for judgement \\
\hline $\begin{array}{ll}\text { Intervention independent } \\
\text { (ITS)? }\end{array}$ & Low risk & $\begin{array}{l}\text { 4 years' data pre- and 3 years' data postintervention, so enough data to ac- } \\
\text { count for seasonal change }\end{array}$ \\
\hline \hline
\end{tabular}


Saizy-Callaert 2003 (Continued)
Analysed appropriately Low risk
Re-analysed. Not done in original paper: comparison of means (uncontrolled (ITS) ? before-after) with Fisher's exact test.

\section{Shape of effect pre-speci- Low risk fied (ITS) ?}

Done, intended effect was decrease in primary outcome, and point of analysis was point of intervention.

\section{Unlikely to affect data col- Low risk lection (ITS)?} Done, data were from routine systems and unlikely to change over study period.

\begin{tabular}{|c|c|c|}
\hline $\begin{array}{l}\text { Knowledge of the alloca- } \\
\text { tion adequately prevent- }\end{array}$ & Low risk & $\begin{array}{l}\text { Done, data were from routine systems and unlikely to change over study peri- } \\
\text { od. }\end{array}$ \\
\hline
\end{tabular}
ed(ITS)?

Incomplete outcome data High risk
addressed (ITS)?

Free of selected reporting Unclear risk
(ITS)?
(ITS) ?
There is no information about change in price of antibiotics over the study period.

Free of other bias (ITS) ? Unclear risk

The intervention was targeted at specific antibiotics, but no information is provided about their use or cost.
No adjustment of antibiotic costs for change in price, so change in price of antibiotics (rather than change in use) over the study period may have been responsible for reduction in cost per patient over the study period. No data about number of admissions pre-intervention.

\section{Salama 1996}

\begin{tabular}{|c|c|c|}
\hline Methods & \multicolumn{2}{|l|}{$\begin{array}{l}\text { STUDY DESIGN: ITS } \\
\text { Risk of Bias: LOW }\end{array}$} \\
\hline Participants & \multicolumn{2}{|c|}{$\begin{array}{l}\text { PROVIDERS: all physicians in the hospital } \\
\text { PARTICIPANTS: all patients in the hospital } \\
\text { CLINICAL PROBLEM: requiring antibiotic therapy } \\
\text { SETTING: } 1 \text { university hospital in Canada }\end{array}$} \\
\hline Interventions & \multicolumn{2}{|c|}{$\begin{array}{l}\text { FORMAT: Interventions: audit and feedback; educational meetings with dissemination of guidelines; } \\
\text { educational outreach by academic detailing; reminders (circumstantial, physical, and verbal: newslet- } \\
\text { ters, posters, pocket charts, educational rounds, and triggered by prescribing of target drugs); re- } \\
\text { minders (physical); restrictive by compulsory order form plus automatic 3-day stop order for all antibi- } \\
\text { otics and review and make change (therapeutic substitution of selected drugs) } \\
\text { Intervention Functions: education, enablement, environmental restructuring, persuasion, restriction } \\
\text { DESIRED CHANGE: reduction in vancomycin and ceftazidime use }\end{array}$} \\
\hline Outcomes & \multicolumn{2}{|c|}{$\begin{array}{l}\text { PRESCRIBING: Choice: vancomycin and ceftazidime use in units, antibiotic cost as a percentage of total } \\
\text { drug cost }\end{array}$} \\
\hline Notes & \multicolumn{2}{|c|}{$\begin{array}{l}\text { FINANCIAL SUPPORT: no information } \\
\text { ADDITIONAL DATA: no response from authors to request for additional data }\end{array}$} \\
\hline \multicolumn{3}{|l|}{ Risk of bias } \\
\hline Bias & Authors' judgement & Support for judgement \\
\hline $\begin{array}{l}\text { Intervention independent } \\
\text { (ITS)? }\end{array}$ & Low risk & $\begin{array}{l}>12 \text { months' data pre- and postintervention, enough to account for seasonal } \\
\text { change }\end{array}$ \\
\hline
\end{tabular}


Salama 1996 (Continued)

\begin{tabular}{|c|c|c|}
\hline $\begin{array}{l}\text { Analysed appropriately } \\
\text { (ITS) ? }\end{array}$ & Low risk & $\begin{array}{l}\text { Re-analysed. Not done in original paper: comparison of means (uncontrolled } \\
\text { before-after). }\end{array}$ \\
\hline
\end{tabular}
(ITS) ?

Done, intended effect was decrease in primary outcome, and point of analysis

Shape of effect pre-speci- Low risk fied (ITS) ? was point of intervention.

Unlikely to affect data col- Low risk
lection (ITS)?
lection (ITS) ?

\section{Knowledge of the alloca- Low risk} tion adequately prevented(ITS)?
Done, data were from routine systems and unlikely to change over study period.

Done, data were from routine systems and unlikely to change over study period.

\begin{tabular}{lll}
\hline $\begin{array}{l}\text { Incomplete outcome data } \\
\text { addressed (ITS) ? }\end{array}$ & Low risk & $\begin{array}{l}\text { Done, data were from routine systems and unlikely to change over study peri- } \\
\text { od. }\end{array}$ \\
\hline $\begin{array}{l}\text { Free of selected reporting } \\
\text { (ITS) } ?\end{array}$ & Low risk & $\begin{array}{l}\text { Done, data were from routine systems and unlikely to change over study peri- } \\
\text { od. }\end{array}$
\end{tabular}

Free of other bias (ITS)? Low risk No other apparent biases found.

\section{Schnoor 2010}

\begin{tabular}{ll}
\hline Methods & STUDY DESIGN: cluster RCT, hospital level \\
& Risk of Bias: HIGH \\
\hline Participants & PROVIDERS: doctors managing patients with community-acquired pneumonia \\
& PARTICIPANTS: 623 patients with community-acquired pneumonia (275 intervention, 348 control), 8 \\
& Clusters (hospitals) \\
& CLINICAL PROBLEM: community-acquired pneumonia \\
& SETTING: 8 hospitals in Germany \\
\hline
\end{tabular}

\begin{tabular}{ll}
\hline Interventions & FORMAT: Interventions: audit and feedback; educational meetings with dissemination of guideline; re- \\
minders (physical, posters, electronic and pocket versions of guideline) \\
Intervention Functions: education, enablement, environmental restructuring
\end{tabular}

Intervention Functions: education, enablement, environmental restructuring

DESIRED CHANGE: increase in compliance of initial treatment with guideline recommendation and decrease in duration of treatment

POWER CALCULATION: no information

\begin{tabular}{ll}
\hline Outcomes & PRESCRIBING: Choice: \% guideline compliant for initial treatment \\
& CLINICAL: Balancing: mortality, length of stay \\
\hline Notes & FINANCIAL SUPPORT: Funding: German Medical Assembly grant 06-69 and German Federal Ministry of \\
& Education and Research grant 01K10103-105. Competing Interests: none declared \\
& ADDITIONAL DATA: no response from authors to request for additional data
\end{tabular}

\section{Risk of bias}

Bias Authors' judgement Support for judgement


Schnoor 2010 (Continued)

Random sequence genera- Low risk $\quad$ Computer, by hospital
tion (selection bias)

Allocation concealment Low risk
(selection bias)

(selection bias)

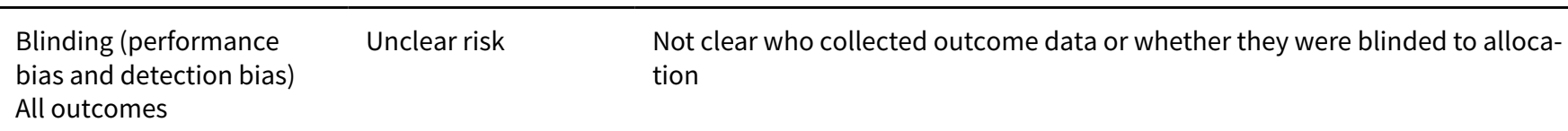

\begin{tabular}{|c|c|c|}
\hline $\begin{array}{l}\text { Incomplete outcome data } \\
\text { (attrition bias) } \\
\text { All outcomes }\end{array}$ & Unclear risk & All outcome data given as \%, so unclear if some patients were missing. \\
\hline $\begin{array}{l}\text { Selective reporting (re- } \\
\text { porting bias) }\end{array}$ & Unclear risk & No details of data collection \\
\hline Other bias & High risk & $\begin{array}{l}\text { Intervention period (1 April } 2007 \text { to } 29 \text { February 2008) was different than con- } \\
\text { trol period ( } 1 \text { September } 2006 \text { to } 28 \text { February 2007). }\end{array}$ \\
\hline $\begin{array}{l}\text { Baseline Outcomes simi- } \\
\text { lar? }\end{array}$ & High risk & $\begin{array}{l}\text { Duration of inpatient antibiotic at baseline was appropriate in only } 47 \% \text { inter- } \\
\text { vention (versus } 57 \% \text { control). }\end{array}$ \\
\hline Free of contamination? & Low risk & Randomised by site \\
\hline $\begin{array}{l}\text { Baseline characteristics } \\
\text { similar? }\end{array}$ & High risk & $\begin{array}{l}75 \% \text { inpatients in control group versus } 50 \% \text { for intervention, also fewer CURB } \\
0 \text { and more CURB } 3\end{array}$ \\
\hline
\end{tabular}

Schouten 2007

\begin{tabular}{ll}
\hline Methods & STUDY DESIGN: cluster RCT, hospital level \\
& Risk of Bias: MEDIUM \\
\hline Participants & PROVIDERS: all physicians \\
& PARTICIPANTS: 827 patients with lower respiratory tract infection (before intervention, 212 interven- \\
& tion, 166 control; after intervention, 276 intervention, 166 control). 6 clusters (hospitals) \\
& CLINICAL PROBLEM: patients with lower respiratory tract infection \\
& SETTING: 6 hospitals in the Netherlands
\end{tabular}

Interventions $\quad$ FORMAT: Interventions: audit and feedback; educational meetings with dissemination of guideline; educational outreach by academic detailing; reminders (physical, desktop on computers, and pocket card)

Intervention Functions: education, enablement, environmental restructuring, persuasion

DELIVERER: AMT

COMPARISON: usual care

DESIRED CHANGE: decrease excessive (choice and streamlining) and increase effective (timeliness)

POWER CALCULATION: no information

Outcomes $\quad$ PRESCRIBING: Choice: \% patients compliant with guideline for selected drug, timing (within $4 \mathrm{~h}$ of presentation), switching from IV to oral and streamlining

CLINICAL: Balancing: mortality, length of stay

Notes

FINANCIAL SUPPORT: Funding: The Netherlands Organisation for Health Research and Development (Zon/Mw; 2300.0024). Competing Interests: none declared 
Schouten 2007 (Continued)

ADDITIONAL DATA: no response from authors to request for additional data

\section{Risk of bias}

\begin{tabular}{|c|c|c|}
\hline Bias & Authors' judgement & Support for judgement \\
\hline $\begin{array}{l}\text { Random sequence genera- } \\
\text { tion (selection bias) }\end{array}$ & Low risk & Blinded researcher coin flip, hospital level \\
\hline $\begin{array}{l}\text { Allocation concealment } \\
\text { (selection bias) }\end{array}$ & Low risk & Allocation at hospital level \\
\hline $\begin{array}{l}\text { Blinding (performance } \\
\text { bias and detection bias) } \\
\text { All outcomes }\end{array}$ & Unclear risk & No information \\
\hline $\begin{array}{l}\text { Incomplete outcome data } \\
\text { (attrition bias) } \\
\text { All outcomes }\end{array}$ & Low risk & Outcome data for all patients \\
\hline $\begin{array}{l}\text { Selective reporting (re- } \\
\text { porting bias) }\end{array}$ & Unclear risk & All relevant outcomes reported. \\
\hline Other bias & Low risk & \\
\hline $\begin{array}{l}\text { Baseline Outcomes simi- } \\
\text { lar? }\end{array}$ & Low risk & Table 3, also pair-matched clusters for important variables \\
\hline Free of contamination? & Low risk & Allocation at hospital level \\
\hline $\begin{array}{l}\text { Baseline characteristics } \\
\text { similar? }\end{array}$ & Low risk & No clinically relevant differences \\
\hline
\end{tabular}

\section{Schroeder 2009}

\begin{tabular}{ll}
\hline Methods & STUDY DESIGN: RCT \\
& Risk of Bias: HIGH \\
\hline Participants & PROVIDERS: all physicians in the ICU \\
& PARTICIPANTS: all patients with sepsis in the ICU \\
& CLINICAL PROBLEM: receiving antibiotics for suspected intra-abdominal sepsis \\
& SETTING: 1 university hospital in Germany
\end{tabular}

Interventions $\quad$ FORMAT: Interventions: reminders (circumstantial, decision support algorithm with each PCT test); structural, introduction of PCT testing

Intervention Functions: enablement, environmental restructuring

DELIVERER: departmental physicians

COMPARISON: usual care

DESIRED CHANGE: decrease excessive

POWER CALCULATION: no information

PRESCRIBING: Exposure: duration of antibiotic treatment (days)
CLINICAL: Balancing: length of hospital stay


Schroeder 2009 (Continued)

Notes
FINANCIAL SUPPORT: Funding: none declared. Competing Interests: 1 author had speaking engagements for B.R.A.H.M.S AG.

ADDITIONAL DATA: no response from authors to request for additional data

\section{Risk of bias}

\begin{tabular}{|c|c|c|}
\hline Bias & Authors' judgement & Support for judgement \\
\hline $\begin{array}{l}\text { Random sequence genera- } \\
\text { tion (selection bias) }\end{array}$ & Unclear risk & No information \\
\hline $\begin{array}{l}\text { Allocation concealment } \\
\text { (selection bias) }\end{array}$ & Unclear risk & No information \\
\hline $\begin{array}{l}\text { Blinding (performance } \\
\text { bias and detection bias) } \\
\text { All outcomes }\end{array}$ & High risk & Not blinded \\
\hline $\begin{array}{l}\text { Incomplete outcome data } \\
\text { (attrition bias) } \\
\text { All outcomes }\end{array}$ & Low risk & Outcomes reported on all patients. \\
\hline $\begin{array}{l}\text { Selective reporting (re- } \\
\text { porting bias) }\end{array}$ & Low risk & Outcomes reported on all patients. \\
\hline Other bias & High risk & Only 27 of 125 screened patients were randomised. \\
\hline $\begin{array}{l}\text { Baseline Outcomes simi- } \\
\text { lar? }\end{array}$ & Unclear risk & No data \\
\hline Free of contamination? & Low risk & PCT only measured for intervention patients. \\
\hline $\begin{array}{l}\text { Baseline characteristics } \\
\text { similar? }\end{array}$ & Low risk & Table 1 \\
\hline
\end{tabular}

Schuetz 2009

\begin{tabular}{ll}
\hline Methods & STUDY DESIGN: RCT \\
& Risk of Bias: MEDIUM \\
\hline Participants & PROVIDERS: all physicians \\
& PARTICIPANTS: 1381 patients with lower respiratory tract infection randomised (687 intervention, 694 \\
& Control), 6 clusters (hospitals) \\
& CLINICAL PROBLEM: lower respiratory tract infection \\
& SETTING: 6 hospitals in Switzerland \\
\hline Interventions & FORMAT: Interventions: reminders (circumstantial, decision support algorithm with each PCT test); \\
& Structural, introduction of PCT testing \\
Intervention Functions: enablement, environmental restructuring \\
DELIVERER: departmental physician (respiratory) \\
COMPARISON: usual care \\
DESIRED CHANGE: decrease excessive \\
POWER CALCULATION: yes, 1002 participants total. Details in Appendix 3 \\
\hline
\end{tabular}


Schuetz 2009 (Continued)

Outcomes
PRESCRIBING: Exposure: \% patients treated
FINANCIAL SUPPORT: Funding: grant SNF 3200BO-116177/1 from the Swiss National Science Foundation and contributions from santésuisse and the Gottfried und Julia Bangerter-Rhyner Foundation and participating hospitals. B.R.A.H.M.S Inc, the major manufacturer of the procalcitonin assay, provided all assay-related material, Kryptor machines if not already available on site, and kits and maintenance required for 10,000 measurements related to the study.

Competing Interests: 3 authors received support from B.R.A.H.M.S Inc to attend meetings and fulfil speaking engagements, and 1 author served as a consultant and received research support from B.R.A.H.M.S Inc.

ADDITIONAL DATA: authors provided additional data

\section{Risk of bias}

\begin{tabular}{|c|c|c|}
\hline Bias & Authors' judgement & Support for judgement \\
\hline $\begin{array}{l}\text { Random sequence genera- } \\
\text { tion (selection bias) }\end{array}$ & Low risk & Prespecified, computer-generated randomisation list \\
\hline $\begin{array}{l}\text { Allocation concealment } \\
\text { (selection bias) }\end{array}$ & Low risk & Centralised, password-protected website \\
\hline $\begin{array}{l}\text { Blinding (performance } \\
\text { bias and detection bias) } \\
\text { All outcomes }\end{array}$ & Low risk & Password-protected website with instructions for PCT and control groups \\
\hline $\begin{array}{l}\text { Incomplete outcome data } \\
\text { (attrition bias) } \\
\text { All outcomes }\end{array}$ & Low risk & $\begin{array}{l}\text { Only } 1 \text { of } 1381 \text { patients lost to follow-up; } 16(2 \%) \text { patients in PCT group and } 6 \\
(1 \%) \text { patients in control group withdrew. }\end{array}$ \\
\hline $\begin{array}{l}\text { Selective reporting (re- } \\
\text { porting bias) }\end{array}$ & Low risk & $>95 \%$ surviving patients completed 30-day interview. \\
\hline Other bias & Low risk & \\
\hline $\begin{array}{l}\text { Baseline Outcomes simi- } \\
\text { lar? }\end{array}$ & Unclear risk & No baseline outcome data \\
\hline Free of contamination? & High risk & $\begin{array}{l}\text { The study was conducted in } 6 \text { hospitals, but patients in each hospital were in } \\
\text { both intervention and control groups. }\end{array}$ \\
\hline $\begin{array}{l}\text { Baseline characteristics } \\
\text { similar? }\end{array}$ & Low risk & Table 1 \\
\hline
\end{tabular}

Schwann 2011

\begin{tabular}{ll}
\hline Methods & STUDY DESIGN: ITS \\
& Risk of Bias: MEDIUM \\
\hline Participants & PROVIDERS: all physicians \\
& PARTICIPANTS: all patients undergoing elective surgery requiring antibiotic prophylaxis \\
CLINICAL PROBLEM: timing of first dose of antibiotic \\
SETTING: 1 hospital network in the USA
\end{tabular}


Schwann 2011 (Continued)

Interventions
FORMAT: Interventions: reminders (circumstantial and physical, point-of care electronic prompt (triggered by operating room admission)); reminders (physical); restrictive; structural

Intervention Functions: enablement, environmental restructuring

DELIVERER: AMT

COMPARISON: usual care

DESIRED CHANGE: decrease excessive

PRESCRIBING: Choice: \% patients with first dose administered within 1 hour of incision

CLINICAL: Intended: surgical-site infection

Notes

FINANCIAL SUPPORT: Funding: Lehigh Valley Hospital Network and Allentown Anesthesia Associates.

Competing Interests: none declared

ADDITIONAL DATA: no response from authors to request for additional data

\section{Risk of bias}

\begin{tabular}{lll}
\hline Bias & Authors' judgement & Support for judgement \\
\hline $\begin{array}{l}\text { Intervention independent } \\
\text { (ITS) }\end{array}$ & Low risk & \\
\hline $\begin{array}{l}\text { Analysed appropriately } \\
\text { (ITS)? }\end{array}$ & Low risk & Statistical process control charts \\
\hline $\begin{array}{l}\text { Shape of effect pre-speci- } \\
\text { fied (ITS)? }\end{array}$ & Low risk & Point of intervention was point of analysis. \\
\hline $\begin{array}{l}\text { Unlikely to affect data col- } \\
\text { lection (ITS)? }\end{array}$ & Low risk & Electronic data for prescribing \\
\hline $\begin{array}{l}\text { Knowledge of the alloca- } \\
\text { tion adequately prevent- } \\
\text { ed(ITS)? }\end{array}$ & Unclear risk & $\begin{array}{l}\text { Infection control personnel were blinded for assessment of wound infection, } \\
\text { unsure about compliance data. }\end{array}$ \\
\hline $\begin{array}{l}\text { Incomplete outcome data } \\
\text { addressed (ITS) ? }\end{array}$ & Low risk & \\
\hline $\begin{array}{l}\text { Free of selected reporting } \\
\text { (ITS)? }\end{array}$ & Low risk & Electronic data for prescribing \\
\hline \begin{tabular}{l} 
Free of other bias (ITS)? \\
\hline
\end{tabular} & Low risk & Electronic data for prescribing \\
\hline
\end{tabular}

\section{Schwartz 2007}

$\begin{array}{ll}\text { Methods } & \text { STUDY DESIGN: ITS } \\ & \text { Risk of Bias: MEDIUM }\end{array}$

Participants

PROVIDERS: all physicians in the long-term care facility

PARTICIPANTS: all patients receiving antibiotics

CLINICAL PROBLEM: patients receiving antimicrobials

SETTING: 1 hospital 
Schwartz 2007 (Continued)

Interventions
FORMAT: Interventions: educational meetings with dissemination of guidelines and treatment algorithms; reminders (physical, pocket guidelines)

The guideline has 16 algorithms for management of clinical problems (fever, leukocytosis, confusion, diarrhoea) and common infections in older people.

Intervention Functions: education, environmental restructuring

DELIVERER: AMT

COMPARISON: usual care

DESIRED CHANGE: decrease excessive
PRESCRIBING: Exposure: antibiotic days/100 OBD

FINANCIAL SUPPORT: Funding: Chicago Antimicrobial Resistance Project, Centers for Disease Control and Prevention (U50/ CCU515853). Competing Interests: no information

ADDITIONAL DATA: email response with the guideline. The guidelines are supposed to be available online, but the link does not work.

\section{Risk of bias}

\begin{tabular}{|c|c|c|}
\hline Bias & Authors' judgement & Support for judgement \\
\hline $\begin{array}{l}\text { Intervention independent } \\
\text { (ITS)? }\end{array}$ & Low risk & \\
\hline $\begin{array}{l}\text { Analysed appropriately } \\
\text { (ITS)? }\end{array}$ & Low risk & Segmented regression analysis \\
\hline $\begin{array}{l}\text { Shape of effect pre-speci- } \\
\text { fied (ITS) ? }\end{array}$ & Low risk & Point of intervention was point of analysis. \\
\hline $\begin{array}{l}\text { Unlikely to affect data col- } \\
\text { lection (ITS)? }\end{array}$ & Low risk & Days of antimicrobial use calculated automatically by pharmacy computer. \\
\hline $\begin{array}{l}\text { Knowledge of the alloca- } \\
\text { tion adequately prevent- } \\
\text { ed(ITS)? }\end{array}$ & Low risk & Days of antimicrobial use calculated automatically by pharmacy computer. \\
\hline $\begin{array}{l}\text { Incomplete outcome data } \\
\text { addressed (ITS)? }\end{array}$ & Unclear risk & $\begin{array}{l}1 \text { and } 2 \text { January } 2000 \text { start data were censored, but this was reported and } \\
\text { would have little impact on the other } 48 \text { data points. }\end{array}$ \\
\hline $\begin{array}{l}\text { Free of selected reporting } \\
\text { (ITS)? }\end{array}$ & Unclear risk & Days of antimicrobial use calculated automatically by pharmacy computer. \\
\hline Free of other bias (ITS)? & High risk & $\begin{array}{l}\text { Only } 10 \text { months' pre-intervention data, so secular trends could not be ad- } \\
\text { dressed. }\end{array}$ \\
\hline
\end{tabular}

Senn 2004

\begin{tabular}{ll}
\hline Methods & STUDY DESIGN: RCT \\
& Risk of bias: MEDIUM
\end{tabular}

Participants

PROVIDERS: residents on medical and surgical wards

PATIENTS: 251 patients were recruited, 126 intervention and 125 control 
Senn 2004 (Continued)

CLINICAL PROBLEM: adult patients receiving IV antibiotics for 3 to 4 days with no modification since starting treatment

SETTING: single 800-bed university hospital in Switzerland. Data collected over 5 months.

POWER CALCULATION: yes, 135 patients in each group, but the trial was underpowered because the observed effect was lower than predicted. Details in Appendix 3

\begin{abstract}
Interventions
FORMAT: Interventions: dissemination of questionnaire about guidelines; reminders (circumstantial and physical, questionnaire mailed to the resident in charge of patients who were receiving IV antibiotic treatment. The questionnaire asked 3 questions regarding possible adaptation of antibiotic therapy on day 3 or 4 , and was collected 24 hours later. If the resident had not yet completed it at that time, he/ she was reminded once to do so.)

Intervention Functions: education, enablement, environmental restructuring

DELIVERER: AMT

COMPARISON: control patients with no intervention

DESIRED CHANGE: reduction in established management (reduction in duration of IV therapy)

TIMING: intervention at the point of decision making (potential modification 3 to 4 days after start of antibiotics)
\end{abstract}

Outcomes PRESCRIBING: Choice: \% of patients discontinuing IV antibiotics and hazard ratio adjusted for patients' Karnofsky functional index

Notes

FINANCIAL SUPPORT: Funding: Quality Improvement Committee of the Lausanne University Hospital and grant 32-63128.00 of the Swiss National Science Foundation. Competing Interests: no information

ADDITIONAL DATA: no response from authors to request for additional data

\title{
Risk of bias
}

\section{Bias} Authors' judgement Support for judgement

Random sequence genera- Low risk "Patients allocated ... by using a computer generated randomizations list" tion (selection bias)

\begin{tabular}{ll}
\hline $\begin{array}{l}\text { Allocation concealment } \\
\text { (selection bias) }\end{array}$ & Low risk Concealment of allocation was achieved as the physician in charge of the pa- \\
tient was involved after randomizations"
\end{tabular}

\begin{tabular}{lll}
\hline $\begin{array}{l}\text { Blinding (performance } \\
\text { bias and detection bias) } \\
\text { All outcomes }\end{array}$ & High risk & "This was a randomised, controlled, open trial" \\
\hline $\begin{array}{l}\text { Incomplete outcome data } \\
\text { (attrition bias) }\end{array}$ & Low risk & $\begin{array}{l}\text { Primary outcome measure (duration of IV antibiotics) collected on all patients. } \\
\text { All outcomes }\end{array}$ \\
& $\begin{array}{l}\text { Only } 70 \% \text { of questionnaires returned for the intervention group, which could } \\
\text { account for the intervention effect being lower than expected. However, this } \\
\text { did not affect outcome assessment. }\end{array}$
\end{tabular}

\begin{tabular}{lll}
\hline $\begin{array}{l}\text { Selective reporting (re- } \\
\text { porting bias) }\end{array}$ & Low risk & Complete primary outcome data \\
\hline Other bias & High risk & The study was underpowered. \\
\hline $\begin{array}{l}\text { Baseline Outcomes simi- } \\
\text { lar? }\end{array}$ & Low risk & $\begin{array}{l}\text { Pre-study group, data collected for 2 months before intervention to estimate } \\
\text { the magnitude of possible observation bias (Figure 2). }\end{array}$ \\
\hline
\end{tabular}


Senn 2004 (Continued)

$\begin{array}{ll}\text { Free of contamination? Low risk } & \text { The pre-intervention group data were comparable to the control group, sug- } \\ \text { gesting minimal observation bias. }\end{array}$
gesting minimal observation bias.

Baseline characteristics Low risk $\quad$ Presented in Table 1

similar?

Shehabi 2014

\begin{tabular}{ll} 
Methods & STUDY DESIGN: RCT \\
& Risk of Bias: MEDIUM \\
\hline Participants & PROVIDERS: all physicians in the ICU \\
& PARTICIPANTS: 400 patients; 6 withdrew consent, leaving 196 in the intervention and 198 in the control \\
& group \\
& CLINICAL PROBLEM: patients with suspected sepsis and likely to receive antibiotics/remain in the ICU \\
& for at least $24 \mathrm{~h}$ \\
& SETTING: 11 university hospitals in Australia
\end{tabular}

Interventions Interventions: reminders (circumstantial, decision support algorithm with each PCT test); structural, introduction of PCT testing

Intervention Functions: enablement, environmental restructuring

DELIVERER: departmental physicians (ICU)

COMPARISON: usual care

DESIRED CHANGE: decrease excessive

POWER CALCULATION: yes, 165 participants per group. Details in Appendix 3

Outcomes PRESCRIBING: Exposure: duration of antibiotic treatment (days)

CLINICAL: mortality, re-admission, and length of hospital stay

Notes

FINANCIAL SUPPORT: Funding: Intensive Care Foundation of Australia and New Zealand. Material support was provided by Roche Diagnostics, Thermo Fisher Scientific, and bioMérieux. Roche Diagnostics and Thermo Fisher Scientific provided additional unrestricted grant funding. Competing Interests: none declared

ADDITIONAL DATA: email from authors with additional data

\section{Risk of bias}

\begin{tabular}{lll}
\hline Bias & Authors' judgement & Support for judgement \\
\hline $\begin{array}{l}\text { Random sequence genera- } \\
\text { tion (selection bias) }\end{array}$ & Low risk & $\begin{array}{l}\text { Patients were variable block randomised 1:1 via a secured central study web- } \\
\text { site into either a PCT-guided (PCT) group or clinician-guided (standard care) } \\
\text { group. Randomisation was stratified according to the presence of septic shock } \\
\text { (defined by the receipt of inotropes and/or any vasopressors within the previ- } \\
\text { ous 24 hours). }\end{array}$ \\
\hline $\begin{array}{l}\text { Allocation concealment } \\
\text { (selection bias) }\end{array}$ & Low risk & See above \\
\hline $\begin{array}{l}\text { Blinding (performance } \\
\text { bias and detection bias) } \\
\begin{array}{l}\text { All outcomes } \\
\hline\end{array}\end{array}$ & High risk & Single-blind \\
\hline
\end{tabular}


Shehabi 2014 (Continued)

Incomplete outcome data Low risk Outcomes reported on 196/200 intervention and 198/200 control participants. (attrition bias)

All outcomes

Selective reporting (re- Low risk
porting bias)

\begin{tabular}{lll}
\hline Other bias & Low risk & $\begin{array}{l}\text { 1567 patients screened, but 1167 excluded; full details of how many patients } \\
\text { met each of the exclusion criteria (Figure 1) }\end{array}$ \\
\hline $\begin{array}{l}\text { Baseline Outcomes simi- } \\
\text { lar? }\end{array}$ & Unclear risk & No data \\
\hline Free of contamination? & Low risk & PCT only reported for intervention participants. \\
\hline $\begin{array}{l}\text { Baseline characteristics } \\
\text { similar? }\end{array}$ & Low risk & Table 1 \\
\hline
\end{tabular}

\section{Shen 2011}

\begin{tabular}{ll}
\hline Methods & STUDY DESIGN: RCT \\
& Risk of Bias: HIGH \\
\hline Participants & PROVIDERS: all physicians on 2 respiratory wards \\
& PARTICIPANTS: all patients on the wards \\
CLINICAL PROBLEM: receiving antibiotics for respiratory infection \\
SETTING: 1 hospital
\end{tabular}

FORMAT: Interventions: educational outreach by review and recommend change
Intervention Functions: enablement, persuasion
DELIVERER: AMT
COMPARISON: usual care
DESIRED CHANGE: decrease excessive
POWER CALCULATION: no information

Outcomes PRESCRIBING: Choice: score on 6 indicators of inappropriate antibiotic use: indication, choice, dosage,
dosing schedule, duration, conversion

CLINICAL: Balancing: length of stay

FINANCIAL: cost (mean, SD) of antibiotics and total patient costs

Notes $\quad$ FINANCIAL SUPPORT: Funding: none. Competing Interests: none declared

ADDITIONAL DATA: no response from authors to request for additional data

\section{Risk of bias}

\begin{tabular}{lll}
\hline Bias & Authors' judgement & Support for judgement \\
\hline $\begin{array}{l}\text { Random sequence genera- } \\
\text { tion (selection bias) }\end{array}$ & Unclear risk & Says it was randomised, no further information. \\
\hline
\end{tabular}


Shen 2011 (Continued)

$\begin{array}{ll}\begin{array}{l}\text { Allocation concealment } \\ \text { (selection bias) }\end{array} & \text { High risk } \\ \end{array}$

$\begin{aligned} & \text { Blinding (performance } \\ & \text { bias and detection bias) }\end{aligned}$
$\begin{aligned} & \text { All outcomes } \\ & \text { Low risk }\end{aligned}$

\begin{tabular}{|c|c|c|}
\hline $\begin{array}{l}\text { Incomplete outcome data } \\
\text { (attrition bias) } \\
\text { All outcomes }\end{array}$ & Low risk & All outcomes reported. \\
\hline $\begin{array}{l}\text { Selective reporting (re- } \\
\text { porting bias) }\end{array}$ & Low risk & All outcomes reported. \\
\hline Other bias & Low risk & \\
\hline $\begin{array}{l}\text { Baseline Outcomes simi- } \\
\text { lar? }\end{array}$ & Unclear risk & No information \\
\hline Free of contamination? & High risk & Intervention and control patients were on both wards. \\
\hline $\begin{array}{l}\text { Baseline characteristics } \\
\text { similar? }\end{array}$ & Low risk & Table 1 \\
\hline
\end{tabular}

\section{Shojania 1998}

Methods STUDY DESIGN: RCT with nested ITS analysis (Figures 3 and 4)

\section{Risk of Bias: HIGH}

Participants

PROVIDERS: unit of randomisation - 396 physicians in 7 specialties. Non-physicians (nurses or pharmacists) who were authorised to enter orders that required eventual signing off by physicians were also randomised.

PARTICIPANTS: There were 5536 episodes of care in 1798 patients.

CLINICAL PROBLEM: receiving vancomycin treatment

SETTING: 1 university hospital in the USA

Interventions

FORMAT: Interventions: dissemination of guideline; reminders (circumstantial, delivered through computer screen at the time of physician order entry and after 72 hours of therapy). The reminder required prescribers to produce a response: when someone would enter an order for intravenous vancomycin, a pop-up screen would appear and display the appropriate indications for vancomycin use, which was a checkbox list of indications based on CDC guidelines. Users had to pick a reason or enter free text under 'other' in order to proceed.

Intervention Functions: education, enablement, environmental restructuring

DELIVERER: AMT

COMPARISON: no reminder. ITS analysis used 9 months' pre-intervention data.

DESIRED CHANGE: reduction of established management (reduction in use of vancomycin)

POWER CALCULATION: no information

Outcomes

PRESCRIBING: Choice: initiation and renewal of vancomycin therapy. Duration of vancomycin therapy on a per-prescriber basis. Total use of vancomycin in the hospital.

FINANCIAL: estimated savings 
Shojania 1998 (Continued)

Notes
FINANCIAL SUPPORT: Funding: grant R01-HS08927 from the Agency for Healthcare Policy and Research. Competing Interests: no information

ADDITIONAL DATA: email from authors with additional details about the intervention

\section{Risk of bias}

\begin{tabular}{|c|c|c|}
\hline Bias & Authors' judgement & Support for judgement \\
\hline $\begin{array}{l}\text { Random sequence genera- } \\
\text { tion (selection bias) }\end{array}$ & Unclear risk & $\begin{array}{l}\text { "The study was a randomised controlled trial"; no details on how randomisa- } \\
\text { tion sequence was generated }\end{array}$ \\
\hline $\begin{array}{l}\text { Allocation concealment } \\
\text { (selection bias) }\end{array}$ & High risk & $\begin{array}{l}\text { States "possible that physicians in the control group could learn of the inter- } \\
\text { vention from physicians in the study group" }\end{array}$ \\
\hline $\begin{array}{l}\text { Blinding (performance } \\
\text { bias and detection bias) } \\
\text { All outcomes }\end{array}$ & High risk & Not done \\
\hline $\begin{array}{l}\text { Incomplete outcome data } \\
\text { (attrition bias) } \\
\text { All outcomes }\end{array}$ & Unclear risk & Not clear for primary outcome \\
\hline $\begin{array}{l}\text { Selective reporting (re- } \\
\text { porting bias) }\end{array}$ & Low risk & Based on numbers of vancomycin orders \\
\hline Other bias & Low risk & No issues noted. \\
\hline $\begin{array}{l}\text { Baseline Outcomes simi- } \\
\text { lar? }\end{array}$ & Unclear risk & No information about pre-intervention vancomycin use \\
\hline Free of contamination? & High risk & $\begin{array}{l}\text { States "possible that physicians in the control group could learn of the inter- } \\
\text { vention from physicians in the study group" }\end{array}$ \\
\hline $\begin{array}{l}\text { Baseline characteristics } \\
\text { similar? }\end{array}$ & Low risk & Table 1 \\
\hline
\end{tabular}

Singh 2000

\begin{tabular}{ll}
\hline Methods & STUDY DESIGN: RCT, allocation by patient \\
& Risk of Bias: HIGH \\
\hline Participants & PROVIDERS: all physicians on 1 ICU \\
& PARTICIPANTS: 81 episodes of care ( 39 intervention, 42 control) \\
CLINICAL PROBLEM: suspected ventilator-associated pneumonia with low CPIS \\
SETTING: 1 hospital in the USA
\end{tabular}

Interventions

FORMAT: Intervention: restrictive by expert approval and review and make change

Intervention Function: restriction

DELIVERER: ID physician

COMPARISON: choice, number, and duration of antibiotics at the discretion of the care providers DESIRED CHANGE: reduction of established management (reduction in duration of antibiotic treatment) 
Singh 2000 (Continued)

POWER CALCULATION: yes, 88 patients per group. The study was terminated early. Details in Appendix 3

Outcomes

PRESCRIBING: Exposure: total duration of all antibiotic treatment

CLINICAL: Balancing: mortality, length of ICU stay

MICROBIAL: number of patients with "antimicrobial resistance and/or superinfections" from randomisation until hospital discharge

FINANCIAL: total costs of care for patients with CPIS $<6$ at 3 days and no extrapulmonary infections

Notes

FINANCIAL SUPPORT: Funding: Bayer Corporation. Competing Interests: no information

ADDITIONAL DATA: no response from authors to request for additional data

\section{Risk of bias}

\begin{tabular}{lll}
\hline Bias & Authors' judgement & Support for judgement \\
\hline $\begin{array}{l}\text { Random sequence genera- } \\
\text { tion (selection bias) }\end{array}$ & Unclear risk & $\begin{array}{l}\text { "Patients were randomized to either the control group or experimental } \\
\text { group"; no information about how randomisation sequence was generated }\end{array}$ \\
\hline $\begin{array}{l}\text { Allocation concealment } \\
\text { (selection bias) }\end{array}$ & Unclear risk & Not stated \\
\hline $\begin{array}{l}\text { Blinding (performance } \\
\text { bias and detection bias) } \\
\text { All outcomes }\end{array}$ & High risk & $\begin{array}{l}\text { Page 509: "Because the study was not blinded, physicians and care providers } \\
\text { could see the results" }\end{array}$ \\
\hline
\end{tabular}

\begin{tabular}{|c|c|c|}
\hline $\begin{array}{l}\text { Incomplete outcome data } \\
\text { (attrition bias) }\end{array}$ & Low risk & $\begin{array}{l}\text { Most outcomes are reported for } 78(96 \%) \text { episodes of care; antimicrobial resis- } \\
\text { tance and superinfection in } 74 \text { ( } 91 \%) \text { of episodes. }\end{array}$ \\
\hline
\end{tabular}

(attrition bias) tance and superinfection in 74 (91\%) of episodes.

\begin{tabular}{l}
$\begin{array}{l}\text { Selective reporting (re- } \\
\text { porting bias) }\end{array}$ \\
\hline
\end{tabular}

Other bias High risk
Microbial Risk of Bias HIGH. Case definition for microbial outcome NOT CLEAR: "Follow-up respiratory cultures or cultures from clinical specimens performed 7 to $28 \mathrm{~d}$ after initiation of antibiotics were evaluated to assess the emergence of antimicrobial resistance or superinfections. Emergence of re- sistance was defined as the detection of new antimicrobial resistance pattern in the old or previously isolated organism. Superinfection was defined as the detection of the following organisms not present at study entry: Acinetobac- ter species, Serratia marcescens, Pseudomonas aeruginosa, Stenotrophomonas maltophilia, Enterobacter species, Citrobacter species, methicillin-resistant Staphylococcus aureus (MRSA), Enterococcus species, and Candida species." It is therefore impossible to assess the impact of the intervention on colonisa- tion or infection with bacteria resistant to specific antibiotics. Infection control NOT CLEAR. Planned intervention YES

\begin{tabular}{lll}
\hline $\begin{array}{l}\text { Baseline Outcomes simi- } \\
\text { lar? }\end{array}$ & Unclear risk & $\begin{array}{l}\text { Not stated, no information about pre-intervention duration of antibiotic treat- } \\
\text { ment }\end{array}$ \\
\hline Free of contamination? & Unclear risk & Not stated \\
\hline $\begin{array}{l}\text { Baseline characteristics } \\
\text { similar? }\end{array}$ & Low risk & See Table 1 in study. \\
\hline
\end{tabular}


Sirinavin 1998

\begin{tabular}{ll} 
Methods & STUDY DESIGN: ITS \\
& Risk of Bias: MEDIUM \\
\hline Participants & PROVIDERS: all physicians in the hospital \\
& PARTICIPANTS: all patients in the hospital \\
& CLINICAL PROBLEM: patients requiring treatment with imipenem vancomycin or injectable \\
& Ciprofloxacin \\
SETTING: 1 hospital in Thailand
\end{tabular}

Interventions $\quad$ FORMAT: Interventions: educational meetings with dissemination of antimicrobial order form; educational outreach by review and recommend change of cases of inappropriate prescribing by ID consultant; restrictive by compulsory order form

Intervention Functions: education, enablement, persuasion, restriction

Figure 2 suggests that expenditure increased sharply in the final year of the study when ID consultant review ceased.

DELIVERER: specialist physician (ID)

COMPARISON: data for 4 years' pre-restriction

DESIRED CHANGE: decrease excessive

\begin{tabular}{ll}
\hline Outcomes & PRESCRIBING: Choice: restricted drugs cost in million THB/200,000 OBD \\
\hline Notes & FINANCIAL SUPPORT: Funding: Ramathibodi Research Fund. Competing Interests: no information \\
& ADDITIONAL DATA: no response from authors to request for additional data \\
\hline
\end{tabular}

\section{Risk of bias}

\begin{tabular}{|c|c|c|}
\hline Bias & Authors' judgement & Support for judgement \\
\hline $\begin{array}{l}\text { Intervention independent } \\
\text { (ITS)? }\end{array}$ & Low risk & 4 years' data pre- and postintervention \\
\hline $\begin{array}{l}\text { Analysed appropriately } \\
\text { (ITS)? }\end{array}$ & Low risk & Re-analysed. Not done in original paper: run charts with no statistical analysis. \\
\hline $\begin{array}{l}\text { Shape of effect pre-speci- } \\
\text { fied (ITS)? }\end{array}$ & Low risk & $\begin{array}{l}\text { Done, intended effect was decrease in primary outcome, and point of analysis } \\
\text { was point of intervention. }\end{array}$ \\
\hline $\begin{array}{l}\text { Unlikely to affect data col- } \\
\text { lection (ITS)? }\end{array}$ & Low risk & $\begin{array}{l}\text { Done, data were from routine systems and unlikely to change over study peri- } \\
\text { od. }\end{array}$ \\
\hline $\begin{array}{l}\text { Knowledge of the alloca- } \\
\text { tion adequately prevent- } \\
\text { ed(ITS)? }\end{array}$ & Low risk & $\begin{array}{l}\text { Done, data were from routine systems and unlikely to change over study peri- } \\
\text { od. }\end{array}$ \\
\hline $\begin{array}{l}\text { Incomplete outcome data } \\
\text { addressed (ITS)? }\end{array}$ & High risk & $\begin{array}{l}\text { NOT DONE, there is no information about change in price of antibiotics over } \\
\text { the study period. }\end{array}$ \\
\hline $\begin{array}{l}\text { Free of selected reporting } \\
\text { (ITS)? }\end{array}$ & Low risk & $\begin{array}{l}\text { Done, data were from routine systems and unlikely to change over study peri- } \\
\text { od. }\end{array}$ \\
\hline Free of other bias (ITS)? & Unclear risk & $\begin{array}{l}\text { NOT CLEAR, no adjustment of antibiotic costs for change in price, so change in } \\
\text { price of antibiotics (rather than change in use) over the study period may have }\end{array}$ \\
\hline
\end{tabular}


Sirinavin 1998 (Continued)

been responsible for some of the change in cost. Data were not adjusted for number of admissions or occupied bed days.

Skaer 1993

Methods STUDY DESIGN: ITS

\section{Risk of Bias: LOW}

Participants PROVIDERS: physicians (numbers not clear)

PATIENTS: all patients in the hospital

CLINICAL PROBLEM: adult patients receiving imipenem treatment

SETTING: 1 hospital in the USA

Interventions $\quad$ FORMAT: Intervention: educational outreach by review and recommend change

Intervention Functions: enablement, persuasion

DELIVERER: pharmacist

COMPARISON: usual care in the pre-intervention phase

DESIRED CHANGE: reduce excessive

\begin{tabular}{ll}
\hline Outcomes & PRESCRIBING: Choice: Monthly use (doses) of imipenem \\
& CLINICAL: cohort data about length of stay and hospital charges for patients with a primary diagnosis \\
of infection
\end{tabular}

\begin{tabular}{ll}
\hline Notes & FINANCIAL SUPPORT: Funding: Washington State University College of Pharmacy and Pullman Memor- \\
ial Hospital. Competing Interests: no information \\
ADDITIONAL DATA: no response from authors to request for additional data
\end{tabular}

\section{Risk of bias}

\begin{tabular}{lll}
\hline Bias & Authors' judgement & Support for judgement \\
\hline $\begin{array}{l}\text { Intervention independent } \\
\text { (ITS) ? }\end{array}$ & Low risk & \\
\hline $\begin{array}{l}\text { Analysed appropriately } \\
\text { (ITS) ? }\end{array}$ & Low risk & $\begin{array}{l}\text { Re-analysed. Not done in original paper: comparison of means (uncontrolled } \\
\text { before-after). }\end{array}$ \\
\hline $\begin{array}{l}\text { Shape of effect pre-speci- } \\
\text { fied (ITS)? }\end{array}$ & Low risk & $\begin{array}{l}\text { Done, intended effect was decrease in primary outcome, and point of analysis } \\
\text { was point of intervention. }\end{array}$ \\
\hline
\end{tabular}

Unlikely to affect data col- Low risk lection (ITS) ?

Knowledge of the alloca-
tion adequately prevent-
ed(ITS)?


Skaer 1993 (Continued)
Free of selected reporting Low risk

(ITS) ?

Free of other bias (ITS) ? Low risk

Yes for primary outcome but fatally flawed (UBA) for secondary outcomes.

Skrlin 2011

\begin{tabular}{ll}
\hline Methods & STUDY DESIGN: ITS \\
& Risk of Bias: LOW \\
\hline Participants & PROVIDERS: all physicians in the hospital \\
& PARTICIPANTS: all patients in the hospital \\
CLINICAL PROBLEM: use of ceftriaxone following removal of restriction & SETTING: 1 hospital in Croatia
\end{tabular}

\begin{tabular}{ll}
\hline Interventions & FORMAT: Intervention: restrictive, removal of restriction by expert approval \\
& Intervention Function: restriction \\
DELIVERER: AMT & COMPARISON: removal of restriction versus restriction \\
DESIRED CHANGE: decrease excessive & PRESCRIBING: Choice: use of ceftriaxone in DDD/1000 OBD \\
\hline MICROBIAL: number of ESBL-producing strains/1000 OBD \\
FINANCIAL SUPPORT: Funding none. Competing Interests: none declared \\
ADDITIONAL DATA: no response from authors to request for additional data \\
Microbial Risk of Bias: LOW case definition Low, planned intervention Low, other infection control \\
LOW
\end{tabular}

Low

\section{Risk of bias}

\begin{tabular}{lll}
\hline Bias & Authors' judgement & Support for judgement \\
\hline $\begin{array}{l}\text { Intervention independent } \\
\text { (ITS) }\end{array}$ & Low risk & \\
\hline $\begin{array}{l}\text { Analysed appropriately } \\
\text { (ITS) }\end{array}$ & Low risk & Re-analysed \\
\hline $\begin{array}{l}\text { Shape of effect pre-speci- } \\
\text { fied (ITS) ? }\end{array}$ & Low risk & Point of intervention was point of analysis. \\
\hline $\begin{array}{l}\text { Unlikely to affect data col- } \\
\text { lection (ITS) ? }\end{array}$ & Low risk & Data from pharmacy and microbiology computers \\
\hline $\begin{array}{l}\text { Knowledge of the alloca- } \\
\text { tion adequately prevent- } \\
\text { ed(ITS)? }\end{array}$ & Low risk & Data from pharmacy and microbiology computers \\
\hline $\begin{array}{l}\text { Incomplete outcome data } \\
\text { addressed (ITS) ? }\end{array}$ & Low risk & Data from pharmacy and microbiology computers \\
\hline
\end{tabular}


Skrlin 2011 (Continued)

Free of selected reporting Low risk Data from pharmacy and microbiology computers (ITS) ?

Free of other bias (ITS)? Low risk 24 months' data pre- and postintervention

Solomon 2001

Methods STUDY DESIGN: cluster RCT, service level

\section{Risk of Bias: HIGH}

\section{Participants}

PROVIDERS: 17 Internal Medicine services randomly assigned to intervention (9 services) or control (8 services)

PARTICIPANTS: a total of 4500 patients admitted during the baseline and study periods, of whom 260 patients received 278 unnecessary prescriptions for the target drugs; 17 clusters (services)

CLINICAL PROBLEM: patients receiving ceftazidime or levofloxacin.

SETTING: 1 hospital in the USA

POWER CALCULATION: no information. The methods say that the statistical model adjusted for clustering, but no results are given (see risk of bias).

FORMAT: Interventions: educational meetings with dissemination of policy for necessary use; educational outreach by review and recommend change, either verbal (face to face or telephone) or by email Intervention Functions: education, enablement, persuasion

COMPARISON: randomly assigned control services

DESIRED CHANGE: reduce excessive

POWER CALCULATION: no information. Note from Statistician: The study adjusted for some clustering, but possibly only in the repeated measures, not in the hospitals. Just using the results from Table 2 , I do not get the $P$ value that they state in the table using a unit of analysis error approach. This suggests to me that they are adjusting for "things". I therefore think on balance that it is probably OK to use the results.

Outcomes

PRESCRIBING: Choice: $\%$ patients with target antibiotics discontinued. Exposure: $\%$ patients with all antibiotics discontinued

CLINICAL: inpatient mortality, transfer to ICU, length of stay, and re-admission within 30 days of discharge

FINANCIAL: estimated annual cost of the intervention

Notes

FINANCIAL SUPPORT: Funding: Brigham and Women's Hospital and Arthritis Foundation Investigator Award. Competing Interests: no information

ADDITIONAL DATA: email from authors with information about the intervention

\section{Risk of bias}

\begin{tabular}{lll}
\hline Bias & Authors' judgement & Support for judgement \\
\hline $\begin{array}{l}\text { Random sequence genera- } \\
\text { tion (selection bias) }\end{array}$ & Low risk & $\begin{array}{l}\text { "We assigned services to intervention or control status using a blocked ran- } \\
\text { domization design" }\end{array}$ \\
\hline $\begin{array}{l}\text { Allocation concealment } \\
\text { (selection bias) }\end{array}$ & Unclear risk & Not concealed \\
\hline $\begin{array}{l}\text { Blinding (performance } \\
\text { bias and detection bias) }\end{array}$ & High risk & No blinding \\
\hline
\end{tabular}


Solomon 2001 (Continued)

All outcomes

Incomplete outcome data Unclear risk $\quad$ Figure 2 and text give \%, no denominator.
(attrition bias)

(attrition bias)

All outcomes

Selective reporting (re- Unclear risk $\quad$ Figure 2 and text give \%, no denominator.
porting bias)

Other bias Unclear risk

\begin{abstract}
The methods say: "To estimate the relative reduction in unnecessary use of target antibiotics in the intervention group, we used a fixedeffects model (PROC GENMOD in SAS statistical software).20 This model used a log-linear link function, assumed a Poisson distribution, and accounted for overdispersion. Experimental group assignment (intervention or control) was the independent variable of interest, the individual service was considered a class effect, and covariates included level of baseline prescribing and time, modeled as both a linear and categorical effect. The interaction between assignment and time was also assessed. We further considered a linear randomeffects model to account for variation between services (PROC MIXED in SAS statistical software)20; the results of this analysis were similar to those found in the fixed-effects models with respect to the level of statistical significance, and only the fixedeffects model results are presented." However, no model outputs are given in the results (only point estimates), and the discussion says only: "This significant effect of the intervention remained after adjusting for baseline prescribing, clustering of repeated measures within a given service, and duration of the intervention."
\end{abstract}

\begin{tabular}{lll}
\hline $\begin{array}{l}\text { Baseline Outcomes simi- } \\
\text { lar? }\end{array}$ & Low risk & Figures 1 and 2 \\
\hline Free of contamination? & High risk & The services were in the same hospital. \\
\hline $\begin{array}{l}\text { Baseline characteristics } \\
\text { similar? }\end{array}$ & Low risk & Table 1 \\
\hline
\end{tabular}

\title{
Standiford 2012
}

\begin{tabular}{ll}
\hline Methods & STUDY DESIGN: ITS \\
& Risk of Bias: MEDIUM
\end{tabular}

PROVIDERS: all physicians in the hospital
PARTICIPANTS: all patients in the hospital
CLINICAL PROBLEM: cost of animicrobials
SETTING: 1 hospital in the USA

Interventions

FORMAT: Interventions: educational outreach by review and recommend change

Intervention Functions: enablement, persuasion

DELIVERER: AMT

COMPARISON: usual care pre-intervention and impact of removal of the intervention (2 years)

DESIRED CHANGE: decrease excessive

Outcomes

PRESCRIBING: Choice: quarterly cost of all antimicrobials

CLINICAL: Balancing: cohort data for mortality, length of stay, and unplanned re-admission. The DRG case mix index was monitored to ensure that changes in outcomes were not related to this index. 
Standiford 2012 (Continued)

Notes
FINANCIAL SUPPORT: Funding: none. Competing Interests: none declared

ADDITIONAL DATA: no response from authors to request for additional data

\section{Risk of bias}

\begin{tabular}{|c|c|c|}
\hline Bias & Authors' judgement & Support for judgement \\
\hline $\begin{array}{l}\text { Intervention independent } \\
\text { (ITS)? }\end{array}$ & High risk & $\begin{array}{l}\text { No information is given about changes in drug pricing over the } 12 \text { years of data } \\
\text { collection, which is likely to have changed the outcome measure. In addition, } \\
\text { there were changes in pharmacy data systems after the intervention, but the } \\
\text { timing is clearly documented in Figure } 1 .\end{array}$ \\
\hline $\begin{array}{l}\text { Analysed appropriately } \\
\text { (ITS)? }\end{array}$ & Low risk & Re-analysed \\
\hline $\begin{array}{l}\text { Shape of effect pre-speci- } \\
\text { fied (ITS)? }\end{array}$ & Low risk & Point of intervention was point of analysis. \\
\hline $\begin{array}{l}\text { Unlikely to affect data col- } \\
\text { lection (ITS) ? }\end{array}$ & Low risk & $\begin{array}{l}\text { Data were from the Pharmacy Administration and were independent from the } \\
\text { AMT. }\end{array}$ \\
\hline $\begin{array}{l}\text { Knowledge of the alloca- } \\
\text { tion adequately prevent- } \\
\text { ed(ITS)? }\end{array}$ & Low risk & $\begin{array}{l}\text { Data were from the Pharmacy Administration and were independent from the } \\
\text { AMT. }\end{array}$ \\
\hline $\begin{array}{l}\text { Incomplete outcome data } \\
\text { addressed (ITS)? }\end{array}$ & Low risk & $\begin{array}{l}\text { Data were from the Pharmacy Administration and were independent from the } \\
\text { AMT. }\end{array}$ \\
\hline $\begin{array}{l}\text { Free of selected reporting } \\
\text { (ITS)? }\end{array}$ & Low risk & $\begin{array}{l}\text { Data were from the Pharmacy Administration and were independent from the } \\
\text { AMT. }\end{array}$ \\
\hline Free of other bias (ITS)? & Low risk & $>1$ year data pre- and postintervention \\
\hline
\end{tabular}

\section{Stevenson 1988}

\begin{tabular}{ll}
\hline Methods & STUDY DESIGN: ITS \\
& Risk of Bias: LOW \\
\hline Participants & PROVIDERS: all physicians in the hospital \\
& PARTICIPANTS: all patients in the hospital \\
CLINICAL PROBLEM: receiving antibiotics & SETTING: 1 hospital in the UK \\
\hline
\end{tabular}

Interventions $\quad$ FORMAT: Interventions: dissemination of antibiotic policy

Intervention Function: education

DELIVERER: pharmacist

COMPARISON: 10 quarters (30 months) pre-intervention

DESIRED CHANGE: reduce excessive

Outcomes PRESCRIBING and FINANCIAL: Choice: average cost of antibiotics per patient. Prices were indexed to
1980.

Notes $\quad$ FINANCIAL SUPPORT: no information


Stevenson 1988 (Continued)

ADDITIONAL DATA: no response from authors to request for additional data

\section{Risk of bias}

\begin{tabular}{|c|c|c|}
\hline Bias & Authors' judgement & Support for judgement \\
\hline $\begin{array}{l}\text { Intervention independent } \\
\text { (ITS)? }\end{array}$ & Low risk & 2 years' data pre- and postintervention, enough to account for seasonal effects \\
\hline $\begin{array}{l}\text { Analysed appropriately } \\
\text { (ITS)? }\end{array}$ & Low risk & $\begin{array}{l}\text { Done in original paper: regression analysis testing for structural break associ- } \\
\text { ated with intervention. }\end{array}$ \\
\hline $\begin{array}{l}\text { Shape of effect pre-speci- } \\
\text { fied (ITS)? }\end{array}$ & Low risk & $\begin{array}{l}\text { Done, intended effect was decrease in primary outcome, and point of analysis } \\
\text { was point of intervention. }\end{array}$ \\
\hline $\begin{array}{l}\text { Unlikely to affect data col- } \\
\text { lection (ITS)? }\end{array}$ & Low risk & $\begin{array}{l}\text { Done, data were from routine systems and unlikely to change over study peri- } \\
\text { od. }\end{array}$ \\
\hline $\begin{array}{l}\text { Knowledge of the alloca- } \\
\text { tion adequately prevent- } \\
\text { ed(ITS)? }\end{array}$ & Low risk & $\begin{array}{l}\text { Done, data were from routine systems and unlikely to change over study peri- } \\
\text { od. }\end{array}$ \\
\hline $\begin{array}{l}\text { Incomplete outcome data } \\
\text { addressed (ITS)? }\end{array}$ & Low risk & $\begin{array}{l}\text { Done, data were from routine systems and unlikely to change over study peri- } \\
\text { od. }\end{array}$ \\
\hline $\begin{array}{l}\text { Free of selected reporting } \\
\text { (ITS)? }\end{array}$ & Low risk & Done, drug costs were adjusted to 1980 prices. \\
\hline Free of other bias (ITS) ? & Low risk & $\begin{array}{l}\text { Drug costs were adjusted to } 1980 \text { prices and adjusted for number of discharges } \\
\text { or deaths. }\end{array}$ \\
\hline
\end{tabular}

Stocker 2010

$\begin{array}{ll}\text { Methods } & \text { STUDY DESIGN: RCT } \\ & \text { Risk of Bias: MEDIUM }\end{array}$

Participants

PROVIDERS: all physicians in the neonatal ICU

PARTICIPANTS: 121 neonates (60 intervention, 61 control)

CLINICAL PROBLEM: suspected sepsis

SETTING: 1 hospital in Switzerland

Interventions

FORMAT: Interventions: reminders (circumstantial, decision support algorithm with each PCT test); structural, introduction of PCT testing

Intervention Functions: enablement, environmental restructuring

DELIVERER: departmental physician (Paediatrics)

COMPARISON: usual care

DESIRED CHANGE: decrease excessive

POWER CALCULATION: unclear. The trial was designed to obtain a power of $90 \%$ to detect a $30 \%$ difference between the 2 groups in the duration of antibiotic therapy, with an estimated standard deviation of $50 \%$. Sample size: no information

\begin{tabular}{ll}
\hline Outcomes & PRESCRIBING: Exposure: duration, \% treated $>72 \mathrm{~h}$ \\
\hline Notes & FINANCIAL SUPPORT: Funding: commercial B.R.A.H.M.S Diagnostica (Berlin, Germany) provided the \\
& testing kits for PCT. Competing Interests: no information
\end{tabular}




\section{Risk of bias}

\begin{tabular}{|c|c|c|}
\hline Bias & Authors' judgement & Support for judgement \\
\hline $\begin{array}{l}\text { Random sequence genera- } \\
\text { tion (selection bias) }\end{array}$ & Low risk & Randomised using assignment cards in envelopes \\
\hline $\begin{array}{l}\text { Allocation concealment } \\
\text { (selection bias) }\end{array}$ & Low risk & Randomised using assignment cards in envelopes \\
\hline $\begin{array}{l}\text { Blinding (performance } \\
\text { bias and detection bias) } \\
\text { All outcomes }\end{array}$ & High risk & Not blinded \\
\hline $\begin{array}{l}\text { Incomplete outcome data } \\
\text { (attrition bias) } \\
\text { All outcomes }\end{array}$ & Low risk & Outcomes on all patients \\
\hline $\begin{array}{l}\text { Selective reporting (re- } \\
\text { porting bias) }\end{array}$ & Low risk & Outcomes on all patients \\
\hline Other bias & Low risk & \\
\hline $\begin{array}{l}\text { Baseline Outcomes simi- } \\
\text { lar? }\end{array}$ & Unclear risk & No data \\
\hline Free of contamination? & Low risk & PCT results only reported for intervention patients. \\
\hline $\begin{array}{l}\text { Baseline characteristics } \\
\text { similar? }\end{array}$ & Low risk & Table 1 \\
\hline
\end{tabular}

\section{Stolz 2007}

\begin{tabular}{ll}
\hline Methods & STUDY DESIGN: RCT \\
& Risk of Bias: HIGH \\
\hline Participants & PROVIDERS: all physicians in Internal Medicine \\
& PARTICIPANTS: all patients hospitalised with exacerbations of chronic obstructive pulmonary disease; \\
& 288 screened, 226 randomised (113 intervention, 113 control) \\
CLINICAL PROBLEM: use of therapeutic antibiotics \\
SETTING: 1 hospital
\end{tabular}

Interventions $\quad$ FORMAT: Interventions: reminders (circumstantial, decision support algorithm with each PCT test); structural, introduction of PCT testing Intervention Functions: enablement, environmental restructuring

DELIVERER: departmental physician (Respiratory)

COMPARISON: usual care

DESIRED CHANGE: decrease excessive

POWER CALCULATION: yes, total 186 participants. Details in Appendix 3

Outcomes

PRESCRIBING: Exposure: \% antibiotic use for the exacerbation and in the subsequent 6 months 
Stolz 2007 (Continued)

CLINICAL: Balancing: length of stay, death, symptom scores

Notes $\quad$ FINANCIAL SUPPORT: Funding: part commercial University Hospital Basel. B.R.A.H.M.S provided procalcitonin assays for this investigator-driven study. Competing Interests: 1 author served as consultant and received payments from B.R.A.H.M.S to attend meetings and for travel expenses, speaking engagements, or research.

ADDITIONAL DATA: email response from authors with additional information about intervention

\section{Risk of bias}

\begin{tabular}{|c|c|c|}
\hline Bias & Authors' judgement & Support for judgement \\
\hline $\begin{array}{l}\text { Random sequence genera- } \\
\text { tion (selection bias) }\end{array}$ & Unclear risk & $\begin{array}{l}\text { No details: "Patients satisfying the entry criteria were randomly assigned to } \\
\text { one of two groups at the time of admission to the emergency department " }\end{array}$ \\
\hline $\begin{array}{l}\text { Allocation concealment } \\
\text { (selection bias) }\end{array}$ & Unclear risk & No details \\
\hline $\begin{array}{l}\text { Blinding (performance } \\
\text { bias and detection bias) } \\
\text { All outcomes }\end{array}$ & High risk & SIngle-blind \\
\hline $\begin{array}{l}\text { Incomplete outcome data } \\
\text { (attrition bias) } \\
\text { All outcomes }\end{array}$ & Low risk & Outcome data reported on all patients. \\
\hline $\begin{array}{l}\text { Selective reporting (re- } \\
\text { porting bias) }\end{array}$ & High risk & $\begin{array}{l}11(10 \%) \text { patients excluded from intervention and } 7(6 \%) \text { from control group } \\
\text { for "absence of COPD according to GOLD", but this should have occurred pre- } \\
\text { randomisation. }\end{array}$ \\
\hline Other bias & Low risk & \\
\hline $\begin{array}{l}\text { Baseline Outcomes simi- } \\
\text { lar? }\end{array}$ & High risk & No data \\
\hline Free of contamination? & Low risk & PCT only reported for intervention patients. \\
\hline $\begin{array}{l}\text { Baseline characteristics } \\
\text { similar? }\end{array}$ & Low risk & Table 1 \\
\hline
\end{tabular}

\section{Stolz 2009}

\begin{tabular}{ll}
\hline Methods & STUDY DESIGN: RCT \\
& Risk of Bias: MEDIUM \\
\hline Participants & PROVIDERS: all staff in adult ICUS \\
& PARTICIPANTS: 101 patients with VAP ( 51 intervention, 50 control) \\
& CLINICAL PROBLEM: receiving antibiotics for VAP \\
& SETTING: 3 university hospitals in Switzerland and the USA \\
\hline Interventions & FORMAT: Interventions: reminders (circumstantial, decision support algorithm with each PCT test); \\
& Structural, introduction of PCT testing \\
& Intervention Functions: enablement, environmental restructuring \\
& DELIVERER: respiratory physicians \\
& COMPARISON: usual care
\end{tabular}


Stolz 2009 (Continued)

DESIRED CHANGE: decrease excessive

POWER CALCULATION; yes, 84 participants total. Details in Appendix 3

Outcomes PRESCRIBING: Exposure: duration of antibiotic treatment

CLINICAL: Balancing: mortality, hospital length of stay

Notes

FINANCIAL SUPPORT: Funding: Swiss National Foundation, Margarete und Walter Liechtenstein Foundation, Freiwillige Akademische Gesellschaft Basel, Will Rogers Foundation, and participating hospitals. B.R.A.H.M.S AG funded assay material and logistics. Competing Interests: not clear. The published paper says that a statement of interest for the study itself is available but the web address provided online and in print does not work.

ADDITIONAL DATA: email response from authors with additional information about intervention

\section{Risk of bias}

\begin{tabular}{|c|c|c|}
\hline Bias & Authors' judgement & Support for judgement \\
\hline $\begin{array}{l}\text { Random sequence genera- } \\
\text { tion (selection bias) }\end{array}$ & Low risk & Block size 20 envelopes \\
\hline $\begin{array}{l}\text { Allocation concealment } \\
\text { (selection bias) }\end{array}$ & Low risk & Sealed, opaque envelopes \\
\hline $\begin{array}{l}\text { Blinding (performance } \\
\text { bias and detection bias) } \\
\text { All outcomes }\end{array}$ & High risk & $\begin{array}{l}\text { Primary outcome measure required collection of data from case noes by inves- } \\
\text { tigators. }\end{array}$ \\
\hline $\begin{array}{l}\text { Incomplete outcome data } \\
\text { (attrition bias) } \\
\text { All outcomes }\end{array}$ & Low risk & $\begin{array}{l}\text { Text shows that primary outcome was reported for all } 101 \text { randomised pa- } \\
\text { tients. }\end{array}$ \\
\hline $\begin{array}{l}\text { Selective reporting (re- } \\
\text { porting bias) }\end{array}$ & Low risk & $\begin{array}{l}\text { Text shows that primary outcome was reported for all } 101 \text { randomised pa- } \\
\text { tients. }\end{array}$ \\
\hline Other bias & Low risk & $\begin{array}{l}\text { Multivariate analysis to adjust primary outcome for age, microbiology and cen- } \\
\text { tre effect }\end{array}$ \\
\hline $\begin{array}{l}\text { Baseline Outcomes simi- } \\
\text { lar? }\end{array}$ & Unclear risk & No data about baseline outcomes \\
\hline Free of contamination? & Low risk & Procalcitonin only measured for intervention patients. \\
\hline $\begin{array}{l}\text { Baseline characteristics } \\
\text { similar? }\end{array}$ & Low risk & Table 1 \\
\hline
\end{tabular}

\section{Strom 2010}

Methods STUDY DESIGN: cluster RCT, professional level

\section{Risk of Bias: MEDIUM}

Participants

PROVIDERS: A total of 1971 clinicians were assigned to either an intervention group receiving a nearly hard-stop alert or a control group receiving the standard practice. 
PARTICIPANTS: 342 patients receiving warfarin and trimethoprim-sulfamethoxazole (194 intervention, 148 control), 1971 clusters (physicians)

CLINICAL PROBLEM: reduce risk of interaction between warfarin and trimethoprim-sulfamethoxazole SETTING: 2 hospitals in the USA

POWER CALCULATION: "It is generally accepted that randomization of at least 100 subjects will produce balance between the study groups and, of course, the present sample size is much larger than this."

FORMAT: Interventions: reminder (circumstantial) and restrictive by compulsory
that would not allow concomitant orders of warfarin and trimethoprim-sulfametho
ception allowed by the order form was the indication of Pneumocystis carinii pne
Expert approval was allowed for other patients when discussed with pharmacy.
Intervention Functions: enablement, environmental restructuring, restriction
DELIVERER: pharmacist
COMPARISON: usual care
DESIRED CHANGE: decrease excessive

Outcomes

PRESCRIBING: Choice: the proportion of desired responses (i.e. not reordering the alert-triggering drug within 10 minutes of firing)

CLINICAL: Balancing: 2 potential adverse outcomes of the computerised hard-stop alert were monitored and reported to the Institutional Review Board. The first was a delay in obtaining trimethoprim-sulfamethoxazole when the practitioner believed that an infection was best treated with trimethoprim-sulfamethoxazole and when the potential warfarin interaction was judged less important than the need for the antibiotic. The second was unintentional warfarin cessation in a patient previously undergoing long-term warfarin therapy. The study therefore also assessed the incidence of warfarin cessation on the day when an order of trimethoprim-sulfamethoxazole was attempted in a patient already receiving warfarin.

Notes FINANCIAL SUPPORT: Funding: University of Pennsylvania Health System and Agency for Healthcare Research and Quality. Competing Interests: none declared

ADDITIONAL DATA: email response from authors with additional data

\section{Risk of bias}

\begin{tabular}{lll}
\hline Bias & Authors' judgement & Support for judgement \\
\hline $\begin{array}{l}\text { Random sequence genera- } \\
\text { tion (selection bias) }\end{array}$ & Low risk & Number randomisation \\
\hline $\begin{array}{l}\text { Allocation concealment } \\
\text { (selection bias) }\end{array}$ & Low risk & $\begin{array}{l}\text { "Each medical practitioner has a unique access code to use the electronic or- } \\
\text { dering system, and the order system menu can be varied by individual user. In } \\
\text { addition, we wanted to keep each practitioner in the same study group for the } \\
\text { duration of the study to minimize contamination between the } 2 \text { groups. How- } \\
\text { ever, there is the possibility" }\end{array}$ \\
\hline
\end{tabular}

\begin{tabular}{lll}
\hline Blinding (performance & High risk & Not blinded \\
bias and detection bias) & \\
All outcomes & \\
\hline
\end{tabular}

Incomplete outcome data Low risk Outcome reported on all patients, determined electronically.

\begin{tabular}{l}
$\begin{array}{l}\text { Selective reporting (re- } \quad \text { Low risk } \\
\text { porting bias) }\end{array}$ \\
\hline
\end{tabular}


Strom 2010 (Continued)

\begin{tabular}{lll} 
Other bias & Low risk & \\
\hline $\begin{array}{l}\text { Baseline Outcomes simi- } \\
\text { lar? }\end{array}$ & Unclear risk & No information \\
\hline Free of contamination? & Low risk & $\begin{array}{l}\text { "We attempted to reduce contamination by trying to complete this study as } \\
\text { rapidly as possible. It was initially planned to last 7 months but had to be ter- } \\
\text { minated early." }\end{array}$
\end{tabular}

\begin{tabular}{ll}
$\begin{array}{l}\text { Baseline characteristics } \\
\text { similar? }\end{array}$ & Low risk \\
\hline
\end{tabular}

similar?

Sun 2011

\begin{tabular}{ll}
\hline Methods & STUDY DESIGN: ITS \\
& Risk of Bias: MEDIUM \\
\hline Participants & PROVIDERS: all cardiac surgeons and other professionals \\
& PARTICIPANTS: all patients undergoing coronary artery bypass surgery \\
& CLINICAL PROBLEM: improve reliability of administration of prophylaxis (first dose within $1 \mathrm{~h}$ of inci- \\
& Sion and duration not $>24 \mathrm{~h}$ ) \\
SETTING: 1 hospital in Taiwan
\end{tabular}

\begin{tabular}{ll}
\hline Interventions & FORMAT: Interventions: audit and feedback; educational meetings with dissemination of guidelines \\
& and evidence base \\
Intervention Functions: education, enablement \\
DELIVERER: AMT \\
COMPARISON: usual care \\
DESIRED CHANGE: decrease excessive
\end{tabular}

\begin{tabular}{ll}
\hline Outcomes & PRESCRIBING: Choice and exposure: time to first antibiotic dose, $\%$ of prophylaxis $\leq 24 \mathrm{~h}$ \\
\hline Notes & FINANCIAL SUPPORT: no information \\
& ADDITIONAL DATA: no response from authors to request for additional data \\
\hline
\end{tabular}

\section{Risk of bias}

\begin{tabular}{lll}
\hline Bias & Authors' judgement & Support for judgement \\
\hline $\begin{array}{l}\text { Intervention independent } \\
\text { (ITS) }\end{array}$ & Low risk & \\
\hline $\begin{array}{l}\text { Analysed appropriately } \\
\text { (ITS) }\end{array}$ & Low risk & Re-analysed \\
\hline $\begin{array}{l}\text { Shape of effect pre-speci- } \\
\text { fied (ITS) ? }\end{array}$ & Low risk & Point of intervention was point of analysis. \\
\hline $\begin{array}{l}\text { Unlikely to affect data col- } \\
\text { lection (ITS) ? }\end{array}$ & Low risk & From Taiwan Quality Improvement Project database \\
\hline $\begin{array}{l}\text { Knowledge of the alloca- } \\
\text { tion adequately prevent- } \\
\text { ed(ITS)? }\end{array}$ & Low risk & Outcome data from Taiwan Quality Improvement Project database. \\
\hline \hline
\end{tabular}


Sun 2011 (Continued)

Incomplete outcome data Low risk Outcome reported on all patients pre- and postintervention. addressed (ITS)?

Free of selected reporting Low risk Objective outcomes from Taiwan Quality Improvement Project database (ITS) ?

Free of other bias (ITS) ? High risk <1 year data pre- and postintervention

\section{Suwangool 1991}

\begin{tabular}{ll}
\hline Methods & STUDY DESIGN: ITS \\
& Risk of Bias: MEDIUM \\
\hline Participants & PROVIDERS: all physicians in the Department of Medicine \\
& PARTICIPANTS: all patients in the Department of Medicine \\
CLINICAL PROBLEM: inappropriate antibiotic prescribing \\
SETTING: single university hospital in Thailand
\end{tabular}

\begin{tabular}{ll}
\hline Interventions & FORMAT: Interventions: dissemination of guidelines; restrictive by expert approval \\
Intervention Functions: education, restriction
\end{tabular}

DELIVERER: AMT

COMPARISON: 6 months' data pre-intervention

DESIRED CHANGE: reduce excessive (cost)

\begin{tabular}{ll}
\hline Outcomes & PRESRIBING: Choice: monthly cost of target antibiotics \\
& CLINICAL: cohort data about mortality \\
\hline Notes & FINANCIAL SUPPORT: no information \\
& ADDITIONAL DATA: no response from authors to request for additional data
\end{tabular}

\section{Risk of bias}

\begin{tabular}{lll}
\hline Bias & Authors' judgement & Support for judgement \\
\hline $\begin{array}{l}\text { Intervention independent } \\
\text { (ITS) }\end{array}$ & Low risk & \\
\hline $\begin{array}{l}\text { Analysed appropriately } \\
\text { (ITS)? }\end{array}$ & Low risk & Re-analysed \\
\hline $\begin{array}{l}\text { Shape of effect pre-speci- } \\
\text { fied (ITS) ? }\end{array}$ & Low risk & Point of intervention was point of analysis. \\
\hline $\begin{array}{l}\text { Unlikely to affect data col- } \\
\text { lection (ITS)? }\end{array}$ & Low risk & Data from pharmacy computer \\
\hline $\begin{array}{l}\text { Knowledge of the alloca- } \\
\text { tion adequately prevent- } \\
\text { ed(ITS)? }\end{array}$ & Low risk & Data from pharmacy computer \\
\hline $\begin{array}{l}\text { Incomplete outcome data } \\
\text { addressed (ITS) ? }\end{array}$ & Low risk & \\
\hline
\end{tabular}


Suwangool 1991 (Continued)

Free of selected reporting Low risk Data from pharmacy computer (ITS) ?

Free of other bias (ITS) ? Unclear risk

$<1$ year data pre- and postintervention. During the 18-month study period, no adjustment was made to antibiotic costs for changes in prices, so changes in cost may have been due to changes in price as well as use.

Talpaert 2011

\begin{tabular}{ll}
\hline Methods & STUDY DESIGN: ITS \\
& Risk of Bias: MEDIUM \\
\hline Participants & PROVIDERS: all physicians in the hospital \\
& PARTICIPANTS: all patients in the hospital \\
& CLINICAL PROBLEM: patients receiving antibiotics for prophylaxis or treatment. The intervention tar- \\
geted fluoroquinolones, cephalosporins, clindamycin, amoxicillin, and co-amoxiclav, as they were con- \\
sidered to be "high risk" for Clostridium difficile infection \\
SETTING: 1 hospital
\end{tabular}

Interventions

FORMAT: Interventions: educational meetings with dissemination of guidelines; educational outreach by review and recommend change; reminders (verbal (on rounds) and physical (laminated pocket cards and posters)); restrictive by removal of target drugs from clinical areas

Intervention Functions: education, enablement, environmental restructuring, persuasion restriction DELIVERER: AMT

COMPARISON: usual care

DESIRED CHANGE: decrease excessive

PRESCRIBING: Choice: use of target antibiotics in DDD/1000 OBD
MICROBIAL: monthly cases of $C$ difficile infection

Notes

FINANCIAL SUPPORT: Funding: none. Competing Interests: 1 author was paid lecture fees and provided sponsorship to attend conferences by pharmaceutical companies unrelated to this study.

ADDITIONAL DATA: no response from authors to request for additional data

Microbial Risk of Bias LOW: case definition Low (new cases), planned intervention Low, other infection control Low, fully reported in ORION format

\section{Risk of bias}

\begin{tabular}{lll}
\hline Bias & Authors' judgement & Support for judgement \\
\hline $\begin{array}{l}\text { Intervention independent } \\
\text { (ITS) }\end{array}$ & Unclear risk & Change in site - moved to another building \\
\hline $\begin{array}{l}\text { Analysed appropriately } \\
\text { (ITS) }\end{array}$ & Low risk & Segmented regression analysis \\
\hline $\begin{array}{l}\text { Shape of effect pre-speci- } \\
\text { fied (ITS) ? }\end{array}$ & Low risk & Point of intervention was point of analysis. \\
\hline $\begin{array}{l}\text { Unlikely to affect data col- } \\
\text { lection (ITS) ? }\end{array}$ & Low risk & From electronic records, so unlikely \\
\hline
\end{tabular}


Talpaert 2011 (Continued)

Knowledge of the alloca- Low risk From electronic records, so unlikely tion adequately prevented(ITS)?

\begin{tabular}{lll}
\hline $\begin{array}{l}\text { Incomplete outcome data } \\
\text { addressed (ITS) }\end{array}$ & Low risk & From electronic records, so unlikely \\
\hline $\begin{array}{l}\text { Free of selected reporting } \\
\text { (ITS) } ?\end{array}$ & Low risk & From electronic records, so unlikely \\
\hline Free of other bias (ITS) ? & Low risk & 1 year data pre- and postintervention \\
\hline
\end{tabular}

Tangdén 2011

\begin{tabular}{|c|c|}
\hline Methods & $\begin{array}{l}\text { STUDY DESIGN: ITS } \\
\text { Risk of Bias: LOW }\end{array}$ \\
\hline Participants & $\begin{array}{l}\text { PROVIDERS: all physicians in the hospital } \\
\text { PARTICIPANTS: all patients receiving therapeutic antibiotics } \\
\text { CLINICAL PROBLEM: aim (i) to reduce the consumption of } 2 \text { nd- and 3rd-generation cephalosporins; } \\
\text { and (ii) to avoid increased prescription of fluoroquinolones and carbapenems. } \\
\text { SETTING: } 1 \text { hospital in Sweden }\end{array}$ \\
\hline Interventions & $\begin{array}{l}\text { FORMAT: Interventions: educational meetings with dissemination of guidelines; educational outreach } \\
\text { by academic detailing } \\
\text { Intervention Functions: education, persuasion } \\
\text { DELIVERER: AMT } \\
\text { COMPARISON: usual care } \\
\text { DESIRED CHANGE: decrease excessive }\end{array}$ \\
\hline Outcomes & PRESCRIBING: Choice: use of target drugs in DDD/1000 OBD \\
\hline Notes & $\begin{array}{l}\text { FINANCIAL SUPPORT: Funding: no external. Competing Interests: none declared } \\
\text { ADDITIONAL DATA: no response from authors to request for additional data } \\
\text { Microbial Risk of Bias: HIGH, Case definition Low, Unplanned intervention High (outbreak), Other in- } \\
\text { fection control High. "In August 2006, the hospital director organized a steering group (SG) with the as- } \\
\text { signment to implement the necessary measures to contain the outbreak, including reinforcement of } \\
\text { hygienic measures, such as hand disinfection, use of disposable gloves and aprons, and isolation of pa- } \\
\text { tients colonized or infected with ESBL-KP.14 In addition to hygienic measures, the SG decided to per- } \\
\text { form an antibiotic intervention." }\end{array}$ \\
\hline
\end{tabular}

\section{Risk of bias}

Bias Authors' judgement Support for judgement

Intervention independent Low risk

(ITS) ?

Analysed appropriately $\quad$ Low risk $\quad$ Segmented regression analysis
(ITS)?

Shape of effect pre-speci- Low risk Point of intervention was point of analysis.
fied (ITS) ?


Tangdén 2011 (Continued)

Unlikely to affect data col- Low risk DDD from pharmacy computer lection (ITS) ?

Knowledge of the alloca- Low risk DDD from pharmacy computer
tion adequately prevented(ITS)?

Incomplete outcome data Low risk $\quad$ DDD from pharmacy computer
addressed (ITS)?

Free of selected reporting Low risk $\quad$ DDD from pharmacy computer
(ITS)?

Free of other bias (ITS) ? Low risk >1 year data pre- and postintervention

\section{Toltzis 1998}

\begin{tabular}{ll}
\hline Methods & STUDY DESIGN: ITS \\
& Risk of Bias: MEDIUM \\
\hline Participants & PROVIDERS: all physicians in the mixed medical and surgical paediatric ICU \\
PARTICIPANTS: all patients in the paediatric ICU \\
CLINICAL PROBLEM: patients requiring antibiotic treatment \\
SETTING: a paediatric ICU in 1 hospital in the USA
\end{tabular}

Interventions $\quad$ FORMAT: Intervention: restrictive, probably by expert approval ("Prohibition of ceftazidime use unless the patient's microbiological results indicated that the drug was necessary for cure.")

Intervention Function: restriction

DELIVERER: specialist (ID) physician

COMPARISON: 7 months' data before the start of the intervention

DESIRED CHANGE: reduce excessive

\begin{tabular}{|c|c|c|}
\hline Outcomes & \multicolumn{2}{|c|}{ PRESCRIBING: Choice: ceftazidime use in doses } \\
\hline Notes & \multicolumn{2}{|c|}{$\begin{array}{l}\text { FINANCIAL SUPPORT: Funding: grant HD31323-02 from the National Institutes of Health. Competing } \\
\text { Interests: no information }\end{array}$} \\
\hline & \multicolumn{2}{|c|}{ ADDITIONAL DATA: no response from authors to request for additional data } \\
\hline \multicolumn{3}{|l|}{ Risk of bias } \\
\hline Bias & Authors' judgement & Support for judgement \\
\hline $\begin{array}{l}\text { Intervention independent } \\
\text { (ITS)? }\end{array}$ & Unclear risk & $\begin{array}{l}\text { NOT CLEAR, data for } 7 \text { months pre- and } 12 \text { months postintervention, not } \\
\text { enough to adjust for seasonal variation }\end{array}$ \\
\hline $\begin{array}{l}\text { Analysed appropriately } \\
\text { (ITS)? }\end{array}$ & Low risk & $\begin{array}{l}\text { Re-analysed. Not done in original paper: comparison of means (uncontrolled } \\
\text { before-after) with } x^{2} \text { test. }\end{array}$ \\
\hline $\begin{array}{l}\text { Shape of effect pre-speci- } \\
\text { fied (ITS)? }\end{array}$ & Low risk & $\begin{array}{l}\text { Done, intended effect was decrease in primary outcome, and point of analysis } \\
\text { was point of intervention. }\end{array}$ \\
\hline
\end{tabular}


Toltzis 1998 (Continued) $\begin{array}{ll}\text { Unlikely to affect data col- } & \text { Low risk } \\ \text { lection (ITS) ? } & \text { Done, data were from routine systems and unlikely to change over study peri- }\end{array}$

Knowledge of the alloca- Low risk tion adequately preventDone, data were from routine systems and unlikely to change over study peried(ITS)? od.

\begin{tabular}{lll}
\hline $\begin{array}{l}\text { Incomplete outcome data } \\
\text { addressed (ITS) } ?\end{array}$ & Low risk & $\begin{array}{l}\text { Done, data were from routine systems and unlikely to change over study peri- } \\
\text { od. }\end{array}$ \\
\hline $\begin{array}{l}\text { Free of selected reporting } \\
\text { (ITS) ? }\end{array}$ & Low risk & $\begin{array}{l}\text { Done, data were from routine systems and unlikely to change over study peri- } \\
\text { od. }\end{array}$
\end{tabular}

Free of other bias (ITS) ? High risk <1 year data pre-intervention

\section{Toltzis 2002}

\begin{tabular}{ll}
\hline Methods & STUDY DESIGN: NRT \\
& Risk of Bias: HIGH \\
\hline Participants & PROVIDERS: all physicians (paediatricians) on the ICU \\
& PARTICIPANTS: all neonates in the ICU \\
CLINICAL PROBLEM: neonates with proven or suspected infections caused by gram-negative bacteria \\
SETTING: 1 neonatal ICU in 1 hospital in the USA
\end{tabular}

FORMAT: no valid prescribing data. Restrictive by removal, monthly rotation of the antibiotic regimen
used for empirical prescribing of patients with proven or suspected gram-negative infections
DELIVERER: specialist physician (ICU)
COMPARISON: standard practice
DESIRED CHANGE: reduce excessive (colonisation with multiresistant bacteria)

\begin{tabular}{ll}
\hline Outcomes & MICROBIAL: incidence of colonisation with multiantibiotic-resistant aerobic gram-negative bacilli \\
\hline Notes & $\begin{array}{l}\text { FINANCIAL SUPPORT: Funding: grant HD 31323-05 from the National Institutes of Health Competing } \\
\text { Interests: no information }\end{array}$
\end{tabular}

ADDITIONAL DATA: no response from authors to request for additional data

Microbial Risk of Bias: MEDIUM Case definition Low, Planned intervention Low, Other infection control Unclear

\begin{tabular}{lll}
\hline Risk of bias & & \\
\hline Bias & Authors' judgement & Support for judgement \\
\hline $\begin{array}{l}\text { Random sequence genera- } \\
\text { tion (selection bias) }\end{array}$ & High risk & NRT with monthly rotation of regimens \\
\hline $\begin{array}{l}\text { Allocation concealment } \\
\text { (selection bias) }\end{array}$ & High risk & Not possible with this study design \\
\hline $\begin{array}{l}\text { Blinding (performance } \\
\text { bias and detection bias) } \\
\text { All outcomes }\end{array}$ & High risk & Not possible with this study design \\
\hline
\end{tabular}


Toltzis 2002 (Continued)
Incomplete outcome data
Unclear risk
Not stated whether screening samples obtained from all patients
(attrition bias)

All outcomes

Selective reporting (re- Unclear risk $\quad$ Not stated whether screening samples obtained from all patients
porting bias)

Other bias Unclear risk NOT CLEAR Microbial Outcome Risk of Bias Criteria Case definition: DONE

Colonisation by screening. "For the purpose of this study, an 'antibiotic-resistant Gram-negative organism' was defined as any Gram-negative bacillus resistant to gentamicin, piperacillin-tazobactam, or ceftazidime. Pharyngeal and rectal swab specimens were obtained on all infants every Monday, Wednesday, and Friday". Planned intervention: DONE; Other infection control, Isolation: IC practices: NOT CLEAR Not described, but it is reasonable to assume that they were the same for the intervention and control groups due to the controlled clinical trial design.

\begin{tabular}{lll}
\hline $\begin{array}{l}\text { Baseline Outcomes simi- } \\
\text { lar? }\end{array}$ & Unclear risk & Not stated \\
\hline Free of contamination? & Unclear risk & $\begin{array}{l}\text { Not stated, but doctors likely to have been managing patients in more than } 1 \\
\text { study phase. }\end{array}$ \\
\hline $\begin{array}{l}\text { Baseline characteristics } \\
\text { similar? }\end{array}$ & Low risk & Results, paragraph 1 \\
\hline
\end{tabular}

\section{Toltzis 2014}

\begin{tabular}{ll}
\hline Methods & STUDY DESIGN: ITS \\
& Risk of Bias: HIGH \\
\hline
\end{tabular}

PROVIDERS: all paediatric surgeons and anaesthetists
PARTICIPANTS: all children undergoing surgery
CLINICAL PROBLEM: increase \% of patients receiving antibiotic prophylaxis within 1 hour of incision as
1 of 3 components of a bundle of care
SETTING: 8 paediatric hospitals in the USA

Interventions
DERMAT: no valid prescribing data. Audit and feedback
COMPARISON: usual care
DESIRED CHANGE: increase effective

\begin{tabular}{ll}
\hline Outcomes & CLINICAL: surgical-site infection rate per 100 procedures \\
\hline Notes & FINANCIAL SUPPORT: Funding: Ohio Business Roundtable, the Cardinal Health Foundation, and the \\
& Ohio Children's Hospital Association. Competing Interests: none declared
\end{tabular}

ADDITIONAL DATA: no response from authors to request for additional data

\section{Risk of bias}

\begin{tabular}{lll}
\hline Bias & Authors' judgement & Support for judgement \\
\hline $\begin{array}{ll}\text { Intervention independent } \\
\text { (ITS)? }\end{array}$ & High risk & $\begin{array}{l}\text { Administration of antibiotics within } 1 \text { hour was } 1 \text { component of the bundle; } \\
\text { the other 2 were avoiding shaving and encouraging use of clorhexidine for dis- } \\
\text { infection. In addition, 9 months after the intervention began an additional an- }\end{array}$ \\
\hline
\end{tabular}


Toltzis 2014 (Continued)

tibiotic element was added to encourage administration of an additional dose for operations lasting more than 3 hours.

\begin{tabular}{lll}
\hline $\begin{array}{l}\text { Analysed appropriately } \\
\text { (ITS) } ?\end{array}$ & Low risk & Segmented regression analysis \\
\hline $\begin{array}{l}\text { Shape of effect pre-speci- } \\
\text { fied (ITS) ? }\end{array}$ & Low risk & Point of intervention was point of analysis. \\
\hline $\begin{array}{l}\text { Unlikely to affect data col- } \\
\text { lection (ITS) ? }\end{array}$ & Low risk & $\begin{array}{l}\text { Patient administration systems and routine collection of surgical-site infection } \\
\text { data by each hospital's infection prevention teams }\end{array}$ \\
\hline
\end{tabular}

\begin{tabular}{|c|c|c|}
\hline $\begin{array}{l}\text { Knowledge of the alloca- } \\
\text { tion adequately prevent- }\end{array}$ & High risk & $\begin{array}{l}\text { Infection prevention teams were not prevented from knowing about alloca- } \\
\text { tion. }\end{array}$ \\
\hline
\end{tabular}
ed(ITS)?

Incomplete outcome data Low risk
addressed (ITS)?

\begin{tabular}{lll}
\hline $\begin{array}{l}\text { Free of selected reporting } \\
\text { (ITS) ? }\end{array}$ & Low risk & Data reported for all months when operations took place \\
\hline Free of other bias (ITS) ? & High risk & Only 8 months' pre-intervention data \\
\hline
\end{tabular}

Trenholme 1989

\begin{tabular}{ll}
\hline Methods & STUDY DESIGN: RCT \\
& Risk of Bias: HIGH \\
\hline Participants & PROVIDERS: all physicians in the hospital \\
& PARTICIPANTS: 226 patients (110 intervention, 116 control) \\
CLINICAL PROBLEM: patients with bacteraemia \\
SETTING: 1 hospital in the USA
\end{tabular}

Interventions

FORMAT: Interventions: educational outreach by review and recommend change (intervention and control); structural, rapid processing and reporting of antimicrobial susceptibility tests (intervention only)

Intervention Functions: enablement, environmental restructuring, persuasion

DESIRED CHANGE: reduce excessive

POWER CALCULATION: no information

PRESCRIBING: Choice: \% changes in therapy in response to recommendation
FINANCIAL: savings in drug costs

Notes

FINANCIAL SUPPORT: no information

ADDITIONAL DATA: no response from authors to request for additional data

\section{Risk of bias}


Trenholme 1989 (Continued)

Random sequence genera- Unclear risk Not stated; "the organism from the patient was randomly assigned" tion (selection bias)

\begin{tabular}{lll}
\hline $\begin{array}{l}\text { Allocation concealment } \\
\text { (selection bias) }\end{array}$ & Unclear risk & Not stated \\
\hline $\begin{array}{l}\text { Blinding (performance } \\
\text { bias and detection bias) }\end{array}$ & Unclear risk & Not stated as blind \\
All outcomes & \\
\hline
\end{tabular}

Incomplete outcome data Low risk Table 2 reports primary outcome for all 226 randomised patients.
(attrition bias)

All outcomes

\begin{tabular}{lll}
\hline $\begin{array}{l}\text { Selective reporting (re- } \\
\text { porting bias) }\end{array}$ & Low risk & Table 2 reports primary outcome for all 226 randomised patients. \\
\hline Other bias & Low risk & No other apparent biases found. \\
\hline $\begin{array}{l}\text { Baseline Outcomes simi- } \\
\text { lar? }\end{array}$ & Unclear risk & $\begin{array}{l}\text { No information about recommendations for changes in therapy before the in- } \\
\text { tervention }\end{array}$ \\
\hline $\begin{array}{l}\text { Free of contamination? } \\
\text { Baseline characteristics }\end{array}$ & Unclear risk & $\begin{array}{l}\text { Likely to be contamination as doctors managing control patients would re- } \\
\text { ceive advice on intervention patients. }\end{array}$ \\
\hline similar? & No information \\
\hline
\end{tabular}

Uçkay 2009

\begin{tabular}{ll}
\hline Methods & STUDY DESIGN: ITS \\
& Risk of Bias: HIGH \\
\hline Participants & PROVIDERS: all physicians in one orthopaedic unit \\
& PARTICIPANTS: all patients in one orthopaedic unit \\
& SETTING: 1 hospital in Switzerland \\
\hline Interventions & FORMAT: Interventions: educational outreach by review and recommend change. The intervention is \\
& reported in 2 phases, the 1st delivered by "Dedicated ID specialist and one internist" and the 2nd deliv- \\
& ered by "ID specialist with experience in Infection Control". \\
Intervention Functions: enablement, persuasion & DELIVERER: specialist (ID) physician \\
COMPARISON: usual care & DESIRED CHANGE: decrease excessive
\end{tabular}

\begin{tabular}{ll}
\hline Outcomes & PRESCRIBING: Choice: use of IV and oral antibiotics in DDD/1000 OBD \\
\hline Notes & FINANCIAL SUPPORT: Funding: none.Competing Interests: none declared. \\
& ADDITIONAL DATA: email response from authors with additional data about the intervention \\
\hline Risk of bias & Authors' judgement Support for judgement \\
\hline Bias & \\
\hline \hline
\end{tabular}


Uçkay 2009 (Continued)

Intervention independent Unclear risk Insufficient information to assess

(ITS) ?

Analysed appropriately $\quad$ Low risk $\quad$ Time series analysis with ARIMA modelling
(ITS)?

\begin{tabular}{lll}
\hline $\begin{array}{l}\text { Shape of effect pre-speci- } \\
\text { fied (ITS) ? }\end{array}$ & Low risk & Point of intervention was point of analysis. \\
\hline $\begin{array}{l}\text { Unlikely to affect data col- } \\
\text { lection (ITS) ? }\end{array}$ & Unclear risk & Outcome data were from routine pharmacy systems. \\
\hline $\begin{array}{l}\text { Knowledge of the alloca- } \\
\text { tion adequately prevent- } \\
\text { ed(ITS)? }\end{array}$ & Low risk & Outcome data were from routine pharmacy systems. \\
\hline $\begin{array}{l}\text { Incomplete outcome data } \\
\text { addressed (ITS) ? }\end{array}$ & Low risk & Outcome data were from routine pharmacy systems. \\
\hline $\begin{array}{l}\text { Free of selected reporting } \\
\text { (ITS) ? }\end{array}$ & High risk & $\begin{array}{l}\text { The information in Table } 1 \text { does not include total antibiotic use or cost, so can- } \\
\text { not be used to support the claims made in the paper. }\end{array}$ \\
\hline $\begin{array}{l}\text { Free of other bias (ITS) ? } \\
\text { High risk }\end{array}$ & $\begin{array}{l}<1 \text { year pre-intervention data } \\
\text { Insufficient information to assess. In particular, it is not clear what difference } \\
\text { the "ID specialist with experience in Infection Control" would make compared } \\
\text { with "Dedicated ID specialist and one internist". }\end{array}$ \\
\hline
\end{tabular}

Valiquette 2007

\begin{tabular}{ll}
\hline Methods & STUDY DESIGN: ITS \\
& Risk of Bias: MEDIUM \\
\hline Participants & PROVIDERS: all physicians in the hospital \\
& PARTICIPANTS: all patients in the hospital \\
CLINICAL PROBLEM: receiving therapeutic or prophylactic antibiotics \\
SETTING: 1 hospital in Canada
\end{tabular}

Interventions

FORMAT: Interventions: educational meetings with dissemination of guideline and letter; educational outreach by review and recommend change; reminders (physical, pocket-size guideline)

Intervention Functions: education, enablement, environmental restructuring, persuasion

DELIVERER: AMT

COMPARISON: usual care

DESIRED CHANGE: decrease excessive

Outcomes

PRESCRIBING: Choice and exposure: use of individual targeted drugs in DDD/1000 OBD; use of all antibiotics in DDD/1000 OBD

MICROBIAL: Clostridium difficile infections/1000 OBD

Notes

FINANCIAL SUPPORT: Funding: National Foundation for Infectious Diseases. Competing Interests: 1 author has been on the speakers' bureau for Wyeth; served on advisory boards for Wyeth and Cubist; and received grants from Wyeth, Genzyme, and Arpida. 1 author has been on the speakers' bureau for Wyeth Canada; served on advisory boards for Bayer, Wyeth, ViroPharma, and Acambis; and received grants from Genzyme. 
Microbial Risk of Bias: HIGH Case definition Low. Planned intervention High, response to epidemic of infection caused by high-virulence strain. Other infection control High, the rate of CDI was already declining in response to infection control intervention when antimicrobial intervention began.

\section{Risk of bias}

\begin{tabular}{|c|c|c|}
\hline Bias & Authors' judgement & Support for judgement \\
\hline $\begin{array}{l}\text { Intervention independent } \\
\text { (ITS)? }\end{array}$ & High risk & $\begin{array}{l}\text { Antimicrobial intervention followed an infection control intervention, so it is } \\
\text { not possible to assess the independent impact on C difficile infection. More- } \\
\text { over, the infection control intervention could have been responsible for some } \\
\text { or all of the reduction in total antibiotic use. }\end{array}$ \\
\hline
\end{tabular}

Analysed appropriately $\quad$ Low risk $\quad$ Re-analysed
(ITS) ?

\begin{tabular}{lll}
\hline $\begin{array}{l}\text { Shape of effect pre-speci- } \\
\text { fied (ITS) ? }\end{array}$ & Low risk & Point of intervention was point of analysis. \\
\hline $\begin{array}{l}\text { Unlikely to affect data col- } \\
\text { lection (ITS) ? }\end{array}$ & Low risk & Data from pharmacy and microbiology computers \\
\hline
\end{tabular}

Knowledge of the alloca- Low risk Data from pharmacy and microbiology computers
tion adequately prevent-
ed(ITS)?

\begin{tabular}{lll}
\hline $\begin{array}{l}\text { Incomplete outcome data } \\
\text { addressed (ITS) } ?\end{array}$ & Low risk & Data from pharmacy and microbiology computers \\
\hline $\begin{array}{l}\text { Free of selected reporting } \\
\text { (ITS) }\end{array}$ & Low risk & Data from pharmacy and microbiology computers \\
\hline Free of other bias (ITS) ? & High risk & Microbial Risk of Bias HIGH \\
& $>1$ year of data pre-intervention \\
\hline
\end{tabular}

van Hees 2008

\begin{tabular}{ll}
\hline Methods & STUDY DESIGN: ITS \\
& Risk of Bias: MEDIUM \\
\hline Participants & PROVIDERS: all physicians in the Departments of Internal Medicine, Gastroenterology, Surgery, Urolo- \\
gy, and Pulmonary Diseases \\
PARTICIPANTS: all patients in the same departments \\
CLINICAL PROBLEM: patients receiving ciprofloxacin \\
SETTING: 1 university hospital in the Netherlands \\
\hline FORMAT: Interventions: educational meetings; educational outreach by review and recommend \\
change \\
Intervention Functions: education, enablement, persuasion \\
DELIVERER: specialist physicians (microbiologists) \\
COMPARISON: usual care \\
DESIRED CHANGE: decrease excessive (reduce unnecessary ciprofloxacin)
\end{tabular}


van Hees 2008 (Continued)

Outcomes PRESCRIBING: Choice: use of ciprofloxacin in prescriptions/1000 OBD

Notes FINANCIAL SUPPORT:Funding: none. Competing Interests: none declared

ADDITIONAL DATA: no response from authors to request for additional data

\title{
Risk of bias
}

\begin{tabular}{|c|c|c|}
\hline Bias & Authors' judgement & Support for judgement \\
\hline $\begin{array}{l}\text { Intervention independent } \\
\text { (ITS)? }\end{array}$ & Low risk & \\
\hline $\begin{array}{l}\text { Analysed appropriately } \\
\text { (ITS)? }\end{array}$ & Low risk & Segmented regression analysis \\
\hline $\begin{array}{l}\text { Shape of effect pre-speci- } \\
\text { fied (ITS) ? }\end{array}$ & Low risk & Point of intervention was point of analysis. \\
\hline $\begin{array}{l}\text { Unlikely to affect data col- } \\
\text { lection (ITS) ? }\end{array}$ & Low risk & Data for primary outcome measure were from pharmacy computer. \\
\hline $\begin{array}{l}\text { Knowledge of the alloca- } \\
\text { tion adequately prevent- } \\
\text { ed(ITS)? }\end{array}$ & Low risk & Data for primary outcome measure were from pharmacy computer. \\
\hline $\begin{array}{l}\text { Incomplete outcome data } \\
\text { addressed (ITS)? }\end{array}$ & Low risk & Data for primary outcome measure were from pharmacy computer. \\
\hline $\begin{array}{l}\text { Free of selected reporting } \\
\text { (ITS)? }\end{array}$ & Low risk & Data for primary outcome measure were from pharmacy computer. \\
\hline Free of other bias (ITS)? & High risk & $\begin{array}{l}\text { Only } 3 \text { months' pre- and } 6 \text { months' postintervention data, so cannot be adjust- } \\
\text { ed for seasonal trends. }\end{array}$ \\
\hline
\end{tabular}

Van Kasteren 2005

\begin{tabular}{ll}
\hline Methods & STUDY DESIGN: ITS \\
& Risk of Bias: MEDIUM \\
\hline Participants & PROVIDERS: all physicians in the hospitals \\
& PATIENTS: all patients undergoing elective surgery \\
& CLINICAL PROBLEM: surgical prophylaxis across 4 surgical disciplines \\
& SETTING: 14 hospitals in the Netherlands \\
\hline Interventions & FORMAT, Interventions: audit and feedback; educational meetings with dissemination of guidelines \\
Intervention Functions: education, enablement
\end{tabular}

\author{
DELIVERER: AMT
}

COMPARISON: pre-intervention periods

DESIRED CHANGE: reduce excessive duration of surgical prophylaxis 
Van Kasteren 2005 (Continued)

Outcomes PRESCRIBING: Exposure: total antibiotic use in DDD/100 procedures

CLINICAL: Balancing: cohort data on surgical-site infections

Notes

FINANCIAL SUPPORT: Funding: Netherlands Organisation for Health Research and Development (Zon$\mathrm{Mw})$. Competing Interests: none declared

ADDITIONAL DATA: no response from authors to request for additional data

\section{Risk of bias}

\begin{tabular}{|c|c|c|}
\hline Bias & Authors' judgement & Support for judgement \\
\hline $\begin{array}{l}\text { Intervention independent } \\
\text { (ITS) ? }\end{array}$ & High risk & $\begin{array}{l}\text { Only } 6 \text { months' pre- and postintervention data, and the model was not adjust- } \\
\text { ed for seasonal trends. }\end{array}$ \\
\hline $\begin{array}{l}\text { Analysed appropriately } \\
\text { (ITS)? }\end{array}$ & Low risk & Done in original paper: segmented regression analysis \\
\hline $\begin{array}{l}\text { Shape of effect pre-speci- } \\
\text { fied (ITS)? }\end{array}$ & Low risk & $\begin{array}{l}\text { Done, intended effect was decrease in primary outcome, and point of analysis } \\
\text { was point of intervention. }\end{array}$ \\
\hline $\begin{array}{l}\text { Unlikely to affect data col- } \\
\text { lection (ITS)? }\end{array}$ & Low risk & $\begin{array}{l}\text { Done, data were from routine systems and unlikely to change over study peri- } \\
\text { od. }\end{array}$ \\
\hline $\begin{array}{l}\text { Incomplete outcome data } \\
\text { addressed (ITS)? }\end{array}$ & Low risk & $\begin{array}{l}\text { Done, data were from routine systems and unlikely to change over study peri- } \\
\text { od. }\end{array}$ \\
\hline $\begin{array}{l}\text { Free of selected reporting } \\
\text { (ITS)? }\end{array}$ & Low risk & $\begin{array}{l}\text { Done, data were from routine systems and unlikely to change over study peri- } \\
\text { od. }\end{array}$ \\
\hline Free of other bias (ITS) ? & Low risk & $\begin{array}{l}\text { Done, data were from routine systems and unlikely to change over study peri- } \\
\text { od. Change in price unlikely to be a problem because only } 6 \text { months' data pre- } \\
\text { and postintervention. }\end{array}$ \\
\hline
\end{tabular}

Volpe 2012

\begin{tabular}{ll}
\hline Methods & STUDY DESIGN: ITS \\
& Risk of Bias: LOW \\
\hline Participants & PROVIDERS: all physicians in the ED \\
& PARTICIPANTS: all patients with fever and suspected neutropenia \\
& CLINICAL PROBLEM: fever and suspected neutropenia \\
& SETTING: 1 university paediatric hospital in the USA \\
\hline Interventions & $\begin{array}{l}\text { FORMAT: Interventions: audit and feedback with action planning; educational meetings with dissem- } \\
\text { ination of care algorithm and forms to facilitate care; educational outreach by academic detailing; re- } \\
\text { minders (circumstantial, root-cause analysis of individual cases not meeting goal); reminders (physical, } \\
\text { posters, email, and verbal, during rounds) } \\
\text { Intervention Functions: education, enablement, environmental restructuring, persuasion } \\
\text { DELIVERER: AMT } \\
\text { COMPARISON: usual care }\end{array}$ \\
\hline
\end{tabular}




PRESCRIBING: Choice: time (minutes) to first antbiotic dose
BALANCING MEASURE OF UNINTENDED CONSEQUENCES: "For balancing measures during the im-
provement period, we chose to follow the timeliness of first b-agonist treatment of patients with asth-
ma and the left without being seen (LWBS) rate."

Notes

FINANCIAL SUPPORT:Funding: no external funding. Competing Interests: none declared

ADDITIONAL DATA: no response from authors to request for additional data

\section{Risk of bias}

\begin{tabular}{lll}
\hline Bias & Authors' judgement & Support for judgement \\
\hline $\begin{array}{l}\text { Intervention independent } \\
\text { (ITS) }\end{array}$ & Low risk & \\
\hline $\begin{array}{l}\text { Analysed appropriately } \\
\text { (ITS) }\end{array}$ & Low risk & Statistical process control chart \\
\hline $\begin{array}{l}\text { Shape of effect pre-speci- } \\
\text { fied (ITS) ? }\end{array}$ & Low risk & Point of intervention was point of analysis. \\
\hline $\begin{array}{l}\text { Unlikely to affect data col- } \\
\text { lection (ITS) ? }\end{array}$ & Low risk & Outcome data from patient administration system \\
\hline $\begin{array}{l}\text { Knowledge of the alloca- } \\
\text { tion adequately prevent- } \\
\text { ed(ITS)? }\end{array}$ & Low risk & Outcome data from patient administration system \\
\hline $\begin{array}{l}\text { Incomplete outcome data } \\
\text { addressed (ITS) ? }\end{array}$ & Low risk & \\
\hline $\begin{array}{l}\text { Free of selected reporting } \\
\text { (ITS) ? }\end{array}$ & Low risk & Outcome data from patient administration system \\
\hline \begin{tabular}{l} 
Free of other bias (ITS) ? \\
\hline
\end{tabular} & Low risk & O 12 months' data pre- and postintervention \\
\hline
\end{tabular}

\section{Walker 1998}

\begin{tabular}{ll}
\hline Methods & STUDY DESIGN: RCT \\
& Risk of Bias: HIGH \\
\hline Participants & PROVIDERS: all physicians in the hospital \\
PARTICIPANTS: 50 patients ( 25 intervention, 25 control) \\
CLINICAL PROBLEM: duration of IV antibiotics for patients with community-acquired pneumonia \\
SETTING: 1 hospital in the USA
\end{tabular}


Walker 1998 (Continued)

DELIVERER: pharmacist

COMPARISON: standard practice (no intervention)

DESIRED CHANGE: reduce excessive

POWER CALCULATION: no information

Outcomes $\quad$ PRESCRIBING: Choice: number of patients changed to oral antibiotic therapy

CLINICAL: Balancing: re-admissions (total and for pneumonia)

Notes

FINANCIAL SUPPORT: Funding: commercial, Pharmacia and Upjohn. Competing Interests: no information

ADDITIONAL DATA: no response from authors to request for additional data

\section{Risk of bias}

\begin{tabular}{|c|c|c|}
\hline Bias & Authors' judgement & Support for judgement \\
\hline $\begin{array}{l}\text { Random sequence genera- } \\
\text { tion (selection bias) }\end{array}$ & Low risk & $\begin{array}{l}\text { "A list of random numbers was generated from Sigmastat version } 1.0 \text { statistical } \\
\text { software" }\end{array}$ \\
\hline $\begin{array}{l}\text { Allocation concealment } \\
\text { (selection bias) }\end{array}$ & Unclear risk & Not stated, but open label, so unlikely to be concealed \\
\hline $\begin{array}{l}\text { Blinding (performance } \\
\text { bias and detection bias) } \\
\text { All outcomes }\end{array}$ & High risk & "Open label" \\
\hline $\begin{array}{l}\text { Incomplete outcome data } \\
\text { (attrition bias) } \\
\text { All outcomes }\end{array}$ & Low risk & No problems found. \\
\hline $\begin{array}{l}\text { Selective reporting (re- } \\
\text { porting bias) }\end{array}$ & Low risk & No problems found. \\
\hline Other bias & Low risk & No other apparent biases found. \\
\hline $\begin{array}{l}\text { Baseline Outcomes simi- } \\
\text { lar? }\end{array}$ & Unclear risk & Not stated \\
\hline Free of contamination? & Unclear risk & Not stated \\
\hline $\begin{array}{l}\text { Baseline characteristics } \\
\text { similar? }\end{array}$ & Low risk & See Table 1 in paper \\
\hline
\end{tabular}

Wang 2014

\begin{tabular}{ll} 
Methods & STUDY DESIGN: ITS \\
& Risk of Bias: MEDIUM \\
\hline Participants & PROVIDERS: all physicians in 16 adult ICUs \\
& PARTICIPANTS: all patients in the ICUs \\
& CLINICAL PROBLEM: use of target antibiotics in patients with positive blood cultures \\
& SETTING: 1 University hospital in Taiwan
\end{tabular}


Wang 2014 (Continued)

Interventions

FORMAT: Intervention: educational outreach by review and recommned change; restrictive by expert approval

Intervention Functions: education, enablement, persuasion, restriction

DELIVERER: AMT

COMPARISON: usual care

DESIRED CHANGE: decrease excessive, reduce cost of antimicrobials by reducing unnecessary use

Outcomes

PRESCRIBING: Choice: primary outcome is cost of all antimicrobials (Figure 4G). Also reports impact on use of 7 target antibacterials and use of antifungals in DDD/1000 OBD.

CLINICAL: Balancing: mortality, ICU re-admission (segmented regression analysis)

Notes

FINANCIAL SUPPORT: Funding: none. Competing Interests: none declared

ADDITIONAL DATA: no response from authors to request for additional data

\section{Risk of bias}

\begin{tabular}{|c|c|c|}
\hline Bias & Authors' judgement & Support for judgement \\
\hline $\begin{array}{l}\text { Intervention independent } \\
\text { (ITS)? }\end{array}$ & Low risk & \\
\hline $\begin{array}{l}\text { Analysed appropriately } \\
\text { (ITS) ? }\end{array}$ & Low risk & Segmented regression analysis \\
\hline $\begin{array}{l}\text { Shape of effect pre-speci- } \\
\text { fied (ITS) ? }\end{array}$ & Low risk & Point of intervention was point of analysis. \\
\hline $\begin{array}{l}\text { Unlikely to affect data col- } \\
\text { lection (ITS)? }\end{array}$ & Low risk & Outcome data from pharmacy computer \\
\hline $\begin{array}{l}\text { Knowledge of the alloca- } \\
\text { tion adequately prevent- } \\
\text { ed(ITS)? }\end{array}$ & Low risk & Outcome data from pharmacy computer \\
\hline $\begin{array}{l}\text { Incomplete outcome data } \\
\text { addressed (ITS)? }\end{array}$ & Low risk & Outcome data from pharmacy computer \\
\hline $\begin{array}{l}\text { Free of selected reporting } \\
\text { (ITS)? }\end{array}$ & Low risk & Outcome data from pharmacy computer \\
\hline Free of other bias (ITS)? & High risk & $\begin{array}{l}>12 \text { months' data pre- and postintervention. However, no adjustment of pri- } \\
\text { mary outcome for changes in drug pricing over the } 5 \text { years of the study. }\end{array}$ \\
\hline
\end{tabular}

Wax 2007

Methods

STUDY DESIGN: ITS

\section{Risk of Bias: MEDIUM}

Participants

PROVIDERS: all anaesthetists in the hospital

PARTICIPANTS: all patients undergoing elective surgery

CLINICAL PROBLEM: time to first dose for antibiotic prophylaxis

SETTING: 1 hospital in the USA 
Wax 2007 (Continued)

Interventions

FORMAT: Interventions: reminders (physical, electronic on screen during all surgical procedures, not just those requiring prophylaxis)

Intervention Functions: education, environmental restructuring, persuasion

DELIVERER: AMT

COMPARISON: usual care

DESIRED CHANGE: increase effective

\begin{tabular}{ll} 
Outcomes & PRESCRIBING: Choice: $\%$ patients with first dose within 1 hour of incision \\
\hline Notes & FINANCIAL SUPPORT: no information \\
& ADDITIONAL DATA: no response from authors to request for additional data
\end{tabular}

\section{Risk of bias}

\begin{tabular}{lll}
\hline Bias & Authors' judgement & Support for judgement \\
\hline $\begin{array}{l}\text { Intervention independent } \\
\text { (ITS) }\end{array}$ & Low risk & \\
\hline $\begin{array}{l}\text { Analysed appropriately } \\
\text { (ITS) } ?\end{array}$ & Low risk & Re-analysed \\
\hline $\begin{array}{l}\text { Shape of effect pre-speci- } \\
\text { fied (ITS) ? }\end{array}$ & Low risk & Point of intervention was point of analysis. \\
\hline $\begin{array}{l}\text { Unlikely to affect data col- } \\
\text { lection (ITS) ? }\end{array}$ & Low risk & $\begin{array}{l}\text { Outcome data from electronic patient record, Anaesthesia Information Man- } \\
\text { agement System (AIMS) }\end{array}$ \\
\hline $\begin{array}{l}\text { Knowledge of the alloca- } \\
\text { tion adequately prevent- } \\
\text { ed(ITS)? }\end{array}$ & Low risk & Outcome data from electronic patient record (AIMS) \\
\hline $\begin{array}{l}\text { Incomplete outcome data } \\
\text { addressed (ITS) ? }\end{array}$ & Low risk & \\
\hline $\begin{array}{l}\text { Free of selected reporting } \\
\text { (ITS) ? }\end{array}$ & Low risk & Outcome data from electronic patient record (AIMS) \\
\hline \begin{tabular}{l} 
Free of other bias (ITS) ? \\
\hline
\end{tabular} & High risk & Outcome data from electronic patient record (AIMS) \\
\hline
\end{tabular}

Weinberg 2001

Methods STUDY DESIGN: controlled ITS

\section{Risk of Bias: MEDIUM}

Participants

PROVIDERS: operating theatre teams at participating hospitals

PARTICIPANGS: low-income women needing C-section

CLINICAL PROBLEM: infection after C-section

SETTING: 2 hospitals in Colombia 
Weinberg 2001 (Continued)

Interventions

FORMAT: Interventions: audit and feedback in the form of run charts for the 2 key process measures (secondary outcomes) with data collected and displayed by the clinical teams; dissemination of flow charts with revised system for administration of prophylactic antibiotics

Intervention Functions: education, enablement

DELIVERER: obstetric teams, doctors and nurses

COMPARISON: physician choice about antibiotic and timing

DESIRED CHANGE: reduce infection after C-section

TIMING: before clinical decision making; the intervention was continued for 2 years

\begin{tabular}{ll} 
Outcomes & PRESCRIBING: Choice: percentage of women who received prophylaxis; percentage who received pro- \\
phylaxis within 1 hour & \\
CLINICAL: Intended: SSI rate per 100 C-sections \\
\hline INSTRUCTIONS: action plan provided, specific target but no specified time for target to be achieved \\
FINANCIAL SUPPORT: Funding: International Society for Infectious Diseases, Paul Schliesman Memori- \\
al Traveling Fellowship, and the Von L. Meyer Award. Competing Interests: no information \\
ADDITIONAL DATA: no response from authors to request for additional data
\end{tabular}

\section{Risk of bias}

\begin{tabular}{|c|c|c|}
\hline Bias & Authors' judgement & Support for judgement \\
\hline $\begin{array}{l}\text { Intervention independent } \\
\text { (ITS)? }\end{array}$ & Low risk & Data collection method was the same pre- and postintervention. \\
\hline $\begin{array}{l}\text { Analysed appropriately } \\
\text { (ITS)? }\end{array}$ & Low risk & Done in original paper: segmented regression analysis \\
\hline $\begin{array}{l}\text { Shape of effect pre-speci- } \\
\text { fied (ITS)? }\end{array}$ & Low risk & $\begin{array}{l}\text { Done, intended effect was decrease in primary outcome, and point of analysis } \\
\text { was point of intervention. }\end{array}$ \\
\hline $\begin{array}{l}\text { Unlikely to affect data col- } \\
\text { lection (ITS)? }\end{array}$ & Low risk & Data collection method was the same pre- and postintervention. \\
\hline $\begin{array}{l}\text { Knowledge of the alloca- } \\
\text { tion adequately prevent- } \\
\text { ed(ITS)? }\end{array}$ & Low risk & Prescribing outcome data were from electronic systems. \\
\hline $\begin{array}{l}\text { Incomplete outcome data } \\
\text { addressed (ITS)? }\end{array}$ & Low risk & For prescribing outcome. Not stated whether SSI was evaluated in all patients \\
\hline $\begin{array}{l}\text { Free of selected reporting } \\
\text { (ITS) ? }\end{array}$ & Low risk & For prescribing outcome. Not stated whether SSI was evaluated in all patients \\
\hline Free of other bias (ITS) ? & High risk & $<1$ year of data in each of the 3 study phases \\
\hline
\end{tabular}

Weiner 2009

\begin{tabular}{ll}
\hline Methods & STUDY DESIGN: ITS \\
& Risk of Bias: MEDIUM \\
\hline
\end{tabular}


Weiner 2009 (Continued)

Participants
PROVIDERS: all attending emergency physicans, physician assistants, and emergency nurses

PARTICIPANTS: all patients with community-acquired pneumonia

CLINICAL PROBLEM: time to first antibiotic dose

SETTING: 1 university hospital in the USA

Intervention Functions: enablement, environmental restructuring, persuasion

DELIVERER: departmental nurse administrator

COMPARISON: usual care

DESIRED CHANGE: increase effective

\begin{tabular}{ll}
\hline Outcomes & PRESCRIBING: Choice: mean time to first antibiotic dose (minutes) \\
\hline Notes & FINANCIAL SUPPORT: Funding: none. Competing Interests: none declared \\
& ADDITIONAL DATA: no response from authors to request for additional data
\end{tabular}

\section{Risk of bias}

\begin{tabular}{|c|c|c|}
\hline Bias & Authors' judgement & Support for judgement \\
\hline $\begin{array}{l}\text { Intervention independent } \\
\text { (ITS)? }\end{array}$ & Low risk & \\
\hline $\begin{array}{l}\text { Analysed appropriately } \\
\text { (ITS)? }\end{array}$ & Low risk & $\begin{array}{l}\text { Re-analysed; our analysis questions the authors' conclusion that the interven- } \\
\text { tion was effective. }\end{array}$ \\
\hline $\begin{array}{l}\text { Shape of effect pre-speci- } \\
\text { fied (ITS)? }\end{array}$ & Low risk & Point of analysis was point of intervention. \\
\hline $\begin{array}{l}\text { Unlikely to affect data col- } \\
\text { lection (ITS)? }\end{array}$ & Low risk & TFAD from patient administration system \\
\hline $\begin{array}{l}\text { Knowledge of the alloca- } \\
\text { tion adequately prevent- } \\
\text { ed(ITS)? }\end{array}$ & Low risk & TFAD from patient administration system \\
\hline $\begin{array}{l}\text { Incomplete outcome data } \\
\text { addressed (ITS)? }\end{array}$ & Low risk & $\begin{array}{l}\text { TFAD from patient administration system, outcome reported on all included } \\
\text { patients. }\end{array}$ \\
\hline $\begin{array}{l}\text { Free of selected reporting } \\
\text { (ITS)? }\end{array}$ & Low risk & $\begin{array}{l}\text { "Patients were excluded if the time of antibiotic administration was not doc- } \\
\text { umented in the electronic medical record, if the patient was documented as } \\
\text { having received antibiotics within } 48 \text { hours prior to arrival, or if the patient was } \\
\text { referred from another facility or clinic with a known diagnosis of pneumonia." } \\
\text { Exclusion rate in pre-intervention period }(37 / 281,13 \%) \text { similar to intervention } \\
\text { period }(40 / 342,12 \%) \text {. }\end{array}$ \\
\hline
\end{tabular}

Free of other bias (ITS) ? High risk Only 11 months' data pre- and postintervention

Weiss 2013

Methods STUDY DESIGN: cluster NRT

\section{Risk of Bias: HIGH}


Weiss 2013 (Continued)

Participants
PROVIDERS: all physicians in the ICU

PARTICIPANTS: all patients in the ICU

CLINICAL PROBLEM: receiving antibiotic treatment

SETTING: 1 University hospital in the USA

FORMAT: Intervention: reminder, verbal (on rounds) based on a scrip
to discuss about antibiotics
Intervention Functions: environmental restructuring, persuasion
DELIVERER: departmental physicians
COMPARISON: usual care
DESIRED CHANGE: decrease excessive

Outcomes PRESCRIBING: Choice: duration of empiric antibiotic treatment before narrowing choice, \% patient
days on which empiric antibiotics were used. Exposure: duration of all antibiotic treatment

CLINICAL: Balancing: mortality (total, standardised mortality ratio, and adjusted odds of death), length of hospital stay, length of ICU stay

Notes

FINANCIAL SUPPORT: National Heart, Lung, and Blood Institute (T32HL076139-07) and Parker B. Francis Fellowship to CHW. Dr Weiss has received funding from the National Institutes of Health. Drs Sung and Rho received a travel award to present a research abstract at American Thoracic Society conference in May 2012 from Northwestern University. Dr Wunderink is a board member for Pfizer and has consulted for Crucell (now Johnson \& Johnson), Trius, AstraZeneca, and GlaxoSmithKline. He has received grant support from bioMérieux and payment for lectures from the American Thoracic Society. The remaining authors have not disclosed any potential conflicts of interest.

ADDITIONAL DATA: online supplementary data for this article and further details of intervention in Weiss 2011. No response from authors to request for additional data

\section{Risk of bias}

\begin{tabular}{|c|c|c|}
\hline Bias & Authors' judgement & Support for judgement \\
\hline $\begin{array}{l}\text { Random sequence genera- } \\
\text { tion (selection bias) }\end{array}$ & Low risk & Coin toss to allocate 1 medical team to intervention and 1 to control \\
\hline $\begin{array}{l}\text { Allocation concealment } \\
\text { (selection bias) }\end{array}$ & High risk & No concealment \\
\hline $\begin{array}{l}\text { Blinding (performance } \\
\text { bias and detection bias) } \\
\text { All outcomes }\end{array}$ & High risk & No blinding \\
\hline $\begin{array}{l}\text { Incomplete outcome data } \\
\text { (attrition bias) } \\
\text { All outcomes }\end{array}$ & Low risk & Outcomes reported on all patients. \\
\hline $\begin{array}{l}\text { Selective reporting (re- } \\
\text { porting bias) }\end{array}$ & High risk & $\begin{array}{l}\text { No information about inter-rater reliability of primary outcome measure, } \\
\text { which was not objective: "empirical antibiotics were defined as any antimicro- } \\
\text { bial agent administered without culture-documented infection". }\end{array}$ \\
\hline Other bias & High risk & Unit of analysis error, no adjustment for clustering \\
\hline $\begin{array}{l}\text { Baseline Outcomes simi- } \\
\text { lar? }\end{array}$ & Unclear risk & No data \\
\hline Free of contamination? & High risk & Intervention and control teams worked on the same ICU. \\
\hline
\end{tabular}


Weiss 2013 (Continued)

Baseline characteristics Low risk
similar?

Welker 2008

Methods STUDY DESIGN: unintended consequences, cohort study

\section{Risk of Bias: MEDIUM}

PROVIDERS: all physicians in the ED
PARTICIPANTS: 548 patients with an admission diagnosis of community-acquired pneumonia
CLINICAL PROBLEM: hospital admission diagnosis of community-acquired pneumonia
SETTING: 1 hospital in the USA

\begin{tabular}{ll}
\hline Interventions & FORMAT: Interventions: audit and feedback; financial, institution incentive \\
Intervention Functions: enablement, incentive \\
DELIVERER: departmental physicians (ED) \\
COMPARISON: usual care (before introduction of core quality measure of 4 hours' time to first antibiot- \\
ic dose) \\
DESIRED CHANGE: increase effective
\end{tabular}

\begin{tabular}{ll}
\hline Outcomes & UNINTENDED CONSEQUENCES: accuracy of admission diagnosis, antibiotic-associated adverse drug \\
events
\end{tabular}

Notes ROBINS-I RISK OF BIAS CRITERIA:

1. Confounding: Low, confounding of the effect of intervention unlikely in this study

2. Selection of participants into the study: Low, selection into the study unrelated to intervention or outcome

3. Measurement of interventions: Low, intervention status well defined, recorded at the time of intervention and unaffected by knowledge of the outcome or risk of the outcome

4. Departures from intended interventions: Low, no switches to other interventions or evidence of intervention failure

5. Missing data: Low, outcome data and intervention status complete in all 548 patients

6. Measurement of outcome: High, outcome measures not objective, and investigators were not blinded to intervention status

7. Selection of the reported result: Low, single analysis of prespecified outcomes

FINANCIAL SUPPORT: Funding: commercial: Pfizer, US Pharmaceutical Corporation. Competing Interests: none declared.

ADDITIONAL DATA: no response from authors to request for additional data

Wenisch 2014

\begin{tabular}{ll}
\hline Methods & STUDY DESIGN: ITS \\
& Risk of Bias: LOW \\
\hline Participants & PROVIDERS: all physicians in the hospital \\
& PARTICIPANTS: all patients in the hospital \\
\hline
\end{tabular}


Wenisch 2014 (Continued)

CLINICAL PROBLEM: patients receiving moxifloxacin

SETTING: 1 university hospital in Austria

\begin{tabular}{ll}
\hline Interventions & FORMAT: Intervention: educational meetings; restrion \\
& Intervention Functions: education, restriction \\
DELIVERER: AMT \\
COMPARISON: usual care \\
DESIRED CHANGE: decrease excessive
\end{tabular}

Outcomes PRESCRIBING: Choice: use of moxifloxacin in DDD

Notes FINANCIAL SUPPORT: no information

ADDITIONAL DATA: no response from authors to request for additional data

Microbial Risk of Bias: Low for case definition, planned intervention, and other infection control

\section{Risk of bias}

\begin{tabular}{|c|c|c|}
\hline Bias & Authors' judgement & Support for judgement \\
\hline $\begin{array}{l}\text { Intervention independent } \\
\text { (ITS)? }\end{array}$ & Low risk & \\
\hline $\begin{array}{l}\text { Analysed appropriately } \\
\text { (ITS)? }\end{array}$ & Low risk & Re-analysed \\
\hline $\begin{array}{l}\text { Shape of effect pre-speci- } \\
\text { fied (ITS)? }\end{array}$ & Low risk & Point of intervention was point of analysis. \\
\hline $\begin{array}{l}\text { Unlikely to affect data col- } \\
\text { lection (ITS)? }\end{array}$ & Low risk & Data from pharmacy and microbiology computers \\
\hline $\begin{array}{l}\text { Knowledge of the alloca- } \\
\text { tion adequately prevent- } \\
\text { ed(ITS)? }\end{array}$ & Low risk & Data from pharmacy and microbiology computers \\
\hline $\begin{array}{l}\text { Incomplete outcome data } \\
\text { addressed (ITS)? }\end{array}$ & Low risk & Data from pharmacy and microbiology computers \\
\hline $\begin{array}{l}\text { Free of selected reporting } \\
\text { (ITS)? }\end{array}$ & Low risk & Data from pharmacy and microbiology computers \\
\hline \multirow[t]{2}{*}{ Free of other bias (ITS) ? } & High risk & $\begin{array}{l}<12 \text { months' data in the pre-intervention ( } 5 \text { months) and postintervention ( } 7 \\
\text { months) phases }\end{array}$ \\
\hline & & $\begin{array}{l}\text { Microbial Risk of Bias LOW: case definition Low, planned intervention Low, } \\
\text { other infection control Low }\end{array}$ \\
\hline
\end{tabular}

Willemsen 2010

\begin{tabular}{ll}
\hline Methods & STUDY DESIGN: ITS \\
& Risk of Bias: LOW
\end{tabular}

Participants

PROVIDERS: all physicians in the hospital 
Willemsen 2010 (Continued)

PARTICIPANTS: all patients receiving therapeutic antibiotics

CLINICAL PROBLEM: decrease use of ciprofloxacin

SETTING: 1 hospital in the Netherlands

Interventions

FORMAT: Interventions: educational meetings with dissemination of guidelines; educational outreach by review and recommend change; reminders (physical, newsletter and on all microbiology reports saying that ciprofloxacin should be prescribed on strict indications only)

Intervention Functions: education, enablement, environmental restructuring, persuasion

DELIVERER: AMT

COMPARISON: usual care

DESIRED CHANGE: decrease excessive

\section{Outcomes}

PRESCRIBING: Choice: prescribed daily doses of ciprofloxacin (IV and oral)

MICROBIAL: \% quionolone-resistant gram-negative clinical isolates

Notes $\quad$ FINANCIAL SUPPORT: Funding: Amphia Hospital, Breda/Oosterhout, Netherlands. Competing Interests: none declared

ADDITIONAL DATA: no response from authors to request for additional data

Microbial Risk of Bias: LOW Case definition infection with quionolone-resistant gram-negative bacteria, Planned intervention Low, Other infection control Low, no changes (information in Discussion)

\section{Risk of bias}

\begin{tabular}{|c|c|}
\hline Bias & Authors' judgement Support for judgement \\
\hline $\begin{array}{l}\text { Intervention independent } \\
\text { (ITS)? }\end{array}$ & Low risk \\
\hline
\end{tabular}

\begin{tabular}{l}
$\begin{array}{l}\text { Analysed appropriately } \\
\text { (ITS) ? }\end{array}$ \\
\hline
\end{tabular}

Shape of effect pre-speci- Low risk Point of intervention was point of analysis.

fied (ITS) ?

Unlikely to affect data col- Low risk Outcomes from pharmacy and microbiology computers lection (ITS) ?

Knowledge of the alloca- Low risk Outcomes from pharmacy and microbiology computers
tion adequately prevented(ITS)?

Incomplete outcome data Low risk Outcomes from pharmacy and microbiology computers
addressed (ITS) ?

Free of selected reporting Low risk Outcomes from pharmacy and microbiology computers
(ITS) ?

Free of other bias (ITS)? Low risk 1 year data pre- and postintervention

Wilson 1991

$\begin{array}{ll}\text { Methods } & \text { STUDY DESIGN: ITS } \\ & \text { Risk of Bias: MEDIUM }\end{array}$


Wilson 1991 (Continued)

Participants

PROVIDERS: all physicians in the hospital

PARTICIPANTS: all patients in the hospital

CLINICAL PROBLEM: patients receiving amoxicillin or pivampicillin

SETTING: 3 hospitals in the UK

Interventions
Intervention Function: education
DELIVERER: pharmacists
COMPARISON: 5 months before introduction of the newsletter
DESIRED CHANGE: reduce excessive

Outcomes PRESCRIBING: Choice: use of amoxicillin and pivampicillin

Notes FINANCIAL SUPPORT: no information

ADDITIONAL DATA: no response from authors to request for additional data

\section{Risk of bias}

\begin{tabular}{lll}
\hline Bias & Authors' judgement & Support for judgement \\
\hline $\begin{array}{l}\text { Intervention independent } \\
\text { (ITS) ? }\end{array}$ & Unclear risk & $\begin{array}{l}\text { Only } 5 \text { months' pre-intervention data. Even with 26 months' postintervention } \\
\text { data, could still be secular changes. }\end{array}$ \\
\hline $\begin{array}{l}\text { Analysed appropriately } \\
\text { (ITS)? }\end{array}$ & Low risk & Re-analysed. Not done in original paper: run chart with no statistical analysis. \\
\hline $\begin{array}{l}\text { Shape of effect pre-speci- } \\
\text { fied (ITS) ? }\end{array}$ & Low risk & $\begin{array}{l}\text { Done, intended effect was decrease in primary outcome, and point of analysis } \\
\text { was point of intervention. }\end{array}$ \\
\hline $\begin{array}{l}\text { Unlikely to affect data col- } \\
\text { lection (ITS) ? }\end{array}$ & Low risk & $\begin{array}{l}\text { Done, data were from routine systems and unlikely to change over study peri- } \\
\text { od. }\end{array}$ \\
\hline $\begin{array}{l}\text { Knowledge of the alloca- } \\
\text { tion adequately prevent- } \\
\text { ed(ITS)? }\end{array}$ & Low risk & $\begin{array}{l}\text { Done, data were from routine systems and unlikely to change over study peri- } \\
\text { od. }\end{array}$ \\
\hline $\begin{array}{l}\text { Incomplete outcome data } \\
\text { addressed (ITS) ? }\end{array}$ & Low risk & $\begin{array}{l}\text { Done, data were from routine systems and unlikely to change over study peri- } \\
\text { od. }\end{array}$ \\
\hline $\begin{array}{l}\text { Free of selected reporting } \\
\text { (ITS) ? }\end{array}$ & Low risk & $\begin{array}{l}\text { Done, data were from routine systems and unlikely to change over study peri- } \\
\text { od. }\end{array}$ \\
\hline \begin{tabular}{l} 
Free of other bias (ITS) ? \\
\hline
\end{tabular} & Low risk & \begin{tabular}{l} 
No other apparent biases found. \\
\hline
\end{tabular}
\end{tabular}

Winters 2010

\begin{tabular}{ll}
\hline Methods & STUDY DESIGN: unintended consequences, cohort study \\
& Risk of Bias: LOW
\end{tabular}

\section{Risk of Bias: LOW}

Participants

PROVIDERS: all physicians in the hospital

PARTICIPANTS: 3251 patients receiving antibiotics

CLINICAL PROBLEM: time to first antibiotic dose 
Winters 2010 (Continued)

SETTING: 1 hospital in the USA

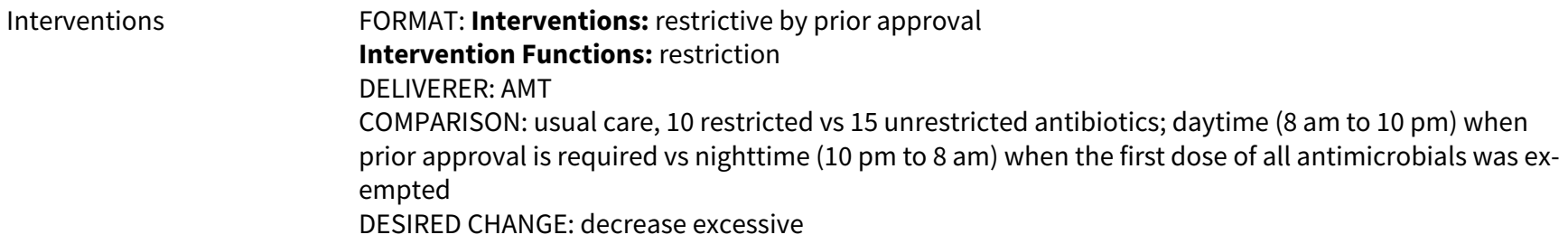

1. Confounding: Low, confounding of the effect of intervention unlikely in this study

2. Selection of participants into the study: Low, selection into the study unrelated to intervention or outcome

3. Measurement of interventions: Low, intervention status well defined, recorded at the time of intervention and unaffected by knowledge of the outcome or risk of the outcome

4. Departures from intended interventions: Low, no switches to other interventions or evidence of intervention failure

5. Missing data: Low, outcome data and intervention status complete in all 3251 patients

6. Measurement of outcome: Low, outcome measures objective and ascertained from patient administration system

7. Selection of the reported result: Low, single analysis of prespecified outcomes

FINANCIAL SUPPORT: no information

ADDITIONAL DATA: no response from authors to request for additional data

\section{Wishaupt 2011}

\begin{tabular}{ll}
\hline Methods & STUDY DESIGN: NRT \\
& Risk of Bias: HIGH \\
\hline Participants & PROVIDERS: all physicians in the hospital \\
& PARTICIPANTS: 614 children $<12$ years old $(309$ intervention, 305 control) \\
CLINICAL PROBLEM: acute respiratory infections (NB only $2 / 3$ of randomised patients admitted to hos- \\
pital) \\
SETTING: 1 hospital in the Netherlands
\end{tabular}

Interventions $\quad$ FORMAT: Intervention: structural, rapid reporting of microbiology results

Intervention Function: environmental restructuring

DELIVERER: specialist physician (Microbiology)

COMPARISON: usual care

DESIRED CHANGE: decrease excessive

Outcomes

PRESCRIBING: Exposure: \% treated with antibiotics and duration if treated

CLINICAL: Intended: length of stay 
Wishaupt 2011 (Continued)

Notes
FINANCIAL SUPPORT:Funding: Research Activity Committee of the Reinier de Graaf Hospital (project 620604). Competing Interests: no information

ADDITIONAL DATA: email response and additional files (protocol) from authors

\section{Risk of bias}

\begin{tabular}{|c|c|c|}
\hline Bias & Authors' judgement & Support for judgement \\
\hline $\begin{array}{l}\text { Random sequence genera- } \\
\text { tion (selection bias) }\end{array}$ & Low risk & By lab number \\
\hline $\begin{array}{l}\text { Allocation concealment } \\
\text { (selection bias) }\end{array}$ & High risk & Not concealed \\
\hline $\begin{array}{l}\text { Blinding (performance } \\
\text { bias and detection bias) } \\
\text { All outcomes }\end{array}$ & High risk & No blinding \\
\hline $\begin{array}{l}\text { Incomplete outcome data } \\
\text { (attrition bias) } \\
\text { All outcomes }\end{array}$ & Low risk & States missing information was retrieved from records \\
\hline $\begin{array}{l}\text { Selective reporting (re- } \\
\text { porting bias) }\end{array}$ & Low risk & Outcomes on all patients \\
\hline Other bias & Low risk & \\
\hline $\begin{array}{l}\text { Baseline Outcomes simi- } \\
\text { lar? }\end{array}$ & Unclear risk & No information \\
\hline Free of contamination? & Low risk & Rapid reporting for intervention only \\
\hline $\begin{array}{l}\text { Baseline characteristics } \\
\text { similar? }\end{array}$ & Low risk & Table 1 \\
\hline
\end{tabular}

Woodward 1987

\begin{tabular}{ll}
\hline Methods & STUDY DESIGN: ITS \\
& Risk of Bias: MEDIUM \\
\hline Participants & PROVIDERS: all physicians in the hospital \\
& PARTICIPANTS: all patients in the hospital \\
& CLINICAL PROBLEM: inpatient prescribing of all antibiotics \\
& SETTING: 1 hospital in the USA \\
\hline Interventions & FORMAT: Interventions: educational meetings; restrictive by expert approval, automatic stop order af- \\
& ter 72 hours' treatment, and by removal from formulary \\
& Intervention Functions: education, restriction \\
& DELIVERER: specialist physician (ID) \\
& DESIRED CHANGE: decrease excessive
\end{tabular}


Woodward 1987 (Continued)

Notes

FINANCIAL SUPPORT: Funding: administration of Barnes Hospital. Competing Interests: no information

ADDITIONAL DATA: no response from authors to request for additional data

\section{Risk of bias}

\begin{tabular}{|c|c|c|}
\hline Bias & Authors' judgement & Support for judgement \\
\hline $\begin{array}{l}\text { Intervention independent } \\
\text { (ITS)? }\end{array}$ & Low risk & 25 months' pre- and 17 months' postintervention data \\
\hline $\begin{array}{l}\text { Analysed appropriately } \\
\text { (ITS) ? }\end{array}$ & Low risk & $\begin{array}{l}\text { Done in original paper: ordinary least squares regression analysis adjusting for } \\
\text { pre-existing time trends, re-analysis with segmented regression performed for } \\
\text { the purposes of comparison of effect size with other studies in the review. }\end{array}$ \\
\hline $\begin{array}{l}\text { Shape of effect pre-speci- } \\
\text { fied (ITS)? }\end{array}$ & Low risk & $\begin{array}{l}\text { Done, intended effect was decrease in primary outcome, and point of analysis } \\
\text { was point of intervention. }\end{array}$ \\
\hline $\begin{array}{l}\text { Unlikely to affect data col- } \\
\text { lection (ITS)? }\end{array}$ & Low risk & $\begin{array}{l}\text { Done, data were from routine systems and unlikely to change over study peri- } \\
\text { od. }\end{array}$ \\
\hline $\begin{array}{l}\text { Knowledge of the alloca- } \\
\text { tion adequately prevent- } \\
\text { ed(ITS)? }\end{array}$ & Low risk & $\begin{array}{l}\text { Done, data were from routine systems and unlikely to change over study peri- } \\
\text { od. }\end{array}$ \\
\hline $\begin{array}{l}\text { Incomplete outcome data } \\
\text { addressed (ITS)? }\end{array}$ & Low risk & $\begin{array}{l}\text { Done, data were from routine systems and unlikely to change over study peri- } \\
\text { od. }\end{array}$ \\
\hline $\begin{array}{l}\text { Free of selected reporting } \\
\text { (ITS)? }\end{array}$ & Low risk & $\begin{array}{l}\text { Done, data were from routine systems and unlikely to change over study peri- } \\
\text { od. }\end{array}$ \\
\hline Free of other bias (ITS)? & Unclear risk & $\begin{array}{l}\text { The abstract states: "Even after some cost increases (not significant) in new } \\
\text { and other antibiotics, the program saved } \$ 1.33 \text { per antibiotic day", but it is not } \\
\text { clear whether the analysis was adjusted for changes in the price of antibiotics } \\
\text { during the } 3 \frac{12 / 2 \text {-year study period. }}{}\end{array}$ \\
\hline
\end{tabular}

Wyatt 1998

Methods STUDY DESIGN: cluster RCT, hospital level

\section{Risk of Bias: MEDIUM}

\section{Participants}

PROVIDERS: a total of 25 hospitals, 13 control and 12 intervention, targeting 2 providers (lead obstetrician and senior midwife manager) in each hospital

PARTICIPANTS: 1318 episodes of care in 1318 patients, 25 clusters (hospitals)

CLINICAL PROBLEM: administration of prophylactic antibiotics to women undergoing Caesarean sec-

tion. The intervention also targeted 3 other care processes.

SETTING: 25 district general (non-teaching) hospitals

POWER CALCULATION: As only 25 obstetric units were available for randomisation, and accurate baseline figures for the rates and variability of the 4 marker clinical practices were not available, sample size calculation was not carried out. 
Wyatt 1998 (Continued)

DESIRED CHANGE: increase effective

Outcomes PRESCRIBING: Exposure: \% women that received antibiotic prophylaxis

Notes

FINANCIAL SUPPORT: Funding: regional research implementation initiatives of the North Thames and

South Thames regional health authorities; the Imperial Cancer Research Fund; and North Staffordshire

Hospital Trust. Competing Interests: none declared

ADDITIONAL DATA: no response from authors to request for additional data

\section{Risk of bias}

\begin{tabular}{lll}
\hline Bias & Authors' judgement & Support for judgement \\
\hline $\begin{array}{l}\text { Random sequence genera- } \\
\text { tion (selection bias) }\end{array}$ & Low risk & $\begin{array}{l}\text { Obstetric units were allocated to intervention or control group by the toss of a } \\
\text { coin. }\end{array}$ \\
\hline $\begin{array}{l}\text { Allocation concealment } \\
\text { (selection bias) }\end{array}$ & Low risk & $\begin{array}{l}\text { To eliminate bias during data collection at follow-up by a second research } \\
\text { midwife, and to allow blinded assessment of guideline quality, the allocation } \\
\text { was concealed from everyone except JCW, DGA, RJ, and the first research mid- } \\
\text { wife. }\end{array}$ \\
\hline $\begin{array}{l}\text { Blinding (performance } \\
\text { bias and detection bias) } \\
\text { All outcomes }\end{array}$ & Low risk & $\begin{array}{l}\text { To eliminate bias during data collection at follow-up by a second research } \\
\text { midwife, and to allow blinded assessment of guideline quality, the allocation } \\
\text { was concealed from everyone except JCW, DGA, RJ, and the first research mid- } \\
\text { wife. }\end{array}$ \\
\hline
\end{tabular}

$\begin{array}{ll}\begin{array}{l}\text { Incomplete outcome data } \\ \text { (attrition bias) }\end{array} & \text { Low risk } \\ \begin{array}{ll}\text { All outcomes } & \text { "No unit was excluded after randomisation, all intervention units participated } \\ & \text { in the visits, and data on clinical practices were available for all units, although } \\ \text { smaller numbers of case notes were obtainable than planned for steroid us- } \\ \text { age" }\end{array}\end{array}$

Selective reporting (re- Low risk $\quad$ See above
porting bias)

porting bias)

Other bias Low risk
"To reduce the impact of ceiling effects, the proportion of cases in which clin- icians failed to carry out each clinical practice was recorded for each obstet- ric unit at baseline and follow up, and then baseline to follow up ratios were computed to yield the risk ratio for failure to implement each practice in each unit."

\begin{tabular}{lll}
\hline $\begin{array}{l}\text { Baseline Outcomes simi- } \\
\text { lar? }\end{array}$ & Unclear risk & $\begin{array}{l}\text { "Accurate baseline figures for the rates and variability of the four marker clini- } \\
\text { cal practices were not available" }\end{array}$ \\
\hline Free of contamination? & Low risk & Randomisation by units that were located in different hospitals \\
\hline $\begin{array}{l}\text { Baseline characteristics } \\
\text { similar? }\end{array}$ & Low risk & $\begin{array}{l}\text { "Despite randomisation there were baseline differences in two of the four clin- } \\
\text { ical practices" (use of ventouse and use of polyglycolic acid sutures). "There } \\
\text { were no other baseline differences." (includes antibiotic prophylaxis) }\end{array}$ \\
\hline
\end{tabular}

Yealy 2005

\begin{tabular}{ll}
\hline Methods & STUDY DESIGN: cluster RCT, hospital level \\
& Risk of Bias: MEDIUM \\
\hline Participants & PROVIDERS: all physicians in the ED \\
\hline
\end{tabular}


Yealy 2005 (Continued)

PARTICIPANTS: 2075 patients admitted from ED (849 intervention, 1227 control), 32 clusters (EDs)

CLINICAL PROBLEM: community-acquired pneumonia

SETTING: 32 EDs in the USA

Interventions

FORMAT: low-intensity (control, 8 hospitals); moderate-intensity (12 hospitals); and high-intensity (12 hospitals) interventions

Low-intensity intervention: audit and feedback of baseline data; dissemination of guidelines

Low-intensity invervention functions: education, enablement

Moderate-intensity intervention: same as low intensity, but with additional on-site educational meeting before patient enrolment

Moderate-intensity intervention additional function: education

High-intensity intervention: same as moderate with additional audit and feedback of data about management of individual patients within a week of enrolment plus 2 monthly feedback of group performance data; educational outreach through academic detailing with Plan Do Study Act cycles to discuss actions to be taken in response to group performance data

High-intensity intervention additional functions: education, enablement, persuasion

DELIVERER: departmental physicians

COMPARISON: usual care

DESIRED CHANGE: increase effective: 4 process measures including time to first antibiotic dose

POWER CALCULATION: Primary outcome was site of treatment rather than the antibiotic process measures. "We estimated that we would need 96 eligible patients per hospital (3072 in total) to achieve $80 \%$ power to detect a $12 \%$ difference across the intervention groups for the site-of-treatment decision among low-risk patients."

"For the site-of-treatment decision, this study achieved greater than $80 \%$ power to detect differences of $10 \%$ between high-intensity and moderate-intensity groups and differences of $12 \%$ between high-intensity and low-intensity groups according to separate 1-tailed tests in which the level was $0.025 . "$

Outcomes

PRESCRIBING: Choice: time to first antibiotic dose and choice compliant with guideline

CLINICAL: Intended: mortality and medical complications

Notes INSTRUCTIONS: action plan provided, no explicit target

FINANCIAL SUPPORT: Funding: Agency for Healthcare Research and Quality (grant number R01 HS10049). National Institute of Allergy and Infectious Diseases (grant number K24 Al001769). Competing Interests: 1 author received consultancies, honoraria or grants from Genesoft Pharmaceuticals, Zynx Health Corporation, Healthcare Communications Inc., Stephen Lynn Klein, Kellogg Grants, and Pfizer Inc.

ADDITIONAL DATA: email response from authors to request for additional data with care pathway, slide sets, order sheets, and protocol (Yealy 2004)

\section{Risk of bias}

\begin{tabular}{lll} 
Bias & Authors' judgement & Support for judgement \\
\hline $\begin{array}{ll}\text { Random sequence genera- } \\
\text { tion (selection bias) }\end{array}$ & Low risk & "After stratifying emergency departments by state, teaching status, and annu- \\
& & $\begin{array}{l}\text { al volume, our statistician randomly assigned these departments to low-inten- } \\
\text { sity, moderate-intensity, and high-intensity guideline implementation strate- } \\
\text { gies in the ratio of 2:3:3, respectively" }\end{array}$
\end{tabular}


Yealy 2005 (Continued)

Allocation concealment Low risk
(selection bias)

\begin{tabular}{|c|c|c|}
\hline $\begin{array}{l}\text { Blinding (performance } \\
\text { bias and detection bias) } \\
\text { All outcomes }\end{array}$ & High risk & Not blinded \\
\hline $\begin{array}{l}\text { Incomplete outcome data } \\
\text { (attrition bias) } \\
\text { All outcomes }\end{array}$ & Low risk & Incomplete chart review on only $19(0.6 \%)$ of 3219 patients \\
\hline $\begin{array}{l}\text { Selective reporting (re- } \\
\text { porting bias) }\end{array}$ & Low risk & \\
\hline Other bias & Low risk & $\begin{array}{l}\text { "The target sample size included an adjustment of } 30 \% \text { to account for the clus- } \\
\text { tering of patients within providers." }\end{array}$ \\
\hline $\begin{array}{l}\text { Baseline Outcomes simi- } \\
\text { lar? }\end{array}$ & Unclear risk & No data \\
\hline Free of contamination? & Low risk & Cluster RCT \\
\hline $\begin{array}{l}\text { Baseline characteristics } \\
\text { similar? }\end{array}$ & Low risk & $\begin{array}{l}\text { Demographic characteristics differed between eligible patients who were and } \\
\text { were not enrolled. Moreover, authors observed some imbalances in levels of } \\
\text { illness severity across the intervention groups; however, their analyses of the } \\
\text { site of treatment were performed separately for low-risk and higher-risk pa- } \\
\text { tients, and their multivariable analyses were not sensitive to the few imbal- } \\
\text { ances that were observed at baseline. }\end{array}$ \\
\hline
\end{tabular}

Yeo 2012

\begin{tabular}{ll}
\hline Methods & STUDY DESIGN: CITS \\
& Risk of Bias: LOW \\
\hline Participants & PROVIDERS: all physicians \\
& PARTICIPANTS: all patients receiving therapeutic antibiotics \\
& CLINICAL PROBLEM: use of all carbapenems (ertapenem, imipenem, and meropenem), 3rd- and 4th- \\
comycin & SETTING: 1 cancer hospital in Singapore
\end{tabular}

Interventions $\quad$ FORMAT: Interventions: audit and feedback; educational outreach by review and recommend change Intervention Functions: enablement, persuasion

DELIVERER: AMT

COMPARISON: usual care

DESIRED CHANGE: decrease excessive

Outcomes $\quad$ PRESCRIBING: Choice: use of target antibiotics in DDD/1000 OBD
\begin{tabular}{ll}
\hline Notes & FINANCIAL SUPPORT: Funding: none. Competing Interests: 1 author received research funding and \\
speaker's honoraria from Pfizer, AstraZeneca, Janssen-Cilag, and Merck Sharp \& Dohme.
\end{tabular}

ADDITIONAL DATA: no response from authors to request for additional data

\section{Risk of bias}


Yeo 2012 (Continued)

\begin{tabular}{|c|c|c|}
\hline Bias & Authors' judgement & Support for judgement \\
\hline $\begin{array}{l}\text { Intervention independent } \\
\text { (ITS) ? }\end{array}$ & Low risk & \\
\hline $\begin{array}{l}\text { Analysed appropriately } \\
\text { (ITS)? }\end{array}$ & Low risk & Segmented regression analysis \\
\hline $\begin{array}{l}\text { Shape of effect pre-speci- } \\
\text { fied (ITS) ? }\end{array}$ & Low risk & Point of intervention was point of analysis. \\
\hline $\begin{array}{l}\text { Unlikely to affect data col- } \\
\text { lection (ITS)? }\end{array}$ & Low risk & Prescribing outcome in DDD from pharmacy computer \\
\hline $\begin{array}{l}\text { Knowledge of the alloca- } \\
\text { tion adequately prevent- } \\
\text { ed(ITS)? }\end{array}$ & Low risk & Prescribing outcome in DDD from pharmacy computer \\
\hline $\begin{array}{l}\text { Incomplete outcome data } \\
\text { addressed (ITS)? }\end{array}$ & Low risk & Prescribing outcome in DDD from pharmacy computer \\
\hline $\begin{array}{l}\text { Free of selected reporting } \\
\text { (ITS) ? }\end{array}$ & Low risk & Prescribing outcome in DDD from pharmacy computer \\
\hline Free of other bias (ITS)? & Low risk & $\begin{array}{l}\text { Same } 11 \text { months of data (Aug-Jun) in consecutive years pre- and postinterven- } \\
\text { tion }\end{array}$ \\
\hline
\end{tabular}

Yong 2010

Methods

STUDY DESIGN: ITS

\section{Risk of Bias: MEDIUM}

PROVIDERS: all physicians in the hospital
PARTICIPANTS: all patients receiving therapeutic antibiotics
CLINICAL PROBLEM: use of broad-spectrum antibiotics (3rd- and 4th-generation cephalosporins,
aminoglycosides, antipseudomonal penicillins, carbapenems, fluoroquinolones)
SETTING: 1 hospital in Australia

$\begin{array}{ll}\text { Interventions } & \text { FORMAT: Interventions: structural, computerised decision support system } \\ \text { Intervention Functions: enablement, environmental restructuring, persuasion } \\ \text { DELIVERER: AMT } \\ \text { COMPARISON: usual care } \\ \text { DESIRED CHANGE: decrease excessive }\end{array}$

Outcomes PRESCRIBING: Choice: use of broad-spectrum antibiotics in DDD/1000 OBD

Notes FINANCIAL SUPPORT: Funding: Victorian Department of Human Services Quality Branch and Australian Commonwealth Biotechnology Information Fund, which funded the development of Guidance DS.

Competing Interests: none declared

ADDITIONAL DATA: email from authors with additional data about intervention (Richards 2003; Thursky 2006)

Microbial Risk of Bias: MEDIUM (Other infection control High) 
Yong 2010 (Continued)

Risk of bias

\begin{tabular}{|c|c|c|}
\hline Bias & Authors' judgement & Support for judgement \\
\hline $\begin{array}{l}\text { Intervention independent } \\
\text { (ITS)? }\end{array}$ & High risk & $\begin{array}{l}\text { Acinetobacter outbreak during intervention period resulting in hand hygiene } \\
\text { and staff education interventions. Also see Table } 4 \text {. }\end{array}$ \\
\hline $\begin{array}{l}\text { Analysed appropriately } \\
\text { (ITS)? }\end{array}$ & Low risk & Segmented regression analysis \\
\hline $\begin{array}{l}\text { Shape of effect pre-speci- } \\
\text { fied (ITS)? }\end{array}$ & Low risk & Point of analysis was point of intervention. \\
\hline $\begin{array}{l}\text { Unlikely to affect data col- } \\
\text { lection (ITS)? }\end{array}$ & Low risk & Data from pharmacy and microbiology computers \\
\hline $\begin{array}{l}\text { Knowledge of the alloca- } \\
\text { tion adequately prevent- } \\
\text { ed(ITS)? }\end{array}$ & Low risk & Data from pharmacy and microbiology computers \\
\hline $\begin{array}{l}\text { Incomplete outcome data } \\
\text { addressed (ITS)? }\end{array}$ & Low risk & Data from pharmacy and microbiology computers \\
\hline $\begin{array}{l}\text { Free of selected reporting } \\
\text { (ITS)? }\end{array}$ & Low risk & Data from pharmacy and microbiology computers \\
\hline \multirow[t]{2}{*}{ Free of other bias (ITS) ? } & Low risk & $>1$ year data pre- and postintervention, so low risk for prescribing outcome \\
\hline & & $\begin{array}{l}\text { Microbial Risk of Bias: MEDIUM Case definition Low, \% susceptibility of } \\
\text { Pseudomonas isolates, Planned intervention Low for outcome (outbreak was } \\
\text { of Acinetobacter), Other infection control High, enhanced during prescribing } \\
\text { intervention }\end{array}$ \\
\hline
\end{tabular}

Yoon 2014

\begin{tabular}{ll}
\hline Methods & STUDY DESIGN: ITS \\
& Risk of Bias: MEDIUM \\
\hline Participants & PROVIDERS: all physicians in the hospital \\
& PARTICIPANTS: all patients in the hospital \\
CLINICAL PROBLEM: requiring therapeutic antibiotics and receiving carbapenems \\
SETTING: 1 university hospital in Korea, same hospital as Kim 2008
\end{tabular}

Interventions

FORMAT: Intervention 1: restrictive by expert approval (same intervention format as Kim 2008)

Intervention 1 functions: restriction

Intervention 2: addition of reminders (circumstantial, electronic triggered by computerised antibiotic order, the system is described in more detail in Kim 2008)

Intervention 2 functions: enablement, environmental restructuring, persuasion

DELIVERER: AMT

COMPARISON: usual care

DESIRED CHANGE: decrease excessive

Outcomes $\quad$ PRESCRIBING: Choice: use of carbapenems in DDD/1000 OBD 
Yoon 2014 (Continued)

MICROBIAL: infections with CRAB (carbapenem-resistant Acinetobacter baumanii)/1000 OBD

CLINICAL: Balancing measures of adverse effects, all-cause mortality

Notes $\quad$ FINANCIAL SUPPORT: Funding: commercial, Merck Sharp \& Dohme. Competing Interests: supported
by Merck Sharp \& Dohme Corp.

ADDITIONAL DATA: no response from authors to request for additional data

Microbial Risk of Bias: HIGH case definition Low, planned intervention Low, other infection control High, ICU cleaning intervention during Phase 3

\section{Risk of bias}

\begin{tabular}{lll}
\hline Bias & Authors' judgement & Support for judgement \\
\hline $\begin{array}{l}\text { Intervention independent } \\
\text { (ITS) ? }\end{array}$ & High risk & $\begin{array}{l}\text { Intensive environmental cleaning implemented in 2012 in ICU, which was in- } \\
\text { tended to reduce infections with CRAB (microbial outcome) }\end{array}$ \\
\hline $\begin{array}{l}\text { Analysed appropriately } \\
\text { (ITS) ? }\end{array}$ & Low risk & Segmented regression analysis \\
\hline $\begin{array}{l}\text { Shape of effect pre-speci- } \\
\text { fied (ITS) ? }\end{array}$ & Low risk & Point of intervention was point of analysis. \\
\hline $\begin{array}{l}\text { Unlikely to affect data col- } \\
\text { lection (ITS) ? }\end{array}$ & Low risk & Data from pharmacy and microbiology computers \\
\hline $\begin{array}{l}\text { Knowledge of the alloca- } \\
\text { tion adequately prevent- } \\
\text { ed(ITS)? }\end{array}$ & Low risk & Data from pharmacy and microbiology computers \\
\hline $\begin{array}{l}\text { Incomplete outcome data } \\
\text { addressed (ITS) ? }\end{array}$ & Low risk & \\
\hline $\begin{array}{l}\text { Free of selected reporting } \\
\text { (ITS) ? }\end{array}$ & Low risk & Data from pharmacy and microbiology computers \\
\hline \begin{tabular}{l} 
Free of other bias (ITS) ? \\
\hline
\end{tabular} & Low risk & Data from pharmacy and microbiology computers \\
\hline
\end{tabular}

Young 1985

\begin{tabular}{ll}
\hline Methods & STUDY DESIGN: ITS \\
& Risk of Bias: MEDIUM \\
\hline Participants & PROVIDERS: all physicians in the hospital \\
& PARTICIPANTS: all patients in the hospital \\
CLINICAL PROBLEM: patients requiring aminoglycoside antibiotic treatment \\
SETTING: 1 hospital in the USA
\end{tabular}

Interventions

FORMAT: Interventions: restrictive by review and make change (substitution of amikacin for gentamicin) and expert approval from the Infectious Diseases Division

Intervention Function: restriction

DELIVERER: pharmacist

DESIRED CHANGE: decrease excessive 
Young 1985 (Continued)

Outcomes PRESCRIBING: Choice: gentamicin usage as a percentage of total aminoglycoside usage

FINANCIAL SUPPORT: Funding: Veterans Adminstration and Bristol-Myers Squibb. Competing Inter-
ests: none declared, but Bristol-Myers Squibb was the manufacturer of amikacin
ADDITIONAL DATA: no response from authors to request for additional data

\section{Risk of bias}

\begin{tabular}{lll}
\hline Bias & Authors' judgement & Support for judgement \\
\hline $\begin{array}{l}\text { Intervention independent } \\
\text { (ITS) }\end{array}$ & Unclear risk & $\begin{array}{l}\text { 3 months' data before, 15 months' during, and 22 months' after the restriction. } \\
\text { Not enough data to adjust for seasonal variation. }\end{array}$ \\
\hline $\begin{array}{l}\text { Analysed appropriately } \\
\text { (ITS)? }\end{array}$ & Low risk & $\begin{array}{l}\text { Re-analysed. Not done in original paper: comparison of means (uncontrolled } \\
\text { before-after). }\end{array}$ \\
\hline $\begin{array}{l}\text { Shape of effect pre-speci- } \\
\text { fied (ITS)? }\end{array}$ & Low risk & $\begin{array}{l}\text { Done, intended effect was decrease in primary outcome, and point of analysis } \\
\text { was point of intervention. }\end{array}$ \\
\hline $\begin{array}{l}\text { Unlikely to affect data col- } \\
\text { lection (ITS)? }\end{array}$ & Low risk & $\begin{array}{l}\text { Done, data were from routine systems and unlikely to change over study peri- } \\
\text { od. }\end{array}$ \\
\hline $\begin{array}{l}\text { Knowledge of the alloca- } \\
\text { tion adequately prevent- } \\
\text { ed(ITS)? }\end{array}$ & Low risk & $\begin{array}{l}\text { Done, data were from routine systems and unlikely to change over study peri- } \\
\text { od. }\end{array}$ \\
\hline $\begin{array}{l}\text { Incomplete outcome data } \\
\text { addressed (ITS) ? }\end{array}$ & Low risk & $\begin{array}{l}\text { Done, data were from routine systems and unlikely to change over study peri- } \\
\text { od. }\end{array}$ \\
\hline $\begin{array}{l}\text { Free of selected reporting } \\
\text { (ITS) ? }\end{array}$ & Low risk & $\begin{array}{l}\text { Done, data were from routine systems and unlikely to change over study peri- } \\
\text { od. }\end{array}$ \\
\hline \begin{tabular}{l} 
Free of other bias (ITS) ? \\
\hline
\end{tabular} & Low risk & \begin{tabular}{l} 
No other apparent biases found. \\
\hline
\end{tabular}
\end{tabular}

Yu 2014

\begin{tabular}{ll}
\hline Methods & STUDY DESIGN: CBA \\
& Risk of Bias: HIGH \\
\hline Participants & PROVIDERS: all physicians \\
& PARTICIPANTS: all patients \\
CLINICAL PROBLEM: patients receiving therapeutic antibiotics \\
SETTING: 5 hospitals in an integrated healthcare system in the USA
\end{tabular}

Interventions FORMAT: Intervention: educational outreach through review and recommend change in 2 hospitals

Intervention Functions: enablement, persuasion

DELIVERER: AMT

COMPARISON: usual care in 3 hospitals

DESIRED CHANGE: decrease excessive

Outcomes

PRESCRIBING: Choice: use of target antibiotics in DDD/1000 OBD

CLINICAL: hospital standardised mortality ratio 
Yu 2014 (Continued)

MICROBIAL: Clostridium difficile infection rates

FINANCIAL: total and direct acquisitional cost of targeted antimicrobials

Notes $\quad$ FINANCIAL SUPPORT: Funding: none. Competing Interests: none declared

ADDITIONAL DATA: no response from authors to request for additional data

Microbial Risk of Bias: HIGH case definition Not Clear, planned intervention Low, other infection control measures Not Clear

\section{Risk of bias}

\begin{tabular}{|c|c|c|}
\hline Bias & Authors' judgement & Support for judgement \\
\hline $\begin{array}{l}\text { Random sequence genera- } \\
\text { tion (selection bias) }\end{array}$ & High risk & Study sites selected from baseline antimicrobial use. \\
\hline $\begin{array}{l}\text { Allocation concealment } \\
\text { (selection bias) }\end{array}$ & High risk & No concealment \\
\hline $\begin{array}{l}\text { Blinding (performance } \\
\text { bias and detection bias) } \\
\text { All outcomes }\end{array}$ & High risk & No blinding \\
\hline $\begin{array}{l}\text { Incomplete outcome data } \\
\text { (attrition bias) } \\
\text { All outcomes }\end{array}$ & Low risk & Data from pharmacy computer \\
\hline $\begin{array}{l}\text { Selective reporting (re- } \\
\text { porting bias) }\end{array}$ & Low risk & Data from pharmacy computer \\
\hline Other bias & Low risk & \\
\hline $\begin{array}{l}\text { Baseline Outcomes simi- } \\
\text { lar? }\end{array}$ & High risk & Table 2 \\
\hline Free of contamination? & Low risk & Intervention and control sites different hospitals \\
\hline $\begin{array}{l}\text { Baseline characteristics } \\
\text { similar? }\end{array}$ & High risk & $\begin{array}{l}\text { Several potentially important differences between intervention and control } \\
\text { sites }\end{array}$ \\
\hline
\end{tabular}

\section{Zanetti 2003}

\begin{tabular}{ll}
\hline Methods & STUDY DESIGN: NRT \\
& Risk of Bias: HIGH \\
\hline Participants & PROVIDERS: all surgeons in the hospital \\
& PARTICIPANTS: 331 patients undergoing cardiac surgery \\
CLINICAL PROBLEM: additional dose of antibiotic prophylaxis for operations that lasted more than 4 \\
hours \\
SETTING: 1 hospital in the USA
\end{tabular}

Interventions

FORMAT: Intervention: dissemination of guideline; reminder (circumstantial, electronic, automated intra-operative alert) 
Zanetti 2003 (Continued)

Intervention Functions: education, enablement, environmental restructuring, persuasion

COMPARISON: control group plus 480 patients from the 6 months before the study period

DESIRED CHANGE: increase effective

Outcomes PRESCRIBING: Exposure: \% patients who received additional intra-operative antibiotics

CLINICAL: Intended: wound infection rate

Notes

FINANCIAL SUPPORT: Funding: Centers for Disease Control and Prevention cooperative agreement, UR8/CCU115079, University Hospital of Lausanne, and the Leenaards Foundation. Competing Inter-

ests: no information

ADDITIONAL DATA: no response from authors to request for additional data

\begin{tabular}{|c|c|c|}
\hline \multicolumn{3}{|l|}{ Risk of bias } \\
\hline Bias & Authors' judgement & Support for judgement \\
\hline $\begin{array}{l}\text { Random sequence genera- } \\
\text { tion (selection bias) }\end{array}$ & High risk & $\begin{array}{l}\text { Based on a case number assigned to every surgical procedure performed in } \\
\text { the hospital, independent of the study itself }\end{array}$ \\
\hline $\begin{array}{l}\text { Allocation concealment } \\
\text { (selection bias) }\end{array}$ & High risk & No concealment \\
\hline $\begin{array}{l}\text { Blinding (performance } \\
\text { bias and detection bias) } \\
\text { All outcomes }\end{array}$ & High risk & No blinding \\
\hline $\begin{array}{l}\text { Incomplete outcome data } \\
\text { (attrition bias) } \\
\text { All outcomes }\end{array}$ & Low risk & Outcome on all 273 patients \\
\hline $\begin{array}{l}\text { Selective reporting (re- } \\
\text { porting bias) }\end{array}$ & Low risk & Outcome on all 273 patients \\
\hline Other bias & Low risk & Outcome on all 273 patients \\
\hline $\begin{array}{l}\text { Baseline Outcomes simi- } \\
\text { lar? }\end{array}$ & Low risk & Cohort data before start of trial \\
\hline Free of contamination? & High risk & $\begin{array}{l}\text { Control patients were operated on by the same surgeons, and the reminder for } \\
\text { intervention patients is likely to have increased awareness of the need for ad- } \\
\text { ditional doses. }\end{array}$ \\
\hline $\begin{array}{l}\text { Baseline characteristics } \\
\text { similar? }\end{array}$ & Low risk & Table 1 \\
\hline
\end{tabular}

$A B$ : antibiotic

AKI: acute kidney injury

AMT: multidisciplinary antibiotic management team

APACHE: Acute Physiology and Chronic Health Evaluation

ARGNB: antibiotic-resistant gram-negative bacilli

ARGPB: antibiotic-resistant gram-positive bacilli

ARIMA: autoregressive integrated moving average

ASP: Antimicrobial Stewardship Program

BCT: behaviour change technique

CAP: community-acquired pneumonia

CBA: controlled before-after study

CBC: complete blood count 
CDAD: Clostridium difficile-associated diarrhoea CDC: Centers for Disease Control and Prevention CDI: Clostridium difficile infection

CDSS: clinical decision support system

$\mathrm{Cl}$ : confidence interval

CITS: comparative interrupted time series

CPIS: clinical pulmonary infection score

CRP: C-reactive protein

C-section: Caesarean section

DACT: double anaerobic coverage therapy

DDD: defined daily dose

DRG: diagnosis-related group

ED: emergency department

EPOC: Effective Practice and Organisation of Care

ER: emergency room

ESBL-EB: extended-spectrum beta-lactamase-producing Enterobacteriaceae

FTE: full-time equivalent

GRE: glycopeptide-resistant enterococci

IC: infectious control

ICD: International Classification of Diseases

ICU: intensive care unit

ID: infectious diseases

IDP: infectious diseases physician

IHC: Intermountain Healthcare

IL-8: interleukin-8

ITS: interrupted time series

IQR: interquartile range

IV: intravenous

LOS: length of stay

MRSA: methicillin-resistant Staphylococcus aureus

MSSA: methicillin-sensitive Staphylococcus aureus

LRTI: lower respiratory tract infection

MICU: medical intensive care unit

NHAP: nursing home-acquired pneumonia

NIH: National Institutes of Health

NRT: non-randomised (controlled) trial

NRSI: non-randomised studies of interventions

OBD: occupied bed day

OR: odds ratio

PA: parenteral antibiotics

PCR: polymerase chain reaction

$\mathrm{PCT}$ : procalcitonin

$\mathrm{RCT}$ : randomised controlled trial

RCOG: Royal College of Obstetricians and Gynaecologists

RDD: recommended daily doses

ROB: risk of bias

ROBINS-I: risk of bias in non-randomised studies of interventions

RR: risk ratio

SCIP: Surgical Care Improvement Project

SD: standard deviation

SE: standard error

SHEA: Society for Healthcare Epidemiology of America

SICU: surgical intensive care unit

SNF: skilled nursing facilities

SSI: surgical-site infection

TFAD: time to first antibiotic dose

TREAT: computerised decision support system for antibiotic treatment

UBA: uncontrolled before-after study

VAP: ventilator-associated pneumonia

VRE: vancomycin-resistant enterococci 
Characteristics of excluded studies [ordered by study ID]

\begin{tabular}{ll}
\hline Study & Reason for exclusion \\
\hline Ahronheim 2000 & $\begin{array}{l}\text { RCT with no relevant data. Antibiotics were only part of a complex care plan for } 6 \% \text { of participants } \\
\text { in the intervention group, and the outcome data do not include information about the effect of the } \\
\text { intervention on antibiotic prescribing. }\end{array}$
\end{tabular}

Bruno-Murtha 2005

ITS of antibiotic cycling with no interpretable data because there are no pre-cycling data. Only provides data for 4 phases of cycling.

Burke 1997

ITS with no interpretable data. 2 different interventions (education, then restriction via order form) with 3 points before the education intervention and 3 after, but the restriction intervention started after the 4th point. Cook 2006 ITS with no interpretable data because no clearly defined point in time at which the intervention
started.

Crist 1987

NRT with no interpretable data. Unacceptable allocation bias ("the allocation of a patient to a particular group was determined by the attending physician").

Cunningham 2008

ITS with no relevant data. The only valid outcome data are about compliance with a guideline about generic documentation of prescription rather than any specific antibiotic prescribing outcome. The data about time to first antibiotic dose are UBA.

Dellinger 2005

ITS with no interpretable data because no clearly defined point in time at which the intervention started. Only 4 data points for antibiotic use, and the intervention included multiple components in addition to antibiotic use, so even if an intervention effect could be calculated reliably it could not be attributed to change in antibiotic prescribing.

Destache 1990

RCT with no interpretable data because of incomplete and selective reporting of outcome data. The primary outcome measure was length of stay, but $32 \%$ of participants in the intervention group were excluded because they had prolonged length of stay.

Ehrenkranz 1992 RCT with no interpretable data. Only report data for participants whose physicians followed recommendations.

\section{Ehrenkranz 1993}

RCT with no interpretable data. Only report data for participants whose physicians followed recommendations.

Evans 1994

NRT with no interpretable data. The first part compared the drugs that the Antibiotic Consultant programme recommended, with the drugs actually prescribed by physicians. Data from the second part are presented in an uninterpretable format, with the denominator as cultures, not participants or physicians.

Foy 2004

Cluster RCT with no relevant data. Intervention targeted 5 care processes for women having an abortion. Only 1 included antibiotic prescribing within a composite (antibiotic prophylaxis or screening for lower genital tract organisms). Effect of intervention on prescribing cannot be estimated.

Garcia-San Miguel 2014

Cluster RCT with no interpretable data. The study included 9 hospitals with 32 hospitalisation units (wards). Patients were included if they had drugs dispensed from an electronic system.

Baseline: Jan-June 2003 baseline, no intervention

1. Jan-June 2004, intervention in half of the wards that were randomised in each hospital

2. Jan-June 2005, cross-over, intervention in wards that were randomised to control in Period 2 


\section{Study Reason for exclusion}

There is no description of the randomisation process. The primary outcome measure was adherence to recommendations; text on page 658 says they do not present data about mortality or re-admission, but that appears to be what is in Figure 4. Figure 4: legend (and text) says it is about DDD and cost of drugs, but labelling says it is mortality and re-admission. We asked authors to clarify and provide valid outcome data but received no reply.

Gerding 1991

ITS with no interpretable data. Describes 10 years of experience with aminoglycoside cycling, but the intervention periods cannot be mapped onto the outcome data about prescribing or resistance.

Kolar 1999 ITS with no interpretable data due to inadequate control for the effect of other interventions (infec-
tion control measures; see detailed critique by Monnet 2000).

Lan 2003

ITS with unacceptable missing data and inappropriate statistical analysis. There are 3 monthly data points pre-intervention, then a gap in colonisation data for 3 months at the start of the intervention period followed by 3 monthly data points from months 4 to 6 of the intervention phase.

Lee $2004 \quad \begin{aligned} & \text { ITS with no interpretable data. There were no isolates of ESBL-Klebsiella pneumoniae in the last } \\ & 3 \text { months of the intervention phase, but no data are provided about the number of specimens } \\ & \text { screened. Appropriate statistical analysis in original paper not done (averages pre- and postinter- } \\ & \text { vention with } x^{2} \text { and Fisher's exact test). Re-analysis not possible because there are only } 2 \text { reliable } \\ & \text { data points in the postintervention phase. }\end{aligned}$

MacCosbe 1985 RCT with no interpretable data. Only 29\% of randomised doctors were followed up, and recommendations were only made in $6 \%$ of the intervention group.

Marrie 2000

Cluster RCT with no relevant data. Antibiotic prescribing was only 1 component of a care pathway, results for impact on antibiotic prescribing and its contribution to outcome not reported separately.

Martin 2005 ITS with no interpretable data. No antibiotic data pre-intervention, only data about MRSA; this in-
formation is uninterpretable without information about pre-intervention antibiotic prescribing.
not done, and re-analysis not possible from the data presented.

Nagao 2010

ITS with no interpretable data. Figure 1 reports the number of participants with inappropriate antibiotic use, consultations, significant laboratory test results, and total number of blood cultures obtained. However, the number of participants in each category is not clear in the figure. We asked the authors for raw data but they were unable to provide this information. vere pneumonia. The comparison was between the same intervention delivered by a multidisciplinary team (intervention) versus a physician (control). There was no difference in the intervention effect, but the study provides no reliable evidence of intervention effect (UBA data in all 10 skilled nursing facilities).

\begin{tabular}{ll}
\hline Pastel 1992 & $\begin{array}{l}\text { NRT in } 1 \text { hospital, no interpretable data because no protection against contamination and unreli- } \\
\text { able primary outcome measure. }\end{array}$ \\
\hline Ronning 1998 & $\begin{array}{l}\text { RCT with no relevant data. Not primarily an intervention on antibiotic therapy, compared stroke } \\
\text { unit versus general medical ward. }\end{array}$
\end{tabular}

NRT with no relevant data. Antibiotic prescribing was only 1 of 3 components of a care pathway, results for impact on antibiotic prescribing and its contribution to outcome not reported separately. 


\begin{tabular}{|c|c|}
\hline Study & Reason for exclusion \\
\hline & $\begin{array}{l}\text { was responsible for reduction in P aeruginosa and MRSA infections, whereas the figures clearly } \\
\text { show the reduction happened between July and December } 2006 \text {. The paper does not include valid } \\
\text { data about prescribing outcomes, and the authors were unable to provide these data. }\end{array}$ \\
\hline Thomas 2002 & CBA in 64 hospitals, no interpretable data because no clear point in time for the intervention. \\
\hline Tiley 2003 & $\begin{array}{l}\text { ITS with no interpretable data. Multiple interventions are described without clear definition of in- } \\
\text { tervention points. }\end{array}$ \\
\hline Tsiata 2001 & $\begin{array}{l}\text { RCT with no interpretable data. These are provider interventions, but allocation was by patient ran- } \\
\text { domisation. The unequal numbers of patients in each group (134 Group A, } 141 \text { Group B, and } 105 \\
\text { Group C) and the differences in baseline characteristics indicate unacceptable allocation bias. }\end{array}$ \\
\hline Van Loon 2005 & $\begin{array}{l}\text { ITS with no interpretable data about the impact of antibiotic cycling on resistance because there } \\
\text { are no pre-cycling data. }\end{array}$ \\
\hline Wahlstrom 2003 & $\begin{array}{l}\text { RCT with no relevant data. Antibiotics included in the indicators for treatment of hospitalised cas- } \\
\text { es of pneumonia (compliance with policy, dose and duration) and diarrhoea (no use of antibiotics } \\
\text { without bacterial identification), but no separate data are presented for these outcomes. The only } \\
\text { data provided are mean scores on a single composite indicator for each condition. }\end{array}$ \\
\hline
\end{tabular}

CBA: controlled before-after study

DDD: defined daily dose

ESBL: extended-spectrum beta-lactamase

ITS: interrupted time series

MRSA: methicillin-resistant Staphylococcus aureus

NRT: non-randomised trial

$\mathrm{RCT}$ : randomised controlled trial

UBA: uncontrolled before-after study

\section{DATA AND ANALYSES}

\section{Comparison 1. Effectiveness: Prescribing outcomes from RCTs of interventions to reduce unnecessary antibiotic use}

\begin{tabular}{lllll}
\hline Outcome or subgroup title & No. of studies & $\begin{array}{l}\text { No. of partici- } \\
\text { pants }\end{array}$ & Statistical method & Effect size \\
\hline $\begin{array}{l}1 \text { Dichotomous outcomes, increase in desired } \\
\text { practice }\end{array}$ & 29 & 23394 & $\begin{array}{l}\text { Risk Difference (M-H, } \\
\text { Fixed, 95\% Cl) }\end{array}$ & $0.15[0.14,0.16]$ \\
\hline $\begin{array}{l}2 \text { Dichotomous outcomes, all RCTs with re- } \\
\text { sults of cluster RCTs adjusted by inflation fac- } \\
\text { tor }\end{array}$ & 29 & 5802 & Risk Difference (M-H, & $0.17[0.15,0.19]$ \\
\hline $\begin{array}{l}3 \text { Dichotomous outcomes, low or medium } \\
\text { 'Risk of bias' studies only }\end{array}$ & 15 & Fixed, 95\% Cl) & \\
\hline $\begin{array}{l}4 \text { Continuous outcomes, duration of all an- } \\
\text { tibiotic treatment (days) }\end{array}$ & 14 & 13086 & Risk Difference (M-H, & $0.11[0.10,0.12]$ \\
\hline $\begin{array}{l}5 \text { Continuous outcomes, duration of all an- } \\
\text { tibiotic treatment with results of cluster RCTs } \\
\text { adjusted by inflation factor }\end{array}$ & 14 & 3318 & Fixed, 95\% Cl) & Mean Difference (IV, \\
\hline
\end{tabular}




\begin{tabular}{lllll}
\hline Outcome or subgroup title & No. of studies & $\begin{array}{l}\text { No. of partici- } \\
\text { pants }\end{array}$ & Statistical method & Effect size \\
\hline $\begin{array}{l}6 \text { Continuous outcomes, low or medium 'Risk } \\
\text { of bias' studies only }\end{array}$ & 3 & 755 & $\begin{array}{l}\text { Mean Difference (IV, } \\
\text { Fixed, 95\% Cl) }\end{array}$ & $-3.06[-3.76$, \\
\hline $\begin{array}{l}7 \text { Continuous outcome, consumption of tar- } \\
\text { geted antibiotic only, standardised mean re- } \\
\text { duction (original outcome cost, days or DDD) }\end{array}$ & 4 & 1053 & Std. Mean Difference & $-0.25[-0.37$, \\
\hline
\end{tabular}

Analysis 1.1. Comparison 1 Effectiveness: Prescribing outcomes from RCTs of interventions to
reduce unnecessary antibiotic use, Outcome 1 Dichotomous outcomes, increase in desired practice.

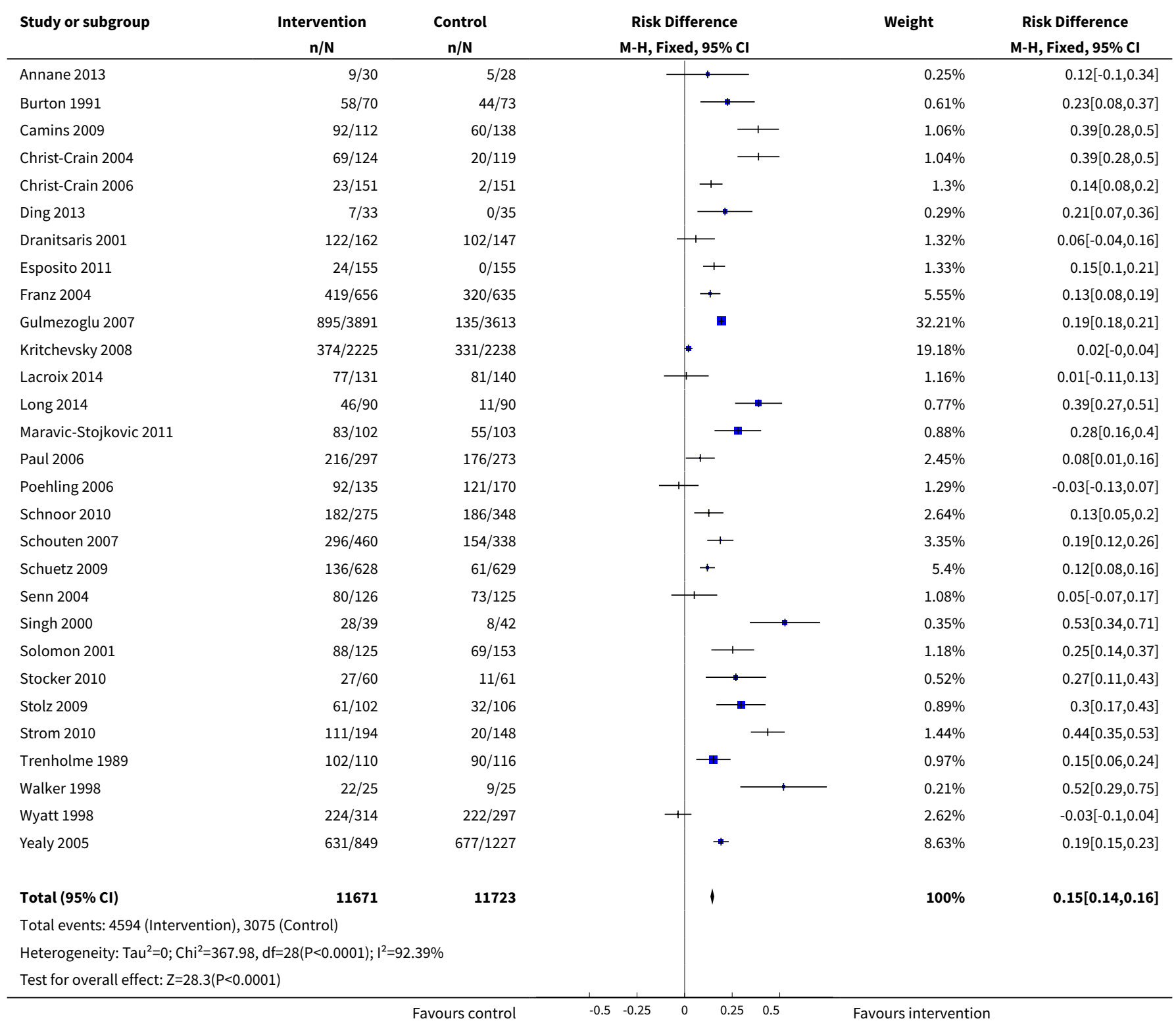


Analysis 1.2. Comparison 1 Effectiveness: Prescribing outcomes from RCTs of interventions to reduce unnecessary antibiotic use, Outcome 2 Dichotomous outcomes, all RCTs with results of cluster RCTs adjusted by inflation factor.

\begin{tabular}{|c|c|c|c|c|c|}
\hline Study or subgroup & $\begin{array}{c}\text { Intervention } \\
n / N\end{array}$ & $\begin{array}{c}\text { Control } \\
n / N\end{array}$ & $\begin{array}{c}\text { Risk Difference } \\
\text { M-H, Fixed, } 95 \% \mathrm{Cl}\end{array}$ & Weight & $\begin{array}{c}\text { Risk Difference } \\
\text { M-H, Fixed, } 95 \% \mathrm{Cl}\end{array}$ \\
\hline Annane 2013 & 9/30 & $5 / 28$ & +1 & $1 \%$ & $0.12[-0.1,0.34]$ \\
\hline Burton 1991 & $58 / 70$ & $44 / 73$ & 一 & $2.47 \%$ & $0.23[0.08,0.37]$ \\
\hline Camins 2009 & $19 / 23$ & $12 / 28$ & $\longrightarrow$ & $0.87 \%$ & $0.4[0.16,0.64]$ \\
\hline Christ-Crain 2004 & $18 / 32$ & $5 / 31$ & 1 & $1.09 \%$ & $0.4[0.19,0.62]$ \\
\hline Christ-Crain 2006 & $23 / 151$ & $2 / 151$ & + & $5.22 \%$ & $0.14[0.08,0.2]$ \\
\hline Ding 2013 & $7 / 33$ & $0 / 35$ & 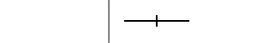 & $1.18 \%$ & $0.21[0.07,0.36]$ \\
\hline Dranitsaris 2001 & $122 / 162$ & $102 / 147$ & + & $5.33 \%$ & $0.06[-0.04,0.16]$ \\
\hline Esposito 2011 & $24 / 155$ & $0 / 155$ & + & $5.36 \%$ & $0.15[0.1,0.21]$ \\
\hline Franz 2004 & $419 / 656$ & $320 / 635$ & + & $22.33 \%$ & $0.13[0.08,0.19]$ \\
\hline Gulmezoglu 2007 & $23 / 102$ & $4 / 94$ & + & $3.38 \%$ & $0.18[0.09,0.27]$ \\
\hline Kritchevsky 2008 & $18 / 106$ & $16 / 106$ & $\vdash$ & $3.67 \%$ & $0.02[-0.08,0.12]$ \\
\hline Lacroix 2014 & $77 / 131$ & $81 / 140$ & - & $4.68 \%$ & $0.01[-0.11,0.13]$ \\
\hline Long 2014 & $46 / 90$ & $11 / 90$ & 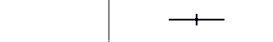 & $3.11 \%$ & $0.39[0.27,0.51]$ \\
\hline Maravic-Stojkovic 2011 & $83 / 102$ & $55 / 103$ & $\leftarrow$ & $3.55 \%$ & $0.28[0.16,0.4]$ \\
\hline Paul 2006 & $26 / 35$ & $21 / 33$ & + & $1.18 \%$ & $0.11[-0.11,0.33]$ \\
\hline Poehling 2006 & $92 / 135$ & $121 / 170$ & & $5.21 \%$ & $-0.03[-0.13,0.07]$ \\
\hline Schnoor 2010 & $11 / 17$ & $11 / 21$ & - & $0.65 \%$ & $0.12[-0.19,0.44]$ \\
\hline Schouten 2007 & $11 / 17$ & $6 / 12$ & $\rightarrow$ & $0.49 \%$ & $0.15[-0.22,0.51]$ \\
\hline Schuetz 2009 & $3 / 15$ & $1 / 15$ & $\rightarrow$ & $0.52 \%$ & $0.13[-0.11,0.37]$ \\
\hline Senn 2004 & $80 / 126$ & $73 / 125$ & + & $4.34 \%$ & $0.05[-0.07,0.17]$ \\
\hline Singh 2000 & $28 / 39$ & $8 / 42$ & 1 & $1.4 \%$ & $0.53[0.34,0.71]$ \\
\hline Solomon 2001 & $22 / 31$ & $17 / 38$ & 1 & $1.18 \%$ & $0.26[0.04,0.49]$ \\
\hline Stocker 2010 & $27 / 60$ & $11 / 61$ & $\longrightarrow$ & $2.09 \%$ & $0.27[0.11,0.43]$ \\
\hline Stolz 2009 & $61 / 102$ & $32 / 106$ & 十 & $3.6 \%$ & $0.3[0.17,0.43]$ \\
\hline Strom 2010 & $133 / 232$ & $24 / 177$ & $\rightarrow$ & $6.95 \%$ & $0.44[0.36,0.52]$ \\
\hline Trenholme 1989 & $102 / 110$ & $90 / 116$ & + & $3.91 \%$ & $0.15[0.06,0.24]$ \\
\hline Walker 1998 & $22 / 25$ & $9 / 25$ & $\longrightarrow$ & $0.86 \%$ & $0.52[0.29,0.75]$ \\
\hline Wyatt 1998 & $39 / 55$ & $39 / 52$ & - & $1.85 \%$ & $-0.04[-0.21,0.13]$ \\
\hline Yealy 2005 & $46 / 62$ & $49 / 89$ & 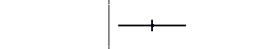 & $2.53 \%$ & $0.19[0.04,0.34]$ \\
\hline Total $(95 \% \mathrm{Cl})$ & 2904 & 2898 & $\downarrow$ & $100 \%$ & $0.17[0.15,0.19]$ \\
\hline \multicolumn{6}{|c|}{ Total events: 1649 (Intervention), 1169 (Control) } \\
\hline \multicolumn{6}{|c|}{ Heterogeneity: $\mathrm{Tau}^{2}=0 ; \mathrm{Chi}^{2}=143.98, \mathrm{df}=28(\mathrm{P}<0.0001) ; \mathrm{I}^{2}=80.55 \%$} \\
\hline \multicolumn{6}{|c|}{ Test for overall effect: $Z=15.03(P<0.0001)$} \\
\hline
\end{tabular}

Analysis 1.3. Comparison 1 Effectiveness: Prescribing outcomes from RCTs of interventions to reduce unnecessary antibiotic use, Outcome 3 Dichotomous outcomes, low or medium 'Risk of bias' studies only.

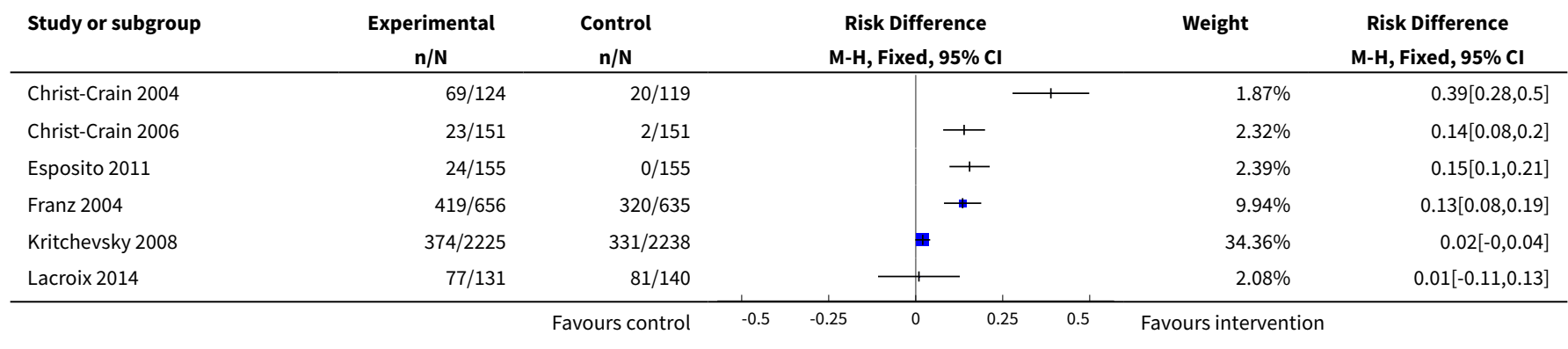




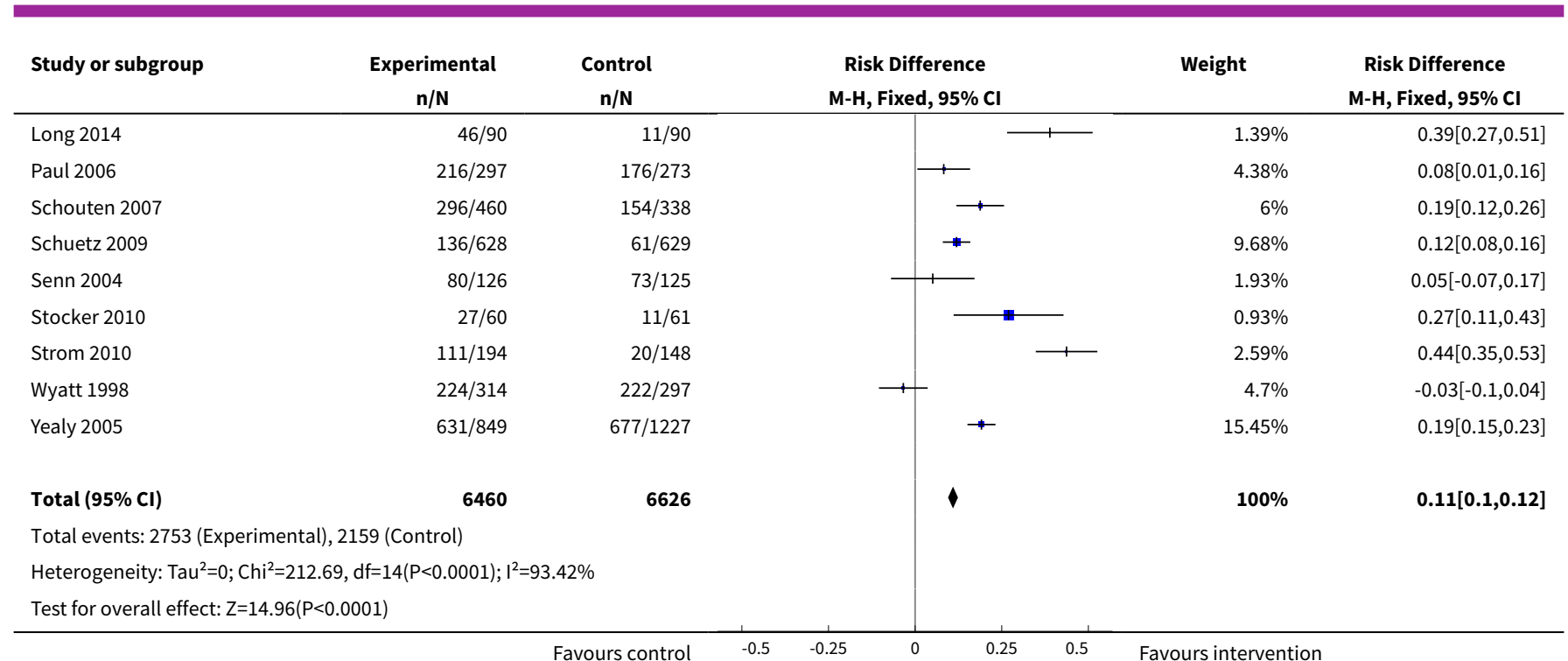

Analysis 1.4. Comparison 1 Effectiveness: Prescribing outcomes from RCTs of interventions to reduce unnecessary antibiotic use, Outcome 4 Continuous outcomes, duration of all antibiotic treatment (days).

\begin{tabular}{|c|c|c|c|c|c|c|c|c|}
\hline \multirow{3}{*}{$\begin{array}{l}\text { Study or subgroup } \\
\text { Bouza } 2004\end{array}$} & \multicolumn{2}{|c|}{ Experimental } & \multicolumn{2}{|c|}{ Control } & \multirow{2}{*}{\multicolumn{2}{|c|}{$\begin{array}{c}\text { Mean Difference } \\
\text { Fixed, } 95 \% \mathrm{Cl}\end{array}$}} & \multirow[t]{2}{*}{ Weight } & \multirow{2}{*}{$\begin{array}{c}\text { Mean Difference } \\
\text { Fixed, } 95 \% \mathrm{Cl}\end{array}$} \\
\hline & $\mathbf{N}$ & $\operatorname{Mean}(\mathrm{SD})$ & $\mathbf{N}$ & $\operatorname{Mean}(S D)$ & & & & \\
\hline & 167 & $15.7(9.5)$ & 83 & $18.9(10.9)$ & $\longrightarrow$ & & $0.99 \%$ & $-3.2[-5.95,-0.45]$ \\
\hline Christ-Crain 2004 & 119 & $10.9(3.6)$ & 124 & $12.8(5.5)$ & $\longrightarrow$ & & $5.56 \%$ & $-1.9[-3.06,-0.74]$ \\
\hline Christ-Crain 2006 & 151 & $6.8(5.1)$ & 151 & $13.1(6.4)$ & 1 & & $4.42 \%$ & $-6.3[-7.61,-4.99]$ \\
\hline Danaher 2009 & 14 & $4.5(3)$ & 38 & $6.6(4.6)$ & 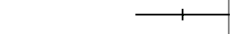 & & $1.64 \%$ & $-2.1[-4.25,0.05]$ \\
\hline Ding 2013 & 33 & $8.7(6.6)$ & 35 & $14.5(5.2)$ & $一$ & & $0.94 \%$ & $-5.8[-8.64,-2.96]$ \\
\hline Kerremans 2008 & 497 & $26.6(24.5)$ & 503 & $32.9(31.9)$ & + & & $0.61 \%$ & $-6.3[-9.82,-2.78]$ \\
\hline Kristoffersen 2009 & 103 & $5.1(3.6)$ & 107 & $6.8(4.8)$ & 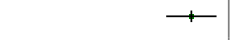 & & $5.75 \%$ & $-1.7[-2.84,-0.56]$ \\
\hline Layios 2012 & 258 & $14.7(20.6)$ & 251 & $14.1(13.7)$ & $\longrightarrow$ & $\$$ & $0.82 \%$ & $0.62[-2.41,3.65]$ \\
\hline Liu 2013 & 42 & $8.1(1.9)$ & 40 & $9.3(1.9)$ & + & & $10.91 \%$ & $-1.2[-2.03,-0.37]$ \\
\hline Micek 2004 & 150 & $6(4.9)$ & 140 & $8(5.6)$ & $千$ & & $5.11 \%$ & $-2[-3.21,-0.79]$ \\
\hline Oliveira 2013 & 49 & $8.1(3.7)$ & 45 & $7.2(3.5)$ & & 1 & $3.56 \%$ & $0.9[-0.56,2.36]$ \\
\hline Schroeder 2009 & 14 & $6.6(1.1)$ & 13 & $7.1(0.7)$ & $\rightarrow$ & & $15.8 \%$ & $-0.5[-1.19,0.19]$ \\
\hline 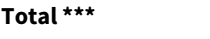 & 1695 & & 1623 & & $\checkmark$ & & $100 \%$ & $-1.95[-2.22,-1.67]$ \\
\hline \multicolumn{9}{|c|}{ Heterogeneity: $\mathrm{Tau}^{2}=0 ; \mathrm{Chi}^{2}=119.95, \mathrm{df}=13(\mathrm{P}<0.0001) ; \mathrm{I}^{2}=89.16 \%$} \\
\hline \multicolumn{9}{|c|}{ Test for overall effect: $Z=13.91(P<0.0001)$} \\
\hline
\end{tabular}


Analysis 1.5. Comparison 1 Effectiveness: Prescribing outcomes from RCTs of interventions to reduce unnecessary antibiotic use, Outcome 5 Continuous outcomes, duration of all antibiotic treatment with results of cluster RCTs adjusted by inflation factor.

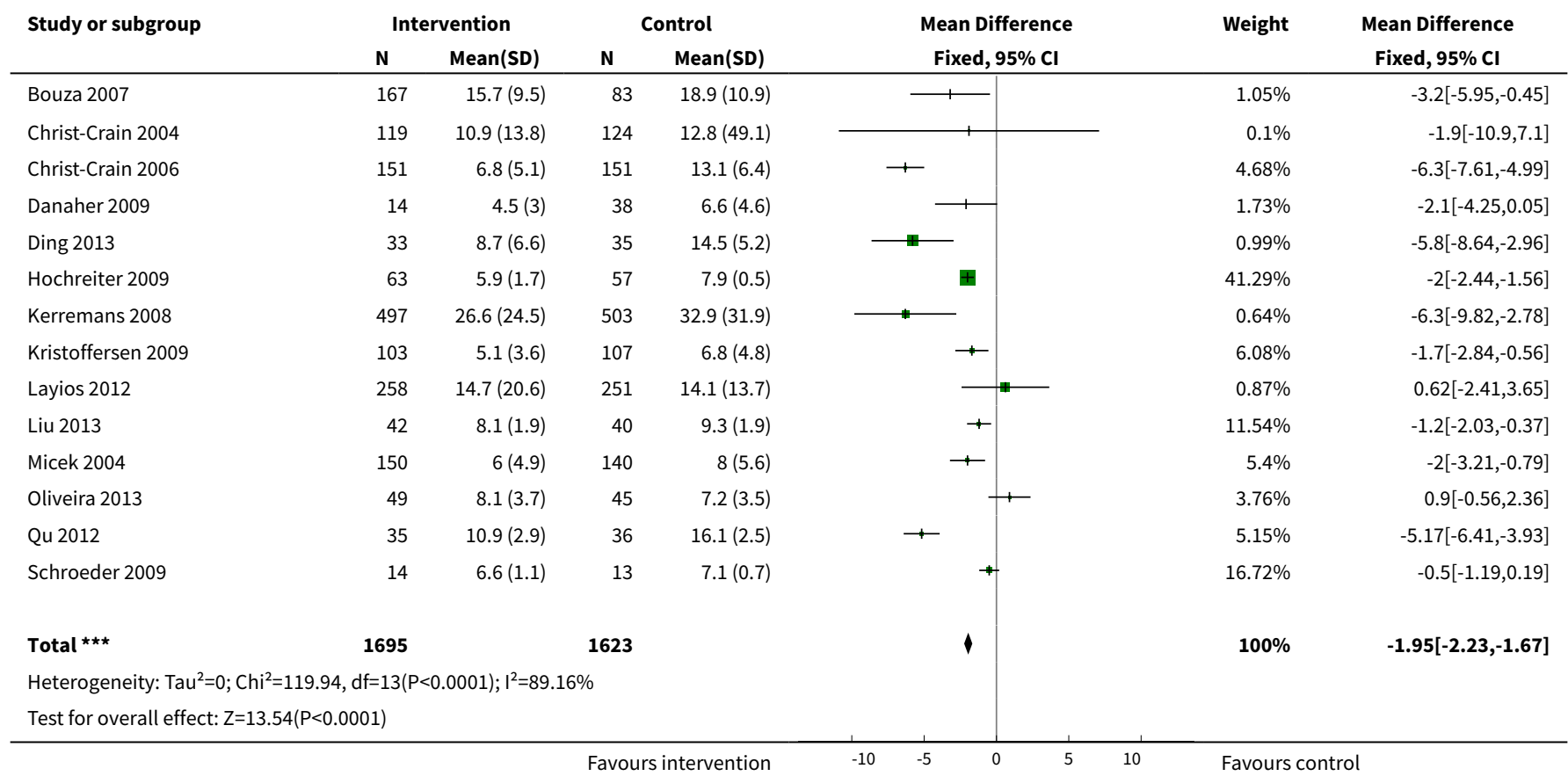

Analysis 1.6. Comparison 1 Effectiveness: Prescribing outcomes from RCTs of interventions to reduce unnecessary antibiotic use, Outcome 6 Continuous outcomes, low or medium 'Risk of bias' studies only.

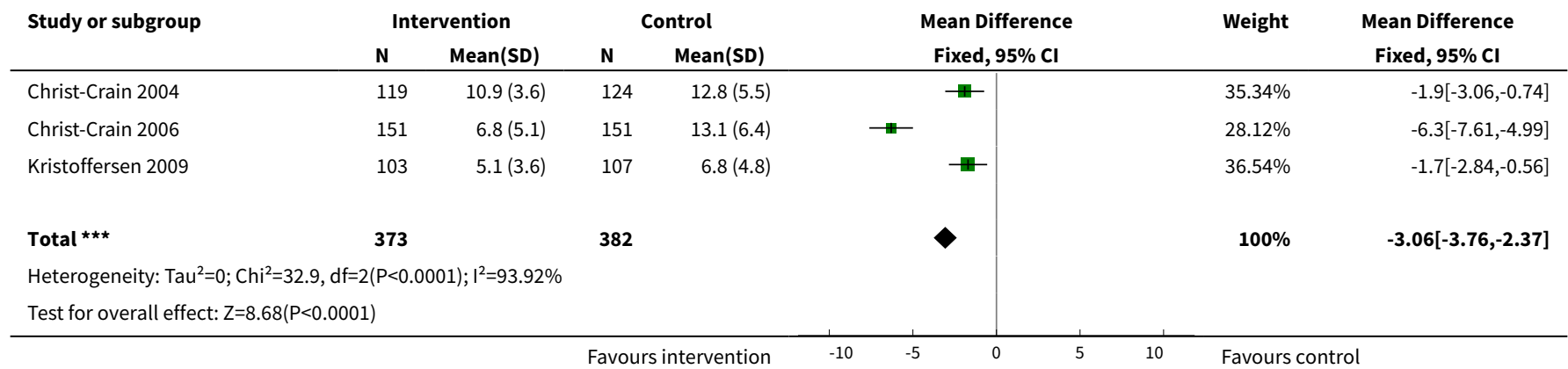

Analysis 1.7. Comparison 1 Effectiveness: Prescribing outcomes from RCTs of interventions to reduce unnecessary antibiotic use, Outcome 7 Continuous outcome, consumption of targeted antibiotic only, standardised mean reduction (original outcome cost, days or DDD).

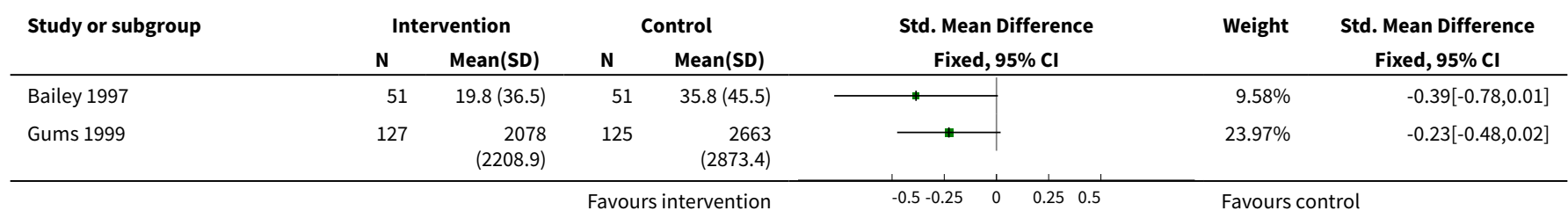




\begin{tabular}{|c|c|c|c|c|c|c|c|}
\hline \multirow{3}{*}{$\begin{array}{l}\text { Study or subgroup } \\
\text { Shen } 2011\end{array}$} & \multicolumn{2}{|c|}{ Intervention } & \multicolumn{2}{|c|}{ Control } & \multirow{2}{*}{$\begin{array}{c}\text { Std. Mean Difference } \\
\text { Fixed, } 95 \% \mathrm{Cl} \\
\end{array}$} & \multirow{3}{*}{$\begin{array}{l}\text { Weight } \\
33.55 \%\end{array}$} & \multirow{3}{*}{$\begin{array}{c}\text { Std. Mean Difference } \\
\text { Fixed, 95\% Cl } \\
-0.28[-0.49,-0.07]\end{array}$} \\
\hline & \multirow{2}{*}{$\frac{\mathbf{N}}{176}$} & \multirow{2}{*}{$\frac{\text { Mean(SD) }}{832(373)}$} & \multirow{2}{*}{$\frac{\mathbf{N}}{178}$} & \multirow{2}{*}{$\frac{\text { Mean(SD) }}{943.9(412)}$} & & & \\
\hline & & & & & 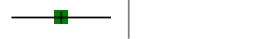 & & \\
\hline Shojania 1998 & 174 & $1.8(1.1)$ & 171 & $2(1.1)$ & 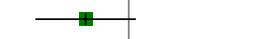 & $32.9 \%$ & $-0.18[-0.39,0.03]$ \\
\hline Total $* \star \star$ & 528 & & 525 & & & $100 \%$ & $-0.25[-0.37,-0.13]$ \\
\hline \multicolumn{8}{|c|}{ Heterogeneity: $\mathrm{Tau}^{2}=0 ; \mathrm{Chi}^{2}=0.99, \mathrm{df}=3(\mathrm{P}=0.8) ; \mathrm{I}^{2}=0 \%$} \\
\hline \multicolumn{3}{|c|}{ Test for overall effect: $Z=3.98(P<0.0001)$} & & & & & \\
\hline
\end{tabular}

Comparison 2. Adverse effects: Clinical outcomes from RCTs of interventions to reduce unnecessary antibiotic use

\begin{tabular}{|c|c|c|c|c|}
\hline Outcome or subgroup title & No. of studies & $\begin{array}{l}\text { No. of partici- } \\
\text { pants }\end{array}$ & Statistical method & Effect size \\
\hline 1 Mortality, all RCTs & 28 & 15827 & $\begin{array}{l}\text { Risk Difference (M-H, Fixed, } \\
95 \% \mathrm{Cl})\end{array}$ & $-0.00[-0.01,0.00]$ \\
\hline $\begin{array}{l}2 \text { Mortality, all RCTs with results of } \\
\text { cluster RCTs adjusted by inflation fac- } \\
\text { tor }\end{array}$ & 28 & 8332 & $\begin{array}{l}\text { Risk Difference (M-H, Fixed, } \\
95 \% \mathrm{Cl})\end{array}$ & $-0.01[-0.02,0.01]$ \\
\hline $\begin{array}{l}3 \text { Mortality, low or medium 'Risk of } \\
\text { bias' RCTs }\end{array}$ & 8 & 6249 & $\begin{array}{l}\text { Risk Difference (M-H, Fixed, } \\
95 \% \mathrm{Cl})\end{array}$ & $-0.00[-0.02,0.01]$ \\
\hline 4 Length of stay, all RCTs & 15 & 3834 & $\begin{array}{l}\text { Mean Difference (IV, Fixed, } \\
95 \% \mathrm{Cl} \text { ) }\end{array}$ & $-1.12[-1.54,-0.70]$ \\
\hline $\begin{array}{l}5 \text { Length of stay, all RCTs with results of } \\
\text { cluster RCTs adjusted by inflation fac- } \\
\text { tor }\end{array}$ & 15 & 3834 & $\begin{array}{l}\text { Mean Difference (IV, Fixed, } \\
95 \% \mathrm{Cl} \text { ) }\end{array}$ & $-1.22[-1.68,-0.76]$ \\
\hline $\begin{array}{l}6 \text { Length of stay, low or medium 'Risk } \\
\text { of bias' RCTs only }\end{array}$ & 6 & 1731 & $\begin{array}{l}\text { Mean Difference (IV, Fixed, } \\
95 \% \mathrm{CI})\end{array}$ & $-0.85[-1.38,-0.32]$ \\
\hline
\end{tabular}

Analysis 2.1. Comparison 2 Adverse effects: Clinical outcomes from RCTs of interventions to reduce unnecessary antibiotic use, Outcome 1 Mortality, all RCTs.

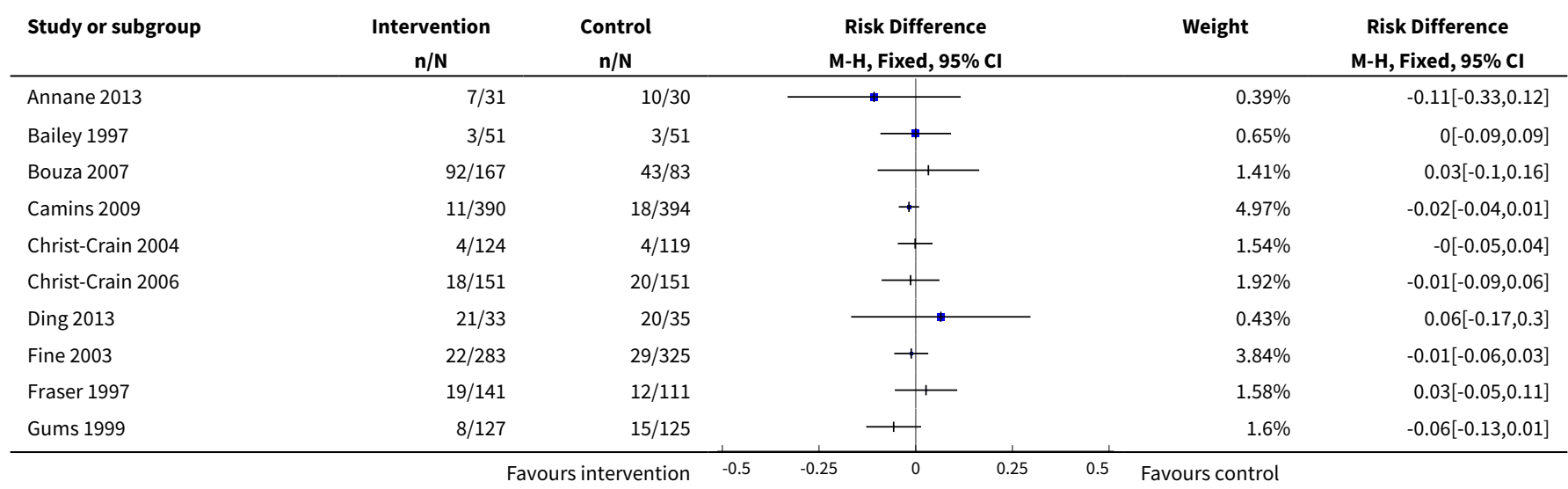




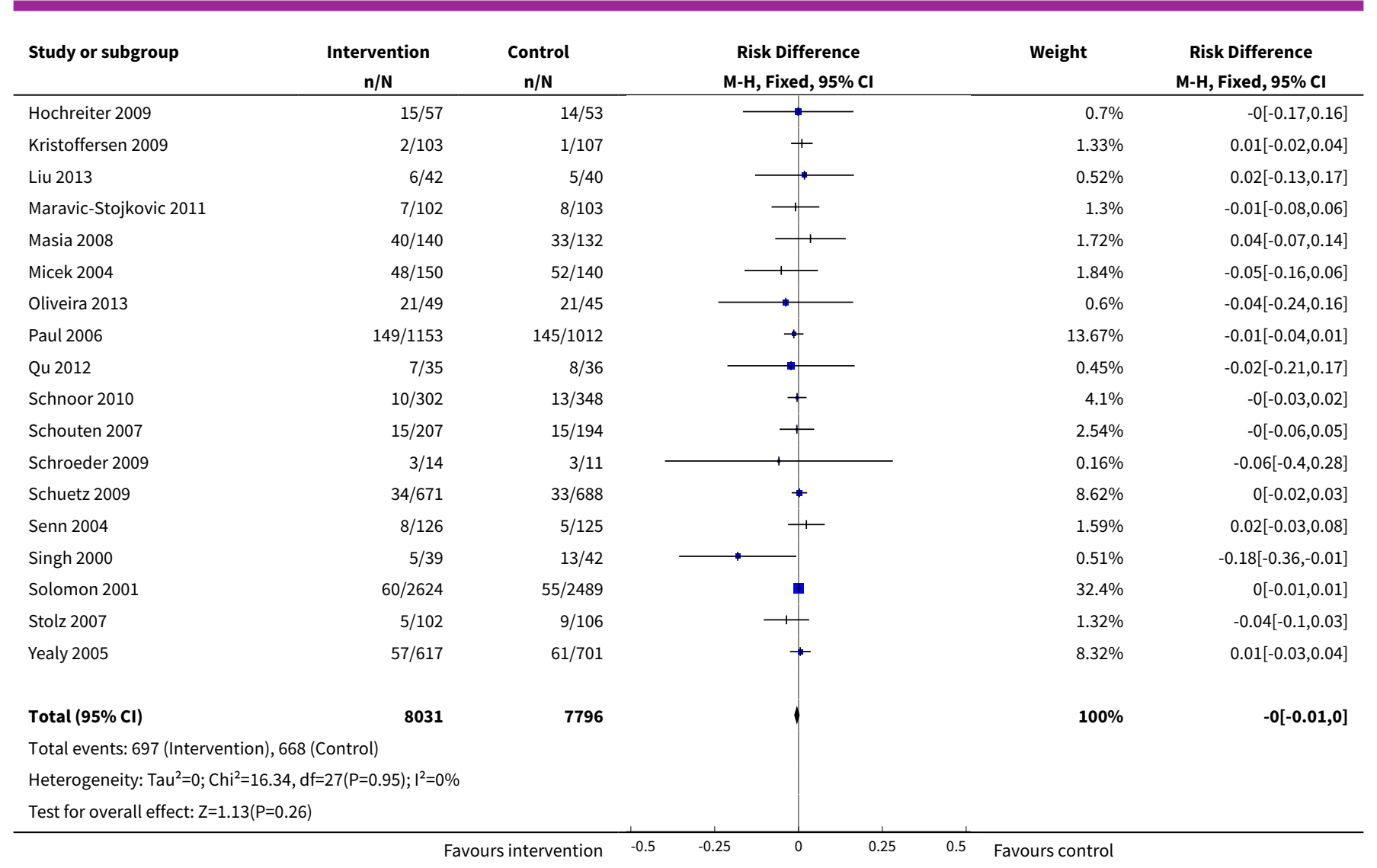

\section{Analysis 2.2. Comparison 2 Adverse effects: Clinical outcomes from RCTs of interventions to reduce unnecessary antibiotic use, Outcome 2 Mortality, all RCTs with results of cluster RCTs adjusted by inflation factor.}

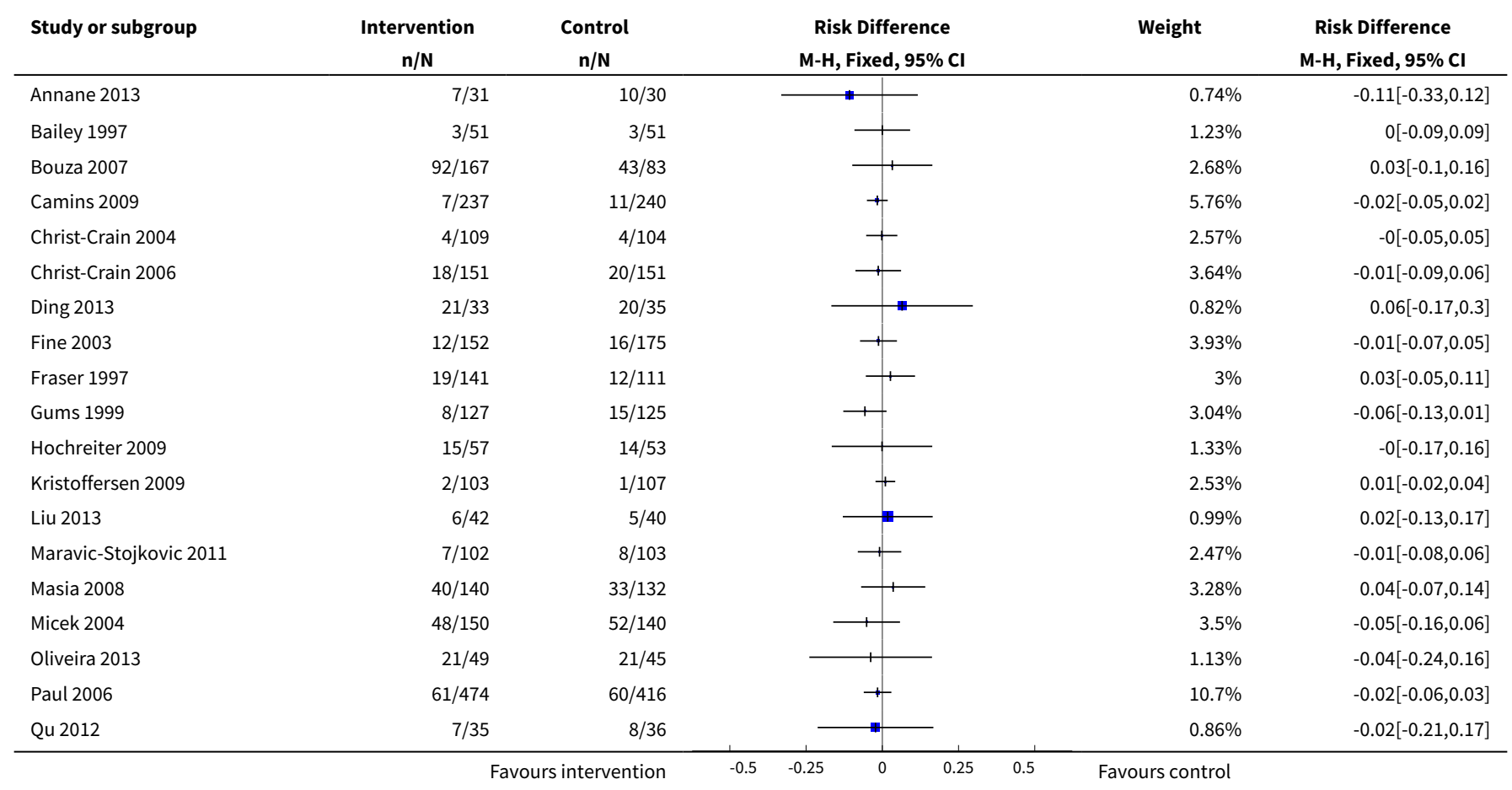




\begin{tabular}{|c|c|c|c|c|c|}
\hline Study or subgroup & $\begin{array}{c}\text { Intervention } \\
\mathrm{n} / \mathrm{N}\end{array}$ & $\begin{array}{c}\text { Control } \\
n / N\end{array}$ & $\begin{array}{c}\text { Risk Difference } \\
\text { M-H, Fixed, } 95 \% \mathrm{Cl}\end{array}$ & Weight & $\begin{array}{c}\text { Risk Difference } \\
\text { M-H, Fixed, } 95 \% \mathrm{Cl}\end{array}$ \\
\hline Schnoor 2010 & $6 / 168$ & $7 / 193$ & + & $4.34 \%$ & $-0[-0.04,0.04]$ \\
\hline Schouten 2007 & $9 / 125$ & $9 / 117$ & + & $2.92 \%$ & $-0[-0.07,0.06]$ \\
\hline Schroeder 2009 & $3 / 14$ & $3 / 11$ & $\rightarrow$ & $0.3 \%$ & $-0.06[-0.4,0.28]$ \\
\hline Schuetz 2009 & $10 / 206$ & $10 / 211$ & + & $5.03 \%$ & $0[-0.04,0.04]$ \\
\hline Senn 2004 & $8 / 126$ & $5 / 125$ & + & $3.03 \%$ & $0.02[-0.03,0.08]$ \\
\hline Singh 2000 & $5 / 39$ & $13 / 42$ & $\rightarrow$ & $0.98 \%$ & $-0.18[-0.36,-0.01]$ \\
\hline Solomon 2001 & $15 / 656$ & $14 / 623$ & * & $15.42 \%$ & $0[-0.02,0.02]$ \\
\hline Stolz 2007 & $5 / 102$ & $9 / 106$ & 1 & $2.51 \%$ & $-0.04[-0.1,0.03]$ \\
\hline Yealy 2005 & $41 / 440$ & $44 / 500$ & + & $11.3 \%$ & $0.01[-0.03,0.04]$ \\
\hline Total $(95 \% \mathrm{CI})$ & 4227 & 4105 & 1 & $100 \%$ & $-0.01[-0.02,0.01]$ \\
\hline \multicolumn{6}{|c|}{ Total events: 500 (Intervention), 470 (Control) } \\
\hline \multicolumn{6}{|c|}{ Heterogeneity: $\mathrm{Tau}^{2}=0 ; \mathrm{Chi}^{2}=14.33, \mathrm{df}=27(\mathrm{P}=0.98) ; \mathrm{I}^{2}=0 \%$} \\
\hline Test for overall effect & & & & & \\
\hline
\end{tabular}

\section{Analysis 2.3. Comparison 2 Adverse effects: Clinical outcomes from RCTs of interventions to reduce unnecessary antibiotic use, Outcome 3 Mortality, low or medium 'Risk of bias' RCTs.}

\begin{tabular}{|c|c|c|c|c|c|}
\hline Study or subgroup & $\begin{array}{c}\text { Intervention } \\
\mathrm{n} / \mathrm{N}\end{array}$ & $\begin{array}{c}\text { Control } \\
n / N\end{array}$ & $\begin{array}{c}\text { Risk Difference } \\
\text { M-H, Fixed, 95\% Cl }\end{array}$ & Weight & $\begin{array}{c}\text { Risk Difference } \\
\text { M-H, Fixed, } 95 \% \mathrm{Cl}\end{array}$ \\
\hline Christ-Crain 2004 & $4 / 124$ & $4 / 119$ & - & $3.9 \%$ & $-0[-0.05,0.04]$ \\
\hline Christ-Crain 2006 & $18 / 151$ & $20 / 151$ & & $4.84 \%$ & $-0.01[-0.09,0.06]$ \\
\hline Kristoffersen 2009 & $2 / 103$ & $1 / 107$ & + & $3.37 \%$ & $0.01[-0.02,0.04]$ \\
\hline Paul 2006 & $149 / 1153$ & $145 / 1012$ & $\longrightarrow$ & $34.58 \%$ & $-0.01[-0.04,0.01]$ \\
\hline Schouten 2007 & $15 / 207$ & $15 / 194$ & & $6.43 \%$ & $-0[-0.06,0.05]$ \\
\hline Senn 2004 & $8 / 126$ & $5 / 125$ & $r$ & $4.03 \%$ & $0.02[-0.03,0.08]$ \\
\hline Yealy 2005 & $57 / 617$ & $61 / 701$ & $\longrightarrow$ & $21.06 \%$ & $0.01[-0.03,0.04]$ \\
\hline Total $(95 \% \mathrm{Cl})$ & 3152 & 3097 & & $100 \%$ & $-0[-0.02,0.01]$ \\
\hline \multicolumn{6}{|c|}{ Total events: 287 (Intervention), 284 (Control) } \\
\hline \multicolumn{6}{|c|}{ Heterogeneity: $\operatorname{Tau}^{2}=0 ; \mathrm{Chi}^{2}=2.66, \mathrm{df}=7(\mathrm{P}=0.91) ;\left.\right|^{2}=0 \%$} \\
\hline
\end{tabular}

Analysis 2.4. Comparison 2 Adverse effects: Clinical outcomes from RCTs of interventions to reduce unnecessary antibiotic use, Outcome 4 Length of stay, all RCTs.

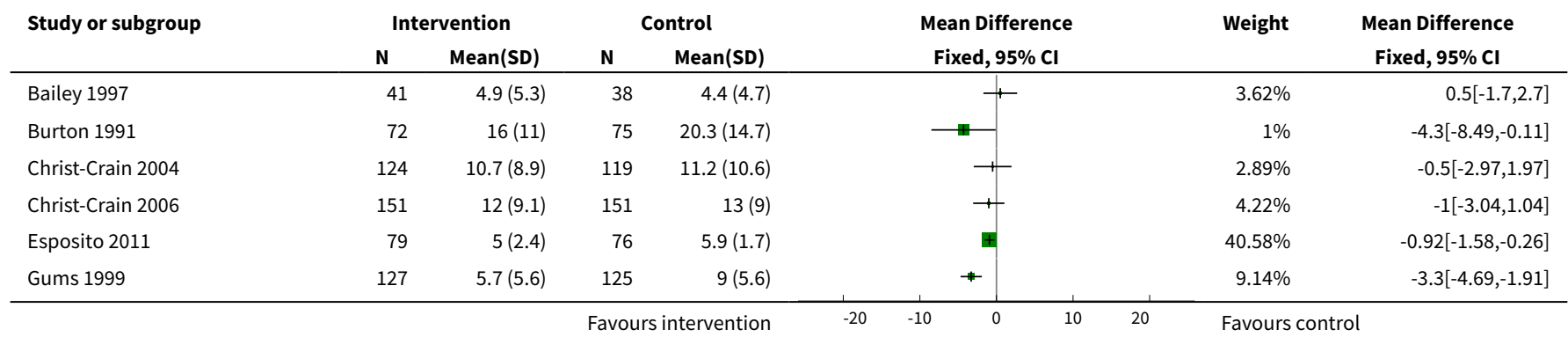




\begin{tabular}{|c|c|c|c|c|c|c|c|}
\hline \multirow[t]{2}{*}{ Study or subgroup } & \multicolumn{2}{|c|}{ Intervention } & \multicolumn{2}{|c|}{ Control } & \multirow{2}{*}{$\begin{array}{c}\text { Mean Difference } \\
\text { Fixed, } 95 \% \mathrm{Cl}\end{array}$} & \multirow[t]{2}{*}{ Weight } & \multirow{2}{*}{$\begin{array}{c}\text { Mean Difference } \\
\text { Fixed, } 95 \% \mathrm{Cl}\end{array}$} \\
\hline & $\mathbf{N}$ & Mean(SD) & $\mathbf{N}$ & Mean(SD) & & & \\
\hline Kristoffersen 2009 & 103 & $5.9(5.2)$ & 107 & $6.7(5.2)$ & + & $9.02 \%$ & $-0.8[-2.2,0.6]$ \\
\hline Liu 2013 & 42 & $27(31.7)$ & 40 & $32(34.1)$ & 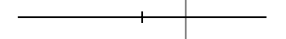 & $0.09 \%$ & $-5[-19.27,9.27]$ \\
\hline Maravic-Stojkovic 2011 & 102 & $12.1(11.3)$ & 103 & $12.9(10.7)$ & 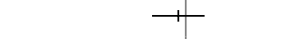 & $1.93 \%$ & $-0.85[-3.86,2.16]$ \\
\hline Micek 2004 & 150 & $15.7(18.2)$ & 140 & $15.4(15.9)$ & 1 & $1.14 \%$ & $0.29[-3.64,4.22]$ \\
\hline Paul 2006 & 297 & $8.8(11.3)$ & 273 & $9.5(11.5)$ & + & $5 \%$ & $-0.62[-2.5,1.26]$ \\
\hline Qu 2012 & 35 & $16.7(23.7)$ & 36 & $23.8(45.3)$ & & $0.06 \%$ & $-7.15[-23.9,9.6]$ \\
\hline Schnoor 2010 & 275 & $10(7.6)$ & 348 & $10.7(9.5)$ & - & $9.75 \%$ & $-0.7[-2.04,0.64]$ \\
\hline Senn 2004 & 126 & $19.4(24.5)$ & 125 & $19.3(16.2)$ & - & $0.67 \%$ & $0.1[-5.04,5.24]$ \\
\hline Shen 2011 & 176 & $14.2(6.2)$ & 178 & $15.8(6)$ & + & $10.88 \%$ & $-1.6[-2.87,-0.33]$ \\
\hline Total $\star \star \star ~$ & 1900 & & 1934 & & 1 & $100 \%$ & $-1.12[-1.54,-0.7]$ \\
\hline \multicolumn{8}{|c|}{ Heterogeneity: $\operatorname{Tau}^{2}=0 ; \mathrm{Chi}^{2}=17.32, \mathrm{df}=14(\mathrm{P}=0.24) ; \mathrm{I}^{2}=19.15 \%$} \\
\hline \multicolumn{3}{|c|}{ Test for overall effect: $Z=5.25(P<0.0001)$} & & & & & \\
\hline
\end{tabular}

Analysis 2.5. Comparison 2 Adverse effects: Clinical outcomes from RCTs of interventions to reduce unnecessary antibiotic use, Outcome 5 Length of stay, all RCTs with results of cluster RCTs adjusted by inflation factor.

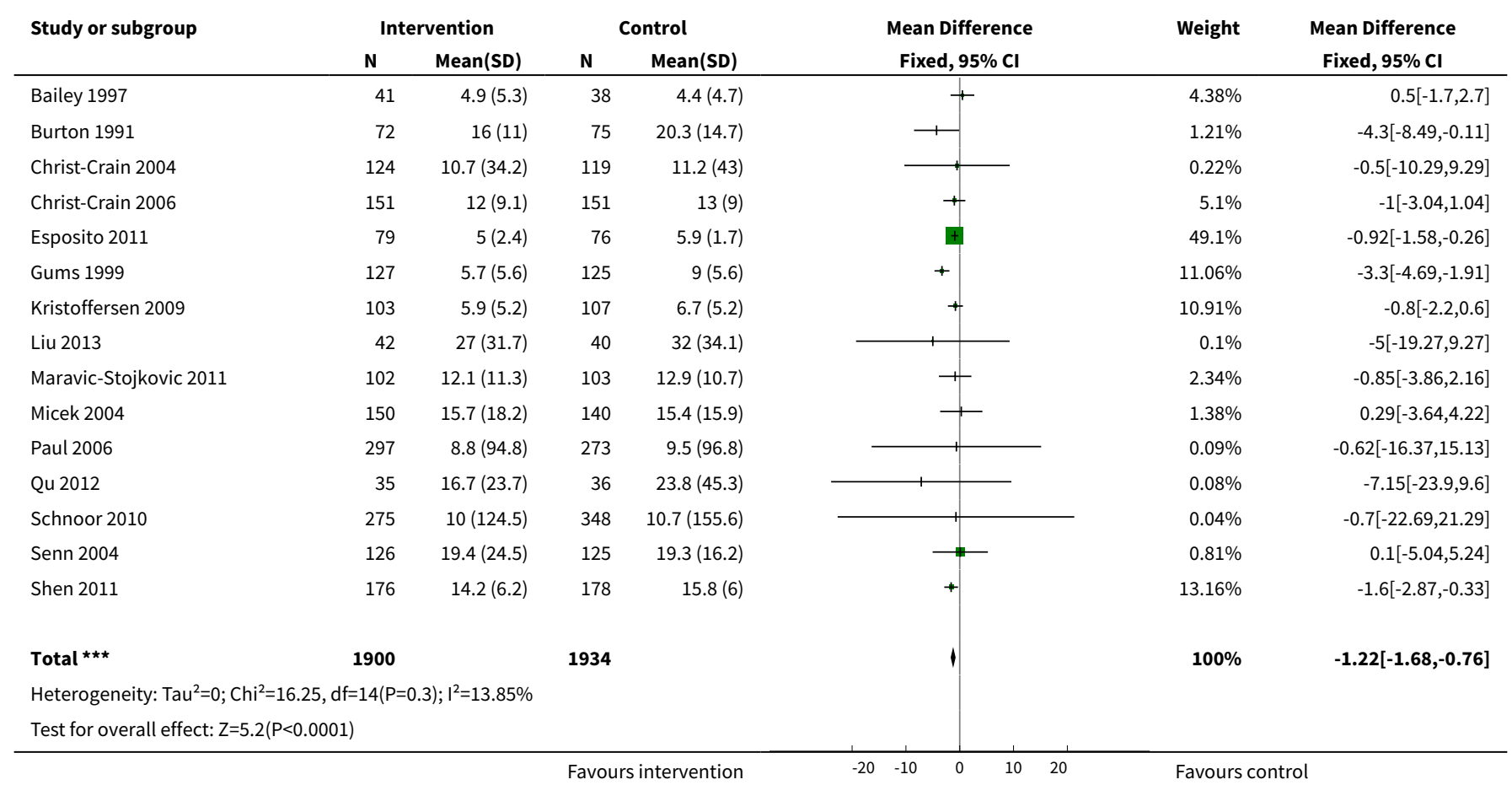

Analysis 2.6. Comparison 2 Adverse effects: Clinical outcomes from RCTs of interventions to reduce
unnecessary antibiotic use, Outcome 6 Length of stay, low or medium 'Risk of bias' RCTs only.

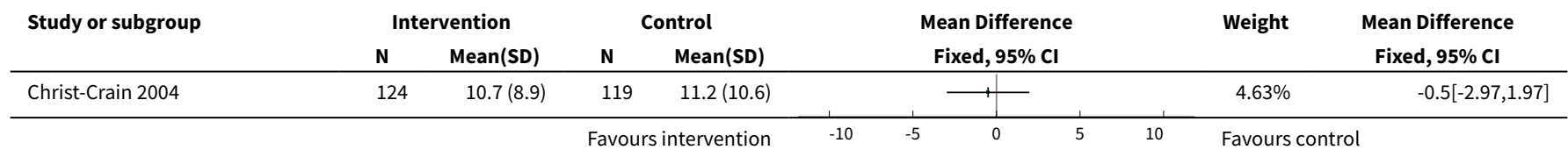




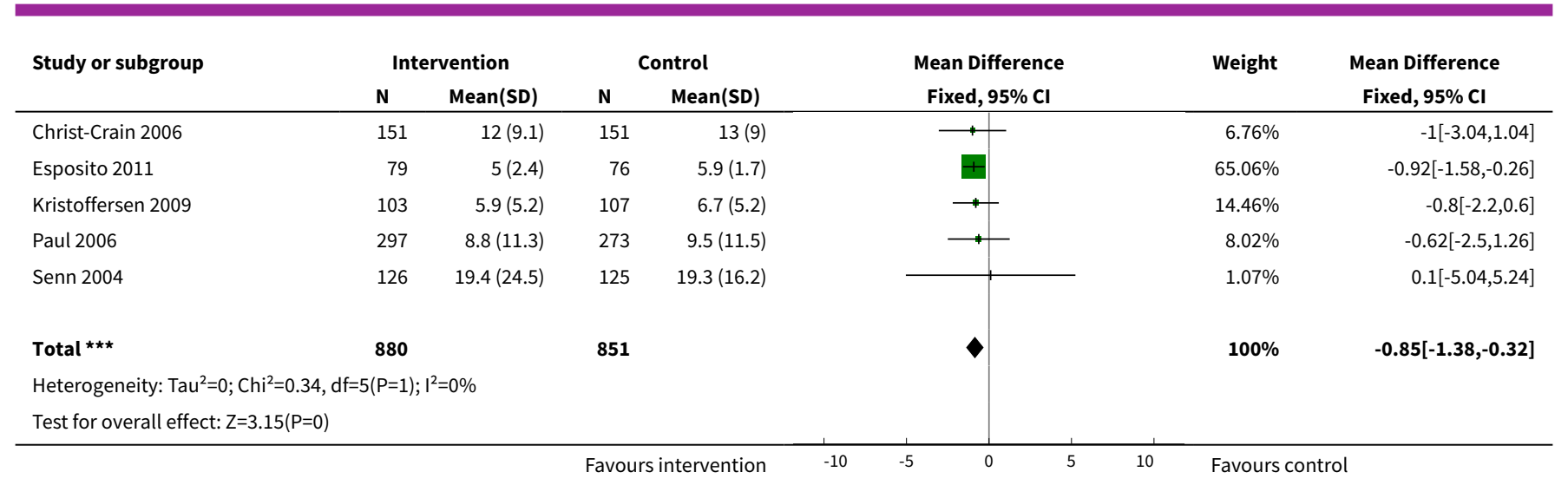

Comparison 3. Adverse effects: Clinical outcomes of interventions targeting antibiotic choice

\begin{tabular}{lllll}
\hline Outcome or subgroup title & No. of studies & $\begin{array}{l}\text { No. of partici- } \\
\text { pants }\end{array}$ & Statistical method & Effect size \\
\hline 1 Mortality for trial patients & 11 & 7658 & $\begin{array}{l}\text { Risk Difference (M-H, Fixed, 95\% } \\
\text { CI) }\end{array}$ & -0.00 [-0.02, 0.01] \\
\hline 2 Length of stay for trial patients & 7 & 2276 & $\begin{array}{l}\text { Mean Difference (IV, Fixed, 95\% } \\
\text { Cl) }\end{array}$ & -1.50 [-2.16, -0.83] \\
\hline
\end{tabular}

Analysis 3.1. Comparison 3 Adverse effects: Clinical outcomes of interventions targeting antibiotic choice, Outcome 1 Mortality for trial patients.

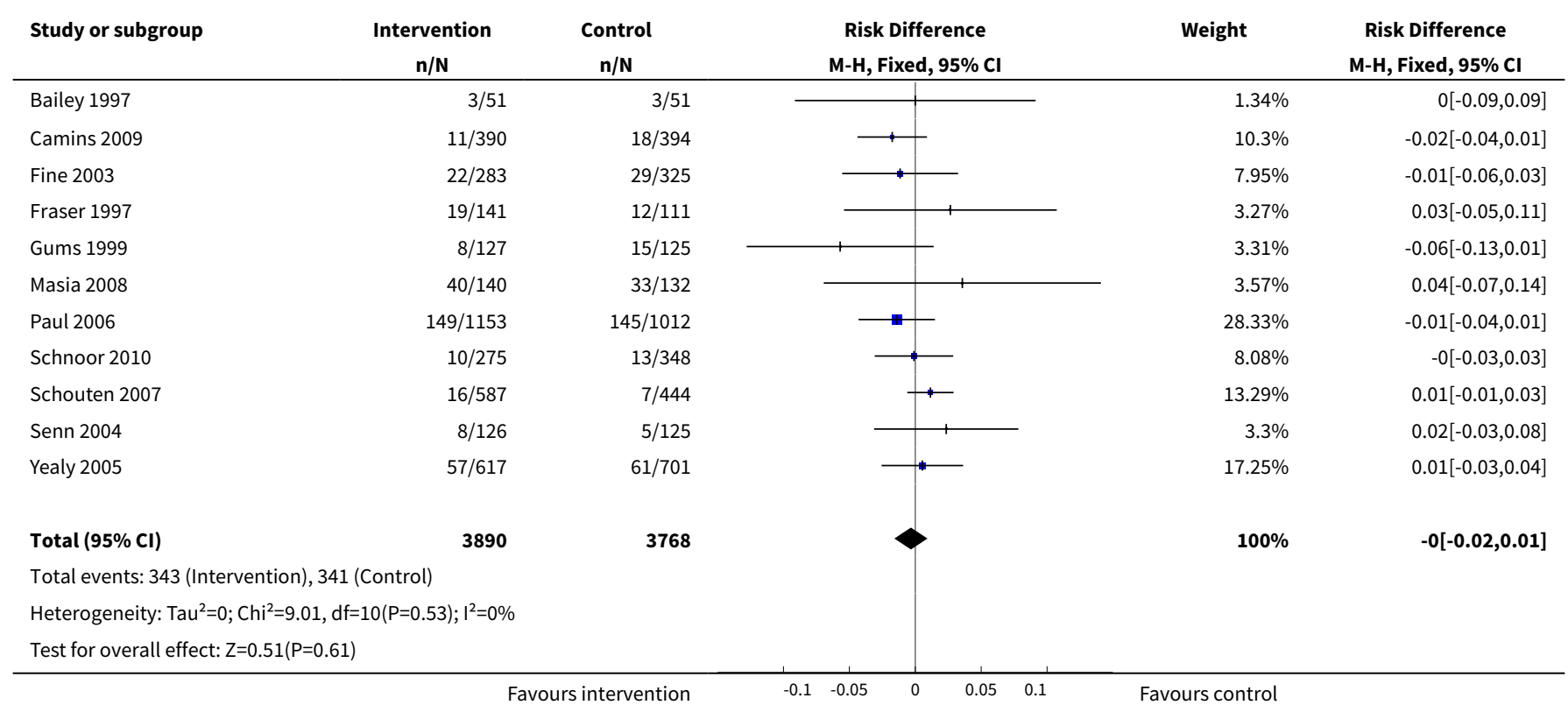


Analysis 3.2. Comparison 3 Adverse effects: Clinical outcomes of interventions targeting antibiotic choice, Outcome 2 Length of stay for trial patients.

\begin{tabular}{|c|c|c|c|c|c|c|c|c|}
\hline \multirow[t]{2}{*}{ Study or subgroup } & \multicolumn{2}{|c|}{ Intervention } & \multicolumn{2}{|c|}{ Control } & \multirow{2}{*}{\multicolumn{2}{|c|}{$\begin{array}{c}\text { Mean Difference } \\
\text { Fixed, } 95 \% \mathrm{Cl}\end{array}$}} & \multirow[t]{2}{*}{ Weight } & \multirow{2}{*}{$\begin{array}{c}\text { Mean Difference } \\
\text { Fixed, } 95 \% \mathrm{Cl}\end{array}$} \\
\hline & $\mathbf{N}$ & Mean(SD) & $\mathbf{N}$ & Mean(SD) & & & & \\
\hline Bailey 1997 & 41 & $4.9(5.3)$ & 38 & $4.4(4.7)$ & & \# & $9.04 \%$ & $0.5[-1.7,2.7]$ \\
\hline Burton 1991 & 72 & $16(11)$ & 75 & $20.3(14.7)$ & & & $2.49 \%$ & $-4.3[-8.49,-0.11]$ \\
\hline Gums 1999 & 127 & $5.7(5.6)$ & 125 & $9(5.6)$ & $\longrightarrow$ & & $22.83 \%$ & $-3.3[-4.69,-1.91]$ \\
\hline Paul 2006 & 297 & $8.8(11.3)$ & 273 & $9.5(11.5)$ & $\longrightarrow$ & - & $12.48 \%$ & $-0.62[-2.5,1.26]$ \\
\hline Schnoor 2010 & 275 & $10(7.6)$ & 348 & $10.7(9.5)$ & $\longrightarrow$ & 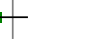 & $24.34 \%$ & $-0.7[-2.04,0.64]$ \\
\hline Shen 2011 & 176 & $14.2(6.2)$ & 178 & $15.8(6)$ & $\rightarrow-$ & & $27.16 \%$ & $-1.6[-2.87,-0.33]$ \\
\hline Total *** & 1114 & & 1162 & & & & $100 \%$ & $-1.5[-2.16,-0.83]$ \\
\hline \multicolumn{9}{|c|}{ Heterogeneity: $\mathrm{Tau}^{2}=0 ; \mathrm{Chi}^{2}=13.96, \mathrm{df}=6(\mathrm{P}=0.03) ; \mathrm{I}^{2}=57.01 \%$} \\
\hline Test for overall effect & & & & & & & & \\
\hline
\end{tabular}

Comparison 4. Adverse effects: Clinical outcomes of interventions targeting antibiotic exposure

\begin{tabular}{lllll}
\hline Outcome or subgroup title & No. of studies & $\begin{array}{l}\text { No. of partici- } \\
\text { pants }\end{array}$ & Statistical method & Effect size \\
\hline 1 Mortality for trial patients & 18 & 9173 & $\begin{array}{l}\text { Risk Difference (M-H, Fixed, 95\% } \\
\text { Cl) }\end{array}$ & $-0.00[-0.01,0.01]$ \\
\hline 2 Length of stay for trial patients & 8 & 1558 & $\begin{array}{l}\text { Mean Difference (IV, Fixed, 95\% } \\
\text { Cl) }\end{array}$ & $-0.87[-1.42,-0.33]$ \\
\hline
\end{tabular}

Analysis 4.1. Comparison 4 Adverse effects: Clinical outcomes of interventions targeting antibiotic exposure, Outcome 1 Mortality for trial patients.

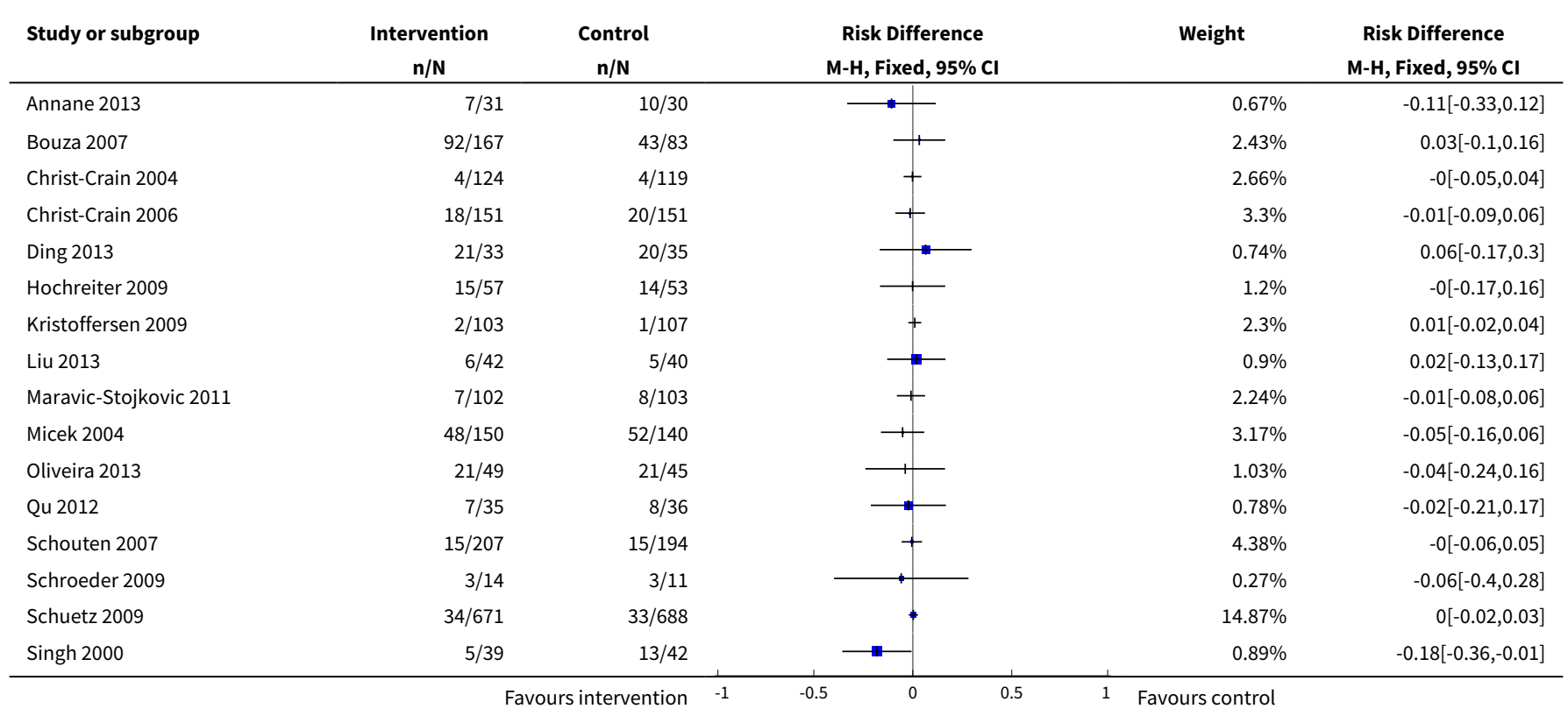




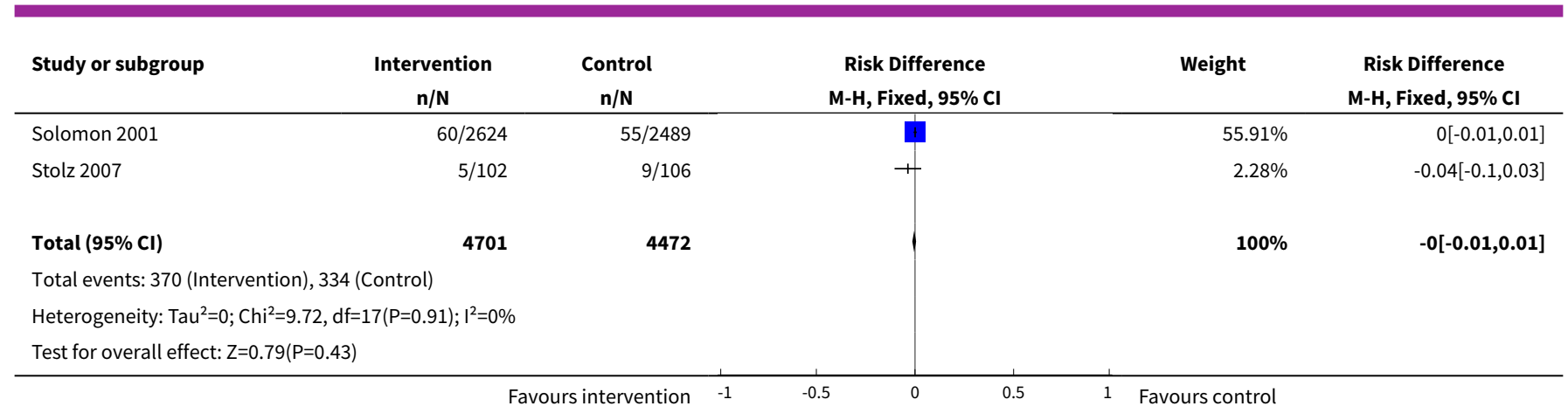

Analysis 4.2. Comparison 4 Adverse effects: Clinical outcomes of interventions targeting antibiotic exposure, Outcome 2 Length of stay for trial patients.

\begin{tabular}{|c|c|c|c|c|c|c|c|}
\hline \multirow[t]{2}{*}{ Study or subgroup } & \multicolumn{2}{|c|}{ Intervention } & \multicolumn{2}{|c|}{ Control } & \multirow{2}{*}{$\begin{array}{c}\text { Mean Difference } \\
\text { Fixed, } 95 \% \mathrm{Cl}\end{array}$} & \multirow[t]{2}{*}{ Weight } & \multirow{2}{*}{$\begin{array}{c}\text { Mean Difference } \\
\text { Fixed, } 95 \% \mathrm{Cl}\end{array}$} \\
\hline & $\mathbf{N}$ & Mean(SD) & $\mathbf{N}$ & Mean(SD) & & & \\
\hline Christ-Crain 2004 & 124 & $10.7(8.9)$ & 119 & $11.2(10.6)$ & $\rightarrow$ & $4.82 \%$ & $-0.5[-2.97,1.97]$ \\
\hline Christ-Crain 2006 & 151 & $12(9.1)$ & 151 & $13(9)$ & $\rightarrow$ & $7.04 \%$ & $-1[-3.04,1.04]$ \\
\hline Esposito 2011 & 79 & $5(2.4)$ & 76 & $5.9(1.7)$ & $T$ & $67.71 \%$ & $-0.92[-1.58,-0.26]$ \\
\hline Kristoffersen 2009 & 103 & $5.9(5.2)$ & 107 & $6.7(5.2)$ & $\rightarrow$ & $15.05 \%$ & $-0.8[-2.2,0.6]$ \\
\hline Liu 2013 & 42 & $27(31.7)$ & 40 & $32(34.1)$ & 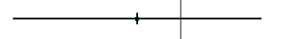 & $0.14 \%$ & $-5[-19.27,9.27]$ \\
\hline Maravic-Stojkovic 2011 & 102 & $12.1(11.3)$ & 103 & $12.9(10.7)$ & 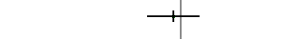 & $3.23 \%$ & $-0.85[-3.86,2.16]$ \\
\hline Micek 2004 & 150 & $15.7(18.2)$ & 140 & $15.4(15.9)$ & 1 & $1.9 \%$ & $0.29[-3.64,4.22]$ \\
\hline Qu 2012 & 35 & $16.7(23.7)$ & 36 & $23.8(45.3)$ & & $0.1 \%$ & $-7.15[-23.9,9.6]$ \\
\hline Total $\star \star \star ~$ & 786 & & 772 & & 1 & $100 \%$ & $-0.87[-1.42,-0.33]$ \\
\hline \multicolumn{8}{|c|}{ Heterogeneity: $\mathrm{Tau}^{2}=0 ; \mathrm{Chi}^{2}=1.33, \mathrm{df}=7(\mathrm{P}=0.99) ; \mathrm{I}^{2}=0 \%$} \\
\hline \multicolumn{8}{|c|}{ Test for overall effect: $Z=3.16(P=0)$} \\
\hline & & & Favo & rvention & -10 & Favours & \\
\hline
\end{tabular}

Comparison 5. Modifiers of intended effect: Comparison of enabling interventions with and without feedback

\begin{tabular}{lllll}
\hline Outcome or subgroup title & No. of studies & $\begin{array}{l}\text { No. of partici- } \\
\text { pants }\end{array}$ & Statistical method & Effect size \\
\hline 1 Enablement with feedback & 4 & 3747 & Risk Difference (M-H, Fixed, 95\% Cl) & $0.19[0.16,0.22]$ \\
\hline $\begin{array}{l}\text { 2 Enablement without feed- } \\
\text { back }\end{array}$ & 7 & 1827 & Risk Difference (M-H, Fixed, 95\% Cl) & $0.13[0.09,0.17]$ \\
\hline
\end{tabular}

Analysis 5.1. Comparison 5 Modifiers of intended effect: Comparison of enabling interventions with and without feedback, Outcome 1 Enablement with feedback.

\begin{tabular}{|c|c|c|c|c|c|c|c|}
\hline Study or subgroup & $\begin{array}{c}\text { Intervention } \\
\mathrm{n} / \mathrm{N} \\
\end{array}$ & $\begin{array}{c}\text { Control } \\
\mathrm{n} / \mathrm{N}\end{array}$ & & $\begin{array}{r}\text { Ris } \\
\text { M-H } \\
\end{array}$ & $\begin{array}{l}\text { fference } \\
\text { d, } 95 \% \mathrm{Cl}\end{array}$ & Weight & $\begin{array}{c}\text { Risk Difference } \\
\text { M-H, Fixed, 95\% CI }\end{array}$ \\
\hline Camins 2009 & $92 / 112$ & $60 / 138$ & & & $\longrightarrow$ & $6.78 \%$ & $0.39[0.28,0.5]$ \\
\hline Schnoor 2010 & $182 / 275$ & $186 / 348$ & & & $\longrightarrow$ & $16.84 \%$ & $0.13[0.05,0.2]$ \\
\hline
\end{tabular}




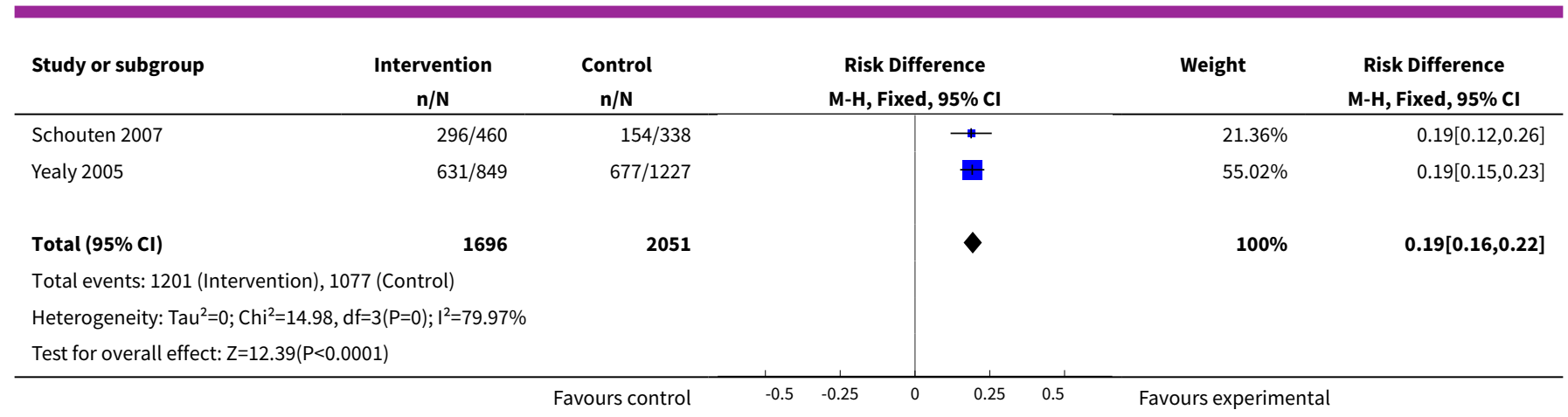

Analysis 5.2. Comparison 5 Modifiers of intended effect: Comparison of enabling interventions with and without feedback, Outcome 2 Enablement without feedback.

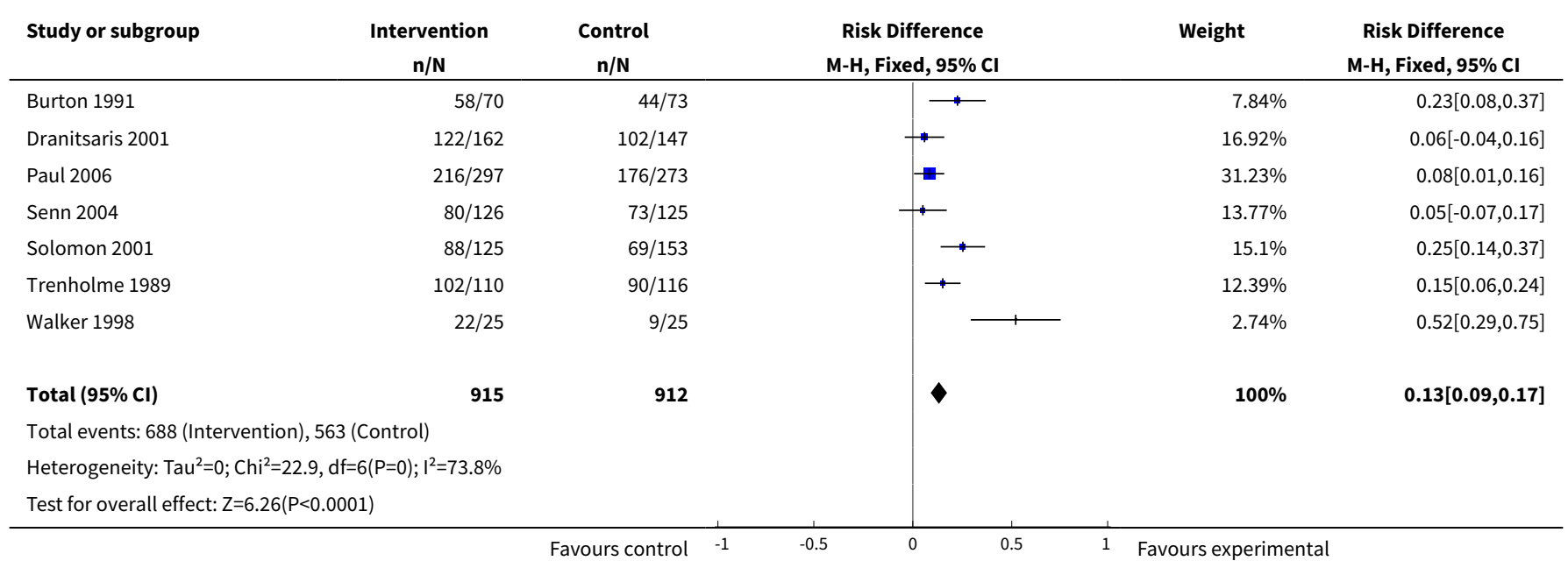

\section{ADDITIONAL TABLES}

Table 1. Definition of behaviour change techniques and intervention functions

\begin{tabular}{lll}
\hline Intervention Function & Definition & Intervention components \\
\hline Education & Increasing knowledge or understanding & Educational meetings; \\
& & $\begin{array}{l}\text { Dissemination of educational materials; } \\
\text { Educational outreach }\end{array}$ \\
\hline Persuasion & $\begin{array}{l}\text { Using communication to induce positive } \\
\text { or negative feelings or to stimulate action }\end{array}$ & $\begin{array}{l}\text { Educational outreach by academic detailing or review and } \\
\text { recommend change }\end{array}$ \\
\hline Restriction & $\begin{array}{l}\text { Using rules to reduce the opportunity } \\
\text { to engage in the target behaviour (or in- } \\
\text { crease the target behaviour by reducing } \\
\text { the opportunity to engage in competing } \\
\text { behaviours) }\end{array}$ & \\
\hline
\end{tabular}




\section{Table 1. Definition of behaviour change techniques and intervention functions (Continued)}

Environmental restruc- Changing the physical context turing
Reminders (physical) such as posters, pocket-size or credit card-size summaries or on laboratory test reports;

Structural (e.g. new laboratory tests or rapid reporting of results)

Audit and feedback;

Decision support through computerised systems or through circumstantial reminders that were triggered by actions or events related to the targeted behaviour;

Educational outreach by review and recommend change

Table 2. Unintended consequences of ITS studies: mortality*

\begin{tabular}{llllll}
\hline Study & Prescribing target & Restriction & $\begin{array}{l}\text { Design of analy- } \\
\text { sis }\end{array}$ & Effect estimate & 95\% Cl \\
\hline Lee 2014 & Choice of drug & No & Cohort & Incidence rate ratio 1.1 & 0.9 to 1.5 \\
\hline Popovski 2015 & Choice of drug & No & Cohort & Increase by 1.4\% & $-1.2 \%$ to $4.1 \%$ \\
\hline Wang 2014 & Choice of drug & Yes & $\begin{array}{l}\text { ITS, segmented re- } \\
\text { gression }\end{array}$ & Change in slope - 0.0172 & No data \\
\hline Yoon 2014 & Choice of drug & Yes & Cohort & +0.43 per 1000 OBD & No data \\
\hline
\end{tabular}

*Mortality was measured in all patients in the hospital rather than just those patients who were the targets of the interventions.

$\mathrm{Cl}$ : confidence interval

ITS: interrupted time series

OBD: occupied bed day

Table 3. Unintended consequences of ITS studies: length of stay*

\begin{tabular}{llllll}
\hline Study & Prescribing target & Restrictive & $\begin{array}{l}\text { Design of analy- } \\
\text { sis }\end{array}$ & Effect estimate & 95\% Cl \\
\hline Mittal 2014 & Exposure, \% treated & No & Cohort & -0.5 days & No data \\
\hline Skaer 1993 & Choice of drug & No & Cohort & -0.1 days & -0.49 to +0.29 \\
\hline
\end{tabular}

*Length of stay was measured in all patients in the hospital rather than just those patients who were the targets of the interventions. $\mathrm{Cl}$ : confidence interval

ITS: interrupted time series

Table 4. Unintended consequences of ITS studies: other

\begin{tabular}{|c|c|c|c|c|c|}
\hline Study & Prescribing target & $\begin{array}{l}\text { Design of } \\
\text { analysis }\end{array}$ & Effect measure & $\begin{array}{l}\text { Effect esti- } \\
\text { mate }\end{array}$ & $95 \% \mathrm{Cl}$ \\
\hline Bell 2014 & Antibiotic choice & $\begin{array}{l}\text { ITS, segmented } \\
\text { regression }\end{array}$ & $\begin{array}{l}\text { Risk of postoperative acute kid- } \\
\text { ney injury }\end{array}$ & Increase $98 \%$ & $\begin{array}{l}93.8 \% \text { to } \\
94.2 \%\end{array}$ \\
\hline
\end{tabular}


Table 4. Unintended consequences of ITS studies: other (Continued)

\begin{tabular}{llllll}
$\begin{array}{l}\text { Van Kasteren } \\
2005\end{array}$ & Exposure, duration & Cohort & Surgical-site infection & Decrease $0.8 \%$ & $-2.2 \%$ to $0.6 \%$ \\
\hline Volpe 2012 & $\begin{array}{l}\text { Time to first antibiotic } \\
\text { dose }\end{array}$ & Cohort & Left without being seen rate & Decrease 0.4\% & No data
\end{tabular}

$\mathrm{Cl}$ : confidence interval

ITS: interrupted time series

Table 5. Unintended consequences studies (case control, cohort, or qualitative)

\begin{tabular}{|c|c|c|c|c|c|}
\hline Study & Design & Patients & $\begin{array}{l}\text { Intended tar- } \\
\text { get }\end{array}$ & Unintended consequence & $\begin{array}{l}\text { Effect esti- } \\
\text { mate }\end{array}$ \\
\hline
\end{tabular}

\section{Interventions with a restrictive component}

\begin{tabular}{|c|c|c|c|c|c|c|}
\hline $\begin{array}{l}\text { Baysari } \\
2013\end{array}$ & Qualitative & $\begin{array}{l}36 \text { physi- } \\
\text { cians }\end{array}$ & \multirow{3}{*}{$\begin{array}{l}\text { Reduce unnec- } \\
\text { essary use of } \\
\text { restricted an- } \\
\text { tibiotics }\end{array}$} & Inaccurate feedback & \multicolumn{2}{|c|}{$\begin{array}{l}\text { Not quantified; qualitative } \\
\text { study }\end{array}$} \\
\hline Calfee 2003 & $\begin{array}{l}\text { Case con- } \\
\text { trol }\end{array}$ & Not clear & & $\begin{array}{l}\text { Increase in physician-based diagnosis } \\
\text { of nosocomial infection }\end{array}$ & \multicolumn{2}{|c|}{ No denominator data } \\
\hline $\begin{array}{l}\text { Connor } \\
2007\end{array}$ & Cohort & 120 & & $\begin{array}{l}\text { Failure to warn prescribers about dis- } \\
\text { continuation }\end{array}$ & - & - \\
\hline $\begin{array}{l}\text { Duvoisin } \\
2014\end{array}$ & Cohort & 222 & $\begin{array}{l}\text { Reduce unnec- } \\
\text { essary labora- } \\
\text { tory tests }\end{array}$ & $\begin{array}{l}\text { Delay in TFAD (HR }>1 \text { shows delay less } \\
\text { likely in intervention period) }\end{array}$ & $\begin{array}{l}\text { Multivari- } \\
\text { ate HR } 1.56\end{array}$ & 1.17 to 2.07 \\
\hline \multirow[t]{2}{*}{$\begin{array}{l}\text { LaRosa } \\
2007\end{array}$} & $\begin{array}{l}\text { Cross-sec- } \\
\text { tional }\end{array}$ & 15,440 & \multirow{5}{*}{$\begin{array}{l}\text { Reduce unnec- } \\
\text { essary use of } \\
\text { restricted an- } \\
\text { tibiotics }\end{array}$} & $\begin{array}{l}\text { Orders for restricted antibiotics (\% all } \\
\text { orders) from } 10 \text { to } 11 \mathrm{pm} \text { vs all other } \\
\text { hours }\end{array}$ & - & - \\
\hline & Cohort & 360 & & $\begin{array}{l}\% \text { appropriate orders } 10 \text { to } 11 \mathrm{pm} \text { vs } 9 \\
\text { to } 10 \mathrm{pm}\end{array}$ & $-23.7 \%$ & $\begin{array}{l}-31.8 \% \text { to } \\
-15.5 \%\end{array}$ \\
\hline Linkin 2007 & Cohort & 200 & & $\begin{array}{l}\text { Risk of inaccurate information in or- } \\
\text { ders judged inappropriate vs appropri- } \\
\text { ate }\end{array}$ & OR 2.2 & 1.0 to 4.4 \\
\hline \multirow{2}{*}{$\begin{array}{l}\text { Winters } \\
2010\end{array}$} & Cohort & 3251 & & Risk of 1-hour delay in TFAD & OR 1.5 & 1.2 to 1.8 \\
\hline & & & & Risk of 2-hour delay in TFAD & OR 1.8 & 1.4 to 2.2 \\
\hline
\end{tabular}

\section{Interventions with no restrictive component}

\begin{tabular}{|c|c|c|c|c|c|c|}
\hline $\begin{array}{l}\text { Friedberg } \\
2009\end{array}$ & Cohort & 13,042 & $\begin{array}{l}\text { Reduce time } \\
\text { to first antibi- }\end{array}$ & $\%$ CAP diagnoses & $\begin{array}{l}1 \% \text { in- } \\
\text { crease }\end{array}$ & $\begin{array}{l}\text { No denomi- } \\
\text { nator data }\end{array}$ \\
\hline $\begin{array}{l}\text { Kanwar } \\
2007\end{array}$ & Cohort & 518 & $\begin{array}{l}\text { patients with } \\
\text { community-ac- }\end{array}$ & $\%$ correct CAP diagnoses & $\begin{array}{l}-7.9 \% \text { de- } \\
\text { crease }\end{array}$ & $\begin{array}{l}-15.4 \% \text { to } \\
-0.4 \%\end{array}$ \\
\hline $\begin{array}{l}\text { Welker } \\
2008\end{array}$ & Cohort & 548 & monia & $\%$ correct CAP diagnoses & $\begin{array}{l}-16.0 \% \text { de- } \\
\text { crease }\end{array}$ & $\begin{array}{l}-7.6 \% \text { to } \\
-24.4 \%\end{array}$ \\
\hline
\end{tabular}

CAP: community-acquired pneumonia 
$\mathrm{Cl}$ : confidence interval

HR: hazard ratio

OR: odds ratio

TFAD: time to the first antibiotic dose

Table 6. Summary of intervention components for 29 RCTs (Analysis 1.1; Figures 3 and 7 ) and 91 ITS studies (Figure 10)

\begin{tabular}{|c|c|c|}
\hline Intervention function and components & RCT & ITS \\
\hline \multirow[t]{2}{*}{ Enablement } & 24 & 59 \\
\hline & studies & studies \\
\hline Number of enabling or restrictive intervention components & 27 & 76 \\
\hline \multirow[t]{2}{*}{ Studies with $>1$ Enabling intervention component } & 2 & 19 \\
\hline & $8 \%{ }^{*}$ & $32 \%{ }^{\star}$ \\
\hline \multirow[t]{2}{*}{ Audit and feedback } & 4 & 24 \\
\hline & $17 \%$ & $41 \%$ \\
\hline \multirow[t]{2}{*}{ Computerised decision support } & 1 & 3 \\
\hline & $4 \%$ & $5 \%$ \\
\hline \multirow[t]{2}{*}{ Circumstantial reminders } & 16 & 18 \\
\hline & $67 \%$ & $31 \%$ \\
\hline \multirow[t]{2}{*}{ Review and recommend change } & 6 & 31 \\
\hline & $25 \%$ & $53 \%$ \\
\hline \multirow[t]{2}{*}{ Restriction } & 2 & 29 \\
\hline & studies & studies \\
\hline Number of Restrictive intervention components & 3 & 41 \\
\hline \multirow[t]{2}{*}{ Studies with $>1$ Restrictive intervention component } & 1 & 10 \\
\hline & $50 \%$ & $34 \%$ \\
\hline \multirow[t]{2}{*}{ Expert approval } & 1 & 18 \\
\hline & $50 \%$ & $62 \%$ \\
\hline \multirow[t]{2}{*}{ Compulsory order form } & 1 & 7 \\
\hline & $50 \%$ & $24 \%$ \\
\hline \multirow[t]{2}{*}{ Removal } & 0 & 10 \\
\hline & & $34 \%$ \\
\hline \multirow[t]{2}{*}{ Review and make change } & 1 & 6 \\
\hline & $50 \%$ & $21 \%$ \\
\hline
\end{tabular}


Table 6. Summary of intervention components for 29 RCTs (Analysis 1.1; Figures 3 and 7) and 91 ITS studies (Figure 10) (Continued)

\begin{tabular}{lll} 
No Enablement or Restriction & 4 & 18 \\
& studies & studies \\
\hline Number of intervention components & 6 & 25 \\
\hline Studies with > 1 intervention component & 2 & 6 \\
& $50 \%$ & $33 \%$ \\
\hline Educational materials or meetings & 3 & 16 \\
\hline Educational outreach (academic detailing) & $75 \%$ & $89 \%$ \\
\hline Physical reminders & 1 & 6 \\
\hline Structural intervention & $25 \%$ & $33 \%$ \\
\hline
\end{tabular}

*The denominator for all percentages is the number of studies for each intervention function. One RCT, Strom 2010, and 16 ITS studies (Figure 11) included both enabling and restrictive intervention components.

ITS: interrupted time series

$\mathrm{RCT}$ : randomised controlled trial

Table 7. Data from 5 studies about the effect of removal of interventions. The intended effect of all interventions was reduction in unnecessary antibiotic use

\begin{tabular}{|c|c|c|c|c|}
\hline Study & $\begin{array}{l}\text { Intervention func- } \\
\text { tion }\end{array}$ & $\begin{array}{l}\text { Intervention effect ( } 95 \% \\
\mathrm{Cl} \text { ) }\end{array}$ & $\begin{array}{l}\text { Time intervention } \\
\text { was in place }\end{array}$ & Effect of removal $(95 \% \mathrm{Cl})$ \\
\hline \multirow[t]{2}{*}{ Kallen 2009} & Restriction & $-87.5 \%$ & 6 months & $398.9 \%$ \\
\hline & & -115.4 to -59.7 & & 238.2 to 559.5 \\
\hline \multirow[t]{2}{*}{ Kim 2008} & Restriction & $-23.1 \%$ & 9 months & $6.0 \%$ \\
\hline & & -53.7 to +7.4 & & -23.4 to 35.4 \\
\hline \multirow[t]{2}{*}{ Standiford 2012} & Enablement & $-28.6 \%$ & 7 years & $31.0 \%$ \\
\hline & & -46.5 to -10.6 & & 6.8 to 55.3 \\
\hline \multirow{2}{*}{$\begin{array}{l}\text { Himmelberg } \\
1991\end{array}$} & Restriction & No data & "long-standing" & $301.2 \%$ \\
\hline & & & & 230.9 to 371.5 \\
\hline \multirow[t]{2}{*}{ Skrlin 2011} & Restriction & & 2 years & $255.8 \%$ \\
\hline & & & & 194.7 to 316.9 \\
\hline
\end{tabular}


$\mathrm{Cl}$ : confidence interval

Table 8. Randomised controlled trials with microbial outcomes

\begin{tabular}{llll}
\hline Study & Design & Microbial outcome & Reason not in meta-analysis \\
\hline Annane 2013 & RCT & $\begin{array}{l}\text { Colonisation with MRSA (nasal swab) } \\
\text { and GNRB (rectal swabs) }\end{array}$ & Not comparable with any other RCT \\
\hline Bouza 2007 & RCT & Number of cases of Clostridium difficile & Not in prescribing meta-analysis \\
\hline Lesprit 2013 & RCT & $\begin{array}{l}\text { Secondary infection and/or colonisation } \\
\text { with multidrug-resistant bacteria in the } \\
\text { 6 months following randomisation }\end{array}$ & $\begin{array}{l}\text { Not in prescribing meta-analysis. It is im- } \\
\text { possible to assess the impact of the inter- } \\
\text { vention on colonisation or infection with } \\
\text { bacteria resistant to specific antibiotics. }\end{array}$ \\
\hline Palmay 2014 & RCT & $\begin{array}{l}\text { CDI and infection with antibiotic resis- } \\
\text { tant organisms cases/1000 OBD }\end{array}$ & \begin{tabular}{l} 
Not in prescribing meta-analysis \\
\hline Singh 2000
\end{tabular} \\
\hline RCT & $\begin{array}{l}\text { Number of participants with "antimicro- } \\
\text { bial resistance and/or superinfections" } \\
\text { from randomisation until discharge } \\
\text { from hospital }\end{array}$ & $\begin{array}{l}\text { It is impossible to assess the impact of the } \\
\text { intervention on colonisation or infection } \\
\text { with bacteria resistant to specific antibi- } \\
\text { otics. }\end{array}$ \\
\hline
\end{tabular}

CDI: Clostridium difficile infection

GNRB: gram-negative resistant bacteria

MRSA: methicillin-resistant Staphylococcus aureus

OBD: occupied bed day

$\mathrm{RCT}$ : randomised controlled trial

Table 9. Microbial outcomes from 26 ITS studies from the prescribing meta-analysis that include reliable data about prescribing outcomes at 6 months and microbial outcomes at 12 months postintervention

\begin{tabular}{llll}
\hline Prescribing target & Microbial outcome & N & Study ID \\
\hline Cephalosporins & GNRB & 8 & $\begin{array}{l}\text { Grohs 2014; Kim 2008; Knudsen 2014; Lee 2007; McNulty 1997; } \\
\text { Meyer 2009; Petrikkos 2007; Tangdén 2011 }\end{array}$ \\
\cline { 2 - 4 } & MRSA & 1 & May 2000 \\
\hline Carbapenems & GNRB & 1 & Goldstein 2009 \\
\hline Fluoroquinolones & GNRB & 3 & Cook 2011b; Lafaurie 2012; Willemsen 2010 \\
\cline { 2 - 4 } & MRSA & 1 & Lafaurie 2012 \\
\hline High-risk antibi- & CDI & 6 & $\begin{array}{l}\text { Aldeyab 2012; Chan 2011; Dancer 2013; Fowler 2007; Talpaert } \\
\text { 2011; Valiquette 2007 }\end{array}$ \\
\cline { 2 - 4 } & GNRB & 4 & Buising 2008a; Chan 2011; Dancer 2013; Liebowitz 2008 \\
\cline { 2 - 4 } & MRSA & 6 & $\begin{array}{l}\text { Aldeyab 2014; Ananda-Rajah 2010; Chan 2011; Dancer 2013; } \\
\text { Fowler 2007; Liebowitz 2008 }\end{array}$ \\
\hline Total antibiotic use & CDI & 2 & \begin{tabular}{l} 
Cook 2011a; Jump 2012 \\
\cline { 2 - 4 }
\end{tabular} \\
\cline { 2 - 4 } & MRSA & 1 & Cook 2011a \\
\hline
\end{tabular}


Table 9. Microbial outcomes from 26 ITS studies from the prescribing meta-analysis that include reliable data about prescribing outcomes at 6 months and microbial outcomes at 12 months postintervention (Continued)

\begin{tabular}{|c|c|c|c|}
\hline Vancomycin & VRE & 1 & Lautenbach 2003 \\
\hline & Total microbial & $34^{\star}$ & \\
\hline
\end{tabular}

*Some studies had more than one microbial outcome, so the total is 34 microbial outcomes from 26 studies.

CDI: Clostridium difficile infection

GNRB: gram-negative resistant bacteria

ITS: interrupted time series

MRSA: methicillin-resistant Staphylococcus aureus

VRE: vancomycin-resistant enterococci

\section{AP P E N DICES}

\section{Appendix 1. Search strategies}

\section{MEDLINE <1946 to Present> and MEDLINE In-Process \& Other Non-Indexed Citations (Searched 19 January 2015) (OvidSP)}

1 (hospital\$ and antibiotic?).ti.

2 ((antibiotic? or alamethicin? or amdinocillin? or amdinocillin pivoxil? or amikacin? or amoxicillin? or amoxicillin-potassium clavulanate combination? or amphotericin? or ampicillin? or anisomycin? or antimycin? or aurodox? or azithromycin? or azlocillin? or aztreonam? or bacitracin? or bacteriocin? or bambermycin? or bongkrekic acid? or brefeldin? or butirosin sulfate? or calcimycin? or candicidin? or capreomycin? or carbenicillin? or carfecillin? or cefaclor? or cefadroxil? or cefamandole? or cefatrizine? or cefazolin? or cefixime? or cefmenoxime? or cefmetazole? or cefonicid? or cefoperazone? or cefotaxime? or cefotetan? or cefotiam? or cefoxitin? or cefsulodin? or ceftazidime? or ceftizoxime? or ceftriaxone? or cefuroxime? or cephacetrile? or cephalexin? or cephaloglycin? or cephaloridine? or cephalosporin? or cephalothin? or cephamycin? or cephapirin? or cephradine? or chloramphenicol? or chlortetracycline? or citrinin? or clarithromycin? or clavulanic acid? or clavulanic acid? or clindamycin? or cloxacillin? or colistin? or cyclacillin? or dactinomycin? or daptomycin? or demeclocycline? or dibekacin? or dicloxacillin? or dihydrostreptomycin sulfate? or diketopiperazine? or distamycin? or doxycycline? or echinomycin? or edeine? or enviomycin? or erythromycin? or erythromycin estolate? or erythromycin ethylsuccinate? or filipin? or floxacillin? or fluoroquinolone? or fosfomycin? or framycetin? or fusidic acid? or gentamicin? or gramicidin? or hygromycin? or imipenem? or josamycin? or kanamycin? or kitasamycin? or lactam? or lasalocid? or leucomycin? or lincomycin? or lincosamide? or lucensomycin? or lymecycline? or mepartricin? or methacycline? or methicillin? or mezlocillin? or mikamycin? or minocycline? or miocamycin? or moxalactam? or mupirocin? or mycobacillin? or nafcillin? or natamycin? or nebramycin? or neomycin? or netilmicin? or netropsin? or nigericin? or nisin? or norfloxacin? or novobiocin? or nystatin? or ofloxacin? or oleandomycin? or oligomycin? or oxacillin? or oxytetracycline? or paromomycin? or penicillanic acid? or penicillic acid? or penicillin?? or piperacillin? or pivampicillin? or polymyxin b? or polymyxin? or pristinamycin? or prodigiosin? or ribostamycin? or rifabutin? or rifamycin? or ristocetin? or rolitetracycline? or roxarsone? or roxithromycin? or rutamycin? or sirolimu? or sisomicin? or spectinomycin? or spiramycin? or streptogramin?? or streptomycin? or streptovaricin? or sulbactam? or sulbenicillin? or sulfamerazine? or sulfamethoxypyridazine? or talampicillin? or teicoplanin? or tetracycline? or thiamphenicol? or thienamycin? or thiostrepton? or ticarcillin? or tobramycin? or troleandomycin? or tunicamycin? or tylosin? or tyrocidine? or tyrothricin? or valinomycin? or vancomycin? or vernamycin? or viomycin? or virginiamycin? or beta-lactams) adj2 (resistant or resistance)).ti,ab. and (pc.fs. or (preventi\$ or best practice? or evidence\$ or policy or policies or pathway?).ti,ab,hw. or (guidance or guiding or guide? or guideline? or algorithm? or collaborat\$ or computer\$ or decision\$ or emergency or formulary or guidance or guideline? or icu or impact or initiat\$ or intensive care interdisciplin\$ or interprofession\$ or multidisciplin\$ or multi-disciplin $\$$ or notification? or order entry or pharmacist? or pharmacy or pharmacies or policy or policies or prescrib\$ or (quality adj2 (manag\$ or improv\$ or circle?)) or ((patient? or hospital?) adj2 record?) or reminder? or rotating or rotation or support or team\$).ti,ab.)

3 (antibiotic? and (education\$ or continuing-education\$ or cme or decision-making or evidence-based or ebm or guidance or guideline? or habit? or impact or improper\$ or inappropriat\$ or influenc\$ or intervention? or management or overprescrib\$ or overuse or overusing or pattern? or policy or policies or prescribing or prudent\$ or stewardship? or rational or unnecessary or "use" or "usage")).ti.

4 (antibiotic? adj4 (education\$ or continuing-education\$ or cme or decision-making or evidence-based or ebm or guidance or guideline? or habit? or impact or improper\$ or inappropriat\$ or influenc\$ or intervention? or management or overprescrib\$ or overuse or overusing or pattern? or policy or policies or prescribing or prudent\$ or rational or stewardship or unnecessary or "use" or "usage")).ab.

5 antibiotic?.ti. and evidence-based.hw.

6 ((antimicrobial? or anti-microbial? or penicillin?) and (stewardship or guidance or guideline? or policy or policies)).ti. 
7 ((antimicrobial? or anti-microbial? or penicillin?) adj3 (stewardship or guidance or guideline? or policy or policies)).ab.

8 (antibiotic? adj5 (hour? or immediat\$ or emergency)).ab. or (antibiotic? and (hour? or immediat\$ or emergency)).ti. or (antibiotic? adj3 (rotat\$ or timing or time or decision\$ or notification or appropriat\$)).ab. or (antibiotic? and (rotat\$ or timing or time or decision\$ or notification or appropriat\$)).ti.

9 or $11-8$

10 exp anti-bacterial agents/

11 antibiotic?.ti,ab.

12 (alamethicin or amdinocillin or amdinocillin pivoxil or amikacin or amoxicillin or amoxicillin-potassium clavulanate combination or amphotericin or ampicillin or anisomycin or antimycin or aurodox or azithromycin or azlocillin or aztreonam or bacitracin or bacteriocins or bambermycins or bongkrekic acid or brefeldin or butirosin sulfate or calcimycin or candicidin or capreomycin or carbenicillin or carfecillin or cefaclor or cefadroxil or cefamandole or cefatrizine or cefazolin or cefixime or cefmenoxime or cefmetazole or cefonicid or cefoperazone or cefotaxime or cefotetan or cefotiam or cefoxitin or cefsulodin or ceftazidime or ceftizoxime or ceftriaxone or cefuroxime or cephacetrile or cephalexin or cephaloglycin or cephaloridine or cephalosporins or cephalothin or cephamycins or cephapirin or cephradine or chloramphenicol or chlortetracycline or citrinin or clarithromycin or clavulanic acid or clavulanic acids or clindamycin or cloxacillin or colistin or cyclacillin or dactinomycin or daptomycin or demeclocycline or dibekacin or dicloxacillin or dihydrostreptomycin sulfate or diketopiperazines or distamycins or doxycycline or echinomycin or edeine or enviomycin or erythromycin or erythromycin estolate or erythromycin ethylsuccinate or filipin or floxacillin or fluoroquinolones or fosfomycin or framycetin or fusidic acid or gentamicins or gramicidin or hygromycin or imipenem or josamycin or kanamycin or kitasamycin or lactams or lasalocid or leucomycins or lincomycin or lincosamides or lucensomycin or lymecycline or mepartricin or methacycline or methicillin or mezlocillin or mikamycin or minocycline or miocamycin or moxalactam or mupirocin or mycobacillin or nafcillin or natamycin or nebramycin or neomycin or netilmicin or netropsin or nigericin or nisin or norfloxacin or novobiocin or nystatin or ofloxacin or oleandomycin or oligomycins or oxacillin or oxytetracycline or paromomycin or penicillanic acid or penicillic acid or penicillin? or piperacillin or pivampicillin or polymyxin b or polymyxins or pristinamycin or prodigiosin or ribostamycin or rifabutin or rifamycins or ristocetin or rolitetracycline or roxarsone or roxithromycin or rutamycin or sirolimus or sisomicin or spectinomycin or spiramycin or streptogramin? or streptomycin or streptovaricin or sulbactam or sulbenicillin or sulfamerazine or sulfamethoxypyridazine or talampicillin or teicoplanin or tetracycline or thiamphenicol or thienamycins or thiostrepton or ticarcillin or tobramycin or troleandomycin or tunicamycin or tylosin or tyrocidine or tyrothricin or valinomycin or vancomycin or vernamycin or viomycin or virginiamycin or beta-lactams).ti,ab.

13 (infection control\$ or nosocomial\$ or cross infection? or hospital acquired infection? or mrsa).ti,ab.

14 methicillin resistan $\$ . t i, a b$.

15 aminoglycosides/ or metronidazole/ or anti-infective agents/ or anti-infective agents, urinary/

\section{6 or/10-15}

17 (programs or programmes).ti.

18 empiric.ti.

19 (quality adj3 improvement?).ti.

20 (adherence or alert? or benchmark\$ or (change adj3 treatment) or computer assist\$ or computer support or computeri?ed or clinical decision\$ or dosing or education\$ or formulary or guidance or guideline? or impact or intervention or justification or methicillan-resistant or overuse or over-prescrib\$ or overprescrib\$ or pathway? or pharmacist? or policy or policies or program or programme or (quality adj3 improv\$) or reminder? or resistance or restriction? or rotation? or timing or turnaround or unnecessary).ti.

21 or/17-20

2216 and 21

2322 not 9

24 (randomized controlled trial or controlled clinical trial).pt. or randomized.ab. or placebo.ab. or clinical trials as topic.sh. or randomly.ab. or trial.ti.

25 exp animals/ not humans.sh.

2643 not 45 
27 intervention?.ti. or (intervention? adj6 (clinician? or collaborat\$ or community or complex or design\$ or doctor? or educational or family doctor? or family physician? or family practitioner? or financial or gp or general practice? or hospital? or impact? or improv\$ or individuali? e? or individuali?ing or interdisciplin\$ or multicomponent or multi-component or multidisciplin\$ or multi-disciplin\$ or multifacet\$ or multi-facet\$ or multimodal\$ or multi-modal\$ or personali?e? or personali?ing or pharmacies or pharmacist? or pharmacy or physician? or practitioner? or prescrib\$ or prescription? or primary care or professional\$ or provider? or regulatory or regulatory or tailor\$ or target \$ or team\$ or usual care)).ab.

28 (pre-intervention? or preintervention? or "pre intervention?" or post-intervention? or postintervention? or "post intervention?").ti,ab.

29 (hospital\$ or patient?).hw. and (study or studies or care or health\$ or practitioner? or provider? or physician? or nurse? or nursing or doctor?).ti,hw.

30 demonstration project?.ti,ab.

31 (pre-post or "pre test\$" or pretest\$ or posttest\$ or "post test\$" or (pre adj5 post)).ti,ab.

32 (pre-workshop or post-workshop or (before adj3 workshop) or (after adj3 workshop)).ti,ab.

33 trial.ti. or ((study adj3 aim?) or "our study").ab.

34 (before adj10 (after or during)).ti,ab.

35 ("quasi-experiment\$" or quasiexperiment\$ or "quasi random\$" or quasirandom\$ or "quasi control\$" or quasicontrol\$ or ((quasi\$ or experimental) adj3 (method\$ or study or trial or design\$))).ti,ab,hw.

36 ("time series" adj2 interrupt\$).ti,ab,hw.

37 (time points adj3 (over or multiple or three or four or five or six or seven or eight or nine or ten or eleven or twelve or month\$ or hour? or day? or "more than")).ab.

38 pilot.ti.

39 pilot projects/ [ml]

40 (clinical trial or controlled clinical trial or multicenter study).pt. [ml]

41 (multicentre or multicenter or multi-centre or multi-center).ti.

42 andom\$.ti,ab. or controlled.ti.

43 (control adj3 (area or cohort? or compare? or condition or design or group? or intervention? or participant? or study)).ab. not (controlled clinical trial or randomized controlled trial).pt. [ml]

44 "comment on".cm. or review.ti,pt. or randomized controlled trial.pt. [ml]

45 review.ti.

46 (rat or rats or cow or cows or chicken? or horse or horses or mice or mouse or bovine or animal?).ti.

47 exp animals/ not humans.sh.

48 (animal\$ not human\$).sh,hw.

49 *experimental design/ or * pilot study/ or quasi experimental study/ [em]

50 ("quasi-experiment\$" or quasiexperiment\$ or "quasi random\$" or quasirandom\$ or "quasi control\$" or quasicontrol\$ or ((quasi\$ or experimental) adj3 (method\$ or study or trial or design\$))).ti,ab.

51 ("time series" adj2 interrupt\$).ti,ab.

52 or $/ 26-43$

53 or $/ 44-48$

5452 not 53

559 or 23 
5654 and 55

\section{EMBASE <1996 to 2015 Week 03> (Searched 22 January 2015) (OvidSP)}

\section{1 exp *antibiotic agent/}

2 (bundle or bundles or education\$ or continuing-education\$ or cme or decision-making or guidance or (guideline? adj2 (adherence or implement or complian $\$$ or comply $\$)$ ) or improper\$ or inappropriat or incorrect $\$$ or nurse led or overprescrib\$ or overuse or overusing or pharmacist initiated or physician? practice? or policy or policies or practice pattern? or (prescribing adj2 (ebm or evidence-based or habit? or pattern? or practice or practices)) or prudent\$ or rational or stewardship or unnecessary or underprescrib\$).ti.

3 ("antibiotic use" or "antibiotic usage").ti.

4 (hospital\$ and antibiotic?).ti.

5 ((antibiotic? or alamethicin? or amdinocillin? or amdinocillin pivoxil? or amikacin? or amoxicillin? or amoxicillin-potassium clavulanate combination? or amphotericin? or ampicillin? or anisomycin? or antimycin? or aurodox? or azithromycin? or azlocillin? or aztreonam? or bacitracin? or bacteriocin? or bambermycin? or bongkrekic acid? or brefeldin? or butirosin sulfate? or calcimycin? or candicidin? or capreomycin? or carbenicillin? or carfecillin? or cefaclor? or cefadroxil? or cefamandole? or cefatrizine? or cefazolin? or cefixime? or cefmenoxime? or cefmetazole? or cefonicid? or cefoperazone? or cefotaxime? or cefotetan? or cefotiam? or cefoxitin? or cefsulodin? or ceftazidime? or ceftizoxime? or ceftriaxone? or cefuroxime? or cephacetrile? or cephalexin? or cephaloglycin? or cephaloridine? or cephalosporin? or cephalothin? or cephamycin? or cephapirin? or cephradine? or chloramphenicol? or chlortetracycline? or citrinin? or clarithromycin? or clavulanic acid? or clavulanic acid? or clindamycin? or cloxacillin? or colistin? or cyclacillin? or dactinomycin? or daptomycin? or demeclocycline? or dibekacin? or dicloxacillin? or dihydrostreptomycin sulfate? or diketopiperazine? or distamycin? or doxycycline? or echinomycin? or edeine? or enviomycin? or erythromycin? or erythromycin estolate? or erythromycin ethylsuccinate? or filipin? or floxacillin? or fluoroquinolone? or fosfomycin? or framycetin? or fusidic acid? or gentamicin? or gramicidin? or hygromycin? or imipenem? or josamycin? or kanamycin? or kitasamycin? or lactam? or lasalocid? or leucomycin? or lincomycin? or lincosamide? or lucensomycin? or lymecycline? or mepartricin? or methacycline? or methicillin? or mezlocillin? or mikamycin? or minocycline? or miocamycin? or moxalactam? or mupirocin? or mycobacillin? or nafcillin? or natamycin? or nebramycin? or neomycin? or netilmicin? or netropsin? or nigericin? or nisin? or norfloxacin? or novobiocin? or nystatin? or ofloxacin? or oleandomycin? or oligomycin? or oxacillin? or oxytetracycline? or paromomycin? or penicillanic acid? or penicillic acid? or penicillin?? or piperacillin? or pivampicillin? or polymyxin b? or polymyxin? or pristinamycin? or prodigiosin? or ribostamycin? or rifabutin? or rifamycin? or ristocetin? or rolitetracycline? or roxarsone? or roxithromycin? or rutamycin? or sirolimu? or sisomicin? or spectinomycin? or spiramycin? or streptogramin?? or streptomycin? or streptovaricin? or sulbactam? or sulbenicillin? or sulfamerazine? or sulfamethoxypyridazine? or talampicillin? or teicoplanin? or tetracycline? or thiamphenicol? or thienamycin? or thiostrepton? or ticarcillin? or tobramycin? or troleandomycin? or tunicamycin? or tylosin? or tyrocidine? or tyrothricin? or valinomycin? or vancomycin? or vernamycin? or viomycin? or virginiamycin? or beta-lactams) adj2 (resistant or resistance) adj10 (best practice? or (chang\$ adj (practice or clinical practice)) or evidence-base? or policy or policies or pathway? or ((treatment or care) adj (algorithm? or pathway? or protocol)) or collaborat $\$$ or computeri?ed or computer-supported or decision-mak\$ or (support adj decision?) or formulary or guidance or (guideline? adj (adher\$ or implement\$ or concord\$ or comply or complian\$)) or interdisciplin\$ or interprofession $\$$ or multidisciplin\$ or multi-disciplin\$ or notification? or order entry or (pharmacist? adj2 (led or initiat\$ or intervention? or participat\$)) or policy or policies or (prescrib\$ adj (practice? or method? or algorithm? or protocol? or habit?)) or (quality adj (manag\$ or improv\$ or circle?)) or ((patient? or medical or electronic) adj2 record?) or reminder? or rotating or rotation or team\$)).ti,ab.

6 (antibiotic? and (bundle or bundles or education\$ or continuing-education\$ or cme or decision-making or guidance or (guideline? adj2 (adherence or implement\$ or complian\$ or comply\$)) or improper $\$$ or inappropriat $\$$ or incorrect $\$$ or nurse led or overprescrib\$ or overuse or overusing or pharmacist initiated or physician? practice? or policy or policies or practice pattern? or (prescribing adj2 (ebm or evidencebased or habit? or pattern? or practice or practices)) or prudent $\$$ or rational or stewardship or unnecessary or underprescrib\$)).ti.

7 (antibiotic? adj3 (bundle or bundles or education\$ or continuing-education\$ or cme or decision-making or guidance or (guideline? adj2 (adherence or implement or complian\$ or comply\$)) or improper\$ or inappropriat\$ or incorrect or nurse led or overprescrib\$ or overuse or overusing or pharmacist initiated or physician? practice? or policy or policies or practice pattern? or (prescribing adj2 (ebm or evidencebased or habit? or pattern? or practice or practices)) or prudent\$ or rational or stewardship or unnecessary or underprescrib\$)).ab.

8 ((antimicrobial? or anti-microbial? or penicillin?) and (bundle or bundles or education\$ or continuing-education\$ or $\mathrm{cme} \mathrm{or} \mathrm{decision-}$ making or guidance or (guideline? adj2 (adherence or implement $\$$ or complian\$ or comply\$)) or improper\$ or inappropriat $\$$ or incorrect $\$$ or nurse led or overprescrib\$ or overuse or overusing or pharmacist initiated or physician? practice? or policy or policies or practice pattern? or (prescribing adj2 (ebm or evidence-based or habit? or pattern? or practice or practices)) or prudent\$ or rational or stewardship or unnecessary or underprescrib\$)).ab. or ((antimicrobial? or anti-microbial? or penicillin?) and (bundle or bundles or education\$ or continuing-education\$ or cme or decision-making or guidance or (guideline? adj2 (adherence or implement\$ or complian\$ or comply\$)) or improper\$ or inappropriat\$ or incorrect\$ or nurse led or overprescrib\$ or overuse or overusing or pharmacist initiated or physician? practice? or policy or policies or practice pattern? or (prescribing adj2 (ebm or evidence-based or habit? or pattern? or practice or practices)) or prudent\$ or rational or stewardship or unnecessary or underprescrib\$)).ti. 
91 and 2

10 or/3-8

119 or 10

12 intervention?.ti. or (intervention? adj6 (clinician? or collaborat\$ or community or complex or design\$ or doctor? or educational or family doctor? or family physician? or family practitioner? or financial or gp or general practice? or hospital? or impact? or improv\$ or individuali? e? or individuali?ing or interdisciplin\$ or multicomponent or multi-component or multidisciplin\$ or multi-disciplin\$ or multifacet\$ or multi-facet\$ or multimodal\$ or multi-modal\$ or personali?e? or personali?ing or pharmacies or pharmacist? or pharmacy or physician? or practitioner? or prescrib\$ or prescription? or primary care or professional\$ or provider? or regulatory or regulatory or tailor\$ or target $\$$ or team\$ or usual care)).ab.

13 (pre-intervention? or preintervention? or "pre intervention?" or post-intervention? or postintervention? or "post intervention?").ti,ab.

14 (hospital\$ or patient?).hw. and (study or studies or care or health\$ or practitioner? or provider? or physician? or nurse? or nursing or doctor?).ti,hw.

15 demonstration project?.ti,ab.

16 (pre-post or "pre test\$" or pretest\$ or posttest\$ or "post test\$" or (pre adj5 post)).ti,ab.

17 (pre-workshop or post-workshop or (before adj3 workshop) or (after adj3 workshop)).ti,ab.

18 trial.ti. or ((study adj3 aim?) or "our study").ab.

19 (before adj10 (after or during)).ti,ab.

20 (time points adj3 (over or multiple or three or four or five or six or seven or eight or nine or ten or eleven or twelve or month\$ or hour? or day? or "more than")).ab.

21 pilot.ti.

22 (multicentre or multicenter or multi-centre or multi-center).ti.

23 random\$.ti,ab. or controlled.ti.

24 review.ti.

25 or/12-23

$2625 \operatorname{not} 24$

2711 and 26

Cochrane Central Register of Controlled Trials (CENTRAL) in The Cochrane Library Issue 12015 (Searched 22 January 2015)

\#1 antibiotic?:ti,ab,kw

\#2 ((antibacterial or anti-bacterial or antiinfective or anti-infective) and (agent? or drug?)):ti,ab,kw

\#3 ((alamethicin? or amdinocillin? or amdinocillin pivoxil? or amikacin? or amoxicillin? or amoxicillin-potassium clavulanate combination? or amphotericin? or ampicillin? or anisomycin? or antimycin? or aurodox? or azithromycin? or azlocillin? or aztreonam? or bacitracin? or bacteriocin? or bambermycin? or bongkrekic acid? or brefeldin? or butirosin sulfate? or calcimycin? or candicidin? or capreomycin? or carbenicillin? or carfecillin? or cefaclor? or cefadroxil? or cefamandole? or cefatrizine? or cefazolin? or cefixime? or cefmenoxime? or cefmetazole? or cefonicid? or cefoperazone? or cefotaxime? or cefotetan? or cefotiam? or cefoxitin? or cefsulodin? or ceftazidime? or ceftizoxime? or ceftriaxone? or cefuroxime? or cephacetrile? or cephalexin? or cephaloglycin? or cephaloridine? or cephalosporin? or cephalothin? or cephamycin? or cephapirin? or cephradine? or chloramphenicol? or chlortetracycline? or citrinin? or clarithromycin? or clavulanic acid? or clavulanic acid? or clindamycin? or cloxacillin? or colistin? or cyclacillin? or dactinomycin? or daptomycin? or demeclocycline? or dibekacin? or dicloxacillin? or dihydrostreptomycin sulfate? or diketopiperazine? or distamycin? or doxycycline? or echinomycin? or edeine? or enviomycin? or erythromycin? or erythromycin estolate? or erythromycin ethylsuccinate? or filipin? or floxacillin? or fluoroquinolone? or fosfomycin? or framycetin? or fusidic acid? or gentamicin? or gramicidin? or hygromycin? or imipenem? or josamycin? or kanamycin? or kitasamycin? or lactam? or lasalocid? or leucomycin? or lincomycin? or lincosamide? or lucensomycin? or lymecycline? or mepartricin? or methacycline? or methicillin? or mezlocillin? or mikamycin? or minocycline? or miocamycin? or moxalactam? or mupirocin? or mycobacillin? or nafcillin? or natamycin? or nebramycin? or neomycin? or netilmicin? or netropsin? or nigericin? or nisin? or norfloxacin? or novobiocin? or nystatin? or ofloxacin? or oleandomycin? or oligomycin? or oxacillin? or 
oxytetracycline? or paromomycin? or penicillanic acid? or penicillic acid? or penicillin?? or piperacillin? or pivampicillin? or polymyxin b? or polymyxin? or pristinamycin? or prodigiosin? or ribostamycin? or rifabutin? or rifamycin? or ristocetin? or rolitetracycline? or roxarsone? or roxithromycin? or rutamycin? or sirolimu? or sisomicin? or spectinomycin? or spiramycin? or streptogramin?? or streptomycin? or streptovaricin? or sulbactam? or sulbenicillin? or sulfamerazine? or sulfamethoxypyridazine? or talampicillin? or teicoplanin? or tetracycline? or thiamphenicol? or thienamycin? or thiostrepton? or ticarcillin? or tobramycin? or troleandomycin? or tunicamycin? or tylosin? or tyrocidine? or tyrothricin? or valinomycin? or vancomycin? or vernamycin? or viomycin? or virginiamycin? or beta-lactams) and (prescrib\$ or resistance or "use" or "usage" or utlii?ation)):ti,ab,kw

\#4 ((antibacterial agent? or anti-bacterial agent?) and (prescrib\$ or resistance or "use" or "usage" or utili?ation)):ti,ab,kw

\#5 "stewardship":ti,ab,kw

\#6 (antibiotic ${ }^{\star}$ or antimicrobial $\left.{ }^{\star}\right)$ and $\left(\right.$ prescrib* $^{\star}$ or prescrip*):ti,ab,kw

$\# 7$ \#1 or \#2 or \#3 or \#4 or \#5 or \#6

Appendix 2. Decisions based on 5 GRADE criteria about quality of evidence from RCTs in 'Summary of findings' table Outcome prescribing, \% compliance with guideline

\begin{tabular}{lll}
\hline Criterion & Evidence & Decision \\
\hline Risk of bias & $\begin{array}{l}\text { Effect estimate lower for 15 studies } \\
\text { with low/medium risk of bias. }\end{array}$ & $\begin{array}{l}\text { Not serious, 95\% confidence interval for effect estimate 10\% to } \\
12 \% \text { in studies at low or medium risk of bias. }\end{array}$ \\
\hline Imprecision1 & 23,394 patients and 3660 events & Not serious \\
\hline Inconsistency & $\begin{array}{l}\text { Chi2 }=367.98, \text { df }=28(P<0.00001) ;\left.\right|^{2} \\
=92 \%\end{array}$ & $\begin{array}{l}\text { Not serious, effect size rather than direction (Figure 3). Variation } \\
\text { partially explained by prespecified subgroup analysis by inter- } \\
\text { vention function (Figure 7). Direction of effect consistent despite } \\
\text { high levels of statistical heterogeneity. }\end{array}$ \\
\hline Indirectness & $\begin{array}{l}\text { Only 2 RCTs of restrictive interven- } \\
\text { tions (Singh 2000; Strom 2010) }\end{array}$ & $\begin{array}{l}\text { Not serious because this is a concern for safety rather than effec- } \\
\text { tiveness. }\end{array}$ \\
\hline Publication bias & $\begin{array}{l}\text { Large trials, few commercially spon- } \\
\text { sored }\end{array}$ & Not serious \\
\hline
\end{tabular}

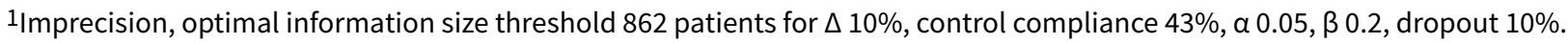

Outcome prescribing, reduction in duration of all antibiotic treatment

\begin{tabular}{lll}
\hline Criterion & Evidence & Decision \\
\hline Risk of bias & $\begin{array}{l}\text { Effect estimate greater for 3 studies with low/medium } \\
\text { risk of bias (Analysis 1.6). }\end{array}$ & Not serious \\
\hline Imprecision1 & 3318 patients & $\begin{array}{l}\text { Not serious, number of patients is }>\text { OIS to de- } \\
\text { tect } \Delta 1 \text { day (3018 patients). }\end{array}$ \\
\hline Inconsistency2 & All trials: Chi2 $=119.95, \mathrm{df}=13(\mathrm{P}<0.00001) ; 12=89 \%$ & $\begin{array}{l}\text { Not serious, most variation is effect size } \\
\text { rather than direction (Figure 4). }\end{array}$ \\
\hline Indirectness & Not serious for effectiveness & Not serious \\
\hline
\end{tabular}


(Continued)

Publication bias $\quad$ Large trials, few commercially sponsored Not serious

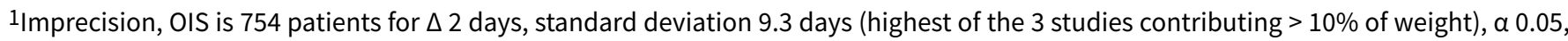
$\beta 0.8$, dropout $10 \%$, and 3018 patients for $\Delta 1$ day.

OIS: optimal information size

\section{Outcome mortality}

\begin{tabular}{llc}
\hline Criterion & Evidence & Decision \\
\hline Risk of bias & $\begin{array}{l}\text { Effect estimate and confidence interval similar for } 8 \text { studies with low/medium } \\
\text { risk of bias }\end{array}$ & Not serious \\
\hline Imprecision 1 & $\begin{array}{l}17,697 \text { patients and } 1587 \text { events } \\
\text { This is }>\text { OIS for } 2 \% \text { difference in mortality }(6726 \text { patients). }\end{array}$ & Not serious \\
\hline Inconsistency & Heterogeneity: Chi2 $=16.55$, df $=28(P=0.96) ; 12=0 \%$ & Sot serious (Figure 5) \\
\hline Indirectness & No trials of restrictive interventions. & Not serious \\
\hline Publication bias & Mortality lower in trials at low/medium risk of bias. & \\
\hline
\end{tabular}

1Imprecision, OIS threshold for patients for non-inferiority is 6726 patients for a $2 \%$ difference in mortality.

OIS: optimal information size

\section{All trials:}

Mortality, control $11 \%$, power $80 \%$, dropout $10 \%$

\begin{tabular}{ll}
\hline Non-inferiority criteria & Total number of patients to be recruited \\
\hline $1 \%$ & 26,900 \\
\hline $2 \%$ & 6726 \\
\hline $3 \%$ & 2988 \\
\hline $4 \%$ & 1682 \\
\hline
\end{tabular}

\section{Outcome length of hospital stay}

\begin{tabular}{llc}
\hline Criterion & Evidence & Decision \\
\hline
\end{tabular}


(Continued)

Risk of bias $\quad$ Effect size only slightly smaller for 6 RCTs at low or medium risk of bias, and Not serious the $95 \% \mathrm{Cl}$ did not include increase in length of stay.

\begin{tabular}{ll}
\hline Imprecision 1 & $\begin{array}{l}3834 \text { patients }(>\text { OIS for } \triangle 1 \text { day but not } 0.5 \text { day). The lower bound of } \mathrm{Cl} \text { is re- } \\
\text { duction by } 0.7 \text { days for all RCTs and } 0.3 \text { days for RCTs at low or medium risk of } \\
\text { bias. }\end{array}$ \\
\hline Inconsistency & Heterogeneity: $\mathrm{Chi}^{2}=17.32, \mathrm{df}=14(\mathrm{P}=0.24) ; 12=19 \% \quad \begin{array}{l}\text { Not serious, effect size } \\
\text { rather than direction } \\
\text { (Figure } 6)\end{array}$
\end{tabular}

\begin{tabular}{ll}
\hline Indirectness & No trials of restrictive interventions \\
\hline Publication bias & Large trials, few commercially sponsored \\
\hline
\end{tabular}

1 Imprecision, OIS is 2014 patients for $\Delta 1$ day and 7640 patients for $\Delta 0.5$ day, standard deviation 7.6 (highest of the 3 studies contributing $>20 \%$ of weight), a $0.05, \beta 0.2$, dropout $10 \%$.

$\mathrm{Cl}$ : confidence interval

OIS: optimal information size

$\mathrm{RCT}$ : randomised controlled trial

\section{Appendix 3. Details of power calculations for RCTs}

\section{Annane 2013}

Based on a previous study, the authors estimated that on day $5, \sim 85 \%$ of control patients would be on antibiotics. They thus calculated that 57 patients in each arm would be needed to detect in a two-sided test with an $80 \%$ probability and a 0.05 type I error, a $25 \%$ absolute reduction in the proportion of antibiotic-treated patients on day 5 . They also estimated that $20 \%$ of patients would eventually be withdrawn from the study after showing indisputable infection. One hundred and forty patients in total (70 in each arm) would thus be needed.

\section{Bouadma 2010}

Power: Assuming a mean of 12 days without antibiotics for the control group, 133 patients per study group would provide $90 \%$ power to detect a 3-day increase in number of days without antibiotics.

\section{Bruins 2005}

The sample calculation was based on the difference in mortality of $6.5 \%$ as detected by Doern 1994 . With 296 patients in each study group in each study period, the study would have power of $80.1 \%$ to yield a statistically significant result ( $\alpha=0.05$, two-tailed, specific proportions 0.120 vs 0.055$)$.

\section{Christ-Crain 2004}

We designed the trial to enrol 105 patients with completed follow-up in each group. This number gave the study $95 \%$ power to detect a $30 \%$ reduction in antibiotic exposure. Assumptions included use of a two-tailed test, a $5 \%$ level of significance, and a standard deviation (SD) of 6 days in both groups.

\section{Christ-Crain 2006}

A study sample of 150 patients in each group gave the study a power of $95 \%$ to detect a $30 \%$ reduction in antibiotic exposure from 10 to 7 days per patient assuming a two-tailed test, a $1 \%$ level of significance, and a SD of 6 days in both groups. This sample size gave the study a power of $74 \%$ to detect a $10 \%$ increase in the combined treatment failure and complication rate (from $10 \%$ to $20 \%$ ), using the procalcitonin algorithm with a one-sided value of 0.05 .

\section{Dranitsaris 2001}

This study was designed to compare the two cefotaxime groups with the hypothesis that a higher proportion of cefotaxime orders would be within hospital guidelines in the intervention group. Inappropriate antibiotic prescribing has been shown to be as high as $40 \%$ (17). By assuming an alpha of $5 \%$ (two-tailed), power of $80 \%$, probability of appropriate prescribing with and without the intervention at $75 \%$ and 
$60 \%$ (absolute difference $=15 \%$ ), respectively, the case sample size for the uncorrected $\mathrm{Chi}^{2}$ test in this randomised study was 300 , which was then increased by $10 \%$ to account for patient dropouts.

\section{Esposito 2011}

Pre-study power calculations (with $90 \%$ power) showed that 76 patients in each group were necessary to detect a $15 \%$ lower antibiotic use, considering that $100 \%$ of children hospitalised for community-acquired pneumonia were treated with antibiotics and assuming a two-tailed test and a $5 \%$ level of significance. Since we planned to analyse the data in subgroups of mild and severe community-acquired pneumonia, we doubled the number of patients per group $(n=152)$. We thus decided to enrol 160 patients in each group to allow for a $5 \%$ dropout participant.

\section{Fine 2003}

This study was designed with $80 \%$ power to detect a 1-day decrease in length of stay from an assumed baseline of 7.2 days. The sample size was adjusted for the clustering on physician group assuming an average of 3.5 patients per group and an intraclass correlation coefficient of 0.1 .

\section{Franz 2004}

The sample size calculation was based on the following assumptions: a significance level .05 , a power .80 , a proportion of initially missed infections of $4 \%$ in the interleukin-8 group and $9 \%$ in the standard group, and an equivalence limit of 3\%. On the basis of these assumptions, a sample size of 207 patients with infection in each group was required to demonstrate 1-sided equivalence of the proportions of initially missed infections. Assuming a rate of bacterial infection of $18 \%$ in the study population, a total of 1150 patients needed to be enrolled into the study.

\section{Gulmezoglu 2007}

We calculated the power using standard formulae for comparison of proportions in a completely randomised design and estimated that with 40 hospitals, we would have $90 \%$ power to detect a decrease or an increase in a practice equal to the SD between hospitals, in a onesided significance test at $5 \%$ level of significance. For example, if the SD of use of episiotomy is $20 \%$, we would be able to detect a decrease in the end-of-study rate of use of episiotomy from $70 \%$ to $50 \%$. We used a one-sided significance test because we believed the intervention could only improve the use of evidence-based practices.

Jensen 2011

The final (adjusted) sample size of 1200 patients was based on an estimated mortality in the standard-of-care-only group of $31.0 \%$ and a proposed absolute risk reduction of $7.5 \%$. Detailed sample size considerations are available in the supplemental data (see Supplemental Digital Content 2, links.lww.com/CCM/A257).

Kerremans 2008

It was calculated that 1500 patients were needed to demonstrate a $6 \%$ absolute reduction in mortality (power of $80 \%$ and a two-sided alpha of 0.05 ) from $25 \%$ in the control group to $18 \%$ in the rapid group (Sample Power, SPSS, Chicago, USA).

\section{Kristoffersen 2009}

Pre-study power calculations (with $90 \%$ power) showed that 107 patients in each group were necessary to detect a $20 \%$ reduction in antibiotic use (from 10 to 8 days), assuming a two-tailed test and a $5 \%$ level of significance.

Kritchevsky 2008

A priori power calculations determined that 40 hospitals sampling 100 cases per measurement period would give $80 \%$ power to detect a $15 \%$ difference in the pre-post change between groups in the timing of prophylaxis based on an intraclass correlation coefficient of 0.15 , estimated from an earlier study of intensive care unit process improvement (0.05, 2-tailed test).

Lacroix 2014

Power calculation suggested that 97 patients should be enrolled in each group to give $80 \%$ power at the $5 \%$ level of significance to detect a $20 \%$ difference in antibiotic prescription rate. Taking into account the possibility for lost to follow-up patients or missing or incomplete results, we considered including 140 patients in each group.

Layios 2012

Assuming a mean stay of 7 days with $50 \%$ antibiotic exposure, a study sample of at least 250 patients in each group was deemed necessary to detect a $20 \%$ reduction in antibiotic consumption with $95 \%$ power at the $5 \%$ significance level. 
Lesprit 2013

We hypothesized that the intervention might result in a $20 \%$ reduction of the duration of hospitalisation. The sample size was estimated based on the results of previous observations performed in our hospital showing that the mean length of hospital stay for patients treated with one of the targeted antibiotics was $15 \pm 7$ days. To detect a $20 \%$ reduction in the length of hospital stay in the intervention group with a type I error of $5 \%$ and a type II error of $80 \%$, it was necessary to enrol a total of 506 patients (253 patients in each group).

Long 2014

"Assuming 90\% of the patients in the control group would use antibiotics, and anticipating a 15\% decrease in antibiotic usage in the procalcitonin (PCT) group, a sample size of 158 patients ( 79 patients per group) was necessary to detect a significant difference in antibiotic prescription rate between the groups with $80 \%$ power and an a error of 0.05 . To account for possible loss of patients to follow-up, we planned to enrol 180 patients." One hundred and eighty eligible patients were randomised to intervention $(n=90)$ or control $(n=90)$.

Masia 2008

We hypothesised a difference of at least $15 \%$ in defined daily doses of the targeted antibiotics between intervention and control groups based on the results of previous reports. One hundred and forty-four patients were required in each group to reach $80 \%$ power, alpha 0.05 , and, within awaited group, standard deviation of 5 days.

Nobre 2008

The trial was designed to enrol at least 66 patients to obtain a power of $90 \%$ to detect a $33 \%$ (4-day) difference in the duration of antibiotic therapy for the initial infection between the two groups based on an estimated baseline duration of 12 days.

\section{Oliveira 2013}

Sample size calculation was based on data from a previous study, in which the mean duration of antibiotic therapy for the index infection was $8.6 \pm 5.0$ days among patients treated according to a PCT-guided protocol, as compared with $10.7( \pm 4.0)$ days in the control group (V. Nobre, unpublished observation, 2008). We thus hypothesised that the duration of the antibiotic therapy in patients treated with a PCTguided protocol would be at least $25 \%$ shorter than the duration observed in patients treated according to a protocol based on the serum Creactive protein levels. We found that 58 patients per group (a total of 116 individuals) would be necessary to demonstrate this difference, with a power of $80 \%$ and an alpha error of $5 \%$.

\section{Oosterheert 2005}

In the control group, all patients were expected to receive a complete course of antibiotic treatment. On the basis of an expected detection rate of $20 \%$ for atypical and viral pathogens in the intervention group and an estimate of the number of possible dropouts, 100 patients would be required to demonstrate a reduction in the use of antibiotic treatment from $100 \%$ to $80 \%$.

\section{Paul 2006}

The primary outcome measure was \% inappropriate treatment, which could only be assessed in patients with microbiologically documented infections. The planned sample of 1500 patients in 15 wards had a power of greater than $99 \%$ to detect a $15 \%$ reduction in inappropriate antibiotic treatment (from $35 \%$ to $20 \%$ ), for a two-tailed test, assuming cluster randomisation of wards stratified within three hospitals by a two-way analysis of variance and a between-ward variance of 0.0005 . We chose a sample size that would allow us to detect a difference even if two wards defaulted. The authors say that "Owing to the grant time limits the trial was stopped before attaining the planned sample size"; they recruited 570 patients for the primary outcome measure instead of the planned 1500.

\section{Schuetz 2009}

To define non-inferiority with regard to the primary combined endpoint, the planning committee agreed on a $7.5 \%$ absolute difference as the clinically tolerable upper limit (i.e. at worst the risk of an overall adverse outcome in the PCT group was increased by $7.5 \%$ ). Based on this non-inferiority boundary, a minimal sample size of 1002 patients was determined, allowing for an overall adverse outcome rate in the control group of at most $20 \%$ and aiming for a power of $90 \%$. Instead of a fixed sample size, we predefined a fixed recruitment period of 18 months with the goal to randomise all eligible patients from the 6 participating hospitals during that period and an extension if fewer than 1002 patients had been recruited. This prospective rule allows for the possibility of a higher number of patients and thus better power for subgroup analyses, while maintaining the integrity of the trial.

\section{Senn 2004}

The sample size was estimated according to the Freedman method of sample size estimation under the proportional-hazards model, on the basis of pre-study observation. One hundred and thirty-five patients were required in each group to reach $80 \%$ power of demonstrating a $40 \%$ increase in the hazard ratio (a difference that would correspond approximately to a $25 \%$ reduction in the expected number of antibiotic-days until modification). For practical reasons, study duration was determined before the beginning of prospective data 
collection: we chose a five-month period, which was the estimated time necessary to achieve the calculated sample size. However, the observed effect (14\% reduction) was lower than predicted, so the trial was underpowered.

Shehabi 2014

Sample size calculations were derived from the findings of Schuetz in which patients with lower respiratory tract infections treated with a PCT-based algorithm showed a 35\% (29\% to $40 \%)$ reduction in antibiotic exposure. Assuming a median baseline exposure level of 9 days and a standard deviation of 6 days, with 165 patients per group this study had greater than $90 \%$ power to detect a clinically relevant reduction in duration of antibiotic usage of $25 \%$ (9.0 versus 6.7 days). As duration of antibiotic usage is unlikely to follow a normal distribution, in accordance with Lehmann this figure was inflated by $15 \%$. To further account for potential dropout or loss to follow-up (anticipated to be less than 5\%), a total of 400 participants were recruited.

Singh 2000

Assuming that the patients in the experimental therapy group would have $10 \%$ worse outcome than patients in the standard therapy arm, a sample size of 200 patients (100 in each arm) would detect a difference at 0.05 and power 0.5 . Assuming a $20 \%$ incidence of development of resistance in the standard therapy group and 5\% in the experimental therapy group, a sample size of 176 patients (88 in each group) would be needed for significance at 0.05 and power 0.8 .

NB: The study was terminated prematurely because providers caring for patients in the control group were influenced by the favourable results in the intervention group.

\section{Stolz 2007}

The trial was designed to demonstrate the persistent superiority of procalcitonin guidance in decreasing antibiotic use up to six months after the index exacerbation. The sample size was calculated from the following assumptions: a $75 \%$ use of antibiotics to treat the index exacerbation and an expected absolute reduction of this frequency from $75 \%$ to $45 \%$ with procalcitonin guidance. Considering an exacerbation rate of $70 \%$ within 6 months and $75 \%$ antibiotic use in the following exacerbations, a sample size of 186 patients (93 patients per group) was necessary to detect a significant difference in antibiotic use between both groups with a power of $85 \%$ and an error of 0.05 . Considering a $20 \%$ dropout rate after assignment to the study, 223 inclusions were planned.

\section{Stolz 2009}

Considering 13 antibiotic-free days in the control group and 18 antibiotic-free days in the procalcitonin group, a sample size of 84 patients (42 per group) was necessary to detect a significant difference in antibiotic-free days alive between both groups with a power of $90 \%$ and an error of 0.05 using a two-tailed test. Assuming $8 \%$ lost to follow-up, we planned the inclusion of 100 participants.

Yealy 2005

The primary outcome was site of treatment rather than the antibiotic process measures. "We estimated that we would need 96 eligible patients per hospital (3072 in total) to achieve $80 \%$ power to detect a $12 \%$ difference across the intervention groups for the site-of-treatment decision among low-risk patients."

"For the site-of-treatment decision, this study achieved greater than $80 \%$ power to detect differences of $10 \%$ between high-intensity and moderate-intensity groups and differences of $12 \%$ between high-intensity and low-intensity groups according to separate 1-tailed tests in which the level was 0.025." 


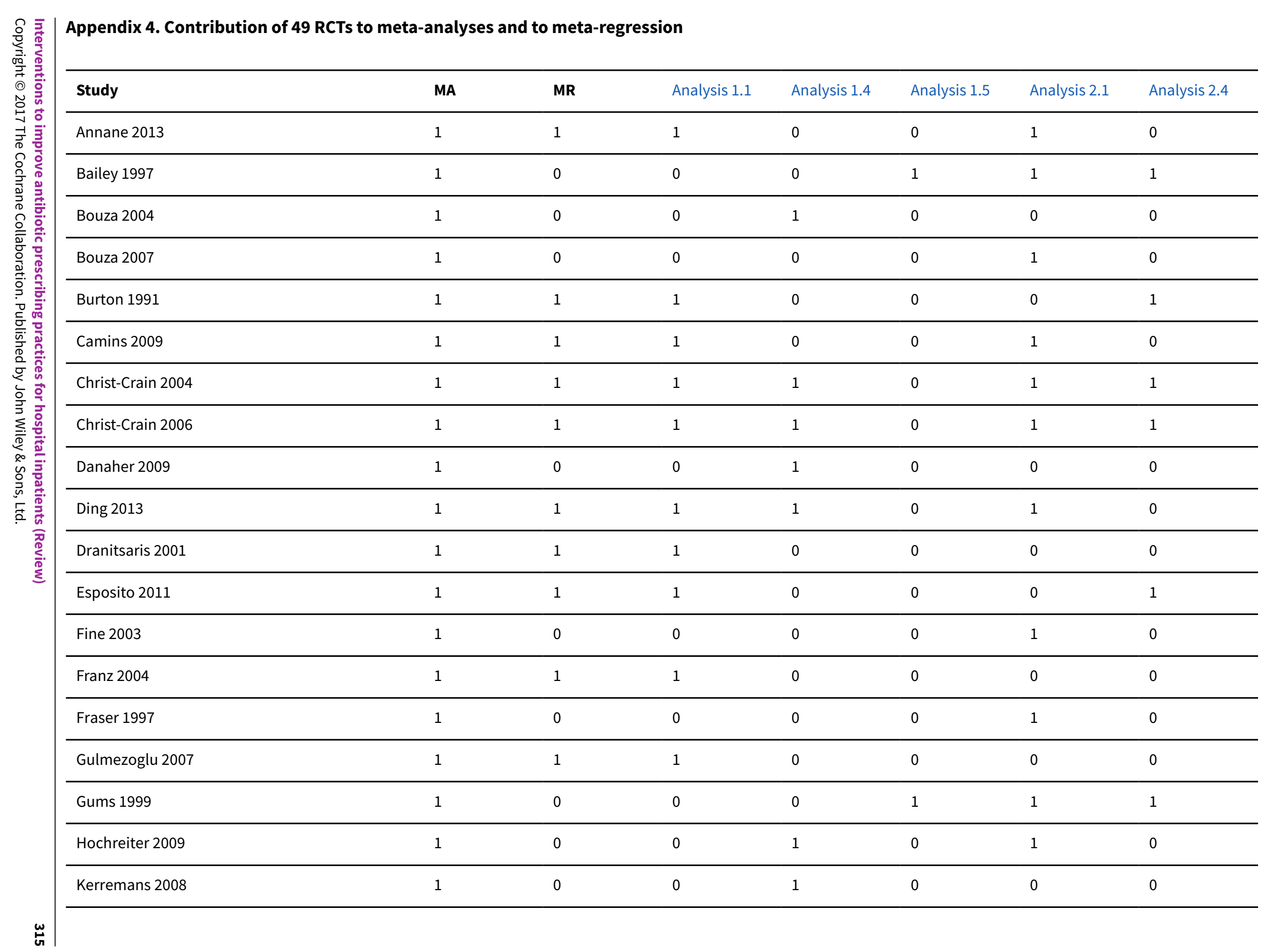




\begin{tabular}{|c|c|c|c|c|c|c|c|c|}
\hline \multirow{21}{*}{ 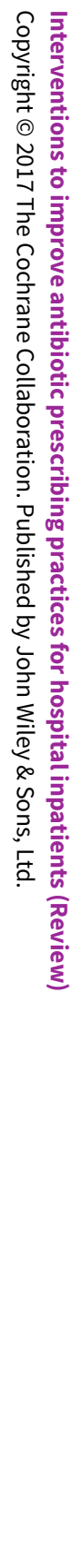 } & \multicolumn{7}{|l|}{ (Continued) } & 1 \\
\hline & Kritchevsky 2008 & 1 & 1 & 1 & 0 & 0 & 0 & 0 \\
\hline & Lacroix 2014 & 1 & 1 & 1 & 0 & 0 & 0 & 0 \\
\hline & Layios 2012 & 1 & 0 & 0 & 1 & 0 & 0 & 0 \\
\hline & Liu 2013 & 1 & 0 & 0 & 1 & 0 & 1 & 1 \\
\hline & Long 2014 & 1 & 1 & 1 & 0 & 0 & 0 & 0 \\
\hline & Maravic-Stojkovic 2011 & 1 & 1 & 1 & 0 & 0 & 1 & 1 \\
\hline & Masia 2008 & 1 & 0 & 0 & 0 & 0 & 1 & 0 \\
\hline & Micek 2004 & 1 & 0 & 0 & 1 & 0 & 1 & 1 \\
\hline & Oliveira 2013 & 1 & 0 & 0 & 1 & 0 & 1 & 0 \\
\hline & Paul 2006 & 1 & 1 & 1 & 0 & 0 & 1 & 1 \\
\hline & Poehling 2006 & 1 & 1 & 1 & 0 & 0 & 0 & 0 \\
\hline & Qu 2012 & 1 & 0 & 0 & 1 & 0 & 1 & 1 \\
\hline & Schnoor 2010 & 1 & 1 & 1 & 0 & 0 & 1 & 1 \\
\hline & Schouten 2007 & 1 & 1 & 1 & 0 & 0 & 1 & 0 \\
\hline & Schroeder 2009 & 1 & 0 & 0 & 1 & 0 & 1 & 0 \\
\hline & Schuetz 2009 & 1 & 1 & 1 & 0 & 0 & 1 & 0 \\
\hline & Senn 2004 & 1 & 1 & 1 & 0 & 0 & 1 & 1 \\
\hline & Shen 2011 & 1 & 0 & 0 & 0 & 1 & 0 & 1 \\
\hline & Shojania 1998 & 1 & 0 & 0 & 0 & 1 & 0 & 0 \\
\hline & Singh 2000 & 1 & 1 & 1 & 0 & 0 & 1 & 0 \\
\hline
\end{tabular}




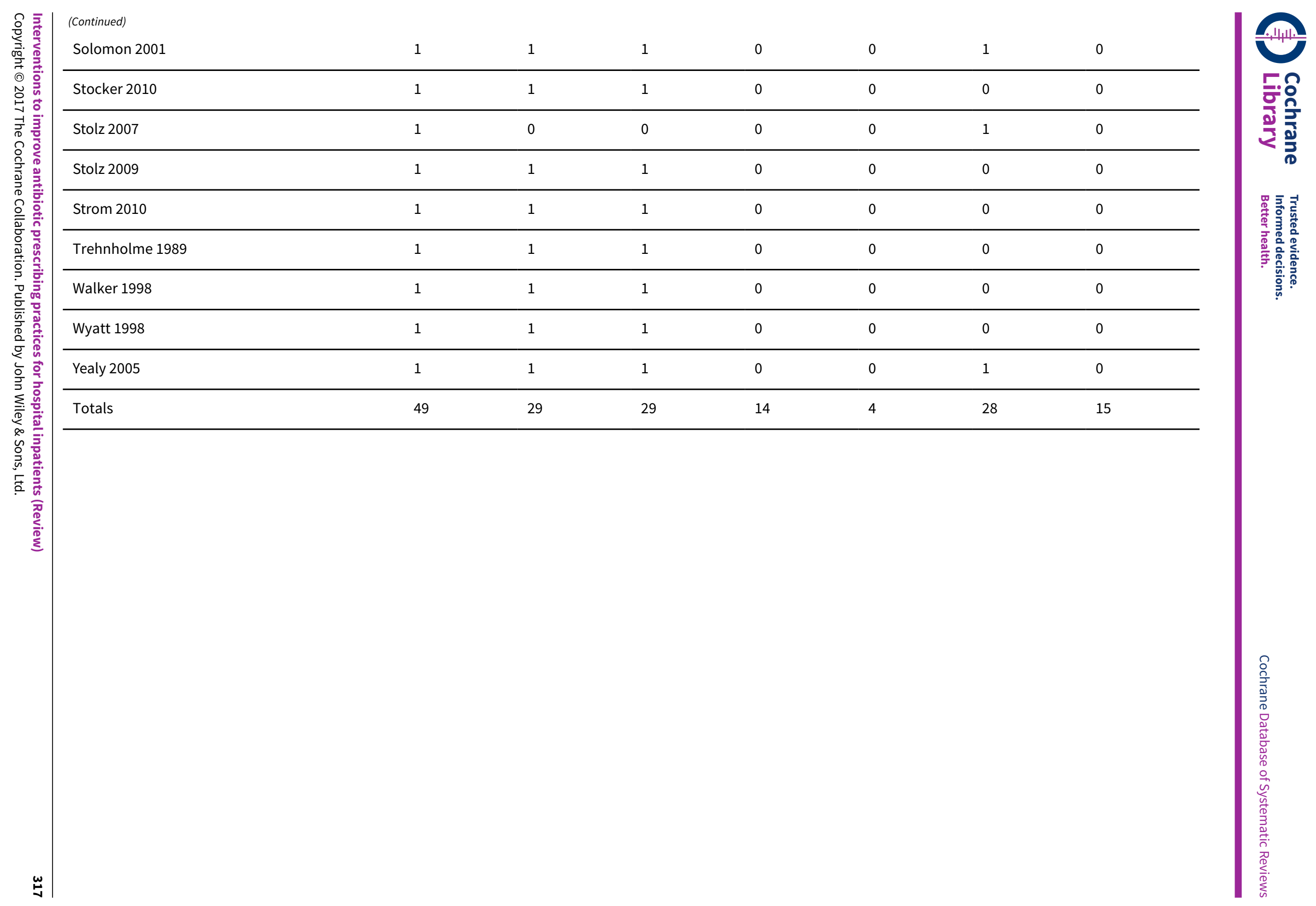


Appendix 5. Contribution of 109 ITS studies to meta-regression of prescribing outcomes for intervention effect $(n=$ 107) or removal ( $n=5,2$ studies only had data about intervention removal)

\begin{tabular}{|c|c|c|c|c|c|}
\hline & $\begin{array}{l}\text { Intervention } \\
\text { effect }\end{array}$ & $\begin{array}{l}\text { Intervention } \\
\text { removal Ta- } \\
\text { ble } 7\end{array}$ & Figure 10 & Figure 11 & Figure 12 \\
\hline TOTALS & 107 & 5 & 91 & 29 & 43 \\
\hline \multicolumn{6}{|l|}{ Study } \\
\hline Abramowitz 1982 & 1 & 0 & 1 & 0 & 1 \\
\hline Adachi 1997 & 1 & 0 & 1 & 0 & 1 \\
\hline Akenroye 2014 & 1 & 0 & 1 & 0 & 1 \\
\hline Aldeyab 2012 & 1 & 0 & 1 & 1 & 0 \\
\hline Ananda Rajah 2010 & 1 & 0 & 0 & 0 & 0 \\
\hline Ansari 2003 & 1 & 0 & 1 & 0 & 1 \\
\hline Avorn 1988 & 1 & 0 & 1 & 0 & 1 \\
\hline Bantar 2006 & 1 & 0 & 1 & 1 & 0 \\
\hline Barlow 2007 & 1 & 0 & 1 & 0 & 1 \\
\hline Bassetti 2009 & 1 & 0 & 1 & 1 & 0 \\
\hline Belliveau 1996 & 1 & 0 & 1 & 1 & 0 \\
\hline Benson 2014 & 1 & 0 & 1 & 0 & 1 \\
\hline Berild 2002 & 1 & 0 & 0 & 0 & 0 \\
\hline Borde $2014 a$ & 1 & 0 & 1 & 0 & 1 \\
\hline Borde 2015a & 1 & 0 & 1 & 0 & 1 \\
\hline Borde 2015b & 1 & 0 & 1 & 0 & 1 \\
\hline Bradley 1999 & 1 & 0 & 1 & 1 & 0 \\
\hline Buising 2008a & 1 & 0 & 1 & 1 & 0 \\
\hline Buising 2008b & 1 & 0 & 1 & 0 & 1 \\
\hline Bunz 1990 & 1 & 0 & 1 & 1 & 0 \\
\hline Buyle 2010 & 1 & 0 & 1 & 0 & 1 \\
\hline Chan 2011 & 1 & 0 & 1 & 1 & 0 \\
\hline Chan 2014 & 1 & 0 & 1 & 1 & 0 \\
\hline
\end{tabular}


(Continued)

\begin{tabular}{|c|c|c|c|c|c|}
\hline Chandy 2014 & 1 & 0 & 1 & 0 & 0 \\
\hline Cheng 2009 & 1 & 0 & 1 & 0 & 1 \\
\hline Cook 2011 & 1 & 0 & 1 & 0 & 1 \\
\hline Cook 2011a & 1 & 0 & 1 & 1 & 0 \\
\hline Cortoos 2011 & 1 & 0 & 1 & 0 & 0 \\
\hline Dancer 2013 & 1 & 0 & 1 & 1 & 0 \\
\hline Dull 2008 & 1 & 0 & 1 & 0 & 1 \\
\hline Elligsen 2012a & 1 & 0 & 1 & 0 & 1 \\
\hline Everitt 1990 & 1 & 0 & 1 & 1 & 0 \\
\hline Fitzpatrick 2008 & 1 & 0 & 0 & 0 & 0 \\
\hline Fowler 2007 & 1 & 0 & 1 & 0 & 1 \\
\hline Fukuda 2014 & 1 & 0 & 1 & 0 & 1 \\
\hline Grohs 2014 & 1 & 0 & 0 & 0 & 0 \\
\hline Gupta 1989 & 1 & 0 & 1 & 1 & 0 \\
\hline Hadi 2008 & 1 & 0 & 1 & 0 & 0 \\
\hline Hess 1990 & 1 & 0 & 1 & 0 & 1 \\
\hline Hitti 2012 & 1 & 0 & 1 & 0 & 0 \\
\hline Huber 1982 & 1 & 0 & 0 & 0 & 0 \\
\hline Hulgan 2004 & 1 & 0 & 1 & 0 & 1 \\
\hline Inaraja 1986 & 1 & 0 & 0 & 0 & 0 \\
\hline Jobson 2015 & 1 & 0 & 1 & 0 & 1 \\
\hline Jump 2012 & 1 & 0 & 1 & 0 & 1 \\
\hline Kallen 2009 & 1 & 1 & 0 & 0 & 0 \\
\hline Kim 2008 & 1 & 1 & 1 & 1 & 0 \\
\hline Knudsen 2014 & 1 & 0 & 1 & 0 & 1 \\
\hline Kumana 2001 & 1 & 0 & 1 & 0 & 1 \\
\hline Lafuarie 2012 & 1 & 0 & 1 & 0 & 1 \\
\hline
\end{tabular}


(Continued)

\begin{tabular}{|c|c|c|c|c|c|}
\hline Lautenbach 2003 & 1 & 0 & 0 & 0 & 0 \\
\hline Lee 1995 & 1 & 0 & 1 & 0 & 1 \\
\hline Lee 2007 & 1 & 0 & 0 & 0 & 0 \\
\hline Lee 2014 & 1 & 0 & 1 & 0 & 1 \\
\hline Liebowitz 2008 & 1 & 0 & 1 & 0 & 0 \\
\hline Magedanz 2012 & 1 & 0 & 1 & 0 & 1 \\
\hline Marwick 2013 & 1 & 0 & 1 & 0 & 1 \\
\hline May 2000 & 1 & 0 & 1 & 0 & 0 \\
\hline McElnay 1995 & 1 & 0 & 1 & 1 & 0 \\
\hline McGowan 1976 & 1 & 0 & 0 & 0 & 0 \\
\hline McNulty 1997 & 1 & 0 & 1 & 1 & 0 \\
\hline Mercer 1999 & 1 & 0 & 1 & 1 & 0 \\
\hline Meyer 2007 & 1 & 0 & 1 & 0 & 0 \\
\hline Meyer 2009 & 1 & 0 & 1 & 0 & 0 \\
\hline Meyer 2010 & 1 & 0 & 1 & 0 & 0 \\
\hline Mittal 2014 & 1 & 0 & 1 & 0 & 1 \\
\hline Mol 2005 & 1 & 0 & 0 & 0 & 0 \\
\hline Newland 2012 & 1 & 0 & 1 & 0 & 1 \\
\hline Parikh 2014 & 1 & 0 & 1 & 0 & 0 \\
\hline Patel 1989 & 1 & 0 & 0 & 0 & 0 \\
\hline Perez 2003, Intervention 2 & 1 & 0 & 1 & 0 & 1 \\
\hline Peto 2008 & 1 & 0 & 1 & 1 & 0 \\
\hline Petrikkos 2007 & 1 & 0 & 1 & 0 & 0 \\
\hline Po 2012, Intervention 1 & 1 & 0 & 1 & 0 & 0 \\
\hline Popovski 2014 & 1 & 0 & 1 & 0 & 0 \\
\hline Price 2010 & 1 & 0 & 1 & 1 & 0 \\
\hline Richards 2003 & 1 & 0 & 1 & 1 & 0 \\
\hline Ross 2014 & 1 & 0 & 1 & 0 & 0 \\
\hline
\end{tabular}


(Continued)

\begin{tabular}{|c|c|c|c|c|c|}
\hline Saizy-Callaert 2003 & 1 & 0 & 0 & 0 & 0 \\
\hline Salama 1996 & 1 & 0 & 1 & 1 & 0 \\
\hline Schwann 2011 & 1 & 0 & 1 & 0 & 1 \\
\hline Schwartz 2007 & 1 & 0 & 1 & 0 & 0 \\
\hline Sirinavin 1998 & 1 & 0 & 0 & 0 & 0 \\
\hline Skaer 1993 & 1 & 0 & 1 & 0 & 1 \\
\hline Standiford 2012 & 1 & 1 & 1 & 0 & 1 \\
\hline Stevenson 1988 & 1 & 0 & 1 & 0 & 0 \\
\hline Sun 2011 & 1 & 0 & 1 & 0 & 1 \\
\hline Suwangool 1991 & 1 & 0 & 1 & 1 & 0 \\
\hline Talpaert 2011 & 1 & 0 & 1 & 1 & 0 \\
\hline Tangden 2011 & 1 & 0 & 1 & 0 & 0 \\
\hline Toltzis 1998 & 1 & 0 & 1 & 1 & 0 \\
\hline Valiquette 2009 & 1 & 0 & 1 & 0 & 1 \\
\hline van Kasteren 2005 & 1 & 0 & 1 & 0 & 1 \\
\hline Volpe 2012 & 1 & 0 & 1 & 0 & 1 \\
\hline Wang 2014 & 1 & 0 & 1 & 1 & 0 \\
\hline Wax 2007 & 1 & 0 & 1 & 0 & 0 \\
\hline Weinberg 2001 & 1 & 0 & 0 & 0 & 0 \\
\hline Weiner 2009 & 1 & 0 & 1 & 0 & 1 \\
\hline Wenisch 2014 & 1 & 0 & 1 & 1 & 0 \\
\hline Willemsen 2010 & 1 & 0 & 1 & 0 & 1 \\
\hline Wilson 1991 & 1 & 0 & 1 & 0 & 0 \\
\hline Woodward 1987 & 1 & 0 & 1 & 1 & 0 \\
\hline Yeo 2012 & 1 & 0 & 1 & 0 & 1 \\
\hline Yong 2010 & 1 & 0 & 1 & 0 & 1 \\
\hline Yoon 2014 & 1 & 0 & 1 & 1 & 0 \\
\hline Young 1985 & 1 & 0 & 1 & 1 & 0 \\
\hline
\end{tabular}




\section{Appendix 6. RCTs and ITS studies not included in any evidence synthesis}

Reasons for exclusion of 9 RCTs from prescribing meta-analysis. Note that these studies had no valid clinical outcome data and so were not included in any meta-analysis:

\begin{tabular}{lll}
\hline Reason & Number & Studies \\
\hline $\begin{array}{l}\text { Prescribing outcome continuous variable with no stan- } \\
\text { dard deviation }\end{array}$ & 5 & $\begin{array}{l}\text { Lesprit 2013; Nobre 2008; Oosterheert 2005; } \\
\text { Palmay 2014; Shehabi 2014 }\end{array}$ \\
\hline $\begin{array}{l}\text { Insufficient detail to quantify impact on prescribing out- } \\
\text { comes used in the meta-analyses }\end{array}$ & 4 & $\begin{array}{l}\text { Bouadma 2010; Farinas 2012; Jensen 2011; } \\
\text { Kerremans 2009 }\end{array}$ \\
\hline
\end{tabular}

Reasons for exclusion of 28 ITS studies from meta-regression:

16 ITS studies did not include time series data about prescribing outcomes: Aldeyab 2014; Calil 2001; Carling 2003; Charbonneau 2006; Climo 1998; de Champs 1994; Dempsey 1995; Dua 2014; Gerding 1985; Khan 2003; Landman 1999; Lawes 2012; Leverstein-van Hall 2001; Nuila 2008; Pear 1994; Toltzis 2014. Note that Bell 2014 did not include data about prescribing outcomes but did include valid clinical outcome data (Table 4).

13 ITS studies included time series data about prescribing outcomes but were excluded from meta-regression for the following reasons:

\begin{tabular}{ll}
\hline Study & Reason \\
\hline Borde 2014b & $\begin{array}{l}\text { Only } 3 \text { postintervention points and compound outcome (choice and dose) not comparable with } \\
\text { other studies }\end{array}$ \\
\hline Goldstein 2009 & $\begin{array}{l}\text { Intervention was substitution of ertapenem for ampicillin-sulbactam, but there are no ampi- } \\
\text { cillin-sulbactam data. }\end{array}$ \\
\hline Madaras-Kelly 2006 & Effect size reported for segmented regression analysis but no variance. \\
\hline McLaughlin 2005 & Large, unjustified gap between pre- and postintervention data \\
\hline Meyer 1993 & $\begin{array}{l}\text { Restriction of cephalosporins was in place throughout the study period. The paper reports an out- } \\
\text { break of cephalosporin-resistant Klebsiella pneumoniae. Following the outbreak "approvals were } \\
\text { reduced by } 80 \% ", \text { but unclear whether this was because of change in restriction or reduction in re- } \\
\text { quests. }\end{array}$
\end{tabular}

Pemoval of restriction of fluoroquinolone and effect on MRSA, BUT only one data point prior to re-
moval so cannot be re-analysed.

\begin{tabular}{ll}
\hline Ostrowsky 2014 & Non-standardised intervention and prescribing outcomes across multiple hospitals \\
\hline Pires 2011 & $\begin{array}{l}\text { "Intervention" was introduction of ertapenem into the formulary with no instruction to use less of } \\
\text { anything else. }\end{array}$ \\
\hline Pulcini 2011 & $\begin{array}{l}\text { 4 months' pre- and postintervention data in } 2 \text { weekly time points. Data format not compatible with } \\
\text { other studies. }\end{array}$ \\
\hline Rattanaumpawan 2011 & $\begin{array}{l}\text { Removal of restriction only, and there is not enough unnecessary use before de-restriction to de- } \\
\text { tect change. }\end{array}$ \\
\hline
\end{tabular}


(Continued)

Not truly 3 pre-intervention time points, and time intervals irregular.

\author{
Uçkay 2009
}

Comparison is between the deliverer of the same intervention (infectious disease physicians with and without infection control training). No pre-intervention data

\title{
Appendix 7. Details of disagreements with other reviews
}

A systematic review on current evidence about antimicrobial stewardship objectives reported that "guideline-adherent empirical therapy was associated with a relative risk reduction for mortality of $35 \%$ (odds ratio $0.65,95 \% \mathrm{Cl} 0.54-0.80$ )" (Schuts 2016). This analysis was based on 39 studies, of which 19 were identified by our literature search. We have reviewed the 20 studies that were not identified by our literature search. Only two of the 39 studies in this review reported an intervention, and both were identified by our literature review: one was invalid because it was an uncontrolled before-after study (Garcia 2007), and one controlled before-after study (CBA) is in our 'Characteristics of included studies' table (Dean 2006). The remaining 27 studies used case control or cohort designs to compare the outcomes of patients with and without guideline-adherent antibiotic treatment, and did not include an intervention to change professional practice. The results of this review are in marked contrast to our analysis of mortality in 11 randomised controlled trials targeting antibiotic choice (Analysis 3.1). The aim of these interventions was to increase adherence with antibiotic guidelines for the antibiotic or route of administration. We have presented results as risk differences (Figure 8), but the odds ratio for mortality in these 11 randomised controlled trials is 0.96 (95\% confidence interval $(\mathrm{Cl}) 0.82$ to 1.13). The most likely explanation for the discrepancy between our results and those of Schuts 2016 is confounding by indication. It is likely that patients with less complex or severe illness were more likely to receive guideline-adherent antibiotic treatment and that there was residual confounding after adjustment for available clinical information. The only valid intervention study in the analysis by Schuts 2016 was a CBA. This study compared outcomes for community-acquired pneumonia (CAP) for patients in 16 hospitals that had implemented a policy based on national guidelines with 19 control hospitals from the same state (Dean 2006). The CAP policy included several important elements in addition to antibiotic choice, such as antibiotic administration in the outpatient or emergency department before admission to hospital; administration of enoxaparin; and early ambulation of hospital inpatients. This study did not include any measures of process compliance, so it is unclear whether there is any relationship between mortality and adherence with the antibiotics recommended in the CAP policy.

A systematic review on the effect of antibiotic stewardship programmes on Clostridium difficile infection (CDI) reported that interventions were associated with a consistent, significant protective effect (pooled risk ratio for CDI 0.48, 95\% CI 0.38 to 0.62) (Feazel 2014). This analysis was based on 16 studies, of which 10 were identified by our literature search. We have reviewed the six studies that were not identified by our literature search. Of the 16 studies included in this systematic review, four were interrupted time series (ITS) studies that we have included in our review (Elligsen 2012; Fowler 2007; Price 2010; Talpaert 2011); the remaining 12 studies were either uncontrolled beforeafter or inadequate ITS studies. Elligsen 2012 only has reliable data about prescribing outcomes; CDI data are in the form of an inadequate CBA with aggregated before and after data from one intervention and one control site. The statistical analysis in this review, Feazel 2014, was not appropriate for the three ITS studies included in our review (Fowler 2007; Price 2010; Talpaert 2011). Calculation of risk ratios for the post- versus pre-intervention periods is an uncontrolled before-after analysis, which does not provide a reliable estimate of intervention effect. This is most clearly demonstrated by the results of one study (Price 2010), in which CDIs were declining pre-intervention by -0.04 cases per 1000 occupied bed days per month $(95 \% \mathrm{Cl}-0.08$ to $-0.01 ; \mathrm{P}=0.03)$. Postintervention CDI continued to decline at a slightly greater rate, but our estimate of the intervention effect was only a $10 \%$ reduction at 12 months ( $95 \% \mathrm{Cl} 85 \%$ reduction to $65 \%$ increase). In the systematic review (Feazel 2014), the reported risk ratio in the post- versus pre-intervention phase was $0.52(95 \% \mathrm{Cl} 0.44$ to 0.61$)$, but this result is mainly attributable to a steady decline in $\mathrm{CDI}$ over the entire study period rather than to any intervention effect.

\section{WHAT'S NEW}

\begin{tabular}{lll}
\hline Date & Event & Description \\
\hline 20 February 2017 & Amended & $\begin{array}{l}\text { The review has been amendment with a correction to the techni- } \\
\text { cal settings of the primary analysis. }\end{array}$ \\
\hline
\end{tabular}

\section{H I S T O R Y}

Protocol first published: Issue 1, 2002

Review first published: Issue 3, 2005 


\begin{tabular}{lll}
\hline Date & Event & Description \\
\hline
\end{tabular}

19 January $2015 \quad$ New citation required and conclusions have changed
The addition of new data to the review has strengthened the conclusions regarding the effect on antibiotic prescribing and mortality. The review shows that there is a reduction in length of hospital stay.

The review now has identified that interventions are consistently more effective if they contain enabling components, which provide advice or feedback to help physicians make more informed decisions about their prescribing. However only $10 \%$ of interventions used the most effective enabling techniques: goal setting, feedback and action planning.

Given the high certainty of evidence for our primary outcome we believe that additional trials comparing antibiotic stewardship with no intervention are unlikely to change our conclusions or build on our understanding of the current evidence.

This review includes 221 studies.
New searches performed to January 2015 and 132 new studies have been included in the review.

New authors: Charis Marwick, Kirsty McNeil, Claire Scott, replacing Lynda Fenelon, Alison Holmes, Phil Wiffen, and Mark Wilcox.

Important changes to the methods are inclusion of case control, cohort, or qualitative studies of unintended consequences, new data extraction forms to identify behaviour change techniques in the interventions, and a prespecified subgroup analysis and meta-regression by behaviour change technique.

Cluster non-randomised controlled trials and randomised controlled trials (RCTs) with fewer than 2 intervention or control sites have been excluded, including 1 non-randomised controlled trial from the previous version of the review.

Results updated, 'Characteristics of included studies' and 'Characteristics of excluded studies' tables re-written and updated to end of December 2014. Meta-analysis of RCTs completed prior to meta-regression of RCTs and interrupted time series studies.

Major edits in preparation for next update, 'Characteristics of included studies' table re-written and updated to end of December 2012.

\begin{tabular}{lll}
\hline 1 May 2014 & Amended & Protocol completely revised. \\
\hline 26 February 2013 & New search has been performed & New search, 89 studies found. \\
\hline 26 February 2013 & $\begin{array}{l}\text { New citation required and conclusions } \\
\text { have changed }\end{array}$ & New search, 89 new studies found. \\
\hline 12 February 2009 & Amended & Minor edits, tables modified. \\
\hline 29 July 2008 & Amended & Converted to new review format. \\
\hline 28 July 2005 & $\begin{array}{l}\text { New citation required and conclusions } \\
\text { have changed }\end{array}$ & Substantive amendment \\
\hline
\end{tabular}




\section{CONTRIBUTIONS OF AUTHORS}

Peter Davey (Clinical Pharmacologist) wrote the protocol; assisted with the literature search; reviewed all intervention studies for risk of bias using Cochrane Effective Practice and Organisation of Care (EPOC) Group methodology; contributed to re-analysis of data from interrupted time series (ITS) studies and meta-regression of ITS studies and randomised controlled trials (RCTs); wrote the first draft of the review and was responsible for final decisions about included studies; contributed to EPOC check sheets, data extraction, and GRADE assessment of certainty of evidence.

Charis Marwick (Infectious Diseases Physician) re-analysed all of the ITS studies and performed meta-regression of ITS studies and RCTs with an analysis plan written by Craig Ramsay (Statistician); was a member of the review writing group; and contributed to EPOC check sheets, data extraction, and GRADE assessment of certainty of evidence.

Claire Scott (Psychologist) managed the review; set up the database; was a member of the review writing group; and contributed to EPOC check sheets, data extraction, and GRADE assessment of certainty of evidence.

Esmita Charani (Pharmacist) and Kirsty McNeil (Medical Student) were members of the review writing group and contributed to EPOC check sheets, data extraction, and GRADE assessment of certainty of evidence.

Erwin Brown (Medical Microbiologist) initiated the review in 2000 and for this update handsearched bibliographies of individual papers for additional references; screened titles and abstracts; and reviewed all papers to identify those that reported the results of an intervention to change antibiotic prescribing.

Ian Gould (Medical Microbiologist) reviewed papers for microbial risk of bias and was a member of the review writing group.

Craig Ramsay (Statistician) wrote the analysis plan for re-analysis of ITS studies and meta-regression of ITS studies and RCTs.

Susan Michie (Psychologist) advised on the design of data extraction for behaviour change techniques and the analysis of intervention functions; was a member of the review writing group; and contributed to GRADE assessment of certainty of evidence.

\section{DECLARATIONS OF INTEREST}

Peter Davey is an author of four of the included studies. Charis Marwick is an author of two of the included studies. Ian Gould is an author of one of the included studies. Craig Ramsay is an author of one of the included studies. Other review authors completed data extractions for these studies. The institutions of the following authors received funding from the Chief Scientist Office that helped to support the conduct of this review: Peter Davey, Charis Marwick, Esmita Charani.

Peter Davey, none other than as indicated above.

Charis Marwick, none other than as indicated above.

Claire Scott, none other than as indicated above.

Esmita Charani, none other than as indicated above.

Kirsty McNeil, none other than as indicated above.

Susan Michie, none other than as indicated above.

Erwin Brown, none other than as indicated above.

lan Gould, none other than as indicated above.

Craig Ramsay, none other than as indicated above.

\section{SOURCES OF SUPPORT}

\section{Internal sources}

- Aberdeen Royal Infirmary, Aberdeen, Scotland, UK.

- Imperial College, London, England, UK.

- University of Dundee, Dundee, Scotland, UK.

- University of Aberdeen, UK.

- UK Cochrane Centre, UK.

- University College London, UK.

\section{External sources}

- British Society for Antimicrobial Chemotherapy, UK.

- Chief Scientist Office for Scotland, UK.

Major grant CZH4861 


\section{DIFFERENCES BETWEEN PROTOCOLAND REVIEW}

The protocol was completely revised for this update of the review. The most notable changes to the original protocol used for the first version of the review are as follows.

1. We amended the main outcome of interest to reflect desired change in practice. This fits better with the overall objective of the review relating to appropriate prescription in order to provide evidence of better targeting of antibiotic prescribing.

2. We changed the measure of effect from risk ratios to risk differences to better convey the intervention effect in absolute terms.

3. We adjusted for the effect of clustering in sensitivity analyses, as we had not considered this aspect of trial design in the previous version of the review.

\section{IN DEX TERMS}

\section{Medical Subject Headings (MeSH)}

*Drug Resistance, Bacterial; *Practice Patterns, Physicians'; Anti-Bacterial Agents [administration \& dosage] [adverse effects] [ ${ }^{\star}$ therapeutic use]; Bacterial Infections [ ${ }^{*}$ drug therapy] [prevention \& control]; Cross Infection [ ${ }^{*}$ drug therapy] [prevention \& control]; Inpatients; Non-Randomized Controlled Trials as Topic; Randomized Controlled Trials as Topic; Time Factors

\section{MeSH check words}

Humans 